\title{
The Future of Geothermal Energy
}

Impact of Enhanced Geothermal Systems (EGS) on the United States in the $21^{\text {st }}$ Century

November 2006

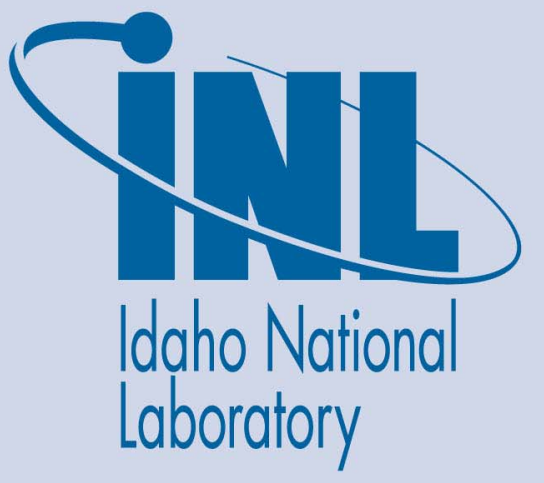

The INL is a U.S. Department of Energy National Laboratory operated by Battelle Energy Alliance 
INL/EXT-06-11746

\section{The Future of Geothermal Energy}

Impact of Enhanced Geothermal Systems (EGS) on the United States in the $21^{\text {st }}$ Century

November 2006

Idaho National Laboratory
Idaho Falls, Idaho 83415

Prepared for the

U.S. Department of Energy

Assistant Secretary for Energy Efficiency and Renewable Energy

Under DOE Idaho Operations Office

Contract DE-AC07-05ID14517 
This report is available on the Internet at:

http://geothermal.inel.gov and

http://www1.eere.energy.gov/geothermal/egs_technology.html

Send requests for printed copies to:

Geothermal Program, MS 3830

Renewable Energy and Power Department

Idaho National Laboratory

PO Box 1625

Idaho Falls, ID 83415-3830

\section{Copyright Notice}

The submitted manuscript has been authored by a contractor for the U.S. Government under D.O.E. Contract DE-AC07-05ID14517. Accordingly, the U.S. Government retains a nonexclusive, royalty-free license to publish or reproduce the published form of this contribution, or allow others to do so, for U.S. Government purposes.

\section{(c) 2006 Massachusetts Institute of Technology}

All rights reserved. No part of this report may be reproduced in any form by any electronic or mechanical means (including photocopying, recording, or information storage and retrieval) without permission in writing from the panel.

Prepared under Idaho National Laboratory Subcontract No. 6300019 for the U.S. Department of Energy, Assistant Secretary for Energy Efficiency and Renewable Energy, Office of Geothermal Technologies, Under DOE Idaho Operations Office Contract DE-AC07-05ID14517.

\section{INL/EXT-06-11746}

ISBN: 0-615-13438-6

PSB Job 06-06-0413

Copy Editor: Michelle Kubik

Design and Layout: Ink Design

Production Supervision/Management: Gwen Wilcox, MIT 


\section{Panel Members}

Jefferson W. Tester, Chair

H.P. Meissner Professor of Chemical Engineering,

Massachusetts Institute of Technology

Brian J. Anderson

Assistant Professor/Verl Purdy Faculty Fellow of

Chemical Engineering, West Virginia University

\section{Anthony S. Batchelor}

Chairman and Managing Director, GeoScience Limited; Former Director, U.K. Hot Dry Rock Geothermal Project, Camborne School of Mines

\section{David D. Blackwell}

W.B. Hamilton Professor of Geophysics,

Southern Methodist University

\section{Ronald DiPippo}

Chancellor Professor Emeritus of Mechanical

Engineering/Former Associate Dean of Engineering, University of Massachusetts - Dartmouth

Elisabeth M. Drake

Emeritus Associate Director for New Technologies, MIT Energy Lab, Massachusetts Institute of Technology

\section{John Garnish}

Geothermal and CO2 Sequestration Consultant,

Chairman, Soultz-sous-Forets Scientific Advisory Panel
Bill Livesay

Drilling Engineering Consultant

Michal C. Moore

Senior Fellow, Institute for Sustainable Energy, Environment, and Economy, University of Calgary; Former Chief Economist, National Renewable Energy Laboratory

Kenneth Nichols

CEO Emeritus, Barber Nichols Inc.

\section{Susan Petty}

Principal, Black Mountain Technology - Geothermal project analysis and reservoir engineering

\section{Nafi Toksöz}

Robert R. Shrock Professor of Geophysics/Founder and Former Director, Earth Resources Laboratory, Massachusetts Institute of Technology

Ralph W. Veatch, Jr.

President, Software Enterprises Inc.

Former supervisor of hydraulic fracturing and well completions, Amoco Production Co.

\section{Associate Panel Members}

\section{Roy Baria}

Reservoir Geophysics Consultant, MIL-TECH UK; Former Deputy Director, U.K. Geothermal Project at Rosemanowes, and Scientist in Charge at Soultz

\section{Chad Augustine}

Research Assistant, Chemical Engineering,

Massachusetts Institute of Technology

\section{Enda Murphy}

Research Assistant, Civil and Environmental

Engineering, Massachusetts Institute of Technology

\section{Petru Negraru}

Postdoctoral Researcher, Geophysics and Geothermal

Laboratory, Southern Methodist University

Maria Richards

Research Associate, Geothermal Laboratory, Southern Methodist University 


\section{Contents}

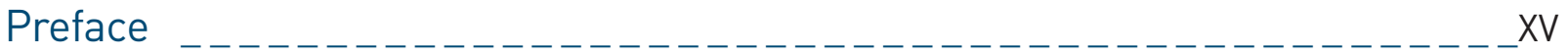

Acknowledgments _.-

CHAPTER 1

Synopsis and Executive Summary

Synopsis _.

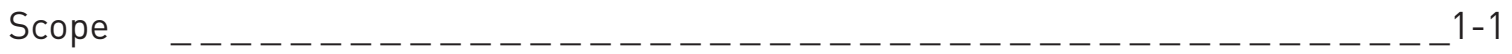

Motivation

Pursuing the geothermal option

Approach _- - - - - - -

Findings _- -

Major recommendations

Executive Summary _.

1.1 Motivation and Scope

1.2 Defining EGS _.

1.3 U.S. Geothermal Resource Base _

1.4 Estimating the Recoverable Portion of EGS

1.5 Geothermal Drilling Technology and Costs _ _ _ _ _ _

1.6 EGS Reservoir Stimulation -

Status of International Field Testing and Design Issues _ _ _ _ _ _ _ _ _ _ _ _ 1-20

1.7 Geothermal Energy Conversion Technology $\ldots \ldots \ldots \ldots \ldots$

1.8 Environmental Attributes of EGS _ _ _

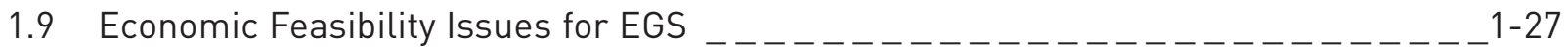

References _.

CHAPTER 2

\section{Geothermal Resource-Base Assessment}

2.1 Introduction

2.2 EGS Resource-Base Calculation-Temperature-at-Depth Maps _ _ _ _ $2-5$

2.2.1 Heat flow

2.2.2 Geothermal gradients _ 
2.2.3 Thermal conductivity

2.2.4 Sediment thickness $\ldots \ldots \ldots-\ldots-\ldots$

2.2.5 Ground surface temperature $\ldots \ldots \ldots-\ldots \ldots \ldots-\ldots \ldots \ldots-\ldots-\ldots-\ldots-\ldots-13$

2.2.6 Tectonic and radioactive components of heat flow

2.3 EGS Resource Maps and Resource-Base

Estimates_Lower 48 States _._.

2.3.1 Heat (thermal energy) content $\ldots \ldots \ldots \ldots \ldots-\ldots$

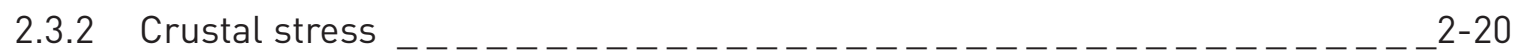

2.3.3 EGS geology $\ldots-\ldots-\ldots-\ldots-\ldots$

2.3.4 Crustal permeability _._-

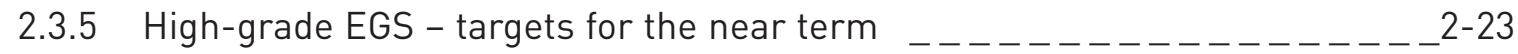

2.4 EGS Potential of Alaska $\ldots \ldots \ldots \ldots$

2.4.1 Volcano system _

2.5 EGS Potential of Hawaii

2.6 Unconventional EGS Associated with Coproduced Fluids and Geopressured Fluids _

2.6.1 Introduction $\ldots$

2.6.2 Coproduced fluids $\ldots \ldots \ldots \ldots \ldots-\ldots \ldots-\ldots$

2.6.3 Geopressured geothermal resources _.

2.6.4 EGS in sedimentary basins beneath hydrocarbon-bearing fields _ _ _ _ _ _ 2-34

2.7 Concluding Remarks _

References _._-

Appendices _.

A.2.1 Geothermal Resource-Base Data _

A.2.2 Coprocessed Water Associated with Oil and Gas Production _._.

\section{CHAPTER 3}

\section{Recoverable EGS Resource Estimates}

3.1 Scope and Approach

3.2 Resource Base vs. Reserves _ _ _ _ _ _ _ _ _ _ _ _ _ _ _ _ _ _ _ $3-4$

3.3 Metrics that Influence the Recoverable Resource

3.3.1 Temperature _-

3.3.2 Fractured rock volume $\ldots \ldots \ldots \ldots \ldots-\ldots$

3.3.3 Fracture spacing

3.3.4 Fracture surface area

3.4 Determining the Recoverable Fraction $\ldots \ldots-\ldots-\ldots-\ldots-\ldots-\ldots$ 
3.5 Usable Energy - Converting Heat to Power

3.6 Access to the EGS Resource

CHAPTER 4

\section{Review of EGS and Related Technology - Status and Achievements}

4.1 Scope and Organization

4.2 Overview _

4.3 Fenton Hill

4.3.1 Project history _.

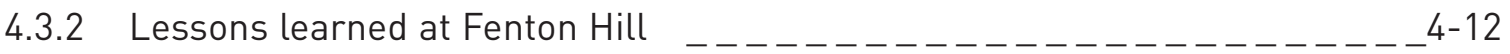

4.4 Rosemanowes _.

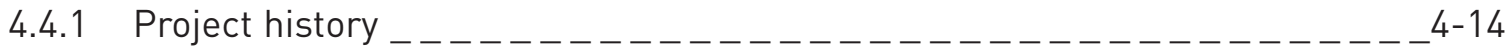

4.4.2 Lessons learned at Rosemanowes _

4.5 Hijiori _.

4.5.1 Project history

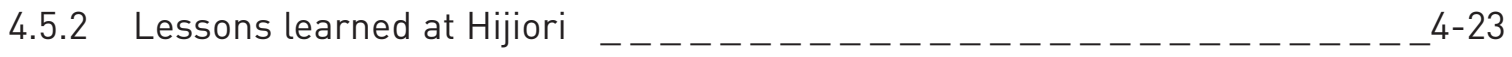

4.6 Ogachi _.

4.6.1 Project history

4.6.2 Lessons learned at Ogachi _.

4.7 Soultz _

4.7.1 Project history

4.7.2 Lessons learned at Soultz _

4.8 Cooper Basin _

4.8.1 Project history

4.8.2 Lessons learned at Cooper Basin $\ldots \ldots-\ldots-\ldots \ldots-\ldots$

4.9 Other EGS Studies _

4.9.1 United States _

4.9.2 Europe and Australia _.

4.10 Generalizations from EGS Field Testing _ $\ldots \ldots \ldots \ldots \ldots \ldots \ldots \ldots \ldots-\ldots 4-43$

4.11 Remaining Needs _ $\ldots \ldots \ldots \ldots \ldots$

References _. 


\section{CHAPTER 5}

\section{Subsurface System Design Issues and Approaches}

5.1 Scope and Approach: EGS vs. Hydrothermal Reservoirs $5-3$

5.2 Formation Characteristics-Porosity, Permeability, Fracture Distribution, Density and Orientation, and Connectivity _ _ _ _ _ _ _ _ _ 5-3

5.3 Rock-Fluid Interactions _ _ _ _ _

5.4 Temperature Variation with Depth $\ldots \ldots \ldots \ldots-\ldots$

5.5 Geology

5.6 Water Availability _

5.7 Susceptibility to Induced Seismicity

5.8 Remaining Issues for Successful Stimulation

5.8.1 Site selection

5.8.2 Instrumentation _-_-_-_-_-_-

5.8.3 Downhole pumps _.

5.8.4 High-temperature packers or other well-interval isolation systems _._-__ 5-9

5.8.5 Short-circuit prevention and repair _

5.8.6 Fracture design models _._.

5.8.7 Rock property quantification

5.8.8 Fracturing fluid loss

5.8.9 Fracture mapping methods _

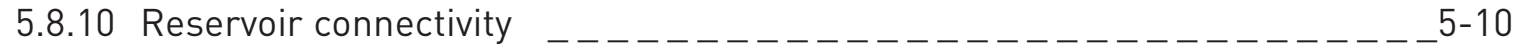

5.8.11 Rock-fluid interactions _._.

5.9 Approach for Targeting EGS Reservoirs _ _ _ _

5.10 Diagnostics for EGS Reservoir Characterization _ _ _ _ _ $\ldots \ldots \ldots-\ldots-\ldots-12$

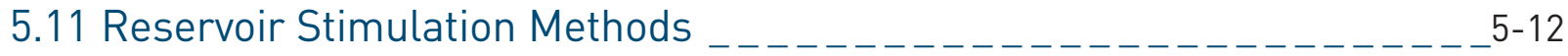

5.11.1 Geologic case studies _ _ _

5.12 Long-Term Reservoir Management _ _ _ _ _ _ _ _ _ _ _ _ _ _ _ _ _ 5-18

5.13 Conclusions - Stimulation Technologies and Estimated Costs _ _ _ _ 5-19

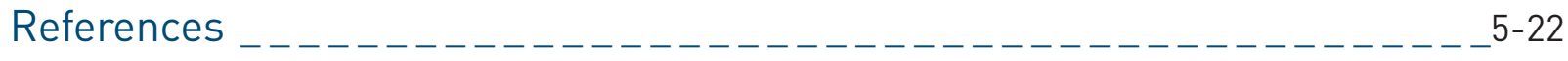

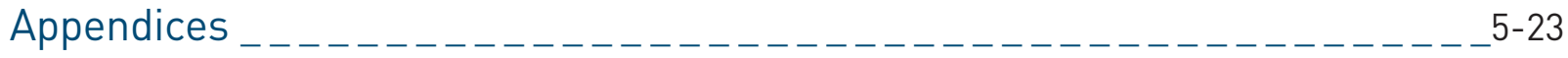




\section{CHAPTER 6}

\section{Drilling Technology and Costs}

6.1 Scope and Approach

6.2 Review of Geothermal Drilling Technology _

6.2.1 Early geothermal/EGS drilling development $\ldots \ldots \ldots \ldots \ldots \ldots \ldots \ldots \ldots-\ldots-\ldots-\ldots$

6.2.2 Current EGS drilling technology _ _ _

6.3 Historical Well-Cost Data $\ldots \ldots-\ldots$

6.3.1 General trends in oil and gas well-completion costs $\ldots \ldots \ldots \ldots \ldots \ldots-\ldots-\ldots$

6.3.2 MIT Depth Dependent (MITDD) drilling-cost index _

6.3.3 Updated geothermal well costs _-

6.4 Predicting Geothermal Well Costs with the Wellcost Lite Model _ _-_-_6-18

6.4.1 History of the Wellcost Lite model

6.4.2 Wellcost Lite model description _

6.5 Drilling-Cost Model Validation _

6.5.1 Base-case geothermal wells _._.

6.5.2 Comparison with geothermal wells $\ldots \ldots \ldots \ldots \ldots \ldots \ldots \ldots \ldots \ldots \ldots-\ldots-22$

6.5.3 Comparison with oil and gas wells _ _

6.5.4 Model input parameter sensitivities and drilling-cost breakdown $\ldots-\ldots \ldots-\ldots 6-23$

6.6 Emerging Drilling Technologies _ _ _ _ _ _ _ _ _ _ _

6.6.1 Current oil and gas drilling technologies adaptable to EGS _ _ _ _ _ _ $6-27$

6.6.2 Revolutionary drilling technologies

6.7 Conclusions _

References _.

Appendices _. _

A.6.1 Well-Cost Data _ _.

A.6.2 Wellcost Lite Model _._.

A.6.2.1 Background and brief history of the development of Wellcost Lite _ _- _- - 6-37

A.6.2.2 Wellcost Lite - How does the cost model work? _ _ _

A.6.3 Model Results for Specific Areas and Depths _ _ _ _ _ _ _

A.6.4 Model Results for Reworked Wells

A.6.4.1 Rig on drilling/deepening $460 \mathrm{~m}(1,500 \mathrm{ft}) / \mathrm{rig}$ still on the well $\ldots$

A.6.4.2 Rig on drilling/sidetracked lateral/as a planned part of the well design _ _ 6-51

A.6.4.3 Reworks/rig has to be mobilized/add a lateral for

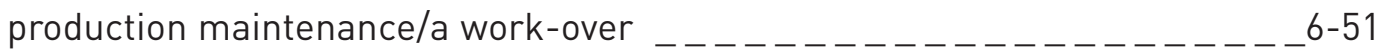

A.6.4.4 Redrills to enhance production/a work-over/rig to be mobilized _ _ _ _ _ $6-51$ 


\section{CHAPTER 7}

\section{Energy Conversion Systems - Options and Issues}

7.1 Introduction $----------------------------------7-3$

7.2 Electric Power Generation _ _ _

7.2.1 Electricity from coproduced oil and gas operations

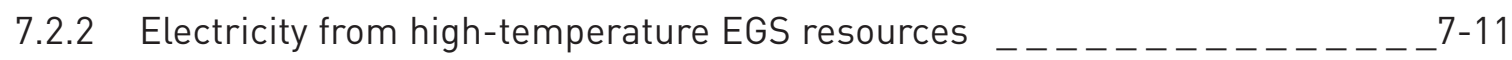

7.2.3 Electricity from EGS resources at supercritical conditions _ _ _ _ _ _ _ _ 7-17

7.3 Cogeneration of Electricity and Thermal Energy _ _ _ _ _ _ _ _ _

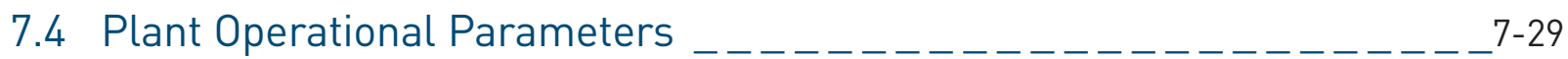

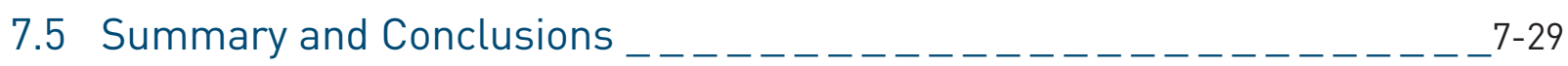

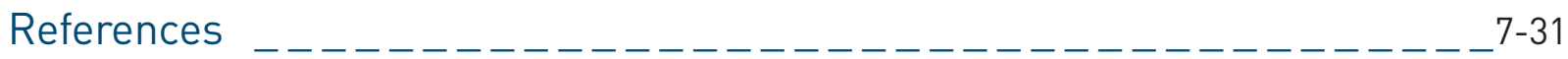

CHAPTER 8

Environmental Impacts, Attributes, and Feasibility Criteria

8.1 Scope and Approach to Geothermal Environmental Effects _ _ _ _ _ _ $8-3$

8.2 Potential Environmental Impacts from Geothermal Development

8.2.1 Gaseous emissions

8.2.2 Water pollution

8.2.3 Solids emissions

8.2.4 Noise pollution

8.2.5 Land use

8.2.6 Land subsidence

8.2.7 Induced seismicity

8.2.8 Induced landslides _

8.2.9 Water use

8.2.10 Disturbance of natural hydrothermal manifestations _

8.2.11 Disturbance of wildlife habitat, vegetation, and scenic vistas _

8.2.12 Catastrophic events _.

8.2.13 Thermal pollution 
8.3 Environmental Attributes of EGS Power Projects

8.3.1 No greenhouse gas emissions during operations _ $\ldots \ldots \ldots \ldots-\ldots \ldots \ldots-\ldots-16$

8.3.2 Modest use of land _

8.3.3 Possible sequestration of carbon dioxide

8.3.4 Low overall environment impact

8.4 Environmental Criteria for Project Feasibility _ _ _ _ _

8.5 Concluding Remarks _

References

CHAPTER 9

Energy-Sector Fundamentals: Economic Analysis, Projections, and Supply Curves

9.1 EGS in the Energy Sector

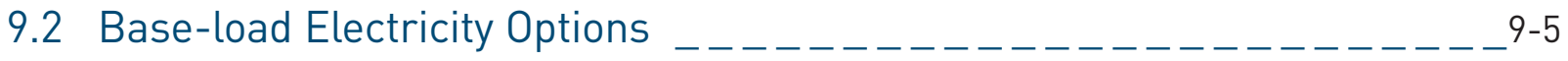

9.3 Transmission Access _

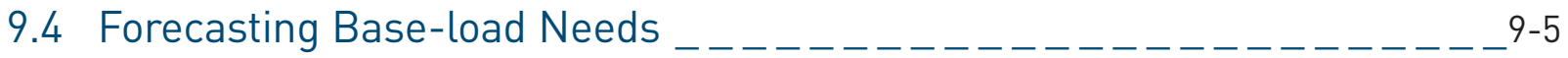

9.5 Forecast Demand and Supply Calculations _ $-\ldots-\ldots-\ldots-\ldots-\ldots-\ldots-\ldots-6-6$

9.6 Risk _-

9.7 Economics and Cost of Energy

9.8 Using Levelized Costs for Comparison _

9.8.1 Fixed costs

9.8.2 Variable costs of operation _

9.8.3 Levelized cost projections _

9.8.4 Supply and capacity

9.8.5 The aggregate industry supply curve

9.8.6 Geothermal supply characteristics _

9.9 EGS Economic Models

9.9.1 GETEM model description _ _

9.9.2 Updated MIT EGS model _ _ _ _ _

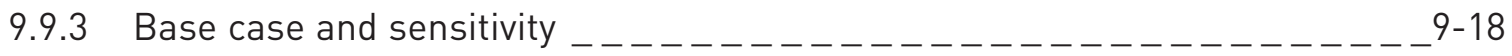

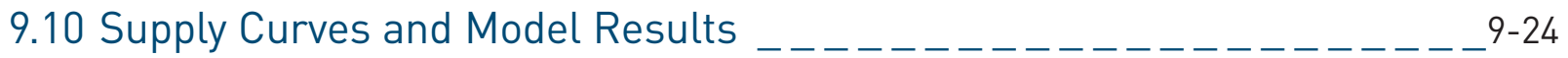

9.10.1 Supply of EGS power on the edges of existing hydrothermal systems _ _- $9-26$

9.10.2 Supply of EGS power from conductive heating _ _

9.10.3 Effects of learning on supply curves _ _ _ 
9.10.4 Supply curve for EGS _

9.10.5 EGS well characteristics _

9.11 Learning Curves and Supply Curves _ _ _ _ _

9.12 Forecast Supply of Geothermal Energy _ $\ldots \ldots \ldots-\ldots$

9.12.1 The role of technology

9.12.2 Variable debt/equity rates vs. fixed charge rates (FCRs) _ _ _ _ _ _ _ _ $9-39$

9.12.3 Deriving cost and supply curves

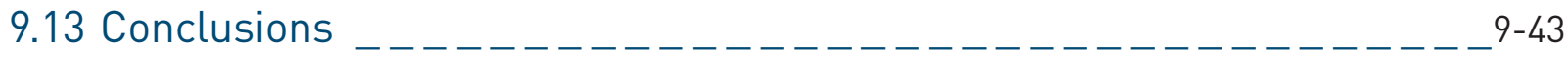

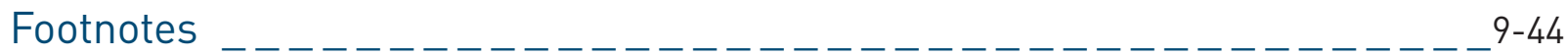

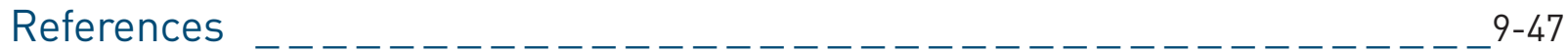

Appendices

Appendix A: Energy Conversion Factors _

Appendix B: Panel-Member Biographies _

Appendix C: Glossary of Scientific Terms and Abbreviations _ 


\section{Preface}

Recent national focus on the value of increasing our supply of indigenous, renewable energy underscores the need for reevaluating all alternatives, particularly those that are large and welldistributed nationally. This analysis will help determine how we can enlarge and diversify the portfolio of options we should be vigorously pursuing. One such option that is often ignored is geothermal energy, produced from both conventional hydrothermal and Enhanced (or engineered) Geothermal Systems (EGS). An I8-member assessment panel was assembled in September 2005 to evaluate the technical and economic feasibility of EGS becoming a major supplier of primary energy for U.S. base-load generation capacity by 2050. This report documents the work of the panel at three separate levels of detail. The first is a Synopsis, which provides a brief overview of the scope, motivation, approach, major findings, and recommendations of the panel. At the second level, an Executive Summary reviews each component of the study, providing major results and findings. The third level provides full documentation in eight chapters, with each detailing the scope, approach, and results of the analysis and modeling conducted in each area.

\section{Acknowledgments}

The panel wishes to thank the many individuals who contributed significantly to this assessment. The presentations by representatives of the Department of Energy (DOE) and its national laboratories, as well as many other individuals and organizations, provided the panel with invaluable information and insight into the history and evolution of geothermal energy technologies and ongoing economic analyses and modeling.

In particular, we would like to thank the following U.S. DOE and national laboratory staff: Roy Mink and Allan Jelacic: Office of the Geothermal Technology Program, U.S. DOE; Jay Nathwani: Office of Project Management, U.S. DOE; Joel Renner: Idaho National Laboratory; Gerald Nix: National Renewable Energy Laboratory; Craig Tyner, Steven Bauer, and Arthur Mansure: Sandia National Laboratories.

Other contributors include: Hal Curlett: Deep Heat Energy Corp.; Roland Horne: Stanford University; Steven Karner and Gregory Mines: Idaho National Laboratory; Richard Polizzotti: ExxonMobil Research \& Engineering Co.; Jared Potter and Robert Potter: Potter Drilling LLC.; Ann Robertson-Tait: GeothermEx Inc.; Peter Rose: University of Utah; Subir Sanyal: GeothermEx Inc.; Debonny Shoaf: National Energy Technology Laboratory; Valgardur Stefansson: International Geothermal Association; Ralph Weidler: Q-con GmbH; Colin Williams: U.S. Geological Survey; P. Michael Wright: Idaho National Laboratory (retired); Doone Wyborn: Geodynamics Ltd.; and Hildigunnur Thorsteinsson: MIT.

The panel would like to recognize and thank Gwen Wilcox of MIT for her hard work in organizing and planning committee meetings and report production along with Michelle Kubik for her diligent efforts and competent treatment in copy editing the manuscript.

The chairman also wishes to recognize and thank the panel members for their exhaustive individual efforts in gathering information and writing sections of the report.

Finally, the panel gratefully acknowledges the U.S. Department of Energy's Office of the Geothermal Technology Program for its sponsorship of this assessment. 


\section{CHAPTER 1 \\ Synopsis and \\ Executive Summary}

Synopsis

Scope - - -

Motivation

Pursuing the geothermal option

Approach _- - - - -

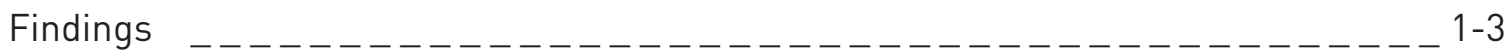

Major recommendations

Executive Summary

1.1 Motivation and Scope _._.

1.2 Defining EGS _

1.3 U.S. Geothermal Resource Base

1.4 Estimating the Recoverable Portion of EGS

1.5 Geothermal Drilling Technology and Costs _

1.6 EGS Reservoir Stimulation -

Status of International Field Testing and Design Issues _ _ _ _ _

1.7 Geothermal Energy Conversion Technology _ $\ldots \ldots \ldots \ldots \ldots \ldots \ldots \ldots$

1.8 Environmental Attributes of EGS _ _ _

1.9 Economic Feasibility Issues for EGS _

References _. 


\section{Synopsis}

Scope: A comprehensive assessment of enhanced, or engineered, geothermal systems was carried out by an I8-member panel assembled by the Massachusetts Institute of Technology (MIT) to evaluate the potential of geothermal energy becoming a major energy source for the United States. Geothermal resources span a wide range of heat sources from the Earth, including not only the more easily developed, currently economic hydrothermal resources; but also the Earth's deeper, stored thermal energy, which is present anywhere. Although conventional hydrothermal resources are used effectively for both electric and nonelectric applications in the United States, they are somewhat limited in their location and ultimate potential for supplying electricity. Beyond these conventional resources are EGS resources with enormous potential for primary energy recovery using heat-mining technology, which is designed to extract and utilize the earth's stored thermal energy. In between these two extremes are other unconventional geothermal resources such as coproduced water and geopressured geothermal resources. EGS methods have been tested at a number of sites around the world and have been improving steadily. Because EGS resources have such a large potential for the long term, we focused our efforts on evaluating what it would take for EGS and other unconventional geothermal resources to provide I0०,000 $\mathrm{MW}_{\mathrm{e}}$ of base-load electric-generating capacity by 2050 .

Although somewhat simplistic, the geothermal resource can be viewed as a continuum in several dimensions. The grade of a specific geothermal resource would depend on its temperature-depth relationship (i.e., geothermal gradient), the reservoir rock's permeability and porosity, and the amount of fluid saturation. High-grade hydrothermal resources have high average thermal gradients, high rock permeability and porosity, sufficient fluids in place, and an adequate reservoir recharge of fluids - all EGS resources lack at least one of these. For example, reservoir rock may be hot enough but not produce sufficient fluid for viable heat extraction, either because of low formation permeability/connectivity and insufficient reservoir volume, and/or the absence of naturally contained fluids.

Three main components were considered in the analysis:

I. Resource - estimating the magnitude and distribution of the U.S. EGS resource.

2. Technology - establishing requirements for extracting and utilizing energy from EGS reservoirs including drilling, reservoir design and stimulation, and thermal energy conversion to electricity.

3. Economics - estimating costs for EGS-supplied electricity on a national scale using newly developed methods for mining heat from the earth. Developing levelized energy costs and supply curves as a function of invested R\&D and deployment levels in evolving U.S. energy markets.

Motivation: There are several compelling reasons why the United States should be concerned about the security of its energy supply for the long term. They include growth in demand, as a result of an increasing U.S. population, along with increased electrification of our society. According to the Energy Information Administration (EIA, 2006), U.S. nameplate generating capacity has increased more than $40 \%$ in the past Io years and is now more than I TWe. Most of this increase resulted from adding gas-fired combined-cycle generation plants. In addition, the electricity supply system is threatened with losing existing capacity in the near term, as a result of retirement of existing nuclear and coalfired generating plants (EIA, 2006). It is likely that $50 \mathrm{GW}_{\mathrm{e}}$ or more of coal-fired capacity will need to be retired in the next I5 to 25 years because of environmental concerns. In addition, during that period, $40 \mathrm{GW}_{\mathrm{e}}$ or more of nuclear capacity will be beyond even the most generous relicensing procedures and will have to be decommissioned. 
The current nonrenewable options for replacing this anticipated loss of U.S. base-load generating capacity are coal-fired thermal, nuclear, and combined-cycle gas-combustion turbines. While these are clearly practical options, there are some concerns. First, demand and prices for cleaner natural gas will escalate substantially during the next 25 years, making it difficult to reach gas-fired capacity. Large increases in imported gas will be needed to meet growing demand - further compromising U.S. energy security beyond just importing the majority of our oil for meeting transportation needs. Second, local, regional, and global environmental impacts associated with increased coal use will most likely require a transition to clean-coal power generation, possibly with sequestration of carbon dioxide. The costs and uncertainties associated with such a transition are daunting. Also, adopting this approach would accelerate our consumption of coal significantly, compromising its use as a source of liquid transportation fuel for the long term. It is also uncertain whether the American public is ready to embrace increasing nuclear power capacity, which would require siting and constructing many new reactor systems.

On the renewable side, there is considerable opportunity for capacity expansion of U.S. hydropower potential using existing dams and impoundments. But outside of a few pumped storage projects, hydropower growth has been hampered by reductions in capacity imposed by the Federal Energy Regulatory Commission (FERC), as a result of environmental concerns. Concentrating solar power (CSP) provides an option for increased base-load capacity in the Southwest where demand is growing. Although renewable solar and wind energy also have significant potential for the United States and are likely to be deployed in increasing amounts, it is unlikely that they alone can meet the entire demand. Furthermore, solar and wind energy are inherently intermittent and cannot provide 24-hour-a-day base load without mega-sized energy storage systems, which traditionally have not been easy to site and are costly to deploy. Biomass also can be used as a renewable fuel to provide electricity using existing heatto-power technology, but its value to the United States as a feedstock for biofuels for transportation may be much higher, given the current goals of reducing U.S. demand for imported oil.

Clearly, we need to increase energy efficiency in all end-use sectors; but even aggressive efforts cannot eliminate the substantial replacement and new capacity additions that will be needed to avoid severe reductions in the services that energy provides to all Americans.

Pursuing the geothermal option: Could U.S.-based geothermal energy provide a viable option for providing large amounts of generating capacity when it is needed? This is exactly the question we are addressing in our assessment of EGS.

Although geothermal energy has provided commercial base-load electricity around the world for more than a century, it is often ignored in national projections of evolving U.S. energy supply. This could be a result of the widespread perception that the total geothermal resource is often associated with identified high-grade, hydrothermal systems that are too few and too limited in their distribution in the United States to make a long-term, major impact at a national level. This perception has led to undervaluing the long-term potential of geothermal energy by missing an opportunity to develop technologies for sustainable heat mining from large volumes of accessible hot rock anywhere in the United States. In fact, many attributes of geothermal energy, namely its widespread distribution, base-load dispatchability without storage, small footprint, and low emissions, are desirable for reaching a sustainable energy future for the United States.

Expanding our energy supply portfolio to include more indigenous and renewable resources is a sound approach that will increase energy security in a manner that parallels the diversification ideals that have 
made America strong. Geothermal energy provides a robust, long-lasting option with attributes that would complement other important contributions from clean coal, nuclear, solar, wind, hydropower, and biomass.

Approach: The composition of the panel was designed to provide in-depth expertise in specific technology areas relevant to EGS development, such as resource characterization and assessment, drilling, reservoir stimulation, and economic analysis. Recognizing the potential that some bias might emerge from a panel of knowledgeable experts who, to varying degrees, are advocates for geothermal energy, panel membership was expanded to include experts on energy technologies and economics, and environmental systems. The panel took a completely new look at the geothermal potential of the United States. This was partly in response to short- and long-term needs for a reliable low-cost electric power and heat supply for the nation. Equally important was a need to review and evaluate international progress in the development of EGS and related extractive technologies that followed the very active period of U.S. fieldwork conducted by Los Alamos National Laboratory during the I970s and I980s at the Fenton Hill site in New Mexico.

The assessment team was assembled in August 2005 and began work in September, following a series of discussions and workshops sponsored by the Department of Energy (DOE) to map out future pathways for developing EGS technology.

The first phase of the assessment considered the geothermal resource in detail. Earlier projections from studies in 1975 and 1978 by the U.S. Geological Survey (USGS Circulars 726 and 790) were amplified by ongoing research and analysis being conducted by U.S. heat-flow researchers and analyzed by David Blackwell's group at Southern Methodist University (SMU) and other researchers. In the second phase, EGS technology was evaluated in three distinct parts: drilling to gain access to the system, reservoir design and stimulation, and energy conversion and utilization. Previous and current field experiences in the United States, Europe, Japan, and Australia were thoroughly reviewed. Finally, the general economic picture and anticipated costs for EGS were analyzed in the context of projected demand for base-load electric power in the United States.

Findings: Geothermal energy from EGS represents a large, indigenous resource that can provide base-load electric power and heat at a level that can have a major impact on the United States, while incurring minimal environmental impacts. With a reasonable investment in R\&D, EGS could provide IO० $\mathrm{GW}_{\mathrm{e}}$ or more of cost-competitive generating capacity in the next 50 years. Further, EGS provides a secure source of power for the long term that would help protect America against economic instabilities resulting from fuel price fluctuations or supply disruptions. Most of the key technical requirements to make EGS work economically over a wide area of the country are in effect, with remaining goals easily within reach. This achievement could provide performance verification at a commercial scale within a Io- to I5-year period nationwide.

In spite of its enormous potential, the geothermal option for the United States has been largely ignored. In the short term, R\&D funding levels and government policies and incentives have not favored growth of U.S. geothermal capacity from conventional, high-grade hydrothermal resources. Because of limited R\&D support of EGS in the United States, field testing and supporting applied geoscience and engineering research has been lacking for more than a decade. Because of this lack of support, EGS technology development and demonstration recently has advanced only outside the United States with accompanying limited technology transfer. This has led to the perception that 
insurmountable technical problems or limitations exist for EGS. However, in our detailed review of international field-testing data so far, the panel did not uncover any major barriers or limitations to the technology. In fact, we found that significant progress has been achieved in recent tests carried out at Soultz, France, under European Union (EU) sponsorship; and in Australia, under largely private sponsorship. For example, at Soultz, a connected reservoir-well system with an active volume of more than $2 \mathrm{~km}^{3}$ at depths from 4 to $5 \mathrm{~km}$ has been created and tested at fluid production rates within a factor of 2 to 3 of initial commercial goals. Such progress leads us to be optimistic about achieving commercial viability in the United States in a next phase of testing, if a national-scale program is supported properly. Specific findings include:

I. EGS is one of the few renewable energy resources that can provide continuous base-load power with minimal visual and other environmental impacts. Geothermal systems have a small footprint and virtually no emissions, including carbon dioxide. Geothermal energy has significant base-load potential, requires no storage, and, thus, it complements other renewables - solar (CSP and PV), wind, hydropower - in a lower-carbon energy future. In the shorter term, having a significant portion of our base load supplied by geothermal sources would provide a buffer against the instabilities of gas price fluctuations and supply disruptions, as well as nuclear plant retirements.

2. The accessible geothermal resource, based on existing extractive technology, is large and contained in a continuum of grades ranging from today's hydrothermal, convective systems through high- and mid-grade EGS resources (located primarily in the western United States) to the very large, conduction-dominated contributions in the deep basement and sedimentary rock formations throughout the country. By evaluating an extensive database of bottom-hole temperature and regional geologic data (rock types, stress levels, surface temperatures, etc.), we have estimated the total EGS resource base to be more than I3 million exajoules (EJ). Using reasonable assumptions regarding how heat would be mined from stimulated EGS reservoirs, we also estimated the extractable portion to exceed 200,000 EJ or about 2,000 times the annual consumption of primary energy in the United States in 2005 . With technology improvements, the economically extractable amount of useful energy could increase by a factor of Io or more, thus making EGS sustainable for centuries.

3. Ongoing work on both hydrothermal and EGS resource development complement each other. Improvements to drilling and power conversion technologies, as well as better understanding of fractured rock structure and flow properties, benefit all geothermal energy development scenarios. Geothermal operators now routinely view their projects as heat mining and plan for managed injection to ensure long reservoir life. While stimulating geothermal wells in hydrothermal developments are now routine, the understanding of why some techniques work on some wells and not on others can only come from careful research.

4. EGS technology has advanced since its infancy in the I970s at Fenton Hill. Field studies conducted worldwide for more than 30 years have shown that EGS is technically feasible in terms of producing net thermal energy by circulating water through stimulated regions of rock at depths ranging from 3 to $5 \mathrm{~km}$. We can now stimulate large rock volumes (more than $2 \mathrm{~km}^{3}$ ), drill into these stimulated regions to establish connected reservoirs, generate connectivity in a controlled way if needed, circulate fluid without large pressure losses at near commercial rates, and generate power using the thermal energy produced at the surface from the created EGS system. Initial concerns regarding five key issues - flow short circuiting, a need for high injection pressures, water losses, geochemical impacts, and induced seismicity - appear to be either fully resolved or manageable with proper monitoring and operational changes. 
5. At this point, the main constraint is creating sufficient connectivity within the injection and production well system in the stimulated region of the EGS reservoir to allow for high per-well production rates without reducing reservoir life by rapid cooling. U.S. field demonstrations have been constrained by many external issues, which have limited further stimulation and development efforts and circulation testing times - and, as a result, risks and uncertainties have not been reduced to a point where private investments would completely support the commercial deployment of EGS in the United States. In Europe and Australia, where government policy creates a more favorable climate, the situation is different for EGS. There are now seven companies in Australia actively pursuing EGS projects and two commercial projects in Europe.

6. Research, Development, and Demonstration (RD\&D) in certain critical areas could greatly enhance the overall competitiveness of geothermal in two ways. First, it would lead to generally lower development costs for all grade systems, which would increase the attractiveness of EGS projects for private investment. Second, it could substantially lower power plant, drilling, and stimulation costs, which increases accessibility to lower-grade EGS areas at depths of $6 \mathrm{~km}$ or more. In a manner similar to the technologies developed for oil and gas and mineral extraction, the investments made in research to develop extractive technology for EGS would follow a natural learning curve that lowers development costs and increases reserves along a continuum of geothermal resource grades.

Examples of impacts that would result from research-driven improvements are presented in three areas:

- Drilling technology - both evolutionary improvements building on conventional approaches to drilling such as more robust drill bits, innovative casing methods, better cementing techniques for high temperatures, improved sensors, and electronics capable of operating at higher temperature in downhole tools; and revolutionary improvements utilizing new methods of rock penetration will lower production costs. These improvements will enable access to deeper, hotter regions in highgrade formations or to economically acceptable temperatures in lower-grade formations.

- Power conversion technology - improving heat-transfer performance for lower-temperature fluids, and developing plant designs for higher resource temperatures to the supercritical water region would lead to an order of magnitude (or more) gain in both reservoir performance and heat-topower conversion efficiency.

- Reservoir technology - increasing production flow rates by targeting specific zones for stimulation and improving downhole lift systems for higher temperatures, and increasing swept areas and volumes to improve heat-removal efficiencies in fractured rock systems, will lead to immediate cost reductions by increasing output per well and extending reservoir lifetimes. For the longer term, using $\mathrm{CO}_{2}$ as a reservoir heat-transfer fluid for EGS could lead to improved reservoir performance as a result of its low viscosity and high density at supercritical conditions. In addition, using $\mathrm{CO}_{2}$ in EGS may provide an alternative means to sequester large amounts of carbon in stable formations.

7. EGS systems are versatile, inherently modular, and scalable from I to $50 \mathrm{MW}_{\mathrm{e}}$ for distributed applications to large "power parks," which could provide thousands of $\mathrm{MW}_{\mathrm{e}}$ of base-load capacity. Of course, for most direct-heating and heat pump applications, effective use of shallow geothermal energy has been demonstrated at a scale of a few kilowatts-thermal $(\mathrm{kWt})$ for individual buildings or homes. For these applications, stimulating deeper reservoirs using EGS technology is not relevant. However, EGS also can be easily deployed in larger-scale district heating and combined heat and power (cogeneration) applications to service both electric power and heating and cooling for buildings without a need for storage on-site. For other renewable options such as wind, hydropower, and solar PV, these applications are not possible. 
8. Using coproduced hot water, available in large quantities at temperatures up to $100^{\circ} \mathrm{C}$ or more from existing oil and gas operations, it is possible to generate up to $\mathrm{II}, 0 \circ 0 \mathrm{MW}_{\mathrm{e}}$ of new generating capacity with standard binary-cycle technology, and increase hydrocarbon production by partially offsetting parasitic losses consumed during production.

9. A cumulative capacity of more than Io०,000 $\mathrm{MW}_{\mathrm{e}}$ from EGS can be achieved in the United States within 50 years with a modest, multiyear federal investment for RD\&D in several field projects in the United States.

Because the field-demonstration program involves staged developments at different sites, committed support for an extended period will be needed to demonstrate the viability, robustness, and reproducibility of methods for stimulating viable, commercial-sized EGS reservoirs at several locations. Based on the economic analysis we conducted as part of our study, a \$300 million to $\$ 400$ million investment over I5 years will be needed to make early-generation EGS power plant installations competitive in evolving U.S. electricity supply markets.

These funds compensate for the higher capital and financing costs expected for early-generation EGS plants, which would be expected as a result of somewhat higher field development (drilling and stimulation) costs per unit of power initially produced. Higher generating costs, in turn, lead to higher perceived financial risk for investors with corresponding higher-debt interest rates and equity rates of return. In effect, the federal investment can be viewed as equivalent to an "absorbed cost" of deployment. In addition, investments in R\&D will also be needed to reduce costs in future deployment of EGS plants.

To a great extent, energy markets and government policies will influence the private sector's interest in developing EGS technology. In today's economic climate, there is reluctance for private industry to invest its funds without strong guarantees. Thus, initially, it is likely that government will have to fully support EGS fieldwork and supporting R\&D. Later, as field sites are established and proven, the private sector will assume a greater role in cofunding projects - especially with government incentives accelerating the transition to independently financed EGS projects in the private sector. Our analysis indicates that, after a few EGS plants at several sites are built and operating, the technology will improve to a point where development costs and risks would diminish significantly, allowing the levelized cost of producing EGS electricity in the United States to be at or below market prices.

Given these issues and growing concerns over long-term energy security, the federal government will need to provide funds directly or introduce other incentives in support of EGS as a long-term "public good," similar to early federal investments in large hydropower dam projects and nuclear power reactors.

Based on growing markets in the United States for clean, base-load capacity, the panel thinks that with a combined public/private investment of about $\$ 800$ million to \$I billion over a I5-year period, EGS technology could be deployed commercially on a timescale that would produce more than I0०,000 $\mathrm{MW}_{\mathrm{e}}$ or $\mathrm{I00} \mathrm{GW}_{\mathrm{e}}$ of new capacity by 2050 . This amount is approximately equivalent to the total R\&D investment made in the past 30 years to EGS internationally, which is still less than the cost of a single, new-generation, clean-coal power plant.

The panel thinks that making such an investment now is appropriate and prudent, given the enormous potential of EGS and the technical progress that has been achieved so far in the field. Having EGS as an option will strengthen America's energy security for the long term in a manner that complements other renewables, clean fossil, and next-generation nuclear. 
Major recommendations: Because prototype commercial-scale EGS will take a few years to develop and field-test, the time for action is now. Supporting the EGS program now will move us along the learning curve to a point where the design and engineering of well-connected EGS reservoir systems is technically reliable and reproducible.

We believe that the benefit-to-cost ratio is more than sufficient to warrant such a modest investment in EGS technology. By enabling roo $\mathrm{GW}_{\mathrm{e}}$ of new base-load capacity, the payoff for EGS is large, especially in light of how much will have to be spent for deployment of conventional gas, nuclear, or coal-fired systems to meet replacement of retiring plants and capacity increases, as there are no other options with sufficient scale on the horizon.

The panel specifically recommends that:

I. There should be a federal commitment to supporting EGS resource characterization and assessment. An aggressive, sufficiently supported, multiyear national program with USGS and DOE and other agency participation is needed to further quantify and refine the EGS resource as extraction and conversion technologies improve.

2. High-grade EGS resources should be developed first at targets of opportunity on the margins of existing hydrothermal systems and in areas with sufficient natural recharge, or in oil fields with high-temperature water and abundant data, followed by field efforts at sites with above-average temperature gradients. Representative sites in high-grade areas, where field development and demonstration costs would be lower, should be selected initially to prove that EGS technology will work at a commercial scale. These near-term targets of opportunity include EGS sites that are currently under consideration at Desert Peak (Nevada), and Coso and Clear Lake (both in California), as well as others that would demonstrate that reservoir-stimulation methods can work in other geologic settings, such as the deep, high-temperature sedimentary basins in Louisiana, Texas, and Oklahoma. Such efforts would provide essential reservoir stimulation and operational information and would provide working "field laboratories" to train the next generation of scientists and engineers who will be needed to develop and deploy EGS on a national scale.

3. In the first 15 years of the program, a number of sites in different regions of the country should be under development. Demonstration of the repeatability and universality of EGS technologies in different geologic environments is needed to reduce risk and uncertainties, resulting in lower development costs.

4. Like all new energy-supply technologies, for EGS to enter and compete in evolving U.S. electricity markets, positive policies at the state and federal levels will be required. These policies must be similar to those that oil and gas and other mineral-extraction operations have received in the past - including provisions for accelerated permitting and licensing, loan guarantees, depletion allowances, intangible drilling write-offs, and accelerated depreciations, as well as those policies associated with cleaner and renewable energies such as production tax credits, renewable credits and portfolio standards, etc. The success of this approach would parallel the development of the U.S. coal-bed methane industry.

5. Given the significant leveraging of supporting research that will occur, we recommend that the United States actively participate in ongoing international field projects such as the EU project at Soultz, France, and the Cooper Basin project in Australia.

6. A commitment should be made to continue to update economic analyses as EGS technology improves with field testing, and EGS should be included in the National Energy Modeling System (NEMS) portfolio of evolving energy options. 


\section{Executive Summary}

\subsection{Motivation and Scope}

The goal of this assessment is to provide an evaluation of geothermal energy as a major supplier of energy in the United States. An I8-member assessment panel with broad experience and expertise was formed to conduct the study beginning in September 2005. The work evaluated three major areas of Enhanced Geothermal Systems (EGS):

I. Magnitude and distribution of the EGS resource

2. Status and remaining requirements of EGS technology needed to demonstrate feasibility at a commercial-scale

3. Economic projections of impact of EGS on U.S. energy supply to 2050

Although there have been earlier assessments of EGS technology and economics, none has been as comprehensive as this one - ranging from providing a detailed evaluation of the geothermal resource to analyzing evolving energy markets for EGS. Our group was able to review technical contributions and progress, spanning more than 30 years of field testing, as well as several earlier economic and resource estimates.

Substantial progress has been made in developing and demonstrating certain components of EGS technology in the United States, Europe, Australia, and Japan, but further work is needed to establish the commercial viability of EGS for electrical power generation, cogeneration, and direct heat supply.

Based on the analysis of experienced researchers, it is important to emphasize that while further advances are needed, none of the known technical and economic barriers limiting widespread development of EGS as a domestic energy source are considered to be insurmountable.

Our assessment evaluates the status of EGS technology, details lessons-learned, and prioritizes R\&D needs for EGS. It will inform the ongoing debate of how to provide a more sustainable and secure energy supply for Americans for the long term, without compromising our economic capacity and political and social stability, and while minimizing environmental impacts. Therefore, energy researchers and developers, utility analysts and executives, and government policy makers should find our report useful.

The study addresses two critical questions facing the future of EGS:

I. Can EGS have a major impact on national energy supply?

2. How much investment in R\&D is needed to realize that impact?

One means of illustrating the potential of any alternative energy technology is to predict how a supply curve of energy costs vs. energy supply capacity would evolve as a result of moving down a learning curve and lowering capital costs. These positive economic effects reflect both R\&D improvements to individual technology components, as well as lower risks and uncertainties in investments to deploy EGS by repeating the process at several field locations. In addition, given that the grade of the EGS resource varies widely in the United States, the supply curve analysis also indicates a gradual transition from deployment of higher- to lower-grade resources. 
The panel has defined the impact threshold for EGS technology as being able to provide I००,००० MW of additional electrical capacity competitively by 2050. While we recognize that this specific goal is not part of the current DOE program, a IO\% impact is a reasonable goal for EGS to become a major player as a domestic energy supply. Our assessment deals directly with the technical and economic feasibility of having EGS achieve this goal, emphasizing the quantitative requirements of both science and engineering in subsurface environments. We develop supply curves for EGS and lay out a rationale that specifies what technology and learning improvements will be needed to reduce risks and lower costs to a point where EGS could have a major impact on the U.S. energy supply. A key aspect of our work is to evaluate whether the costs of the additional R\&D needed to demonstrate the technology at a commercial scale are low enough, and the potential energy security benefits high enough, to justify federal and private investment in EGS.

This first chapter of our report summarizes our overall approach, as well as the main findings in the three focus areas. Included in this chapter are recommendations for research and development, regulatory and governmental policies, and evolving energy markets for EGS that would achieve this high level of impact on the U.S. energy supply.

\subsection{Defining EGS}

In general terms, geothermal energy consists of the thermal energy stored in the Earth's crust. Thermal energy in the earth is distributed between the constituent host rock and the natural fluid that is contained in its fractures and pores at temperatures above ambient levels. These fluids are mostly water with varying amounts of dissolved salts; typically, in their natural in situ state, they are present as a liquid phase but sometimes may consist of a saturated, liquid-vapor mixture or superheated steam vapor phase. The amounts of hot rock and contained fluids are substantially larger and more widely distributed in comparison to hydrocarbon (oil and gas) fluids contained in sedimentary rock formations underlying the United States.

Geothermal fluids of natural origin have been used for cooking and bathing since before the beginning of recorded history; but it was not until the early 2oth century that geothermal energy was harnessed for industrial and commercial purposes. In I904, electricity was first produced using geothermal steam at the vapor-dominated field in Larderello, Italy. Since that time, other hydrothermal developments, such as the steam field at The Geysers, California; and the hot-water systems at Wairakei, New Zealand; Cerro Prieto, Mexico; and Reykjavik, Iceland; and in Indonesia and the Philippines, have led to an installed world electrical generating capacity of nearly ı०,००० $\mathrm{MW}_{\mathrm{e}}$ and a direct-use, nonelectric capacity of more than I0०,००० MWt (thermal megawatts of power) at the beginning of the 2 Ist century.

The source and transport mechanisms of geothermal heat are unique to this energy source. Heat flows through the crust of the Earth at an average rate of almost $59 \mathrm{~mW} / \mathrm{m}^{2}\left[\mathrm{I} .9 \times 10^{-2} \mathrm{Btu} / \mathrm{h} / \mathrm{ft}^{2}\right]$. The intrusion of large masses of molten rock can increase this normal heat flow locally; but for most of the continental crust, the heat flow is due to two primary processes:

I. Upward convection and conduction of heat from the Earth's mantle and core, and

2. Heat generated by the decay of radioactive elements in the crust, particularly isotopes of uranium, thorium, and potassium. 
Local and regional geologic and tectonic phenomena play a major role in determining the location (depth and position) and quality (fluid chemistry and temperature) of a particular resource. For example, regions of higher than normal heat flow are associated with tectonic plate boundaries and with areas of geologically recent igneous activity and/or volcanic events (younger than about I million years). This is why people frequently associate geothermal energy only with places where such conditions are found such as Iceland, New Zealand, or Japan (plate boundaries), or with Yellowstone National Park (recent volcanism) - and neglect to consider geothermal energy opportunities in other regions.

In all cases, certain conditions must be met before one has a viable geothermal resource. The first requirement is accessibility. This is usually achieved by drilling to depths of interest, frequently using conventional methods similar to those used to extract oil and gas from underground reservoirs. The second requirement is sufficient reservoir productivity. For hydrothermal systems, one normally needs to have large amounts of hot, natural fluids contained in an aquifer with high natural rock permeability and porosity to ensure long-term production at economically acceptable levels. When sufficient natural recharge to the hydrothermal system does not occur, which is often the case, a reinjection scheme is necessary to ensure production rates will be maintained.

Thermal energy is extracted from the reservoir by coupled transport processes (convective heat transfer in porous and/or fractured regions of rock and conduction through the rock itself). The heatextraction process must be designed with the constraints imposed by prevailing in situ hydrologic, lithologic, and geologic conditions. Typically, hot water or steam is produced and its energy is converted into a marketable product (electricity, process heat, or space heat). Any waste products must be properly treated and safely disposed of to complete the process. Many aspects of geothermal heat extraction are similar to those found in the oil, gas, coal, and mining industries. Because of these similarities, equipment, techniques, and terminology have been borrowed or adapted for use in geothermal development, a fact that has, to some degree, accelerated the development of geothermal resources. Nonetheless, there are inherent differences that have limited development such as higher well-flow requirements and temperature limitations to drilling and logging operations (see Chapters 4 and 6 for details).

The U.S. Department of Energy has broadly defined Enhanced (or engineered) Geothermal Systems (EGS) as engineered reservoirs that have been created to extract economical amounts of heat from low permeability and/or porosity geothermal resources. For this assessment, we have adapted this definition to include all geothermal resources that are currently not in commercial production and require stimulation or enhancement. EGS would exclude high-grade hydrothermal but include conductiondominated, low-permeability resources in sedimentary and basement formations, as well as geopressured, magma, and low-grade, unproductive hydrothermal resources. In addition, we have added coproduced hot water from oil and gas production as an unconventional EGS resource type that could be developed in the short term and possibly provide a first step to more classical EGS exploitation.

EGS concepts would recover thermal energy contained in subsurface rocks by creating or accessing a system of open, connected fractures through which water can be circulated down injection wells, heated by contact with the rocks, and returned to the surface in production wells to form a closed loop (Figure I.I). The idea itself is a simple extrapolation that emulates naturally occurring hydrothermal circulation systems - those now producing electricity and heat for direct application commercially in some 7I countries worldwide. 


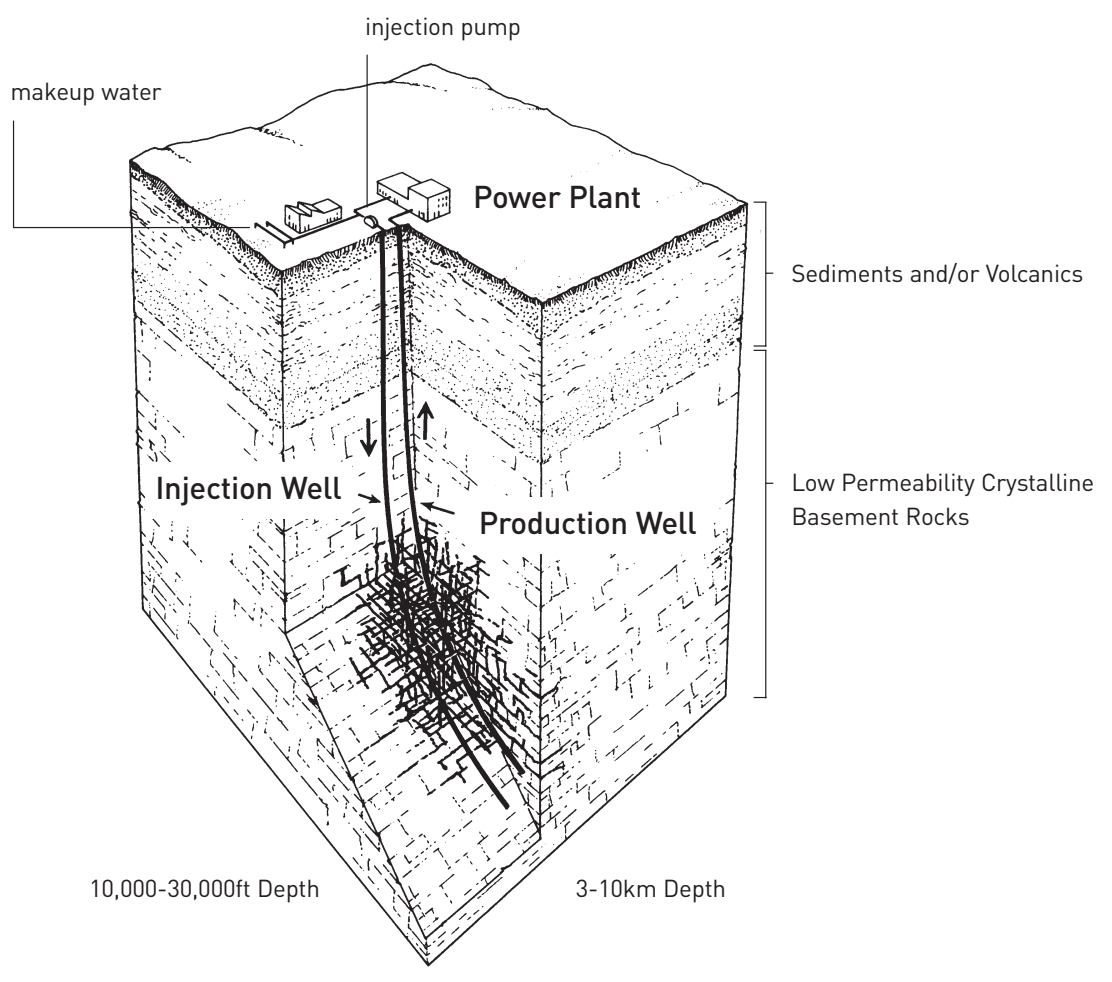

Figure 1.1 Schematic of a conceptual two-well Enhanced Geothermal System in hot rock in a low-permeability crystalline basement formation.

In principle, conduction-dominated EGS systems in low-permeability sediments and basement rock are available all across the United States. The first step would be exploration to identify and characterize the best candidate sites for exploitation. Holes then would be drilled deep enough to encounter useful rock temperature to further verify and quantify the specific resource at relevant depths for exploitation. If low-permeability rock is encountered, it would be stimulated hydraulically to produce a large-volume reservoir for heat extraction and suitably connected to an injectionproduction well system. If rock of sufficient natural permeability is encountered in a confined geometry, techniques similar to water-flooding or steam-drive employed for oil recovery might be used effectively for heat mining (Tester and Smith, I977; Bodvarsson and Hanson, I977). Other approaches for heat extraction employing downhole heat exchangers or pumps, or alternating injection and production (huff-puff) methods, have also been proposed.

\subsection{U.S. Geothermal Resource Base}

The last published comprehensive study of geothermal energy by the U.S. Geological Survey appeared in 1979 (USGS Circular 790). As a result, we have relied on published data and projections that have appeared since I979 to update and refine the earlier USGS estimates.

We have not tried to improve on USGS estimates of the hydrothermal resources, as they represent a high-grade component of the geothermal resource that is already undergoing commercial development in the United States. For this assessment, we have divided the EGS resource into categories as shown in Table I.I. (For information on energy conversion factors, see Appendix A.) In addition to the conduction-dominated portions of the EGS resource in sediments and basement rock formations, we added three categories: geopressured, volcanic, and coproduced fluids. Resource base estimates for geopressured and supercritical volcanic systems were taken directly from the USGS Circulars 726 and 790. Coproduced fluids is a new category of EGS that was also included in our assessment. It represents heated water that is produced as an integral part of oil and gas production. Estimates in this category were based on ongoing work in Blackwell's group (McKenna et al., 2005, in Chapter 2). 
Table 1.1 Estimated U.S. geothermal resource base to $10 \mathrm{~km}$ depth by category.

\begin{tabular}{|c|c|c|}
\hline Category of Resource & $\begin{array}{l}\text { Thermal Energy, in } \\
\text { Exajoules }\left(1 \mathrm{EJ}=10^{18} \mathrm{~J}\right)\end{array}$ & Reference \\
\hline \multicolumn{3}{|l|}{ Conduction-dominated EGS } \\
\hline Sedimentary rock formations & 100,000 & This study \\
\hline Crystalline basement rock formations & $13,300,000$ & This study \\
\hline Supercritical Volcanic EGS* & 74,100 & USGS Circular 790 \\
\hline Hydrothermal & $2,400-9,600$ & USGS Circulars 726 and 790 \\
\hline Coproduced fluids & $0.0944-0.4510$ & McKenna, et al. (2005) \\
\hline Geopressured systems & $71,000-170,000 * *$ & USGS Circulars 726 and 790 \\
\hline
\end{tabular}

* Excludes Yellowstone National Park and Hawaii

** Includes methane content

While this report uses SI units with energy expressed in exajoules (EJ), these are relatively unfamiliar to most people. Table A.I provides energy equivalents for other unit systems.

Today's hydrothermal systems rarely require drilling deeper than $3 \mathrm{~km}$ (I०,००० ft), while the technical limit for today's drilling technology is to depths greater than Io $\mathrm{km}(30,000 \mathrm{ft})$. Consistent with earlier USGS assessments, we adopted a Io km limiting depth to define the total geothermal resource base. We assumed that resources at depths of less than $3 \mathrm{~km}$ are contained in hydrothermal resource base or are associated with hydrothermal temperature anomalies. Consequently, a minimum depth of $3 \mathrm{~km}$ was used for EGS resources in this study. The recoverable resource associated with identified hydrothermal resources has been separately estimated by the USGS and others.

Without question, the largest part of the EGS resource base resides in the form of thermal energy stored in sedimentary and basement rock formations, which are dominated by heat conduction and radiogenic processes. These are reasonably quantifiable on a regional basis in terms of rock temperatures at depth, densities, and heat capacities. Southern Methodist University has developed a quantitative model for refining estimates of the EGS resource in sedimentary and basement rocks. While Chapter 2 details their methodology and calculations, here we present only salient results regarding the magnitude and distribution of the U.S. EGS resource.

Figure I.2 shows the heat flow of the conterminous United States where one easily sees that the western region of the country has higher heat flow than the eastern part. This fact leads to substantial regional differences in rock temperature as a function of depth. Figures I.3-I.5 illustrate this by showing temperatures at depths of 3.5, 6.5 , and io $\mathrm{km}$, respectively. The resource base for the sedimentary and basement sections of EGS resources were computed by first subdividing the subsurface into I km-thick, horizontal slices of rock. Using the temperature versus depth information from the SMU database, the amount of stored thermal energy for a given location (specified by longitude and latitude coordinates within the United States) could easily be determined for each slice (see Figure 2.3 and the corresponding discussion). Figure I.6 shows the amount of energy in each slice as a function of temperature at depths to Io $\mathrm{km}$ for the entire United States. This histogram provides a rough estimate of the energy potentially available for each EGS resource grade (given by initial rock temperature and the depth). Higher grades would correspond to hotter, shallower resources. 


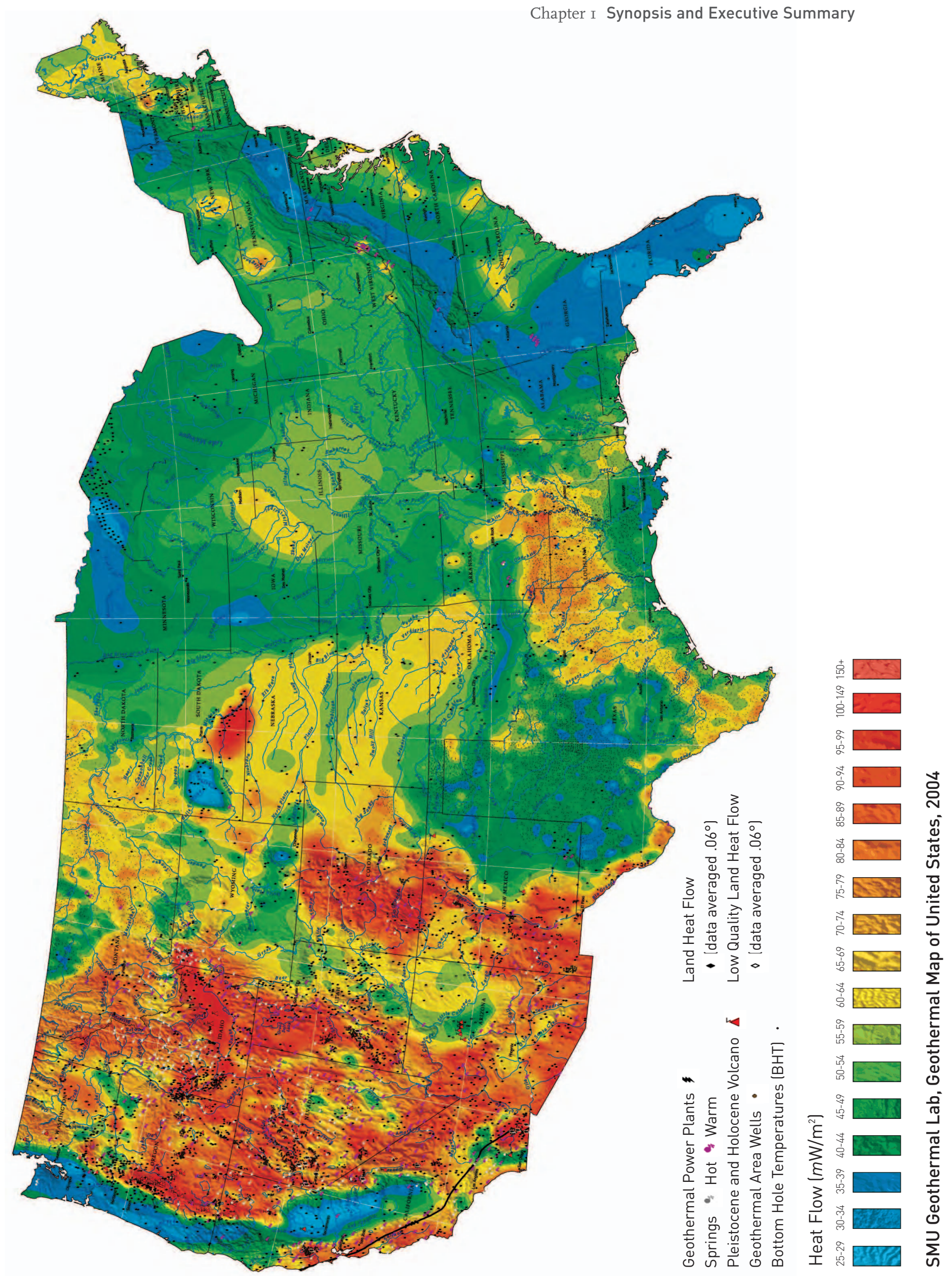

Figure 1.2 Heat-flow map of the conterminous United States - a subset of the geothermal map of North America (Blackwell and Richards, 2004) 


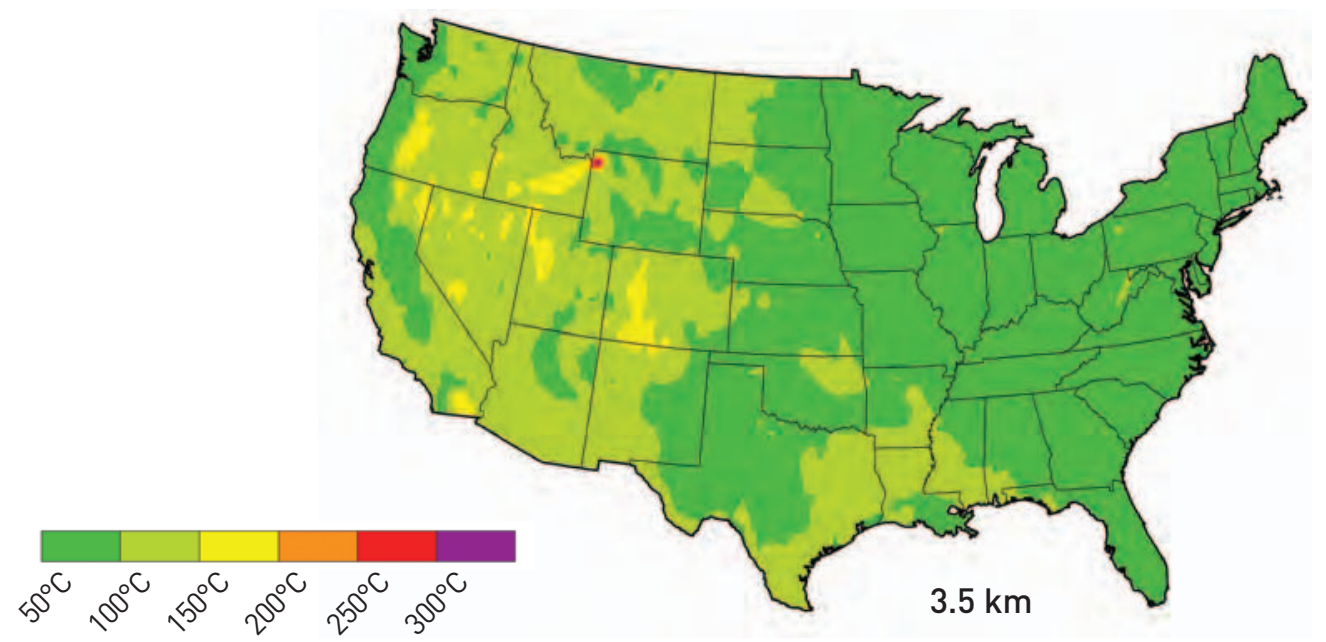

Figure 1.3 Temperatures at a depth of $3.5 \mathrm{~km}$.

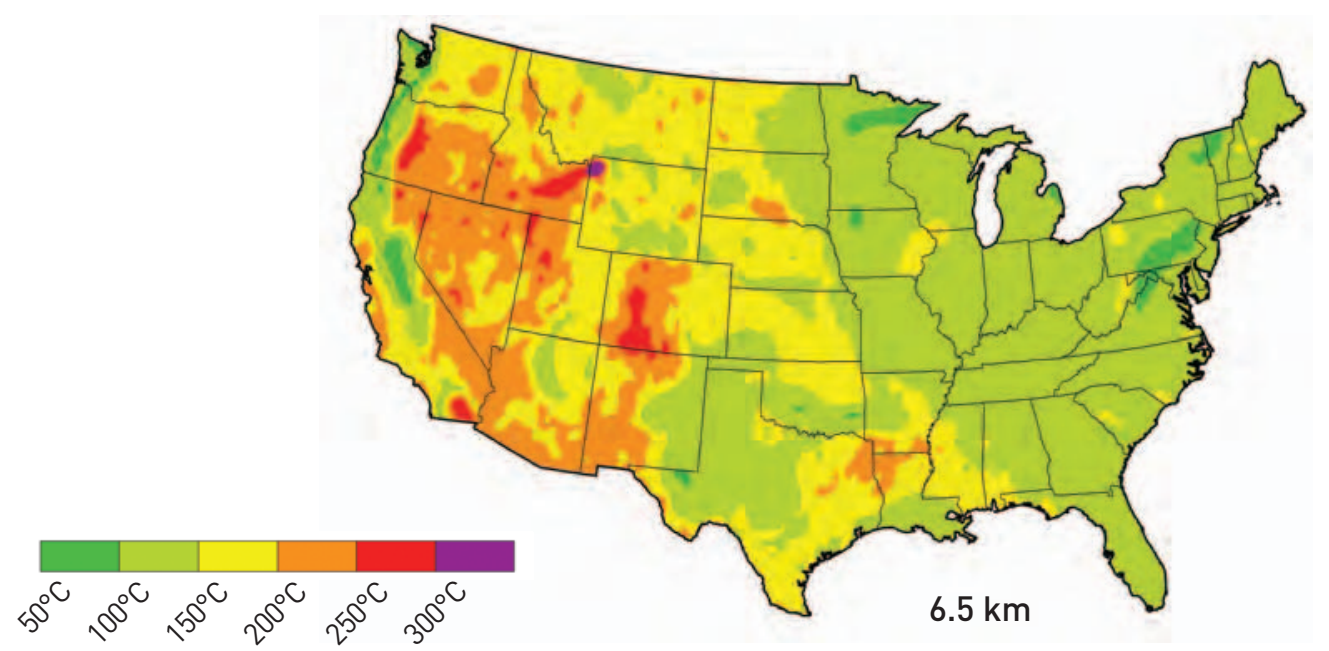

Figure 1.4 Temperatures at a depth of $6.5 \mathrm{~km}$.

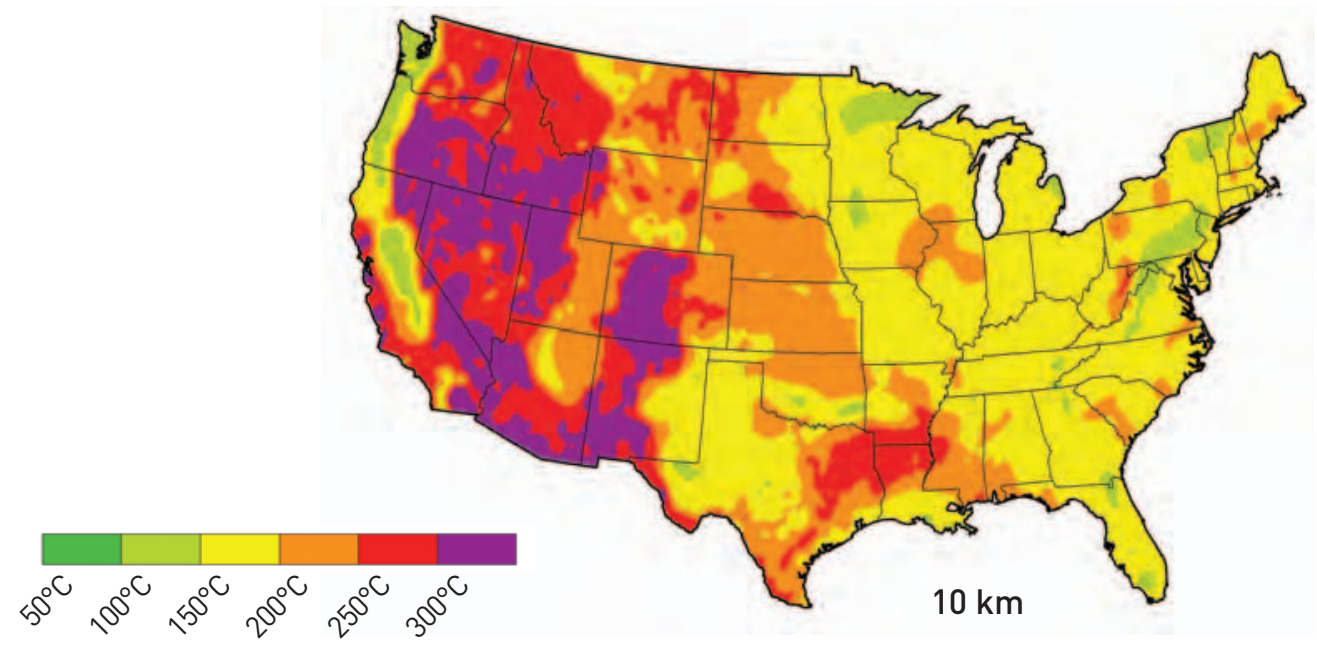

Figure 1.5 Temperatures at a depth of $10 \mathrm{~km}$. 


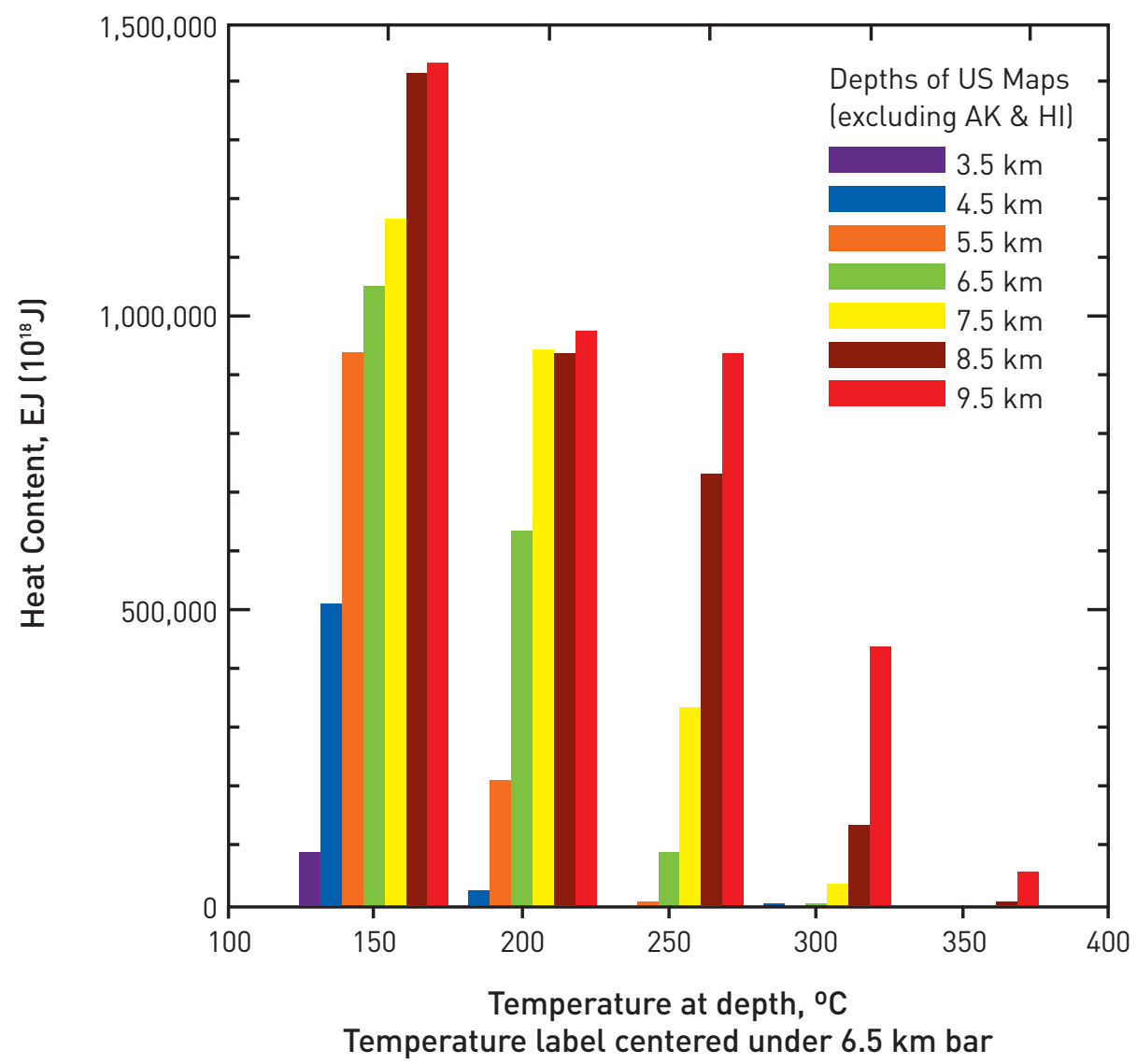

Figure 1.6 Histograms of heat content as thermal energy, as a function of depth for $1 \mathrm{~km}$ slices. For each temperature indicated, the total thermal energy content contained in a $1 \mathrm{~km}$-thick slice over the entire U.S. area is plotted.

The total resource base to a depth of io $\mathrm{km}$ can also be estimated. Values are tabulated in Table I.I. By almost any criteria, the accessible U.S. EGS resource base is enormous - greater than I3 million quads or 130,000 times the current annual consumption of primary energy in the United States. Of course, the economically recoverable reserve for EGS will be much lower, subject to many technical and economic constraints that are evaluated throughout this report.

We can easily see that, in terms of energy content, the sedimentary and basement EGS resources are by far the largest and, for the long term, represent the main target for development. However, in the shorter term, it makes sense to develop higher-grade EGS resources. For example, very high thermal gradients often exist at the margins of hydrothermal fields. Because wells there would be shallower $(<4 \mathrm{~km})$ and hotter $\left(>200^{\circ} \mathrm{C}\right)$ with infrastructure for power generation and transmission often in place, such high-grade regions could easily be viewed as initial targets of opportunity.

To extract thermal energy economically, one must drill to depths where the rock temperatures are sufficiently high to justify investment in the heat-mining project. For generating electricity, this will normally mean drilling to rock temperatures in excess of $150^{\circ} \mathrm{C}$ to $200^{\circ} \mathrm{C}$; for many space or process heating applications, much lower temperatures would be acceptable, such as $100^{\circ} \mathrm{C}$ to $150^{\circ} \mathrm{C}$.

Although beyond the scope of this assessment, it is important to point out that even at temperatures below $50^{\circ} \mathrm{C}$, geothermal energy can have a significant impact. Geothermal heat pumps provide an important example of how low-grade thermal energy, available at shallow depths from 2 to $200 \mathrm{~m}$, leads to substantial energy savings in the heating and cooling of buildings. For example, with a practical coefficient of performance (COP) of 4 or better year-round in the U.S. Midwest, it is often 
possible to achieve more than $75 \%$ savings in electrical energy consumption per unit of heating or cooling delivered to the building. Because the use of geothermal heat pumps is often treated as an energy efficiency measure rather than as energy supply - and because they are readily available commercially - more than I million units had been installed in the United States by the end of 2005 .

For a geothermal resource to be viable, in addition to having sufficiently high temperature, in situ hydrologic and lithologic conditions need to be favorable. In existing vapor- and liquid-dominated hydrothermal systems, this amounts to having a rock system (reservoir) that has high permeability and high porosity filled with steam or water under pressure. If such conditions do not exist naturally, then the rock system must be stimulated to generate or modify a reservoir to make it sufficiently productive. This is the essence of EGS, where the reservoir is engineered to have it emulate the productivity of a viable hydrothermal system. A range of lithologic and geologic properties are important for determining EGS stimulation approaches. Most important, the state of stress at depths of interest must be known. In addition, other features of the rock mass that influence the probability of creating suitable inter-well connectivity include natural fracture spacing, rock strength, and competence.

\subsection{Estimating the Recoverable Portion of EGS}

Estimating the recoverable fraction of any underground resource is inherently speculative, whether it is for oil or gas, geothermal energy, or a specific mineral. Typically, some type of reservoir simulation model is used to estimate how much can be extracted. To reduce errors, predicted results are validated with field data when available. This type of "history matching" is commonly used in reservoir analysis.

Sanyal and Butler (2005) have modeled flow in fractured reservoirs using specified geometries to determine the sensitivity of the calculated recoverable heat fraction to rock temperature, fractured volume, fracture spacing, fluid circulation rate, well configuration, and post-stimulation porosity and permeability. They used a 3-dimensional finite difference model and calculated the fraction of the thermal energy in place that could be mined for a specified set of reservoir properties and geometry. Interestingly, for a range of fracture spacings, well geometries, and fracture permeabilities, the percentage of recoverable thermal energy from a stimulated volume of at least I x I० ${ }^{8} \mathrm{~m}^{3}\left(0 . \mathrm{I} \mathrm{km}^{3}\right)$ under economic production conditions is nearly constant at about $40 \pm 7 \%$ (see Figure 3.I). Furthermore, this recovery factor is independent of well arrangements, fracture spacing, and permeability, as long as the stimulated volume exceeds I x $10^{8} \mathrm{~m}^{3}-$ a value significantly below what has been already achieved in several field projects.

The Sanyal-Butler model was used as a starting point to make a conservative estimate for EGS resource recovery. Channeling, short circuiting, and other reservoir-flow problems sometimes have been seen in early field testing, which would require remediation or they would limit capacity. Furthermore, multiple EGS reservoirs would have a specified spacing between them in any developed field, which reduces the reservoir volume at depth per unit surface area. Given the early stage of EGS technology, Sanyal-Butler estimated $40 \%$ recovery factor was lowered to $20 \%$ and $2 \%$ to account for these effects, and reservoir spacings of $\mathrm{I} \mathrm{km}$ at depth were specified to provide a more conservative range for EGS.

With a reservoir recovery factor specified, another conservative feature was introduced by limiting the thermal drawdown of a region where heat mining is occurring. The resource base figures given in Table I.I use the surface temperature as the reference temperature to calculate the total thermal energy content. A much smaller interval was selected to limit the amount of energy extracted by specifying a reservoir abandonment temperature just $10^{\circ} \mathrm{C}$ below the initial rock temperature at depth. 
Finally, the recoverable heat in $\mathrm{kJ}$ or $\mathrm{kW}$-s in a given $\mathrm{I} \mathrm{km}$ slice per unit of surface area was then determined from the total energy in place at that depth, i.e., the resource-base amount (results are shown in Figure I.7). A final limiting factor was introduced to account for the fact that only a portion of the land area in the United States is accessible for EGS development. Areas within national parks and monuments, wilderness areas, etc., would be off-limits to EGS, as well as some locations near and within large urban areas or utility and transportation corridors.

In addition to estimating the recoverable fraction of energy that can be extracted from the total EGS resource, it is important to also estimate the amount of surface-land area and subsurface rock volume required for an EGS plant. For scaling purposes, we have based an analysis of above-ground requirements on those needed for existing hydrothermal systems (see Chapters 7 and 8), while belowground requirements were based on the amount of rock volume needed to sustain plant operations for a 20 -year period. These are tabulated for a range of plant sizes on a per $\mathrm{MW}_{\mathrm{e}}$ basis for the surface plant and auxiliaries, and for the subsurface reservoir in Table I.2.

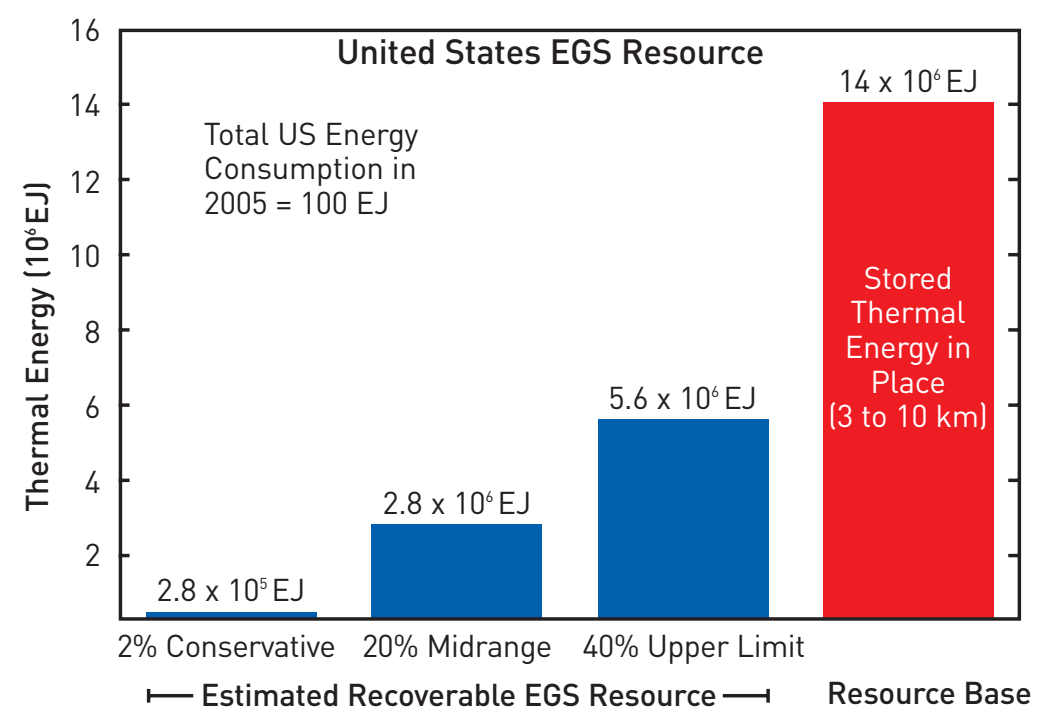

Figure 1.7 Estimated total geothermal resource base and recoverable resource given in EJ or $10^{18}$ Joules. Note: Other energy equivalent units can be obtained using conversion factors given in Appendix A.

Table 1.2 Estimated land area and subsurface reservoir volumes needed for EGS development. Note: Above $100 \mathrm{MW}_{\mathrm{e}}$, reservoir size scaling should be linear.

\begin{tabular}{l|l|l}
\hline Plant size in $\mathrm{MW}_{\mathrm{e}}$ & $\begin{array}{l}\text { Surface area for power plant } \\
\text { and auxiliaries in } \mathrm{km}^{2}\end{array}$ & $\begin{array}{l}\text { Subsurface reservoir } \\
\text { volume in } \mathrm{km}^{3}\end{array}$ \\
\hline 25 & 1 & 1.5 \\
\hline 50 & 1.4 & 2.7 \\
\hline 75 & 1.8 & 3.9 \\
\hline 100 & 2.1 & 5.0 \\
\hline
\end{tabular}

I. Assuming Io\% heat to electric-power efficiency, typical of binary plants.

2. Introduces a factor of 4 to surface area and volumes to deal with redrilling of reservoir at 5-year intervals over a 20 -year projected lifetime. 


\subsection{Geothermal Drilling Technology and Costs}

Well costs are a significant economic component of any geothermal development project. For lowergrade EGS, the cost of the well field can account for $60 \%$ or more of the total capital investment. For making economic projections, estimates of well drilling and completion costs to depths of I०,००० $\mathrm{m}$ $(30,000 \mathrm{ft})$ are needed for all grades of EGS resources. Drill-site specifics, stimulation approaches, well diameters and depths, and well production interval lengths and diameters are just some of the parameters that need to be considered. Drilling records for geothermal wells do not exist in sufficient quantity or detail for making such projections. In recent years, there have been fewer than Ioo geothermal wells drilled per year in the United States and very few of them are deeper than $2,800 \mathrm{~m}(9,000 \mathrm{ft})$, which provides no direct measure of well costs for deeper EGS targets for the long term.

Insight into geothermal well costs is gained by examining trends from experience in the oil and gas well-drilling industry. Thousands of oil and gas wells are drilled each year in the United States, and data on their costs are available on a yearly basis from the American Petroleum Institute's Joint Association Survey (JAS) (see API, 2006). Additionally, the similarity between oil and gas wells and geothermal wells makes it possible to develop a drilling cost index that can be used to normalize any geothermal well cost from the past three decades to present current values, so that the well costs can be compared on a common dollar basis.

Because of the limited data available for geothermal drilling, our analysis employed the Wellcost Lite model, developed by Bill Livesay and coworkers at Sandia National Laboratories during the past 20 years, to estimate the cost of EGS wells. The model can accommodate expected ranges in a multitude of parameters (well diameter, bit life, penetration rate, casing design, geologic formation conditions, etc.). Improvements in drilling technology can also be incorporated into the model, as well as directional drilling with multilateral completion legs. Wells in the depth ranges from I,500 $\mathrm{m}(4,920$ $\mathrm{ft})$ to $10,000 \mathrm{~m}(32,800 \mathrm{ft})$ were modeled in three categories: shallow wells $(\mathrm{I}, 500-3,000 \mathrm{~m})$, midrange wells (4,000-5,000 $\mathrm{m})$, and deep wells (6,000-10,000 m).

EGS well costs are significantly influenced by the number of casing strings used. For example, two 5,000 m-deep wells were modeled, one with four casing intervals and another with five casing intervals. Whereas the former requires fewer casing intervals, the increased lengths of individual sections may raise concerns about wellbore stability. This is less of a risk if more casing strings are used, but costs will be adversely affected by an increase in the diameter of the upper casing strings, the size of the rig required, and a number of other parameters. The $6,000 \mathrm{~m}$ well was modeled with both five- and six-casing intervals. Costs for the 7,500 $\mathrm{m}$ and $10,000 \mathrm{~m}$ wells were estimated using six casing intervals.

Shallow wells at depths of I,500, 2,500, and 3,000 $\mathrm{m}$ are representative of current hydrothermal practice. Predicted costs from the Wellcost Lite model were compared to actual EGS and hydrothermal well drilling-cost records, where available. Figure r.8 shows the actual costs of geothermal wells, including some EGS wells. The costs predicted by the Wellcost Lite model show adequate agreement with actual geothermal well costs, within the normal ranges of expected variation for all depths. 


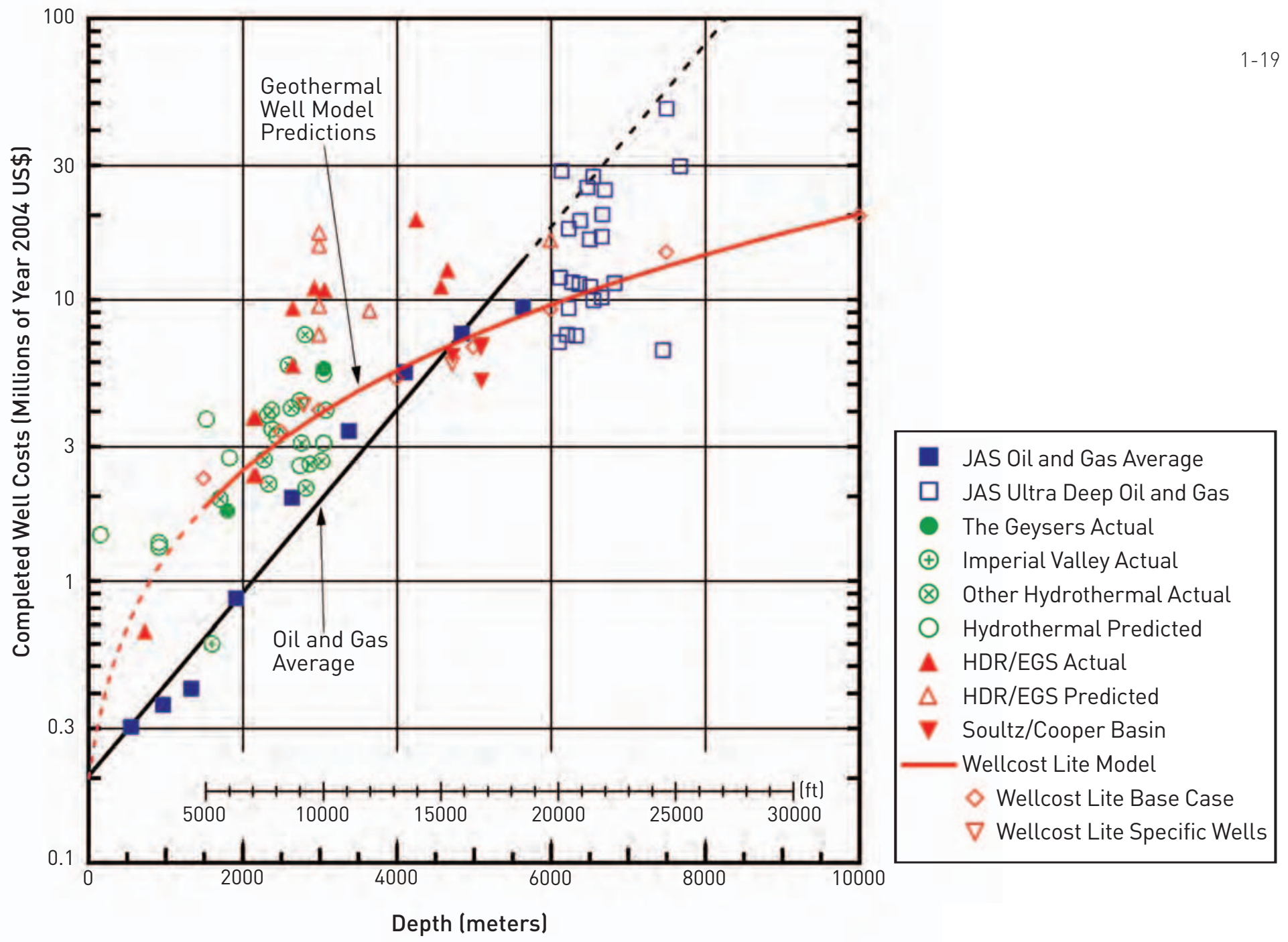

1. JAS = Joint Association Survey on Drilling Costs.

2. Well costs updated to US\$ (yr. 2004) using index made from 3-year moving average for each depth interval listed in JAS (1976-2004) for onshore, completed US oil and gas wells. A 17\% inflation rate was assumed for years pre-1976.

3. Ultra deep well data points for depths greater than $6 \mathrm{~km}$ are either individual wells or averages from a small number of wells listed in JAS (1994-2000).

4. “Other Hydrothermal Actual” data include some non-US wells (Source: Mansure 2004).

Figure 1.8 Completed oil, gas, and geothermal well costs as a function of depth in 2004 U.S.\$, including estimated costs from the Wellcost Lite model. The red line provides average well costs for the base case used in the assessment.

Nonetheless, given the scarcity of the geothermal well cost data compared to oil and gas wells, estimating statistically meaningful well costs at particular depths was not possible, so average costs were based on model predictions with a large degree of inherent uncertainty. Well-design concepts and predictions for the deeper categories $-6,000 \mathrm{~m}, 7,500 \mathrm{~m}$, and 10,000 m (19,680 ft, 24,600 ft, and 32,800 ft) - are obviously even more speculative, as there have been only two or three wells drilled close to depths of I०,০०० $\mathrm{m}$ in the United States. Because of this, a conservative well design was used to reflect this higher uncertainty. 
Emerging technologies, which have yet to be demonstrated in geothermal applications and are still going through development and commercialization, can be expected to significantly reduce the cost of these wells, especially those at 4,000 $\mathrm{m}$ and deeper. One technology that will potentially reduce the cost of the well construction (casing and cementing) is expandable tubular casing, a patented invention by Shell Oil (Lohbeck, I993). The concept has been licensed to two commercial firms. There are still concerns about the effect of thermal expansion and the depth of reliable application of the expanded casing when in place.

Drilling-with-casing is another new technology that has the potential to reduce cost. This approach may permit longer casing intervals, leading to fewer strings and, therefore, reduced costs. Research is needed to improve our understanding of cementing practices that apply to the drilling-with-casing technique.

Well-design changes, particularly involving the use of smaller increments in casing diameters with depth, are likely to significantly reduce EGS well costs. This well-design approach requires detailed analysis to resolve concerns about pressure drops during cementing. It may be limited to cemented liners.

Being able to increase borehole diameter by under-reaming is a key enabling technology for almost all of the EGS drilling applications, including current and future drilling technologies. The development of an under-reamer that is reliable and can penetrate at the same rate as the lead bit is a necessity. Current work at Sandia on small-element drag cutters in geothermal formations may enable drag-cutter under-reamers (the standard for oil and gas applications) to be a viable tool for geothermal application.

Rate-of-penetration ( $R O P$ ) issues can significantly affect drilling costs in crystalline formations. ROP problems can cause well-cost increases by as much as $15 \%$ to $20 \%$ above those for more easily drilled basin and range formations.

Casing diameters that decrease with depth are commonplace in conventional casing designs for the hydrothermal, and oil and gas industries. Unfortunately, geothermal wells currently require largerdiameter casings than oil/gas wells. However, this simply means that EGS wells will benefit even more from the use of successful evolving technologies, which have the potential to reduce the cost of the deep wells by as much as \$2.5 million to \$3 million per well.

In the longer term, particularly when lower-grade EGS resources are being developed, more revolutionary approaches could have a large impact on lowering EGS drilling costs, in that they could increase both ROP and bit lifetime as well as facilitate under-reaming. For example, such approaches would reduce the number of times the drill string would have to be removed from the hole to change drill bits. Three revolutionary drilling technology examples include hydrothermal flame spallation and fusion drilling (Potter and Tester, I998), chemically enhanced drilling (Polizotti, 2003), and metal shot abrasive-assisted drilling (Curlett and Geddes, 2006). Each of these methods augments or avoids the traditional method of penetration based on crushing and grinding rock with a hardened material in the drill bit itself, thereby reducing the tendency of the system to wear or fail.

\subsection{EGS Reservoir Stimulation - Status of International Field Testing and Design Issues}

Creating an Enhanced Geothermal System requires improving the natural permeability of hot rock. Rocks are naturally porous by virtue of minute fractures and pore spaces between mineral grains. 
When some of this porosity is interconnected so that fluids (water, steam, natural gas, crude oil) can flow through the rock, such interconnected porosity is called permeability.

Rock permeability extends in a continuum over several orders of magnitude, from rocks that are highly permeable and whose contained fluids can be produced by merely drilling wells (e.g., oil and gas wells, water wells, hydrothermal systems), to those that are almost completely impermeable (e.g., tight gas sands, hot dry rock). Extensive drilling for petroleum, geothermal, and mineral resources during the past century has demonstrated that the largest heat resource in the Earth's crust, by far, is contained in rocks of low natural permeability. Recovery of heat from such rocks at commercial rates and competitive costs is the object of the EGS program.

This EGS assessment draws heavily on research funded by the DOE and ongoing EGS work around the world. The knowledge gained from this research in the United States and elsewhere, reviewed below, forms a robust basis for the future enhancements of this growing knowledge base.

Since the I970s, research projects aimed at developing techniques for the creation of geothermal reservoirs in areas that are considered noncommercial for conventional hydrothermal power generation have been - and are being - conducted around the world. These include the following:

- United States: Fenton Hill, Coso, Desert Peak, Glass Mountain, and The Geysers/Clear Lake

- United Kingdom: Rosemanowes

- France: Soultz, Le Mayet de Montagne

- Japan: Hijiori and Ogachi

- Australia: Cooper Basin, Hunter Valley, and others

- Sweden: Fjallbacka

- Germany: Falkenberg, Horstberg, and Bad Urach

- Switzerland: Basel and Geneva

Techniques for extracting heat from low-permeability, hot dry rock (HDR) began at the Los Alamos National Laboratory in 1974 (Armstead and Tester, I987). For low-permeability formations, the initial concept is quite straightforward: drill a well to sufficient depth to reach a useful temperature, create a large heat-transfer surface area by hydraulically fracturing the rock, and intercept those fractures with a second well. By circulating water from one well to the other through the stimulated region, heat can be extracted from the rock. Fundamentally, this early approach - as well as all later refined methods requires that good hydraulic conductivity be created between injection and production wells through a large enough volume of rock to sustain economically acceptable energy-extraction rates and reservoir lifetimes. Ultimately, field testing will need to produce a commercial-sized reservoir that can support electricity generation or cogeneration of electrical power and heat for a variety of applications such as heat for industrial processes and local district heating.

As expected in the early development of any new technology, many lessons have been learned from 30 years of EGS field research in the eight countries listed above. For example, the initial concept of producing discrete hydraulic fractures has largely been replaced by stimulating the natural fracture system. Although the goal of operating a commercial-sized EGS reservoir has not been achieved yet, 
field testing has successfully demonstrated that reservoirs of sufficient size with nearly sufficient connectivity to produce fluids at commercial rates can be established.

Through field tests in low-permeability crystalline rock, researchers have made significant progress in understanding reservoir characteristics, including fracture initiation, dilation and propagation, thermal drawdown, water loss rates, flow impedance, fluid mixing, and fluid geochemistry. In addition to using hydraulic stimulation methods to establish connectivity in the far field, it is feasible to create permeability near injection or production wellbores by explosive fracturing, chemical leaching, and thermal stress cracking (Armstead and Tester, I987; Tester et al., I989).

Included among the milestones that have been achieved are:

- Drilling deep directionally oriented wells to specific targets.

- Creation of contained fracture systems in large volumes of rock of $\mathrm{I} \mathrm{km}^{3}$ or more.

- Improved understanding of the thermal-hydraulic mechanisms controlling the opening of fracture apertures.

- Improved methods for sequencing the drilling of wells, stimulating reservoirs, and managing fluid flow and other hydraulic characteristics.

- Circulation of fluid at well-flow rates of up to $25 \mathrm{~kg} / \mathrm{s}$ on a continuous basis.

- Methods to monitor and manage induced microseismicity during stimulation and circulation.

- Extraction of heat from well-defined regions of hot fractured rock without excessive thermal drawdown.

- Generation of electrical power in small pilot plants.

Nonetheless, there are outstanding issues that must be resolved before EGS can be considered commercial. In general, these are all connected to enhancing the connectivity of the stimulated reservoir to the injection and production well network. Notably, they are incremental in their scope, representing extending current knowledge and practical field methods. There are no anticipated "showstoppers" or fundamental constraints that will require new technologies to be discovered and implemented to achieve success. The remaining priority issue is demonstrating commercial levels of fluid production from several engineered EGS reservoirs over acceptable production periods. Specific research and field-testing goals can be placed into two categories:

1. Primary goals for commercial feasibility:

- Develop and validate methods to achieve a twofold to fourfold increase in production well-flow rate from current levels, while maintaining sufficient contact with the rock within the reservoir and ensuring sufficient reservoir lifetime.

- Validate long-term operability of achieving commercial rates of heat production from EGS reservoirs for sustained periods of time at several U.S. sites.

2. Secondary goals connected to EGS technology improvement:

- Develop better methods of determining the distribution, density, and orientation of pre-existing and stimulated fractures to optimize overall hydraulic connectivity within the stimulated reservoir. 
- Improve methods to repair or remedy any flow short circuits that may develop.

- Understand the role of major, pre-existing faults in constraining or facilitating the flow in the reservoir.

- Develop robust downhole tools to measure temperature, pressure, flow rate, and natural gamma emissions, capable of surviving in a well at temperatures of $200^{\circ} \mathrm{C}$ or higher for long-term monitoring.

- Predict scaling or deposition through better understanding of the rock-fluid geochemistry.

The advancement of EGS greatly depends on our understanding of the pre-existing, unstimulated, rock-fracture system - and on our ability to predict how the reservoir will behave under stimulation and production. So far, no EGS reservoir has been operated long enough to provide the data needed to validate a simulation model. A reliable reservoir-simulation model will allow us to better estimate the operating and maintenance costs of an EGS energy facility.

As we demonstrate in Chapter 2, the heat stored in the earth beneath the United States - at a depth accessible with today's drilling technology - is truly vast. However, the fraction of this resource base that can be economically recovered is dependent on improving the technology to map, penetrate, fracture, and maintain productive EGS reservoirs - and on improving our understanding of reservoir behavior under long-term energy extraction. These improvements, in turn, are directly connected to the level of research, development, testing, and demonstration of EGS.

While support of research will pay rapid dividends in providing measurable improvements to these important components of EGS technology - as well as technologies for drilling and power conversion mentioned earlier - there is also an opportunity for developing more revolutionary, potentially groundbreaking technologies in the longer term that could make EGS even more useful and universally accessible. For example, in Section I.5, we mentioned three revolutionary drilling methods that could, if perfected, provide increased economic access to EGS by dramatically lowering costs, particularly for low-grade, low-gradient resources. In the reservoir area, there are possibilities as well. One such possibility involves the proposed use of carbon dioxide (in a supercritical state) as a fluid for heat extraction within an EGS reservoir (Brown, 2000). Recently, Pruess and Azaroual (2006) estimated reservoir performance using supercritical carbon dioxide in place of water. Early modeling results suggest improvements in heat-extraction efficiency, as well as the ability to store and sequester carbon dioxide within the confined EGS reservoir for carbon management.

With a fully supported federal R\&D program and anticipated market price increases for electric power, the technology developed in this program could be implemented in a relatively short period of time in high- and mid-grade areas in the Western United States. The knowledge and momentum generated during this early deployment would enable EGS methods to be applied widely across the United States, including lower-grade areas of the Midwest and the East, which have not had any hydrothermal geothermal development yet.

\subsection{Geothermal Energy Conversion Technology}

There are several options for utilizing the thermal energy produced from geothermal systems. The most common is base-load electric power generation, followed by direct use in process and spaceheating applications. In addition, combined heat and power in cogeneration and hybrid systems, and as a heat source and sink for heat pump applications, are options that offer improved energy savings. 
Today, with nearly Iо,००० $\mathrm{MW}_{\mathrm{e}}$ of electricity generated by geothermal worldwide, there are several energy conversion technologies commercially available at various stages of maturity. These include direct steam expansion, single- and multistage steam flashing, organic binary Rankine cycles, and two-phase flow expanders. Figure I.9 shows several representative flow sheets of conversion options applicable for a range of EGS resource grades. Direct-use and heat pump applications are also having an increasing impact, with a combined, estimated market penetration of about I००,००० MWt worldwide.

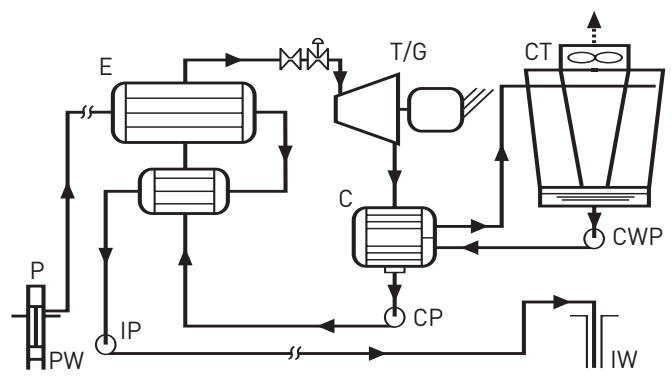

(a)

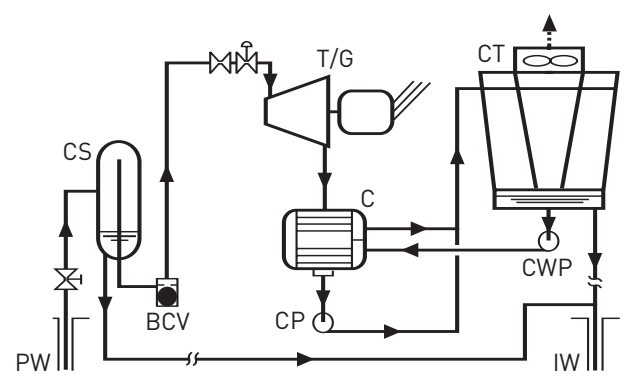

(b)

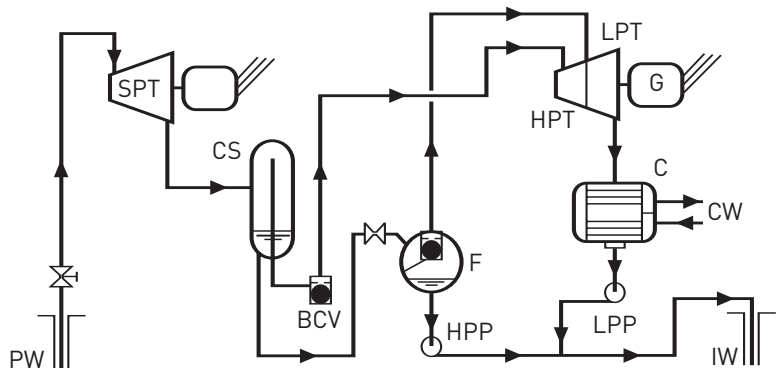

(c)

Figure 1.9 Schematics of EGS power conversion systems: (a) a basic binary power plant; (b) a single-flash power plant; (c) a triple-expansion power plant for supercritical EGS fluids.

There are inherent limitations on converting geothermal energy to electricity, because of the lower temperature of geothermal fluids in comparison to much higher combustion temperatures for fossil fuels. Lower energy source temperatures result in lower maximum work-producing potential in terms of the fluid's availability or exergy; and in lower heat-to-power efficiencies as a consequence of the Second Law of thermodynamics. The value of the availability determines the maximum amount of electrical power that could be produced for a given flow rate of produced geofluid, given a specified temperature and density or pressure. Figure I.Io illustrates how the availability of the geofluid (taken as pure water) varies as a function of temperature and pressure. It shows that increasing pressure and increasing temperature have a nonlinear effect on the maximum work-producing potential. For example, an aqueous geofluid at supercritical conditions with a temperature of $400^{\circ} \mathrm{C}$ and pressure of 250 bar has more than five times the power-producing potential than a hydrothermal liquid water geofluid at $225^{\circ} \mathrm{C}$. Ultimately, this performance enhancement provides an incentive for developing supercritical EGS reservoirs. 


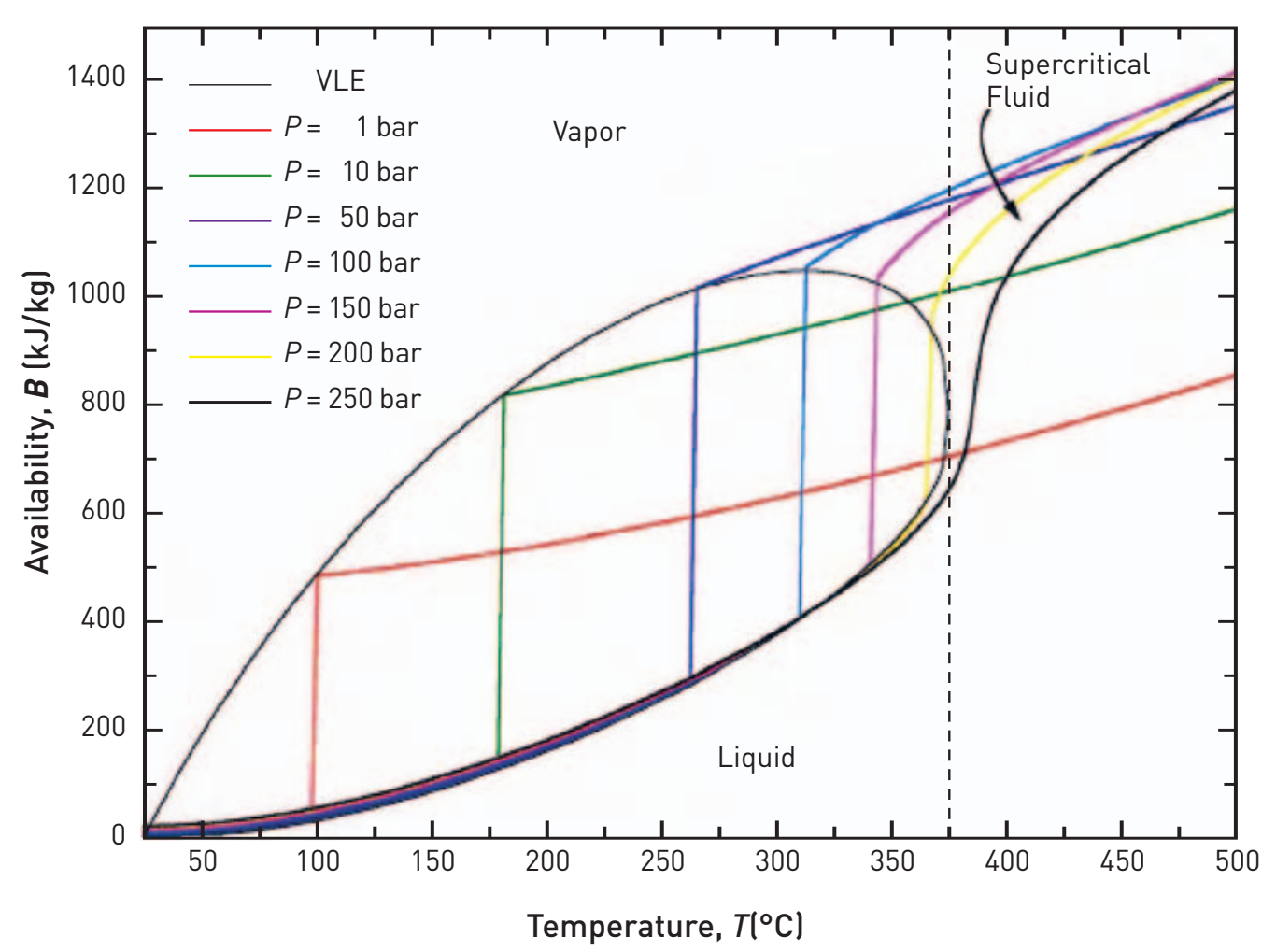

Figure 1.10 Availability diagram for water. The magnitude of the availability is a direct measure of the maximum electrical work- or power-producing potential of aqueous-produced geofluid at specific-state conditions of temperature and pressure.

The large capital investment that is contained in the well-field/reservoir portion of the system places a premium on achieving as high an efficiency as possible for a given geothermal resource, so it is worth putting considerable effort into mitigating these thermodynamic limitations. A utilization efficiency, defined as the ratio of actual net power to maximum possible power, provides a measure of how close the conversion system comes to ideal, reversible operation. Current practice for geothermal conversion systems shows utilization efficiencies typically range from $25 \%$ to $50 \%$. Future engineering practice would like to increase these to $60 \%$ or more, which requires further investments in $R \& D$ to improve heat-transfer steps by minimizing temperature differences and increasing heat-transfer coefficients, and by improving mechanical efficiencies of converters such as turbines, turbo-expanders, and pumps.

Keeping these issues in mind, the panel considered specific cases for a range of EGS resource types and applications:

I. Electricity generation using EGS geofluids from sedimentary and basement rock formations and similar reservoirs, ranging in temperature from $100^{\circ} \mathrm{C}$ to $400^{\circ} \mathrm{C}$, including one case at supercritical conditions;

2. Electricity generation from coproduced oil and gas operations using organic binary power plant designs over resource temperatures ranging from $100^{\circ} \mathrm{C}$ to $180^{\circ} \mathrm{C}$;

3. Combined heat and power - cogeneration of electricity and thermal energy where the conditions at the MIT COGEN plant (nominally $20 \mathrm{MW}_{\mathrm{e}}$ and $\mathrm{I} 40,000 \mathrm{lb} / \mathrm{h}$ steam) were used as a model system. 
Each case in (I)-(3) involved the following steps, using standard methods of engineering design and analysis:

a) identification of the most appropriate conversion system;

b) calculation of the net power per unit mass flow of geofluid;

c) calculation of mass flow required for I, IO, and $50 \mathrm{MW}$ plants;

d) estimation of capital and installed plant costs

Our analysis of surface-conversion systems shows the following:

- Practical, commercial-scale energy conversion systems exist for all EGS geofluid types from low-temperature liquid water at $100^{\circ} \mathrm{C}$ to supercritical water at $400^{\circ} \mathrm{C}$.

- 6,000 to II,000 $\mathrm{MW}_{\mathrm{e}}$ of generating capacity exists in coproduced hot waters associated with land-based domestic oil and gas production operations.

- Installed capital costs for surface conversion plants ranged from $\$ 2,300 / \mathrm{kWe}$ for $100^{\circ} \mathrm{C}$ resource temperatures to $\$ \mathrm{I}, 500 / \mathrm{kWe}$ for $400^{\circ} \mathrm{C}$ resource temperature.

General EGS system properties were treated in one part of the analysis to provide design equations and costs, while several near-term targets of opportunity were also evaluated in somewhat more detail. Chapter 7 describes the technologies analyzed, along with plant-flow sheets and layouts for specific cases.

\subsection{Environmental Attributes of EGS}

When examining the full life cycle of geothermal energy developments, their overall environmental impacts are markedly lower than conventional fossil-fired and nuclear power plants. In addition, they may have lower impacts in comparison to other renewables such as solar, biomass, and wind on an equivalent energy-output basis. This is primarily because a geothermal energy source is contained underground, and the surface energy conversion equipment is relatively compact, making the overall footprint of the entire system small. EGS geothermal power plants operating with closed-loop circulation also provide environmental benefits by having minimal greenhouse gas and other emissions. Being an indigenous resource, geothermal - like other renewable resources - can reduce our dependence on imported fossil fuels. As it provides dispatchable base-load capacity, geothermal even at high levels of penetration - would have no storage or backup-power requirements.

With geothermal energy, there is no need to physically mine materials from a subsurface resource, or to modify the earth's surface to a significant degree as, for example, in strip mining of coal or uranium. Unlike fossil and biomass fuels, geothermal energy is not processed and transported over great distances (an energy-consuming and potentially environmentally damaging process), there are minimal discharges of nitrogen or sulfur oxides or particulate matter resulting from its use, and there is no need to dispose of radioactive materials. However, there still are impacts that must be considered and managed if this energy resource is to be developed as part of a more environmentally sound, sustainable energy portfolio for the future. 
The major environmental issues for EGS are associated with ground-water use and contamination, with related concerns about induced seismicity or subsidence as a result of water injection and production. Issues of noise, safety, visual impacts, and land use associated with drilling and production operations are also important but fully manageable.

As geothermal technology moves away from hydrothermal and more toward larger EGS developments, it is likely that environmental impacts and risks will be further reduced relative to those associated with hydrothermal systems. For example, EGS plants should only rarely have a need for abatement of hydrogen sulfide $\left(\mathrm{H}_{2} \mathrm{~S}\right)$, ammonia $\left(\mathrm{NH}_{3}\right)$, and other chemical emissions.

\subsection{Economic Feasibility Issues for EGS}

This section highlights the role that EGS can play in supplying base-load and distributed electricity in evolving U.S. energy markets. Important factors that favor having EGS as an option will be discussed, including projected demand growth, retirement of existing conventional capacity, transmission access, fuel supply limitation, environmental, and other constraints on expanding fossil and nuclear supply.

Major components affecting risk in geothermal-based electricity and thermal energy production are discussed in Section 9.7.

Geothermal energy, which is transformed into delivered energy (electricity or direct heat), is an extremely capital-intensive and technology-dependent industry. Capital investment can be divided into three distinct phases:

I. Exploration, and drilling of test and production wells

2. Construction of power conversion facilities

3. Discounted future redrilling and well stimulation.

Estimated levelized costs were used as a basis for comparing EGS projections to existing and new energy-supply technologies. The methodology used for the supply curves was analyzed in detail to show how access to potential growth in EGS generation capacity would be available in the United States as a result of the diversity, large size, and distribution of the EGS resource.

Two different economic models - Geothermal Electric Technology Evaluation Model (GETEM) and MIT EGS - were updated and modified to estimate levelized electricity prices for EGS technology over a range of conditions. Starting with specified base-case values that represent financial parameters (debt interest, equity rate of return, etc.), system performance (thermal drawdown rate or reservoir lifetime, well flow rate, number of production and injection wells, etc.), capital costs (site exploration, drilling and redrilling, reservoir stimulation, and surface plant facilities), and operating and maintenance costs, we calculated and validated predicted costs for EGS at targeted, representative sites using both models (see Table I.3), and explored the effects of sensitivity to uncertain parameters, as shown in Figures I.II and I.I2. 


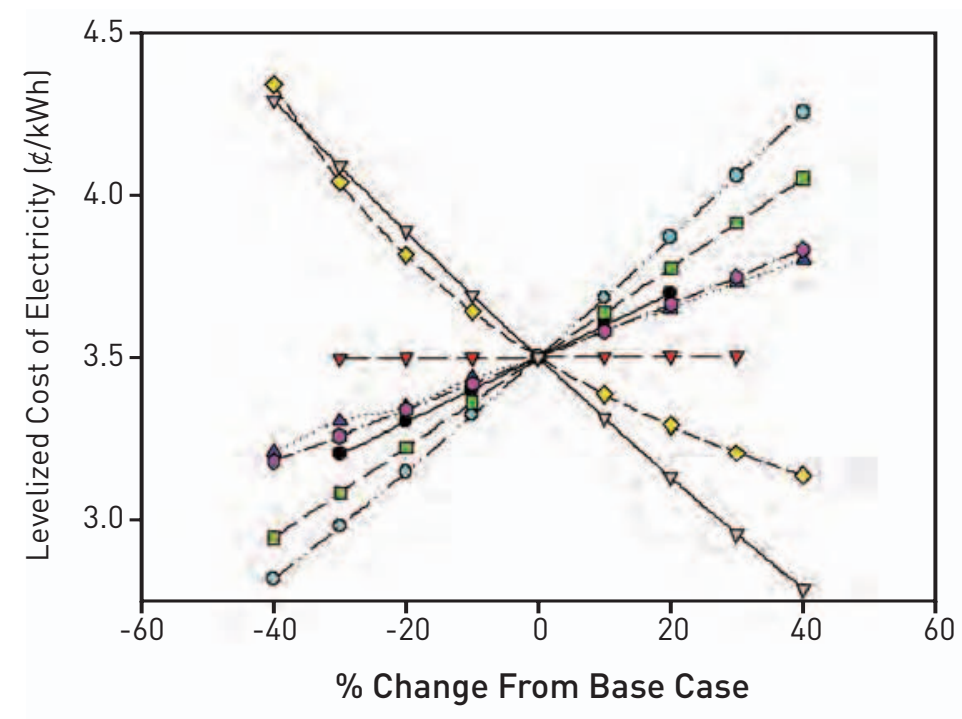

\begin{tabular}{|c|c|}
\hline $\begin{array}{l}\longrightarrow-\text { Drilling \& Completion Cost } \\
-\rightarrow-\text { Stimulation Cost } \\
-\rightarrow-- \text { Surface Plant Capital Cost } \\
---- \text { Flow Rate/Production Well }\end{array}$ & $\begin{array}{l}\ldots \text { Thermal Drawdown Rate } \\
-\ldots-\text { Bond Debt Interest Rate } \\
\square-\ldots \text { Equity Rate of Return } \\
\square \quad \text { Bond vs Equity Debt }\end{array}$ \\
\hline
\end{tabular}

Figure 1.11 Sensitivity for mature technology at a representative high-grade EGS site: $80 \mathrm{~kg} / \mathrm{s}$ flow rate per production well in a quartet configuration (1 injector : 3 producers) for the Clear Lake (Kelseyville, Calif.) scenario showing levelized cost of electricity. (MIT EGS economic model results shown.)

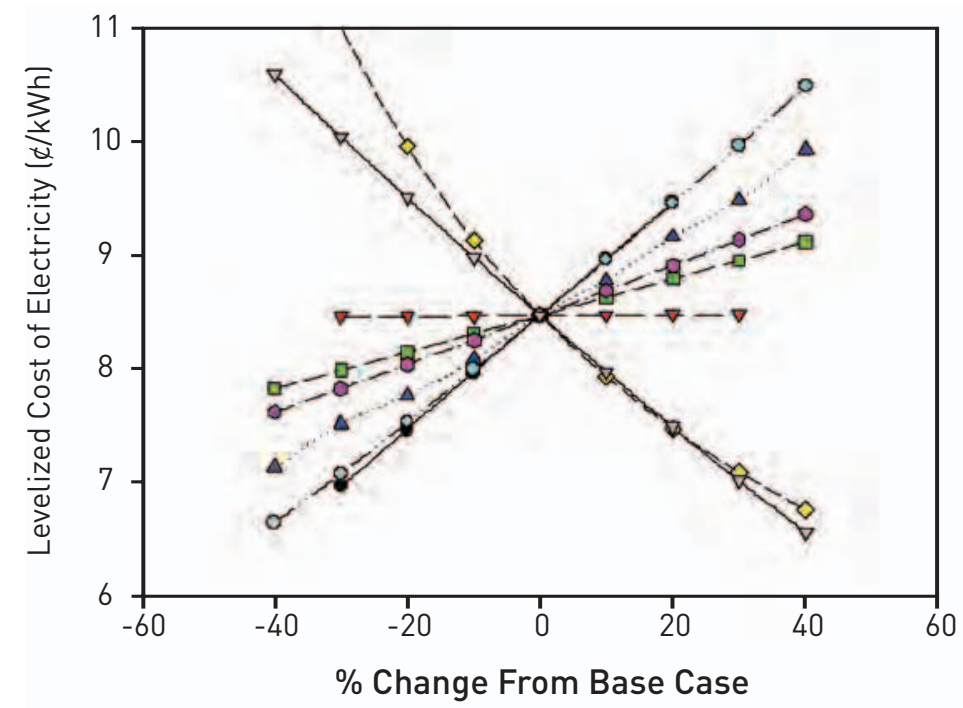

$$
\begin{aligned}
& \longrightarrow \text { Drilling \& Completion Cost } \\
& -\rightarrow-\text { Stimulation Cost } \\
& -\rightarrow-- \text { Surface Plant Capital Cost } \\
& --\diamond-- \text { Flow Rate/Production Well } \\
& \text { ….......... Thermal Drawdown Rate } \\
& \text { - - - - Bond Debt Interest Rate } \\
& \text { _...-.... Equity Rate of Return } \\
& \longrightarrow \text { \% Bond vs Equity Debt }
\end{aligned}
$$

Figure 1.12 Sensitivity for mature technology at a representative low-grade EGS site: $80 \mathrm{~kg} / \mathrm{s}$ flow rate per production well in a quartet configuration ( 1 injector : 3 producers) for the Conway, N.H., scenario showing levelized cost of electricity. (MIT EGS economic model results shown.) 
We assumed a six-year nominal lifetime period for each stimulated reservoir, which led to a complete redrilling and restimulation of the system in six-year intervals for the lifetime of the surface plant facilities, typically 20 to 30 years. Other important factors affecting the levelized energy cost (LEC) include equity and debt interest rates for invested capital, well-drilling costs, surface plant costs, and reservoir flow rate per production well. Table I.3 gives estimated values for six representative EGS sites for the United States, showing the dramatic effect that reservoir fluid flow rate has on LEC, going from an initial value of $20 \mathrm{~kg} / \mathrm{s}$ per well to $80 \mathrm{~kg} / \mathrm{s}$ per well for the two base cases shown.

Table 1.3 Levelized energy cost (LEC) for six selected EGS sites for development.

\begin{tabular}{|c|c|c|c|c|c|c|c|c|}
\hline \multirow[t]{2}{*}{$\begin{array}{l}\text { Site } \\
\text { Name }\end{array}$} & \multirow[t]{2}{*}{$\begin{array}{l}\text { Average } \\
\text { gradient } \\
\partial \mathrm{T} / \partial \mathrm{z} \\
\left({ }^{\circ} \mathrm{C} / \mathrm{km}\right) \\
\text { to well } \\
\text { depth }\end{array}$} & \multirow[t]{2}{*}{$\begin{array}{l}\text { Depth } \\
\text { to } \\
\text { Granite } \\
\text { (km) }\end{array}$} & \multirow[t]{2}{*}{$\begin{array}{l}\text { Well } \\
\text { Depth } \\
(\mathrm{km})\end{array}$} & \multicolumn{2}{|c|}{$\begin{array}{l}\text { Base Case } \\
\text { Initial Values } \\
20 \mathrm{~kg} / \mathrm{s} \\
\text { production rate } \\
\text { LEC }(\$ / \mathrm{kWh})\end{array}$} & \multicolumn{3}{|c|}{$\begin{array}{l}\text { Base Case } \\
\text { Mature Technology } \\
80 \mathrm{~kg} / \mathrm{s} \\
\text { production rate } \\
\text { LEC }(\$ / \mathrm{kWh})\end{array}$} \\
\hline & & & & $\begin{array}{l}\text { MIT } \\
\text { EGS }\end{array}$ & GETEM & $\begin{array}{l}\text { MIT } \\
\text { EGS }\end{array}$ & GETEM & $\begin{array}{l}\text { Depth } \\
(\mathrm{km})\end{array}$ \\
\hline $\begin{array}{l}\text { E. } \\
\text { Texas } \\
\text { Basin, } \\
\text { TX }\end{array}$ & 40 & 5 & 5 & 29.5 & 21.7 & 6.2 & 5.8 & 7.1 \\
\hline $\begin{array}{l}\text { Nampa, } \\
\text { ID }\end{array}$ & 43 & 4.5 & 5 & 24.5 & 19.5 & 5.9 & 5.5 & 6.6 \\
\hline $\begin{array}{l}\text { Sisters } \\
\text { Area, } \\
\text { OR }\end{array}$ & 50 & 3.5 & 5 & 17.5 & 15.7 & 5.2 & 4.9 & 5.1 \\
\hline $\begin{array}{l}\text { Poplar } \\
\text { Dome a, } \\
\text { MT }\end{array}$ & 55 & 4 & 2.2 & 74.7 & 104.9 & 5.9 & 4.1 & 4.0 \\
\hline $\begin{array}{l}\text { Poplar } \\
\text { Dome b, } \\
\text { MT }\end{array}$ & 37 & 4 & 6.5 & 26.9 & 22.3 & 5.9 & 4.1 & 4.0 \\
\hline $\begin{array}{l}\text { Clear } \\
\text { Lake, } \\
\text { CA }\end{array}$ & 76 & 3 & 5 & 10.3 & 12.7 & 3.6 & 4.1 & 5.1 \\
\hline $\begin{array}{l}\text { Conway } \\
\text { Granite, } \\
\mathrm{NH}\end{array}$ & 24 & 0 & 7 & 68.0 & 34.0 & 9.2 & 8.3 & $10 \ddagger$ \\
\hline
\end{tabular}

$\ddagger 10 \mathrm{~km}$ limit put on drilling depth - MIT EGS LEC reaches $7.3 \$ / \mathrm{kWh}$ at $12.7 \mathrm{~km}$ and $350^{\circ} \mathrm{C}$ geofluid temperature. 
Figure I.I3 illustrates a predicted aggregate supply curve for the U.S. EGS resource, regardless of region and not described by a particular depth or stored thermal energy content, using the variable rate of return (VRR) MIT EGS costing model. As expected for any new technology, costs at low levels of penetration are higher than existing markets for electric power, but rapidly decline. When EGS increases above roo $\mathrm{MW}_{\mathrm{e}}$ of capacity, which amounts to only a few EGS projects, costs begin to become competitive. The segmented structure of the supply curve is a reflection of dividing the EGS resource into I km-thick segments (see Figure I.6). The slight increase in break-even price that occurs at higher levels of penetration (above $5,000 \mathrm{MW}_{\mathrm{e}}$ ) is due to extraction of heat from somewhat lower-grade EGS resources (with lower average gradient and heat flow) that require deeper, more costly drilling. However, by the time these levels are reached, it is expected that competitive electricity prices will be equal to or greater than the EGS values, so that further deployment will not be constrained.

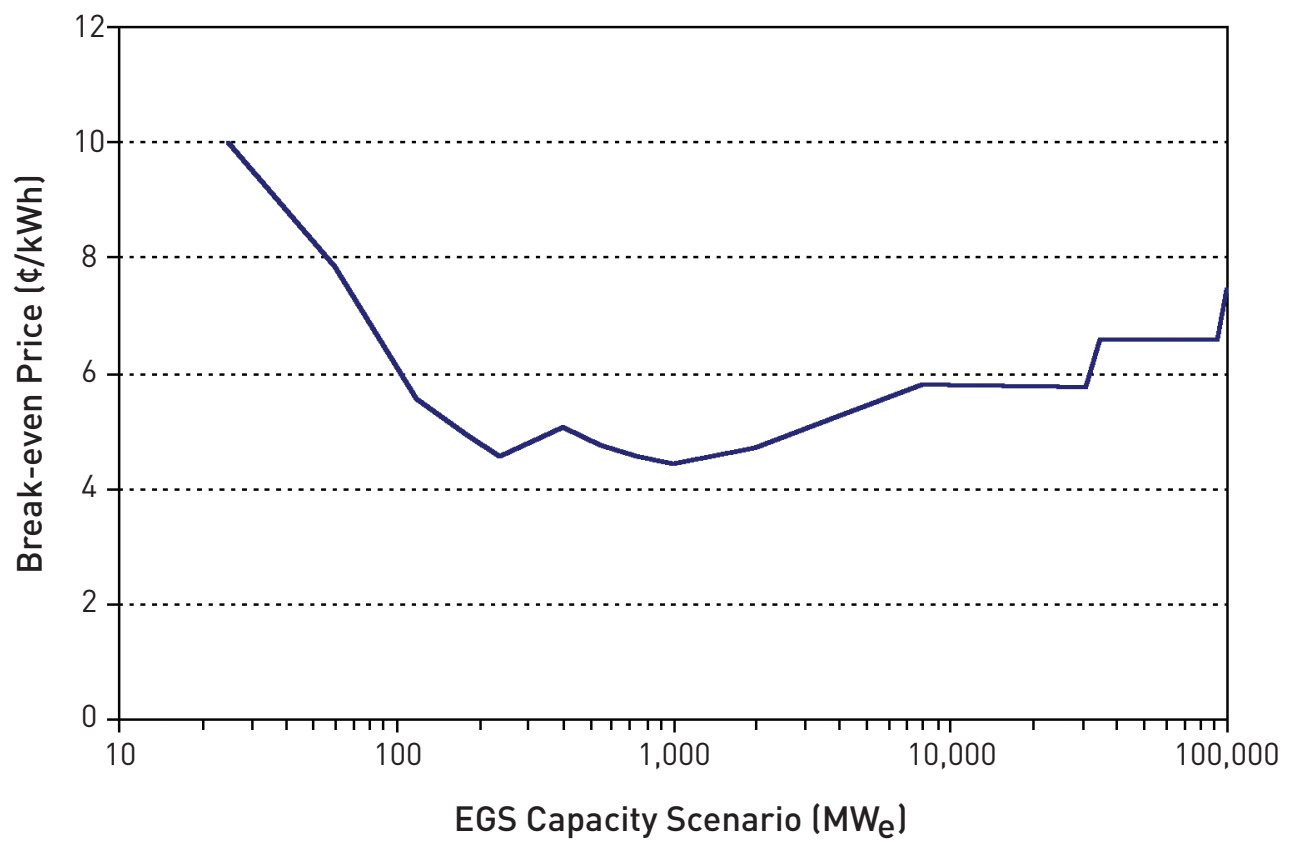

Figure 1.13 Aggregate supply using MIT EGS, variable rate of return (VRR) model with quartet well configurations and a maximum flow per well of $80 \mathrm{~kg} / \mathrm{s}$.

Next, we analyzed the effects of experience. Learning curves were developed to reflect cost reductions resulting from improvements in drilling, reservoir stimulation, and surface plant technologies. These stem from the combination of R\&D investments that lower costs, and experience gained by repeating the deployment of EGS plants at different U.S. sites as part of a focused national initiative. Figures I.I4 to I.IG illustrate these supply curves using both GETEM and MIT EGS models over a range of assumed conditions. When the EGS break-even prices are greater than competitive market prices for electricity, additional institutional investment is needed. For example, on Figure I.I4, this corresponds to the period from $\circ$ to about I2 years. The total amount of investment required is proportional to the area between the EGS price curve and the market price curve. weighted by the amount of EGS capacity online. 


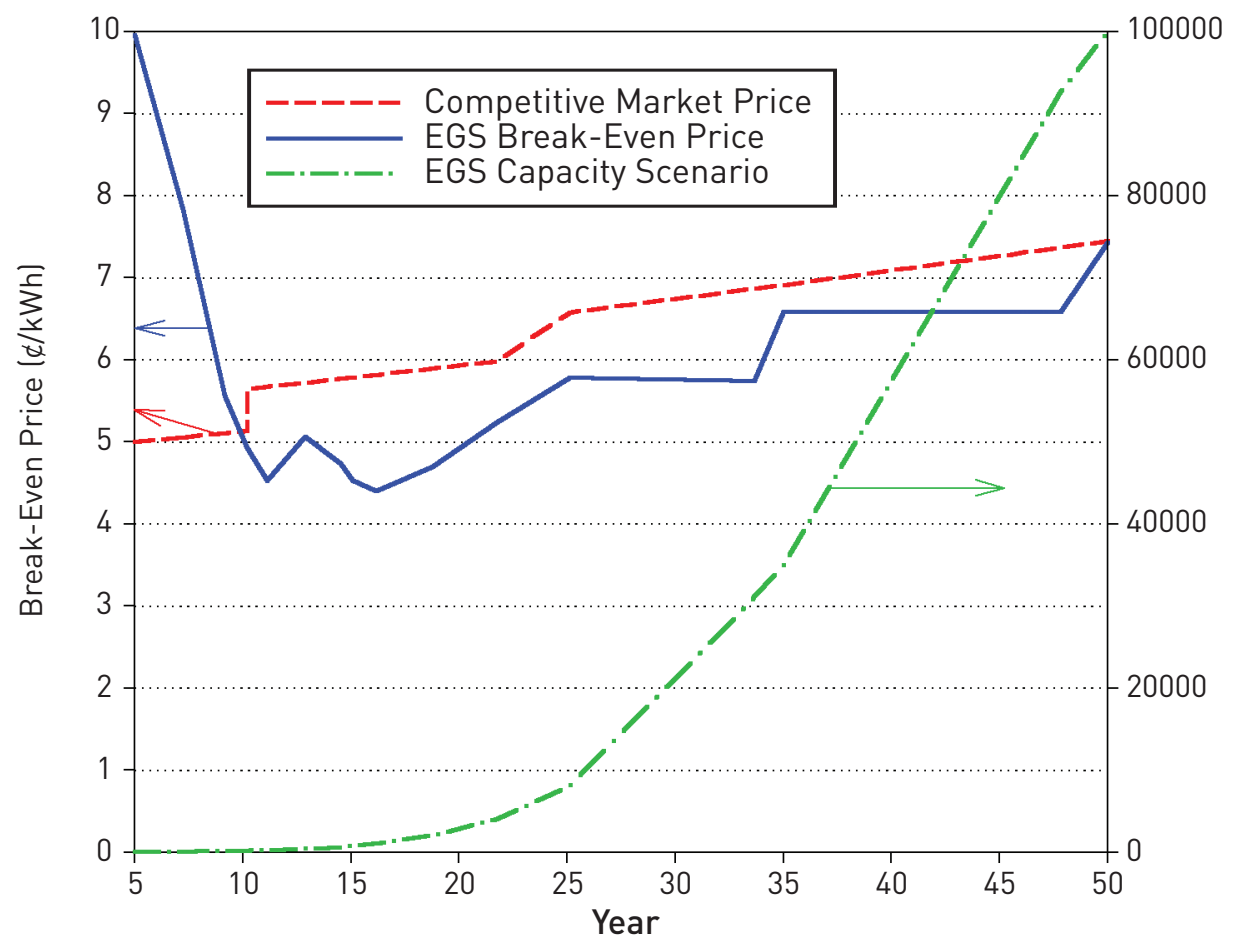

Figure 1.14 Levelized break-even COE using the MIT EGS model for the 100,000 MW - 50-year scenario and variable debt and equity rates (VRR). Flow rate per production well (in a quartet configuration -1 injector, 3 producers) follows the $80 \mathrm{~kg} / \mathrm{s}$ learning curve. Thermal drawdown is $3 \% / \mathrm{yr}$ resulting in complete redrilling and restimulation of the system, with a vertical spacing between stacked reservoirs of $1 \mathrm{~km}$ after $\sim 6$ years of operation. Resulting absorbed technology deployment costs are $\$ 216$ million (U.S. 2004).

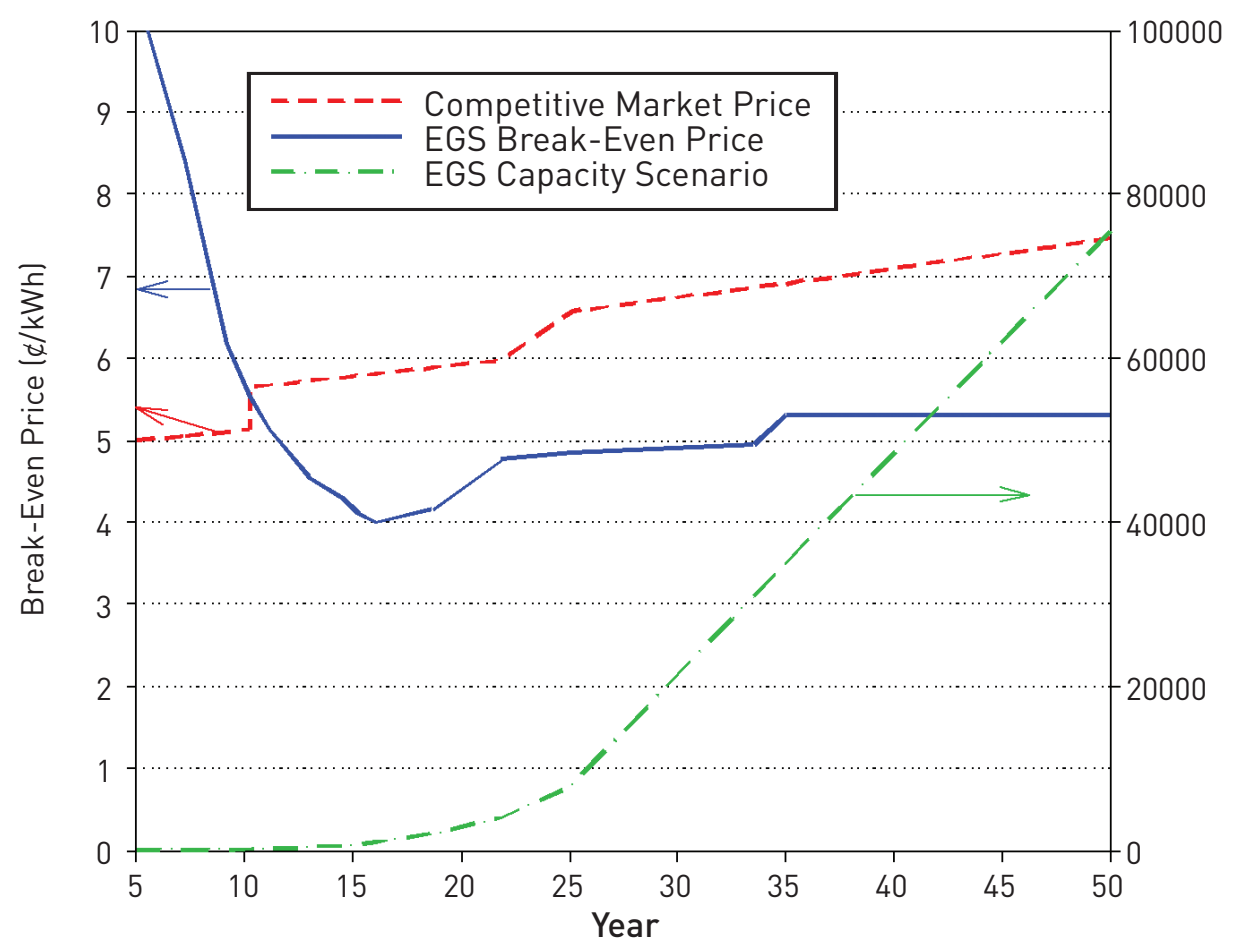

Figure 1.15 Levelized break-even COE using the MIT EGS model for the 100,000 MW - 50-year scenario and a fixed-charge rate of $12.8 \%$ per the NEMS model. Flow rate per production well (in a quartet configuration -1 injector, 3 producers) follows the $80 \mathrm{~kg} / \mathrm{s}$ learning curve. Thermal drawdown is 3\%/yr resulting in complete redrilling and restimulation of the system, with a vertical spacing between stacked reservoirs of $1 \mathrm{~km}$ after $\sim 6$ years of operation. Resulting absorbed technology deployment costs are $\$ 262$ million (U.S. 2004). 


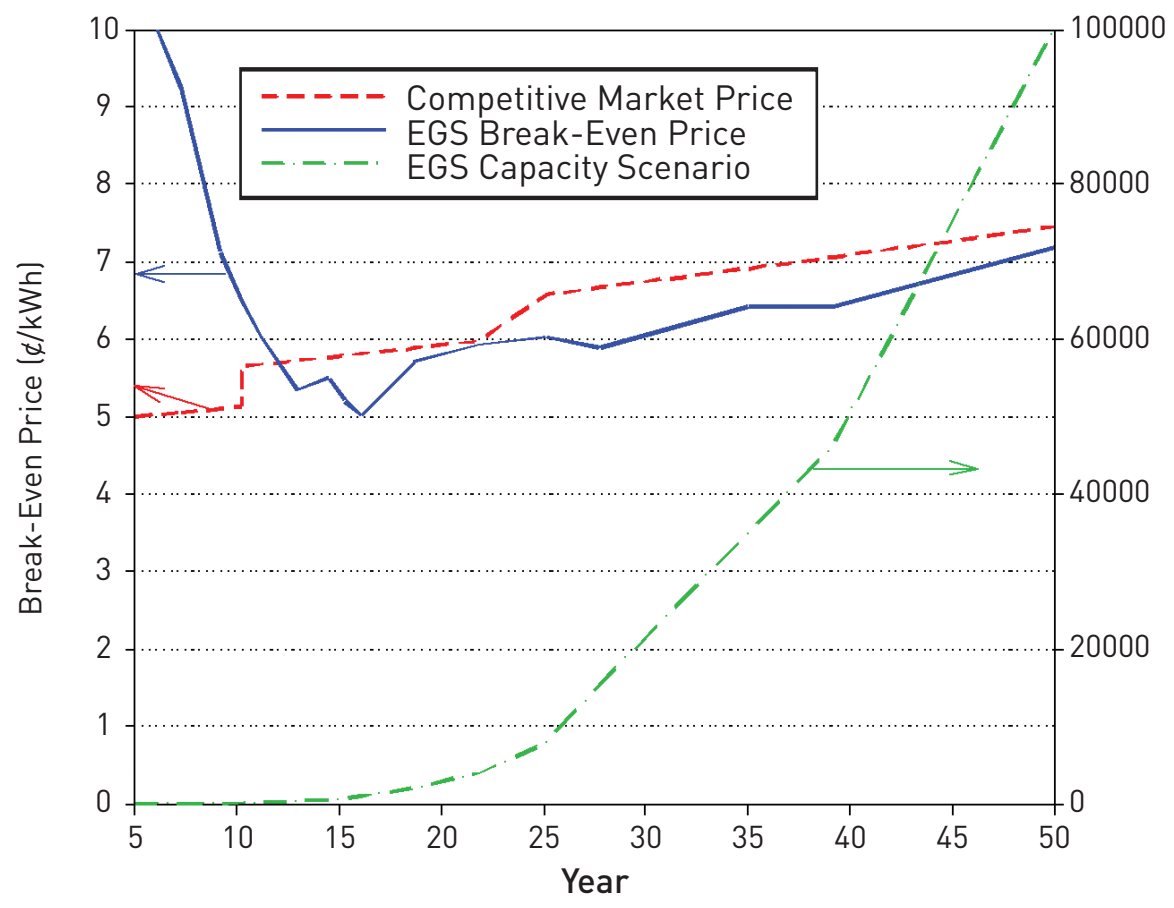

(a) MIT EGS model results

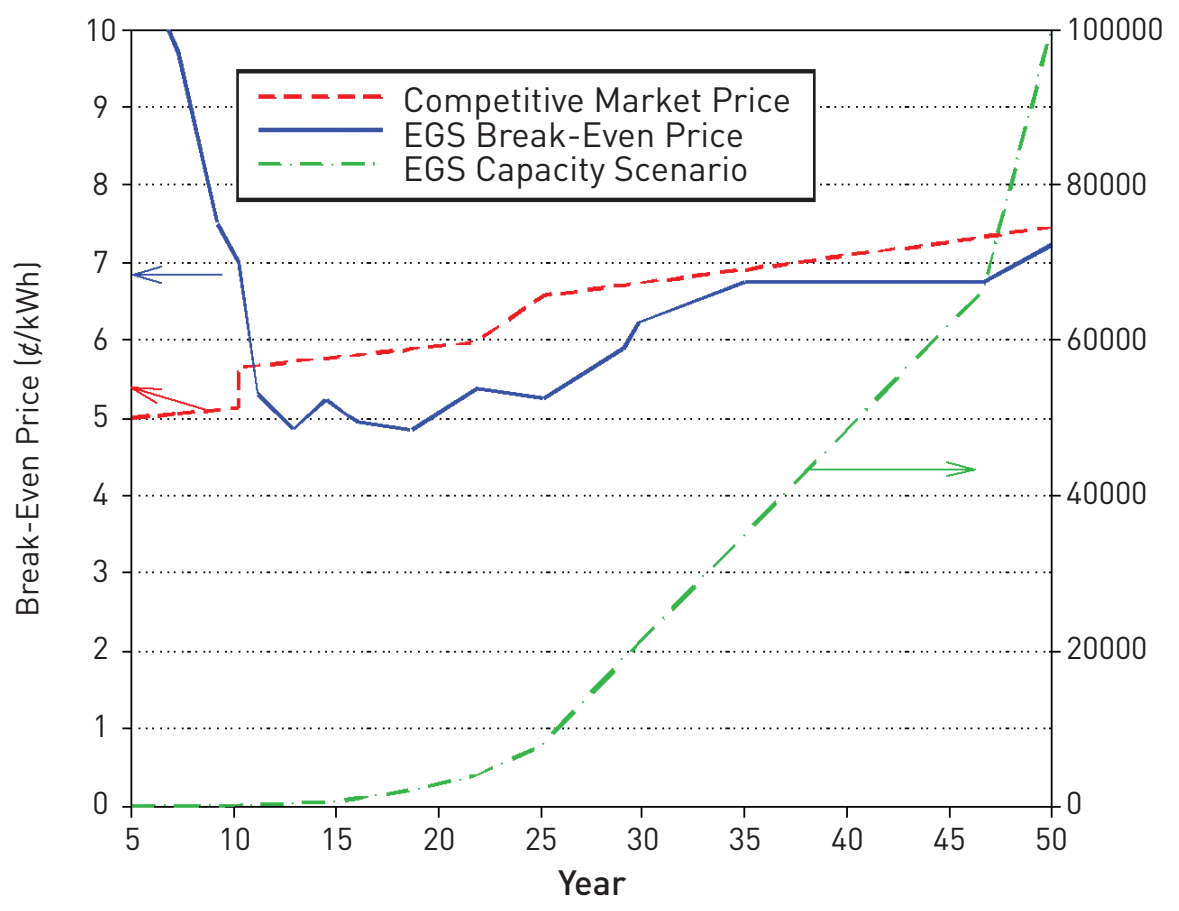

(b) GETEM model results

Figure 1.16 Levelized break-even COE using (a) MIT EGS and (b) GETEM for the 100,000 MW - 50-year scenario using a fixed-charge rate of $12.8 \%$ per the NEMS model. Flow rate per production well lin a triplet configuration - 1 injector, 2 producers) follows the $60 \mathrm{~kg} / \mathrm{s}$ learning curve. Thermal drawdown is $3 \% / y r$ resulting in complete redrilling and restimulation of the system, with a vertical spacing between stacked reservoirs of $1 \mathrm{~km}$ after $\sim 6$ years of operation. Resulting absorbed technology deployment costs are (a) $\$ 368$ million and (b) $\$ 394$ million (U.S. 2004). 
As a result of technology improvements from research and learning curve effects, we have found a strong positive correlation between the early deployment of new EGS facilities and the significant decline in the levelized cost of delivered electricity. This finding reflects not only the economies from new techniques and access to higher-value resources, but also the inevitable changes in availability and increased cost of conventional energy sources. For example, for hydroelectric power, reduced capacity occurs as a result of changed weather patterns and lower resource flows to existing facilities, as well as competition for the resource for alternate uses such as fish and wildlife, recreation, flood control, and capacity losses in dammed areas. In the case of coal-fired electricity, increased bus-bar costs are predicted as result of three effects occurring over time: (i) fuel cost increases, (ii) higher capital costs of new facilities to satisfy higher efficiency and environmental quality goals, including capture and sequestration of $\mathrm{CO}_{2}$, and (iii) retirement of a significant number of low-cost units in the existing fleet due to their age or failure to comply with stiffer environmental standards. In the case of nuclear facilities, we anticipate a shortfall in nuclear supplies through the forecast period, reflecting retirement of the existing power reactors and difficulties in siting and developing new facilities. Without corresponding base-load replacements to meet existing and increased demand, the energy security of the United States will be compromised. It would seem prudent to invest now in developing a portfolio of options that could meet this need.

To sum up, based on our technical and economic analysis, a reasonable investment in R\&D and a proactive level of deployment in the next io years could make EGS a major player in supplying Io\% of U.S. base-load electricity by 2050. Further, the analysis shows that the development of new EGS resources will not be limited by the size and location of the resource in the United States, and it will occur at a critical time when grid stabilization with both replacement and new base-load power will be needed. Adding the EGS option to the U.S. portfolio will reduce growth in natural gas consumption and slow the need for adding expensive natural gas facilities to handle imported liquefied natural gas (LNG).

Although EGS-produced commercial power currently lacks a demonstration of its capability, this can be realized in the short term with a proven application of R\&D support. The potential of EGS in evolving U.S. energy markets is large and warrants a comprehensive research and demonstration effort to move this technology to commercial viability, especially as the country approaches a period when gap between demand for and generation of electricity will most affect the existing system capacity. 


\section{References}

The references listed below are cited within the text of the Synopsis and Executive Summary of this report. For a list of all the literature that was reviewed and evaluated, see the Reference sections of the individual chapters in the full report.

American Petroleum Institute (API). 2006. "Joint Association Survey on Drilling Costs (I976-2004)." Washington, D.C.

Armstead, H. C. H. and J. W. Tester. I987. Heat Mining. E and F. N. Spon, London.

Blackwell, D. D. and M. Richards. 2004. Geothermal Map of North America. Amer. Assoc. Petroleum Geologists, Tulsa, Oklahoma, I sheet, scale I:6,500,000.

Bodvarsson, G. and J.M. Hanson. I977. "Forced Geoheat Extraction from Sheet-like Fluid Conductors." Proceedings of the Second NATO-CCMS Information Meeting on dry hot rock geothermal energy. Los Alamos Scientific Laboratory report, LA-7021:85.

Brown, D.W. 2000. "A Hot Dry Rock Geothermal Energy Concept Utilizing Supercritical $\mathrm{CO}_{2}$ Instead of Water," Proceedings of the Twenty-Fifth Workshop on Geothermal Reservoir Engineering, Stanford University, Stanford, CA, Jan. 24-26, 2000, Paper SGP-TR-I65.

Curlett, H.B. and Geddes, C.J. 2006. "Leveraging a New Energy Source to Enhance Heavy Oil and Oil Sands Production." GRC Bulletin, January/February 2006, Vol. 35/No. I, pp. 32-36.

Energy Information Administration (EIA). 2006. U.S. Department of Energy (DOE) Web site http://www.eia.doe.gov/

Lohbeck, W. C. M. I993. "Method of completing an uncased section of a borehole." Patent publication date: December 23, I993.

McKenna, J., D. Blackwell, C. Moyes, and P. D. Patterson. 2005. "Geothermal electric power supply possible from Gulf Coast, Midcontinent oil field waters.” Oil \& Gas Journal, Sept. 5, pp. 34-40.

Polizzotti, R.S., L.L. Hirsch, A.B. Herhold, and M.D. Ertas. 2003. "Hydrothermal Drilling Method and System." Patent publication date: July 3, 2003.

Potter, R.M. and J.W. Tester. I998. "Continuous Drilling of Vertical Boreholes by Thermal Processes: Including Rock Spallation and Fusion.” Patent publication date: June 30, I998.

Pruess, K. and M. Azaroual. 2006. "On the Feasibility of Using Supercritical $\mathrm{CO}_{2}$ as Heat Transmission Fluid in an Engineered Hot Dry Rock Geothermal System," Proceedings of the Thirty-First Workshop on Geothermal Reservoir Engineering, Stanford University, Stanford, Calif., Jan. 30-Feb. I, 2006.

Sanyal, S. K. and S. J. Butler. 2005. "An Analysis of Power Generation Prospects From Enhanced Geothermal Systems." Geothermal Resources Council Transactions, 29.

Tester, J.W. and M.C. Smith. I977. "Energy Extraction Characteristics of Hot Dry Rock Geothermal Systems." Proceedings of the Twelfth Intersociety Energy Conversion Engineering Conference, Washington, D.C. American Nuclear Society, r:8I6.

Tester, J. W., H. D. Murphy, C. O. Grigsby, R. M. Potter, and B.A. Robinson. I989. "Fractured Geothermal Reservoir Growth Induced by Heat Extraction." SPE J. Reservoir Engineering, 3:97-IO4. 


\section{CHAPTER 2}

\section{Geothermal Resource-Base Assessment}

2.1 Introduction

2.2 EGS Resource-Base Calculation-Temperature-at-Depth Maps _ _ _ _ $2-5$

2.2.1 Heat flow

2.2.2 Geothermal gradients

2.2.3 Thermal conductivity

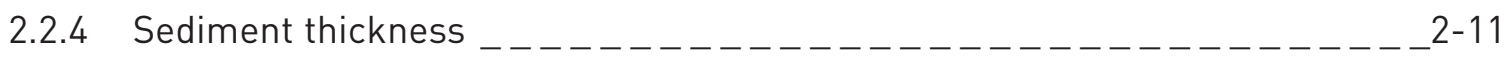

2.2.5 Ground surface temperature $\ldots \ldots \ldots \ldots \ldots \ldots$

2.2.6 Tectonic and radioactive components of heat flow

2.3 EGS Resource Maps and Resource-Base

Estimates_Lower 48 States _ _ _ _ _ _ _ _ _ _ _ _

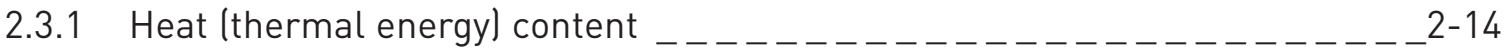

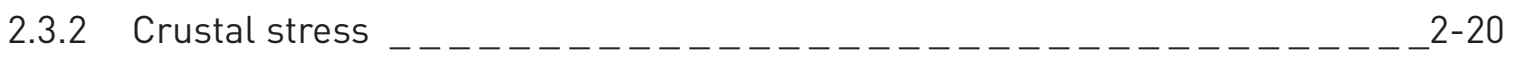

2.3.3 EGS geology

2.3.4 Crustal permeability _-

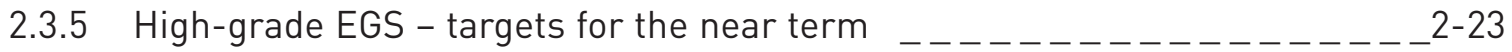

2.4 EGS Potential of Alaska $\ldots \ldots \ldots \ldots \ldots \ldots$

2.4.1 Volcano system _

2.5 EGS Potential of Hawaii _ $\ldots \ldots$

2.6 Unconventional EGS Associated with Coproduced Fluids and Geopressured Fluids _

2.6.1 Introduction

2.6.2 Coproduced fluids $\ldots \ldots \ldots \ldots \ldots \ldots$

2.6.3 Geopressured geothermal resources _. $\ldots \ldots \ldots \ldots \ldots \ldots \ldots \ldots \ldots \ldots-\ldots 2-31$

2.6.4 EGS in sedimentary basins beneath hydrocarbon-bearing fields _. $\ldots+\ldots-\ldots 2-34$

2.7 Concluding Remarks _

References _.

Appendices _.

A.2.1 Geothermal Resource-Base Data $\ldots$

A.2.2 Coprocessed Water Associated with Oil and Gas Production $\ldots \ldots \ldots \ldots \ldots \ldots \ldots$ 


\subsection{Introduction}

Previous analyses have suggested that the amount of thermal energy available for Enhanced Geothermal System (EGS) development is enormous (Armstead and Tester, I987; Rowley, I982; Mock et al., I997; Tester et al., I994; Sass, I993). However, these earlier works did not use detailed geologic information - and, as a result, the methodologies employed and resulting resource estimates were, by necessity, somewhat simplified. This study utilizes published geologic and geophysical data for the United States to calculate the stored thermal energy (or "heat in place") on both a national and state level, at depths from 3 to Io $\mathrm{km}$. The methodology, resource types considered, and the resourcebase calculations are included in this chapter. Recoverability, or useful energy, is discussed in Chapter 3 of this report. A depth of $3 \mathrm{~km}$ was selected as a cutoff for upper depth because, outside of the periphery of active magmatic and hydrothermal systems, temperatures in excess of $150^{\circ} \mathrm{C}$ at less than that depth are rare.

Several classes of geothermal resources are discussed in this chapter (Table 2.I). In earlier analyses USGS Circular 726 (White and Williams, I975), USGS Circular 790 (Muffler and Guffanti, I979), and USGS Circular I249 (Duffield and Sass, 2003) - the geothermal resource was divided into four major categories: hydrothermal, geopressured, magma, and conduction-dominated (Enhanced Geothermal Systems or Hot Dry Rock). The resource classes that are discussed in this report include I) sedimentary Enhanced Geothermal Systems (EGS), 2) basement EGS, 3) geopressured-geothermal systems, and 4) coproduced fluids (hot aqueous fluids that are produced during oil and gas production). Brief mention is also made of supercritical/volcano (i.e., igneous) geothermal systems. There is overlap of some of these categories, which will be explained in the discussion that follows.

Table 2.1 Geothermal resource categories.

\begin{tabular}{l|l}
\hline Category of Resource & Reference \\
\hline $\begin{array}{l}\text { Conduction-dominated EGS } \\
\text { Sedimentary EGS }\end{array}$ & This study, basins $>4 \mathrm{~km}$ \\
Basement EGS & This study \\
Volcano Geothermal Systems & USGS Circular 790 + new data \\
\hline Hydrothermal & USGS Circulars 726 and 790 \\
\hline Coproduced fluids & McKenna et al. (2005) \\
\hline Geopressured systems & USGS Circulars 726 and 790 \\
\hline
\end{tabular}

Conventional hydrothermal resources, presumed to exist at depths of $3 \mathrm{~km}$ or less, are specifically excluded. A team at the United States Geological Survey (USGS) (Williams, 2005) is currently reevaluating these resources. Also not included, because of their relatively small geographic size, are EGS resources on the periphery of hydrothermal systems in the Western United States. While these types of resources are certainly of high grade and can be viewed as near-term targets of opportunity, they are so small in area and site-specific that a regional study of this scale cannot quantitatively assess them. They are, in general, extensions of the hydrothermal resource and will be identified as part of 
the ongoing assessment of hydrothermal geothermal resources being conducted by the USGS. However, some larger basement EGS resource areas that might, in some sense, be considered marginal to hydrothermal systems - such as The Geysers/Clear Lake area in California and the High Cascades Range in Oregon - are included in this discussion (see Section 2.3.5).

The data set used to produce the Geothermal Map of North America, published by the American Association of Petroleum Geologists (AAPG) (Blackwell and Richards, 2004a), is the basic thermal data set used in developing the resource assessment. The conterminous U.S. portion of the map is shown in Figure 2.I. In order to expand coverage from the earlier GSA-DNAG map (Blackwell and Steele, I992; Blackwell et al., I99I) and early versions of this type of resource evaluation (Blackwell et al., I993; Blackwell et al., I994), extensive industry-oriented thermal data sets were used, as well as published heat flow data from research groups. To that end, a western heat-flow data set was developed, based on thermal gradient exploration data collected by the geothermal industry during the I970s and i980s (Blackwell and Richards, 2004C; Kehle, I970; Kehle et al., I970).

The basic information in this data set consists of temperature-depth/gradient information. However, thermal conductivity and heat flow were also determined for as many of the sites as possible, based on thermal conductivity estimates from geologic logs (where available), and geologic maps for other sites where there were no well logs. About 4,000 points were used in the preparation of the map (of the 6,000 sites in the database). The focused nature of the drilling is shown by the clumps of data on Figure 2.2, especially in western Nevada and southwestern Utah.

A second industry data set consisting of about 20,000 point bottom-hole temperature (BHT) measurements, compiled in the early I970s and published in digital form (AAPG CD-ROM, I994), was also utilized. The AAPG BHT data set was augmented in Nevada by BHT data digitized from hydrocarbon exploration well logs in the files of the Nevada Bureau of Mines and Geology. Use of the BHT data required extensive analysis of the error associated with the determination of in situ equilibrium temperatures from these nonequilibrium data. That process is described briefly in Section 2.2.2 and, in more detail, by Blackwell and Richards (2004b, c).

The heat flow varies from less than $20 \mathrm{~mW} / \mathrm{m}^{2}$ in areas of low heat flow to more than $\mathrm{I} 50 \mathrm{~mW} / \mathrm{m}^{2}$ in areas of high heat flow. The causes of the variations and the distribution of heat flow in the conterminous United States are discussed in detail by Roy et al. (1968, I972), Sass et al. (I97I), Lachenbruch and Sass (I977), Reiter et al. (I986), Morgan and Gosnold (I989), Blackwell et al. (I991), and others. The value of surface heat flow is the building block for the temperature-at-depth calculation (see Figure 2.3). Individual sites have thermal conductivity (rock columns) that varies with depth and, thus, the average thermal gradient depends on the depth interval studied - whereas, heat flow does not. In this study, contours of measured heat flow are combined with regionally specific, depth-averaged thermal conductivity models to more accurately represent the larger-scale thermal regime (i.e., average gradients and temperatures as a function of depth). 
To summarize, the values of heat flow used to produce the contours for the United States shown in Figure 2.I were compiled from the following data sets: the SMU compiled Western Geothermal database (includes the USGS Great Basin database http://wrgis.wr.usgs.gov/open-file/of99425/webmaps/home.html); the SMU-compiled U.S. Regional Heat Flow database (approximately 2,000 points, see www.smu.edu/geothermal); and the AAPG BHT database (AAPG I994). The various data site locations are shown in Figure 2.2 by data category. In addition, for completeness, hot and warm spring locations, and Pleistocene and Holocene volcanoes, were shown on the Geothermal Map of North America and on Figure 2.I.

\subsection{EGS Resource-Base Calculation - Temperature-at-Depth Maps}

Several data components are needed to calculate temperature at depth. The heat flow $(Q)$ map is the starting point for the calculations. The thermal conductivity $(K)$ and the geothermal gradient $(\nabla T$, $\partial T / \partial z$ ) complete the trio of quantities directly involved (see Figure 2.3). In addition to the thermal conductivity as a function of depth, the radioactivity of the crustal rocks $(A)$, the thickness of the radioactivity layer $(\mathrm{r})$, the regional heat flow (i.e., the heat flow from below the radioactive layer, $Q_{m}$ ) (Roy et al., I972), and the average surface temperature ( $\left.T_{0}\right)$ must be available at each point in the grid. The components of the analysis used are briefly described below.

The resource maps were prepared at a gridding interval of 5 minutes $\left(5^{\prime}=5\right.$ minutes $\left.=0.08333^{\circ}\right)$ of latitude/longitude. This grid interval corresponds to points with an average spacing of about $8 \mathrm{~km}$ representing an area of about $64 \mathrm{~km}^{2}$. A typical $250 \mathrm{MW}_{\mathrm{e}}$ EGS plant might require about 5 -Io $\mathrm{km}^{2}$ of reservoir planar area to accommodate the thermal resource needed, assuming that heat removal occurs in a I km-thick region of hot rock at depth. Power plant operations, of course, would be confined to a much smaller area, $3 \mathrm{~km}^{2}$ or less. Thus, at the field level, focused exploration and evaluation will be necessary to select optimum sites in a given region, because the grid size used in the analysis is bigger than a reasonable field size. 


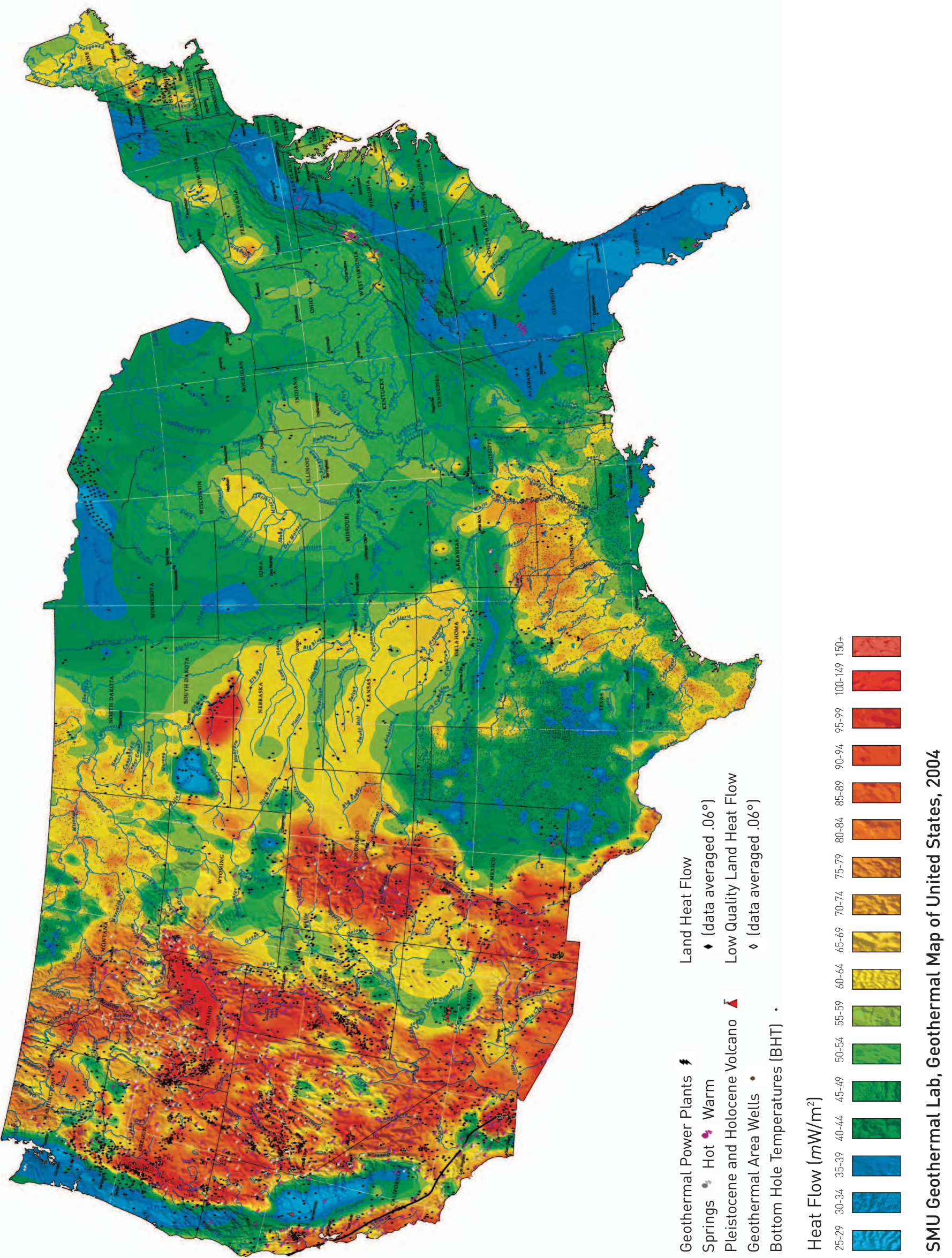

Figure 2.1 Heat-flow map of the conterminous United States - a subset of the geothermal map of North America (Blackwell and Richards, 2004) 


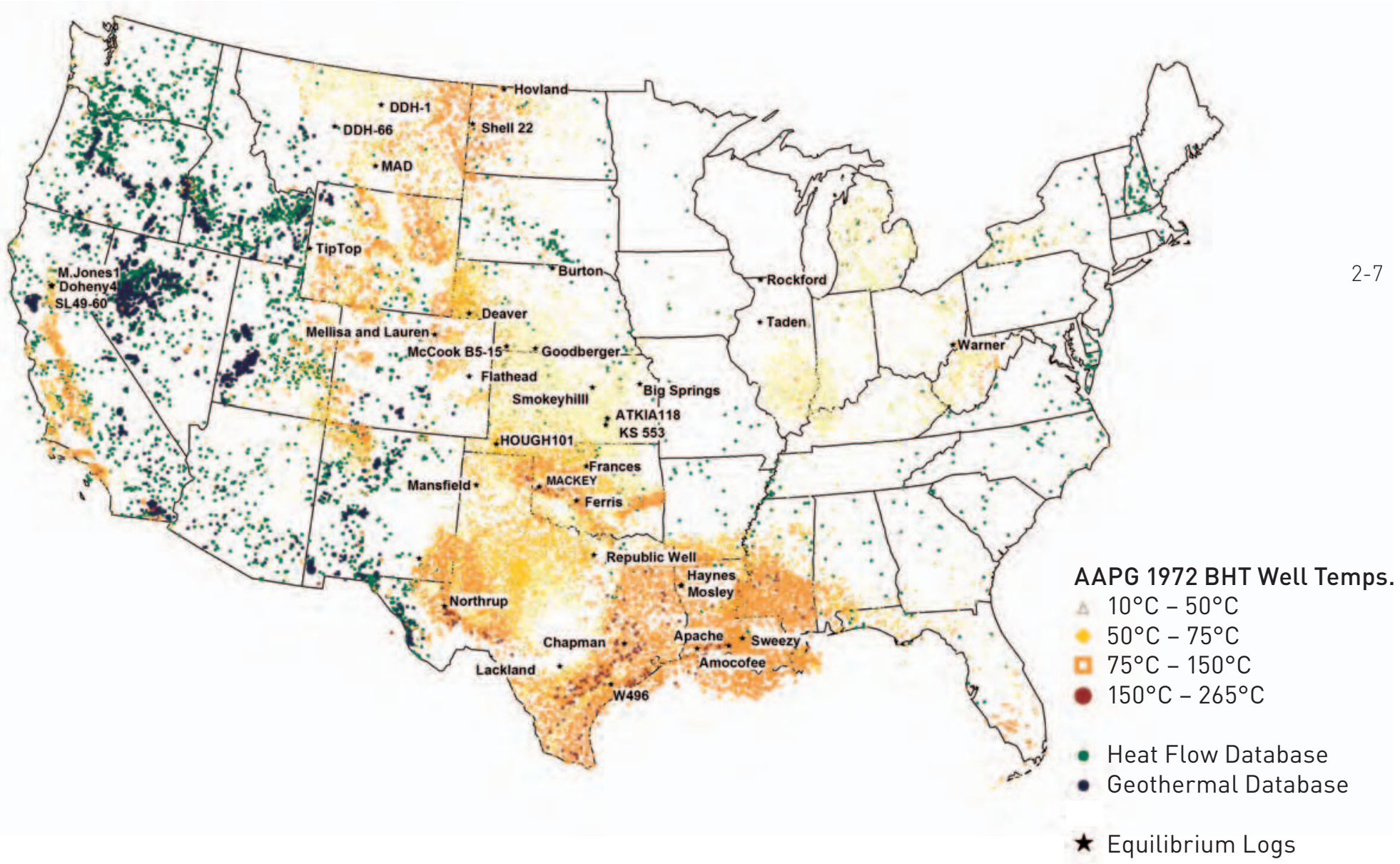

Figure 2.2 All BHT sites in the conterminous United States in the AAPG database. BHT symbols are based on depth and temperature (heat flow is not available for all of the sites, so some were not used for preparation of the Geothermal Map of North Americal. The named wells are the calibration points. The regional heat flow and geothermal database sites are also shown.

\subsubsection{Heat flow}

Before calculation of the heat-flow grid values, individual data points were ranked for quality, based on the uncertainty of the data points (see Blackwell et al., I99I, for a discussion of quality ranking). Hydrothermal system-influenced data (very high values, i.e., generally greater than $\mathrm{I} 20 \mathrm{~mW} / \mathrm{m}^{2}$ ) were excluded from the contouring. All of the heat-flow values obtained from the regional data sets were then merged and contoured using a gridding interval of $5^{\prime}\left(0.08333^{\circ}\right)$ of latitude/longitude (about 8 $\mathrm{km}$ point spacing) with a minimum curvature algorithm. The resulting heat-flow grid (see Figure 2.I) is the starting point for all of the calculations described in this chapter.

Figure 2.2 illustrates that, at the present stage of the analysis, there are still large geographic areas that are under-sampled with respect to the $8 \mathrm{~km}$ grid interval, such that the contours are not well constrained in places where the data are sparse. For example, Kentucky and Wisconsin have no conventional heat-flow data at all (although there are some BHT data points), and there are large gaps in several other areas, especially the eastern part of the United States. Areas in the Appalachian basin may have low thermal conductivity and high heat flow (as is the case in northwestern Pennsylvania), but data are limited in this region. Heat flow for AAPG database BHT points in the eastern United States was not calculated, due to the small and generally scattered nature of the drilling there and limited thermal conductivity information. The deeper wells were used in the preparation of the temperature maps, however. 
Although there are BHT data in some areas to depths of 6,000 $\mathrm{m}$, the maximum depth used for the correction was 4,000 $\mathrm{m}$, due to limited information on the drilling effect for deeper wells, and a lack of calibration wells at those depths. Generalized thermal conductivity models for specific geographic areas of the various sedimentary basins were used to compute the heat flow associated with the BHT gradients. The results were checked against conventional heat-flow measurements in the same regions for general agreement.

Data from the Western Geothermal Database were also used to prepare the contour map. These are heat-flow measurements derived from thermal gradient exploration wells drilled primarily for geothermal resources exploration in the western United States, generally during the late I970s and I980s. The majority of these wells are $150 \mathrm{~m}$ or less in depth. The raw data were processed to calculate heat flow where there was sufficient information. There are site-/well-specific thermal conductivity data for about $50 \%$ of the sites. In the Basin and Range, most of the sites are in the valley fill. Thermal conductivity was assumed for these wells based on lithology logs or, in the absence of even this data, on well-site geology maps.

The flow of the temperature-at-depth calculations is shown in Figure 2.3. There are discussions of each of the main parameters used in the following sections. The important parameters are the measured heat flow (this section), the thermal conductivity distribution (Section 2.2.3 and 2.2.4), the surface temperature (Section 2.2.5), and the distribution of heat due to radioactive elements in the crust (U, Th, K) (Section 2.2.6). In the calculations, $Q_{0}$ is the measured heat flow, $K$ is the thermal conductivity, $Q_{m}$ is the mantle or tectonic component of heat flow (Section 2.2.6), $A$ is the radioactive heat generation, $r$ is the scaled depth of the radioactivity effect (Io $\mathrm{km}$ in these calculations, see Section 2.2.6), $X$ is the depth of the temperature calculation, the subscript $s$ indicates the sediment section, and the subscript $b$ indicates the basement section of the calculation.

\subsubsection{Geothermal gradients}

The mean thermal gradient in the sedimentary section can be found by dividing the heat flow by the thermal conductivity (see Figure 2.3). The variation in the mean gradient is from less than $15^{\circ} \mathrm{C} / \mathrm{km}$ to more than $50^{\circ} \mathrm{C} / \mathrm{km}$ on a regional basis. Within an individual well, the geothermal gradient can vary by up to a factor of 5 or more, depending on the lithology in a particular depth interval. However, the whole sedimentary section is averaged in the approach used here.

Unlike thermal gradient maps produced from direct observations from individual wells (Kron and Stix, I982; Nathenson and Guffanti, I980; DeFord and Kehle, I976), the gradients produced as described in this section and the subsequent temperature-at-depth calculations are not biased by the part of the sedimentary section in which the measurements were made. Thus, the geothermal gradient distribution used here is smoother and more regionally characteristic of the average geothermal gradient to depths below where direct measurements exist. This smoothing process produces a somewhat different temperature-at-depth result than would be obtained from extrapolation of existing gradient compilations that do not include thermal conductivity and heat-flow analyses. 


\section{CALCULATION OF TEMPERATURE AT DEPTH}

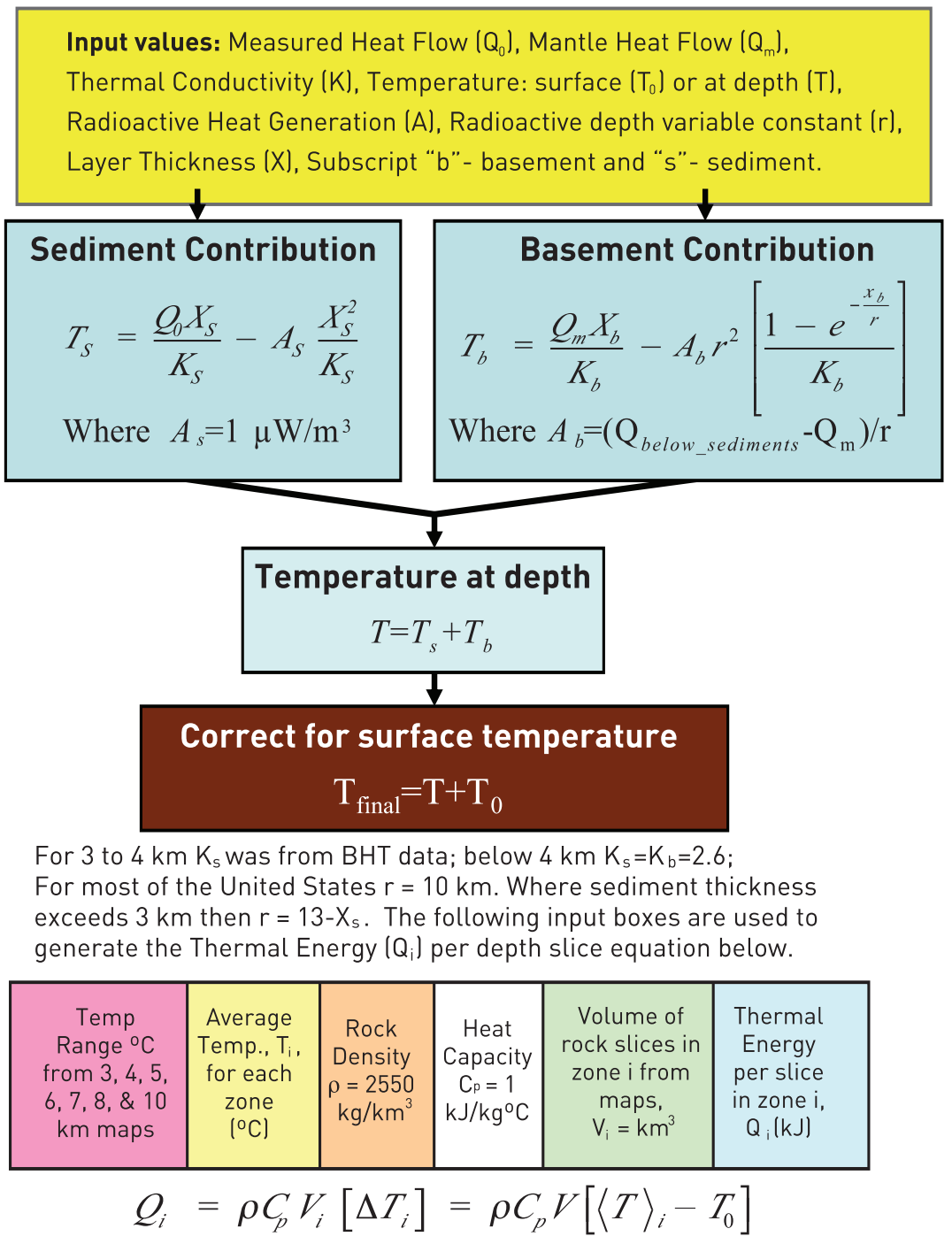

Figure 2.3 Flow chart for calculation of temperature and heat content at depth. Note: $1 \mathrm{~kW}-\mathrm{sec}=1 \mathrm{~kJ}$ and angle brackets denote depth-averaging.

Use of the extensive BHT data set is a new feature of the heat-flow map and this temperature-at-depth analysis used in previous studies. The BHT data were calibrated by comparison to a series of precision temperature measurements made in hydrocarbon wells in thermal equilibrium, and a BHT error was thus established (Blackwell and Richards, 2004b; Blackwell et al., I999). Data up to a maximum depth of 3,000 $\mathrm{m}$ were used (4,000 $\mathrm{m}$ in southern Louisiana). The basic correction was similar to the AAPG BHT correction, with modifications as proposed by Harrison et al. (I983). A secondary correction that is a function of the gradient was applied, so that a bias associated with average geothermal gradient in the well was removed. This correction was checked against the approximately 30 sites in the United States with accurate thermal logs (Figure 2.2). We contend the correction for the average gradient of a group of wells is accurate to about $\pm 10^{\circ} \mathrm{C}$ at $200^{\circ} \mathrm{C}$, based on the direct comparisons described by Blackwell and Richards (2004b).

With the inclusion of the BHT data, there is a higher confidence level in the interpreted temperatures at depth. For geothermal resource potential purposes, the corrected BHT data can be used directly in 
many places, because many of these measurements are at 4 to $6 \mathrm{~km}$ depths. This additional data improves the definition of areas that qualify for further EGS evaluation.

\subsubsection{Thermal conductivity}

For the calculations of temperature at depth, the vertical thermal conductivity is sorted by depth into either one or two layers. The two-layer model for some of the areas is based on the effect of reduction of porosity and mineralogical changes in low-conductivity shale and in volcanic rock at temperatures above $60-80^{\circ} \mathrm{C}$. A value of thermal conductivity of $2.6 \mathrm{~W} / \mathrm{m} / \mathrm{K}$ was assumed for the basement rocks. This value was based on the median of the values for basement rocks from the regional heat-flow database. For some of the sedimentary basins, an upper layer of lower thermal conductivity is assumed to overlie the $2.6 \mathrm{~W} / \mathrm{m} / \mathrm{K}$ value used for the deeper sedimentary rocks and the underlying basement.

A histogram of thermal conductivity for the wells in the regional heat-flow data set is shown in Figure 2.4. There is a peak in the distribution of thermal conductivity values at about I.4 W/m/K. These lowconductivity values are characteristic of lithologies such as volcanic rock, shale, and unconsolidated valley fill. A value of $\mathrm{I} .4 \mathrm{~W} / \mathrm{m} / \mathrm{K}$ was assumed for the Basin and Range valley fill and other highporosity rocks where no measurements were available. There is another smaller peak in the distribution between 2.0-3.0 W/m/K. Rocks in the $>2.2 \mathrm{~W} / \mathrm{m} / \mathrm{K}$ category are generally low-porosity sedimentary rocks and basement lithologies (granite, metamorphic rocks, carbonates, sandstone, etc.). The value of $2.6 \mathrm{~W} / \mathrm{m} / \mathrm{K}$ was used as the crustal value - instead of the $2.8-3.0 \mathrm{~W} / \mathrm{m} / \mathrm{K}$ peak - to partly take into account the effect of temperature on thermal conductivity, which ranges from $5 \%$ to IO\% per $100^{\circ} \mathrm{C}$ change in temperature.

Regional values of thermal conductivity in the upper 2 to $4 \mathrm{~km}$ are based on generalized rock distributions. The peak at $\mathrm{I} .4 \mathrm{~W} / \mathrm{m} / \mathrm{K}$ is related to the thermal conductivity of Late Cenozoic basin fill in the Great Basin. Parts of the Pacific Northwest and the Great Basin were assigned values of thermal conductivity of $2.0 \mathrm{~W} / \mathrm{m} / \mathrm{K}$ to a depth of $2 \mathrm{~km}$, to approximate a mean of basement, volcanic, and Cenozoic rift basin lithologies. In the areas of the Salton Sea/Imperial Valley and the Los Angeles Basin, the upper $2 \mathrm{~km}$ of section was also assigned a thermal conductivity value of $2.0 \mathrm{~W} / \mathrm{m} / \mathrm{K}$. Thus, the vertical thermal-conductivity distribution in sedimentary and volcanic sections is considered only on a semiregional scale.

There are lateral variations of almost I००\% in the mean thermal conductivity within the sedimentary section. Therefore, detailed studies are necessary to identify the most favorable locations from the point of view of temperature and lithology. The highest thermal-conductivity values $(>3.4 \mathrm{~W} / \mathrm{m} / \mathrm{K}$ for relatively thick intervals on a regional basis) are associated with areas where Paleozoic carbonates and evaporates dominate the section such as in the Michigan, Illinois, Anadarko, and Delaware Basin regions. These areas were assigned the $2.6 \mathrm{~W} / \mathrm{m} / \mathrm{K}$ value starting at zero depth. Lower thermal conductivity values $(<2.0 \mathrm{~W} / \mathrm{m} / \mathrm{K}$ on a regional basis $)$ are in areas where a significant part of the upper section is shale, such as in the Great Plains (Williston Basin, Cretaceous shales, Anadarko Basin, Paleozoic shales) and possibly in the northern Allegheny area (Paleozoic shales). Typical thermal-conductivity values for the different lithologies, based on measurements in the Midcontinent region, are given by Blackwell and Steele (I989), Gallardo and Blackwell (I999), Carter et al. (I998), Gosnold (I990), and Speece et al. (I985), for example. 


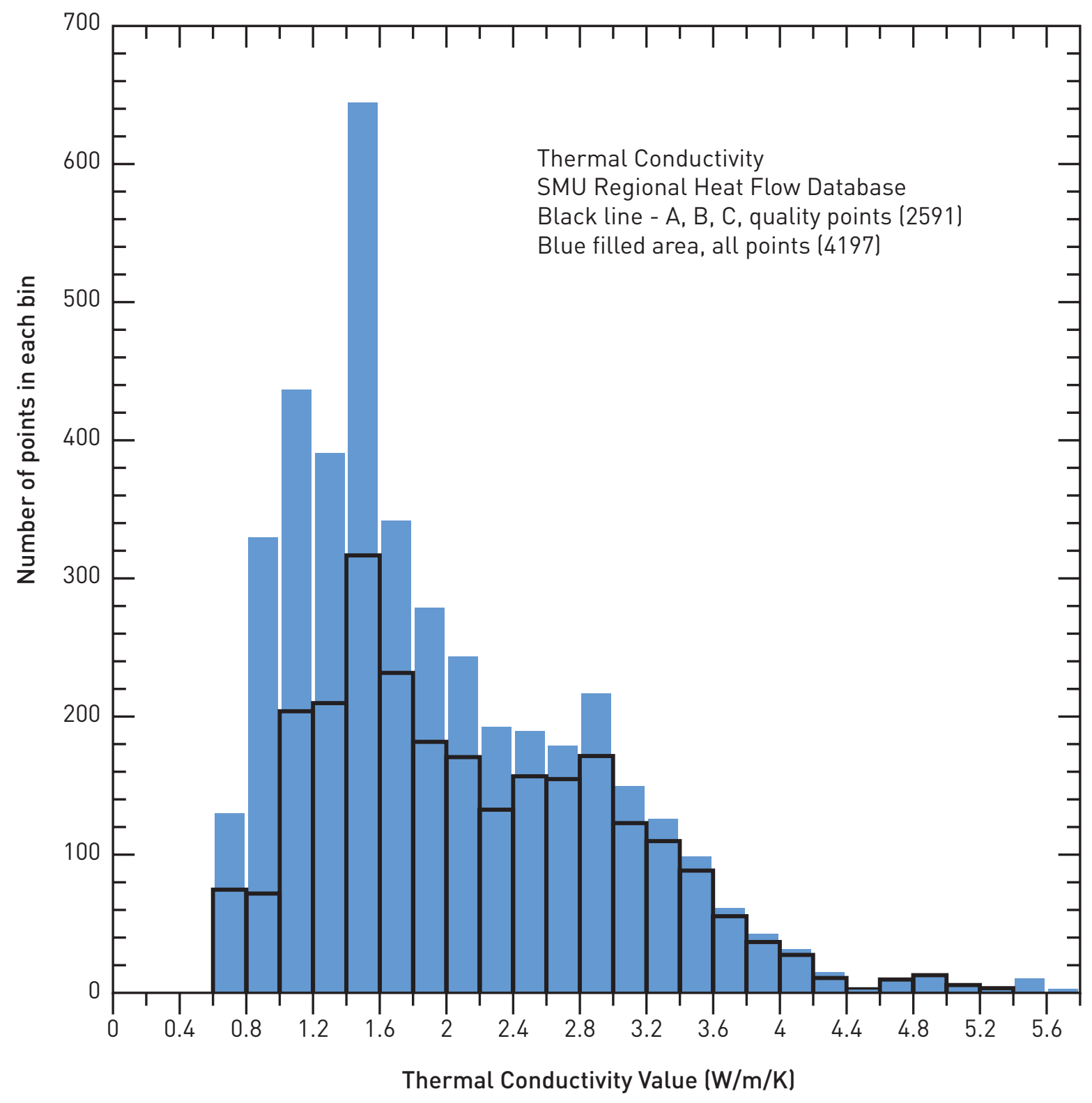

Figure 2.4 Histogram of in situ thermal conductivity, $K$, in the regional heat-flow database. Source: SMU Regional Heat Flow database at www.smu.edu/geothermal.

\subsubsection{Sediment thickness}

A map of the thickness of sedimentary cover was prepared by digitizing the Elevation of Basement Map published by the AAPG (1978). The basement elevation was converted to thickness by subtracting its value from the digital topography, resulting in the map shown in Figure 2.5. Sediment thickness is highly variable from place to place in the tectonic regions in the western United States (west of the Great Plains); and, for this reason, most of the areas of deformation in the western United States do not have basement contours on the AAPG map. Because of the complexity and lack of data, the sediment/basement division in the western United States is not shown, with the exception of the Colorado Plateau (eastern Utah and western Colorado), the Middle Rocky Mountains (Wyoming), and 
the Great Valley of California. The area of most uncertainty is the Northern Rocky Mountain/Sevier thrust belt of the Cordillera - in that area, basement thermal conductivity was assumed. Local late extensional basins such as those in the Basin and Range and the Western Snake River Basin, are also not specifically represented on the sediment thickness map and were assigned a thickness of 2,000 $\mathrm{m}$.

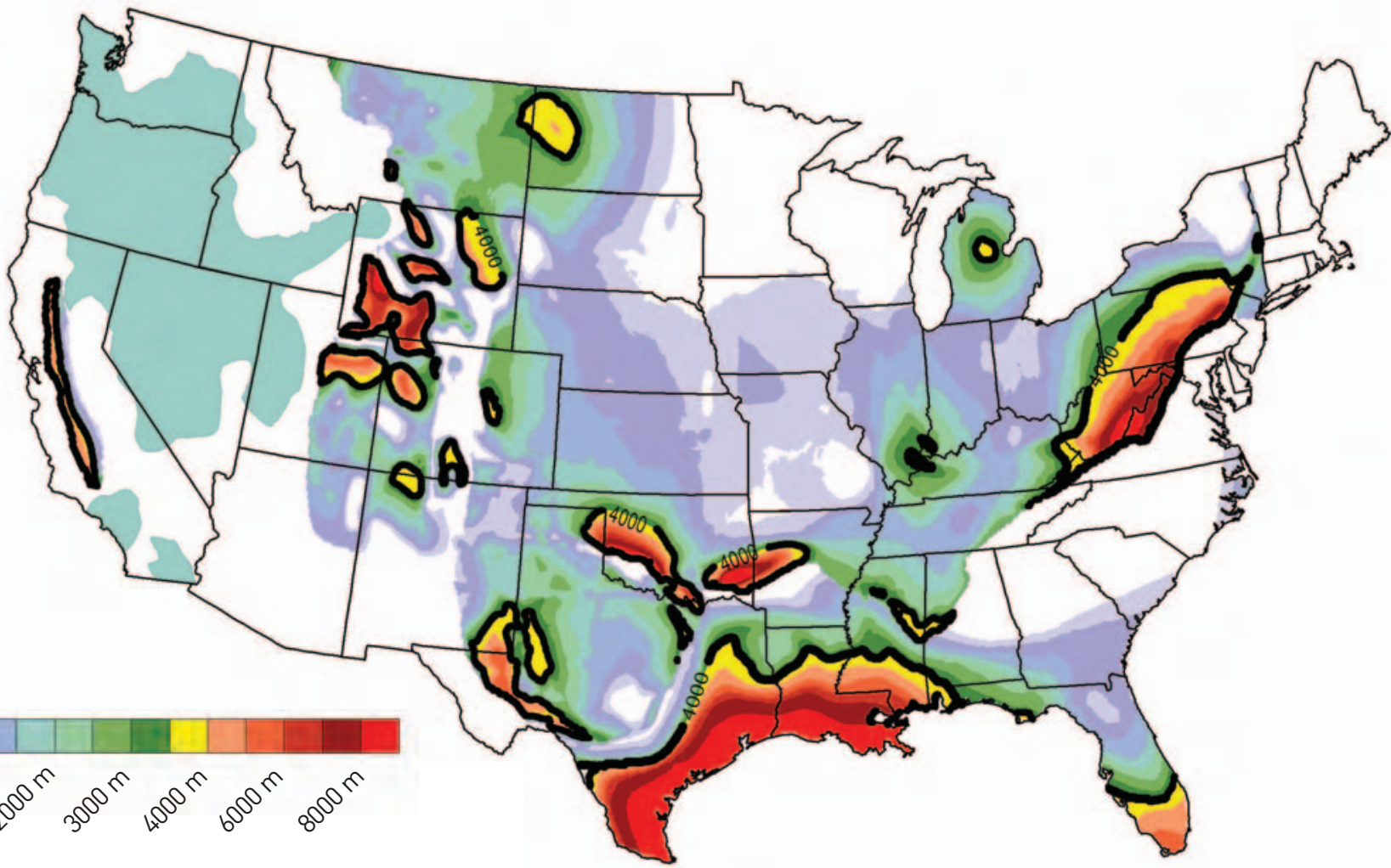

Figure 2.5 Sediment thickness map (in meters, modified from AAPG Basement Map of North America, 1978). The $4 \mathrm{~km}$ depth contour is outlined with a bold black line. The low-conductivity regions in the western United States are in blue/green.

In the Basin and Range and the Southern and Middle Rocky Mountains, there are smaller - but sometimes very deep - basins filled with low thermal-conductivity material. The scale of this study is such that these areas are not examined in detail, and considerable variations are possible in those regions, both hotter and colder than predicted.

The map in Figure 2.5 indicates areas that might be of interest for EGS development in the sediment section (the areas inside the $4 \mathrm{~km}$ sediment thickness contour), and areas of interest for basement EGS. With the exception of the Anadarko basin, the Gulf Coast, and the eastern edge of the Allegheny basin, sedimentary thickness does not exceed $4 \mathrm{~km}$, except in very localized regions in the area east of the Rocky Mountains. Thus, outside the areas identified by the heavy lines on Figure 2.5, development would have to be in basement settings (east of the Rocky Mountains). 


\subsubsection{Ground surface temperature}

The ground surface temperature is shown in Figure 2.6. This temperature represents the lowest value of the average heat rejection temperature possible for any energy-conversion scheme. The values are from measurements of temperature in shallow groundwater wells (Gass, I982). These temperatures can be used as shown in Figure 2.3 to calculate maximum attainable temperature differences, which can then be used to calculate the thermal energy content of a rock volume for any U.S. region (difference of the rock temperature at depth and the average surface temperature).

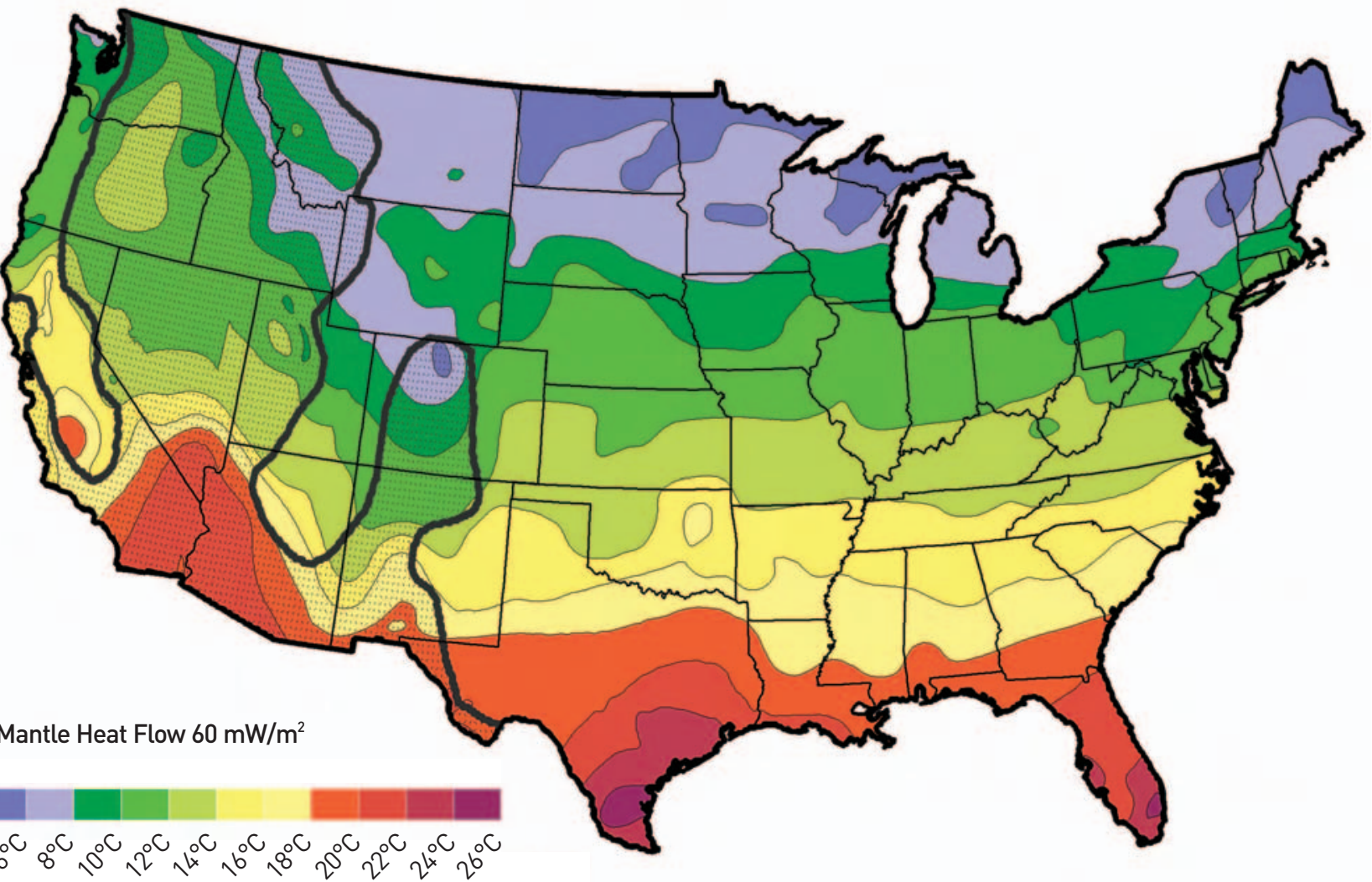

Figure 2.6 Map of surface temperature (colors, Gass, 1982) and generalized mantle heat flow for the conterminous United States (dotted area inside heavy black line is greater than $60 \mathrm{~mW} / \mathrm{m}^{2}$, the remainder of the area is $30 \mathrm{mWm}^{2}$ ).

\subsubsection{Tectonic and radioactive components of heat flow}

The heat flow at the surface is composed of two main components that may, of course, be perturbed by local effects, i.e., the heat generated by radioactive elements in the crust and the tectonic component of heat flow that comes from the interior of the Earth (referred to here as the mantle heat flow). The radioactive component varies from $\circ$ to more than $100 \mathrm{~mW} / \mathrm{m}^{2}$, with a typical value of about 25 $\mathrm{mW} / \mathrm{m}^{2}$. The characteristic depth of the radioelements (U, Th, and $\mathrm{K}$ ) in the crust averages about Io $\mathrm{km}$ (Roy et al., I972), so that most of the variation in heat flow from radioactivity is above that depth. This component can be large and is locally variable, and, thus, there can be areas of high heat flow even in areas that are considered stable continent. For example, in the White Mountains in New Hampshire, the heat flow is as high as $100 \mathrm{~mW} / \mathrm{m}^{2}$, because of the extreme natural radioactivity of the granite (Birch 
et al., I968). In contrast, in parts of the nearby Adirondack Mountains, the heat flow is only $30 \mathrm{~mW} / \mathrm{m}^{2}$, because the upper crustal rocks have very small radioelement content.

In the analysis of temperatures to ro $\mathrm{km}$, the heat flow from below the layer of radioactive elements providing a heat source in the continental crust must be known, because the depth-scale of the radiogenic contribution is similar to the depth of calculation. For the majority of the area covered by the analysis, two different "mantle" heat flow values were used: $60 \mathrm{~mW} / \mathrm{m}^{2}$ for the high heat-flow regions in the west and $30 \mathrm{~mW} / \mathrm{m}^{2}$ for most of the rest of the map area. The region of high mantle heat flow is shown as the dotted area inside the heavy black line in Figure 2.6. The high mantle heat flow is a result of the plate tectonic activity (subduction) that has occurred along the west coast of North America during the past Ioo million years, and the hot spot activity along the Yellowstone/Snake River Plain track (Blackwell, I989). Part of the Cascade Range in the Pacific Northwest (active volcanic arc) and part of the Snake River Plain (hot spot track) were assigned mantle heat flow values of $80 \mathrm{~mW} / \mathrm{m}^{2}$, because they are associated directly with geologically young volcanism. Finally, part of the Great Valley/Sierra Nevada Mountains areas were given a mantle heat flow of $20 \mathrm{~mW} / \mathrm{m}^{2}$ compatible with the outer arc tectonic setting in those areas (see Morgan and Gosnold, I989; Blackwell et al., I991). Transitions in heat flow between these different areas are generally sharp on the scale of the map, but are hard to recognize in some locations, because of the variable heat flow due to the upper crustal effects. Nonetheless, as deeper depths are considered, this regional factor becomes dominant.

\subsection{EGS Resource Maps and Resource-Base Estimates - Lower 48 States}

\subsubsection{Heat (thermal energy) content}

The results of the analysis described in the previous section are presented as temperature-at-depth maps and as thermal energy (or "heat") in place. The temperatures were calculated from the depths of

3 to ro $\mathrm{km}$ at every $\mathrm{km}$. The mean values at $0.5 \mathrm{~km}$ intervals were used in the recoverable resource analysis in subsequent chapters. Maps of the temperature at $3.5 \mathrm{~km}, 4.5 \mathrm{~km}, 5.5 \mathrm{~km}, 6.5 \mathrm{~km}, 7.5 \mathrm{~km}$, and ro $\mathrm{km}$ are shown in Figure 2.7. Heat-in-place was calculated and is listed in Table A.2.I for I $\mathrm{km}$ x I km x I km blocks centered at depths of 3.5, 4.5, 5.5, 6.5, 7.5, 8.5, and $9.5 \mathrm{~km}$ using the assumptions and equations shown in Figure 2.3. The values listed in Table A.2.I, and shown in the histogram in Figure 2.8, represent the geothermal resource base and not the power that can be generated. For demonstration purposes, the values are shown in terms of stored thermal energy, namely, exajoules $\left(\mathrm{EJ}=\mathrm{IO}{ }^{18} \mathrm{~J}\right)$. The only area excluded from the calculation is Yellowstone National Park $\left(8,980 \mathrm{~km}^{2}\right)$. It represents a large area of high temperature, and so its exclusion affects the resourcebase calculation of areas at high temperature at shallow depths. The histogram in Figure 2.8 shows that there is a tremendous resource base of approximately I3 million EJ, between the depths of 3.5 to $7.5 \mathrm{~km}$ in the temperature range of $150^{\circ} \mathrm{C}$ to $250^{\circ} \mathrm{C}$. Even if only $2 \%$ of the resource were to be developed, the thermal energy recovered would be 260,000 EJ. This amount is roughly 2,600 times the annual consumption of primary energy in the United States in 2006.

To understand the magnitude of the thermal energy or heat content of the rock, it is useful to consider the following "thought experiment." Imagine a I4 km long x I4 km wide x I km thick slice of rock below the ground surface, which is at an initial temperature of $250^{\circ} \mathrm{C}$. Reasonable average values are 2,550 
$\mathrm{kg} / \mathrm{m}^{3}$ and $\mathrm{I}, 000 \mathrm{~J} / \mathrm{kg}^{\circ} \mathrm{C}$, for the density (Ú) and heat capacity $\left(C_{p}\right)$ of the rock, respectively. If this mass of rock is cooled through a temperature difference of $200^{\circ} \mathrm{C}$ to a final temperature of $50^{\circ} \mathrm{C}$, then the heat removed is given by

$$
\begin{aligned}
Q & =\rho C_{p} V \Delta T=\left(2550 \mathrm{~kg} / \mathrm{m}^{3}\right)\left(1000 \mathrm{~J} / \mathrm{kg}^{\circ} \mathrm{C}\right)(14 \mathrm{~km} \times 14 \mathrm{~km} \times 1 \mathrm{~km})\left(250^{\circ} \mathrm{C}-50^{\circ} \mathrm{C}\right) \\
& =100 \times 10^{18} \mathrm{~J} \approx 100 \text { quads. }
\end{aligned}
$$

This quantity of thermal energy, which could potentially be released from a $200 \mathrm{~km}^{2}$ area of rock, is equivalent to the total amount of energy consumed annually in the United States, which has a total land area close to Io million $\mathrm{km}^{2}$. This illustration demonstrates the substantial size of the U.S. geothermal resource. Of course, the size of the accessible resource is much smaller than implied by this simplistic analysis. Details relating to the development scenarios are described elsewhere in this report, including Chapter 3 .

The validity of the calculations of temperature at depth is important. In the areas of hydrocarbon development, there are wells that have been drilled to 3 to $6 \mathrm{~km}$ (I0,000 to I9,००० ft) depths, so that the predicted temperatures can be checked against measurements in deep wells. In the case of the areas represented in the AAPG BHT database, this has been done and the agreement is within $\pm 20^{\circ} \mathrm{C}$ in the 3 to $6 \mathrm{~km}$ depth range. In the areas of geothermal drilling, there is some information outside of the immediate influence of geothermal systems, and there are a few research wells that serve as data points at depth. This information has been compared to the calculated values with similar results to the BHT comparison.

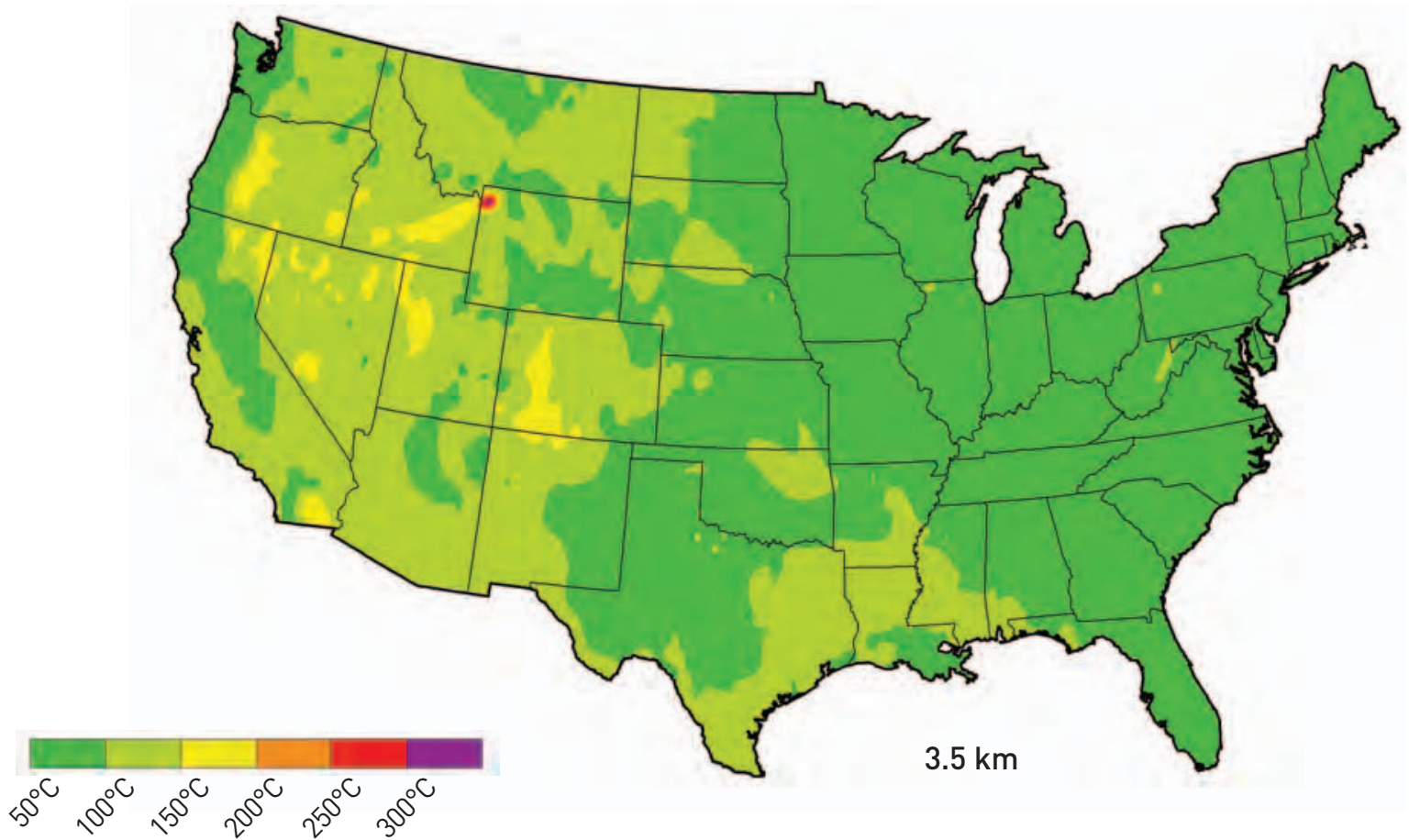

Figure 2.7a Average temperature at $3.5 \mathrm{~km}$. 


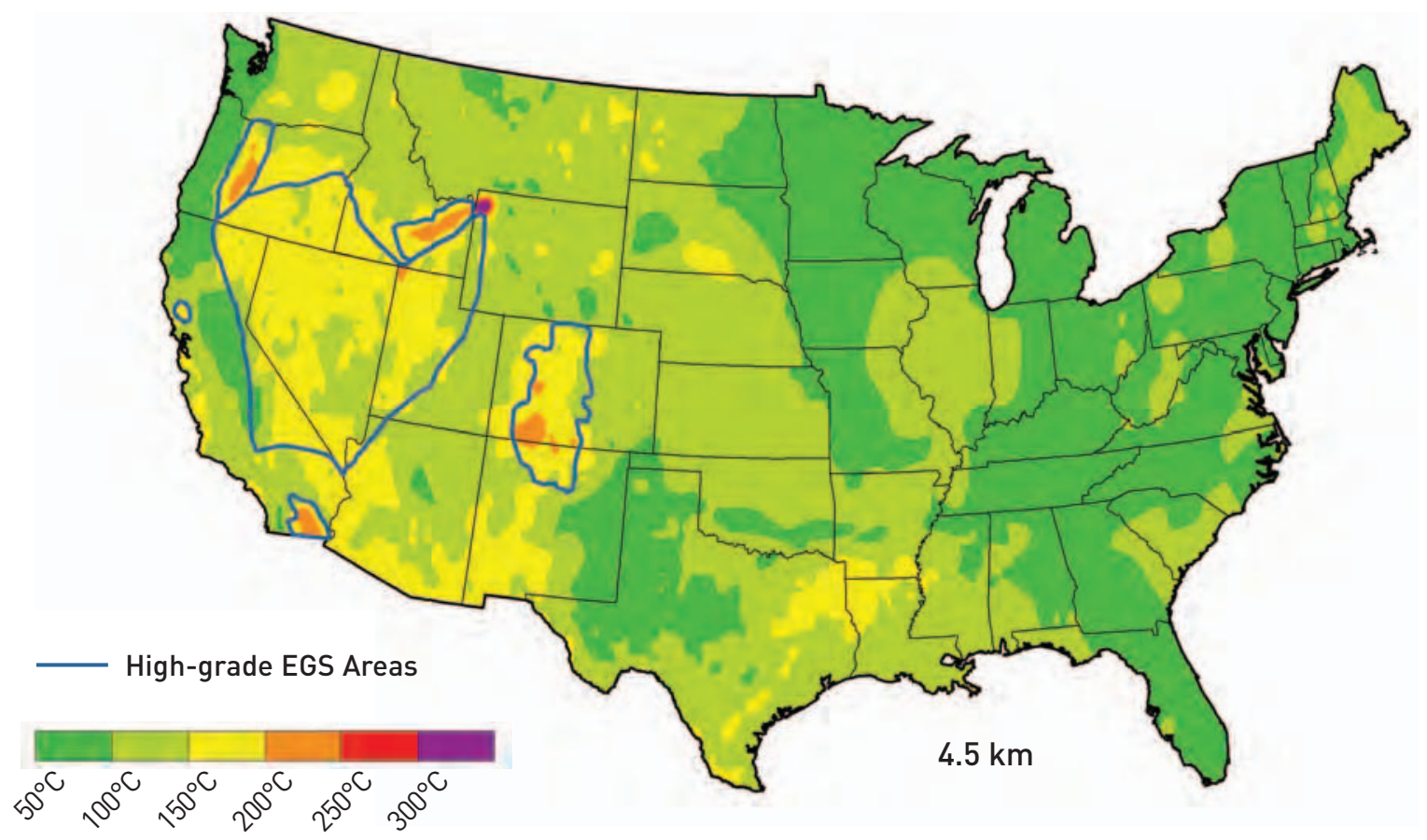

Figure 2.7b Average temperature at $4.5 \mathrm{~km}$. Includes areas of special EGS interest outlined in blue and identified in Table 2.2.

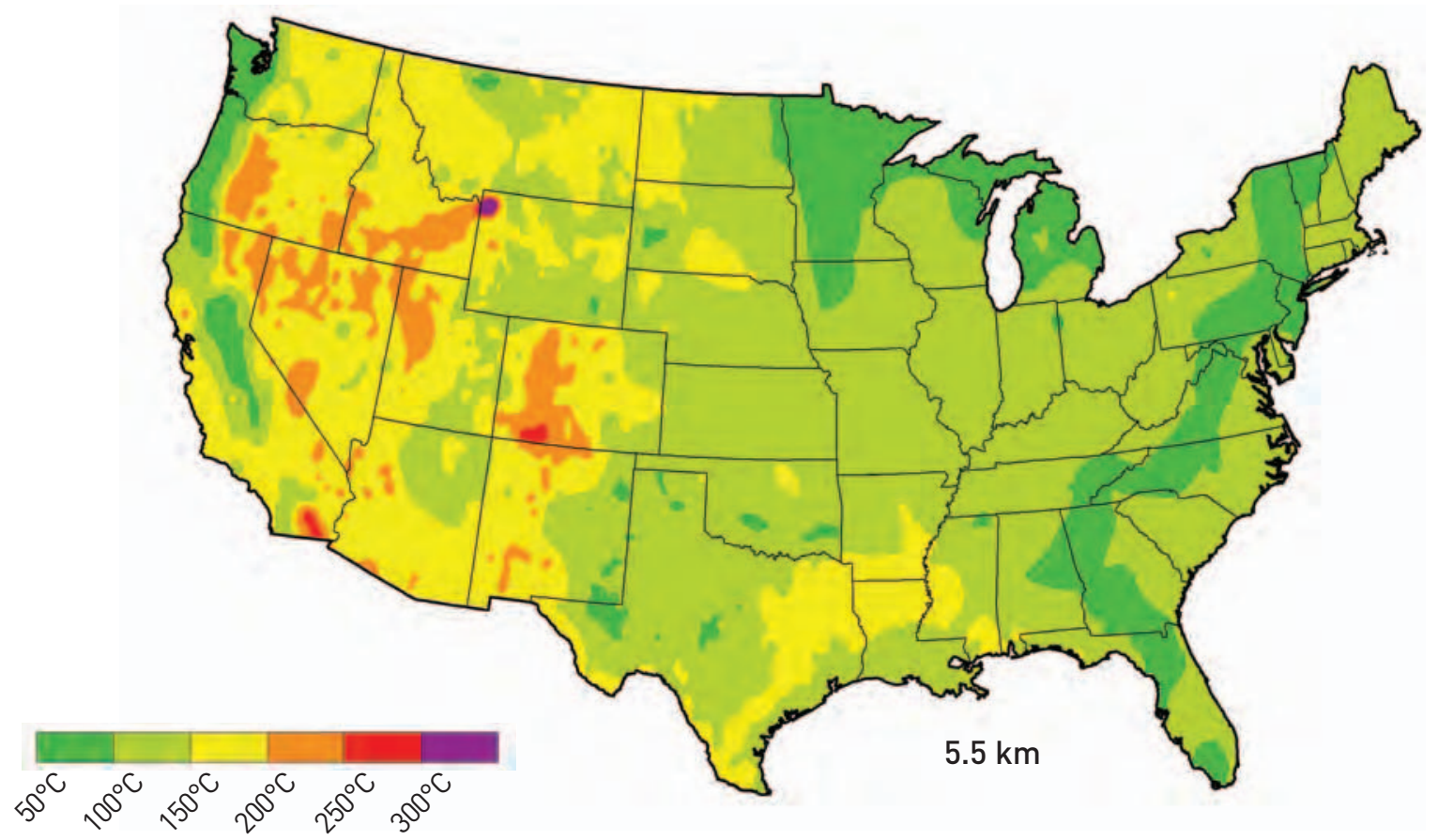

Figure 2.7c Average temperature at $5.5 \mathrm{~km}$. 


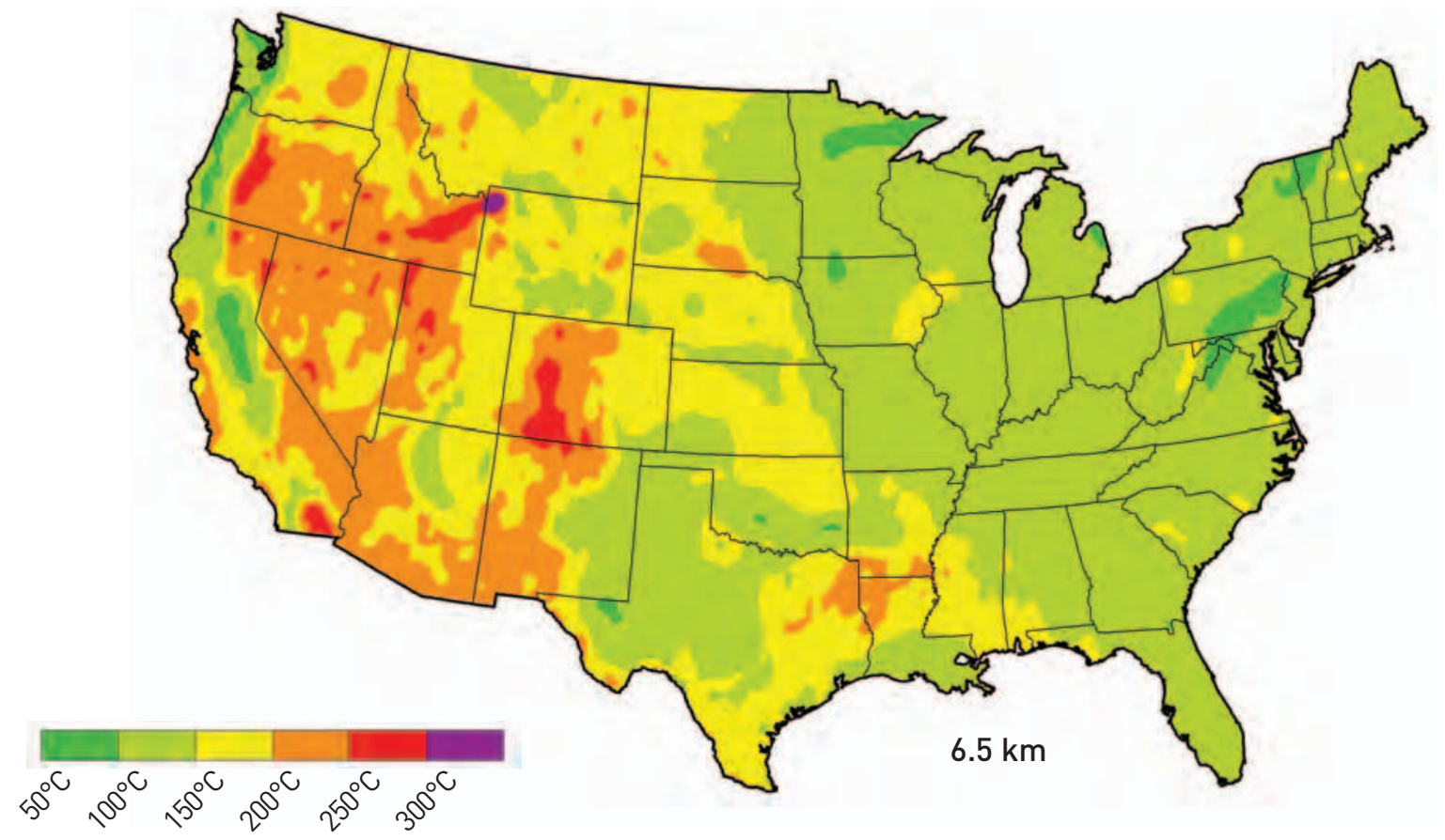

Figure $2.7 \mathrm{~d}$ Average temperature at $6.5 \mathrm{~km}$.

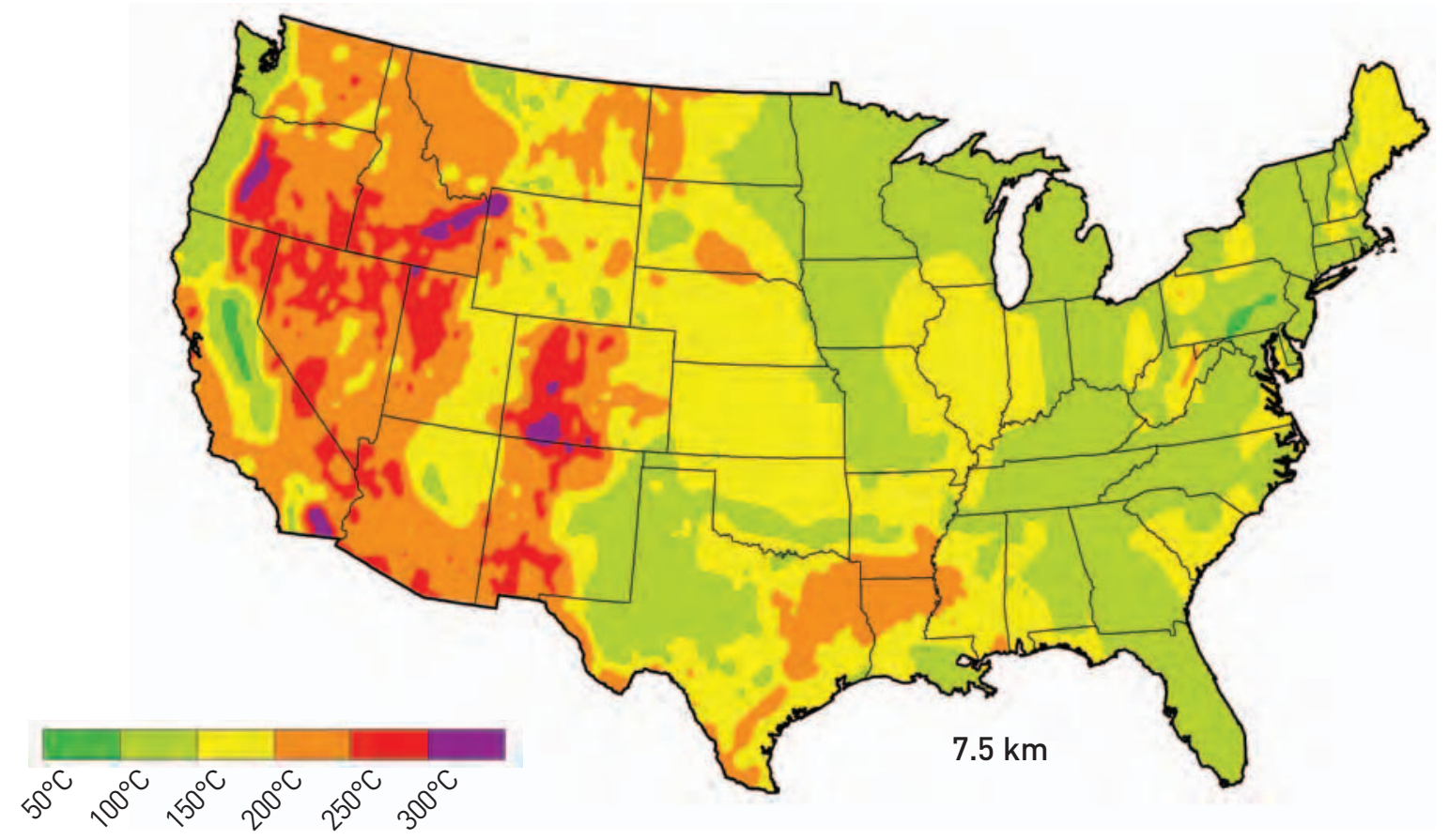

Figure 2.7e Average temperature at $7.5 \mathrm{~km}$. 


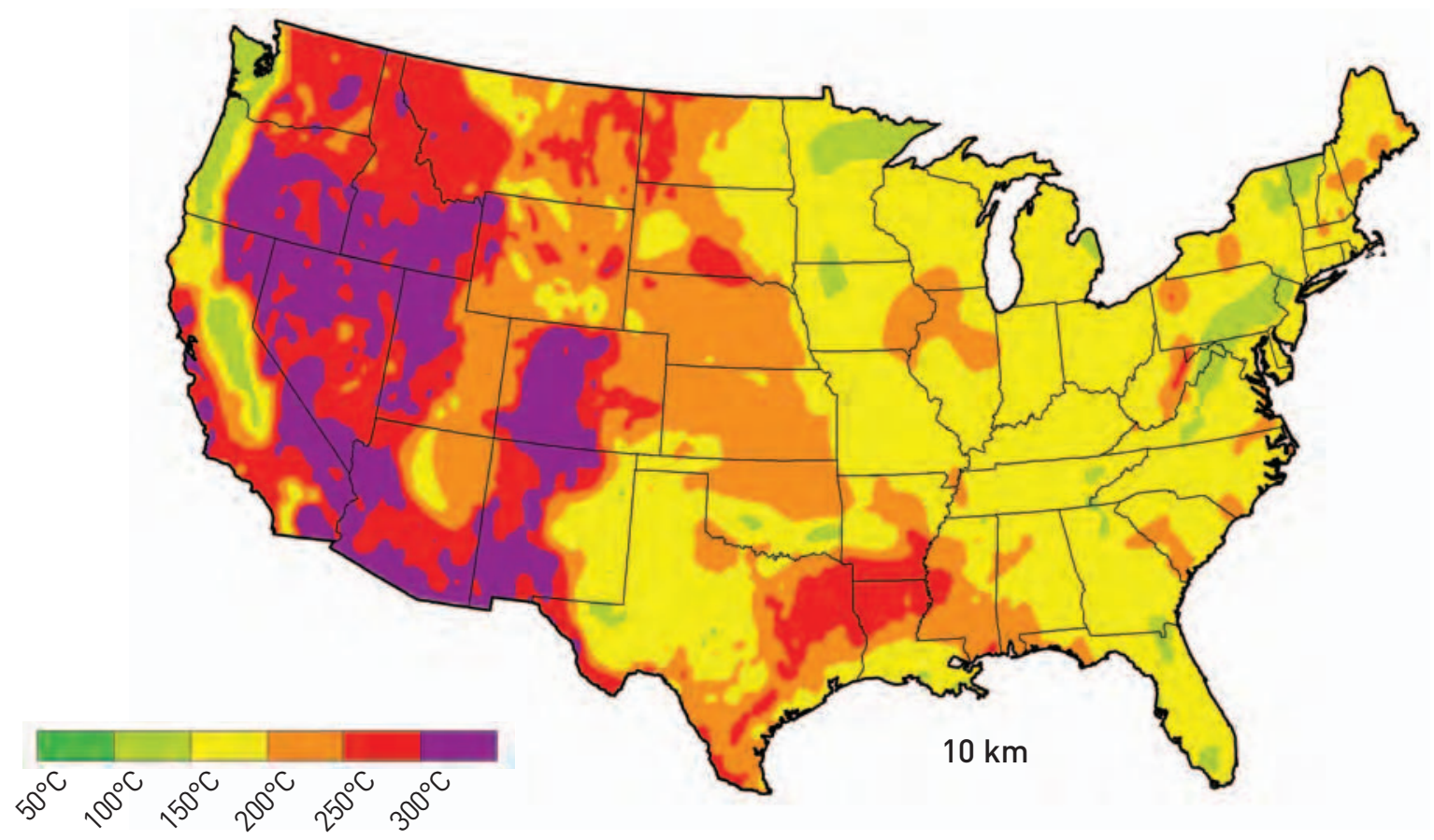

Figure $2.7 \mathrm{f}$ Average temperature at $10.0 \mathrm{~km}$.

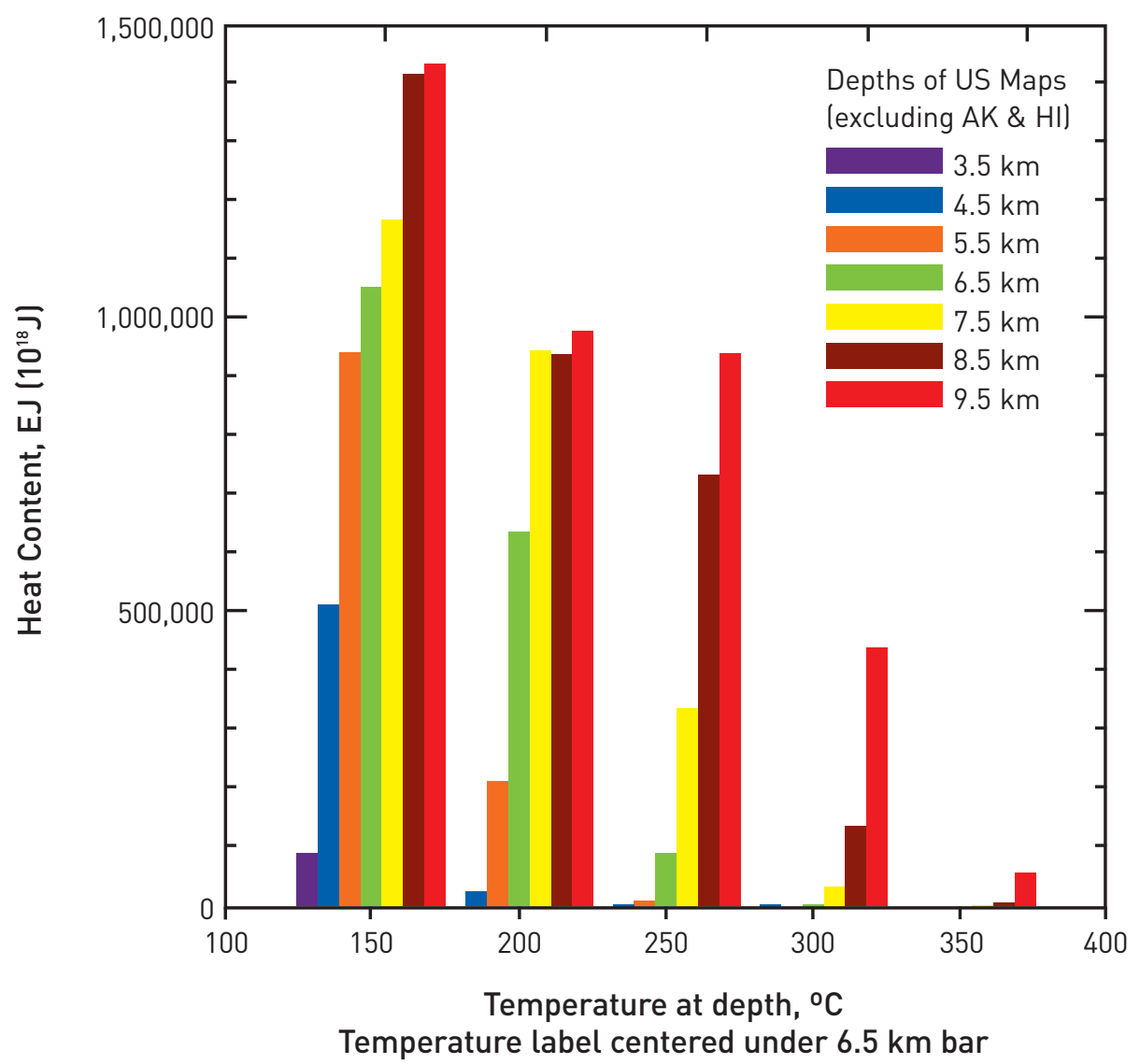

Figure 2.8a Histograms of heat content in EJ, as a function of depth for $1 \mathrm{~km}$ slices. 


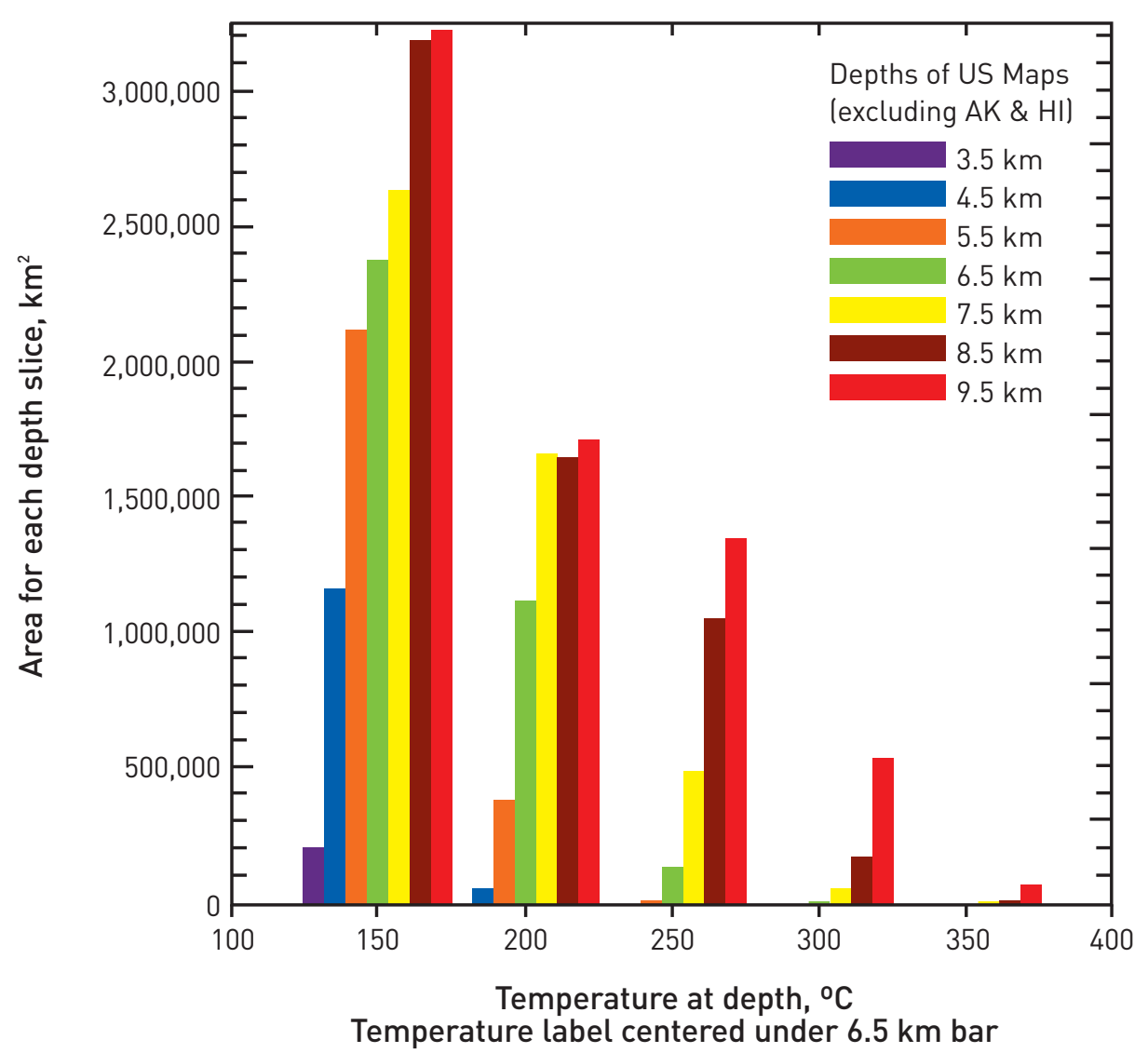

Figure 2.8b Histograms of United States area at a given temperature, as a function of depth for $1 \mathrm{~km}$ slices.

Although the EGS resource base is huge, it is not evenly distributed. Temperatures of more than $\mathrm{I} 50^{\circ} \mathrm{C}$ at depths of less than $6 \mathrm{~km}$ are more common in the active tectonic regions of the western conterminous United States, but by no means are confined to those areas. The highest temperature regions represent areas of favorable configurations of high heat flow, low thermal conductivity, plus favorable local situations. For example, there are high heat-flow areas in the eastern United States where the crustal radioactivity is high, such as the White Mountains in New Hampshire (Birch et al., I968) and northern Illinois (Roy et al., I989). However, the thermal conductivity in these areas is also high, so the crustal temperatures are not as high as areas with the same heat flow and low thermal conductivity, such as coastal plain areas or a Cenozoic basin in Nevada. The most favorable resource areas (e.g., the Southern Rocky Mountains) have a high tectonic component of heat flow, high crustal radioactivity (Decker et al., I988), areas of low thermal conductivity (as in young sedimentary basins), and other favorable circumstances such as young volcanic activity.

There are also areas of low average gradient in both the eastern and western United States. In the tectonically active western United States, the areas of active or young subduction have generally low heat flow and low gradients. For example, areas in the western Sierra Nevada foothills and in the eastern part of the Great Valley of California are as cold as any area on the continent (Blackwell et al., I99I). 


\subsubsection{Crustal stress}

Data on the state of stress are shown in Figure 2.9 (Zoback and Zoback, I99I; Zoback et al., I99I). All stress regimes are represented in the conterminous United States. The stress regime is extensional in areas such as the Basin and Range and the Gulf Coast; and compressional in parts of the eastern United States and locally in the state of Washington. Strike-slip stresses are also typical of large areas such as along the transform plate in California. However, there are still large areas that are not well-characterized; detailed resource evaluation in these areas will have to include stress studies.

There is not enough information to determine the optimum stress regime for EGS geothermal development. In Australia, the planned development in the Cooper Basin is in a highly compressive regime with geopressured conditions (Wyborn et al., 2005); while, at the Soultz area in Europe, the stress regime is extensional (Elsass et al., 1995). Because the stress regime determines drilling strategies (see Chapter 6); and because, in opening fractures, the most favorable ones are along the direction of maximum shearing stress, it is important to have information on regional stress direction and magnitude in the planning of EGS geothermal development.

\subsubsection{EGS geology}

Much of the thermal energy resides in "basement" rocks below the sedimentary section. Because basement is usually defined as areas of metamorphic or igneous rocks, the composition and lithology of "basement" is actually extremely variable. The basement lithology below the sedimentary cover, where present, is as complicated as the surface exposures. While the generic description "granite" is used in this report, the lithology is not exactly specified. Quantification of the most favorable rock composition and structure for EGS development remains to be done. Most of the experimental EGS sites have been in granite (in a strict geologic sense), because of the expected homogeneity of the rock type. In fact, there may be situations where layered rocks might be equally or more favorable because the orientations of fractures might be easier to predict and the rock types may be more extensively fractured. From a more practical point of view, the lithology also affects the heat flow in the form of its radioactive content and the resulting heat flow. As has already been described above, areas of high radioactivity will have higher heat flow and so may have higher temperatures, all other factors being similar.

Some of the EGS resource resides in the sedimentary section, however. In general, as depth and temperature increase, the permeability and porosity of the rocks decreases. So, at depths of $3+\mathrm{km}$ and temperatures of $150+{ }^{\circ} \mathrm{C}$, the rocks are similar to basement in permeability and porosity. In many areas of the country, there is extensive drilling for gas at depths where temperatures are well within the EGS range because the gas deadline is on the order of $200+{ }^{\circ} \mathrm{C}$. In many of these areas, the rocks are "tight" and must be fractured to produce commercial quantities of gas (Holditch, 2006). In fact, much of the gas resource remaining in the United States is related to these types of formations. Examples are the Cretaceous sandstones in the Pieance Basin, Colorado (Mesa Verde and Wasatch Formations), and the East Texas Jurassic section (Bossier, etc.). These sandstones are "granitic" in bulk composition but still have some intrinsic porosity and permeability. Modeling by Nalla and Shook (2004) indicated that even a small amount of intrinsic porosity and permeability increases the efficiency of heat extraction, so that these types of rocks may be better EGS hosts than true granite. Thus, there is a natural progression path from the deep hot gas reservoir stimulation and production to EGS reservoir development in both technology and location. It seems likely that these areas might be developed early in the EGS history, because of the lower reservoir risk than in unknown or poorly known basement settings. 


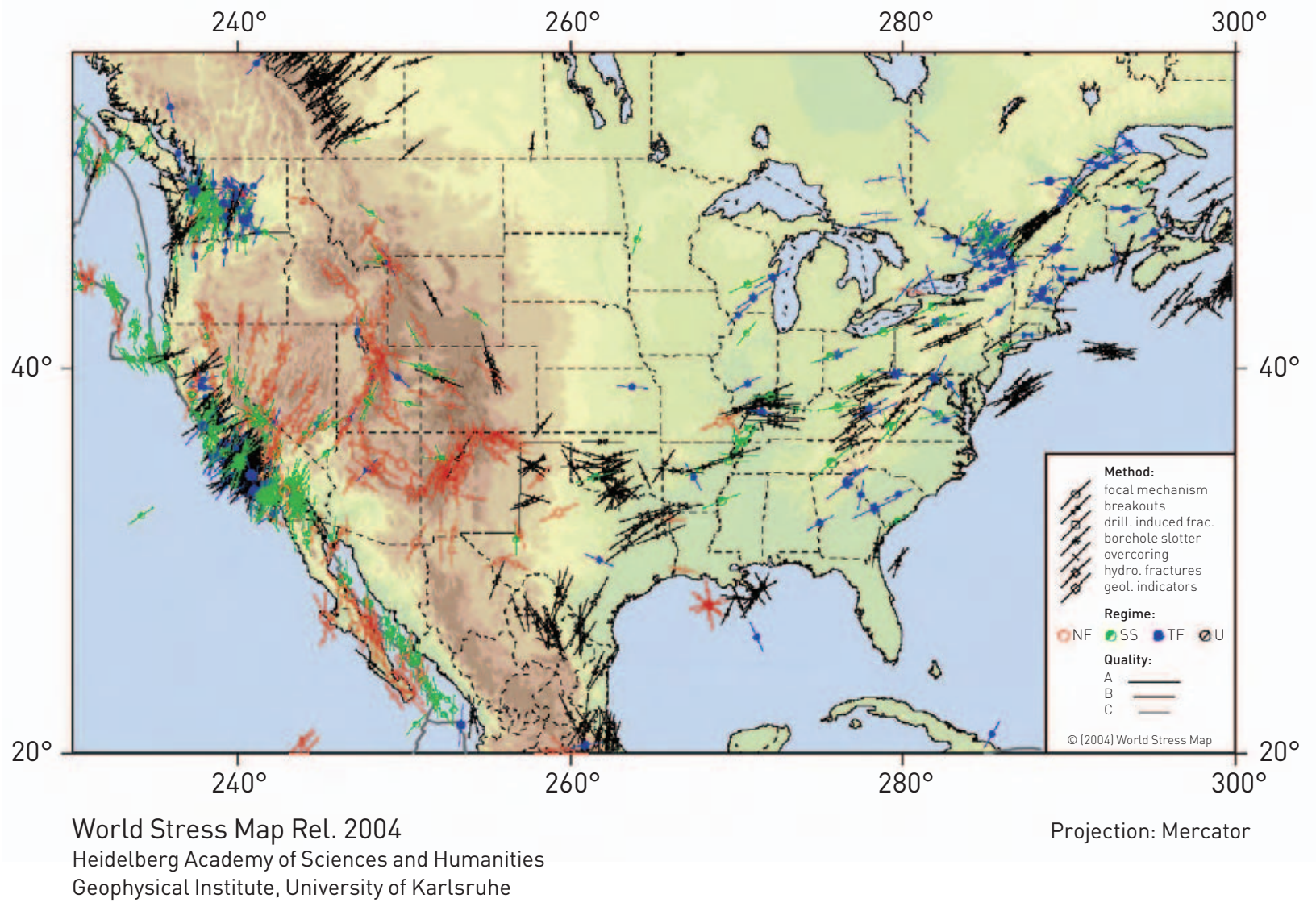

\section{Maximum Horizontal Stress Orientation}

Inferred from:

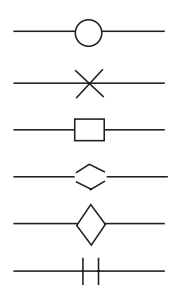

Focal mechanism

Wellbore breakouts

Fault slip data

Volcanic alignments

Hydraulic fracturing

Overcoring
Red data - Normal faulting stress regime: $\mathrm{S}_{\mathrm{v}}>\mathrm{S}_{\mathrm{Hmax}}>\mathrm{S}_{\mathrm{hmin}}$ Green data - Strike-slip faulting stress regime: $S_{H \max }>S_{V}>S_{h m i n}$ Purple data - Thrust faulting stress regime: $S_{H \max }>S_{h \min }>S_{V}$ Black data - Stress regime unknown

Figure 2.9 Subset of the Stress Map of North America (Zoback et al., 1991, World Stress Map, 2004). 


\subsubsection{Crustal permeability}

Crustal permeability is a difficult parameter to characterize. Permeability may be in the form of pore space in a sedimentary rock, such as in a sand, or as fractures in any type of rock strong enough to fracture. In general, permeability will decrease with depth. In sedimentary rocks, there is typically a relatively regular decrease due to compaction and diagenesis as depth and temperature increase. In basement rocks and deep sedimentary rocks, the primary permeability and porosity are related to the fracture and stress regime. General controls on and permeability of the crust have been discussed by Brace (I984), Davis (I981), Black (I987), among others. Ingebritsen and Manning (I999) have summarized a generalized distribution of crustal permeability as shown in Figure 2.IOa. In the upper part of the crust, there is more than 8 orders of magnitude of permeability variation. However, by depths of $5 \mathrm{~km}$, the variation is down to about 5 orders; and by $10 \mathrm{~km}$, the range is closer to 2 orders of magnitude. Modeling of large-scale crustal fluid flow indicates a significant regime change over the permeability range of $10^{-17}$ to $10^{-15} \mathrm{~m}^{2}$. At the smaller value, the crust is basically impermeable; while, at the larger value, large-scale fluid flow is possible with significant reconfiguration of the heat transfer and crustal temperatures (Wisian and Blackwell, 2004). Apparently, general large-scale crustal permeabilities are less than $10^{-16} \mathrm{~m}^{2}$ in most areas, as evidenced by the lack of hot springs over large areas of the United States. Permeability vs. depth plots for the Pierre Shale of the mid-continent, and clastic sediments in the Uinta Basin are shown in Figure 2.Iob (Bredehoeft et al., I994). These measurements show that the Pierre Shale is essentially impermeable. In the case of the clastic sediments of the Uinta Basin, a "tight gas sand" area, the variation is from low to moderate permeability.

As a result of the range of variation and the uncertain controls on the type and nature of permeability, it is generally thought that most deep, hot regions of the crust away from tectonic activity will require extensive characterization and subsequent engineering of a reservoir to be produced. Existing and past studies of such situations are summarized in Chapter 4. This need to understand the rock characteristics and conditions is a major reason that areas of deep drilling for gas production may be the least expensive locations for initial EGS development.

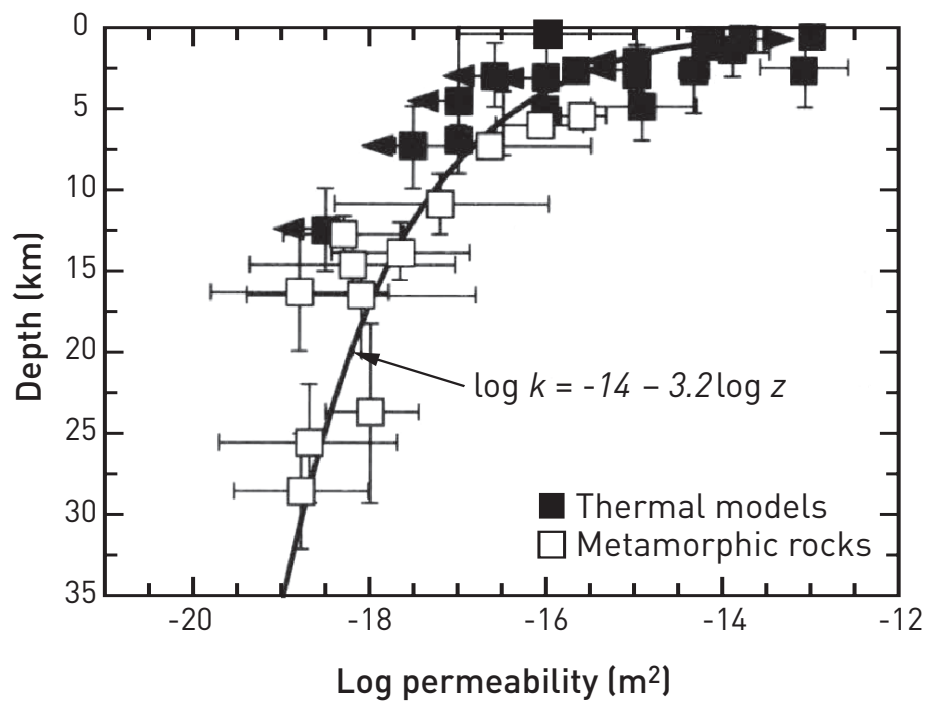

Figure 2.10a Permeability as a function of depth in continental crust (Ingebritsen and Manning, 1999). 


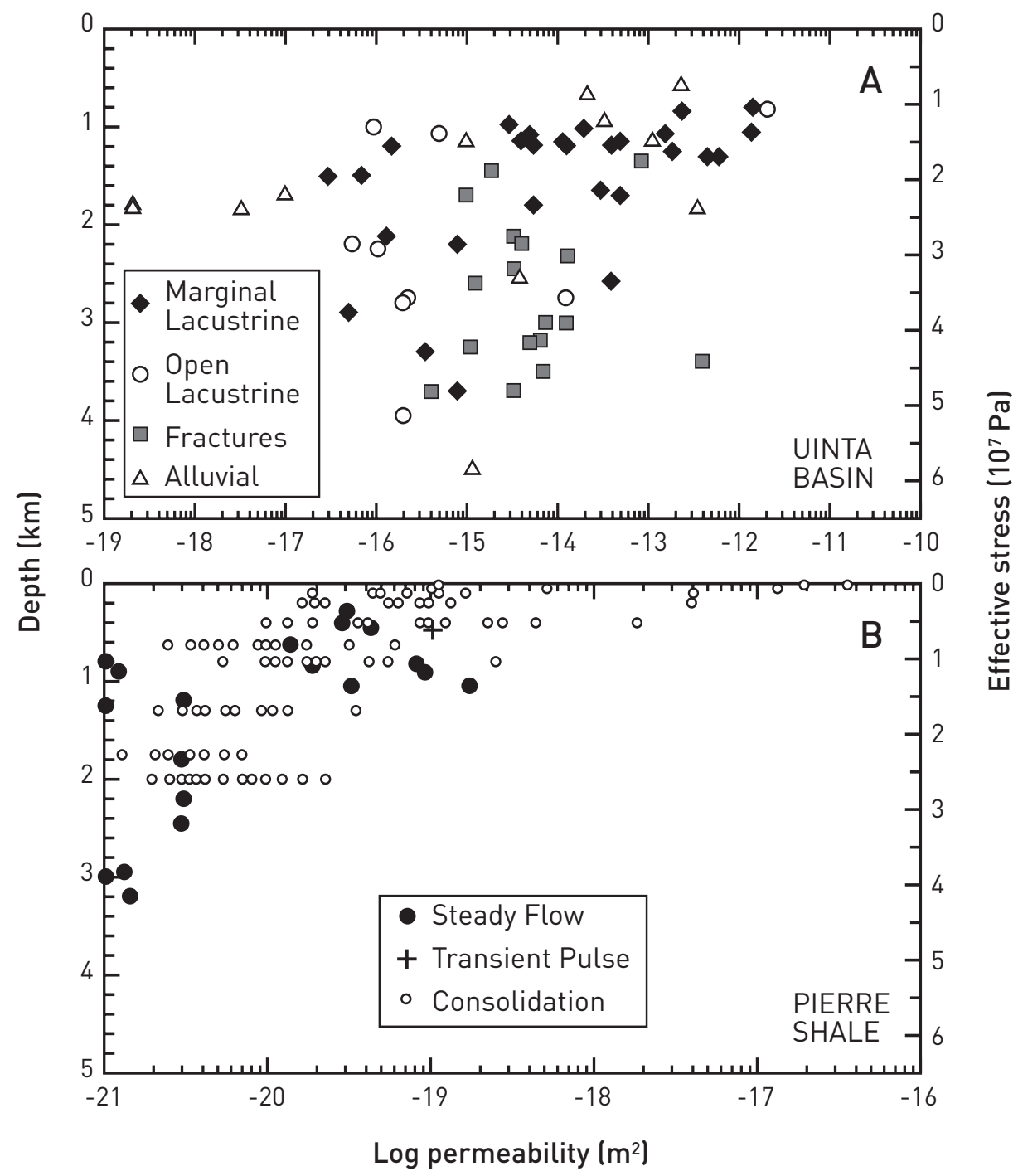

Figure 2.10b Permeability determined by direct hydraulic testing, as function of depth or effective stress in upper $(<5 \mathrm{~km})$ crust (Bredehoeft et al., 1994). Results of drill-stem tests in sedimentary facies in Uinta Basin are shown in A; results of tests on core from Pierre Shale are shown in B.

\subsubsection{High-grade EGS - targets for the near term $\left(>200^{\circ} \mathrm{C}\right.$ at depths of about $\left.4 \mathrm{~km}\right)$}

There are some large areas that have high temperatures at relatively shallow depths $(3-5 \mathrm{~km})$ that deserve special mention as near-term EGS development candidates. These are generally in the western United States, but are not confined to the areas that are presently developed as conventional hydrothermal geothermal systems. The most prominent of these areas are listed in Table 2.2. They include the Great Basin (Sass, 200I), the Snake River Plain, the Oregon Cascade Range, the Southern Rocky Mountains, the Salton Sea, and The Geysers/Clear Lake areas (see Figure 2.7b). In all these areas, detailed site studies could locate temperatures of more than $200^{\circ} \mathrm{C}$ at less than $4 \mathrm{~km}$. 
Table 2.2. High-grade EGS areas $\left(>200^{\circ} \mathrm{C}\right.$ at depths of about $\left.4 \mathrm{~km}\right)$.

\begin{tabular}{l|l}
\hline Region & Characteristics \\
\hline Great Basin & $\begin{array}{l}30 \% \text { of the } 500 \mathrm{~km} \times 500 \mathrm{~km} \text { area is at temperatures }>200^{\circ} \mathrm{C} . \\
\text { Highly variable geologic and thermal conditions with some drilling } \\
\text { confirming deep conditions. Large-scale fluid flow both laterally and } \\
\text { horizontally so extensive fracturing at depth in many areas. The } \\
\text { stress regime is extensional. Rocks are highly variable with depths } \\
\text { of } 4-10 \mathrm{~km} \text {, mostly sedimentary with some granite and other } \\
\text { basement rock types. }\end{array}$ \\
\hline Snake River Plain and margins & $\begin{array}{l}75 \% \text { of the } 75 \mathrm{~km} \times 500 \mathrm{~km} \text { area is at temperatures }>200^{\circ} \mathrm{C} . \\
\text { Details of the geology at depths of } 3-10 \mathrm{~km} \text { unknown, probably } \\
\text { volcanics and sediments overlaying granitic basement at } 3-5 \mathrm{~km}, \\
\text { low permeability. The stress regime is unknown, existing fracturing } \\
\text { may be limited. }\end{array}$ \\
\hline $\begin{array}{l}25 \% \text { of the } 50 \mathrm{~km} \times 200 \mathrm{~km} \text { area is at high, uniform temperatures } \\
\text { Ond with similar geology (volcanic and intrusive rocks dominate). } \\
\text { The margins of the area are accessible. The stratovolcanoes are } \\
\text { excluded from the analysis. Conditions are more variable in } \\
\text { California and Washington, but some high-grade resources probably } \\
\text { exist there as well. }\end{array}$
\end{tabular}

Southern Rocky Mountains

$25 \%$ of the $100 \mathrm{~km} \times 300 \mathrm{~km}$ area is at temperatures $>200^{\circ} \mathrm{C}$.

Geology is variable. Area includes the northern Rio Grande Rift and the Valles Caldera. Can have sediments over basement, generally thermal conditions in basement are unknown. Both high crustal radioactivity and high mantle heat flow contribute to surface heat flow. Probably highest basement EGS potential on a large scale.

Salton Sea $75 \%$ of the $25 \mathrm{~km} \times 50 \mathrm{~km}$ area is at temperatures $>200^{\circ} \mathrm{C}$. Young sedimentary basin with very high heat flow, young metamorphosed sedimentary rocks at depth. There is extensive drilling in the existing geothermal systems and limited background data available from hydrocarbon exploration.

Clear Lake Volcanic Field $50 \%$ of the $30 \times 30 \mathrm{~km}$ area is at temperatures $>200^{\circ} \mathrm{C}$ (steam reservoir is $5 \mathrm{~km} \times 10 \mathrm{~km}$ ). Low-permeability Franciscan sediments, may find granite at deeper depths. Possible access problems. Significant deep drilling with temperatures of $200^{\circ} \mathrm{C}$ at $2 \mathrm{~km}$ over a large area. 
One area that has received some previous study is The Geysers/Clear Lake region in California (Stone, I992). While The Geysers steam field is part of the area, exploration for other steam deposits has identified a large area that is hot at shallow depth, but does not have enough permeability for conventional hydrothermal systems. An interpretation of the temperatures at depth in the area is shown in Figure 2.II (Erkan et al., 2005). Temperature maps at 2, 3, 4, and $5 \mathrm{~km}$ are shown, based on the interpretation of more than 600 drill sites. The actual area of steam development (Stone, I992) is shown as the cross-hatched area in the first panel. Even outside this area and away from its periphery, temperatures are interpreted to exceed $200^{\circ} \mathrm{C}$ at $3 \mathrm{~km}$ over an area about 30 by $40 \mathrm{~km}$. There may be an area almost as large, with temperatures of more than $350^{\circ} \mathrm{C}$ at $5 \mathrm{~km}$. In this area, supercritical geothermal conditions might also exist.
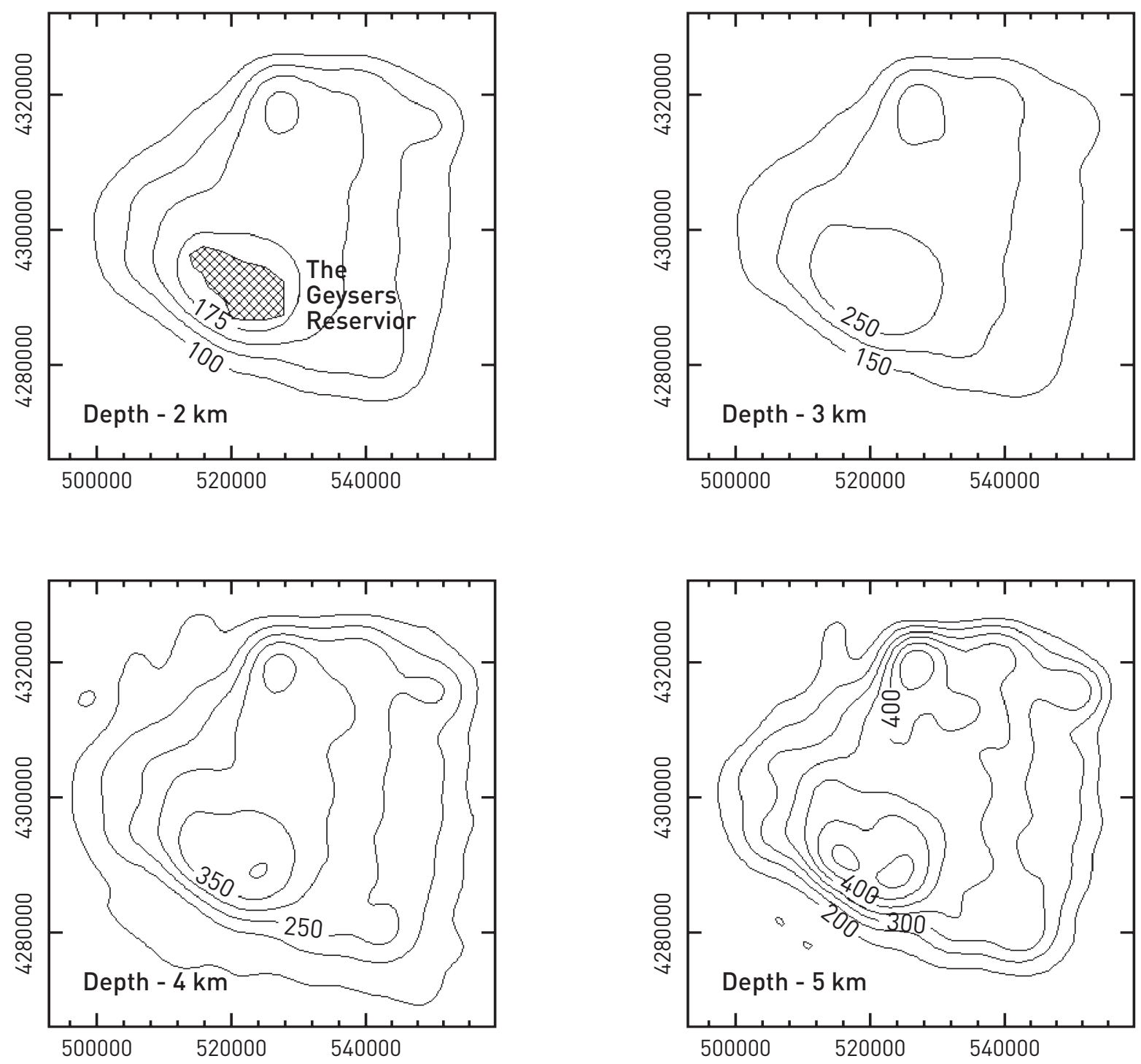

Figure 2.11 Temperatures at depths of 2 to $5 \mathrm{~km}$ in The Geysers/Clear Lake thermal area (Erkan et al., 2005). 


\subsection{EGS Potential of Alaska}

There are all varieties of geothermal resources in Alaska. However, there is almost no information on the thermal regime except in very localized areas. Also, there is only a need for electrical generation development in localized areas, so for Alaska the questions are, first, how closely collocated are the resources with the demand; and, second, are there resources large enough to trigger new local development. The limited data available are shown in Figure 2.I2 as a contour map of heat flow. Also included on the plot are the locations of volcanoes and hot springs. The EGS resource was estimated as in the case of the conterminous U.S. area described above. A thermal conductivity of $2.7 \mathrm{~W} / \mathrm{m} / \mathrm{K}$ was assumed everywhere, and the surface temperature was assumed to be $0^{\circ} \mathrm{C}$. The heat content is shown in Table A.2.I under column AK. This heat has not been added to the other U.S. values, however. The assessment of temperature at depth is diagrammatic only, because of the lack of data and the lack of collocation of information and electrical power need. There are possible conventional geothermal developments at several of the warm springs in central Alaska because of collocation situations. There is an active project at Chena Hot Springs near Fairbanks to develop $500 \mathrm{~kW}$ of power from a $165^{\circ} \mathrm{F}$ resource using binary power-generation equipment (Brasz and Holdmann, 2005). The first $250 \mathrm{~kW}$ unit went online in August 2006.

Coproduced fluids in the Cook Inlet gas developments (Shurr and Ridgley, 2002) are a possible future development scenario, but this area is part of the outer arc low heat-flow regime, and temperatures there are not particularly high.

\subsubsection{Volcano systems}

Electricity prices are high in Alaska, particularly in remote areas with only diesel-generating systems, typically greater than $25 \% / \mathrm{kWh}$. In the longer term, electricity prices will depend partly on the future of oil and gas development on the North Slope, and on the location of a gas pipeline, if one is built. As a result of these and other factors, any long-term geothermal development scenario at this time is speculative. However, more than 40 volcanoes have been historically active, indicating there must be significant heat in a number of areas in Alaska. There are several of these volcanic centers relatively near the population center of Anchorage. Mt. Spurr and Mt. Dedoubt are close enough that geothermal power developed there might be transmitted to the load centers near Anchorage. The Wrangle Mountains are a huge volcanic complex almost certainly with associated geothermal systems. However, as a national park, geothermal energy recovery may not be possible, even if viable resources exist.

Smith and Shaw (I979) evaluated the igneous systems in Alaska for the I978 resource assessment. They examined 27 volcanoes and estimated a resource base of about $2.5 \times 10^{12} \mathrm{MWh}$ for that set of sites. This estimate is certainly minimal, because there are more than 70 volcanoes that have erupted in the past Io,০০০ years along the Aleutian chain (www.UnivAlaska.edu). This is recent enough that there is a significant possibility that there is still heat associated with these areas.

Very high-grade EGS involving reservoir temperatures and pressures in the supercritical region ( $T>374^{\circ} \mathrm{C}$ and $P>220$ bar) are possible in Alaska, because of the many active volcanoes that are present along the Aleutian Island arc. If each one had a supercritical system associated with it, the resource could be quite large. The viability of such geothermal development has not been proven, but is under active research in Iceland (Valgardur, 2000; and Fridleifsson and Elders, 2004). The power 
from such systems in Alaska could be developed in the remote areas and converted to hydrogen for transport to load centers in future energy scenarios. Under the appropriate economic conditions, it is possible that several tens of thousands of megawatts could be developed. Efforts to initiate development are ongoing at the volcanoes Matushkin, on Unalaska, (Reeder, I992; Sifford and Bloomquist, 2000); and Akutan, on the island of Akutan (Starkey Wilson, personal communication, 2005).

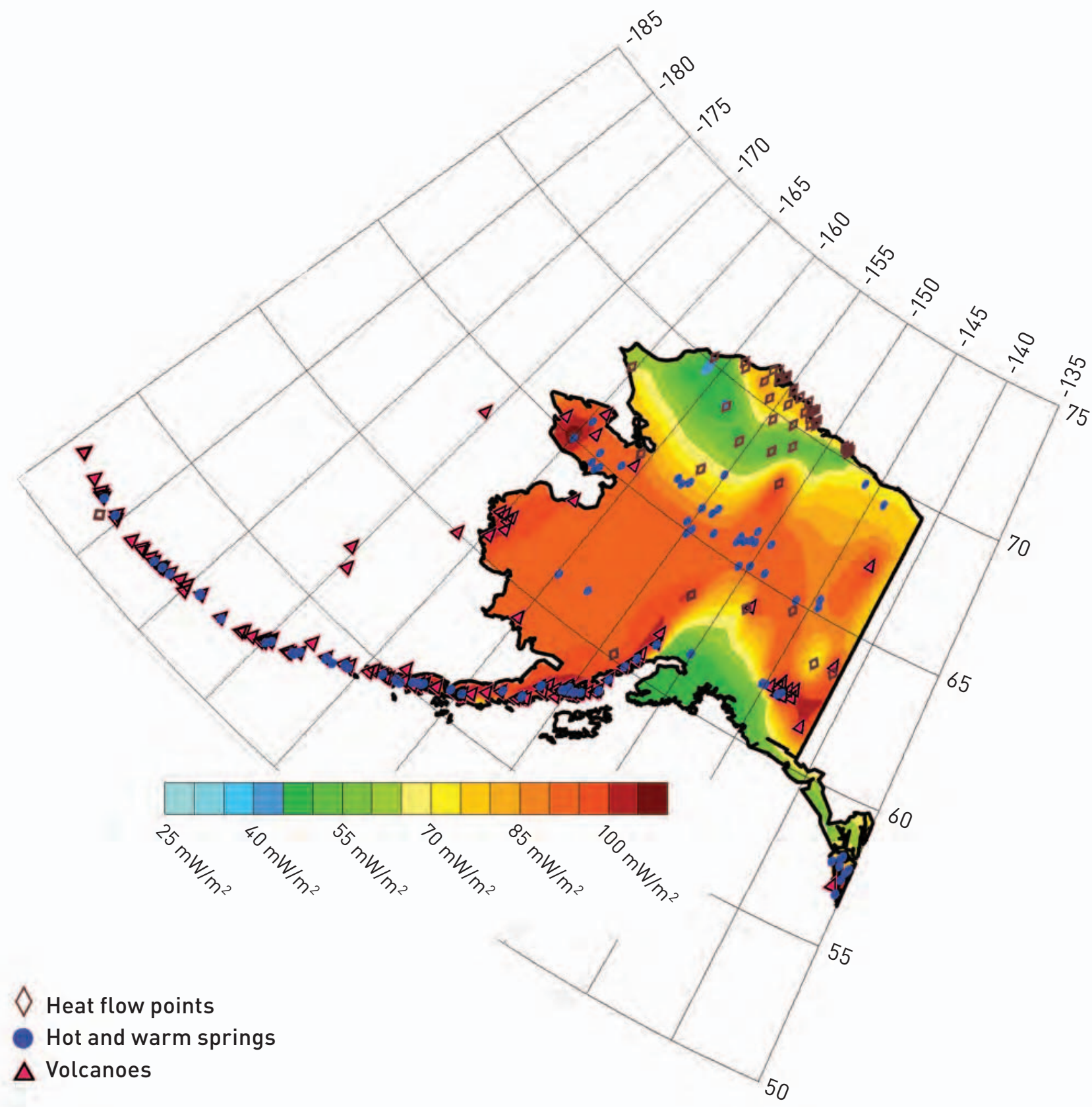

Figure 2.12 Heat-flow map of Alaska (from Blackwell and Richards, 2004). 


\subsection{EGS Potential of Hawaii}

There is an existing power plant on the island of Hawaii along the east rift of the Kilauea volcano (Sifford and Bloomquist, 2000). The temperatures are high in this system of basaltic rift activity. There may be other resources in this area, but these are conventional hydrothermal resources. There is little subsurface information available outside of this area. The deepest drill hole on the Island of Hawaii, near Hilo (DePaolo et al., 200I), has a gradient of about $40^{\circ} \mathrm{C} / \mathrm{km}$ below a depth of about I.9 $\mathrm{km}$ and a BHT at $2.9 \mathrm{~km}$ of $42^{\circ} \mathrm{C}$ (Buttner and Huenges, 2003). There might be geothermal resources on Maui; but, on the other islands, geoelectric grade resources are not likely, due to the older age of volcanic activity there. There is little direct thermal information for these areas though, and the possibility of EGS development has not been ruled out. In a recent analysis of the geothermal potential of Hawaii, Lovekin et al. (2006) calculated resource estimates of I,396 MW for the island of Hawaii (80\% related to Kilauea volcano) and I39 MW for the island of Maui.

The island of Hawaii has the best possibility for the development of supercritical geothermal resources, if the viability of such development becomes feasible. Extensive interest in such development exists in Iceland, where drilling into such systems is planned in the near future (Fridleifsson and Elders, 2004).

\subsection{Unconventional EGS Associated with Coproduced Fluids and Geopressured Fluids}

\subsubsection{Introduction}

There are areas identified in the resource maps (Figure 2.7) where high temperatures are routinely being encountered in sedimentary rock during drilling for hydrocarbons. These temperatures typically reach $150^{\circ} \mathrm{C}\left(330^{\circ} \mathrm{F}\right)$ to more than $200^{\circ} \mathrm{C}\left(400^{\circ} \mathrm{F}\right)$. In some of these areas, significant porosity and permeability exists at depths of 3 to $6 \mathrm{~km}$, and there is potential for large amounts of hot water either with or without stimulation of the reservoirs. In some of these cases, there may be the opportunity to stimulate fluid flows high enough to produce significant quantities of geothermal energy without having to create a new reservoir, or with relatively minor modifications of an existing oil or gas reservoir. So the distinction between an EGS system and a natural hydrothermal system are somewhat blurred. In these areas, there is also a developed infrastructure and an existing energy industry presence. Therefore, it seems possible that EGS or hybrid geothermal systems might be developed before the transition is made to pure, "start-from-scratch" EGS systems (McKenna et al., 2005). For the purpose of this report, these situations are divided into two categories: Coproduced Fluids and Geopressured Fluids. Thus, we have added coproduced hot water from oil and gas production as an unconventional EGS resource type, because it could be developed in the short term and provide a first step to more classical EGS exploitation. 


\subsubsection{Coproduced fluids: "conventional" geothermal development in hydrocarbon fields}

Some areas of oil and gas development have relatively high temperatures at routinely drilled depths for hydrocarbon production. For example, parts of east and south Texas and northwest Louisiana are characterized by temperatures in excess of $150^{\circ} \mathrm{C}\left(300^{\circ} \mathrm{F}\right)$ at depths of 4 to $6 \mathrm{~km}(\mathrm{I} 3, \mathrm{I} 23 \mathrm{ft}$ to $19,684 \mathrm{ft})$ (McKenna and Blackwell, 2005; McKenna et al., 2005) (see Figure 2.7). Data from BHT and highresolution log segments in wells in south Texas indicate temperatures of more than $200^{\circ} \mathrm{C}\left(400^{\circ} \mathrm{F}\right)$ at $5 \mathrm{~km}$ (I6,000 ft). In east Texas, temperatures are more than $150^{\circ} \mathrm{C}$ in the depth range of 3.5 to $4 \mathrm{~km}$ (II,, 00 to I3,, $00 \mathrm{ft}$ ). And, in northwest Louisiana, BHTs and equilibrium temperature logs document temperatures of $\mathrm{I} 2 \mathrm{O}-\mathrm{I} 60^{\circ} \mathrm{C}$ at only $3 \mathrm{~km}$ (IO,000 ft). Because in situ thermal conditions have been verified in these specific areas, the substantial areal extent of potential geothermal resources shown in Figure 2.7 is valid.

In addition to temperature requirements, a geothermal development requires large-volume flows of water, on the order of I,००० GPM per MW (depending on the temperature). There are two typical types of existing situations associated with hydrocarbon development that are very favorable for geothermal development. The first might be considered "conventional" hydrothermal development, in that high volumes of water are produced in some fields as a byproduct of hydrocarbon production. This situation exists, for example, in massive water-flood secondary recovery fields (Table 2.3). Curtice and Dalrymple (2004) show that coproduced water in the conterminous United States amounts to at least 40 billion barrels per year, primarily concentrated in a handful of states (Figure 2.I3). In most mature hydrocarbon fields, the disposal of this coproduced water is an expensive problem (Veil et al., 2004).

Table 2.3 Equivalent geothermal power from coproduced hot water associated with existing hydrocarbon production in selected states (a complete listing is given in Appendix A.2.2).

\begin{tabular}{|c|c|c|c|c|c|}
\hline State & $\begin{array}{l}\text { Total Water } \\
\text { Produced Annually, } \\
\text { in } 1,000 \mathrm{kbbl}\end{array}$ & $\begin{array}{l}\text { Total Water } \\
\text { Production } \\
\text { Rate, kGPM }\end{array}$ & $\begin{array}{l}\text { Equivalent } \\
\text { Power, } \\
\text { MW @ } 100^{\circ} \mathrm{C}\end{array}$ & $\begin{array}{l}\text { Equivalent } \\
\text { Power, } \\
\text { MW@ } 140^{\circ} \mathrm{C}\end{array}$ & $\begin{array}{l}\text { Equivalent } \\
\text { Power, } \\
\text { MW @180 C }\end{array}$ \\
\hline Alabama & 203,223 & 18 & 18 & 47 & 88 \\
\hline Arkansas & 258,095 & 23 & 23 & 59 & 112 \\
\hline California & $5,080,065$ & 459 & 462 & 1,169 & 2,205 \\
\hline Florida & 160,412 & 15 & 15 & 37 & 70 \\
\hline Louisiana & $2,136,573$ & 193 & 194 & 492 & 928 \\
\hline Mississippi & 592,518 & 54 & 54 & 136 & 257 \\
\hline Oklahoma & $12,423,264$ & 1,124 & 1,129 & 2,860 & 5,393 \\
\hline Texas & $12,097,990$ & 1,094 & 1,099 & 2,785 & 5,252 \\
\hline TOTALS & $32,952,141$ & 2,980 & 2,994 & 7,585 & 14,305 \\
\hline
\end{tabular}

The factors required for successful geothermal electrical power generation are sufficiently high fluid flow rates for a well or a group of wells in relatively close proximity to each other, at temperatures in excess of $100^{\circ} \mathrm{C}\left(212^{\circ} \mathrm{F}\right)$. Opportunities can be found in most of the basins in the continental United States. For example, Figure 2.I3 shows the average total produced water as a byproduct of hydrocarbon 
production by state for 3I states (Curtice and Dalrymple, 2004). Oklahoma and Texas alone produce more than 24 billion barrels of water per year. In certain water-flood fields in the Gulf Coast region particularly in northeastern Texas, southwestern Arkansas, and coastal Alabama/Mississippi - more than 50,000 barrels/day of fluid are produced, and paid for (in terms of pumping and disposal costs) by existing operations. Collecting and passing the fluid through a binary system electrical power plant could be a relatively straightforward process; because, in some cases, the produced fluid already is passed to a central collection facility for hydrocarbon separation and water disposal. Hence, piggybacking on existing infrastructure should eliminate most of the need for expensive drilling and hydrofracturing operations, thereby reducing the risk and the majority of the upfront cost of geothermal electrical power production. There is not actual information available for the temperature of the waters available, so example calculations are shown for extreme cases of temperature. If the produced water is exploited for electric power production, the resulting power potential from contemporary binary plants is substantial as shown in Table 2.3. Chapter 7 discusses this subject in more detail.

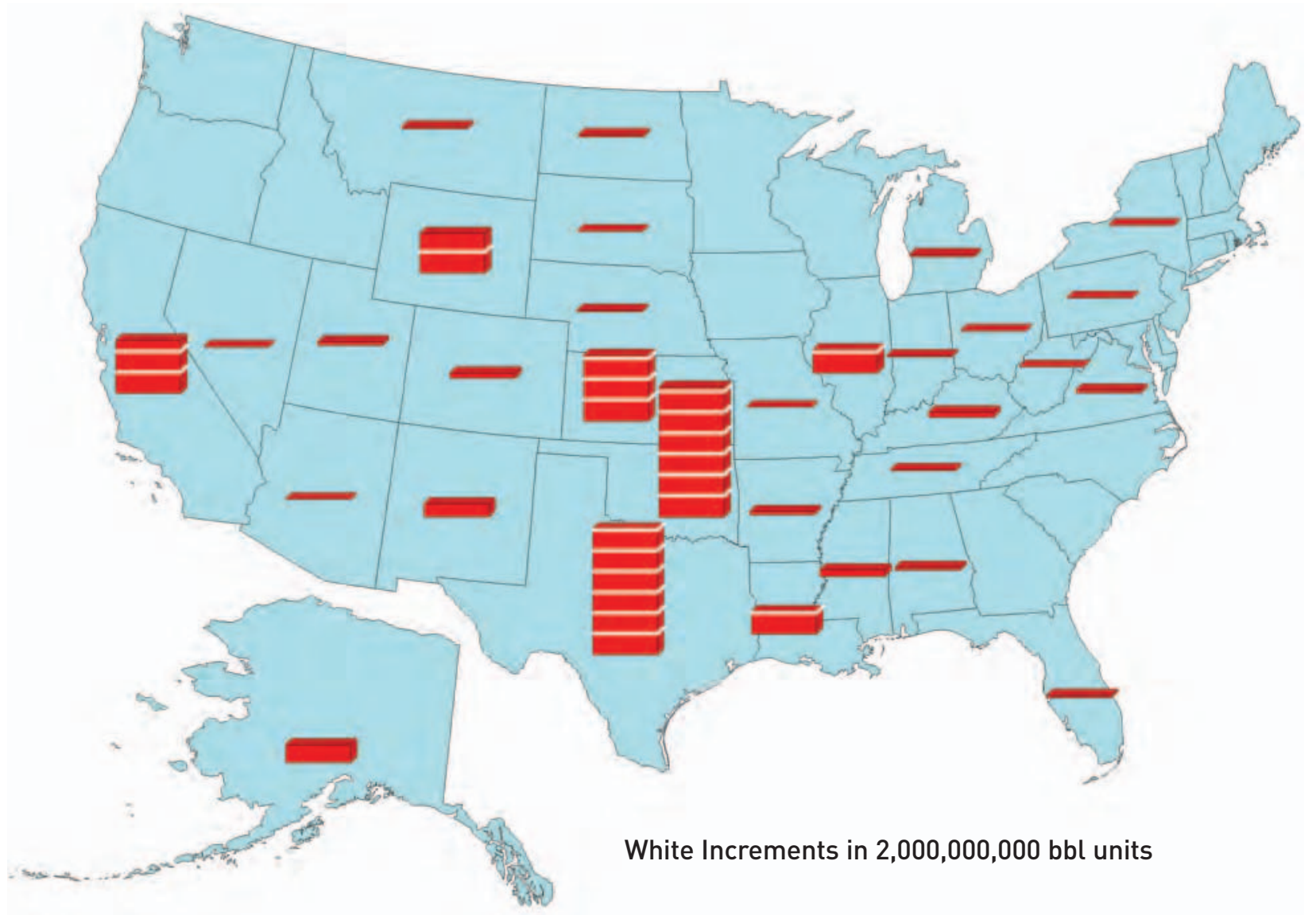

Figure 2.13 Water production from oil and gas wells (Curtice and Dalrymple, 2004).

Some of the fluid is produced from dispersed sites and may not be appropriate for use. However, these figures do give an idea of the absolute minimum of fluid that can be easily produced; and, if collected, could be a feedstock for existing reservoirs or new EGS types of applications. Its use in this way would also mitigate the environmental problems associated with disposal, by introducing a beneficial use of the waste product and ultimately lowering the cost of some forms of hydrocarbon 
extraction. The figures for equivalent power in Table 2.3 represent an upper limit for electricial power generation that could be brought online with relatively low invested cost using all coproduced fluids (see also Chapter 9). The primary unknowns and, hence, limiting factors in these areas are the magnitude of the combined flow rates and the actual temperatures of the produced fluid in these existing hydrocarbon fields. In the case of two fields in Alabama, the temperatures appear to be more than $120^{\circ} \mathrm{C}\left(250^{\circ} \mathrm{F}\right)$, well within the range of binary generation capability.

\subsubsection{Geopressured geothermal resources}

The second category of systems in sedimentary rock is represented by the geopressured areas of deep basins where wells produce at pressures much higher than hydrostatic. The largest areas are in the young Gulf Coast sedimentary basin, but other basins also have geopressured conditions. The geothermal potential of geopressured zones in the northern Gulf of Mexico basin was evaluated in some detail by Papadopulos et al. (I975) and by Wallace et al. (I979). Papadopulos et al. (I975) noted, "Unlike other geothermal areas that are being considered for the development of energy, the energy potential of the waters in the geopressured-geothermal areas of the northern Gulf of Mexico is not limited to thermal energy. The abnormally high fluid pressures that have resulted from the compartmentalization of the sand and shale beds that contain these hot waters are a potential source for the development of mechanical (hydraulic) energy. In addition, dissolved natural gas, primarily methane, contributes significantly to the energy potential of these waters." So the development of this type of geothermal resource will also result in the recovery of significant amounts of natural gas that would otherwise be uneconomic.

Papadopulos et al. (I975) assessed the resource potential of geopressured-geothermal reservoirs within the onshore part of Tertiary sediments, under an area of more than $\mathrm{I} 45,000 \mathrm{~km}^{2}$ along the Texas and Louisiana Gulf Coast - this represents about half of the total area with geopressured conditions (see Figure 2.I4). The assessment included only the pore fluids of sediments that lie in the interval between the top of the geopressured zones and the maximum depth of well control in I975, i.e., a depth of $6 \mathrm{~km}$ in Texas and $7 \mathrm{~km}$ in Louisiana. They did not include the resource potential of

geopressured reservoirs within (i) onshore Tertiary sediments in the interval between the depth of maximum well control and Io km, (ii) offshore Tertiary sediments, and (iii) Cretaceous sediments. They did estimate that the potential of these additional geopressured reservoirs is about I.5 to 2.5 times what was assessed in their study.

In contrast to geothermal areas of the western United States, subsurface information is abundant for the geopressured-geothermal area of the northern Gulf of Mexico basin. The area has been actively explored for oil and gas, and hundreds of thousands of wells have been drilled in search of petroleum deposits in the Texas and Louisiana Gulf Coast. The data presented by Papadopulos et al. (I975) represent general conditions in the various regions outlined. They believed that their information on geologic structure, sand thickness, temperature, and pressure were adequate for the purpose of their study. On the other hand, they noted a lack of sufficient data on porosity, permeability, and salinity. The basis on which various data presented were determined, calculated, or assumed was discussed in the "Appendix" to their report (White and Williams, I975). 


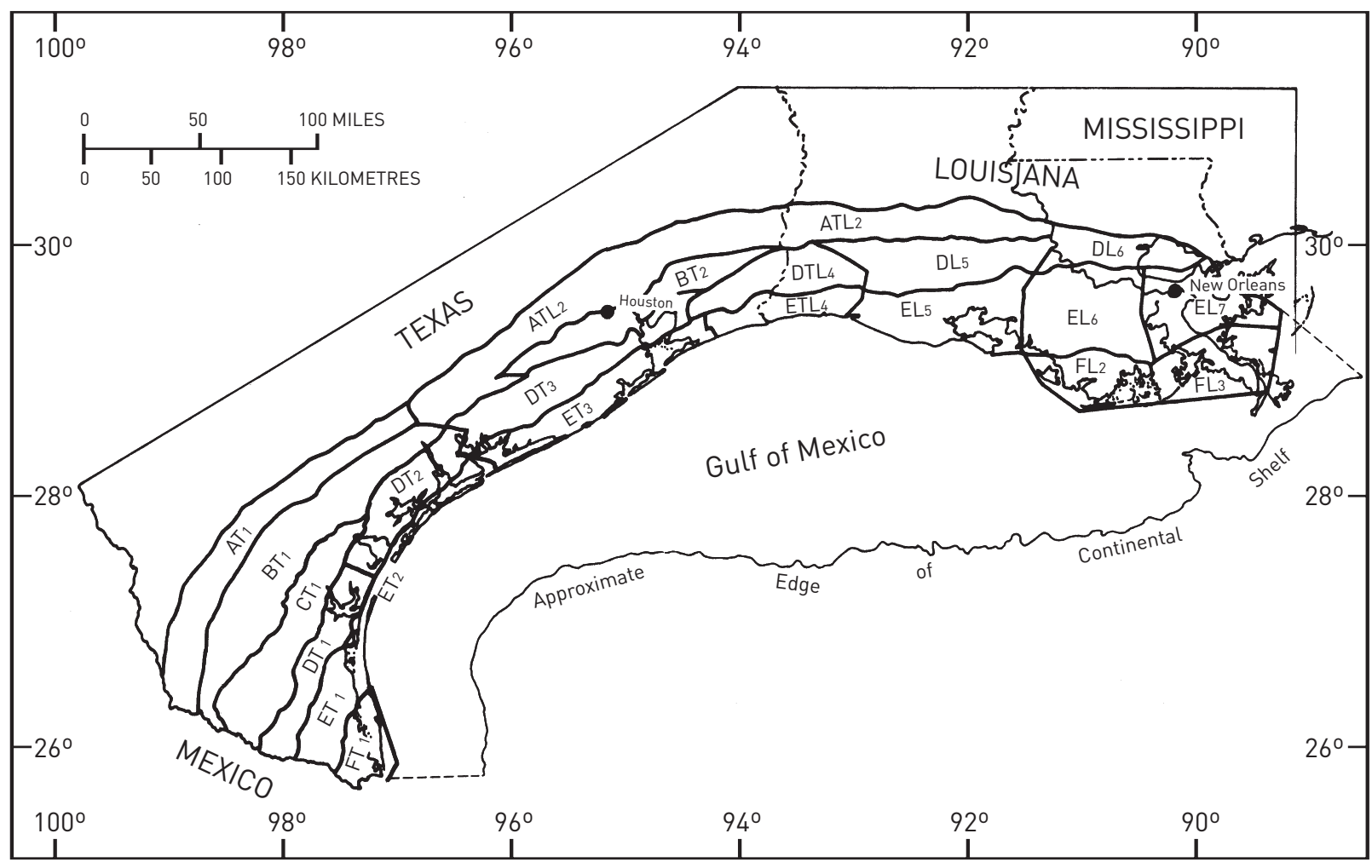

Figure 2.14 Location map showing the extent of the assessed geopressured zones and their division into subareas (AT1, BT1, etc.) (USGS Circular 726, 1975.)

The results of the assessment by Papadopulos et al. (1979) were incorporated into the final conclusions of the overall geothermal resource assessment of Circular 726 (White and Williams, I975). Based on their analysis, they assessed the thermal resource base to be 46,000 EJ and the methane volume to be $23,700 \times 10^{12} \mathrm{SCF}$, with a thermal equivalent of 25,000 EJ. The resource base, according to their calculations, is then about I,००० MW for a century. Even their most conservative estimate of development was 46,000 EJ, excluding the chemical energy in the dissolved gas.

The Wallace et al. (I979) assessment extended the study to Cretaceous rocks north of, and beneath, the Tertiary sediments studied by the 1975 project for a total area of more than $278,500 \mathrm{~km}^{2}$ (including offshore areas). The area they accessed extended from the Rio Grande in Texas northeastward to the vicinity of the mouth of the Pearl River in Louisiana; and from the landward boundary of Eocene growth faulting southeastward to the edge of the Continental Shelf, including unmapped Cretaceous sediments underlying the Tertiary sediments, extending farther inland. They assumed a depth limit of $6.86 \mathrm{~km}(22,500 \mathrm{ft})$ for development and a lower limit of temperature of $150^{\circ} \mathrm{C}\left(300^{\circ} \mathrm{F}\right)$. As was the case for Papadopulos et al. (I975), they did not include the dissolved methane in their calculations. They estimated that the accessible resource was II0,000 EJ of dissolved methane, which was later reported by Wallace et al. (I979) to be about 59,000 x I0 ${ }^{12}$ SCF or only about 60,000 EJ (see Table 2.5). 
These numbers may be compared with the calculated thermal resource base for the Gulf Coast states calculated above. This value for the states of Louisiana, Mississippi, and Texas is I.5 x 10 ${ }^{6}$ EJ. This number does not include the offshore areas of the Gulf of Mexico. The amount calculated by Wallace et al. (I979) was II0,000 EJ. This value includes the stored thermal energy in both the on- and offshore geopressure areas, but does not include the energy stored in dissolved methane or the hydraulic energy resulting from the naturally high pressures of geopressured fluids.

In considering these estimates, it is important to note that the EGS values in this report include the entire states of Texas, Louisiana, and Mississippi, and not just the geopressure areas. The Wallace et al. (I979) value for the specific geopressure value could be considered to add to the baseline EGS figures from the analysis of stored thermal energy reported in Table A.2.I. This is because of the characteristics of the sedimentary basin resource. Wallace et al. (I979) used a value of approximately $20 \%$ for the porosity of the sediments. Because the heat capacity of water is about five times larger than that of rock, the stored thermal energy is approximately twice what would be present in the rock mass with zero porosity as assumed in the analysis summarized in Table A.2.I. The ability to extract the methane for energy from these areas is also an additional resource.

Subsequent to these assessments, technologies for recovering geopressured energy were extensively studied by the U.S. DOE between I979 and I990. From late I989 until early I990, a I MW plant was operated on the Pleasant Bayou well in the Texas Gulf Coast near Houston, which produced hot water and natural gas. About half of the power was generated by a binary cycle plant running on the thermal energy of the water, and about half generated by burning the gas in a reciprocating-engine-operated electric generator (Campbell and Hattar, I990). The economics of the power generation at that time were not favorable, due to the low price of natural gas and oil, and the test was discontinued after the 6-month trial run. The well had been flow tested for a period of about 5 years with limited drawdown, so the geologic system seemed to be a success, and the reservoir sufficiently large to sustain production for many years (Shook, I992). With today's higher gas costs and increasing demand for natural gas, geopressured systems deserve to be reconsidered, because their economics in today's energy markets will be much more favorable as pointed out in a recent study (Griggs, 2005). 


\subsubsection{EGS in sedimentary basins beneath hydrocarbon-bearing fields}

Another scenario exists for geothermal development in many of the areas exploited for deep oil and gas production, especially in the Gulf Coast and mountain states regions. In these areas, EGS development in the deep, high-temperature part of the sedimentary section might be more costeffective than basement EGS systems. Table 2.4 shows a comparison of needs for EGS-type development costs vs. reality in existing hydrocarbon fields. It is clear that many of the upfront reservoir costs have been reduced, and that the existing infrastructure can be readily adapted to geothermal electrical power production.

Table 2.4 Comparison of cost components for "EGS" development (previous model for geothermal development vs. reality in oil patch situations).

\begin{tabular}{|c|c|}
\hline $\begin{array}{l}\text { Components of Direct } \\
\text { EGS Development Cost }\end{array}$ & $\begin{array}{l}\text { - Drill wells that reach hot temperatures. }>150^{\circ} \mathrm{C}\left(>300^{\circ} \mathrm{F}\right) \text {, } \\
\text { - Fracture and/or horizontally drill wells to develop high water } \\
\text { flow and/or acquire make-up water, } \\
\text { - Install infrastructure, roads, piping, and power line routing, } \\
\text { - Build power stations }\end{array}$ \\
\hline Actual Field Conditions & $\begin{array}{l}\text { - Many wells with BHTs of more than } 150^{\circ} \mathrm{C}\left(300^{\circ} \mathrm{F}\right) \text { at } \\
\text { - Wells fractured or horizontally drilled in many cases, } \\
\text { - Water available from the well or adjoining wells in fields or as } \\
\text { externally supplied disposal water (paid for by disposer), } \\
\text { - In-place infrastructure of power lines, roads, pipelines, } \\
\text { - Continued production of gas and oil in otherwise marginally } \\
\text { economic wells. }\end{array}$ \\
\hline $\begin{array}{l}\text { Direct Costs to Develop a Gulf } \\
\text { Coast EGS System }\end{array}$ & $\begin{array}{l}\text { - Build power station, } \\
\text { - Recomplete wells, in some cases, and test flow system, } \\
\text { - Minor surface infrastructure upgrades (i.e., insulating collection } \\
\text { pipes, etc.) }\end{array}$ \\
\hline
\end{tabular}

Future work must be performed on the suitability of some of the wells/fields now being developed as deep, hot, tight, sandstone gas reservoirs; but, overall, it appears that large areas of the United States are suitable for future geothermal exploitation in the near term that have not been considered in the past. Many of these areas are hot, and most are being artificially stimulated (fractured), or horizontally drilled, or both. These areas are clearly "EGS" types of systems but with known drilling and development costs and abundant water. Because of the thousands of wells drilled, the costs may be in some cases one-half to one-third of those for hard rock drilling and fracturing. A failed well in oil and gas exploration often means too much associated water production. In some areas, such as the Wilcox trend in south Texas, there are massive, high-porosity sands filled with water at high temperature. These situations make a natural segue way into large-scale EGS development. 
Theoretical modeling suggests that stimulations in sedimentary settings, where there is some intrinsic porosity and permeability, are more favorable than a fractured basement rock setting (Nalla and Shook, 2004). Production data from the hydrocarbon industry indicate that most of the hydrocarbon-bearing basins and Gulf Coast Plain in Texas, Louisiana, Mississippi, and Alabama host elevated temperatures and the potential for significant water flow (Erdlac and Swift, 2004). Currently, the oil and gas industry feels this is more of a problem than an asset. As an indication of the possibilities, research into the suitability of such basin-hosted geothermal resources has begun in the north German Basin (Zimmermann et al., 2005). In this area, low-formation permeability requires stimulating potential sandstone reservoirs, and/or significant lateral drilling. But those conditions have not deterred initial research.

The detailed size of this resource has not been calculated separately from the general EGS resource, which is mostly in basement rocks. The areas that are in this EGS category are the areas of sedimentary section deeper than $4 \mathrm{~km}$. The deep sections of sediments are present over many areas of the United States (see Figure 2.5). Especially promising large areas are found in the Gulf Coast, the Appalachian Basin, the southern Midcontinent, and the Rocky Mountains. As described above, the thermal energy in such areas is at least equal to that in the geopressure-geothermal resource estimated for the Gulf Coast. Therefore, a very conservative figure of I0०,००० EJ is listed in Table 2.5 for Sedimentary EGS systems. While this number may be a few percent of the total EGS value (Io ${ }^{5}$ quads, about I\% as listed in Table 2.5), the accessible fraction of the energy in a Io- to 25-year time frame may be equal to or greater than the basement EGS value (see Chapter 3). Thus, the main reason for emphasizing this aspect of the EGS resource is its likelihood of earlier development compared to basement EGS, and the thermal advantages pointed out by the heat-extraction modeling of Nalla and Shook (2004).

\subsection{Concluding Remarks}

Table 2.5 provides a summary of resource-base estimates for all components of the geothermal resource. By far, the conduction-dominated components of EGS represent the largest component of the U.S. resource. Nonetheless, the hydrothermal, coproduced resources, and geopressured resources are large and significant targets for short-and intermediate-term development.

The question of sustainability is not addressed in this chapter. However, the geothermal resource is large and is ubiquitous. The temperature of the cooled part of the EGS reservoir will recover about $90 \%$ of the temperature drop, after a rest period of about 3 times the time required to lower it to the point where power production ceased (Pritchett, I998). So development of an area 3 to 5 times the area required for the desired power output could allow cycling of the field and more than ioo years of operation. In areas where there are already large numbers of wells, this type of scenario might be practical and economical. Thus, in some scenarios of development, the geothermal resource is sustainable.

Although the EGS resource base is huge, it is not evenly distributed. Temperatures of more than I $50^{\circ} \mathrm{C}$ at depths of less than $6 \mathrm{~km}$ are more common in the active tectonic regions of the western conterminous United States, but by no means are confined to those areas. While the analysis in this chapter gives a regional picture of the location and grade of the resource, there will be areas within every geological region where conditions are more favorable than in others - and indeed more 
favorable than implied by the map contours. In the western United States, where the resource is almost ubiquitous, the local variations may not be as significant. In the central and eastern United States, however, there will be areas of moderate to small size that are much higher grade than the maps in Figure 2.7 imply; these areas would obviously be the initial targets of development.

The highest temperature regions represent areas of favorable configurations of high heat flow, low thermal conductivity, plus favorable local situations. For example, there are lateral variations of almost I0०\% in the mean thermal conductivity within the sedimentary section. In addition, there are high heat flow areas in the eastern United States, due to the high crustal radioactivity, such as the White Mountains in New Hampshire (Birch et al., I968) and northern Illinois (Roy et al., I989). The most favorable resource areas in the eastern United States will have high crustal radioactivity, low average thermal conductivity, and other favorable circumstances (such as aquifer effects). Detailed exploration studies are necessary to identify the highest temperature locations, because the data density is lowest in the eastern United States, where smaller targets require a higher density of data points.

Table 2.5 Summary of nonhydrothermal U.S. geothermal resource-base estimates.

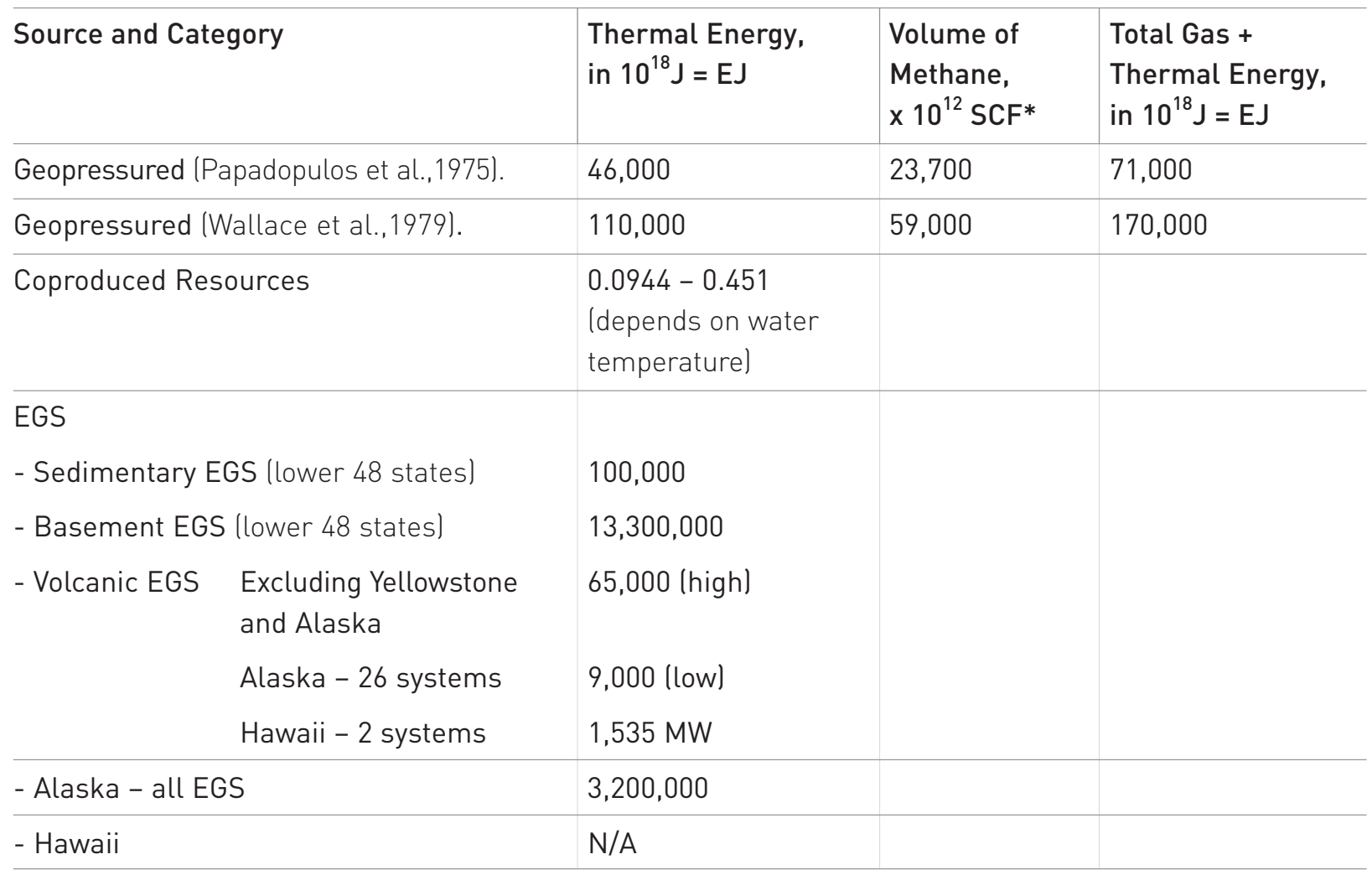

* SCF $=$ standard cubic feet of methane (ideal gas conditions) at $1 \mathrm{~atm}, 60^{\circ} \mathrm{F}$. 


\section{References}

AAPG. I978. Basement map of North America. American Association of Petroleum Geologists. Scale I:5,000,000.

AAPG. I994. CSDE, COSUNA, and Geothermal Survey Data CD-ROM. American Association of Petroleum Geologists.

Armstead, H. C. H. and J. W. Tester. I987. Heat Mining. E and F. N. Spon, London.

Birch, F., R. F. Roy, and E. R. Decker. I968. "Heat flow and thermal history in New England and New York." In Studies of Appalachian Geology: Northern and Maritime, eds. E. Zen, W. S. White, J. B. Hadley, and J. B. Thompson, Jr., Interscience, New York, pp. 437-45I.

Black, J.H.i987. "Flow and flow mechanisms in crystalline rock," in Goff, J.C. and B.P. Williams (eds.), Fluid flow in sedimentary basins and aquifers, Geol. Soc. London Special Pub. 34, pp. 185-200.

Blackwell, D. D. and M. Richards. 2004a. Geothermal Map of North America. Amer. Assoc. Petroleum Geologists, I sheet, scale I:6,500,000.

Blackwell, D. D. and M. Richards. 2004b. "Calibration of the AAPG Geothermal Survey of North America BHT Data Base.” AAPG Annual Meeting, Dallas, TX, Poster session, paper 876I6, 2004.

Blackwell, D. D. and M. Richards. 2004c. "Geothermal Map of North America; Explanation of Resources and Applications." Geothermal Resources Council Trans., 28: 317-320.

Blackwell, D. D. and J. L. Steele. I989. "Thermal conductivity of sedimentary rock-measurement and significance." In Thermal History of Sedimentary Basins: Methods and Case Histories. eds. N. D. Naeser, and T. H. McCulloh, Springer-Verlag, New York, pp. 13-36.

Blackwell, D. D. and J. L. Steele. I992. Geothermal Map of North America, I:5,000,000, Geological Society of America DNAG Map Series.

Blackwell, D. D., J. L. Steele, and L. Carter. I993. "Geothermal resource evaluation for the eastern U.S. based on heat flow and thermal conductivity distribution." Geothermal Resources Council Trans., I7: 97-Ioo.

Blackwell, D. D., J. L. Steele, and L. S. Carter. I991. "Heat flow patterns of the North American continent: A discussion of the DNAG geothermal map of North America." In Neotectonics of North America, eds. D. B. Slemmons, E. R. Engdahl, and D. D. Blackwell, Geological Society of America, DNAG Decade Map, r:423-437.

Blackwell, D. D., J. L. Steele, and K. Wisian. I994. "Results of geothermal resource evaluation for the Eastern United States.” Geothermal Resources Council Trans., I8: I6I-I64.

Blackwell, D. D., G. R. Beardsmore, R. K. Nishimori, and M. J. McMullen, Jr. I999. "High Resolution temperature logs in a petroleum setting, examples and applications." In Geothermics in Basin Analysis, eds. D. Merriam and A. Forster, Plenum Press, New York, pp I-34.

Brace, W.F., I984. "Permeability of crystalline rocks: New in situ measurements", J. Geophys. Res., 89: 4327-4330.

Brasz, J. and G. Holdmann. 2005. "Power production from a moderate-temperature geothermal resource." Geothermal Resources Council Trans., 29:729-733.

Bredehoeft, J.D., J. B. Wesley, and T. D. Fouch. I994. "Simulations of the origin of fluid pressure, fracture generation, and the movement of fluids in the Uinta Basin, Utah," Amer. Assoc. Petrol. Geol. Bulletin; 78: I729-I747. 
Buttner, G. and E. Huenges. 2003. "The heat transfer in the region of the Mauna Kea (Hawaii)Constraints from borehole temperature measurements and coupled thermo-hydraulic modeling." Tectonophysics, 37I: 23-40.

Campbell, R. G. and M. M. Hattar. I990. "Operating results from a hybrid cycle power plant on a geopressured well.” Geothermal Resources Council Trans., I4: 52I-530.

Carter, L. S., S. A. Kelley, D. D. Blackwell, N. D. Naeser. I998. "Heat flow and thermal history of the Anadarko basin, Oklahoma.” Am. Assoc. Petrol. Geol. Bull., 82: 29I-3I6.

Curtice, R. J. and E. D. Dalrymple. 2004. "Just the cost of doing business." World Oil, pp. 77-78.

Davis, S. I98I. "Workshop on hydrology of crystalline basement rocks," LANL Conference LA-89I2-C, 63 pp.

Decker, E. R., H. P. Heasler, K. L. Buelow, K. H. Baker, and J. S. Hallin. I988. "Significance of past and recent radioactivity studies in the Southern Rocky Mountains." Geol. Soc. Amer. Bull., I00: I85I-I885.

DeFord, R. K. and R. O. Kehle. I976. Geothermal gradient map of North America. American Association of Petroleum Geologist and U.S. Geol. Survey, scale I:5,000,000.

DePaolo, D. J., E. Stolper, and D.M. Thomas. 200I. Deep drilling into a Hawaiian volcano, EOS Trans. Am. Geophys. Union, 82(I3), I49-I55.

Duffield, W. A. and J. H. Sass. 2003. “Geothermal Energy - Clean power from the Earth's heat," USGS Circular I249, 36 pp.

Elsass, P., L. Aquilina, A. Beauce, Y. Benderitter, H. Fabriol, A. Genter, and H. Pauwels. I995. “Deep structures of the Soultz-Sous-Forets HDR Site (Alsace France)." Proceedings of the World Geothermal Congress, Florence, Italy, pp. 2643-2647.

Erdlac, R. J. and D. B. Swift. 2004. "Deep permeable strata geothermal energy (DPSGE): Tapping giant reservoirs within deep sedimentary basins-An example from Permian Basin carbonate strata." Geothermal Resources Council Trans., 28: 327-331.

Erkan, K., D. D. Blackwell, and M. Leidig. 2005. "Crustal thermal regime at The Geysers/Clear Lake Area, California.” Proceedings World Geothermal Congress, Antalya, Turkey.

Fridleifsson, G. O. and W. A. Elders. 2004. "The Feasibility of utilizing geothermal energy from supercritical reservoirs in Iceland: A progress report on the Iceland Deep Drilling Project." Geothermal Resources Council Transactions, 27: 423-427.

Gallardo, J. and D. D. Blackwell. I999. "Thermal structure of the Anadarko Basin, Oklahoma." Bull. Amer. Assoc. Petrol. Geol., 83: 333-36r.

Gass, T. E. I982. "Geothermal heat pumps." Geothermal Resources Council Bulletin, II: 3-8.

Gosnold, W.D. I990. "Heat Flow in the Great Plains of the United States." J. Geophys. Res., 95: 353-374.

Griggs, J. 2005. "A re-evaluation of geopressured-geothermal aquifers as an energy resource." Proceedings of the 3oth Workshop on Geothermal Reservoir Engineering, Stanford University, California, 9 pp.

Harrison, W. E., K. V. Luza, M. L Prater, and P. K. Chueng. I983. "Geothermal resource assessment of Oklahoma." Special Publication 83-1, Oklahoma Geological Survey.

Holditch, S. A. 2006. “Tight gas sands," J. Petroleum Tech. June 2006, 86-93.

Ingebritsen, S.E. and C.E. Manning. I999. "Geological implications of a permeability-depth curve for the continental crust," Geology, 27: IIO7-IIIO. 
Kehle, R. O., R. J. Schoppel, and R. K. DeFord. I970. "The AAPG geothermal survey of North America." U.N. Symposium on the Development and Utilization of Geothermal Resources, Pisa, Geothermics Special Issue 2(I): 358-368.

Kehle, R. O. 1973. “Geothermal survey of North America.” I972 Annual Progress Report for the AAPG. Kron, A. and J. Stix. I982. "Geothermal Gradient Map of the United States Exclusive of Alaska and Hawaii.” Los Alamos Nat. Lab. Rep. 82-TGB-ı6.

Lachenbruch, A.H. and J.H. Sass. I977. Heat flow in the United States and the thermal regime of the crust, in The Earth's Crust, Geophys. Mono. Ser., 20, ed. J.G. Heacock, p. 626-675, Am. Geophys. Union, Washington, D.C.

Lovekin, J.W., R.C. Henneberger, and S. Sanyal. 2006. "Energy reserves and costs of geothermal resources in Hawaii," Geothermal Resources Council Trans., 30, 89I-895.

McKenna, J. R. and D. D. Blackwell, 2005. "Geothermal electric power from Hydrocarbon fields." Geothermal Resources Council Trans., 29, 283-288.

McKenna, J., D. Blackwell, C. Moyes, and P. D. Patterson. 2005. "Geothermal electric power supply possible from Gulf Coast, Midcontinent oil field waters.” Oil \& Gas Journal, Sept. 5, pp. 34-40.

Mock, J. E., J. W. Tester, and P. M. Wright. I997. "Geothermal energy from the Earth: Its potential impact as an environmentally sustainable resource." Annual Review Energy Environment, 22: 305-56.

Morgan, P. and W.D. Gosnold. I989. Heat flow and thermal regimes in the continental United States, in Geophysical Framework of the Continental United States, ed. L. C. Pakiser and W. D. Mooney, Geological Society of America Memoir 172, pp. 493-519.

Muffler, L. J. P. and M. Guffanti (eds.). I979. "Assessment of geothermal resources in the United States - I978." US Geol. Surv., Circ. 790.

Nalla, G. and G. M. Shook. 2004. "Engineered geothermal systems using advanced well technology." Geothermal Resources Council Trans., 28: II7-I23.

Nathenson, M. and M. Guffanti. I980. "Preliminary map of temperature gradients in the conterminous United States.” Geothermal Resources Council, 4: 53-7I.

Papadopulos, S. S., R. H. Wallace, Jr., J. B. Wesselman, and R. E. Taylor. I975. "Assessment of onshore geopressured-geothermal resources in the northern Gulf of Mexico basin." In Assessment of Geothermal Resources of the United States-1975, pp. I25-I40, US Geol. Surv. Circular 726

Pritchett, J. W. I998. Modeling post-abandonment electrical capacity recovery for a two phase geothermal reservoir, Geothermal Resources Council Trans., 22, 52I-528.

Reeder, J.W. I992. "The Makushin Volcano water-dominated geothermal reservoir of Unalaska Island, Alaska." EOS Transactions, American Geophysical Union, Abstract.

Reiter, M., R.E. Eggleston, B.R. Broadwell, and J. Minier. I986. "Terrestrial heat flow estimates from deep petroleum tests along the Rio Grande rift in central and southern New Mexico," J. Geophys. Res., 9I, 6225-6245.

Rowley, J. C. I982. "Worldwide geothermal resources." In Handbook of Geothermal Energy. Eds. L. H. Edwards et al., Gulf Publishing Co., Houston, Texas.

Roy, R. F., D. D. Blackwell, and E. R. Decker. I972. "Continental heat flow.” In The Nature of the Solid Earth. Ed. E.C. Robertson, McGraw-Hill, New York, pp. 506-543. 
Roy, R. F., J. L. Rahman, and D. D. Blackwell. I989. "Heat flow at UPH-3, Northern Illinois." EOS, 70: I32I, Abstract.

Roy, R.F., E.R. Decker, D.D. Blackwell, and F. Birch. I968. Heat flow in the United States, J. Geophys. Res., 73, 5207-5221.

Sass, J. I993. "Potential of hot dry rock geothermal energy in the eastern United States." USGS Open File Rep., USGS, Washington, DC, pp. 93-377.

Sass, J. 200I. "Great Basin geothermal." Geothermal Resources Council Bulletin, 30(5): 195-I97.

Sass, J.H., A.H. Lachenbruch, R. J. Munroe, G. W. Greene, and H. Moses Jr. I97I. Heat flow in the western United States, J. Geophys. Res., 76, 6376-6413.

Shook, G. M. I992. An integrated approach to reservoir engineering at Pleasant Bayou geopressuredgeothermal reservoir, DOE Technical Report EGG-EP-I0557, 48 pp.

Shurr, G. and J. Ridgley. 2002. "Unconventional shallow biogenic gas systems." American Association of Petroleum Geologists Bulletin, 86(II): i939-i969.

Sifford, A. and R. G. Bloomquist. 2000. "Geothermal electric power production in the United States: A survey update for I995-I999." Proceedings World Geothermal Congress, Kyushu - Tohoku, Japan, p. 44I-453.

Smith, R. R. and H. R. Shaw. I979. "Igneous-related systems." In Assessment of the Geothermal Resources of the United States-1978, pp. I2-I7, US Geol. Surv. Circular 790, I63 pp.

Speece, M. A., T. D. Bowen, J. L. Folcik, and H. N. Pollack. I985. "Analysis of Temperatures in sedimentary basins: the Michigan basin." Geophysics, 50: I318-I334.

Stone, C. (ed.). I992. "Monograph on The Geysers Geothermal Field." Geothermal Resources Council Special Paper I9:324.

Tester, J. W., H. J. Herzog, Z. Chen, R. M. Potter, and M. G. Frank. I994. "Prospects for universal geothermal energy from heat mining." Sci. Glob. Secur., 5: 99-ı2 I.

Valgardur, S. 2000. "The renewability of geothermal energy." Proceedings World Geothermal Congress, Kyushu - Tohoku, Japan, p. 883-888.

Veil, J. A., M. G. Puder, D. Elcock, and R. J. Redweik Jr. 2004. "A white paper describing produced water from production of crude oil, natural gas, and coal bed methane." Argonne Natl. Lab., NETL Contract W-3I-Io9-Eng-38, 75 pp.

Wallace, R. H. et al. I979. "Assessment of Geothermal Resources of the United States-I978.” In Assessment of geopressured-geothermal resources in the northern Gulf of Mexico basin. Ed. L. J. P. Muffler, U. S. Geol. Surv. Circular 790.

White, D. F. and D. L. Williams. I975. "Assessment of geothermal resources of the United States." U.S. Geological Survey (USGS) Circular 726.

Williams, C.F. 2005. "Evaluating heat flow as a tool for assessing geothermal resources." Proceedings $30^{\text {th }}$ Workshop on Geothermal Reservoir Engineering, Stanford University, California, p. 6.

Wisian, K. W. and D. D. Blackwell. 2004. "Numerical modeling of Basin and Range Geothermal Systems," Geothermics, 33, 7I3-74I.

Wyborn, D., L. de Graaf, and S. Hann. 2005. "Enhanced Geothermal Development in the Cooper Basin, South Australia.” Geothermal Resources Council Trans., pp. I5I-156. 
Zimmermann, G., A. Reinicke, H. Holl, B. Legarth, A. Saadat, and E. Huenges. 2005. "Well Test Analysis After Massive Waterfrac Treatments in a Sedimentary Geothermal Reservoir." In Proceedings of the 2005 World Geothermal Congress, Antalya, Turkey, pp. I,I29-I,I35.

Zoback, M. D. and M. L. Zoback. I99I. "Tectonic stress field of North America and relative plate motions." In Neotectonics of North America, Geological Society of America Decade Map Volume, Eds. D. B. Slemmons, E. R. Engdahl, M. D. Zoback, and D. D. Blackwell, pp. 339-366.

Zoback, M. D. and eight others. I991. Stress Map of North America, Geological Society of America, Continent Scale Map CSM-5, scale i:5,000,000, Boulder, Colorado. 


\section{Appendix A}

\section{A.2.1 Geothermal Resource-Base Data}

Table A.2.1 Geothermal resource base (in exajoules $=10^{18} \mathrm{~J}$ ) for selected states, and the total conterminous United States. Some northeastern states are combined at the end of the table.

\begin{tabular}{|c|c|c|c|c|c|c|c|c|}
\hline Depth & $A K^{1}$ & $\mathrm{AL}$ & $\mathrm{AR}$ & $A Z$ & $C A^{2}$ & $\mathrm{CO}$ & $\mathrm{FL}$ & GA \\
\hline $\begin{array}{l}3.5 \mathrm{~km} \\
150^{\circ} \mathrm{C} \\
200 \\
250 \\
300\end{array}$ & 0 & 0 & 0 & 499 & $\begin{array}{r}10,950 \\
316 \\
414 \\
275\end{array}$ & 17,845 & 0 & 0 \\
\hline $\begin{array}{l}4.5 \mathrm{~km} \\
150^{\circ} \mathrm{C} \\
200 \\
250 \\
300\end{array}$ & 39,588 & 34 & 6,361 & 49,886 & $\begin{array}{r}53,068 \\
4,734 \\
407 \\
796\end{array}$ & $\begin{array}{r}45,890 \\
8,413\end{array}$ & 0 & 0 \\
\hline $\begin{array}{l}5.5 \mathrm{~km} \\
150^{\circ} \mathrm{C} \\
200 \\
250 \\
300\end{array}$ & 387,597 & $\begin{array}{r}1,046 \\
8\end{array}$ & $\begin{array}{r}16,077 \\
125\end{array}$ & $\begin{array}{r}82,432 \\
8,960\end{array}$ & $\begin{array}{r}79,100 \\
23,029 \\
3,332\end{array}$ & $\begin{array}{r}55,161 \\
36,890 \\
5,033\end{array}$ & 1,032 & 0 \\
\hline $\begin{array}{l}6.5 \mathrm{~km} \\
150^{\circ} \mathrm{C} \\
200 \\
250 \\
300\end{array}$ & $\begin{array}{l}361,688 \\
187,722\end{array}$ & $\begin{array}{r}9,148 \\
60\end{array}$ & $\begin{array}{r}20,725 \\
6,373\end{array}$ & $\begin{array}{r}52,335 \\
74,305 \\
473\end{array}$ & $\begin{array}{r}54,243 \\
70,941 \\
9,186 \\
176\end{array}$ & $\begin{array}{r}54,667 \\
51,170 \\
24,029 \\
1,077\end{array}$ & $\begin{array}{r}4,339 \\
2\end{array}$ & 95 \\
\hline
\end{tabular}

$7.5 \mathrm{~km}$

$150^{\circ} \mathrm{C}$

200

$20,603 \quad 33,674$

38,005

35,806

37,983

7,535

9,827

250

503,829

150

16,045

85,611

85,336

52,511

14

300

4,556

115

26,972

36,940

47,984

350

$5,204 \quad 10,517$

\begin{tabular}{|l|r|r|r|r|r|r|r|r|r|}
\hline $8.5 \mathrm{~km}$ & & & & & & & \\
\hline $150^{\circ} \mathrm{C}$ & 66,880 & 32,605 & 38,944 & 28,284 & 37,742 & 19,225 & 10,324 & 15,797 \\
\hline 200 & 218,770 & 2,038 & 21,847 & 45,502 & 57,201 & 55,299 & 1,205 & \\
\hline 250 & 471,901 & & 1,196 & 95,001 & 84,389 & 53,729 & & \\
\hline 300 & & & & 1,363 & 11,419 & 34,801 & & \\
\hline 350 & & & & & 3,627 & 4,269 & & \\
\hline $9.5 \mathrm{~km}$ & 14,408 & 39,537 & 32,749 & 13,959 & 36,234 & 6,260 & 31,540 & 32,705 \\
\hline $150^{\circ} \mathrm{C}$ & 175,463 & 10,425 & 20,115 & 36,486 & 36,780 & 54,748 & 4,503 & \\
\hline 200 & 576,921 & & 14,743 & 94,872 & 91,626 & 46,846 & & \\
\hline 250 & 54,703 & & & 42,529 & 48,111 & 55,326 & & \\
300 & & & & & 7,079 & 18,765 & & \\
\hline 350 & $3,203,825$ & 115,655 & 229,089 & 777,471 & 888,460 & 798,437 & 60,494 & 58,424 \\
\hline Total & & & & & & & & \\
\hline
\end{tabular}




\begin{tabular}{|c|c|c|c|c|c|c|c|c|}
\hline Depth & IA & ID & IL & IN & KS & $\mathrm{KY}$ & LA & ME \\
\hline $\begin{array}{l}3.5 \mathrm{~km} \\
150^{\circ} \mathrm{C} \\
200 \\
250 \\
300\end{array}$ & 0 & $\begin{array}{r}15,845 \\
138\end{array}$ & 0 & 0 & 0 & 0 & 0 & 0 \\
\hline $\begin{array}{l}4.5 \mathrm{~km} \\
150^{\circ} \mathrm{C} \\
200 \\
250 \\
300\end{array}$ & 0 & $\begin{array}{r}36,008 \\
7,218 \\
112\end{array}$ & 0 & 0 & 0 & 0 & 11,455 & 0 \\
\hline $\begin{array}{l}5.5 \mathrm{~km} \\
150^{\circ} \mathrm{C} \\
200 \\
250 \\
300\end{array}$ & 0 & $\begin{array}{r}61,467 \\
31,035 \\
415 \\
90\end{array}$ & 0 & 0 & 266 & 0 & 19,920 & 0 \\
\hline $\begin{array}{l}6.5 \mathrm{~km} \\
150^{\circ} \mathrm{C} \\
200 \\
250 \\
300\end{array}$ & 10,729 & $\begin{array}{r}35,257 \\
53,875 \\
19,510 \\
359\end{array}$ & 2,005 & 0 & 57,556 & 0 & $\begin{array}{l}15,280 \\
11,028\end{array}$ & 785 \\
\hline $\begin{array}{l}7.5 \mathrm{~km} \\
150^{\circ} \mathrm{C} \\
200 \\
250 \\
300 \\
350\end{array}$ & 17,070 & $\begin{array}{r}4,770 \\
71,735 \\
36,102 \\
11,323 \\
303\end{array}$ & 60,518 & 20,997 & 85,427 & 2,728 & $\begin{array}{l}16,380 \\
23,859\end{array}$ & 30,136 \\
\hline $\begin{array}{l}8.5 \mathrm{~km} \\
150^{\circ} \mathrm{C} \\
200 \\
250 \\
300 \\
350\end{array}$ & 40,477 & $\begin{array}{r}0 \\
33,742 \\
75,531 \\
28,026 \\
771\end{array}$ & $\begin{array}{r}61,118 \\
381\end{array}$ & 35,957 & $\begin{array}{r}86,027 \\
7,233\end{array}$ & 42,443 & $\begin{array}{r}18,265 \\
24,313 \\
4,171\end{array}$ & 33,809 \\
\hline $\begin{array}{l}9.5 \mathrm{~km} \\
150^{\circ} \mathrm{C} \\
200 \\
250 \\
300 \\
350\end{array}$ & $\begin{array}{l}43,724 \\
14,099\end{array}$ & $\begin{array}{r}0 \\
5,812 \\
82,886 \\
44,226 \\
17,411\end{array}$ & $\begin{array}{r}59,015 \\
3,086\end{array}$ & 39,003 & $\begin{array}{l}32,540 \\
76,639\end{array}$ & 42,930 & $\begin{array}{l}20,828 \\
12,123 \\
23,396\end{array}$ & $\begin{array}{r}32,849 \\
1,547\end{array}$ \\
\hline Total & 126,100 & 673,966 & 186,123 & 95,956 & 345,689 & 88,100 & 201,019 & 99,126 \\
\hline
\end{tabular}




\begin{tabular}{|c|c|c|c|c|c|c|c|c|}
\hline Depth & MI & $M N$ & MO & MS & MT & NC & ND & NE \\
\hline $\begin{array}{l}3.5 \mathrm{~km} \\
150^{\circ} \mathrm{C} \\
200 \\
250 \\
300\end{array}$ & 0 & 0 & 0 & 0 & 13 & 0 & 0 & 0 \\
\hline $\begin{array}{l}4.5 \mathrm{~km} \\
150^{\circ} \mathrm{C} \\
200 \\
250 \\
300\end{array}$ & 0 & 0 & 0 & 1,512 & 8,373 & 0 & 3,845 & 848 \\
\hline $\begin{array}{l}5.5 \mathrm{~km} \\
150^{\circ} \mathrm{C} \\
200 \\
250 \\
300\end{array}$ & 0 & 0 & 0 & $\begin{array}{r}17,227 \\
65\end{array}$ & $\begin{array}{r}107,436 \\
150\end{array}$ & 150 & $\begin{array}{r}25,288 \\
96\end{array}$ & 6,705 \\
\hline $\begin{array}{l}6.5 \mathrm{~km} \\
150^{\circ} \mathrm{C} \\
200 \\
250 \\
300\end{array}$ & 0 & 0 & 84 & $\begin{array}{r}31,807 \\
1,158\end{array}$ & $\begin{array}{r}123,860 \\
13,265 \\
25\end{array}$ & 2,036 & $\begin{array}{r}36,938 \\
2,534\end{array}$ & $\begin{array}{r}60,446 \\
1,018\end{array}$ \\
\hline $\begin{array}{l}7.5 \mathrm{~km} \\
150^{\circ} \mathrm{C} \\
200 \\
250 \\
300 \\
350\end{array}$ & 0 & 0 & 25,081 & $\begin{array}{r}31,467 \\
10,863 \\
58\end{array}$ & $\begin{array}{r}62,006 \\
109,931 \\
114 \\
5\end{array}$ & $\begin{array}{r}7,728 \\
74\end{array}$ & $\begin{array}{r}31,332 \\
22,289 \\
27\end{array}$ & $\begin{array}{r}77,730 \\
4,053\end{array}$ \\
\hline $\begin{array}{l}8.5 \mathrm{~km} \\
150^{\circ} \mathrm{C} \\
200 \\
250 \\
300 \\
350\end{array}$ & 4,581 & 3,331 & 75,279 & $\begin{array}{r}24,382 \\
30,334 \\
3\end{array}$ & $\begin{array}{r}35,340 \\
143,166 \\
18,204 \\
136\end{array}$ & $\begin{array}{r}22,597 \\
181\end{array}$ & $\begin{array}{r}39,481 \\
38,193 \\
183\end{array}$ & $\begin{array}{r}70,168 \\
17,414 \\
136\end{array}$ \\
\hline $\begin{array}{l}9.5 \mathrm{~km} \\
150^{\circ} \mathrm{C} \\
200 \\
250 \\
300 \\
350\end{array}$ & 40,271 & 32,458 & $\begin{array}{r}76,217 \\
22\end{array}$ & $\begin{array}{r}18,161 \\
37,958 \\
4,534 \\
0\end{array}$ & $\begin{array}{r}25,945 \\
90,470 \\
101,691 \\
109 \\
74\end{array}$ & $\begin{array}{r}36,425 \\
2,247\end{array}$ & $\begin{array}{l}36,731 \\
40,190 \\
12,630\end{array}$ & $\begin{array}{r}16,489 \\
85,119 \\
1,809\end{array}$ \\
\hline Total & 44,852 & 35,789 & 176,684 & 209,528 & 840,312 & 71,437 & 289,756 & 341,935 \\
\hline
\end{tabular}




\begin{tabular}{|c|c|c|c|c|c|c|c|c|}
\hline Depth & $\mathrm{NH}$ & NM & NV & NY & $\mathrm{OH}$ & $\mathrm{OK}$ & OR & PA \\
\hline $\begin{array}{l}3.5 \mathrm{~km} \\
150^{\circ} \mathrm{C} \\
200 \\
250 \\
300\end{array}$ & 0 & 2,229 & 15,906 & 0 & 0 & 0 & 14,395 & 0 \\
\hline $\begin{array}{l}4.5 \mathrm{~km} \\
150^{\circ} \mathrm{C} \\
200 \\
250 \\
300\end{array}$ & 0 & $\begin{array}{r}48,980 \\
1,037\end{array}$ & $\begin{array}{r}85,462 \\
262\end{array}$ & 0 & 0 & 0 & $\begin{array}{r}54,781 \\
5,548\end{array}$ & 0 \\
\hline $\begin{array}{l}5.5 \mathrm{~km} \\
150^{\circ} \mathrm{C} \\
200 \\
250 \\
300\end{array}$ & 59 & $\begin{array}{l}67,955 \\
15,416\end{array}$ & $\begin{array}{l}85,749 \\
43,121\end{array}$ & 0 & 0 & 2,896 & $\begin{array}{l}54,155 \\
29,064\end{array}$ & 564 \\
\hline $\begin{array}{l}6.5 \mathrm{~km} \\
150^{\circ} \mathrm{C} \\
200 \\
250 \\
300\end{array}$ & 1,050 & $\begin{array}{r}34,334 \\
68,390 \\
3,447\end{array}$ & $\begin{array}{r}34,897 \\
106,889 \\
9,585\end{array}$ & 1,860 & 0 & 31,793 & $\begin{array}{l}22,500 \\
63,830 \\
15,248\end{array}$ & 3,134 \\
\hline $\begin{array}{l}7.5 \mathrm{~km} \\
150^{\circ} \mathrm{C} \\
200 \\
250 \\
300 \\
350\end{array}$ & 4,431 & $\begin{array}{r}21,924 \\
69,124 \\
35,654 \\
1,126\end{array}$ & $\begin{array}{r}8,662 \\
91,850 \\
69,176 \\
18\end{array}$ & 6,805 & 10,306 & $\begin{array}{r}53,052 \\
32\end{array}$ & $\begin{array}{r}8,174 \\
57,547 \\
39,841 \\
8,110\end{array}$ & $\begin{array}{r}11,688 \\
420\end{array}$ \\
\hline $\begin{array}{l}8.5 \mathrm{~km} \\
150^{\circ} \mathrm{C} \\
200 \\
250 \\
300 \\
350\end{array}$ & $\begin{array}{r}7,811 \\
115\end{array}$ & $\begin{array}{r}29,305 \\
34,911 \\
84,705 \\
5,884\end{array}$ & $\begin{array}{r}6 \\
40,609 \\
132,887 \\
14,815\end{array}$ & 17,423 & 41,481 & $\begin{array}{l}48,164 \\
20,869\end{array}$ & $\begin{array}{r}4,305 \\
28,063 \\
74,882 \\
21,944\end{array}$ & $\begin{array}{r}23,057 \\
1,924\end{array}$ \\
\hline $\begin{array}{l}9.5 \mathrm{~km} \\
150^{\circ} \mathrm{C} \\
200 \\
250 \\
300 \\
350\end{array}$ & $\begin{array}{l}7,940 \\
1,251\end{array}$ & $\begin{array}{r}41,058 \\
19,195 \\
71,993 \\
52,671 \\
1,674\end{array}$ & $\begin{array}{r}0 \\
10,640 \\
104,280 \\
91,908 \\
17\end{array}$ & $\begin{array}{r}29,872 \\
3,270\end{array}$ & 44,285 & $\begin{array}{r}38,271 \\
41,271 \\
0\end{array}$ & $\begin{array}{r}7,119 \\
10,212 \\
66,719 \\
47,698 \\
12,264\end{array}$ & $\begin{array}{r}25,800 \\
5,838\end{array}$ \\
\hline Total & 22,657 & 711,011 & 946,738 & 59,230 & 96,071 & 236,347 & 646,397 & 72,424 \\
\hline
\end{tabular}




\begin{tabular}{|c|c|c|c|c|c|c|c|c|}
\hline Depth & SC & SD & $\mathrm{TN}$ & $\mathrm{TX}$ & UT & VA & WA & WI \\
\hline $\begin{array}{l}3.5 \mathrm{~km} \\
150^{\circ} \mathrm{C} \\
200 \\
250 \\
300\end{array}$ & 0 & 0 & 0 & 74 & 10,371 & 0 & 24 & 0 \\
\hline $\begin{array}{l}4.5 \mathrm{~km} \\
150^{\circ} \mathrm{C} \\
200 \\
250 \\
300\end{array}$ & 0 & 8,051 & 0 & $\begin{array}{r}32,528 \\
14\end{array}$ & $\begin{array}{r}36,521 \\
1,160\end{array}$ & 0 & 9,796 & 0 \\
\hline $\begin{array}{l}5.5 \mathrm{~km} \\
150^{\circ} \mathrm{C} \\
200 \\
250 \\
300\end{array}$ & 0 & 18,442 & 0 & $\begin{array}{r}83,934 \\
354\end{array}$ & $\begin{array}{l}52,362 \\
20,480\end{array}$ & 0 & $\begin{array}{r}41,967 \\
185\end{array}$ & 0 \\
\hline $\begin{array}{l}6.5 \mathrm{~km} \\
150^{\circ} \mathrm{C} \\
200 \\
250 \\
300\end{array}$ & 2,712 & $\begin{array}{r}32,029 \\
8,979\end{array}$ & 431 & $\begin{array}{r}117,096 \\
21,659\end{array}$ & $\begin{array}{r}50,085 \\
44,178 \\
8,626\end{array}$ & 991 & $\begin{array}{l}44,388 \\
13,290\end{array}$ & 1,733 \\
\hline $\begin{array}{l}7.5 \mathrm{~km} \\
150^{\circ} \mathrm{C} \\
200 \\
250 \\
300 \\
350\end{array}$ & 18,126 & $\begin{array}{l}44,780 \\
17,494\end{array}$ & 4,212 & $\begin{array}{r}120,075 \\
80,165 \\
668\end{array}$ & $\begin{array}{r}35,496 \\
46,958 \\
32,160 \\
1,369\end{array}$ & 7,876 & $\begin{array}{r}17,087 \\
47,972 \\
2,395\end{array}$ & 9,177 \\
\hline $\begin{array}{l}8.5 \mathrm{~km} \\
150^{\circ} \mathrm{C} \\
200 \\
250 \\
300 \\
350\end{array}$ & 28,101 & $\begin{array}{r}58,298 \\
26,030 \\
2,711\end{array}$ & 19,938 & $\begin{array}{r}152,725 \\
111,793 \\
13,340\end{array}$ & $\begin{array}{l}13,841 \\
50,315 \\
49,693 \\
16,700\end{array}$ & 16,758 & $\begin{array}{r}3,831 \\
56,655 \\
15,087\end{array}$ & 31,652 \\
\hline $\begin{array}{l}9.5 \mathrm{~km} \\
150^{\circ} \mathrm{C} \\
200 \\
250 \\
300 \\
350\end{array}$ & $\begin{array}{r}30,597 \\
3,020\end{array}$ & $\begin{array}{l}45,838 \\
39,180 \\
14,239\end{array}$ & $\begin{array}{r}39,322 \\
398\end{array}$ & $\begin{array}{r}159,675 \\
114,015 \\
59,693 \\
409\end{array}$ & $\begin{array}{r}2,540 \\
47,367 \\
48,600 \\
41,421 \\
1,956\end{array}$ & $\begin{array}{r}23,827 \\
1,344\end{array}$ & $\begin{array}{r}3,728 \\
22,915 \\
56,683 \\
2,320\end{array}$ & $\begin{array}{r}56,882 \\
2,711\end{array}$ \\
\hline Total & 82,556 & 316,072 & 64,302 & $1,068,217$ & 612,202 & 50,796 & 338,324 & 102,155 \\
\hline
\end{tabular}




\begin{tabular}{|c|c|c|c|c|c|}
\hline Depth & WV & $W Y^{3}$ & MA_CT_RI_VT & MD_NJ_DE & Continental USA ${ }^{4}$ \\
\hline $\begin{array}{l}3.5 \mathrm{~km} \\
150^{\circ} \mathrm{C} \\
200 \\
250 \\
300\end{array}$ & 0 & 106 & 0 & 0 & $\begin{array}{r}91,760 \\
653 \\
558 \\
283\end{array}$ \\
\hline $\begin{array}{l}4.5 \mathrm{~km} \\
150^{\circ} \mathrm{C} \\
200 \\
250 \\
300\end{array}$ & 0 & $\begin{array}{r}6,795 \\
203 \\
8\end{array}$ & 0 & 0 & $\begin{array}{r}518,041 \\
29,930 \\
734 \\
965\end{array}$ \\
\hline $\begin{array}{l}5.5 \mathrm{~km} \\
150^{\circ} \mathrm{C} \\
200 \\
250 \\
300\end{array}$ & 703 & $\begin{array}{r}34,380 \\
1,319 \\
287\end{array}$ & 0 & 35 & $\begin{array}{r}947,166 \\
218,922 \\
8,745 \\
458\end{array}$ \\
\hline $\begin{array}{l}6.5 \mathrm{~km} \\
150^{\circ} \mathrm{C} \\
200 \\
250 \\
300\end{array}$ & 3,367 & $\begin{array}{r}68,411 \\
7,132 \\
334 \\
177\end{array}$ & 183 & 468 & $\begin{array}{r}1,062,065 \\
641,638 \\
94,405 \\
1,854\end{array}$ \\
\hline $\begin{array}{l}7.5 \mathrm{~km} \\
150^{\circ} \mathrm{C} \\
200 \\
250 \\
300 \\
350\end{array}$ & $\begin{array}{l}9,833 \\
1,738\end{array}$ & $\begin{array}{r}73,849 \\
27,546 \\
1,551 \\
265 \\
94\end{array}$ & 3,559 & $\begin{array}{r}2,576 \\
332\end{array}$ & $\begin{array}{r}1,177,632 \\
954,271 \\
342,032 \\
38,242 \\
397\end{array}$ \\
\hline $\begin{array}{l}8.5 \mathrm{~km} \\
150^{\circ} \mathrm{C} \\
200 \\
250 \\
300 \\
350\end{array}$ & $\begin{array}{r}19,425 \\
3,834\end{array}$ & $\begin{array}{r}51,926 \\
58,148 \\
8,809 \\
445\end{array}$ & 15,198 & $\begin{array}{r}6,760 \\
538\end{array}$ & $\begin{array}{r}1,426,245 \\
944,568 \\
739,995 \\
140,961 \\
8,673\end{array}$ \\
\hline $\begin{array}{l}9.5 \mathrm{~km} \\
150^{\circ} \mathrm{C} \\
200 \\
250 \\
300 \\
350\end{array}$ & $\begin{array}{r}16,561 \\
7,131 \\
1,033\end{array}$ & $\begin{array}{r}27,358 \\
82,408 \\
18,542 \\
1,642 \\
64\end{array}$ & $\begin{array}{r}18,343 \\
136\end{array}$ & $\begin{array}{r}11,624 \\
668 \\
33\end{array}$ & $\begin{array}{r}1,440,428 \\
984,067 \\
946,675 \\
444,280 \\
61,446\end{array}$ \\
\hline Total & 63,626 & 471,799 & 37,419 & 23,033 & $13,267,370$ \\
\hline
\end{tabular}

1. Alaska does not include the Aleutians.

2. California had the addition of the Clear Lake and Salton Sea areas for 3.5 and $4.5 \mathrm{~km}$.

3. Wyoming does not include Yellowstone National Park $\left(8987 \mathrm{~km}^{2}\right)$.

4. Continental U.S. - not including Alaska or Hawaii, or Yellowstone National Park. It does include the addition of Clear Lake and the Salton Sea areas of California at depths of 3.5 and $4.5 \mathrm{~km}$. 


\section{A.2.2 Coprocessed Water Associated with Oil and Gas Production}

Table A.2.2 Water production (Curtice and Dalrymple, 2004) and potential power generation from oil and gas operations for selected states.

\begin{tabular}{|c|c|c|c|c|c|c|c|c|}
\hline State & State & $\begin{array}{l}\text { Total } \\
\text { Processed } \\
\text { Water, 2004, } \\
\text { (bbl) }\end{array}$ & $\begin{array}{l}\text { Water } \\
\text { Production } \\
\text { Rate, } \\
\text { kGPM }\end{array}$ & $\begin{array}{l}\text { Water } \\
\text { Production } \\
\text { Rate } \\
\mathrm{kg} / \mathrm{s}\end{array}$ & $\begin{array}{l}\text { Power, } \\
\text { MW @ } \\
100^{\circ} \mathrm{C}\end{array}$ & $\begin{array}{l}\text { Power, } \\
\mathrm{MW} @ \\
140^{\circ} \mathrm{C}\end{array}$ & $\begin{array}{l}\text { Power, } \\
\text { MW @ } \\
150^{\circ} \mathrm{C}\end{array}$ & $\begin{array}{l}\text { Power, } \\
\text { MW @ } \\
180^{\circ} \mathrm{C}\end{array}$ \\
\hline$A L$ & Alabama & $203,223,404$ & 18 & 1,026 & 18 & 47 & 64 & 88 \\
\hline AK & Alaska & $1,688,215,358$ & 153 & 8,522 & 153 & 389 & 528 & 733 \\
\hline$A Z$ & Arizona & 293,478 & 0.0265 & 1.4814 & 0.0267 & 0.0676 & 0.0918 & 0.1274 \\
\hline AR & Arkansas & $258,095,372$ & 23 & 1,303 & 23 & 59 & 81 & 112 \\
\hline CA & California & $5,080,065,058$ & 459 & 25,643 & 462 & 1,169 & 1,590 & 2,205 \\
\hline $\mathrm{CO}$ & Colorado & $487,330,554$ & 44 & 2,460 & 44 & 112 & 153 & 212 \\
\hline $\mathrm{FL}$ & Florida & $160,412,148$ & 15 & 810 & 15 & 37 & 50 & 70 \\
\hline $\mathrm{IL}$ & Illinois & $2,197,080,000$ & 199 & 11,090 & 200 & 506 & 688 & 954 \\
\hline IN & Indiana & $72,335,588$ & 7 & 365 & 7 & 17 & 23 & 31 \\
\hline KS & Kansas & $6,326,174,700$ & 572 & 31,933 & 575 & 1,456 & 1,980 & 2,746 \\
\hline KY & Kentucky & $447,231,960$ & 40 & 2,257 & 41 & 103 & 140 & 194 \\
\hline LA & Louisiana & $2,136,572,640$ & 193 & 10,785 & 194 & 492 & 669 & 927 \\
\hline MI & Michigan & $188,540,866$ & 17 & 952 & 17 & 43 & 59 & 82 \\
\hline MS & Mississippi & $592,517,602$ & 54 & 2,991 & 54 & 136 & 185 & 257 \\
\hline MO & Missouri & $17,082,000$ & 2 & 86 & 2 & 4 & 5 & 7 \\
\hline MT & Montana & $180,898,616$ & 16 & 913 & 16 & 42 & 57 & 79 \\
\hline $\mathrm{NE}$ & Nebraska & $102,005,344$ & 9 & 515 & 9 & 23 & 32 & 44 \\
\hline NV & Nevada & $13,650,274$ & 1 & 69 & 1 & 3 & 4 & 6 \\
\hline NM & New Mexico & $1,214,796,712$ & 110 & 6,132 & 110 & 280 & 380 & 527 \\
\hline NY & New York & $1,226,924$ & 0.1110 & 6.1931 & 0.1115 & 0.2824 & 0.3840 & 0.5326 \\
\hline ND & North Dakota & $182,441,238$ & 16 & 921 & 17 & 42 & 57 & 79 \\
\hline $\mathrm{OH}$ & Ohio & $12,772,916$ & 1 & 64 & 1 & 3 & 4 & 6 \\
\hline OK & Oklahoma & $12,423,264,300$ & 1,124 & 62,709 & 1,129 & 2,860 & 3,888 & 5,393 \\
\hline PA & Pennsylvania & $18,571,428$ & 2 & 94 & 2 & 4 & 6 & 8 \\
\hline $\mathrm{SD}$ & South Dakota & $6,724,894$ & 1 & 34 & 1 & 2 & 2 & 3 \\
\hline $\mathrm{TN}$ & Tennessee & $62,339,760$ & 6 & 315 & 6 & 14 & 20 & 27 \\
\hline $\mathrm{TX}$ & Texas & $12,097,990,120$ & 1,094 & 61,067 & 1,099 & 2,785 & 3,786 & 5,252 \\
\hline UT & Utah & $290,427,704$ & 26 & 1,466 & 26 & 67 & 91 & 126 \\
\hline WV & Virginia & $2,235,240$ & 0.2022 & 11.2828 & 0.2031 & 0.5145 & 0.6995 & 0.9703 \\
\hline VA & West Virginia & $252,180,000$ & 23 & 1,273 & 23 & 58 & 79 & 109 \\
\hline WY & Wyoming & $3,809,086,632$ & 344 & 19,227 & 346 & 877 & 1,192 & 1,654 \\
\hline
\end{tabular}


CHAPTER 3

Recoverable EGS

Resource Estimates

3.1 Scope and Approach _

3.2 Resource Base vs. Reserves _

3.3 Metrics that Influence the Recoverable Resource

3.3.1 Temperature

3.3.2 Fractured rock volume

3.3.3 Fracture spacing _-

3.3.4 Fracture surface area

3.4 Determining the Recoverable Fraction

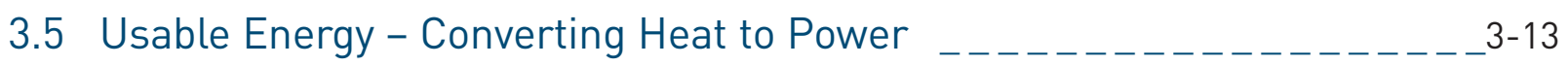

3.6 Access to the EGS Resource $\ldots \ldots \ldots-\ldots$

References _- 


\subsection{Scope and Approach}

This chapter provides a rationale and methodology for estimating the amount of useful energy that could be recovered from Enhanced Geothermal Systems (EGS) over the range of accessible depths and temperatures that exist in the United States. As discussed in Chapter 2, the EGS resource base is defined as the total thermal energy in place in the Earth's crust to the depth that we can reach with current technology. Thus, the estimated resource base for EGS presented in Chapter 2 is a measure of the total contained energy. Here, we want to estimate what fraction of this amount is recoverable.

If we limit our calculation of stored thermal energy in place to a depth of Io $\mathrm{km}$ beneath the land area of the United States, then the amount of thermal energy in the crust is so large (about I4 million quads) that we can view it as sustainable (see Chapter 2, Table A.2.I). Even if we were to use it to provide all the primary energy consumed in the United States, we still would be depleting only a tiny fraction of it.

The depletion aspect requires additional exploration and detail. Geothermal is often classified as a renewable resource, but the time scale for its renewablilty is certainly longer than for solar, wind, or biomass energy, which have daily and annual cycles. For instance, a fractured EGS reservoir is cooled significantly during heat-mining operations over its normal project life of about 20 to 30 years, as a result of heat-mining operations. If the reservoir was abandoned at that point, the rock would recover to its initial temperature in Ioo years or less (Armstead and Tester, I987; and Elsworth, I989 and I990). With the time for full recovery of a former active reservoir approaching a century, one might not categorize geothermal heat mining as a sustainable energy resource. However, as long as the fraction of stored heat that is being mined in any year is a small fraction $(<\mathrm{IO} \%)$ of the total assessable resource base, geothermal can be treated as fully renewable and, therefore, a sustainable resource. Given that the U.S. geothermal resource base is about I4 million EJ, we would always be utilizing much less than Io\% annually of the total thermal energy, even if all of our primary energy came from geothermal resources.

Chapter 2 characterized the EGS resource primarily by depth and temperature. In some regions, the EGS resource is available at high temperatures at shallow depths making energy recovery easier and less costly than other lower-grade regions, where deeper drilling is needed to reach useful rock temperatures. Another positive attribute of EGS for the long term will be the ability to locate heatmining operations near end users. For example, an EGS site being developed in Switzerland is within the city limits of Basel. However, a significant portion of the resource will be inaccessible from the surface, due to its location under state and national parks, wilderness, military sites, or very high elevations. In addition, developed areas will not be suitable for EGS development, including major roads and utility corridors, airports, urban areas, and others. As it turns out, these inaccessible areas amount to only a small fraction of the total, leaving a significant amount of the stored thermal energy contained in accessible regions available for capture and utilization on the surface.

As discussed in Chapter 7 , there are several factors that control the amount of the resource that can be recovered as heat or converted into electricity. These include the initial rock temperature and the maximum temperature drop that can be tolerated by the heat/power plant (i.e., the reservoir abandonment temperature), the volume of rock that can be accessed and stimulated, the active or effective heat-exchange area (controlled by the length, width, and spacing of the existing and stimulated fractures), and the flow rate of the water through the connected fractures (controlled by the permeability and the pattern of the injectors and producers) (Armstead and Tester, I987; Ellsworth, I989; and Sanyal and Butler, 2005). 
Recoverable thermal energy was estimated, assuming an abandonment temperature $10^{\circ} \mathrm{C}$ below the average initial rock temperature in the reservoir. Numerical modeling studies by Sanyal and Butler (2005) have indicated that the recoverable fraction of stored thermal energy referenced to a specified reservoir abandonment temperature was about 40\%, assuming an idealized, well-defined hydrothermal reservoir with homogeneous properties. To be conservative for EGS systems, the analysis applied the Sanyal and Butler model with lower recovery factors, namely, $20 \%$ and $2 \%$ to represent an appropriate range of values that might be deliverable in practice. Recovered thermal energy was calculated from the initial amount contained in specified I km-thick, horizontal rock slices at initial temperatures given in Chapter 2 and for a specified abandonment temperature that was $10^{\circ} \mathrm{C}$ below the initial temperature. The temperature-depth maps (Figure 2.7) were used for estimates of the total stored thermal energy. The recovered thermal energy was then converted to electric energy, using an overall heat-to-power cycle efficiency as discussed in Chapter 7 for binary and flash-steam cycles.

To get a better idea of the potential power supply available in the near future, the EGS resource was divided into two parts: I) a portion associated with hydrothermal systems at depths shallower than $3 \mathrm{~km}$, and 2) the remaining resource at depths between 3 and Io $\mathrm{km}$ as estimated in Chapter 2. Cost of generated power was calculated for each of these two types of EGS resource, using the GETEM code developed for geothermal power costing for the U.S. DOE Geothermal Technologies Program (see Chapter 9, section 9.IO.I for more details).

\subsection{Resource Base vs. Reserves}

It will be helpful to review the way reserves are treated by the oil and gas industry before addressing this subject for EGS. In the energy industry, the estimated amount of oil or gas available with current technology at today's energy prices is often referred to as the reserve. Reserves clearly are much smaller than the resource base; but, in general, reserve estimates will increase as extractive technology improves and/or energy prices increase. For instance, in most deep sedimentary rock, there is some methane dissolved in the water found in the pores of the reservoir rock. This dissolved gas can be considered part of the natural gas resource base. If we calculated all of it contained in subsurface rock, a large amount of energy would be contained in this resource. Today, dissolved methane is usually not included in natural gas reserve estimates, because it is too dilute and/or too expensive to extract.

An excellent example is U.S. geopressured resources that contain a substantial amount of methane as part of their resource base (see Section 2.6.3). If technology were to improve so that dissolved methane could more easily be extracted, the methane contained in geothermal fluids, in general, could be included in reserves estimates. Similar analogies can be drawn using methane trapped in gas hydrates found in permafrost and marine sediments, or regarding the uranium dissolved in seawater as part of the uranium resource base.

U.S. oil and gas reserves correspond to economically extractable resources as specified by the Securities and Exchange Commission (SEC) Staff Accounting Bulletin, Topic I2 (2006). Given that oil and gas prices fluctuate on the commodity market, the competitive price levels are subject to change. When the price of oil was low a few years ago, thousands of small "stripper" wells in the United States were shut in. The oil and gas contained underground, which is connected to these wells, is still regarded as part of the reserves and included in estimates of what would be available but was not economic to produce at the market price at that time. 
Reserve estimates made by the oil and gas industry are further categorized as proven, probable, and possible. The methods for accounting for these reserves are governed by the rules of the SEC (2006). Proven reserves exist where there is a sufficient body of supporting data from geology, geophysics, well tests, and field production to estimate the extent of the oil or gas contained in the body of rock. They are deemed, "commercially recoverable, from a given date forward, from known reservoirs and under current economic conditions, operating methods, and government regulations." Proven reserves can be developed or undeveloped. Probable reserves are unproven reserves, but geological and engineering data suggest that they are more likely than not to be recoverable. Statistical methods are often used in the calculation of probable reserves, and the deciding criterion is usually that there should be at least a 50\% probability that the quantities actually recovered will "equal or exceed the sum of estimated proved plus probable reserves." Probable reserves can be in areas adjoining proven or developed fields or isolated from developed fields, but with drilling and testing data that indicates they are economic with current technology. Possible reserves are unproved reserves that are less likely to be recoverable than probable reserves, based on geological and engineering data analysis. Statistically, they are defined as reserves that, if recovered, have - at most - a Io\% probability of equaling or exceeding the sum of the estimated proven, probable, and possible reserves. Possible reserves have few, if any, wells drilled; and the reservoir has not been produced, or even tested. However, the reservoir displays favorable geology and geophysics, and its size is estimated by statistical analysis. Possible reserves can also be in areas with good data to indicate that oil and gas are present, but they may not be commercially developable, or the technology to develop them may not exist (but such technology improvements can reasonably be expected in the future). Although this sounds very speculative, there is such a long history of oil and gas production that these estimates are regarded with a fair degree of confidence.

With regard to hydrothermal geothermal resources, some fields have been drilled and produced, so there are supporting data to make assessments of proven, probable, and possible reserves. Of course, even here there is some degree of speculation because no hydrothermal fields have been depleted of heat down to the point where they are uneconomic to produce. However, because EGS is an emerging technology that has not been produced commercially, the level of speculation and uncertainty is even higher - too high, in fact, to regard any of the EGS resource base as economic reserves at this time. EGS should to be classified as a "possible" future reserve.

Obviously, there are no commercial EGS reservoirs and no past production history on which to base recovery calculations. Even hydrothermal reservoirs have not been produced to the point where the amount of heat recovered from the rock volume can be accurately calculated. Nonetheless, we have attempted, as a part of our assessment of EGS, to develop a rationale and methodology for making such an estimate. To do this, we used a combination of the experience from hydrothermal power production projects, numerical modeling, and reasonable constraints regarding how we expect the system to operate for determining what fraction of the total EGS resource might be recovered. 


\subsection{Metrics that Influence the Recoverable Resource}

The EGS resource base heat-in-place estimates developed in Chapter 2 are made by assuming a volume of rock with an average rock density, heat capacity, and a minimum reference temperature. For this assessment, the average surface temperature was used to define the minimum reference temperature. To determine the amount of that heat that can be mined, it is also necessary to include several other important parameters. The initial temperature of the rock at depth determines not only how much thermal energy is in place, but also the rate at which it can be recovered. In addition, a final useful production temperature must be specified for that application. This temperature is referred to as the "abandonment temperature" and represents the average temperature of the active reservoir rock volume at the time heat-extraction operations cease.

The volume of rock that can be fractured and the average spacing between the fractures, along with their length and width, will control the effective heat-exchange area of the reservoir. These, in turn, will determine the rate of energy output and the life of the reservoir. Reservoir volume and the effective surface area available for heat transfer will also affect the fraction of the thermal energy stored in the reservoir that can be extracted over time. The rate at which water - the heat transfer medium - is circulated through the system is a critical parameter. The flow pattern of water between injection and production wells controls how much of the fractured volume is actually swept by the circulating fluid. The permeability and porosity of the fractured volume determine the amount of water stored in the rock, as well as how fast it can move through the rock and with what amount of pressure drop. The circulating water exists at a representative temperature that is taken to be the average temperature of the rock. Also important, the actual flow pattern of fluid in the reservoir is influenced by the spatial distribution of permeability and porosity, as well as the relative positions of the production and injection wells.

\subsubsection{Temperature}

The resource base figures in Chapter 2 represent the total stored thermal energy in place, relative to the ambient regional surface temperature, $T_{o}$. We can define the recoverable fraction of that thermal energy, $F_{r}$, as a function of several independent or specified variables, such that:

$$
\begin{aligned}
F_{r} \equiv \frac{Q_{\text {rec }}}{Q_{\text {total }}} & =f\left[V_{\text {active }}, V_{\text {total }}, C_{r}, T_{r, i}, T_{r, a}, T_{o}\right] \\
F_{r} & =\frac{\rho V_{\text {active }} C_{r}\left(T_{r, i}-T_{r, a}\right)}{\rho V_{\text {total }} C_{r}\left(T_{r, i}-T_{o}\right)} \\
F_{r} & =\phi_{v} \frac{\left(T_{r, i}-T_{r, a}\right)}{\left(T_{r, i}-T_{o}\right)}
\end{aligned}
$$


where

$Q_{\text {rec }}=$ recoverable thermal energy content of the reservoir

$Q_{\text {total }}=$ total thermal energy content of the reservoir

$\phi_{v}=$ active reservoir volume/total reservoir volume

$\rho=$ rock density $\left(\mathrm{kg} / \mathrm{m}^{3}\right)$

$V_{\text {total }}=$ total reservoir volume $\left(\mathrm{m}^{3}\right)$

$V_{\text {active }}=$ active or effective reservoir volume $\left(\mathrm{m}^{3}\right)$

$C_{r}=$ rock specific heat $\left(\mathrm{J} / \mathrm{kg}{ }^{\circ} \mathrm{C}\right)$

$T_{r, i}=$ mean initial reservoir rock temperature $\left({ }^{\circ} \mathrm{C}\right)$

$T_{o}=$ mean ambient surface temperature $\left({ }^{\circ} \mathrm{C}\right)$

$T_{r, a}=$ mean rock temperature at which reservoir is abandoned $\left({ }^{\circ} \mathrm{C}\right)$.

The rate of heat extraction from the rock depends on the difference between the temperature of the rock and the temperature of the circulating water at any point within the reservoir. The larger this difference, the more quickly heat will move from the rock into the water and, in the end, the more heat that can be extracted from the rock. On the one hand, if the cool injected water reaches the production well without being sufficiently heated, the total amount of heat mined from the rock will be less than expected, and the project will not achieve its design conditions. On the other hand, if there is no decline in produced fluid temperature over time, then the flow rate is not high enough to efficiently mine the heat contained in the rock. And, again, the project will not be economically optimized because less total thermal energy will be recovered.

Ideally, we want to maximize the total amount of useful energy extracted from the reservoir. The total energy extracted is given by the time integral over the production period of the instantaneous rate of heat extraction from the rock. For an EGS reservoir, the heat extraction rate is equal to the product of the mass flow rate and the specific enthalpy difference between the produced and reinjected fluid. If we increase the mass flow rate too much, the produced fluid temperature and its specific enthalpy will both decline, offsetting a potential increase in heat extraction rate. At some mass flow rate, an optimal balance is achieved between heat extraction rate and thermal drawdown rate.

In addition, there are issues concerning the efficiency of converting the extracted thermal energy to electrical energy. If we had a completely flexible power-conversion system that could use any temperature of fluid to generate electric power or extract usable heat - although at varying efficiency - we could cool the rock significantly and continue to use the same surface equipment. Real electricgenerating power plants, heat pumps, or heat exchangers are designed for a specific set of conditions. The larger the difference between design conditions and actual operating conditions, the less efficient the equipment will become. This places a practical lower limit on the circulating fluid temperature, and consequently a lower limit on the average temperature of the rock in contact with the fluid. We call this latter temperature the "reservoir abandonment temperature," $T_{r, a}$.

The thermal drawdown that occurs in a reservoir will be confined to a localized rock volume defined, in part, by the positions of the injector and producer wells in the stimulated region. The approach for restoring plant output when the thermal drawdown becomes too large will be to drill new infill wells 
into parts of the field that have not been exploited. This strategy has worked for hydrothermal systems and should work for EGS as well. There will come a time when old wells will be abandoned or redrilled, or new wells added.

Assuming that an EGS reservoir consists of discretely fractured flow paths with average spacings of Io० $\mathrm{m}$ or less, then some simplications can be made. Because of the low thermal diffusivity of rock (of order $10^{-6} \mathrm{~m}^{2} / \mathrm{s}$ ), most of the temperature drop in the reservoir occurs near the injection well and adjacent to the fracture faces in contact with the flowing fluid. If the reservoir rock temperature drops only $10^{\circ} \mathrm{C}$ on average, there would be ample energy left in the reservoir for future use with equipment designed to operate at lower temperatures, which would increase the sustainability of the resource for the longer term. For instance, a cube of rock $\mathrm{I} \mathrm{km}$ on a side at $200^{\circ} \mathrm{C}$ would contain $4 \mathrm{x} \mathrm{IO}{ }^{14} \mathrm{~kJ}$ of thermal energy relative to the ambient surface temperature. However, if the average reservoir rock temperature is dropped only $10^{\circ} \mathrm{C}$, the heat recovered from that mass of rock would be $2.5 \times 10^{13} \mathrm{~kJ}$, leaving about $95 \%$ of the original energy in place for later exploitation.

As discussed earlier in this chapter, following active heat-mining operations, production flow and heat removal would cease, allowing rock temperatures to fully recover by conduction in less than roo years (Elsworth, 1989). This would permit EGS energy recovery to operate sustainably into the future. To be conservative, we specified an abandonment temperature of only $10^{\circ} \mathrm{C}$ lower than the initial rock temperature in estimating the recoverable energy fraction.

\subsubsection{Fractured rock volume}

While solid rock is excellent for storing heat, the rate of heat removal by conduction is slow, as a result of its low thermal conductivity. Only that fraction of the rock volume made accessible by the stimulation process can be considered part of the active reservoir where heat extraction occurs. The basic idea is to create permeability and porosity by hydraulic stimulation to open up channels for fluid to circulate through the rock, thereby shortening the rock conduction path. The transfer of heat in such a porous/fractured rock reservoir is a complex process that is not easy to model analytically. Sanyal and Butler (2005) have done sensitivity studies of the impact of various reservoir properties such as fractured volume, fracture spacing, permeability, porosity, and well configuration on the recovery fraction of heat-in-place using 3-dimensional finite element modeling. They varied the permeability, flow rate, fracture spacing, well spacing, injector-to-producer pattern, and fractured volume. They found that the single most important parameter affecting how much of the thermal energy that could be recovered is the fractured volume. In fact, perhaps the most important finding of their study is that the net electrical power that can be achieved from a volume of fractured rock is roughly $0.026 \mathrm{~W}_{\mathrm{e}} / \mathrm{m}^{3}\left(26 \mathrm{MW}_{\mathrm{e}} / \mathrm{km}^{3}\right)$. This factor applies to a wide variety of production-injection well arrangements (doublets, triplets, five-spots), fracture spacings $(3-30 \mathrm{~m}$ ), and permeability (IO-Io० $\mathrm{mD}$ ). The factor seems to hold constant to within about $5 \%$. It also includes reasonable estimates for parasitic power requirements for circulating the fluid through the reservoir.

Based on early field testing of EGS concepts, the geometric arrangement of the production and injection wells, to a large degree, influences the amount of rock that can be stimulated, and the accessible volume of rock that the circulating fluid contacts. EGS wells could be configured in a variety of ways: e.g., with one producer for every injector (a doublet), two producers to each injector (a triplet), or four producers to each injector (the classic five-spot pattern used in enhanced oil recovery operations). The stress regime in the rock volume will determine the fracture pattern and direction, and this will influence the optimal arrangement of injectors and producers. However, having more 
than one producer for each injector reduces the amount of "dead" fractured volume, in which the rock is fractured but the fluid doesn't circulate. See Chapter 5 for more details.

\subsubsection{Fracture spacing}

Earlier researchers cited the importance of reservoir geometric structure on heat-removal effectiveness (see Kruger and Otte, I972; and Armstead and Tester, I987). Later, Sanyal and Butler (2005) found that, while the fractured volume had the largest effect on recovery factor of the parameters they studied, fracture spacing also had a measurable impact because it is part of determining the active reservoir volume. They investigated fracture spacings between 3 and $300 \mathrm{~m}$. For reasonable fracture spacings of 3 to $30 \mathrm{~m}$ that might be realistically accomplished, there is little or no thermal interference, and the fracture spacing is largely irrelevant compared to the total fractured volume in determining how much of the heat-in-place will be recovered. However, for very large fracture spacings $(300 \mathrm{~m})$ and a maximum possible flow rate determined by pump and pressure limitations, the recovery factor using a five-spot pattern with four producers per injector was $2.2 \%$. A smaller fracture spacing of $30.5 \mathrm{~m}$ (again using a five-spot pattern and the same flow rate) yielded a $29.4 \%$ recovery factor. Lowering the flow rate from $500 \mathrm{~kg} / \mathrm{s}$ to $126 \mathrm{~kg} / \mathrm{s}$ per producer (with $30.5 \mathrm{~m}$ fracture spacing) increased the recovery factor from $24 \%$ to $42.5 \%$, and maintained the reservoir life while still producing economic power output.

Many researchers, typified by the work of Sanyal and Butler, identify fractured rock volume as the single most important parameter affecting thermal recovery. To reach this conclusion, they have implicitly assumed that the rock mass has been homogeneously fractured, which will certainly not be the case in practice. While large surface area and fractured volumes are needed to ensure long-term heat extraction at acceptable rates, their mere existence alone does not guarantee performance. Sufficient fracture density and size are needed and fluid must sweep across the fractured surface area reasonably efficiently for long-term performance to be realized. This has been one of the biggest engineering challenges for EGS, and will be discussed extensively in Chapters 4 and 5 .

\subsubsection{Fracture surface area}

The geothermal reservoir operates like an underground heat exchanger. Injected water is circulated through the reservoir and is exposed to the surfaces of hot rock allowing it to remove heat. The rate of heat transfer - and, consequently, the final temperature that the fluid achieves - is related to the mass flow rate of fluid and the surface area the fluid contacts. The heat-transfer system can be thought of as similar to a series of flat plates with gaps (the fractures) between them and a semi-infinite conduction heat source surrounding each fracture. Heat is transferred by conduction through the rock, perpendicular to the surfaces of the fractures. Then heat is transferred by convection at the rockfluid interface to the fluid contained in the fracture. The larger that surface area is relative to the flow rate, the faster heat can be transferred to the fluid and still have its outlet temperature approach the original rock temperature with minimal thermal drawdown. (For more details concerning these coupled transport processes, see Armstead and Tester, I987.) There are several parameters that affect this heat-transfer area:

- Well spacing - This is the distance between the wells in the active part of the reservoir. The well spacing controls the length of the fracture that is actively involved with fluid circulation.

- Fracture spacing - The average distance between fractures that are open and accepting fluid. These are assumed to be connected to the production wells through the fractured rock volume. In reality, these may not act as separate discrete fractures, but as an overall fractured rock mass. 
- Fracture length and width - The fracture length is related to, but not necessarily the same as, the well spacing between producer and injector. The fracture is not likely to be a flat plane, but will take a tortuous path through the rock. The path length will, thus, be longer than the well spacing in most cases. The fracture width is the lateral distance that the fracture extends and has active circulation.

- Well configuration - The arrangement of the production wells in relation to the injector. The actively circulated fracture width is controlled, to some extent, by the geometry of the well configuration.

To produce $50 \mathrm{~kg} / \mathrm{s}$ from a $200^{\circ} \mathrm{C}$ body of rock, with no more than $10^{\circ} \mathrm{C}$ temperature drop in the produced fluid over a project life of 30 years, a large rock surface area relative to the mass flow rate of fluid is needed (see Armstead and Tester, I987). For instance, with eight fractures being used for heat extraction, each must have a length and width sufficient to produce $125,000 \mathrm{~m}^{2}$ of surface area. If these fractures are $100 \mathrm{~m}$ apart, then $700 \mathrm{~m}$ or more of wellbore at the $200^{\circ} \mathrm{C}$ average reservoir temperature is required. To maintain the temperature for a longer life, we would need a longer fracture path length, larger fractures, or more fractures in the wellbore. Real fractures are certainly not the discrete, rectangular channels or circular discs assumed in this simple model. In real situations, fractures often have a greater surface area and path length than the distance between the wells would suggest. At Soultz, for example, in GPK3, about nine open fractures occur in the $540 \mathrm{~m}$ open-hole section. However, one fracture at $4,760 \mathrm{~m}$ takes $70 \%$ of the total fluid flow. This channeling, if left uncontrolled, will effectively reduce the useful recovered thermal energy of the entire reservoir, because heat removal in the fracture that is accepting the higher flow rate is much higher than can be sustained by transient thermal conduction through the surrounding rock.

\subsection{Determining the Recoverable Fraction}

As discussed above, Sanyal and Butler (2005) have modeled flow in fractured systems to determine the sensitivity of the recoverable heat fraction to several important parameters: rock temperature, fractured volume, fracture spacing, fluid-circulation rate, well configuration, and post-stimulation porosity and permeability. They used a 3-dimensional finite difference model and calculated the fraction of the heat-in-place that could be mined as these important parameters were changed. They found that for a variety of fracture spacings, well geometries, and fracture permeabilities, the percentage of heat recoverable from a stimulated volume of at least $\mathrm{I} \times 10^{8} \mathrm{~m}^{3}$ under economic production conditions is nearly constant at about 40\%, with a range between $34 \%$ and $47 \%$ (see Figure 3.I). This recovery factor is independent of well arrangements, fracture spacing, and permeability, as long as the stimulated volume exceeds I x IO ${ }^{8} \mathrm{~m}^{3}$. This roughly corresponds to a block of rock approximately $500 \mathrm{~m}$ x $500 \mathrm{~m}$ x $500 \mathrm{~m}$. Because Phase II of the Fenton Hill project, the Rosemanowes project, the Soultz project (both the shallow and deep stimulated volumes), and the Cooper Basin project have achieved fractured volumes based on acoustic emissions mapping of equal to or greater than or greater than $\mathrm{IO} \mathrm{x}^{8} \mathrm{O}^{8} \mathrm{~m}^{3}$ (or $\left.\mathrm{I} \mathrm{km}^{3}\right)$, this threshold has already been exceeded in practice.

Because in the early stages of EGS technology development, short circuiting and other reservoir management problems will require extra fractured volume to counter too-rapid temperature drop, it was assumed that two to three times the volume would be needed to guarantee a useful reservoir life. This provides sufficient volume of hot rock for extended development in the event of an irreparable short circuit. However, the excess rock volume effectively halves the recovery factor. The Sanyal and Butler (2005) study found recovery factors that ranged from $2.5 \%$ to $90 \%$, with a typical recovery 
factor of about $45 \%$. Very high recovery factors could only be achieved with uneconomic flow rates or other conditions that resulted in a short reservoir life. Recovery factors from $2 \%$ to $40 \%$ were therefore used in the calculation of potentially recoverable resources for this study. A recovery factor of $20 \%$ was used for Table 3.2 and the supply curves developed in Chapter 9. A $2 \%$ recovery factor was used for Table 3.3.

With a recovery factor and an abandonment temperature specified, the recoverable heat can be determined from the total energy in place, i.e., the resource-base amount:

$$
Q_{\text {rec }}=F_{r} \rho V_{\text {total }} C_{r}\left(T_{r, i}-T_{o}\right)
$$

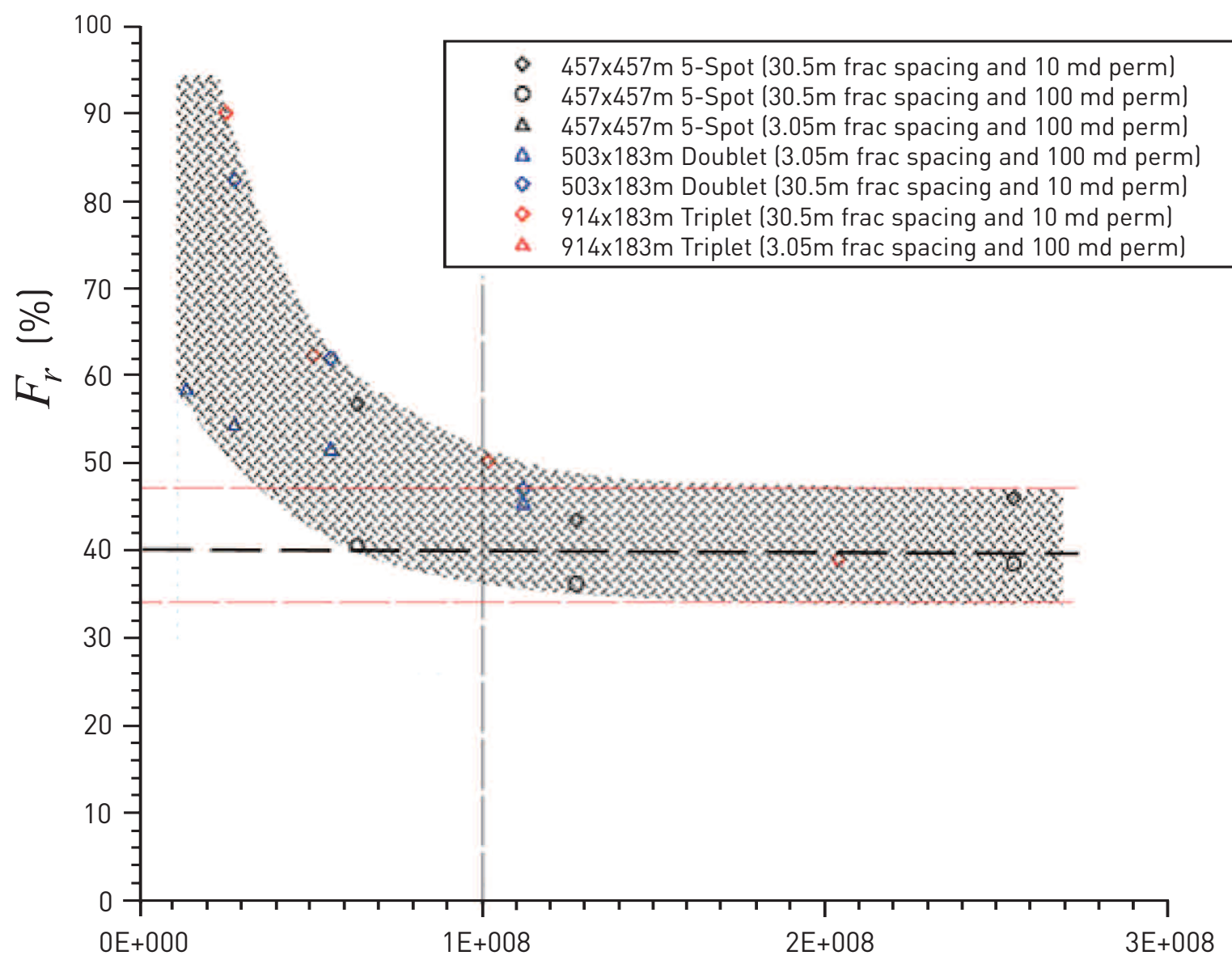

Stimulated Volume $\left(\mathrm{m}^{3}\right)$

Figure 3.1 Recovery factor vs. stimulated volume for a range of well geometries, fracture spacing, and permeability. (Sanyal and Butler, 2005). 
The recovery factor should improve with time as EGS extraction and energy conversion technology matures. The study by Sanyal and Butler (2005) suggests that recoverable energy fractions as high as $45 \%$ can be expected with economic flow rates and energy outputs. The analysis assumed an abandonment temperature that corresponds to only a $10^{\circ} \mathrm{C}$ temperature drop in the rock. There is evidence from 30 years of field testing that strongly suggests that hydrothermal systems achieve recovery amounts for total heat as high as or higher than $45 \%$.

Regarding these estimated recovery factors, it is important to note that they depend strongly on how one defines accessible reservoir volume and characterizes flow through it.

Our ability to create large stimulated rock volumes has certainly improved dramatically. We can now stimulate volumes of $\mathrm{I} \mathrm{km}^{3}$ or more. Figure 3.2 shows the stimulated volume for past EGS experimental sites. By developing technology to control flow short circuits and methods to reduce impedances to flow when needed, the fraction of recoverable thermal energy will certainly increase as well.

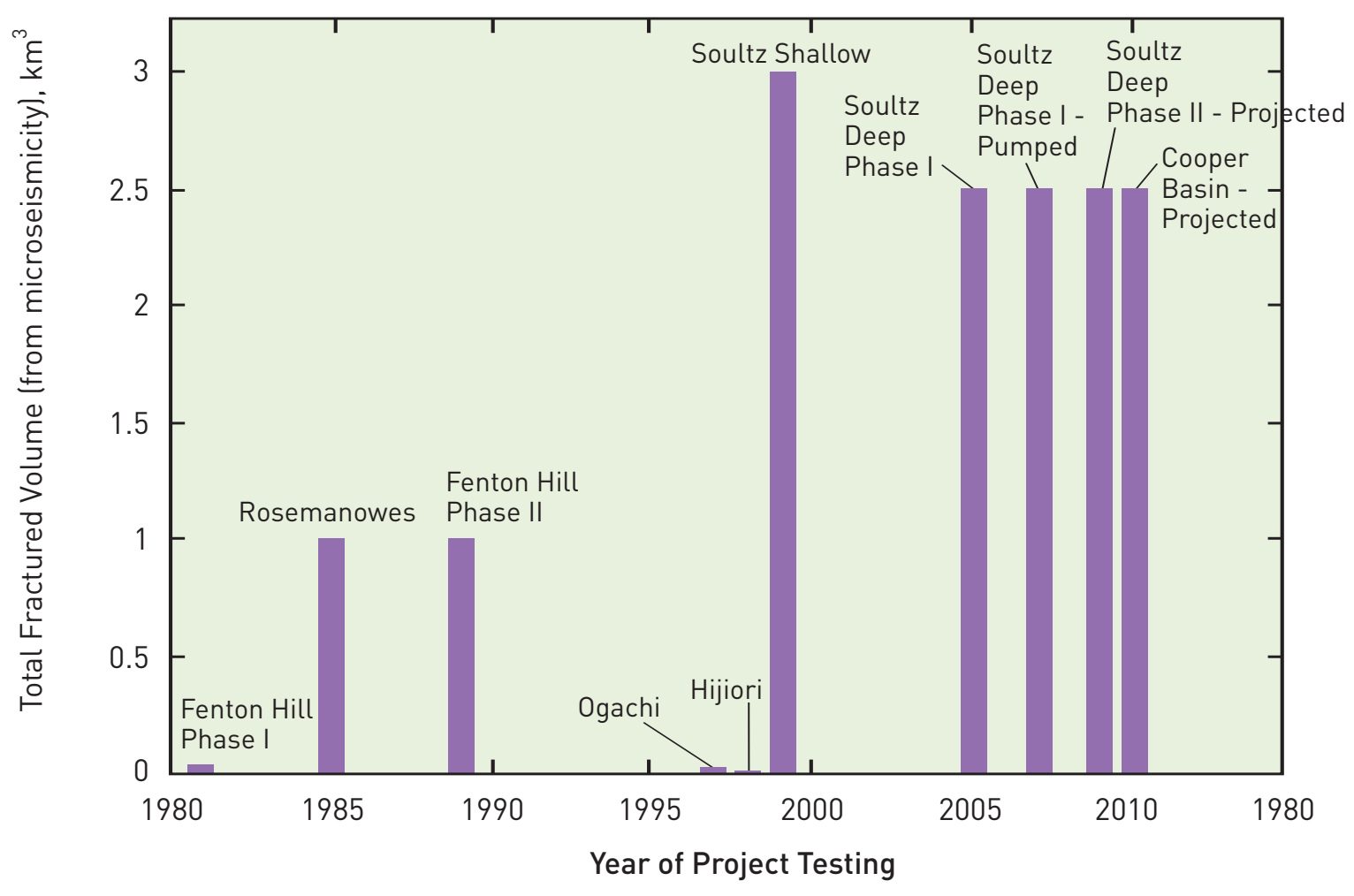

Figure 3.2 Total fractured or stimulated reservoir volume, as determined from microseismic data for representative EGS/hot dry rock (HDR) projects. 


\subsection{Usable Energy - Converting Heat to Power}

Once the amount of recoverable heat from the reservoir has been estimated, it needs to be converted to usable energy, which we assume for this exercise is electricity. Field experience with EGS testing led us to believe that we can extract the heat from the rock for extended periods, with minimal thermal drawdown, if we design and operate the system carefully. As a first approximation, we assume that the production temperature of the fluid at the surface is the average temperature of the rock volume. It is important to note that we are not neglecting the thermal decline within the reservoir that certainly occurs - we are just restricting it to correspond to a specified decline in the average rock temperature at a given depth. Recovered amounts are then estimated from the resource base figures given in Chapter 2 (Figure 2.6) for the conterminous United States.

The power cycle employed, and the ambient surface temperatures along with the fluid temperature, determine the energy conversion efficiency. Chapter 7 discusses power cycles in general, including the conversion efficiency, temperature drop through the system, and other aspects of the conversion of the recoverable heat into electricity. The percentage of heat that can be converted to electricity is quantitatively represented by the thermal efficiency, i.e., the fraction of the total heat delivered to the power cycle by the circulating geofluid that is converted to electrical energy. Thermal efficiencies are based on Figure 7.2 for binary plants at resource temperatures under $200^{\circ} \mathrm{C}$, and on the discussion in Section 7.2.2 for flash plants at temperatures above $200^{\circ} \mathrm{C}$. The effects of ambient temperature, cooling method, and the power-conversion cycle itself are included. Using the net cycle efficiency allows us to convert the recoverable thermal energy for different temperature resources to electric energy. Table 3.I shows the utilization efficiencies from Chapter 7 used for this conversion.

Table 3.1 Cycle thermal efficiencies used for energy conversion (see Chapter 7).

\begin{tabular}{l|l}
\hline Temperature, ${ }^{\circ} \mathrm{C}$ & Cycle Thermal Efficiency $\eta_{\text {th }}, \%$ \\
\hline 150 & 11 \\
\hline 200 & 14 \\
\hline 250 & 16 \\
\hline 300 & 18 \\
\hline 350 & 22 \\
\hline
\end{tabular}

To relate electrical energy to a potential electric-generating capacity, this energy will need to be converted to electric power (power is energy transfer per unit of time). In order to convert electrical energy to electrical power, we need to consider the time over which the energy will be produced. One option is to look at the resource from a project lifetime standpoint. This is the approach used by the United States Geological Survey (USGS) in Circular 790 (Muffler and Guffanti, I978), where they assumed a project life of 20 years and divided the recoverable energy reserves by the number of seconds in 20 years. Since the time of that report, several geothermal projects have been operated for as long as 30 years, and most project planning for future geothermal projects assumes that each plant will last at least 30 years. Assuming this is the case, the average $\mathrm{MW}_{\mathrm{e}}$ of capacity that would result is given by: 


$$
\mathrm{MW}_{\mathrm{e}}=\eta_{t h} Q_{r e c} \times 1 \mathrm{MJ} / 1000 \mathrm{~kJ} \times 1 / \mathrm{t}
$$

where

$Q_{\text {rec }}=$ recoverable thermal energy (heat) in kWs (or kJ)

$\eta_{t h}=$ net cycle thermal efficiency (fraction)

$\mathrm{t}=$ seconds in 30 years $=30 \mathrm{yr} \times 365$ days $/ \mathrm{yr} \times 24 \mathrm{hrs} /$ day $\times 3600 \mathrm{~s} / \mathrm{hr} .=9.46 \times \mathrm{IO}^{8} \mathrm{~s}$

Specifying a recovery factor is arbitrary - however, by assuming a range that spans an order of magnitude and is always lower than the estimates by Sanyal and Butler, we have sufficiently captured the inherent uncertainty in this prediction. The exploitable amount of thermal energy was further reduced by assuming that only a small fraction is actually removed during the period of production to generate electric power. This additional reduction was implemented by specifying a mean temperature of the reservoir at the end of production. This is the abandonment temperature $\left[T_{r, a}\right.$ in Eq. (3-I)] and had a value of $10^{\circ} \mathrm{C}$ below the initial rock temperature, $T_{r, i}$.

Table 3.2 shows the recoverable heat as electric power for the United States, assuming a 30-year project life for each depth and average temperature, and a $20 \%$ recovery factor. Table 3.3 shows the recoverable heat as electric power using a $2 \%$ recovery factor. At only $2 \%$ recovery, we note that the $4-5 \mathrm{~km}$ deep section of the EGS resource on its own represents an increase of about a factor of 25 over today's U.S. electricity production from geothermal energy. As we go deeper, or increase the recovery factor above $2 \%$, the recoverable electrical power increases proportionally. Going forward, we expect both enhancements to occur as a result of EGS technology improvements from invested R\&D and learning curve cost reductions (see Chapter 9 for more details).

Table 3.2 Total recoverable energy in net $\mathrm{MW}_{\mathrm{e}}$ for 30 years, with $20 \%$ recoverable fraction of thermal energy from the reservoir.

\begin{tabular}{|c|c|c|c|c|c|c|}
\hline $\begin{array}{l}\text { Depth of } \\
\text { Slice, km }\end{array}$ & $\begin{array}{l}\text { Power } \\
\text { available for } \\
\text { slice, } \mathrm{MW}_{\mathrm{e}}\end{array}$ & $\begin{array}{l}\text { Amount at } \\
150^{\circ} \mathrm{C} \\
\mathrm{MW}_{\mathrm{e}}\end{array}$ & $\begin{array}{l}\text { Amount at } \\
200^{\circ} \mathrm{C}, \\
\mathrm{MW}_{\mathrm{e}}\end{array}$ & $\begin{array}{l}\text { Amount at } \\
250^{\circ} \mathrm{C}, \\
\mathrm{MW}_{\mathrm{e}}\end{array}$ & $\begin{array}{l}\text { Amount at } \\
300^{\circ} \mathrm{C} \text {, } \\
\mathrm{MW}_{\mathrm{e}}\end{array}$ & $\begin{array}{l}\text { Amount at } \\
350^{\circ} \mathrm{C}, \\
\mathrm{MW}_{\mathrm{e}}\end{array}$ \\
\hline 3 to 4 & 122,000 & 120,000 & 800 & 700 & 400 & \\
\hline 4 to 5 & 719,000 & 678,000 & 39,000 & 900 & 1,200 & \\
\hline 5 to 6 & $1,536,000$ & $1,241,000$ & 284,000 & 11,000 & 600 & \\
\hline 6 to 7 & $2,340,000$ & $1,391,000$ & 832,000 & 114,000 & 2,800 & \\
\hline 7 to 8 & $3,245,000$ & $1,543,000$ & $1,238,000$ & 415,000 & 48,000 & 1,200 \\
\hline 8 to 10 & $4,524,000$ & $1,875,000$ & $1,195,000$ & $1,100,000$ & 302,000 & 54,000 \\
\hline TOTAL & $12,486,000$ & & & & & \\
\hline
\end{tabular}

(a) See Table 3.1 for values of the cycle thermal efficiency used.

(b) $T_{a, i}=T_{r, i}-10^{\circ} \mathrm{C}$, i.e., $10^{\circ} \mathrm{C}$ below the initial rock temperature [see Eq. (3-1)]. 
Table 3.3 Total recoverable energy in net $\mathrm{MW}_{\mathrm{e}}$ for 30 years, with $2 \%$ recoverable fraction of thermal energy from the reservoir.

\begin{tabular}{l|l|l|l|l|l|l}
\hline $\begin{array}{l}\text { Depth of } \\
\text { Slice, } \mathrm{km}\end{array}$ & $\begin{array}{l}\text { Power } \\
\text { available for } \\
\text { slice, } \mathrm{MW}_{\mathrm{e}}\end{array}$ & $\begin{array}{l}\text { Amount at } \\
150^{\circ} \mathrm{C}, \\
\mathrm{MW}_{\mathrm{e}}\end{array}$ & $\begin{array}{l}\text { Amount at } \\
200^{\circ} \mathrm{C}, \\
\mathrm{MW}\end{array}$ & $\begin{array}{l}\text { Amount at } \\
250^{\circ} \mathrm{C}, \\
\mathrm{MW}_{\mathrm{e}}\end{array}$ & $\begin{array}{l}\text { Amount at } \\
300^{\circ} \mathrm{C}, \\
\mathrm{MW}_{\mathrm{e}}\end{array}$ & $\begin{array}{l}\text { Amount at } \\
350^{\circ} \mathrm{C}, \\
\mathrm{MW}_{\mathrm{e}}\end{array}$ \\
\hline 3 to 4 & 12,000 & 12,000 & 80 & 70 & 40 & \\
\hline 4 to 5 & 72,000 & 68,000 & 4,000 & 90 & 120 & \\
\hline 5 to 6 & 154,000 & 124,000 & 28,000 & 1,100 & 60 & \\
\hline 6 to 7 & 234,000 & 139,000 & 83,000 & 11,000 & 300 & \\
\hline 7 to 8 & 324,000 & 154,000 & 124,000 & 41,000 & 5,000 & 120 \\
\hline 8 to 10 & 452,000 & 187,000 & 119,000 & 110,000 & 30,000 & 5,000 \\
\hline TOTAL & $1,249,000$ & & & & & \\
\hline
\end{tabular}

(a) See Table 3.1 for values of the cycle thermal efficiency used.

(b) $T_{a, i}=T_{r, i}-10^{\circ} \mathrm{C}$, that is $10^{\circ} \mathrm{C}$ below the initial rock temperature [see Eq. (3-1)].

\subsection{Access to the EGS Resource}

Only a portion of the total EGS resource will be accessible for development. Urban areas, major roads and utility corridors, as well as national and state parks, recreation areas, wilderness areas, and national monuments will be off-limits for development. Military bases, while possibly accessible for EGS development, are currently treated in a different way from other federal lands - development is severely restricted and royalty structure is different from public or private lands. The panel recommends that these restricted areas should not be considered as part of the EGS resource base. At this point in the evaluation of EGS feasibility, these off-limit areas have not been mapped and have been excluded from the EGS resource - the one exception was the Yellowstone National Park region, which is not included in the U.S. total or in Wyoming, Montana, or Idaho. Quantifying these restricted areas is an important aspect of resource assessment that should be considered in the future.

For this study, we simplified the analysis. The portion of the EGS resource that was not accessible for development was estimated by taking the total fraction of the land in each state - and for the United States as a whole - that was contained in state and national parks, recreation areas, wilderness, national monuments, and military lands. This fraction was assumed to be the fraction of the EGS resource that was inaccessible for development, and it was subtracted from the total recoverable resource:

$$
\text { Accessible } \mathrm{MW}_{\mathrm{e}}=\mathrm{MW}_{\mathrm{e}}(1-\mathrm{IF})
$$

where

$\mathrm{IF}=$ fraction of the total state or U.S. land area that is inaccessible, as described above, due to being located under a park, wilderness or nature preserve, or military base

$\mathrm{MW}_{\mathrm{e}}=$ Calculated electric power capacity accessible if all land area was available for development 
The amount of power that could then be considered recoverable and accessible is calculated using Eq. (3-I) to (3-4). For states such as Washington, New York, or California, with a large fraction of the total land contained in national and state parks, recreation areas, wilderness and military lands, the fraction of the resource that is considered inaccessible is more than $5 \%$. For states in the Midwest or Gulf Coast, the fraction is much lower, closer to I\%.

\section{References}

Armstead, H. C. H. and J. W. Tester. I987. Heat Mining. E. and F. N. Spon Ltd., NY.

Elsworth, D. I990. "A comparative evaluation of the parallel flow and spherical reservoir models of HDR geothermal systems." J. Volcanology and Geothermal Res., 44: 283 - 293.

Elsworth, D. I989. "Theory of thermal recovery from a spherically stimulated HDR reservoir." J. Geophys. Res., 94(B2): I927 - I934.

Kruger, P. and C. Otte. I972. Geothermal Energy, Resources, Production and Stimulation, Stanford University Press, Stanford, Calif.

Muffler, L. J. P. and M. Gaffanti (eds.). I978. "Assessment of geothermal resources in the United States." U.S. Geol. Survey., Circ. 790.

Sanyal, S. K. and S. J. Butler. 2005. "An Analysis of Power Generation Prospects From Enhanced Geothermal Systems." Geothermal Resources Council Transactions, 29.

SEC Staff Accounting Bulletin. 2006. Codification of Staff Accounting Bulletins - Topic I2: Oil and Gas Producing Activities, Accounting Series Release 257 - Requirements for financial accounting and reporting practices for oil and gas producing activities (March 30, 2006) 


\section{CHAPTER 4 \\ Review of EGS and Related Technology - Status and Achievements}

4.1 Scope and Organization

4.2 Overview

4.3 Fenton Hill

4.3.1 Project history _

4.3.2 Lessons learned at Fenton Hill _ _ _ _ _

4.4 Rosemanowes _.

4.4.1 Project history _-_-_-_-_-_-_-_-

4.4.2 Lessons learned at Rosemanowes _

4.5 Hijiori _.

4.5.1 Project history _-_-

4.5.2 Lessons learned at Hijiori

4.6 Ogachi

4.6.1 Project history _-_-_-_-

4.6.2 Lessons learned at Ogachi

4.7 Soultz

4.7.1 Project history _-

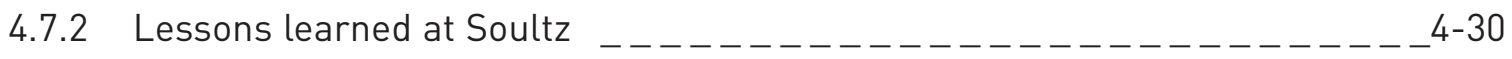

4.8 Cooper Basin _

4.8.1 Project history

4.8.2 Lessons learned at Cooper Basin

4.9 Other EGS Studies

4.9.1 United States _

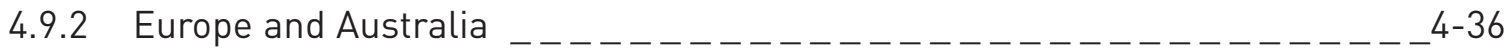

4.10 Generalizations from EGS Field Testing _ _ $\ldots \ldots \ldots \ldots \ldots \ldots \ldots \ldots \ldots-\ldots 43$

4.11 Remaining Needs _

References _. 


\subsection{Scope and Organization}

This chapter reviews several major international Enhanced Geothermal Systems (EGS) R\&D field projects, which have focused on demonstrating the feasibility of mining heat by stimulating and operating an engineered reservoir. Our rationale for covering these projects is twofold: first, to provide historical context on how the technology has progressed, as a result of public and private R\&D support; and, second, to chronicle the lessons learned from these efforts, particularly as they impact our understanding of how subsurface geologic conditions influence the creation and performance of EGS. Later, in Chapter 5, we develop a general approach to designing and stimulating EGS systems, which is largely based on the body of information created by these important experiments.

The remaining sections of this chapter are organized as follows: First, we provide a brief overview of the collective field effort, and then we cover each major project with a description of what was done and accomplished, as well as the "lessons learned" from each site. The major projects discussed include: Fenton Hill, in the United States; Rosemanowes, in the United Kingdom; Soultz, in France; Cooper Basin, in Australia; and Hijiori and Ogachi, in Japan - plus several other smaller projects. At the end of the chapter, we summarize the general state of understanding of EGS reservoir technologies, as well as the remaining needs for commercial-scale operations.

\subsection{Overview}

Field efforts began with the pioneering work of scientists at Los Alamos National Laboratory in the early I970s at the Fenton Hill, New Mexico, site. In the early years, the program was referred to as the Hot Dry Rock or HDR project. Later, this was replaced by Enhanced/Engineered Geothermal Systems (EGS) to more correctly reflect the continuum of grade (or quality of resource) that exists among today's commercial hydrothermal systems, the unproductive margins of hydrothermal regions, and mid- to low-geothermal gradient regions throughout the United States.

The history of the worldwide effort to extract the Earth's heat from rocks that do not have pre-existing high permeability began with the Fenton Hill hot dry rock experiments. This first project was initially funded completely by the U.S. government, but later involved active collaborations under an International Energy Agency agreement with Great Britain, France, Germany, and Japan - the latter two countries providing funding ( $\$ 5$ million) to help support the research over a six-year period. The objective of the project was to develop a heat-extraction system in a high-temperature-gradient area with a large volume of uniform, low-permeability, crystalline basement rock on the margin of a hydrothermal system in the Valles Caldera region of New Mexico.

Building on the experience and data from the Fenton Hill project, the Rosemanowes, Hijiori, Ogachi, and Soultz projects attempted to develop further the concept of creating a reservoir in crystalline rock in other geological settings. These EGS/HDR field experiments were carried out starting about I975 in the United Kingdom, and somewhat later in Japan, France, Sweden, and the Federal Republic of Germany (see timeline in Figure 4.I). 
Chapter 4 Review of EGS and Related Technology - Status and Achievements

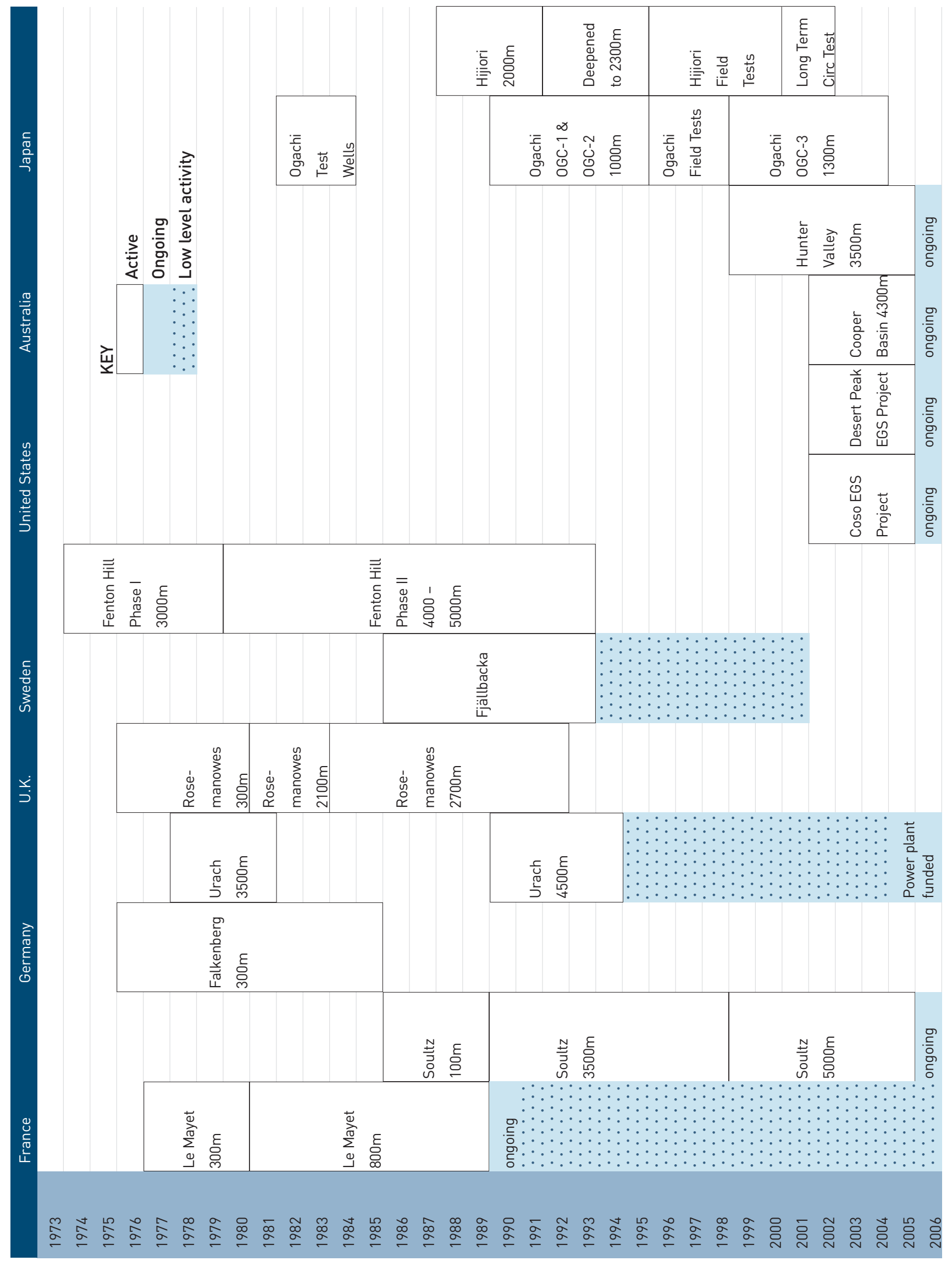

Figure 4.1 Schedule of major HDR and EGS projects worldwide. 
While the Fenton Hill experience demonstrated the technical feasibility of the HDR concept by I980, none of the testing carried out at Fenton Hill yielded all the performance characteristics required for a commercial-sized system. Three major issues remained at the end of the project as constraints to commercialization: (i) the demonstration of sufficient reservoir productivity with high-productivity fracture systems of sufficient size and thermal lifetime to maintain economic fluid production rates (50 to $100 \mathrm{~kg} / \mathrm{s}$ per well pair at wellhead temperatures above $150^{\circ} \mathrm{C}$ ), (ii) the maintenance of these flow rates with sufficiently low pumping pressures, and (iii) the relatively high cost of drilling deep (> 3 $\mathrm{km}$ ) wells in hard rock. Drilling costs become the dominant economic component in low-grade, lowgradient EGS resources (see Chapter 6). In certain geologic situations, controlling water losses will be important, as it can have negative economic and environmental impacts.

Initially, the Los Alamos team and others tried to adapt techniques from oil well stimulation using hydraulic fracturing to produce idealized vertical "penny-shaped" fractures formed in a rock mass that behaves as an isotropic, homogeneous continuum where the minimum stress is in the horizontal direction. The implication of creating a reservoir in such a medium was that the most likely effect of water injection under high pressures would be to create a new fracture by tensile failure, thus forming the required surface area needed for heat mining (Smith et al., I975; Kappelmeyer and Rummel, I980; Duffield et al., I98I; Kappelmeyer and Jung, I987).

After several years of active field work, some researchers recognized that EGS reservoirs probably consisted of 3-dimensional networks of hydraulically activated joints and fractures. These fissure systems contribute to the connection between injection and production boreholes, rather than just one - or even a series of - artificially created hydraulic fractures (see, for example, Batchelor, I977; and Armstead and Tester, I987).

By the early i980s, research at various sites (Pine and Batchelor, I984) confirmed that the creation of new hydraulic fractures was not the dominant process; but that the shearing of natural joints favorably aligned with the principal directions of the local stress field was a more important mechanism. These joints could be completely or partly sealed in their natural state. They fail in shear, because fluid injected under pressure reduces the normal stress across them, but only marginally affects the magnitude of the shear stress. The shearing mechanism allows frictional slippage to occur before tensile failure, i.e., there will be a component of shearing ahead of any hydraulically fractured zone (Baria et al., I985; Baria and Green, I989). Shearing of the fractures increases their aperture through self-propping on the naturally rough surfaces.

The realization that shearing on existing joints constitutes the main mechanism of reservoir growth has been one of the most significant outcomes of the international research projects. This has led to a basic change in how researchers interpret the evolution of the structure of an EGS reservoir, as a result of hydraulic pressurization. It has led to a departure from conventional oil field reservoir development techniques (which emphasize discrete hydraulic fracturing as a means of stimulation) toward a new technology related to the properties of any jointed rock mass that is subjected to a particular anisotropic stress regime. Because all formations that have been investigated so far have some sealed or partly sealed fractures (even those in continental shield areas with very low stresses), we can stimulate fracture networks and have them stay open using pumping pressures just over the critical pressure for shear failure. It should also be mentioned that, in every case, connections between the wells follow multiple paths. Every well has a number of flow entry and exit points. These occur at various depths, and their relative importance can change as a function of different pressure regimes. 
The most important conclusion from all this prior work regarding the development of EGS as a power-producing technology is that we can probably form an EGS reservoir at any depth and anywhere in the world that has both a temperature high enough for energy conversion and sufficient far-field connectivity through existing natural fractures. Nonetheless, uncertainties still exist, for example, regarding the natural state of stress and rock properties, even within well-characterized geologic regions. Most important, the existence of anisotropic stresses in the rock as a prerequisite for stimulation by shear failure is fundamentally different than normal practice in oil- and gas-bearing formations. Other aspects of the reservoir structure may cause operational problems down-hole, such as mapping existing major faults and fractures that may act as flow barriers or conduits - and cause problems for our system.

Today, because of a limited understanding, we cannot predict the long-term effect of injecting water - which is not in chemical or thermal equilibrium with the rock - into the reservoir. Dissolution and precipitation will certainly occur at different points in the system, leading to both improvements and reductions in permeability. If a highly permeable fracture exists (or develops) in the system, it can result in a short circuit that may require aggressive remediation, such as drilling a sidetrack into a new area of rock. Sustained pressurization may also lead to unproductive volumetric reservoir growth and higher water losses.

Many features associated with the technical feasibility of EGS/HDR technology have been demonstrated at more than one site in the past 30 years. However, the major shortcoming of the field testing, so far, is that circulation rates through the stimulated regions have been below commercially viable rates. Recent progress at Soultz and Cooper Basin suggests that the ability to reach commercial levels is reasonably close, as will be discussed later in this chapter.

Taking all uncertainties collectively, we have not yet seen any "show stoppers" to making EGS work technically. While a given stimulation method may not provide for efficient, cost-effective heat mining at today's energy prices, it still extracts net energy. Field efforts have repeatedly demonstrated that EGS wells can be drilled; pre-existing, sealed fractures at depth can be stimulated; and a connection can be made between wells. Fluid can be circulated through the network and heated to economic temperatures; and we can maintain the circulation, and use the heat from the produced fluid directly - or use it to generate electricity. 


\subsection{Fenton Hill}

\subsubsection{Project history}

The project at Fenton Hill was the first attempt anywhere to make a deep, full-scale HDR reservoir. The site - on the edge of the Valles Caldera at the northern end of the Rio Grande rift zone in northcentral New Mexico - was chosen for its heat and rock characteristics, as well as its proximity to the Los Alamos National Laboratory where the project was conceived. The purpose of the project was to develop methods to extract energy economically from HDR systems located in crystalline, granitic/metamorphic basement rock of suitably high temperature.

The R\&D program was roughly divided into two major phases. Phase I, starting in I974 and completed in I980, dealt with field development and associated research on a $3 \mathrm{~km}$ deep reservoir with a temperature of about $200^{\circ} \mathrm{C}$. Phase II followed in I979, with the drilling of EE-2 into a deeper $(4.4 \mathrm{~km})$, hotter $\left(300^{\circ} \mathrm{C}\right)$ reservoir. Figure 4.2 shows a map of the site and some characteristic properties of the formation and stimulated reservoirs.

The first deep well drilled at Fenton Hill, called GT-2, was started on February I7, I974, and was completed to a temporary depth of 2,042 $\mathrm{m}$ in September 1974. Following the completion of the well, a series of hydraulic fracturing tests was run, and completed in early October of 1974. After these tests were completed, the well was deepened to $2,932 \mathrm{~m}$. Bottom-hole temperatures (BHT) were about I80 ${ }^{\circ} \mathrm{C}$.

The second deep hole drilled at Fenton Hill was Energy Extraction Hole I (EE-I). EE-I was drilled from May I975 through October I975, to a total depth of 3,064 m and with a similar BHT as GT-2. Additional hydraulic fracturing was then performed, but the reservoir connecting the wells was deemed inadequate.

It was determined that additional fracturing would likely not create the desired reservoir connection. As a result, it was decided to directionally redrill one of the wells into the fracture system created by the other. In I977, an attempt to establish a high-permeability flow path between the two was performed on GT-2, at approximately 2,500 $\mathrm{m}$ (GT-2A), and was also determined to be inadequate. The lower part of GT-2A was then cemented in May I977; and another hole, named GT-2B, was directionally drilled out of the upper portion of GT2-A at around 2,530 $\mathrm{m}$. An acceptable connection was made between GT2-B and EE-I at 2,673 m, with an average separation between the two boreholes of Ioo m. Figure 4.3 shows the wells in vertical profile with the stimulated fracture zone shown in hatching (Tester and Albright, 1979). 

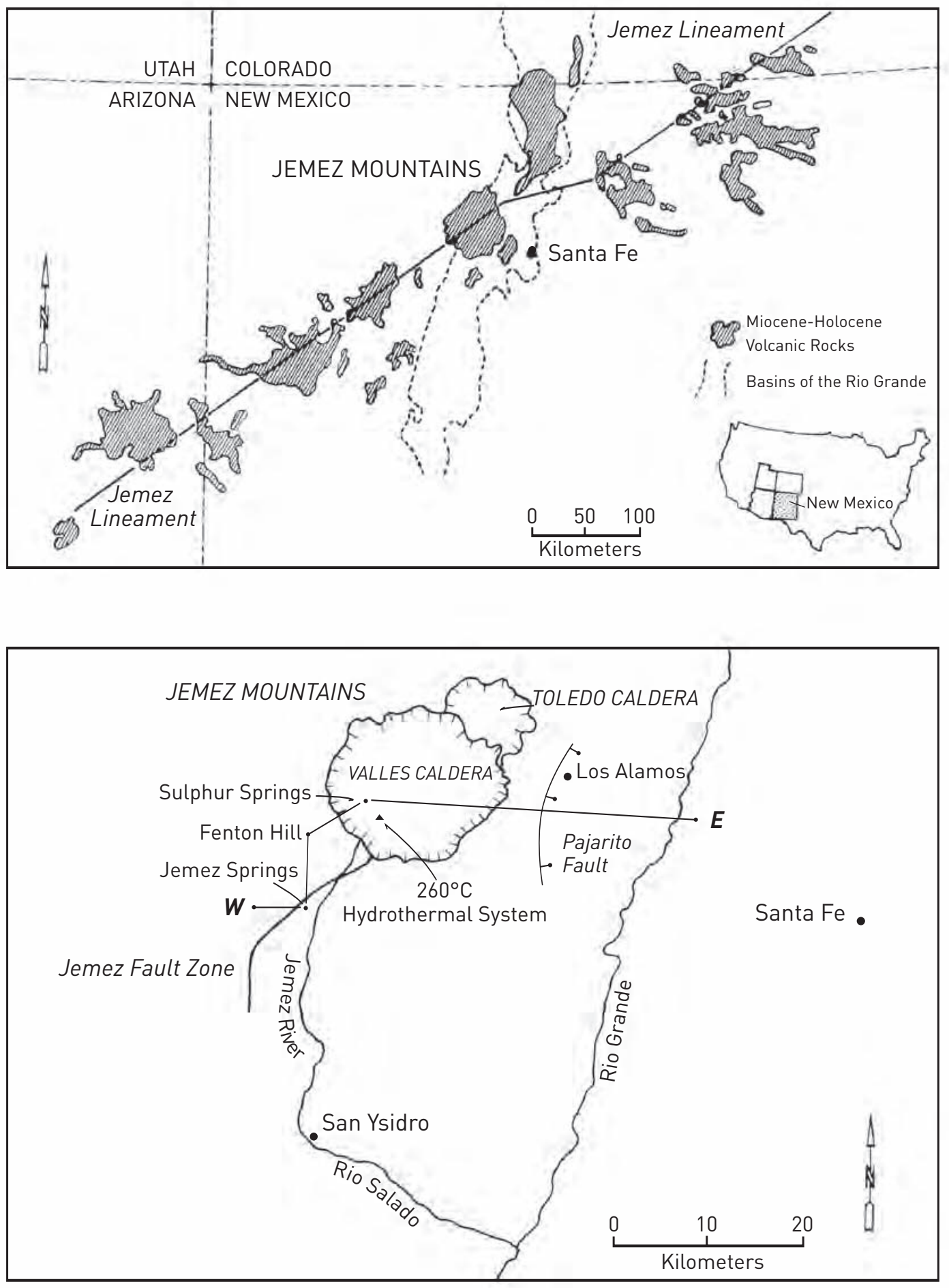

Figure 4.2 Map of Fenton Hill site and properties of formation and stimulated reservoirs. 


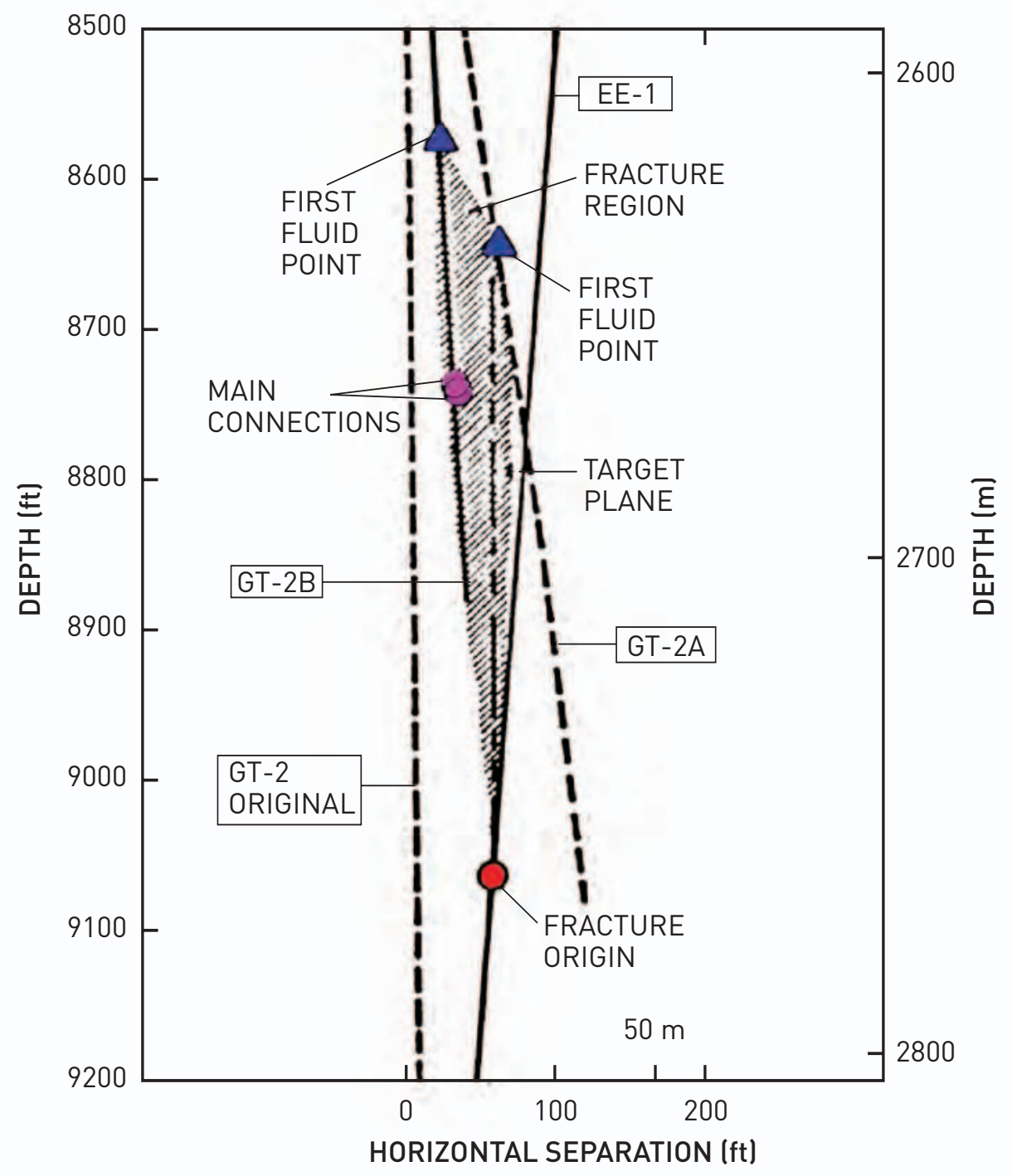

Figure 4.3 Elevation view of wells EE-1, GT-2, GT-2A, and GT-2B at the Fenton Hill site during Phase I testing.

Between June 1977 and December I980, five circulation experiments were conducted in the Phase I system, lasting for 4I7 days. The water run through the system produced between 3 and $5 \mathrm{MWt}$, and powered a $60 \mathrm{~kW}$ binary fluid turbine generator.

In April I979, drilling began on a new set of wells, EE-2 and EE-3, to be drilled deeper than the other wells. The wells were directionally drilled at about $35^{\circ}$ to a vertical plane, and separated by $380 \mathrm{~m}$ vertically. The deeper of the two, EE-2 reached a depth of $4,390 \mathrm{~m}$ and BHT of $327^{\circ} \mathrm{C}$. From I982I984, the wells were then hydraulically fractured at multiple depths. In all these (and subsequent) experiments, the progress of fracture growth was followed by microseismic event monitoring. The reservoir created by these experiments did not grow in the direction predicted, and an inadequate connection was established between the two wells. It was determined that this was caused by an unanticipated shift in the stress field in the deeper part of the formation - a major finding from this phase of the project. 
It appeared unlikely that additional conventional hydraulic fracturing would stimulate the necessary fracture growth, and so the team again chose to directionally redrill one of the existing wells. In September I985, the upper well, EE-3, was sidetracked at 2,830 $\mathrm{m}$ and drilled to a depth of 4,OI8 $\mathrm{m}$ with BHT of $265^{\circ} \mathrm{C}$, and renamed EE-3A (see Figure 4.4A). The newly drilled well intersected several of the fractures created by the hydraulic stimulation, and the connection created was acceptable for large-scale testing.

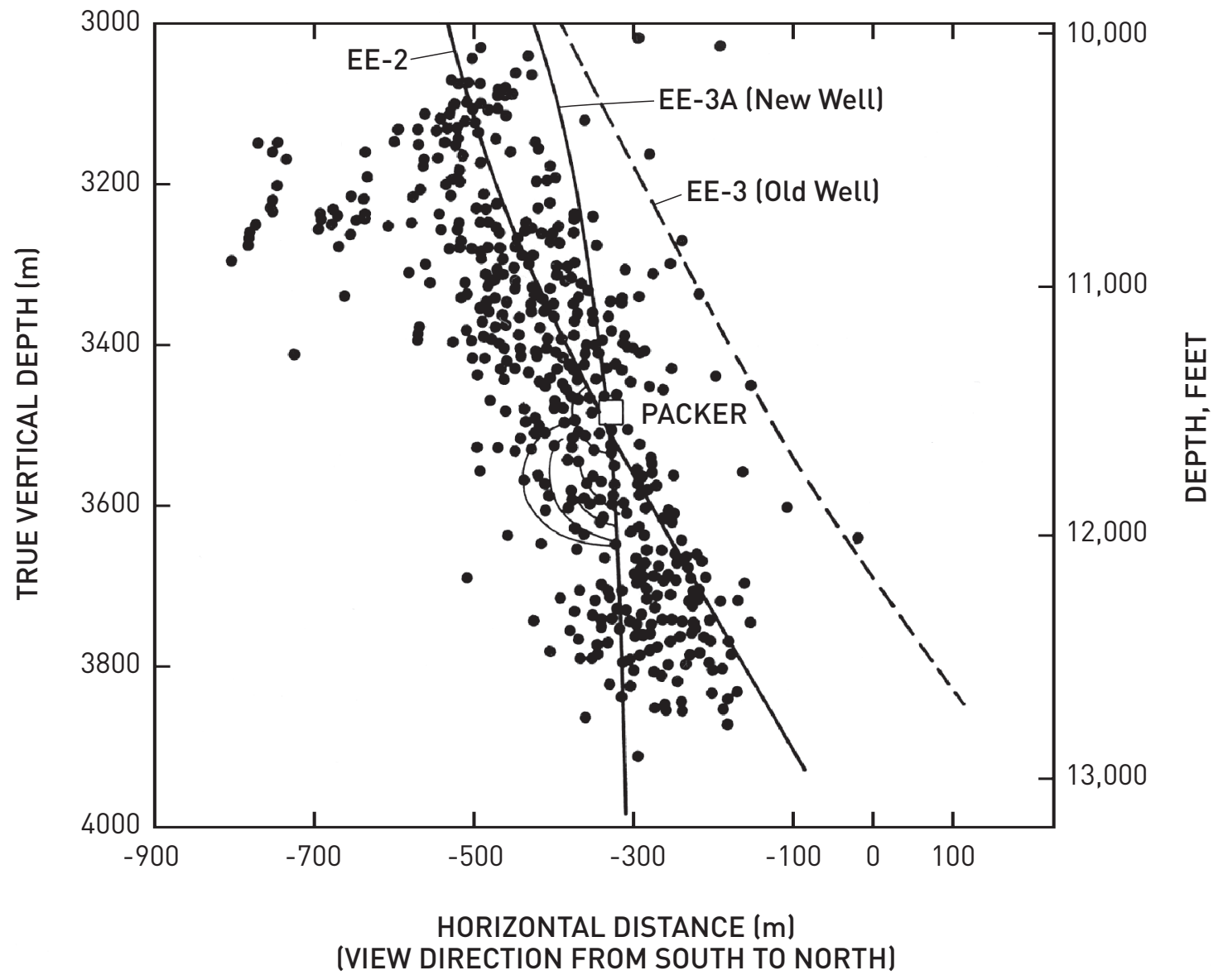

Figure 4.4A Elevation view of wells at Fenton Hill site. The data points represent microseismic events observed during stimulation.

The initial closed-loop flow test of the Phase II system began in May I986 and ran for 30 days. During the test, $37,000 \mathrm{~m}^{3}$ of water was pumped through the system, with $66 \%$ of that being recovered; another $20 \%$ was recovered during venting after the test. Flow rates were between 10.6 and $18.5 \mathrm{~kg} / \mathrm{s}$, with between 26.9 and $30.3 \mathrm{MPa}$ (pascals) of pressure on the injection wellhead. The fluid extracted from the reservoir reached $192^{\circ} \mathrm{C}$, with the temperature still increasing at the end of the test. Results of the flow test were encouraging and further testing was planned. 
During venting in the first flow test on the system, the casing and liner in well EE-2 at 3,200 $\mathrm{m}$ suffered a partial collapse. It was decided that the best way to fix the leakage caused by the collapse was to seal off the well just above the collapse, and redrill the well from that point. The redrilling took only 30 days to drill $800 \mathrm{~m}$, progressing at a rate 2.5 times faster than the rate drilled in I978 and I979. The redrilled wellbore was renamed EE-2A to distinguish it from the earlier well.

Following recompletion of EE-2A, flow testing was conducted in I989-I990 to obtain data for planning the long-term flow test. Tests conducted at equilibrium pressures did not have the high loss of fluid that had been experienced at pressures above the fracture breakdown pressure, which had been found to be less than I9 MPa. Also at pressures below the critical pressure, the reservoir did not continue to grow. While temperature in the produced fluids changed over time, the downhole temperature did not change measurably during the testing. Other testing maintained pressurization of the reservoir by cyclically injecting fluid while sustaining wellhead pressure on the production well (Duchane, I993).

The facility for the long-term flow test was constructed, starting in I990, while shorter flow tests continued. Several pieces of equipment were installed for this phase of testing, including a heat exchanger to dump waste heat from the produced fluid, larger makeup water storage ponds, and larger capacity makeup water pumps and injection pumps. The first stage of the long-term flow test of the Phase II system started on April 8, I992. The test continued for II2 days, until failure of the injection pumps necessitated shutdown on July 3I. Cold water was injected at I2.5-I5 kg/s (90-IIO gpm) and produced at temperatures of more than $180^{\circ} \mathrm{C}$ (Duchane, I993). During the first stage of testing, the pumps were of the reciprocating type driven by diesel engines; but, for the second stage of testing, the pumps were centrifugal and driven by electric motors. This test lasted 55 days with constant downhole temperatures. However, surface temperatures dropped, possibly because low flow rates resulted in heat loss to a shallow, cooler subsurface region.

During the latter phases of work at Fenton Hill, support for the work had declined to the point where it was not possible to maintain sufficient technical staff to perform continuous flow testing of the reservoir - nor was it possible to perform the necessary redrilling and wellbore repairs to upgrade the downhole connections to the large fractured system that had been created (see Figures 4.4A and 4.4B). With prospects for continued funding very low, all field experiments were terminated at the Fenton Hill site by 2000 , after which the site was decommissioned. 


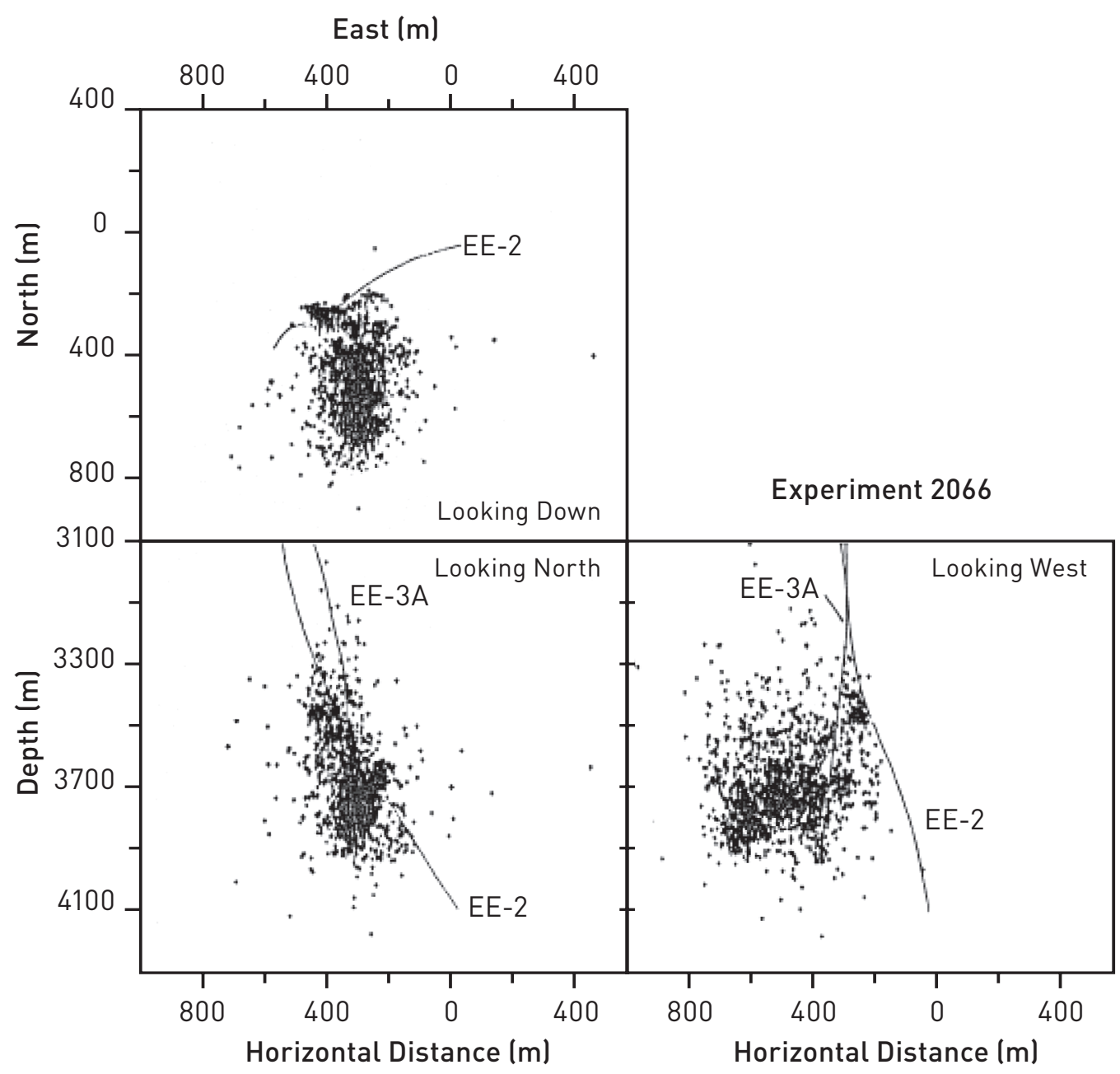

Figure 4.4B Fenton Hill microseismic event locations during stimulation of EE-3A, on January 30, 1986 (Los Alamos National Laboratory).

\subsubsection{Lessons learned at Fenton Hill}

- Deep ( $15,000 \mathrm{ft}, \approx 5 \mathrm{~km}$ ), high-temperature wells can be completed in hard, abrasive rock.

- Low-permeability (microdarcy or lower) crystalline rock can be stimulated to create hydraulically conductive fractures.

- Conventional drilling methods can be adapted for the harsh environments encountered in reaching zones of rock at about $200^{\circ} \mathrm{C}$ to $300^{\circ} \mathrm{C}$, which are hot enough to be suitable for commercial power production.

- Hydraulic-pressurization methods can create permanently open networks of fractures in large enough volumes of rock (>I $\mathrm{km}^{3}$ ) to sustain energy extraction over a long time period.

- The EGS reservoir can be circulated for extended time periods and used to generate electricity.

- Creating the connection between wells was a crucial step in developing the EGS reservoir.

- Connection was easier to establish by drilling into the fractured volume, once it was stimulated and mapped.

- Directional drilling control was possible in hard crystalline rock, and the fractures mapped by microseismic monitoring could be intersected using directional drilling.

- The Phase I reservoir, although too small by design for commercial operation, provided a test-bed for creating the larger volumes needed to achieve commercial rates of production. 
- Techniques were developed to reduce pressure drop in and near the wellbore, often referred to as wellbore impedance.

- Models of flow and heat transfer were developed that, along with data collected during testing, can be used to predict the behavior of the EGS reservoir.

- The thermal-hydraulic performance of the recirculating Phase I system was successfully modeled, and indicated approximately $10,000 \mathrm{~m}^{2}$ of effective surface area when matched to field data. This area is too small by about a factor of Ioo for a commercial-scale system.

- Techniques using chemical tracers, active and passive acoustic emissions methods, and other geophysical logging techniques can be used to map the created fractures.

- At the deeper depths required to reach higher rock temperatures $\left(>300^{\circ} \mathrm{C}\right)$, wells could still be drilled, fractures created through hydraulic stimulation, and the fractured volume mapped.

- Although it took some effort, the fractured volume could be intersected by drilling into the mapped fractures.

- Connections between the wells could be established and fluids circulated at commercial temperatures for extended time periods.

- The high pressures needed to keep the Phase II fractures open caused operational problems and required substantial amounts of power.

- Although the reservoir had the potential of producing I million $\mathrm{m}^{2}$ of heat-transfer surface, based on the fluid volume pumped, the fracture pattern that was observed did not match that predicted by early modeling.

- The reservoir could be circulated in such a manner that the fractured volume did not continue to grow and, thus, water losses were minimized.

- If injection pressures were lowered to reduce water loss and reservoir growth, the flow rates were lower than desired, due to higher pressure drop through the reservoir. If water was injected at high enough pressures to maintain high flow rates, the reservoir grew and water losses were high. This meant that the fractures were being jacked open under high-injection pressures, causing extension of the fractures and increased permeability. At lower pressures, this did not happen, so the pressure drop was higher and flow rates much lower.

- High-temperature tools and equipment for downhole use had to be developed and adapted to evaluate the stress regime; determine the orientation of pre-existing fractures; monitor downhole pressure, temperature, and flow rates; and to provide geophysical data on the reservoir. Much of this equipment was developed by the national laboratory as needed and was not intended for commercial use. 


\subsection{Rosemanowes}

\subsubsection{Project history}

As a result of experience during Phase I at Fenton Hill, in 1977, the Camborne School of Mines undertook an experimental hot dry rock (HDR) project at Rosemanowes Quarry (near Penryn in Cornwall, U.K.) in the Carnmenellis granite (see Figure 4.5). The project was funded by the U.K. Department of Energy and by the Commission of the European Communities, and was intended as a large-scale rock mechanics experiment addressing some of the issues surrounding the stimulation of adequate fracture networks (Batchelor, I982). Because the temperature was restricted deliberately to below $100^{\circ} \mathrm{C}$, to minimize instrumentation problems, this project was never intended as an energy producer. The site was chosen because mine works in the area allowed rock characterization to a depth of more than $\mathrm{I}, \mathrm{O} 0 \mathrm{~m}$, due to the clearly defined vertical jointing evident in the exposed granite - and because of the area's heat flow and high-temperature gradients between 30 and $40^{\circ} \mathrm{C}$ per kilometer. The main tectonic regime of the area is strike-slip.

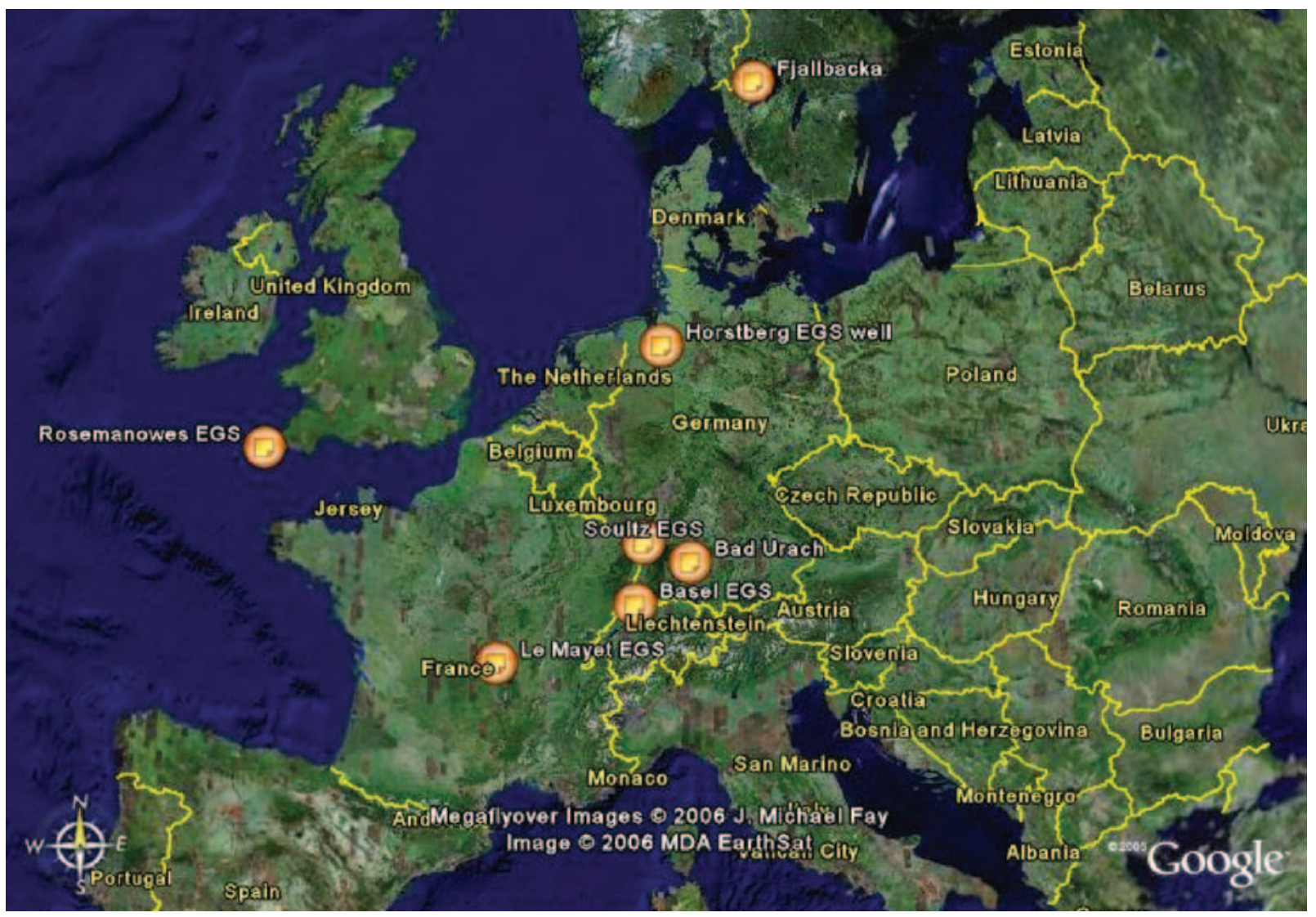

Figure 4.5 European EGS site locations (Google Earth).

The Carnmenellis granite is roughly ellipsoidal in outline, and it forms part of a continuous granite batholith of early Permian age of more than $200 \mathrm{~km}$ in length. The base of the granite extends well below a depth of $9 \mathrm{~km}$. At the Rosemanowes site, the granite is porphyritic near the surface, tending to become equigranular at about $2 \mathrm{~km}$. Phase I of the project started in I977, with the drilling of a number of $300 \mathrm{~m}$ test wells. The purpose of these wells was to test some possible fracture-initiation techniques. It was found, however, that the stress field at this depth was unrepresentative of that to be encountered at depths of real interest. 
For Phase 2A of the project, two wells were planned with a total vertical depth (TVD) of about $2,000 \mathrm{~m}$, where the temperature was expected to be around $80-90^{\circ} \mathrm{C}$ - both were deviated in the same plane to an angle of 30 degrees from the vertical in the lower sections, and separated by $300 \mathrm{~m}$ vertically. In I980, the drilling of RHiı (production) and RHı2 (injection) began, and took only iı 6 days. Bottom-hole temperatures recorded at RHı2 reached $79^{\circ} \mathrm{C}$.

Stimulation of RHı2 (the lower well) then followed, initially with explosives, and then hydraulically at rates up to Ioo $\mathrm{kg} / \mathrm{s}$ and wellhead pressures of I4 MPa. Due to the mainly vertical nature of jointing in the granite, conventional wisdom was that hydraulic fracturing (tensile fracturing; penny-shaped crack) would cause the reservoir to grow vertically upward, especially around 2,000 $\mathrm{m}$, where the minimum principal stress was horizontal. However, microseismic monitoring showed that the majority of fracturing and the reservoir grew by shearing mode and not tensile fracturing; and reservoir growth occurred primarily in a vertically downward direction, opposite the predicted direction (Batchelor et al., I983; Pine and Batchelor I984; Baria et al., I989). The predominant downward growth of the reservoir continued through the subsequent nine months of circulation, and testing of the completed system showed it was not suitable for the purpose of modeling a full-scale commercial HDR reservoir.

Phase 2B began in 1983 and entailed the drilling of a third well, RHr5 (see Figure 4.6), which would be drilled below the existing wells, to access the large reservoir already created in Phase $2 \mathrm{~A}$. The well was drilled to a TVD of $2,600 \mathrm{~m}$ and bottom-hole temperatures around $100^{\circ} \mathrm{C}$ were recorded. Hydraulic stimulation of the well was carried out similar to RHı2, and circulation began in I985 (see Figure 4.7), with RHı2 continuing to be the injection well and RHi5 the primary producer. A series of flow tests was then carried out through September I986, with rates gradually stepping up. The reservoir was then circulated continuously at various flow rates (typically around $20-25 \mathrm{~kg} / \mathrm{s}$ ) for the next four years.

Temperature drawdown over the period of the long-term flow test caused a downhole temperature drop from $80.5^{\circ} \mathrm{C}$ to $70.5^{\circ} \mathrm{C}$. Injection rates through the testing phase varied from 5 to $24 \mathrm{~kg} / \mathrm{s}$. In the $5 \mathrm{~kg} / \mathrm{s}$ case, the return from the production well was $4 \mathrm{~kg} / \mathrm{s}$ and the wellhead pressure was 40 bar. In the $24 \mathrm{~kg} / \mathrm{s}$ case, the return from the production well was I5 kg/s and the wellhead pressure I0.5 MPa. Flow-path analysis based on spinner, temperature, and other well log data showed that a preferential pathway - or short circuit - developed, which allowed cool injected water to return too rapidly to the production well (Batchelor, I986).

The experimental work at Rosemanowes Quarry was continued in Phase 3A (which involved no further drilling) with further circulation and other tests. In the downhole pump test in Phase $2 \mathrm{C}$, lowering the pressure in the production well seemed to close the joint apertures close to the borehole and increase the impedance. An experiment in Phase 3A to place a proppant material in the joints near the production borehole was designed to demonstrate that this might solve the problem in a deep system. The sand used as proppant was carried into the joints as part of a secondary stimulation using a high viscosity (700 centipoise) gel. This stimulation significantly reduced the water losses and impedance, but it also worsened the short circuiting and lowered the flow temperature in the production borehole even further. It was concluded that the proppant technique would need to be used with caution in any attempt to manipulate HDR systems. 


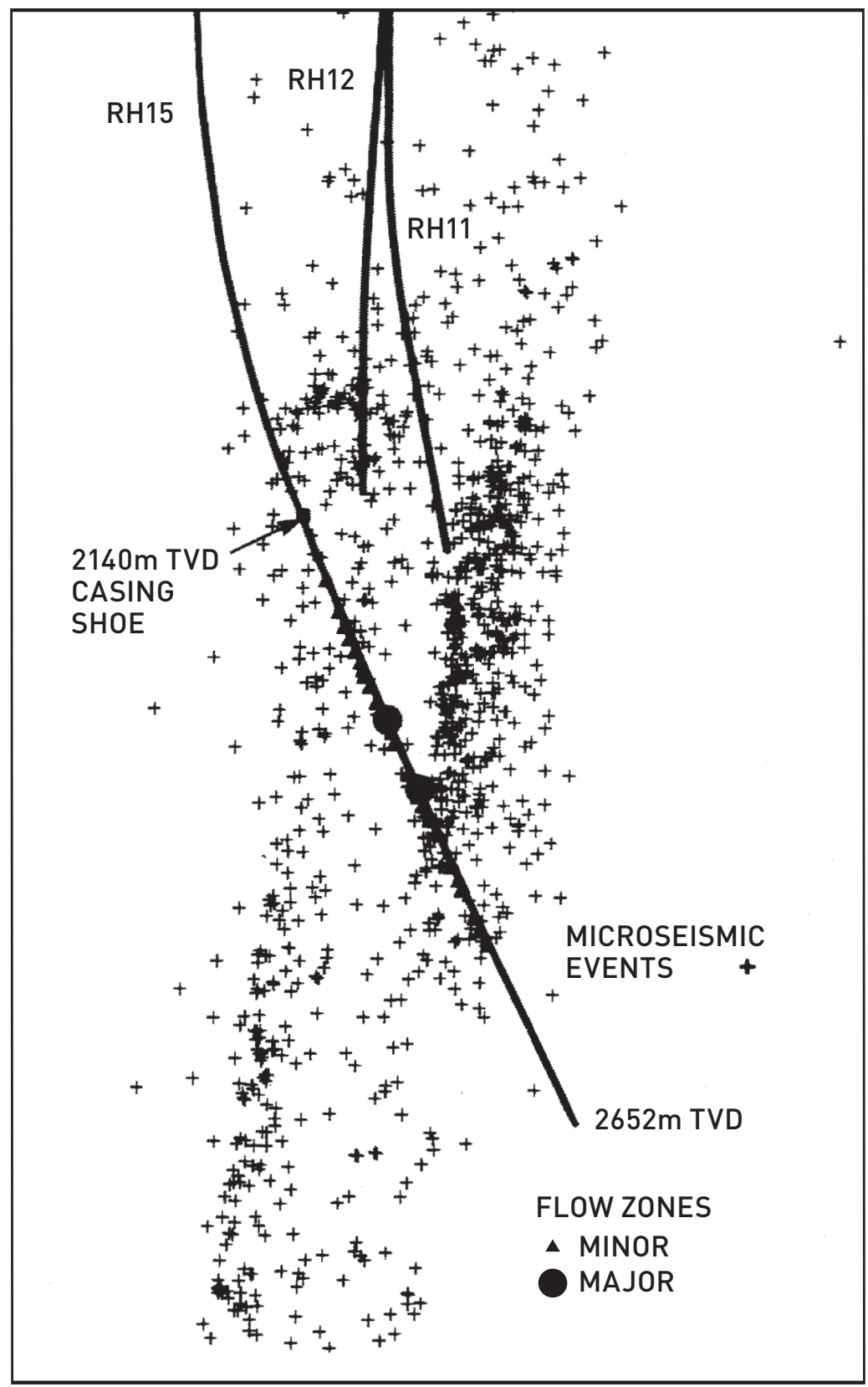

Figure 4.6 Flow zones and microseismicity in RH15. 


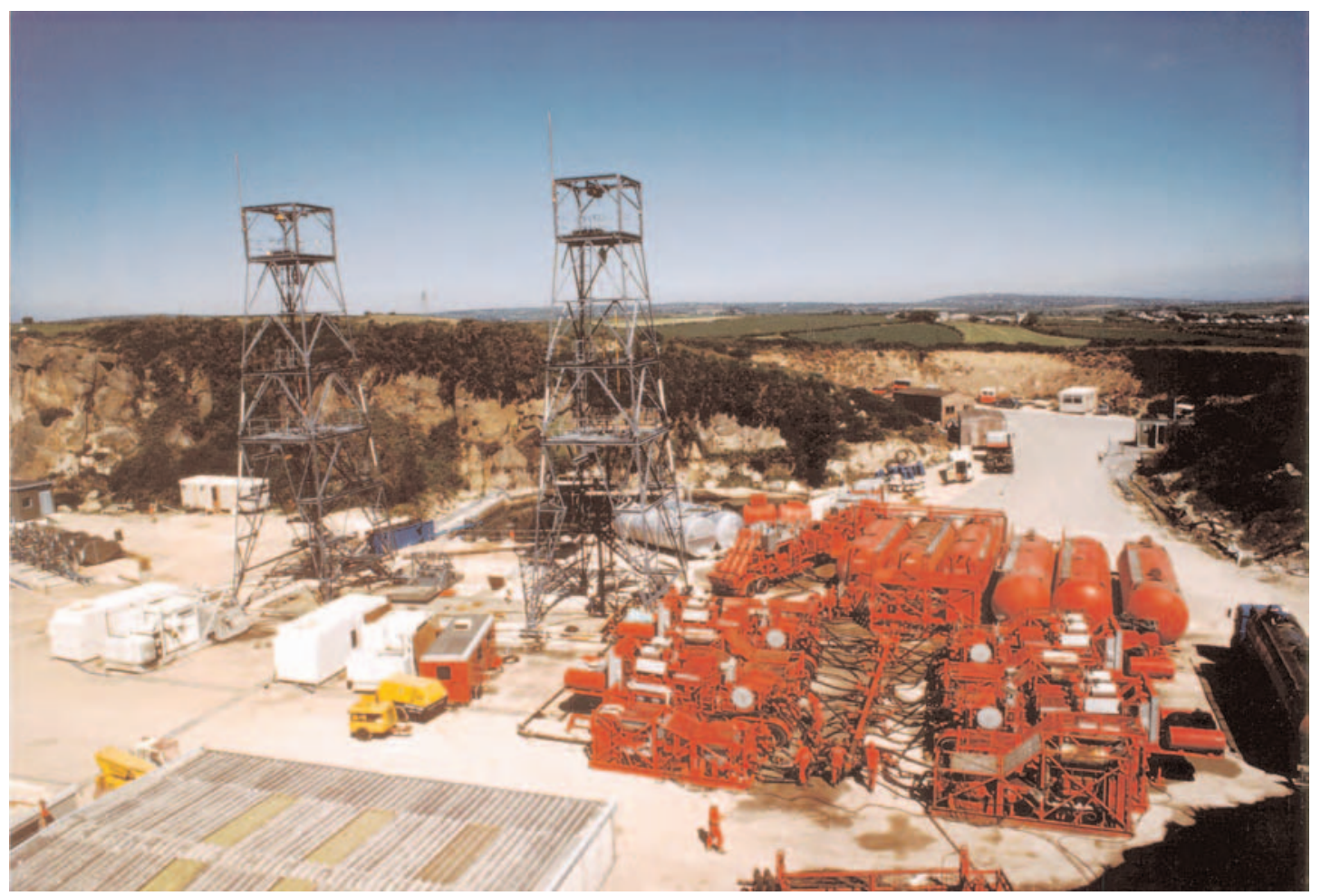

Figure 4.7 Major stimulation of Well RH15 at Rosemanowes in July $1985,5,500 \mathrm{~m}^{3}$ at up to $265 \mathrm{~L} / \mathrm{s}$ (100 $\mathrm{bbl} / \mathrm{min})$, surface pressure of $16 \mathrm{MPa}(2,320 \mathrm{psi})$.

An experiment was also carried out in Phase 3 A to shut off the section of the production borehole that had been shown to contain the outlet from the short circuit. A temporary packer assembly was installed close to the bottom of the borehole to seal off all the upper parts of the wellbore, and a production flow test was carried out to measure the flow rate from the low-flow zone at the bottom of the borehole under these conditions. The short circuit was sealed off, but a very low flow rate was obtained; and a further stimulation carried out from the bottom of the borehole gave no significant increase in flow. A subsequent interpretation of these results suggested that the most recently stimulated zone was parallel to, but largely unconnected with, the previously stimulated zone (Parker, I989). This is a key observation in that it shows individual fractures at the well can have independent connections to the far-field fracture system, i.e., the natural fracture network is not well-connected enough to form a commercial-size reservoir over short sections of a well.

\subsubsection{Lessons learned at Rosemanowes}

- The fractures created by hydraulic stimulation, which best connect across the reservoir, are not formed through tension, as in the hydraulic fracturing used in oil and gas wells. Instead, they are created by shearing on pre-existing joint sets.

- Stress fields in crystalline rock are invariably anisotropic, so the natural fractures fail in shear, long before jacking takes place. Having sheared, the natural fractures then self-prop and stay open.

- It is possible to stimulate natural fractures and improve permeability - and create a connected volume of hot rock.

- Too high an applied pressure results in runaway fracture growth, leading to water loss and/or short circuits. 
- There are always critically oriented natural fractures, so while it is easy to stimulate with lower pressures, it is also very easy to apply too high a pressure.

- The downward growth at Rosemanowes (Figure 5.I in Chapter 5), and that observed at Fenton Hill, are the result of the combination of in situ stress and stress gradient changes caused by imposed temperature and pressure changes in the rock.

- In the general case, a prediction of the direction of fracture growth is difficult in the absence of precise downhole data. Even with near-wellbore data from image logs, the fractures may not grow exactly as predicted. As a result, it is better to create the reservoir first, and then drill into it (Batchelor, I987).

- Pressure drop through the system ("impedance”) was a major problem. This was caused both by the low permeability of the reservoir and by frictional losses in the wellbores and in the near-wellbore area. Pressure drop is a critical parameter for two reasons: (i) the higher the pressure drop, the greater the pumping power required - and, hence, the greater the parasitic losses (an economic issue); and (ii), more important, a high impedance requires high downhole pressures to achieve the required flow rate, and these could easily exceed the levels at which runaway fracture growth and consequent water losses are incurred.

- One way to increase reservoir permeability is to choose areas where there are low permeability, pre-existing fractures closely spaced in the wellbore and that are oriented so that they will be likely to fail during stimulation (Batchelor, I989).

- Near-wellbore permeability reduction ("skin effect”) can increase pressure drop and decrease flow rates. Placing proppants in this near-wellbore area in the injector may require high pressures and flow rates that increase the likelihood of short circuits.

- Probably the most important single lesson from this experiment is that hydro-fracturing and artificial fractures are almost irrelevant. The natural fracture system dominates everything (Batchelor, I989).

- Natural fractures are pervasive in crystalline rocks at all depths and all locations we have investigated. Even if one does generate an artificial fracture, deliberately by hydro-fracturing - or, more often, accidentally while drilling - it will intersect the natural system within meters, and from there on the behavior is dominated by the natural system.

- Overstimulating pre-existing fractures can result in a more direct connection from injector to producer than is desired, so that cool fluid can "short-circuit" through the reservoir resulting in a lower production temperature.

- At Rosemanowes, it became clear that everything one does to pressurize a reservoir is irreversible and not necessarily useful for heat mining. For example, pumping too long at too high a pressure will cause irreversible rock movements that could drive short circuits as well as pathways for water losses to the far field. 


\subsection{Hijiori}

\subsubsection{Project history}

From I98I to I986, the New Energy and Industrial Technology Development Organization (NEDO) participated in a joint research effort into the development of geothermal energy through stimulation of low permeability rock at Fenton Hill, New Mexico. This was carried out with the United States and West Germany under an implementation agreement of the International Energy Agency (IEA). Based on this research, NEDO conducted studies in Hijiori to determine whether the technology developed at Fenton Hill could be adapted to the geological conditions found in Japan. The Hijiori site is in Yamagata Prefecture, on the Japanese island of Honshu (Figure 4.8). The project was sited on the southern edge of Hijiori caldera, a small caldera on the side of the large Pleistocene Gassan volcano, which last erupted about ı,,0०0 years ago.

The location was chosen to take advantage of the high temperature gradient in this area of recent volcanic activity. The area had been extensively mapped and some temperature gradient drilling had been carried out (Figure 4.9). Although the regional tectonics are compressional along the axis of the island of Honshu, the stress regime near the edge of the caldera is very complex. Major faults along with ring fractures associated with the caldera collapse cause stress changes both horizontally and vertically over short distances.

The shallow reservoir was drilled starting in I989. One injector (SKG-2) and three producers (HDRI, HDR-2, and HDR-3) were drilled between I989 and I99I. The depth of all but HDR-I was about I,800 $\mathrm{m}$ - HDR-I was completed at a depth of 2,I5I m. Natural fractures were intersected in all the wells at depths between I,550 and I,800 m depth; see Figure 4.I0 (Swenson et al., I999). The temperature reached more than $225^{\circ} \mathrm{C}$ at I,500 $\mathrm{m}$. The maximum temperature in the $\mathrm{I}, 800 \mathrm{~m}$ deep fractures was close to $250^{\circ} \mathrm{C}$. The spacing between the wells was kept to fairly small distances: the distance from SKG-2 to HDR-I is about $40 \mathrm{~m}$, to HDR-2 about $50 \mathrm{~m}$, and to HDR-3 about $55 \mathrm{~m}$ at the I,800 $\mathrm{m}$ depth (Tenma et al., 200I)

The deep reservoir - below 2,I50 $\mathrm{m}$ - was accessed by deepening HDR-2 (renamed HDR-2a after deepening) and HDR-3, between I99I and I995, to about 2,200 m. HDR-I was used as an injector for the deep reservoir. Natural fractures were intersected in all wells at about 2,200 $\mathrm{m}$. The distance from HDR-I to HDR-2a was about $80 \mathrm{~m}$, and to HDR-3 about $130 \mathrm{~m}$ at 2,200 $\mathrm{m}$.

Hydraulic fracturing experiments began in I988 with 2,000 $\mathrm{m}^{3}$ of water injected into SKG-2. The stimulation was carried out in four stages at rates of I, 2, 4 and $6 \mathrm{~m}^{3} / \mathrm{min}$. A 30-day circulation test was conducted in 1989 following stimulation. A combination of produced water and surface water was injected into SKG-2 at I-2 $\mathrm{m}^{3} / \mathrm{min}(\mathrm{I} 7-34 \mathrm{~kg} / \mathrm{s})$, and steam and hot water were produced from HDR-2 and HDR-3. During the test, a total of 44,500 $\mathrm{m}^{3}$ of water was injected while $13,000 \mathrm{~m}^{3}$ of water was produced. The test showed a good hydraulic connection between the injector and the two producers, but more than $70 \%$ of the injected water was lost to the reservoir. However, the test was short and the reservoir continued to grow during the entire circulation period. 


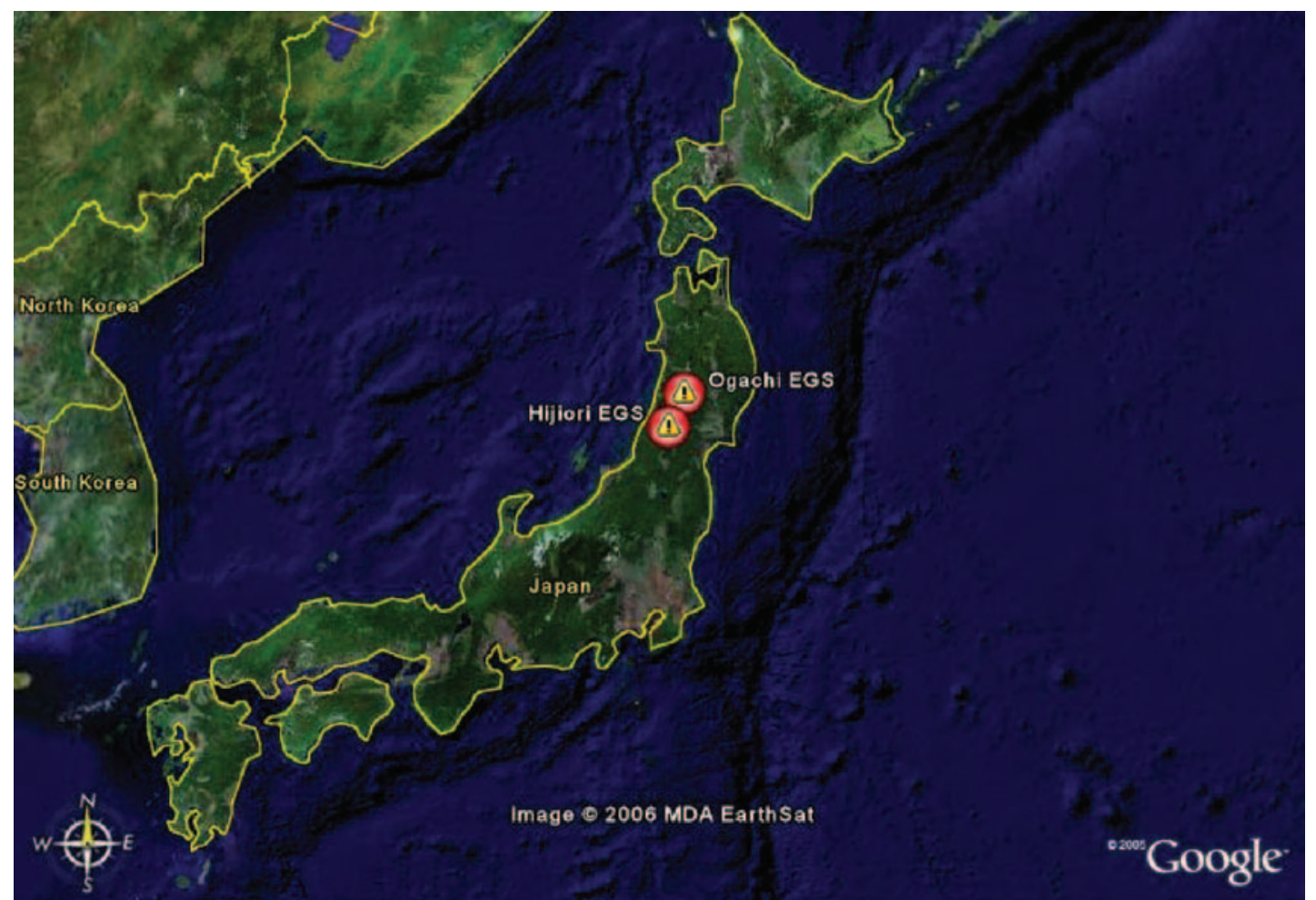

Figure 4.8 Map of EGS site locations in Japan (Google Earth).

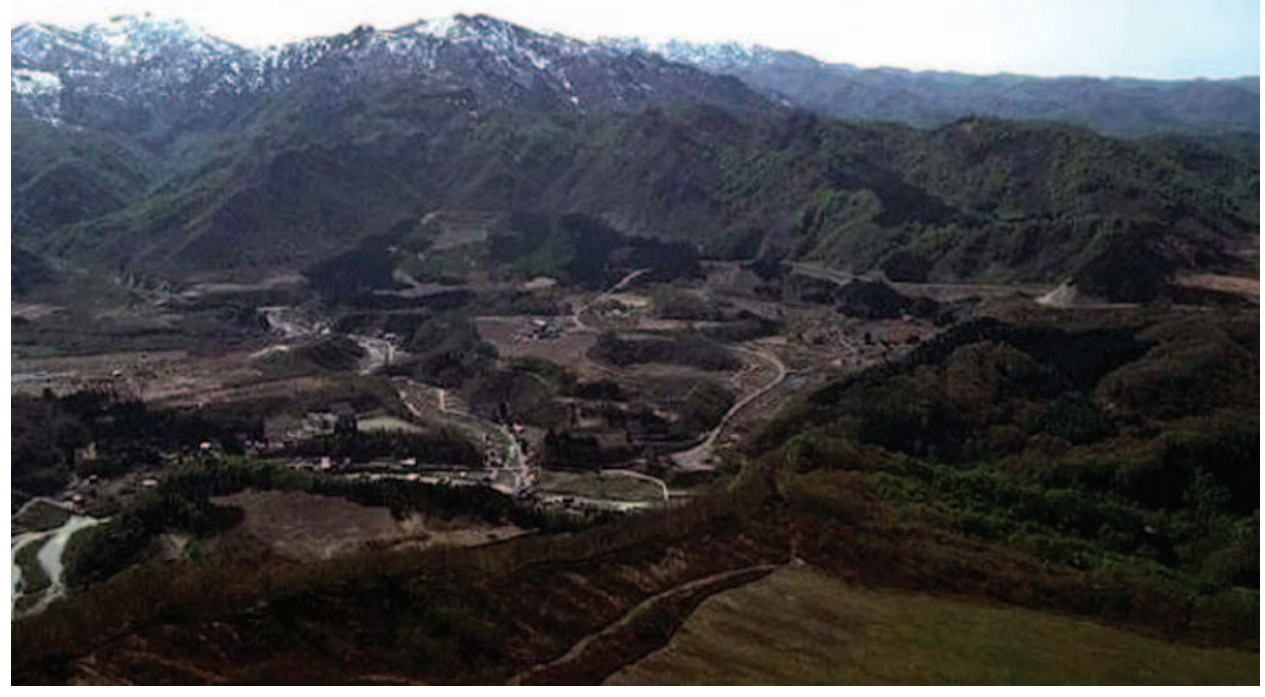

Figure 4.9 Aerial view of Hijiori caldera. 


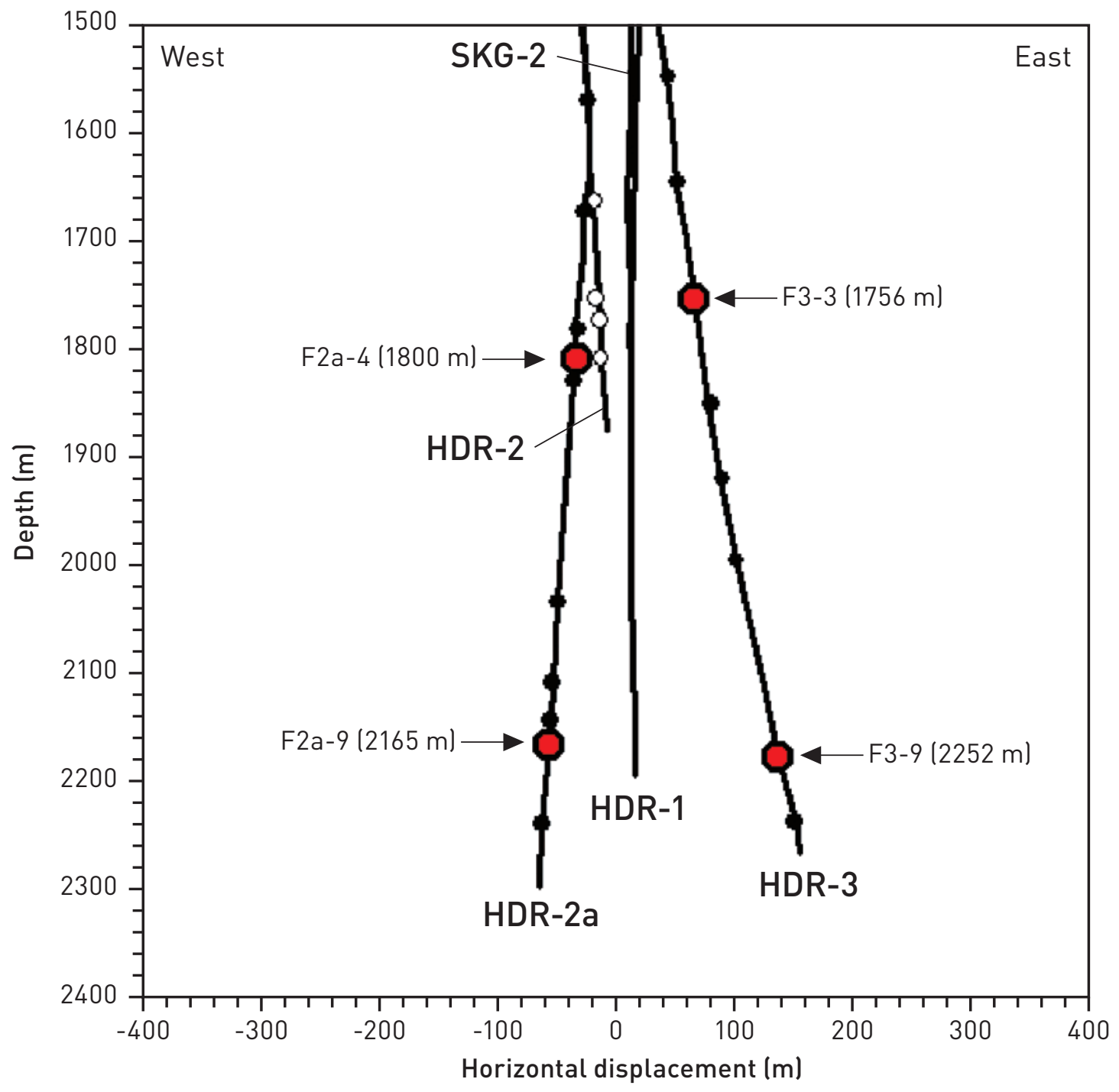

Figure 4.10 Hijiori wells. Red circles show intersections with major fractures.

After HDR-I was deepened to 2,205 $\mathrm{m}$ in I99I, the well was hydraulically fractured in I992 to stimulate the deep fractures. Then, 2,II5 $\mathrm{m}^{3}$ were injected in three stages at rates of $\mathrm{I}, 2$, and $4 \mathrm{~m}^{3} / \mathrm{min}$. Following stimulation, HDR-2a and HDR-3 were deepened to 2,302 m, and a 25-day circulation test was conducted in I995. Injection was into HDR-I at $\mathrm{I}-2 \mathrm{~m}^{3} / \mathrm{min}$, while steam and hot water were produced from HDR-2 and HDR-3. A total of $51,500 \mathrm{~m}^{3}$ of water was injected, while $26,000 \mathrm{~m}^{3}$ of water was produced, i.e., about 50\% recovery.

The stress state at Hijiori prior to stimulation was found using data from compression tests of core, differential strain curve analysis, and analysis of acoustic emissions data. The maximum and intermediate principal stresses were found at a $45^{\circ}$ angle and trending northeast/southwest, while the minimum principal stress was approximately horizontal and north-south. Fracture apertures were measured from core in HDR-3 and are shown in Table 4.I. A borehole televiewer was used to identify fracture dip and direction from HDR-2a and HDR-3. 
Table 4.1 Determination of reservoir volume at Hijiori and Ogachi using different methods (Kruger, 2000).

\begin{tabular}{|c|c|c|c|c|c|}
\hline \multirow[b]{3}{*}{ Method } & \multirow[b]{3}{*}{ Condition } & \multicolumn{4}{|c|}{ Estimated Volume, $10^{6} \mathrm{~m}^{3}$} \\
\hline & & \multicolumn{2}{|c|}{ Hijiori } & \multicolumn{2}{|c|}{ Ogachi } \\
\hline & & $\begin{array}{l}\text { Upper } \\
\text { Reservoir }\end{array}$ & $\begin{array}{l}\text { Lower } \\
\text { Reservoir }\end{array}$ & $\begin{array}{l}\text { Upper } \\
\text { Reservoir }\end{array}$ & $\begin{array}{l}\text { Lower } \\
\text { Reservoir }\end{array}$ \\
\hline \multirow{2}{*}{$\begin{array}{l}\text { Swept } \\
\text { geometric } \\
\text { flow volume }\end{array}$} & Low Est. & \multicolumn{2}{|c|}{6.3} & \multicolumn{2}{|c|}{0.75} \\
\hline & High Est. & \multicolumn{2}{|c|}{20} & \multicolumn{2}{|c|}{8} \\
\hline \multirow{2}{*}{$\begin{array}{l}\text { Microseismic } \\
\text { events } \\
\text { volume }\end{array}$} & Events $>1.5$ & & & 0.012 & $0.65-1$ \\
\hline & $1 \sigma$ envelop & & 1 & 3.7 & 10 \\
\hline $\begin{array}{l}\text { Tracer } \\
\text { testing }\end{array}$ & $\begin{array}{l}\text { Modal Vol./ } \\
\text { Porosity }\end{array}$ & & & 0.2 & $3-5$ \\
\hline $\begin{array}{l}\text { Pressure } \\
\text { testing }\end{array}$ & $\begin{array}{l}\text { Bulk } \\
\text { modulus, K }\end{array}$ & & & 0.2 & 2 \\
\hline $\begin{array}{l}\text { Prior heat- } \\
\text { extraction } \\
\text { modeling }\end{array}$ & $\begin{array}{l}\text { For whole } \\
\text { reservoir }\end{array}$ & \multicolumn{2}{|c|}{$0.7-6.3$} & \multicolumn{2}{|c|}{$0.14-1.8$} \\
\hline
\end{tabular}

During I996, further stimulation and short-term testing was conducted to prepare for a long-term test. In an attempt to better connect the HDR-3 to the injection well HDR-I in the deep reservoir and reduce the amount of fluid loss, HDR-I was used as injector while HDR-3 was produced and back pressure was held on HDR-2a. While there was no marked improvement in the connectivity, this experiment held out the hope that modifying the pressure in the reservoir could have an effect on the results of stimulation. This is an area where more work is needed (Hori et al., I999).

Following additional circulation tests in 1996, a long-term test of the deep and shallow reservoirs was initiated in 2000 with testing continuing into 2002 (Schroeder et al., I998; Tenma et al. 2000, 200I). A one-year circulation test of the deep reservoir was conducted with injection of $36^{\circ} \mathrm{C}$ water into HDRI at $15-20 \mathrm{~kg} / \mathrm{s}$. For the second phase of testing, injection into SKG-2 allowed testing of both the deep and shallow reservoir. Production of steam and water was from HDR-2a at $5 \mathrm{~kg} / \mathrm{s}$ at about $\mathrm{I} 63^{\circ} \mathrm{C}$, and from HDR-3 at $4 \mathrm{~kg} / \mathrm{sec}$ at $172^{\circ} \mathrm{C}$. Total thermal power production was about $8 \mathrm{MWt}$. At the end of the test, the flow was used to run a $130 \mathrm{~kW}$ binary power plant. Test analysis showed that production was from both the deep and shallow reservoir (Matsunaga et al., 2000). During the test, scale problems in boreholes necessitated clean-out of the production wells. One interesting result of the test is that, while the injection flow rate remained constant at about I $6 \mathrm{~kg} / \mathrm{s}$, the pressure required to inject that flow decreased during the course of the test from 84 to 70 bar. Total production from HDR-2a and HDR-3 was $8.7 \mathrm{~kg} / \mathrm{s}$ with a loss rate of $45 \%$ (Okabe et al., 2000).

Well HDR-2a cooled dramatically from an initial temperature of $163^{\circ} \mathrm{C}$ to about $100^{\circ} \mathrm{C}$ during the long-term flow test. The test was finally halted, due to the drop in temperature. The measured change in temperature was larger than that predicted from numerical modeling (Yamaguchi et al., 2000). 


\subsubsection{Lessons learned at Hifiori}

The Hijiori project provided useful data for future projects to build on. Added to the Fenton Hill and Rosemanowes experience, it became clear that it is better to drill one well, stimulate, map the acoustic emissions during stimulation, and then drill into the acoustic emissions cloud, than to try to drill two or more wells and attempt to connect them with stimulated fractures (Okabe et al., 2000).

- The reservoir continued to grow during the circulation test.

- If natural fractures already connect the wellbores, stimulation may result in an improved connection that causes short circuiting, particularly if the wellbore separation distances are small.

- The acoustic emissions (AE) locations from the deep circulation test suggest that the stimulated fractures or the stress field change direction away from the well.

- The lineation found from the AE locations in the shallow reservoir parallel the direction of the lineation found during the stimulation, but the acoustic emissions farther from the well during the circulation test trend in a new direction.

- If the stress direction changes from one part of the reservoir to another, it may be almost impossible to predict how the stimulated fractures will be oriented and where they will grow and be most permeable.

- With current technology, it is difficult - if not impossible - to predict what the stress field will be in the wellbore prior to drilling; and it is even more difficult to know the stress field away from the borehole.

- It is much easier to drill into the zone that is mapped as the fracture zone from AE locations and establish a connection than to attempt to connect two existing wells.

- While attempts to control the stress field by modifying pressure in wells not being directly stimulated did not accomplish what was hoped for at Hijiori, this concept still holds promise. Further work is needed.

- At Hijiori, it was clear that while stimulation by injecting at high pressures for short periods had some effect on the permeability of the naturally fractured reservoir, injecting at low pressures for long time periods had an even more beneficial effect.

- The reservoir grew and connectivity improved more during circulation tests than during efforts to stimulate at high pressures.

- The data suggest that cool water short-circuited the modeled path length, either because fracture growth during injection testing connected the deep reservoir with the shallow one, or because the deep and shallow reservoirs were connected through one of the wellbores penetrating both zones.

- Well spacing needs to be as large as possible while still making a connection.

The Hijiori project also showed the value of understanding not only the stress field but also the natural fracture system. Both the Fenton Hill project and the Hijiori project were on the edges of a volcanic caldera. While very high temperature gradients can provide access to a large reservoir of thermal energy and can make the project economics better since one only needs to drill relatively shallow wells to reach very high temperatures, the geology, stress conditions, and fracture history of rocks in such areas can be extremely complex. This can make project design, construction, and management very challenging. 


\subsection{Ogachi}

\subsubsection{Project history}

The Ogachi project is in Akita Prefecture, near Kurikoma National Park on Honshu Island, Japan (see Figures 4.8 and 4.II). The first exploration wells were drilled between I982 and I984 on the edge of the Akinomiya geothermal area, using the Mt. Yamabushi volcano as the heat source. The site was considered as an EGS project because, while temperatures were high - more than $230^{\circ} \mathrm{C}$ at $\mathrm{I}, 000 \mathrm{~m}$ (see Figure 4.II) - the productivity of the wells was low (Hori, I999).

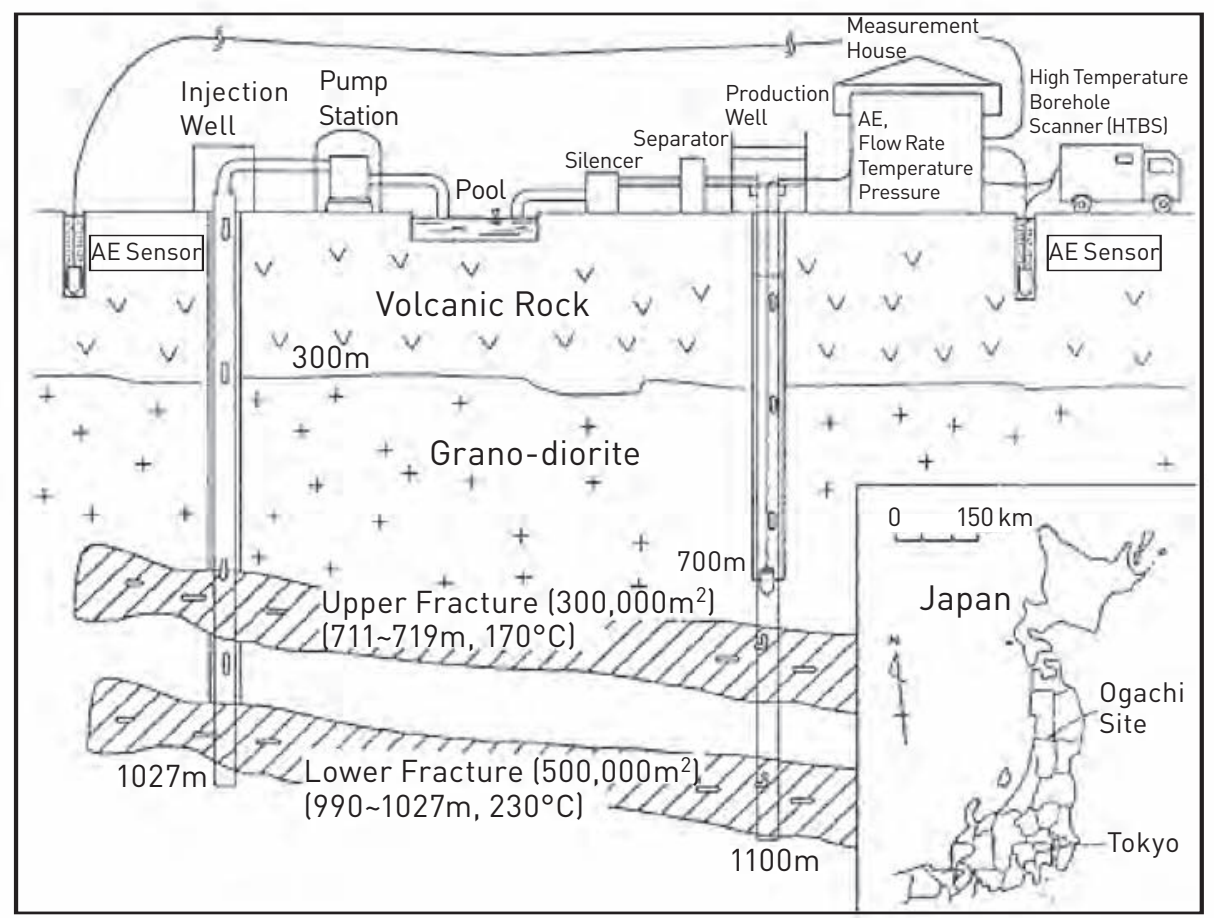

Figure 4.11 Illustration of the Ogachi HDR experiment (Kitano et al., 2000).

The well later used as an injection well, OGC-I, was drilled in I990 to a depth of about I,०00 $\mathrm{m}$ and a temperature of $230^{\circ} \mathrm{C}$. Two fracture stimulations were done in the io meters of open hole in the bottom of the well. Then a window was milled in the casing at a depth of $710 \mathrm{~m}$, and a second fracture (termed the upper reservoir) was created from approximately 710-719 $\mathrm{m}$.

Production well OGC-2 was drilled in 1992 to a depth of I,IOO $\mathrm{m}$, where a temperature of $240^{\circ} \mathrm{C}$ was reached. The well is less than Ioo $\mathrm{m}$ from OGC-I. A circulation test in I993 with injection into OGC-I and production from OGC-2 showed only $3 \%$ of injected water was produced. To improve the connection between the wells, OGC-2 was stimulated in I994. A five-month circulation test following this stimulation showed that only I0\% of the injected water was produced back (Kiho, 2000). The production and injection wells were again stimulated in I995. A one-month circulation test showed an improved recovery of more than $25 \%$ of the total injection. 
The permeability found ranged from $\mathrm{IO}^{-6}-\mathrm{IO}^{-7} \mathrm{~cm} / \mathrm{s}$ (approximately $10^{-3}-\mathrm{IO}^{-4}$ Darcys) before fracturing. Permeability after fracturing improved by at least an order of magnitude to $10^{-4}-10^{-5} \mathrm{~cm} / \mathrm{s}$. It was found that $5 \%$ of the total produced fluid could be attributed to the upper reservoir, while $85 \%$ came from the lower reservoir. The stimulated reservoir volume was about $\mathrm{io} \mathrm{m}^{3}$ in the upper reservoir and $250 \mathrm{~m}^{3}$ in the lower reservoir.

Because the first two wells at Ogachi did not appear to be well-connected, and significant injected water was lost to the reservoir, OGC-3 was drilled in I999 into fractures indicated from acoustic emissions mapping (Figure 4.I2). Borehole televiewer imaging was used to observe fractures in the wellbore, from which better fracture orientations were obtained. Testing also showed an improved response to injection into OGC-I at OGC-3. One important result of the borehole televiewer imaging, which coincided with the results of enhanced analysis of the acoustic emissions data, was that the upper fractures had a NE fracture orientation while the deeper fractures were oriented NNE (Shin et al., 2000).
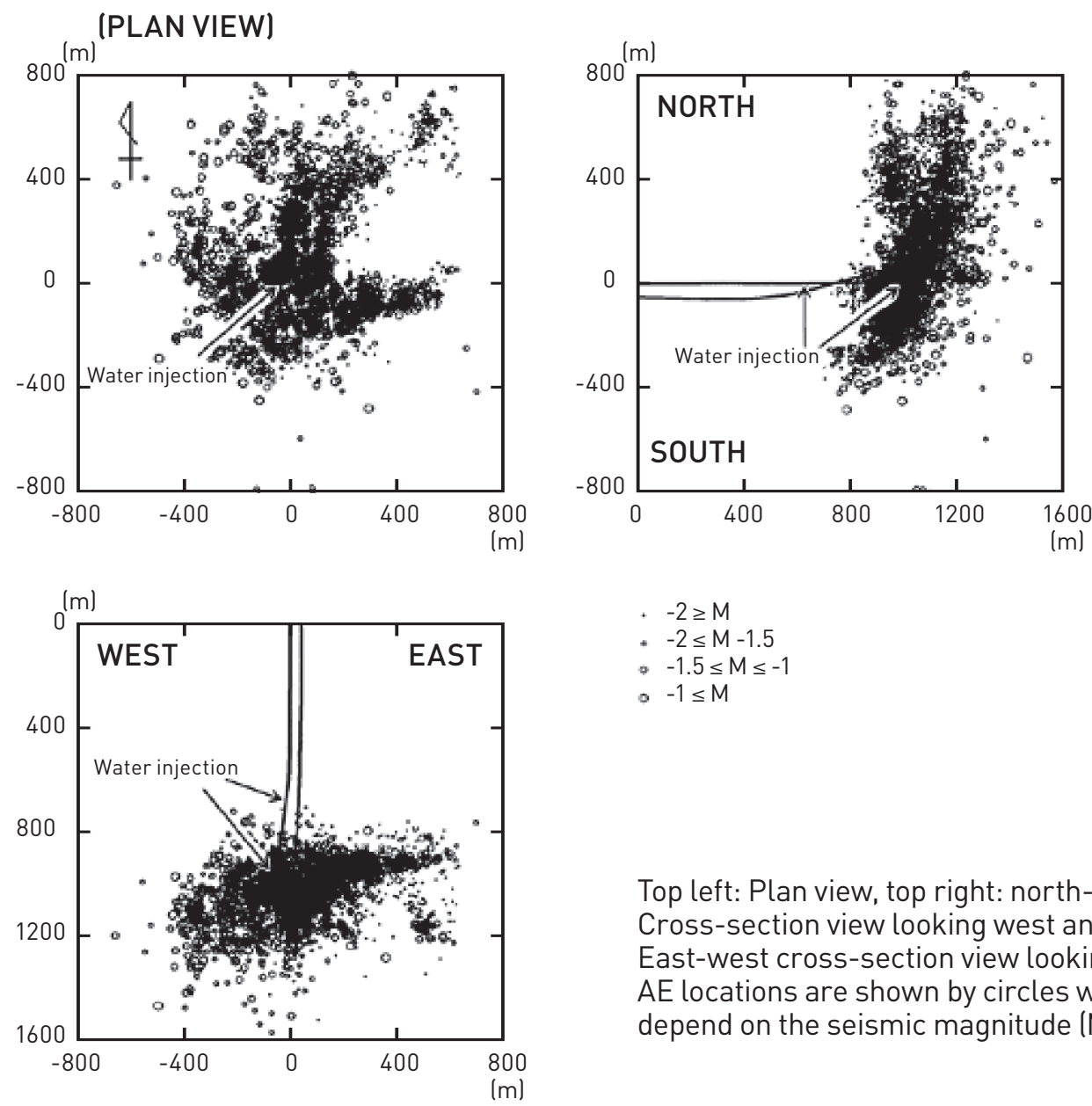

. $-2 \geq M$

$-2 \leq \mathrm{M}-1.5$

. $-1.5 \leq M \leq-1$

o $-1 \leq M$

Top left: Plan view, top right: north-south vertical Cross-section view looking west and bottom left: East-west cross-section view looking north. AE locations are shown by circles which diameter depend on the seismic magnitude (M) shown above.

Figure 4.12 Three-dimensional view of the Ogachi reservoir (Kaieda et al., 2000). 


\subsubsection{Lessons learned at Ogachi}

The experience gained at Ogachi - in attempts to fracture between two wells - reinforced observations at Fenton Hill, Rosemanowes, and Hijiori. These projects showed that drilling, stimulating with acoustic emissions, mapping, and then drilling into the fracture cloud yielded the best connection between injector and producers.

- The complex geologic history at Ogachi made it difficult to predict the direction of fracture growth.

- The stress state in the original boreholes was not well understood until borehole televiewer data was collected and analyzed after the wells had been stimulated.

- Drilling OGC-3 into the mapped fractures from acoustic emissions analysis resulted in a significant improvement in connectivity between the wells.

- Efforts to connect the original two wells at Ogachi by stimulating the production well were unsuccessful, after the initial attempts to connect by stimulating the injection well failed.

- While efforts to stimulate the two wells resulted in reservoir growth, they did not result in better connectivity between the wellbores.

- Fluid losses to the reservoir were high during injection testing, because the wells were not wellconnected. Once OGC-3 was drilled into the stimulated area, connection was improved and fluid loss was reduced.

- Stress changes with depth in the boreholes (found with borehole televiewers and from improved analysis of the acoustic emissions data) allowed the change in stress direction with depth in the reservoir to be determined.

\subsection{Soultz}

\subsubsection{Project history}

As a result of the interest generated by the Fenton Hill project, several European countries began experiments along similar lines. Besides the U.K. project at Rosemanowes, Germany supported two projects - a shallow experiment at Falkenberg, and a deep $(4,500 \mathrm{~m})$ single borehole project at Bad Urach. France ran an experiment in $800 \mathrm{~m}$ boreholes at Le Mayet in the Massif Central and, together with Germany, began a paper study in the mid-I980 of the potential of a site at Soultz-sous-Forêts in the Upper Rhine Valley (Figure 4.5). As the latter is the site of the former Pechelbron oilfield, the geology was very well characterized, down to about I,500 $\mathrm{m}$ (the top of the granitic basement), and temperature gradients in the upper $\mathrm{I}, 000 \mathrm{~m}$ were known to exceed $110^{\circ} \mathrm{C} / \mathrm{km}$.

Because HDR technology (as it was then known) was expected to be fairly generic - and the cost of such large-scale experiments is generally quite high - there was general agreement that it would make more sense to pool both financial and manpower resources on a single site. The goal was to develop a European project that eventually would lead to a commercial demonstration.

Under the coordination of the European Commission, a detailed comparison was made of the suitability of the three major European sites (Rosemanowes, Bad Urach, and Soultz); and, in I987, the decision was made to locate the project at Soultz. Funded initially by the European Commission and relevant energy ministries of France, Germany, and the United Kingdom, a permanent base was 
established on site with a core team (French, German, and British) to plan the work and coordinate the activities of various research teams from the participating countries. Teams from Italy, Switzerland, and, most recently, Norway, later joined the project; several researchers from the United States and Japan have also contributed.

In I987, the first well GPK1 was drilled to 2,002 m depth (see Figure 4.I3) (after Baria et al., 2005). The drilling performance and experience achieved at Rosemanowes was not applied initially at Soultz. The drilling was difficult (directional control, lost circulation, and stuck pipe were the primary problems), and the budget was overrun. The depth was selected from the extrapolation of the available temperature in the first $\mathrm{I}, 000 \mathrm{~m}$, leading to an expectation of about $200^{\circ} \mathrm{C}$ at $2,000 \mathrm{~m}$. The temperature at $2,000 \mathrm{~m}$ was actually found to be $140^{\circ} \mathrm{C}$, which was caused by convective loops within the granite basement (Baria et al., 2006). The sediment is about I,400 $\mathrm{m}$ thick and it overlays a granitic basement. The majority of the old oil wells were drilled only to about 800-I,000 m depth. The depth to the granite was derived from the interpretation of seismic reflection surveys carried out by oil companies.

In I988, three existing former oil wells were deepened, so that they penetrated the granite to provide good coupling for seismic sondes - as experience at Rosemanowes had shown to be necessary. A seismic network, based on those used at Rosemanowes and Fenton Hill, was designed and installed.

In I990, an existing oil well, designated EPSI, was deepened from a depth of $930 \mathrm{~m}$ by continuous coring to $2,227 \mathrm{~m}$, where a temperature of $150^{\circ} \mathrm{C}$ was encountered. Despite drilling problems (largely related to directional control difficulties with coring), which stopped the project from reaching the planned depth of 3,200 $\mathrm{m}$, this gave a very sound characterization of the natural fracture network.

In I99I, GPK1 was stimulated with high flow rates targeting the open-hole section from I,420-2,002 $\mathrm{m}$. A fractured volume of $10,000 \mathrm{~m}^{3}$ was created based on microseismic mapping. It is possible that a natural fracture was intersected that stopped fracture growth and allowed for loss of injected fluid. In I992, GPK1 was deepened from 2,002-3,590 m, reaching a temperature of $168^{\circ} \mathrm{C}$. The deepening of GPK1 was successful, and although the contact depth for deepening was 3,200 $\mathrm{m}$ depth (anticipated $\mathrm{I} 80^{\circ} \mathrm{C}$ ), the actual depth drilled was 3,590 $\mathrm{m}$ because of the use of experienced drilling personnel who had worked in Los Alamos and Rosemanowes. The following year, GPK1 was again stimulated, using large flow rates as used at Los Alamos and Rosemaowes, this time targeting the newly drilled segment from 2,850 to $3,590 \mathrm{~m}$. There was a belief that in a slightly tensional regime like that of Soultz, largescale injection was not necessary and one could access the flowing network just by improving the connection from the well to the network. This was found not to be true, and large-scale injections were necessary to create the connectivity needed (Baria et al., I998). GPK1 was then flow-tested in I994 by producing back the injected fluid. 


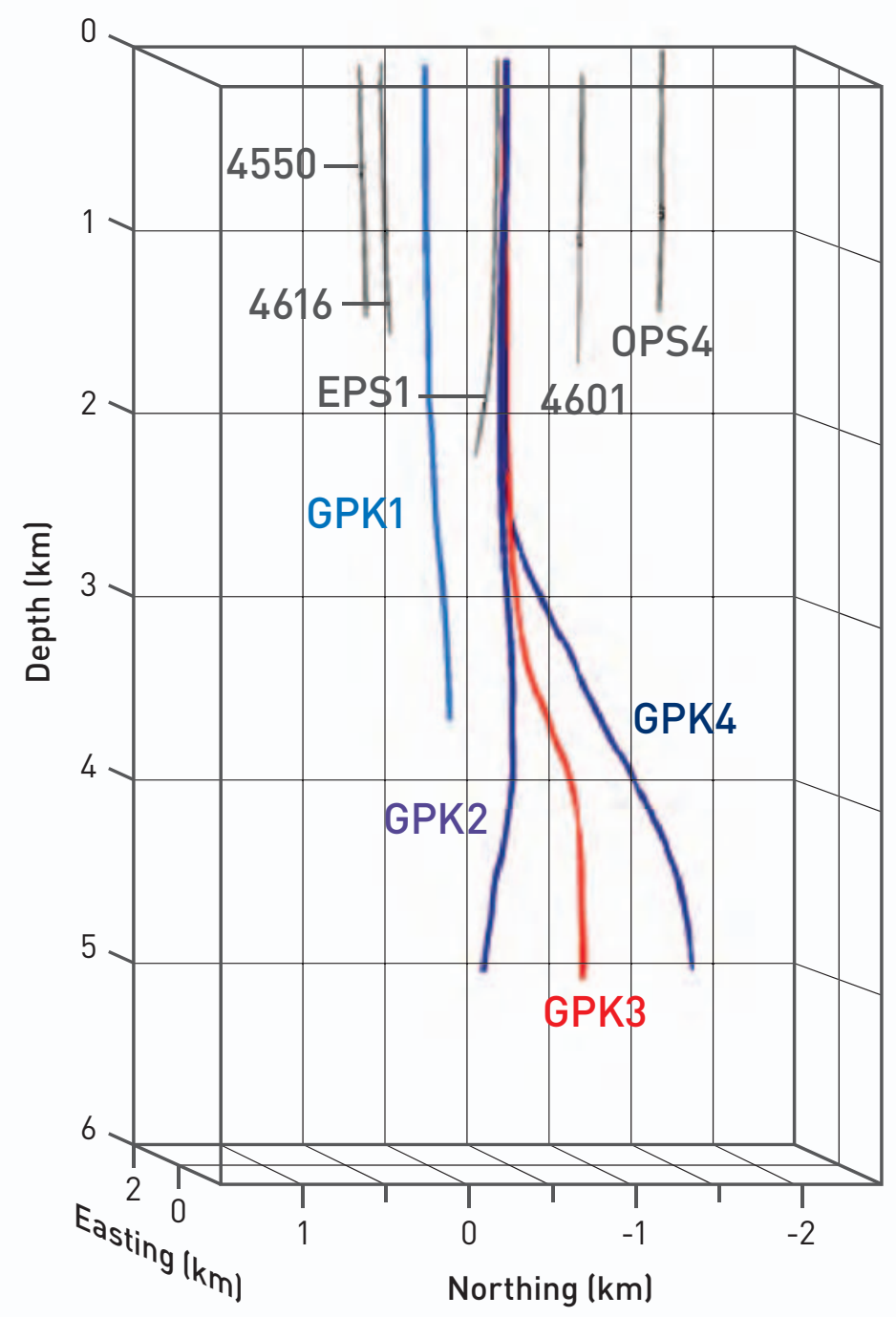

Figure 4.13 Wells drilled at Soultz, France.

Targeting and drilling of GPK2 to 3,876 $\mathrm{m}$ at a temperature of $168^{\circ} \mathrm{C}$ was done in $\mathrm{I} 995$. The bottomhole location was $450 \mathrm{~m}$ from GPK1. During stimulation, analysis of the core and geophysical logs and fault plane solutions from microseismic events - showed that the rock at 2,000-3,000 $\mathrm{m}$ depth contained large numbers of joints and natural fractures. Two joint sets, striking NioE and Ni7oE and dipping $65 \mathrm{~W}$ and $70 \mathrm{E}$, respectively, dominated the natural fractures observed. Hydro-fracture stress measurements suggested that maximum principal horizontal stress $\mathrm{S}_{\mathrm{H}}$ is very close to the principal vertical stress $S_{V}$ at this depth. The minimum principal horizontal stress $S_{h}$ is very low and close to the hydrostatic pressure, suggesting that small pressure increases should result in fractures failing in shear. In fact, there are open natural fractures in the wells at 2,210 $\mathrm{m}$ and 3,500 $\mathrm{m}$ that took fluid before stimulation. The in situ reservoir fluid is saline with total dissolved solids (TDS) of about I0०,००० mg/l (I0\% by weight) (Genter et al., I995).

During 1995, GPK2 was stimulated in the open-hole section from 3,21I-3,876 m, with a maximum pressure of about Io $\mathrm{MPa}$ and a flow of $50 \mathrm{~kg} / \mathrm{s}$. Acoustic monitoring showed the reservoir growing in a NNW-SSE direction, with a tendency for the fracture cloud to grow upward, forming a stimulated volume of about $0.24 \mathrm{~km}^{3}$. GPK1 showed a significant pressure response to the stimulation, which 
showed a connection between the two wells. A two-week circulation test was then performed by injecting into GPK2 and producing from GPK1. The rate was stepped up from an initial rate of I2 $\mathrm{kg} / \mathrm{s}$ to $56 \mathrm{~kg} / \mathrm{s}$ (Jung et al., I996).

During I995-1996, some circulation tests included the use of an electric submersible pump. With the production well pumped, a circulation rate of more than $2 \mathrm{I} \mathrm{kg} / \mathrm{s}$ was achieved. The surface temperature of the produced water approached $136^{\circ} \mathrm{C}$ (injection was at $40^{\circ} \mathrm{C}$ ), with a thermal power output of about $9 \mathrm{MWt}$. The use of a production pump helped maximize power output in this situation, with large open fractures.

In I996, GPK2 was restimulated, using a maximum rate of $78 \mathrm{~kg} / \mathrm{s}$ with a total volume of $58,000 \mathrm{~m}^{3}$ injected. Following this stimulation, in I997, a four-month, closed-loop flow test was conducted injecting into GPK2 and producing from GPK1. Injection and production stabilized at $25 \mathrm{~kg} / \mathrm{s}$, with no net fluid losses. Only $250 \mathrm{kWe}$ pumping power was required to produce the thermal output of Io MWt.

In I997-I998, with the aim of gradually transferring the project to industrial management, several new participants were added to the Soultz project, including Shell and several French and German utility companies. With new funding, the decision was made to deepen GPK2 to a TVD of 5,000 $\mathrm{m}$ to reach at least $200^{\circ} \mathrm{C}$. This required removal of the existing casing, cementing, and reaming out from 6.25 inches to 8.5 inches, and installing new casing to 4,200 m. New high-temperature cement and new metal packers allowed a successful completion of the deepened new GPK2. The predicted temperature of $200^{\circ} \mathrm{C}$ was measured at a depth of 4,950 $\mathrm{m}$ (TVD). An additional acoustic monitoring well, OPS 4 , was drilled to a depth of I,500 $\mathrm{m}$ and instrumented to improve the accuracy of acoustic event locations. The measurement of the initial, natural prestimulation injectivity of about 0.2 $\mathrm{kg} / \mathrm{s} / \mathrm{MPa}$ in the new deep part of GPK2 was consistent with those seen in the depth range of 3,200-3,800 $\mathrm{m}$.

During the summer of 2000, GPK2 was stimulated using heavy brines to attempt to stimulate the deeper zones preferentially. The overpressure needed to create the large reservoir was lower than anticipated. Nearly $23,400 \mathrm{~m}^{3}$ water was injected at flow rates from $30 \mathrm{~kg} / \mathrm{s}$ to $50 \mathrm{~kg} / \mathrm{s}$, with a maximum wellhead pressure of I4.5 MPa. The acoustic emissions mapping shows the stimulated reservoir extending NNW/SSE, about $500 \mathrm{~m}$ wide, I,500 $\mathrm{m}$ long, and I,500 $\mathrm{m}$ tall. No leak-off to the upper reservoir was detected, and the fact that the majority of the fluid exited the open hole at the bottom during stimulation is very encouraging, because most of the injected fluid enters the well where initial rock temperatures are about $195-200^{\circ} \mathrm{C}$.

A number of geophysical logging runs were made to assess the natural and stimulated state of the well. A major conductive fracture set, oriented $\mathrm{Ni} 60 \mathrm{E}$, was observed from this imagery along with two secondary fracture sets oriented Nı4OE and N20E. All fracture sets dip steeply to the west or east (Moriya et al., 2003).

Starting in 200I, the deep production wells for the high-temperature reservoir were drilled. All of the wells were started from the same pad. GPK3 (see Figure 4.I3) was drilled to 5,093 $\mathrm{m}$ to target a zone in the stimulated area created from GPK2 in 2000. The bottom-hole separation between GPK2 and GPK3 was $600 \mathrm{~m}$. The bottom zone of GPK3 was stimulated to extend the existing reservoir of GPK2 by an overlapping volume of enhanced permeability. 
The deviated well GPK4 (see Figure 4.I3) was drilled, starting in August 2003, to a TVD of 5,I05 m from the same platform as GPK2 and GPK3 into a target zone selected from the stimulation of GPK3. The bottom of GPK4 was separated from the bottom of GPK3 by about $650 \mathrm{~m}$ (a total deviation of some I,250 m). The well was not completed until early 2004, because of problems with the mud motor, directional control, low rates of penetration, and an accident while running a casing string. During drilling of GPK4, the reservoir was tested by injecting into GPK3 and producing from GPK2. The tests established there was an excellent connection between the two wells with productivity index of $3.5 \mathrm{~kg} / \mathrm{s} / \mathrm{MPa}$. Pressure response was observed in GPK4 during injection into GPK3.

During testing and stimulation of GPK2 and GPK3, it became more apparent that a small number of induced seismic events were being felt by the local population. No damage was done, but the potential for larger events was unknown, and experiments were conducted to determine what conditions generated the larger events and whether they could be controlled. It was found that by using "soft" shut-ins after injection or production, the number of large events was reduced.

Following completion, GPK4 was stimulated by injecting heavy brine to encourage development of deep fractures. While an area of enhanced reservoir developed, a linear aseismic zone was apparent, separating GPK4 from the other two deep wells. Despite a second stimulation and acidizing, no good connection yet exists between GPK4 and the rest of the reservoir. The injectivity index for this well is good, but the well is not well-connected to the other two.

The aseismic area might be a conductive fracture that prevents pressure buildup, or a barrier to fluid flow of some kind. It appears to limit the connection between GPK4 and the rest of the created reservoir, although the connection has not been thoroughly tested. Other experimental data suggest that it may be possible to inject into more than one well simultaneously to build up pressure in the EGS reservoir far from the wellbores (Baria, 2006). This and other measurements and testing of the connectivity between the wells is planned for the future.

\subsubsection{Lessons learned at Soultz}

The Soultz project clearly benefited from the experience gained in other HDR/EGS projects, because it successfully created an artificially stimulated reservoir of commercial size, but with production rates still about a factor of 2 or so below required levels for a first-generation economical power plant operation. The Soultz project demonstrated that large fractured volumes could be created repeatedly in rock containing pre-existing natural fractures that are ready to fail in shear.

- Large overpressures are not needed to extend the reservoir, and fairly high productivity and injectivity can be created.

- Natural fractures and the natural connectivity of these fractures seem to dominate the enhanced reservoir system.

- Natural fractures can be stimulated, but there seems to be little data to support the creation of a totally artificial reservoir when no natural fractures are present.

- The point at which stimulation commences in an open wellbore - and then becomes focused depends on existing conductive fractures, the stress gradient, and fluid density. 
- In contrast to what happened at Rosemanowes - where stimulation almost always focused on the bottom of the wells - the upper zones at the Soultz project would stimulate readily when fresh water was used; while, with heavier brines, the lower zones would be stimulated.

- While microseismic monitoring works well overall to map fractures, we still do not completely understand the relationship between mapped acoustic emissions events and fluid flow.

- We can drill deep wells into hard crystalline rock, control their direction, and log them.

- There are aspects of drilling these wells that still need work. Problems with high-temperature mud motors make directional control of deep, high-temperature wells difficult.

- Near-wellbore pressure drop can have a significant impact on the overall pressure drop throughout the system.

- There are several methods for reducing near-wellbore pressure drops such as acidizing, emplacing proppants, and stimulating with fracturing fluids. Further testing is needed to determine which of these is most beneficial.

- Acidizing reduced the injection pressure for a given flow rate but the reason for this is not clear.

- Injection testing shows a nearly linear correlation between wellhead pressure and injection rate. This is typical of flow in porous media in general, suggesting that there was an overall fracturing pattern, not separate discrete fractures. It also reinforces the suspicion that the permeability is not dependent on pressure.

- While injecting at high pressures can increase flow rates during operation of the reservoir, it can also stimulate fracture growth. Another alternative to high-pressure injection is pumping the production well.

- Logging tools have temperature limits, and there is little incentive for oil and gas to raise these limits to very high temperatures. 


\subsection{Cooper Basin}

\subsubsection{Project history}

Because the entire Australian continent is under large regional overthrust tectonic stress, it was felt that creating a geothermal reservoir by hydraulic stimulation would require high pressures, and attendant high water losses might be a serious issue. However, the large extent of granitic basement (with high heat flow due to radioactive decay) and the large amount of data available to characterize the resource, in some areas, offset such potential difficulties. Initially, the focus on an EGS project was in the Hunter Valley, where energy markets were close. But, in 2002, this focus turned to granitic basement in the Cooper Basin where oil and gas drilling indicated temperatures approaching $250^{\circ} \mathrm{C}$ at a depth of $4 \mathrm{~km}$ (see Figure 4.I4).

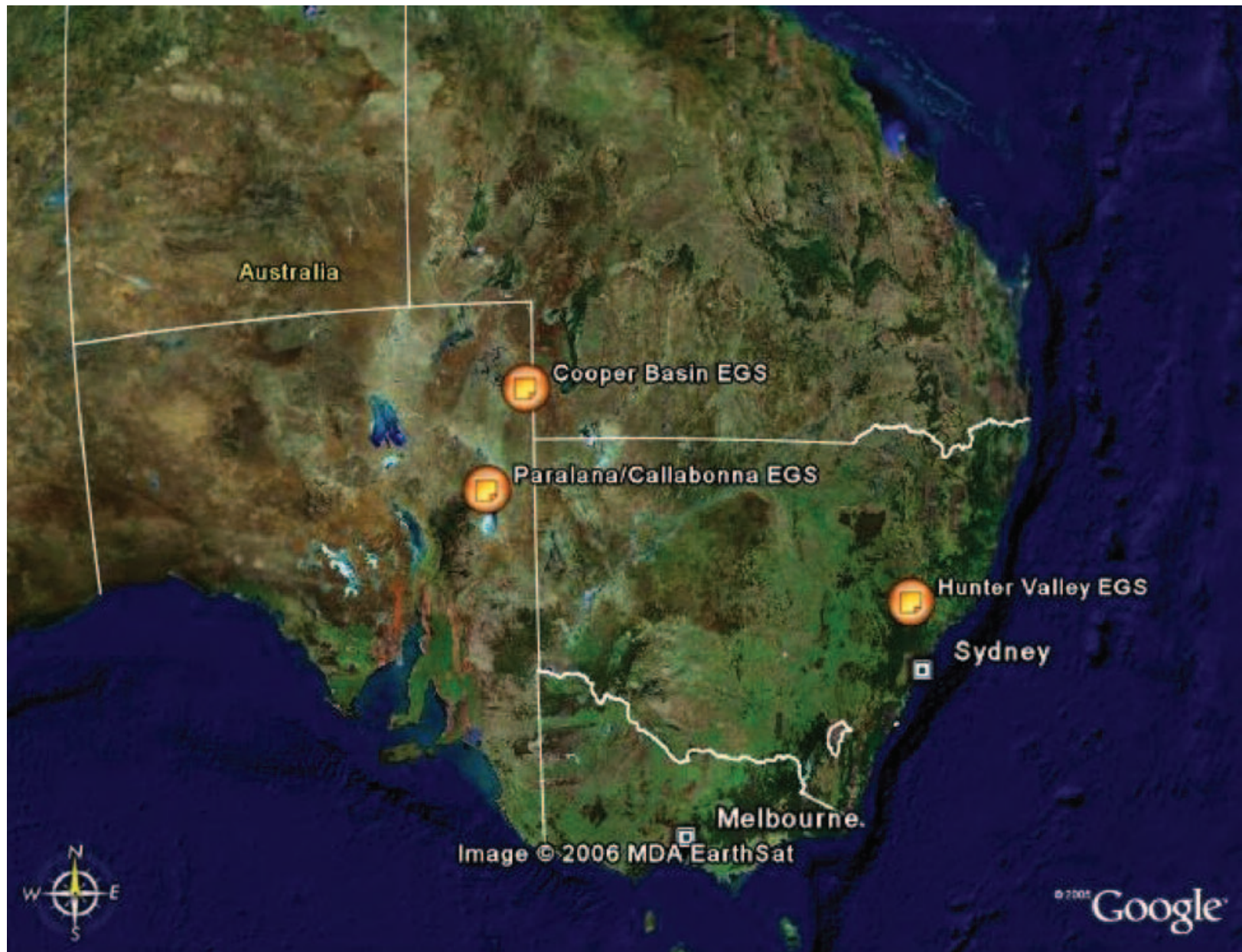

Figure 4.14 EGS sites in Australia (Google Earth).

The Hunter Valley project was started in I999, under the auspices of Pacific Power (the local electricity utility) and Australian National University. A series of shallow (300 $\mathrm{m}$ to $920 \mathrm{~m} \mathrm{deep}$ ) boreholes were drilled over a gravity anomaly, and temperature measurements were made in each borehole. The results of the temperature logging confirmed the existence of the geothermal anomaly and allowed a site to be selected for the drilling of a deeper borehole. This borehole, PPHRI, was 
drilled to a depth of I,946 m near the central region of the anomaly, and more than I $\mathrm{km}$ of continuous core samples were taken to identify the rocks present and their physical properties. The results of the project stimulated commercial interest in Australia's hot dry rock resources to such an extent that a new company, Geodynamics Limited, was successfully floated on the Australian Stock Exchange in 2002. This company has now acquired the Hunter Valley geothermal tenement from Pacific Power. However, Geodynamics' main focus has been the Cooper Basin site.

The Cooper Basin project is in South Australia, due north of Adelaide near the Queensland border (Figure 4.I4). The plan for the project is to demonstrate feasibility of an EGS system in an area with large volumes of high-temperature, fairly uniform granitic basement; and to extend the demonstration site to produce hundreds, if not thousands, of megawatts using advanced binary technology.

Cooper Basin contains substantial oil and gas reserves. The regional stress is overthrust, as is much of Australia. A large-scale gravity low in the deepest part of the basin cannot be explained entirely by the basin itself and indicates the presence of granitic basement over an area of at least I,, $00 \mathrm{~km}^{2}$. Oil exploration encountered high-temperature gradients in this area, and several wells intersected granitic basement containing high abundances of radiogenic elements. Three large leased areas known as Geothermal Exploration Licenses (GELs) lie over almost the entire interpreted granitic basement.

Other companies have followed Geodynamics and started exploration for sites to carry out EGS programs, mostly in South Australia. This area is perceived to have many radiogenic granites and other uranium-rich rocks that could lead to high temperatures at relatively shallow depths in the crust. One such location, being developed by Petratherm, is at the Paralana/Callabonna site shown in Figure 4.I4; and another is at Olympic Dam in South Australia, being developed by Green Rock Energy.

The first Geodynamics well in the Cooper Basin (injection well Habanero-I) was completed in October 2003 to a depth of 4,42I $\mathrm{m}$ near the McLeod-I well, an oil-exploration well that penetrated granitic basement. Habanero-I, which intersected granite at 3,668 m, is completed with a 6-inch open hole. Data collected from oil and gas wells and from Habanero-I suggest that the granite is critically stressed for shear failure in a subhorizontal orientation. Some fractures (Figure 4.I5) intersected in Habanero-I were discovered to be overpressured with water at $35 \mathrm{MPa}$ (5000 psi) above hydrostatic pressure. To control the overpressure, the drilling fluids had to be heavily weighted. However, the fractures encountered were more permeable than expected; they also may have failed and slipped, improving their permeability and resulting in drilling fluids being lost into them. The bottom-hole temperature was $250^{\circ} \mathrm{C}$.

Following completion of Habanero-I, the well was stimulated in November and December 2003. Pressures up to about $70 \mathrm{MPa}$ were used to pump 20,000 cubic meters of water into the fractures at flow rates stepped from $\mathrm{I} 3.5 \mathrm{~kg} / \mathrm{s}$ to a maximum of $26 \mathrm{~kg} / \mathrm{s}$. This first stimulation created a fractured volume estimated from acoustic emissions data estimated at $0.7 \mathrm{~km}^{3}$. The stimulation also involved attempts at injecting through perforated 7-inch casing, at depths between 4,136 m and 3,994 m; but only the zone at 4,I36 m took substantial fluid and generated microseismic events in new areas. Following the series of stimulations, the fractured volume had expanded to cover a horizontal pancake-shaped area of approximately $3 \mathrm{~km}^{2}$. The fractured volume forms a rough ellipsoid with the 
long axis extending in the northeast direction. Habenero-2 was targeted to intersect the fractured reservoir at a depth of 4,310 $\mathrm{m}$, and it did hit the fractures at 4,325 m. During drilling, pressure changes corresponding to wellhead pressure changes in Habanero-2 were observed in Habanero-I.

Some problems encountered during drilling made sidetracking necessary, and a sidetrack to 4,358 m was completed in December 2004. In mid-2005, flow from Habanero-2 was tested, based on the 5,000 psi artesian pressure. Flows of up to $25 \mathrm{~kg} / \mathrm{sec}$ were measured, and a surface temperature of $210^{\circ} \mathrm{C}$ achieved. However, testing of the circulation system between the two wells has been delayed, due to lost equipment downhole progressively blocking the flow in Habanero-2.

During September 2005, Habanero-I again was stimulated with 20,000 cubic meters of water injected and, based on acoustic emissions data, the old reservoir was extended by another $50 \%$ to cover an area of $4 \mathrm{~km}^{2}$.

From April to June 2006 , a second sidetrack was attempted using a snubbing unit rather than a drilling rig. The drilling was performed with water instead of a mud system, and encountered problems with slow tripping times, continuous borehole breakout, and downhole equipment failures. The drilling was curtailed with the intention of bringing in a conventional drilling rig by late 2006 to re-establish connection of a production well to the Habanero EGS reservoir.

\subsubsection{Lessons learned at Cooper Basin}

- Buried radiogenic granite heat sources are ideal in this environment.

- Identifying an extensive body of granite with relatively uniform properties can yield a huge potential heat resource.

- Because the granite was hydrothermally altered, it was relatively easy to drill.

- Water-based overpressure is a surprise, but it assists with stimulation and convective inflow.

- It is difficult to drill multiply fractured zones without underbalanced drilling.

- Subhorizontal fracture zones are present in the granitic basement (either thrust faults or opened unloading features).

- Overthrust stress environments are ideal for stimulation, leading to development of horizontal reservoirs

- Scale-up to multiwell systems on a large scale seems feasible, because of the horizontal reservoir development.

- Scale-up should reduce cost to levels that will compete with other base-load technologies.

- The utility has committed to construction of a transmission line, if economic feasibility can be demonstrated. 


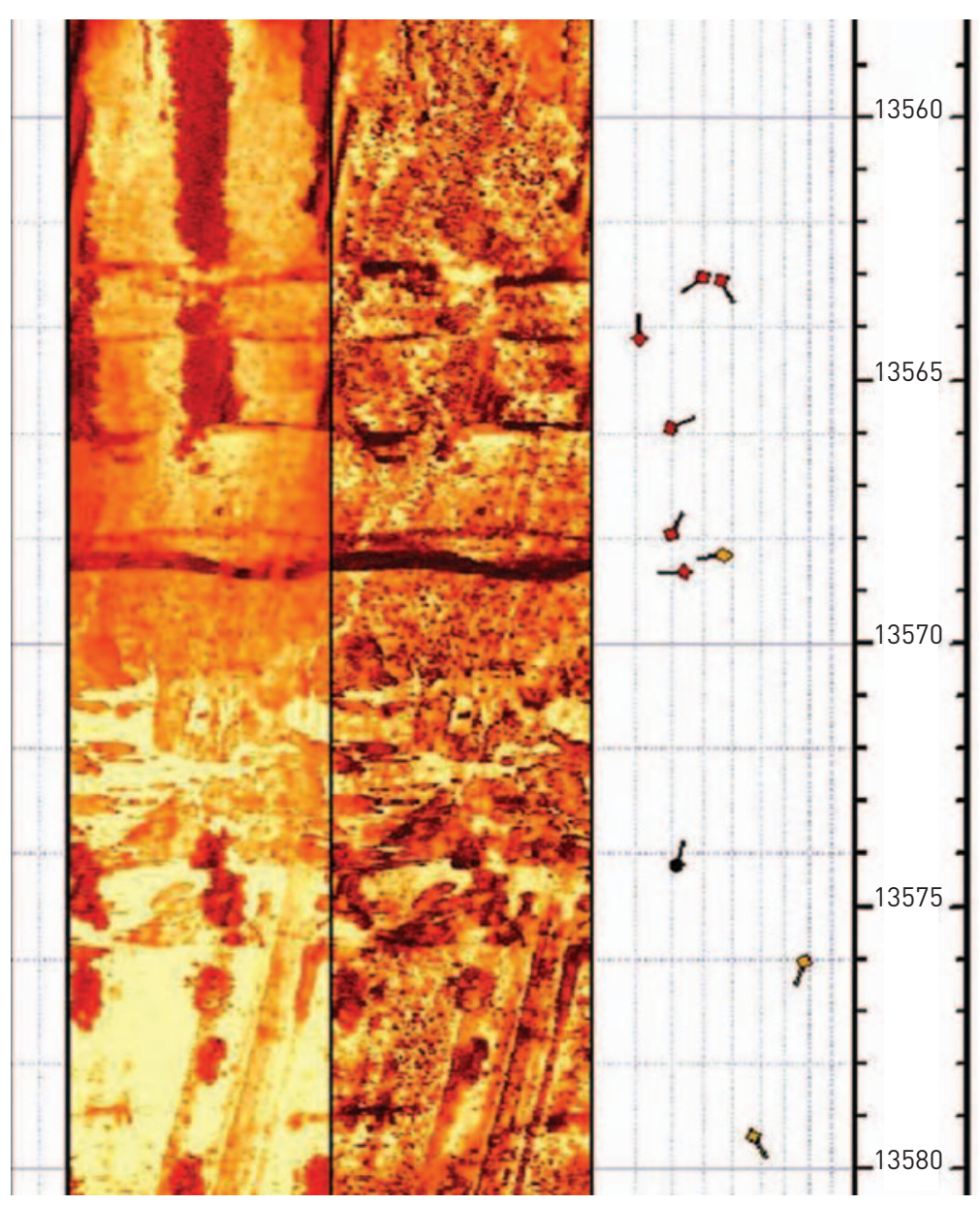

Figure 4.15 Depths in $\mathrm{ft}$ of fracture zones at Cooper Basin.

\subsection{Other EGS Studies}

\subsubsection{United States}

Current EGS field research in the United States is based at three sites on the margins of operating hydrothermal systems: Coso, Desert Peak, and Glass Mountain/Geysers-Clear Lake. The Coso project was designed to test the ability to fracture low-permeability, high-temperature rocks on the edge of the Coso geothermal area. The project has characterized the resource, tested thermal stimulation of a low permeability well of opportunity, and done baseline studies in preparation for a major hydraulic fracture stimulation in a deep high-temperature well. The Desert Peak project has targeted one well not connected with the Desert Peak geothermal system for stimulation to form an EGS. Political and environmental permitting issues have led to the cancellation of the Glass Mountain project, which targeted low-permeability, high-temperature rocks outside a known hydrothermal system. The industry partner has moved the project to its operating plant in an area in The Geysers with lowpermeability, high noncondensable gas, and acidic steam. The new project scope would target stimulation of low-permeability rock on the fringe of the production area to improve steam quality and recharge the reservoir while mining heat. 


\subsubsection{Europe and Australia}

Several sites in Europe and Australia, aside from the projects described above, have been used to test various aspects of EGS technology. The results of these tests and the government-sponsored research conducted at these sites has led to two current projects being undertaken by commercial entities with little or no government support - one at Offenbach, Germany, and the other at Hunter Valley in Australia.

Sweden - Fjällbacka. The Fjällbacka site is to the north of Uddevalla on the west coast of Sweden, where the Bohus granite outcrops. It was established in I984 as a field research facility for studying hydro-mechanical aspects of HDR reservoir development and for addressing geological and hydrogeological questions. Initially, three boreholes (Fjbo, Fjbi, and Fjb2) were percussion drilled to 200 , 500 , and $700 \mathrm{~m}$, respectively, to characterize the prospective reservoir. Based on the experiments, and the associated analysis and modeling, some conclusions concerning the hydro-mechanical behavior of the HDR reservoir have been drawn.

A series of shallow (ca. $200 \mathrm{~m}$ ) and deep-injection tests were conducted to evaluate the response of the virgin rock mass. These culminated in an attempt to develop a reservoir at $450 \mathrm{~m}$ depth, by a carefully planned stimulation injection into Fjbi that featured water, gel, and proppant. Microseismicity was monitored with an array of I5 vertical-component instruments on granite outcrop and a three-component instrument clamped near the bottom of Fjbo. An additional well, Fjb3, was then drilled to $500 \mathrm{~m}$ depth in 1988 to intersect a zone of microseismic activity that lay about $100 \mathrm{~m}$ to the west of Fjbi. Hydraulic communication between the wells was successfully established, although flow tests indicated the presence of an impedance to flow in the vicinity of Fjb3. Thus, a stimulation injection into Fjb3 was conducted, and succeeded in reducing the flow impedance, at least in the near field. A 40-day circulation of the system was conducted in I989. Results are summarized as follows:

- Highly detailed reservoir characterization led to a detailed design of the stimulation program.

- Located in a tectonic shield structure - where the state of stress at reservoir depth is such that the least principal stress is vertical - horizontal fractures form the preferred paths for fluid flow.

- The hydraulic stimulation in Fjbr resulted in a distinct increase in transmissivity in the stimulated reservoir section, and potential stimulation effects to about Ioo $\mathrm{m}$ from this well.

- The evidence of penetration of stimulation fluid, at least to this distance where intense microseismic activity was located, is indisputable. But the relation between seismic shear events and fracturepermeability increase is still insufficiently understood.

- Hydraulic jacking is expected to have occurred in the fractures close to the injection well.

- Natural fractures dominate the stimulation result.

- The microseismic locations were used to target the second well of the HDR doublet, and the results clearly suggest that the regions of seismicity are linked with permeability enhancement and major fluid flow.

- The reservoir provides fairly conductive paths between the wells, but the impedance to flow and fluid losses are too high to enable an economically acceptable circulation and heat-extraction process.

- There seem to be comparatively few hydraulically active fractures linking the major permeable zones in the two wells. However, at this shallow depth, the fracture system is essentially subhorizontal and not representative of behavior at greater depths. 
Germany - Falkenberg. The Falkenberg test site was established in northeastern Bavaria in I978, at a location where the Falkenberg granite essentially extends to the surface. The aim was to conduct fundamental in situ hydro-mechanical experiments at small depths with a high degree of observational control, which would be relevant to the understanding of HDR systems. The research program at Falkenberg lasted until I983 (Tenzer, 200I).

The principal experiments were aimed at determining the hydro-mechanical properties that hydrofractures created in joint-free portions of the wellbore. A large-scale zone was stimulated using packers in an interval free of joints in the drillhole HB4a in the depth range 252-255 $\mathrm{m}$. Six further boreholes intersected the fracture that propagated during this stimulation. The creation of the hydrofracture itself is of particular interest, because it proved that fresh hydro-fractures can be propagated over significant distances in fractured crystalline rock. This was contrary to the conventional wisdom that said fluid leak-off into the natural fracture system would prevent this from happening.

The fracture was initiated in 1979 by injecting $6 \mathrm{~m}^{3}$ of water into borehole HB4a at a rate of $3.5 \mathrm{~kg} / \mathrm{s}$, with a breakdown pressure of I8 MPa. Assuming a penny-shaped crack geometry and allowing for leak-off, a fracture radius at shut-in of $44 \mathrm{~m}$ and a maximum width of $0.62 \mathrm{~mm}$ are inferred. Televiewer images of the induced fracture obtained in several neighboring boreholes indicate multiple parallel fractures near the injection borehole, although it seems that only one of these extended beyond $20 \mathrm{~m}$. At borehole PB8 - about $2 \mathrm{~m}$ from the injection point - eight parallel fractures are evident within a zone I.3 $\mathrm{m}$ thick; whereas, at II $\mathrm{m}$ (borehole SB5), only two fracture traces are evident. At more distant boreholes, ranging up to $50 \mathrm{~m}$ from the injection well, only one fracture trace is visible.

Multiple fracture growth is commonly seen in sedimentary rocks, where it is often associated with high flow impedance. Microseismicity occurring during the injections was monitored by four downhole, three-component seismometers installed in neighboring boreholes. The successful detection of I6 of the induced events concurs with the intersection depth of the created fracture and the boreholes, suggesting a planar structure that strikes E-W, dipping $45^{\circ}$ to the south. The fracture was extended in I98I with a $33 \mathrm{~m}^{3}$ injection, and again in 1983 with $52 \mathrm{~m}^{3}$. Numerous inflation/deflation cycles were made during the intervening periods, though always involving volumes smaller than the previous "extension" injection.

An extensive program of hydraulic tests was undertaken during the project run time. The longest was a I4 h circulation at $3.4 \mathrm{~kg} / \mathrm{s}$, during which a thermal drawdown of $\mathrm{I}^{\circ} \mathrm{C}$ was determined. The variation of fracture hydraulic aperture and transmissivity as functions of inflation pressure were investigated and compared with measurements of mechanical aperture taken with a specially developed caliper sonde.

- In the Falkenberg project, a fracture believed to be artificial was stimulated from a well (HB4a) at a depth of $450 \mathrm{~m}$.

- Seven additional wells were subsequently drilled in a pattern above the fracture.

- Several of these wells intercepted the fracture to the extent that small amounts of water could be circulated through the fracture, and extensive hydraulic and rock mechanical experiments could be conducted. 
- Among other findings, the Falkenberg experiments proved that hydraulic pressure alone could keep joints open.

Germany - Bad Urach. Between I977 and I980, a large-scale investigation was undertaken of the geothermal anomaly around the area of Urach, in the Swabian Alps, approximately $50 \mathrm{~km}$ south of Stuttgart. In addition to examining the scale and nature of the anomaly, the intention was to assess the possibility of utilizing hot aquifers for heating purposes, and also to examine the basement rocks with the view toward future extraction of geothermal energy through HDR (Tenzer, 200I).

The work was conducted by the Forschungs-Kollegium Physik des Erdkörpers (FKPE), a group comprising academic and government research institutes. This group worked in conjunction with a group from the town of Bad Urach, whose objectives were to investigate the availability of hot aquifers for expansion of the spa operation, as well as other applications.

Early work consisted of an intensive geophysical and geological survey of the area. This included the drilling of two $800 \mathrm{~m}$ deep geothermal exploration boreholes (Urach I and II), in I970 and I974, into the Middle Triassic Muschelkalk formation. In October 1977, drilling began on a deep exploration borehole, Urach III. This was completed after 23I days of drilling, reaching a target depth of 3,334 $\mathrm{m}$ and penetrating approximately I,700 $\mathrm{m}$ into the crystalline basement. Drillcore was obtained over approximately $7 \%$ of the crystalline section. In I983, the uncased section of Urach III was extended to $3,488 \mathrm{~m}$. Subsequent testing included BHTV logging and a single hydro-fracture stress measurement at 3,350 $\mathrm{m}$ depth.

A series of small-scale stimulations with subsequent fluid circulation occurred between May and August 1979. During the course of these experiments, a mica-syenite section of the crystalline basement was stimulated seven times over four depth intervals: one open-hole section and three zones accessed through perforated casing. The stimulations carried out through the three zones of perforated casing involved the use of viscous gel and proppant. The perforated sections had a vertical separation of only $70 \mathrm{~m}$. A circulation loop was established between the open-hole stimulated section $(3,320 \mathrm{~m}-3,334 \mathrm{~m})$ and the cased-hole stimulation between 3,293 m-3,298 $\mathrm{m}$ depth. A total of I2 circulation tests were attempted, the most successful of which lasted six hours and I2 hours (Tenzer, 200I).

Over the depth range of the HDR stimulation and circulation experiments (in the mica-syenite between 3,250 and 3,334 m), the fracture density was of the order 0.7 per meter. These open fractures were reported as having encrustations of calcite and pyrite, while the closed joints were largely filled with quartz. It was further noted that the fracture dips ranged from $40^{\circ}-70^{\circ}$.

Limited in situ stress data have been provided by borehole breakouts, by a single hydraulic fracturing stress measurement (HFSM), by fracture inflation pressures, and by the orientation of drilling induced fractures. Breakouts identified over the depth range of 3,334 $\mathrm{m}$ to 3,488 $\mathrm{m}$ exhibited a consistent trend of approximately $82^{\circ}$, indicating a maximum horizontal stress orientated at $172^{\circ}$. This result is consistent with the observed strike of drilling-induced, subvertical extension fractures observed in Urach III. 
The value of minimum horizontal stress derived from the single HFSM $(3,350 \mathrm{~m})$ lies between 42 and $45 \mathrm{MPa}$. The derived value of the maximum horizontal stress is about $88 \mathrm{MPa}$, which is very close to the likely value of the overburden stress at $3,350 \mathrm{~m}$. In summary:

- The stimulation connected one section to another in a single borehole.

- Circulation was established across a section with only $70 \mathrm{~m}$ of separation

- This concept was later used for the single-well concept at Horstberg. For direct-use applications where only low flows are needed, this can reduce the cost of the installation.

Switzerland - Basel and Geneva, Deep Heat Mining. The Deep Heat Mining (DHM) projects underway in Switzerland plan to generate power at sites in Basel and Geneva within the next ro years (Tenzer, 200I). At Basel, a $2.7 \mathrm{~km}$ exploration well was drilled and studied, and is now being equipped with seismic instrumentation. At the Geneva site, detailed investigations are being conducted to site the first exploratory well. A unique aspect of the Basel project is that drilling is taking place within city limits, and the heat produced by the system has the potential for direct use as well as electrical generation. The projects were initiated in 1996 and are partly financed by the Federal Office of Energy (OFEN). Private and public institutions support the activities of the project.

In Basel, Switzerland, a pilot plant is being developed to use energy extracted by EGS technology for cogeneration of electrical power and heat for local district heating. The core of the project, called Deep Heat Mining Basel, is a well triplet into hot granitic basement at a depth of 5,000 m. Two additional monitoring wells into the top of the basement rock will be equipped with multiple seismic receiver arrays. They will record the fracture-induced seismic signals to map the seismic active domain of the stimulated reservoir volume. Reservoir temperature is expected to be $200^{\circ} \mathrm{C}$. Water circulation of Ioo $\mathrm{kg} / \mathrm{s}$ through one injection well and two production wells will result in $30 \mathrm{MW}$ of thermal power at wellheads. It has not yet been decided what conversion cycle will be used for electric power production. The plant is in an industrial area of Basel, where the waste incineration of the municipal water purification plant provides an additional heat source. In combination with this heat source and an additional gas turbine, a combined cogeneration plant can produce annually up to Io8 GWh of electric power and $39 \mathrm{GWh}$ of thermal power to the district heating grid.

Basel is not only situated at the southeastern end of the Rhine Graben, but also at the northern front of the Jura Mountains, the outermost expression and youngest part of the Alpine fold belt. The peculiar coincidence of north-northwest trending compression and west-northwest extension creates a seismically active environment.

The geothermal reservoir and the power plant will be located within this seismically active area. Therefore, it is important to record and understand the natural seismic activity as accurately as possible, prior to stimulation of a deep reservoir volume, which is characteristically accompanied by induced seismicity. The first exploration well, Otterbach 2, was drilled in 200I into granitic basement at $2,650 \mathrm{~m}$, to a total depth of $2,755 \mathrm{~m}$. The well is planned to become a monitoring well to record regional seismic events, as well as the stimulation events.

Borehole deformation logging using acoustic and electric borehole televiewer tools shows induced fractures pointing predominantly in a NNW direction, and induced borehole breakouts in the perpendicular direction. This trend is precisely in line with the regional stress field. No pressure tests 
were performed. The well was drilled with a balanced mud system. The fact that induced fractures are observed already in a balanced well indicates that fracturing in the granite will not require large hydraulic pressures. The EGS project of the European Community at Soultz-sous-Forêts, I50 km north (also situated in the Rhine Graben), experienced similar conditions. In an injection test over a period of I2 6 days, with flow rates around $25 \mathrm{~kg} / \mathrm{s}$ through a reservoir at $3.5 \mathrm{~km}$ depth, injection pressures averaged $3 \mathrm{MPa}$.

The next well is planned to the targeted reservoir depth of 5,000 m. It will be drilled on an industrial site in the city of Basel. It is intended to deviate the well at a depth of 3,000 $\mathrm{m}$ to the east, with an angle of $15^{\circ}$, in order to improve chances to penetrate open fractures associated with the main boundary fault system.

When the main targets of a minimum temperature of $190^{\circ} \mathrm{C}$ and a fractured reservoir rock are found in a favorable stress field, the well will be suspended. A second monitoring well at $2 \mathrm{~km}$ to the east will then be drilled and equipped with a seismic array similar to the Otterbach well. The two extended seismic arrays provide a series of locally independent receiver points, sufficient to compute the location of a seismic source with the required accuracy. Subsequently, injection tests will be conducted in the deep well in order to develop an EGS reservoir.

The final two deep wells will be directionally drilled from the same location. The conversion cycle for power production will be selected following proof of circulation. The exploration phase (proof of circulation) should be completed within two years. Besides the technical challenges to stimulate a fracture system along a fault system in a seismically active area, other environmental challenges, such as drilling-noise mitigation in a city, have to be met.

- This project will be the first project to demonstrate the use of EGS technology to produce both heat and power.

- The wells are drilled in the city of Basel in an industrial part of town, and demonstrate the potential for coexistence of EGS projects with other industrial activities within city limits.

- Drilling problems in the sedimentary section were caused by swelling clays and often led to stuck drill pipe. Problems were encountered in the crystalline basement as well.

- Because of the location of the wells under a city center, the potential for damage from a major seismic event associated with stimulation and production is greater than in rural areas.

France - Le Mayet de Montagne. The Le Mayet site is $25 \mathrm{~km}$ east-southeast of Vichy, France, at the northern fringe of the Massif Central. Granite extends to the surface, forming undulating topography of height less than Ioo m, and offering exposures of fractures in outcrop. Rock- and hydro-mechanical aspects of the problem of exploiting hot dry rock (HDR) reservoirs have been studied. In the late I980 , two, near-vertical boreholes were drilled approximately $800 \mathrm{~m}$ deep and $100 \mathrm{~m}$ apart along a line striking Nı4OE. Well III-8 (780 $\mathrm{m}$ depth) lies to the northwest of III-9 (840 $\mathrm{m} \mathrm{depth).} \mathrm{Borehole}$ packers were used to isolate a number of locations over a span of several hundred meters for multiple stimulation experiments, producing a localized hydraulic linkage of large surface area between the two wells.

The experiments involve high flow-rate $(20-30 \mathrm{~kg} / \mathrm{s})$ stimulation of selected intervals (with and without proppant), conventional hydro-fracture stimulations $(73 \mathrm{~kg} / \mathrm{s})$, and long-term circulations 
tests. Microseismic events induced during these experiments were monitored on a I5-station array (mostly three-component with two downhole) that allowed event locations to be determined to within $4.5 \mathrm{~m}$ horizontally and io $\mathrm{m}$ vertically. The seismic data set featured the best sampling of the seismic radiation field attained at that time in a HDR field experiment. More than 35 events were recorded on sufficient stations to yield fairly well-constrained focal mechanism solutions. The analysis of these focal mechanisms is particularly interesting, because they are used to constrain the local stresses driving fracture failure. Another novel aspect of the work at Le Mayet was the deployment of an array of tiltmeters to monitor surface deformation occurring in response to fluid injection. This deformation reflects the elastic field resulting from dilation of the joints/fractures, and should be detectable if fractures dilate as much as conventional theory predicts. In summary:

- Borehole packers were used to isolate several zones, so that a succession of stimulated zones was created.

- The result was a large-scale fractured heat-exchange area with good connection between two boreholes.

- Tiltmeters were successfully used to monitor the growth of fractures.

Germany - Horstberg. Due to their low transmissivity, most sedimentary formations in the northern German basin are not considered for the extraction of geothermal energy. To overcome these limitations, the GeneSys-project was initiated at the GEOZENTRUM, Hannover (Behrens et al., 2006). It is intended to investigate concepts that allow the use of the widespread low-permeability sediments for geothermal energy extraction and, ultimately, to supply heat for the complex of buildings of the GEOZENTRUM, Hannover. The hydraulic-fracturing technique successfully applied in crystalline rocks for the creation of HDR systems will be used to create large-scale fractures covering areas in the order of $\mathrm{km}^{2}$ in the sediments to increase the productivity of the well to the required flow rates. Because a thermal power of approximately $2 \mathrm{MWt}$ is required for the supply of the GEOZENTRUM, only relative low production rates are required, which can be realized with a onewell concept. Such a concept, where the well is simultaneously used for production and reinjection, can be operated economically even for a relatively low power output of a few MWt. This production is suitable for providing heat to large buildings, or districts, where a district heating system is available.

To test concepts, a series of in situ tests were conducted in the abandoned gas exploration well Horstberg ZI. The well is operated as an in situ laboratory by BGR (Federal Institute for Natural Resources and Geosciences), which belongs to the GEOZENTRUM, Hannover. The experiments started in September 2003. The originally proposed concept envisioned that, by the creation of large fractures, the well would be connected to water-bearing joints, faults, fracture zones, or porous layers not directly accessed by the borehole. The hot water produced from these structures would be injected, after cooling, via the annulus of the same borehole into a permeable rock formation at shallower depth.

Massive hydro-frac tests were performed in a sandstone layer of the Buntsandstone formation at a depth of approximately $3,800 \mathrm{~m}$, by injecting more than $20,000 \mathrm{~m}^{3}$ of fresh water at flow rates up to $50 \mathrm{~kg} / \mathrm{s}$, and at wellhead pressures of about $33 \mathrm{MPa}$. Post-frac venting tests showed that the created fracture has a high storage capacity (about I,000 $\mathrm{m}^{3} / \mathrm{MPa}$ ) and covers an area of several hundred thousand square meters, indicating that the fracture not only propagated in the sandstone layer, but also fractured the adjacent clay-stone horizons. They also showed that the fracture, or at least part of the fracture, stayed open during pressure release, thus allowing venting flow rates of about $8.3 \mathrm{~kg} / \mathrm{s}$, 
at fluid pressures well below the frac-extension pressure. Long-term extrapolations of the venting flow rate, however, showed that the desired flow rate of $6.9 \mathrm{~kg} / \mathrm{s}$ cannot be maintained over a prolonged time period, because the production and reinjection horizons (at I,200 $\mathrm{m} \mathrm{depth)} \mathrm{do} \mathrm{not}$ communicate, and the overall yield of the formation accessed by the fracture is too low.

The results of cyclic tests, consisting of a cold-water injection period, a warm-up period, and a venting period were very promising. The fluid volumes and production temperatures achieved during these tests show that this can be an alternative concept for heat extraction from tight sedimentary rock.

To monitor microseismicity induced during stimulations, a seismic network was installed. It consists of eight stations installed on two circles with radii of 800 and I,600 $\mathrm{m}$, centered around the well position at depth and a surface array of 60 geophones. At each of the stations, a roo $\mathrm{m}$ deep well was drilled, and geophones were installed permanently at the bottom of these wells. Data were analyzed on-site with respect to the occurrence of microseismicity. In contrast to hydro-frac tests in crystalline rock, where several thousands or tens of thousands of microseismic events were detected and located with networks of comparable sensitivity, only a few events were detected here. A reliable source location could not be inferred for any of these events.

The experiences gained within the project, however, are highly relevant for the oil and gas industry in the Northern German Basin, because they have a lively interest in seismic monitoring of stimulation operations. To sum up:

- This project demonstrates the benefits of stimulation in a sedimentary environment - large storage coefficient and pre-existing permeability.

- The concept of using a single borehole was not effective, because there was no connection between the injection zone and the production zone, so the production zone was not recharged and could not support long-term production.

- Few microseismic events were detected during stimulation and circulation tests, especially compared to the large number of microseismic events generated and detected during stimulation in crystalline rock. 


\subsection{Generalizations from EGS Field Testing}

Progress in improving the technology needed to produce commercial-scale EGS reservoirs has been dramatic in the past few years. We have long been able to drill the wells, stimulate the rock to improve tranmissivity, target wells into the stimulated volume, and make a connection between producer and injector. We can circulate the fluids for long time periods, from months to more than one year, at reasonably high rates, I0-30 kg/s. When measurable temperature drops were observed, they were correlated with the size of the stimulated reservoir using a range of thermal hydraulic modeling approaches (for example, see Tester and Albright, I979; Armstead and Tester, I987; and Tester et al., I989). Figure 4.I6 shows the produced thermal energy output for several major EGS projects spanning 30 years. In addition, projections are shown for current EGS projects in the United States, Europe, and Australia. We can monitor the stimulation to map the fractured volume - we can map fractures in the borehole, log the wells for temperature and pressure to a very high degree of accuracy, and determine stress state from borehole data.

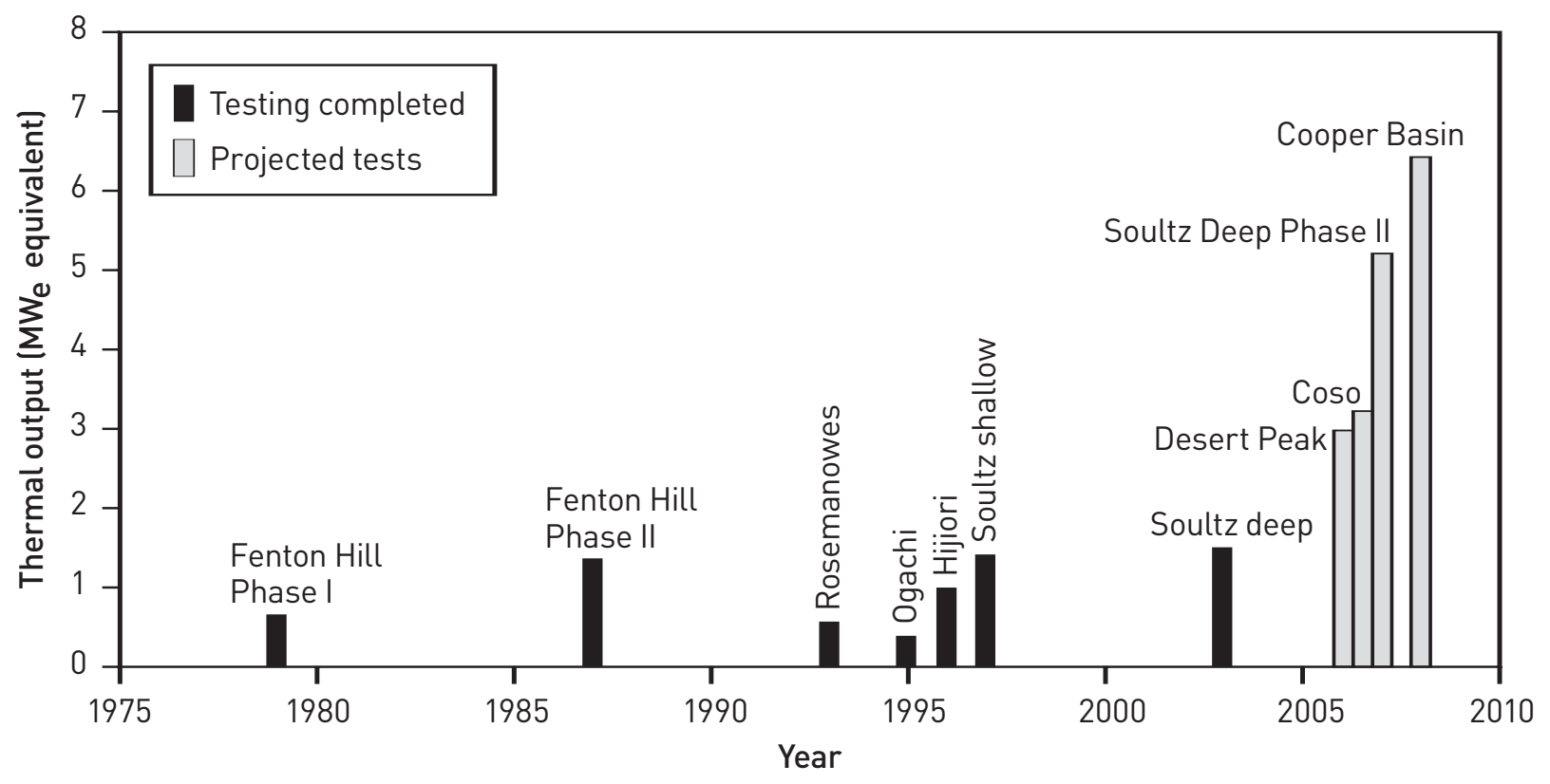

Figure 4.16 Evolution of estimated electrical power output per production well, with time from EGS projects. The Fenton Hill, Coso, and Desert Peak projects received, or are receiving, major funding from the U.S. DOE.

Lessons Learned from Natural Hydrothermal Systems. The basic EGS techniques of permeability enhancement, heat mining, and injection augmentation already work. They are regularly used in regions where the natural fractures support flow and connectivity, but where recharge is limited. At Mahangdong (Yglopaz), and Mindanao (Ramonchito) in the Philippines; and two sites in Indonesia; as well as Coso, (Petty, personal communication), The Geysers, East Mesa, and Steamboat in the United States (Petty, personal communication), hydraulic stimulation, with or without acidizing, has resulted in increased permeability. At East Mesa, cooling of the resource after more than Io years of operation was reduced or halted by moving injectors or drilling new ones, shutting off zones of thermal breakthrough by recompleting wells, and by changing pump-setting depths to produce preferentially from zones with higher temperatures. At The Geysers, drying of the reservoir, increase in noncondensable gases, and pressure drawdown with little or no natural recharge were addressed 
by bringing treated waste water from the city of Santa Rosa and from Lake County, for injection augmentation. At Dixie Valley, pressure drawdown due to lack of natural recharge and limited injection into the reservoir was reversed by injecting all produced fluids, careful selection of injector locations, and augmentation of injection from shallow, non-potable groundwater sources on site.

- High flow rates with long path lengths are needed. By looking at natural hydrothermal systems, we know that we need to have production of about $5 \mathrm{MW}_{\mathrm{e}}$ per production well, which requires flow rates ranging from 30 to $100 \mathrm{~kg} / \mathrm{s}$, depending on the fluid temperature. At the same time, we need a large heat-exchange area or long residence time for water to reheat to production temperatures; this could imply large pressure drops. Better understanding of successful natural systems (in comparable geological settings) should lead to improved methods of generating artificially enhanced geothermal systems. For instance, the residence time of water injected at Dixie Valley is three-six months, and the production wells show little or no cooling due to the aggressive injection program. At Steamboat, though, the residence time for the water is closer to two weeks and there is fairly significant cooling. The well spacing between injectors and producers at Dixie Valley is about $800 \mathrm{~m}$, and there are probably at least two fractures with a somewhat complex connection between the injectors and producers resulting in a long fluid-path length. At the Steamboat hydrothermal site, the distance between producers and injectors is more than I,००० $\mathrm{m}$; but because there are many fractures, the transmissivity is so high that there is low residence time for injected fluids. At the East Mesa hydrothermal site, the reservoir is in fractured sandstone, and the residence time varies from one part of the field to another. Some injectors perform well in the center of the field, while other injectors are in areas with either high matrix permeability in some zones or fractures that cause cold water to break through faster. The large volume of hot water stored in the porous matrix at East Mesa made it possible to operate the field for a long time before problems with cooling developed.

- Stimulation is through shearing of pre-existing fractures. In strong crystalline rock, hydraulic properties are determined by the natural fracture system and the stresses on that fracture system. The expectation of scientists planning the early experiments in enhancing geothermal reservoirs was that fracturing would be tensile. While it may be possible to create tensile fractures, it appears to be much more effective to stimulate pre-existing natural fractures and cause them to fail in shear. Understanding the orientation of the stress field is crucial to designing a successful stimulation. Fortunately, in even the most unpromising tectonic settings, many fractures seem to be oriented for failure. At Cooper Basin, which is in compression, stimulation of two nearly horizontal pre-existing fracture systems appears to have been successful in creating a connected reservoir of large size. Shearing of natural fractures increases hydraulic apertures, and this improvement remains after pressures are reduced. Fortunately, stress fields in strong rocks are anisotropic, so critically aligned natural joints and fractures shear at relatively low overpressures (2-Io $\mathrm{MPa}$ ).

- Fractures that are stimulated are those that will take fluid during pre-stimulation injection. The fractures that are found to be open and capable of receiving fluid during evaluation of the well before stimulation are almost always those that are stimulated and form large-scale connections over a large reservoir volume. This may be because these fractures are connected anyway, or because the fractures that are open are those oriented with the current stress state. It is important, therefore, to target areas that will have some pre-existing fractures due to their stress history and the degree of current differential stress. But even in areas with high compressional stresses - such as Cooper Basin in Australia - there are natural, open fractures. However, with present technology, we cannot create connected fractures where none exist. It may be possible to initiate new fractures, but it is not known 
whether these will form large-scale flow paths and connect over large volumes of the reservoir. This means that the fracture spacing in the final reservoir is governed by the initial, natural fracture spacing. The number of fractures in a wellbore that will take fluid is, therefore, important to assess in each well. The total heat that can be recovered is governed by the fracture spacing, because the temperature drops rapidly away from the fracture face that is in contact with the injected cool fluid.

- We currently do not have a reliable open-hole packer to isolate some zones for stimulation. This is routine in the oil and gas industry; but in the geothermal industry, high-temperature packers for the open hole are not reliable, so we stimulate the entire open interval. Logging shows that the first set of open fractures is the one most improved. If we want to stimulate some zones more than others - or if we want to create new fractures - we will need a good, reliable, high-temperature open-hole packer. Although earlier testing at Soultz using a cement inflatable aluminum packer have been encouraging, more development work remains to be done to improve reliability and increase temperature capability.

- Hydraulic stimulation is most effective in the near-wellbore region. The near-wellbore region experiences the highest pressure drop, so stimulation of this region is important. But we also need connectivity in the far field away from the wells to maintain circulation and accomplish heat mining. We can effectively use a variety of techniques both from the oil and gas industry and from geothermal experience to improve near-wellbore permeability. Hydraulic stimulation through pumping large volumes of cool fluid over long time periods, and acidizing with large volumes of cool fluid and acid (of low concentration), have been most effective. Use of high-viscosity fluids, proppants, and highrate high-pressure stimulation has been tried with mixed success and may still have potential in some settings, particularly in sedimentary reservoirs with high temperatures. However, there are limits to the temperature that packers, proppants, and fracturing fluids can withstand, so some of these techniques are impossible or very costly in a geothermal setting. In crystalline rocks with preexisting fractures, oil and gas stimulation techniques have failed to result in connection to other fractures and may form short circuits that damage the reservoir. Our current efforts to stimulate geothermal wells and EGS wells, in particular, are limited to pumping large volumes of cold water from the wellhead. This means that the fractures that take fluid most readily anyway are stimulated the most. Only a small portion of the natural fractures seen in the wellbore support flow. Because these more open fractures may also be the ones that connect our producers to our injectors, this may not be a disadvantage. However, there may be a large number of fractures observed in the wellbore, and an ability to identify and target the best ones for stimulation is limited because of a lack of research.

- The first well needs to be drilled and stimulated in order to design the entire system. Early efforts to create reservoirs through stimulation relied on drilling two wells, oriented such that there appeared to be a good chance of connecting them, given the stress fields observed in the wellbore and the regional stress patterns. However, at Fenton Hill, Rosemanowes, Hijiori, and Ogachi, this method did not yield a connected reservoir. Stress orientation changes with depth, or with the crossing of structural boundaries, and the presence of natural fractures already connected (and at least somewhat permeable) makes evaluating the stimulated volume difficult. It seems much easier to drill the first well, then stimulate it to create as large a volume as possible of fractured rock, then drill into what we think is the most likely place, and stimulate again. Because of this, we can design wells as either producers or injectors, whereas it would be better if we could design wells for both production and injection. This emphasis on the first well demands that it be properly sited with respect to the local stress conditions. Careful scientific exploration is needed to characterize the region as to the stress field, pre-existing fractures, rock lithology, etc. 
- Monitoring of acoustic emissions is our best tool for understanding the system. Mapping of acoustic events is one of the most important tools we have for understanding the reservoir. In hydrothermal systems, we know from well tests and tracer tests that water is circulating and in contact with large areas of rock. We can assess stimulated fractures in the same way, once we have two or more wells in hydraulic connection to allow for circulation tests. We can map the location of acoustic emissions generated during stimulation and during circulation extremely accurately, i.e., +/- Io-30 m. While we are not completely sure what the presence or absence of acoustic emissions means in terms of fluid flow paths or reservoir connectivity, knowledge of the location and intensity of these events is certainly important. This information helps define targets for future wells.

If we drill into a zone that has already been stimulated and shows a large number of acoustic emissions events, it is commonly assumed that the well is connected to the active reservoir. However, this fact does not always result in a good system for heat extraction. For example, at Soultz, GPK4 was drilled into an area that was within the volume of mapped acoustic emissions, but it did not produce a connected fracture system between the production and injection wells, even after repeated stimulations. Mapping of acoustic emissions has improved, so that we can locate acoustic emissions and determine the focal mechanism for these events more accurately than in the past. As a result, we can better understand the stress field away from the wellbore and how our stimulation affects it.

Methods for mapping fractures in the borehole have been developed, and the upper limit for temperatures at which they can operate is being extended. Ultrasonic borehole televiewers, microresistivity fracture imaging, and wellbore stress tests have all proved very useful in understanding the stress state, nature of existing fractures, and the fluid flow paths (before and after stimulation). Correlating the image logs with high-resolution temperature surveys and with lithology from core and cuttings allows a better determination of which fractures might be productive.

- Rock-fluid interactions may have a long-term effect on reservoir operation. While studies of the interaction of the reservoir rock with the injected fluid have been made at most of the sites where EGS has been tested, there is still a good deal to learn about how the injected fluid will interact with the rock over the long term. The most conductive fractures often show evidence of fluid flow in earlier geologic time such as hydrothermal alteration and mineral deposition. This is encouraging in that it suggests that the most connected pathways will already have experienced some reaction between water and the rock fracture surface. Fresh rock surfaces will not have the protection of a layer of deposited minerals or alteration products. We also do not know how much surface water (which cannot be in equilibrium with the reservoir rock) we will need to add to the system over the long term. Our longest field tests have seen some evidence for dissolution of rock leading to development of preferred pathways and short circuits. Regardless, we will cool the produced fluid through our surface equipment, possibly resulting in precipitation of scale or corrosion (Vuatarez, 2000).

Although not analyzed in this study, the use of carbon dioxide $\left(\mathrm{CO}_{2}\right)$ as the circulating heat transfer fluid in an EGS reservoir has been proposed (Pruess, 2006). Brown (2000) has developed a conceptual model for such a system, based on the Fenton Hill Hot Dry Rock reservoir. The argument is made that supercritical $\mathrm{CO}_{2}$ holds certain thermodynamic advantages over water in EGS applications and could be used to sequester this important greenhouse gas. We also address this topic in Section 8.3.3. 
- Pumping the production well to get the high-pressure drops needed for high flow rates without increasing overall reservoir pressure seems to reduce the risk of short circuiting while producing at high rates. High pressures on the injection well during long-term circulation can result in short circuits. Circulating the fluid by injecting at high pressures was found to consume energy while, at the same time, tending to develop shorter pathways through the system from the injector to the producer. Highpressure injection during circulation also may cause the reservoir to continue to extend and grow, which may be useful for a portion of the time the field is operating - but may not create fractures that are in active heat exchange, given the system of wells that are in place. High-pressure injection can also result in fluid losses to those parts of the reservoir that are not accessed by the production wells. However, by pumping the production wells in conjunction with moderate pressurization of the injection well, the circulating fluid is drawn to the producers from throughout the stimulated volume of fractured rock, minimizing fluid loss to the far field.

- The wells needed to access the stimulated volume can be targeted and drilled into the fractures. While drilling deep wells in hard, crystalline rock may still be fairly expensive, the cost technology has improved dramatically since the first EGS wells were drilled at Fenton Hill. Drill bits have much longer life and better performance, typically lasting as long as 50 hours even in deep, hightemperature environments. The rate of penetration achievable in hard, crystalline rock and in hightemperature environments is continually increasing, partly due to technology developments with funding from the U.S. government. As the oil and gas industry drills deeper, and into areas that previously could not be drilled economically, they will encounter higher temperatures and more difficult drilling environments. This will increase the petroleum industry's demand for geothermaltype drilling. Most geothermal wells need to have fairly large diameters to reduce pressure drop when flow rates are high. Directional control is now done with mud motors, reducing casing wear and allowing better control. Although high temperatures are a challenge for the use of measurement-while-drilling (MWD) tools for controlling well direction, they did not exist when the first EGS well was drilled at Fenton Hill. Furthermore, the temperature range of these tools has been extended since they first became available. Mud motors are now being developed that can function not only at high temperatures, but also with aerated fluids. See Chapter 6 for further discussion.

- Circulation for extended time periods without temperature drop is possible. Although early stimulated reservoirs were small, and long-term circulation tests showed measurable temperature drop, later reservoirs were large enough that no temperature drop could be measured during the extended circulation tests. It is difficult to predict how long the large reservoirs will last, because there is not enough measurable temperature change with time to validate the numerical models. Tracer test data can be used for model verification (see Chapter 5, Figure 5.3), but in cases where extremely large reservoirs have been created, tracer data may not be adequate for determining the important parameters of heat-exchange area and swept volume.

- Models are available for characterizing fractures and for managing the reservoir. Numerical simulation can model fluid flow in discrete fractures, flow with heat exchange in simple to complex fractures, in porous media and in fractured, porous media. Changes in permeability, temperature changes, and pressure changes in fractures can be fit to data to provide predictive methods. However, because long-term tests have not been carried out in the larger, commercial-sized reservoirs, it is not yet known whether the models will adequately predict the behavior of such 
reservoirs. Rock-fluid interactions in porous media or fractured, porous media can also be modeled, but their long-term effects are equally uncertain. Commercial fracture design codes do not take thermal effects into consideration in determining the fracturing outcome. Geothermal codes for fracture stimulation design purposes that do consider thermal, as well as hydraulic effects in fracture growth, are not yet developed (DuTeaux et al., I996).

- Induced seismicity concerns. In EGS tests at the Soultz site, microseismic events generated in the reservoir during stimulation and circulation were large enough to be felt on the surface. Efforts to understand how microearthquakes are produced by stimulation are ongoing, and new practices for controlling the generation of detectable microseismic events are developing. A predictive model that connects reservoir properties and operating parameters such as flow rate, volume injected, and pressure which might affect the generation of detectable microearthquakes is important to realizing the potential of EGS. Such a model has not been quantitatively established.

\subsection{Remaining Needs}

Although we can make an EGS reservoir with connected wells in a deep, high-temperature rock volume, there are still many areas of technology improvement needed that will help make the process more economical and less risky.

- Reduce pressure drop without decreasing reservoir life - We can stimulate a connected fracture system, but we have no way of stimulating specific fractures. This increases the risk that one or more highpermeability fractures will be preferentially stimulated and result in too rapid a temperature decline.

- Prevent or repair short circuits - Short circuiting of flow paths in the connected fracture system is a concern affecting reservoir lifetime. At Rosemanowes, Hijiori, and Ogachi, only some of the preexisting fractures that were stimulated resulted in short circuits. We would like to be able to direct the stimulation to those fractures that are less open and away from the more conductive fractures. This would reduce the risk of short circuiting while increasing the effective heat-exchange area of the system.

- Better understand the influence of major fractures and faults as subsurface barriers or conduits to flow Large-scale features such as faults and major fractures can act as either barriers or conduits to flow and can alter the planned flow paths, either to create short circuits or to move fluid out of the circulating reservoir. For instance, at Soultz, an aseismic zone, which could be either a conduit for flow or a barrier, appears in the acoustic emissions mapping. This feature seems to separate GPK4 from the rest of the wells and prevents this well from being well-connected to the circulating reservoir. While some of the methods we develop for dealing with short circuits will help us deal with large-scale faults and fractures, new methods of characterizing these features are still needed. Improving our understanding of the acoustic emissions patterns associated with these features will be one step in the process. We would also like to be able to characterize these features from the surface before we drill, so that we can take them into account during planning.

- Characterizing rock-fluid interactions - Despite efforts to model rock-fluid interactions, there are still major questions to be answered. Geochemical data gathered during testing has not led to any understanding of what happened during each test, let alone an ability to predict how future reservoirs will react. Several questions remain: 
I) Will mineral deposition occur over time that will diminish connectivity and increase pressure drop?

2) Is mineral dissolution going to create short circuits or improve pressure drop?

3) Where will dissolution and deposition occur in the well/reservoir system if they happen?

4) Will long-term circulation result in some equilibrium being reached with the fluid and reservoir rocks?

5) Can we use rock-fluid interactions to characterize the performance of the reservoir?

6) Can we use chemical methods to stimulate or repair the reservoir?

- Use of oil and gas stimulation methods in geothermal settings - So far, oil and gas hydraulic fracturing has not been successful, either creating open fractures that lead to short circuiting or having no connection to the existing natural fractures. Some oilfield methods may be valuable to us, if we find ways to adapt them to our needs. Use of proppants to improve near wellbore injectivity or productivity may have very real benefits, particularly if we move to downhole production pumps. Controlled rheology fluids might be useful in diverting stimulation to the areas that most need it or in repairing short circuits.

- Use of intermediate strain-rate stimulation - Pressurizing the formation at a rate between explosive (micro-milliseconds) and hydro-frac (minutes-hours) methods should be explored for EGS applications, as a potential means of reducing near-wellbore impedance. 


\section{References}

Armstead, H. C. H. and J. W. Tester. I987. Heat Mining. London: E. and F.N. Spon, 478 pp.

Baria, R., K. C. Hearn, and A. S. Batchelor. I985. "Induced seismicity during the hydraulic stimulation of the potential Hot Dry Rock geothermal reservoir." Submitted to the Fourth Conference on Acoustic Emission/Microseismic Activity in Geology Structures and Materials, Pennsylvania State University.

Baria, R. and A. S. P. Green. I989. “Microseismics: A Key to Understanding Reservoir Growth.” In Hot Dry Rock Geothermal Energy, Proc. Camborne School of Mines International Hot Dry Rock Conference, Ed. Roy Baria, Camborne School of Mines Redruth, Robertson Scientific Publications, London, pp. 363-377.

Baria, R., J. Baumgartner, A. Gérard, and R. Jung. I998. "European Hot Dry Rock geothermal research programme I996-I997." Contract N: JOR3-CT95-0054, Joule III Programme, final report EUR I8925 EN, I5Ipp.

Baria, R., R. Jung, T. Tischner, D. Teza, J. Baumgaertner, B. Dyer, T. Hettkamp, J. Nicholls, S. Michelet, B. Sanjuan, N. Soma, H. Asanuma, and J. Garnish. 2006. "Creation of an HDR/EGS reservoir at $5000 \mathrm{~m}$ depth at the European HDR project," Proc. 31st Stanford Geothermal Workshop, Calif.

Baria, R., S. Michelet, J. Baumgartner, B. Dyer, J. Nicholls, T. Hettkamp, D. Teza, N. Soma, H. Asanuuma, J. Garnish, T. Megel, T. Kohl, and L. Kueperkoch. 2005. "A 5000 m Deep Reservoir Development at the European HDR Site at Soultz," Proc. $30^{\text {th }}$ Workshop on Geothermal Reservoir Engineering, Stanford University, Stanford, Calif., Jan. 3I-Feb. 2, Paper No. SGP-TR-I76.

Batchelor, A. S. I977. "Brief summary of some geothermal related studies in the United Kingdom." $2^{\text {nd }}$ NATO/CCMS Geothermal Conf., Los Alamos, 2224 Jun., Section I.2I, pp.27-29.

Batchelor, A. S. I982. "The stimulation of a Hot Dry Rock geothermal reservoir in the Cornubian Granite, England." Proc. $8^{\text {th }}$ Workshop on Geothermal Reservoir Engineering, Stanford, Ca, USA, I4 I6 Dec. pp.237-248.

Batchelor, A. S., R. Baria, and K. Hearn. I983. "Monitoring the effect of hydraulic stimulation by microseismic event location: a case study." SPE $58^{\text {th }}$ Ann. Tech. Conf., San Francisco, Calif., USA, Oct. (SPE I2I09).

Batchelor, A. S. I986. "Reservoir behaviour in a stimulated Hot Dry Rock system." Proc. $11^{\text {th }}$ Annual Workshop on Geothermal Reservoir Engineering, Stanford University, Calif., USA, 2I-23 Jan., pp.35-4I.

Batchelor, A. S. I987. “Development of Hot-Dry-Rock geothermal systems in the UK.” Thermal Power, IEE Proc., I34A(5): 37I-380.

Batchelor, A. S. I989. "Hot Dry Rock and its relationship to existing geothermal systems." Proc. of Camborne School of Mines Int. Hot Dry Rock Conf., 2730 Jun., pp.r3-29. Pub: Robertson Scientific Publications, ISBN I-85365-2I7-2.

Behrens, H., I. Ghergut, T. Licha, M. Lodemann, J. Orzol, and M. Sauter, 2006. "Reactive behavior of uranine (flourescein) in a deep geothermal-reservoir tracer test," Geophysical Research Abstracts, Vol. 8, I0448.

Brown, D.W. 2000. "A Hot Dry Rock Geothermal Energy Concept Utilizing Supercritical $\mathrm{CO}_{2}$ Instead of Water," Proc. Twenty-Fifth Workshop on Geothermal Reservoir Engineering, Stanford University, Stanford, CA, Jan. 24-26, 2000, Paper SGP-TR-I65. 
Duchane, D. I993. “Geothermal Energy," Encyclopedia of Chemical Technology, I2: 512-539, Wiley, NY.

Duffield, R. B., G. J. Nunz, M. C. Smith, and M. G. Wilson. I98r. "Hot Dry Rock,” Geothermal Energy Development Program, Annual Report FY80, Los Alamos National Laboratory Report, LA-8855-HDR, 2II pp.

DuTeaux, R., D. Swenson, and B. Hardeman. I996. "Insight from modeling discrete fractures with GEOCRACK, a geothermal reservoir model," Proceedings Twenty-First Workshop on Geothermal Reservoir Engineering, Stanford University, Calif.

Genter, A., H. Traineau, C. Dezayes, P. Elsass, B. Ledesert, A. Meunier, and T. Villemin. I995. "Fracture analysis and reservoir characterization of the granitic basement in the HDR Soultz project (France)." Geotherm. Sci. Tech., 4(3): I89-2I4.

Hori, Y., K. Kitano, H. Kaieda, and K. Kiho. I999. "Present status of the Ogachi HDR Project, Japan, and future plans." Geothermics, 28(4/5): 637-645.

Jung, R., F. Rummel, A. Jupe, A. Bertozzi, B. Heinemann, and T. Wallroth. I996. "Large scale hydraulic injections in the granitic basement in the European HDR programme at Soultz, France." Proc. $3^{\text {rd }}$ Int. HDR Forum, Santa Fe.

Kaieda, H., R. H. Jones, H. Moriya, S. Sasaki, and K. Ushijima. 2000. "Ogachi HDR reservoir evaluation by AE and geophysical methods." Proc. World Geothermal Congress 2000, Japan.

Kappelmeyer, O. and F. Rummel. I980. "Investigations on an artificially created frac in a shallow and low permeable environment." Proc. $2^{\text {nd }}$. International Seminar on the Results of EC Geothermal Energy Research, pp. 1048-1053, Strasbourg.

Kappelmeyer, O. and R. Jung. I987. "HDR Experiments at Falkenberg/Bavaria." Proceedings of the first EEC/US workshop on Geothermal Hot Dry Rock Technology, Geothermics Special Issue, I6(4): 375-392.

Kiho, K. 2000. "Study On Surface Area Estimation of the Ogachi HDR Reservoir by Geochemical Method." Proc. World Geothermal Congress 2000, Japan.

Kitano, K., Y. Hori, and H. Kaieda. 2000. "Outline of the Ogachi HDR project and character of the reservoirs.” Proc. World Geothermal Congress 2000, Japan.

Kruger, P., H. Karasawa, N. Tenma, and K. Kitano. 2000. "Analysis of heat extraction from the Hijiori and Ogachi HDR geothermal resources in Japan.” Proceedings World Geothermal Congress 2000, pp. 2,677-3,682, Japan.

Matsunaga, I., H. Tao, and N. Tenma. 2000. "Geochemical evaluation of the Hijiori HDR reservoir at Yamagata, Japan.” Proceedings World Geothermal Congress 2000, pp. 3,787-3,792, Japan.

Moriya, H., H. Niitsuma, and R. Baria. 2003. "Estimation of fine scale structures in Soultz HDR reservoir by using microseismic multiplets." Proc. $28^{\text {th }}$ Workshop on Geothermal Reservoir Engineering, Stanford University, Calif.

Okabe, T., K. Kirihara, K. Hayashi, K. Karasawa, D. Swenson, and R. Schroeder. 2000. "Analysis in Preparation for Hijiori Long Term Circulation Test." Proceedings of the World Geothermal Congress 2000, Kyushu-Tohoku, Japan.

Parker, R. H. (Ed). I989. Hot Dry Rock Geothermal Energy, Phase 2B Final report of the Camborne School of Mines Project, Two Volumes, Pub Pergamon Press, ISBN 0-08-037929-X. 
Pine, R. J. and A. S. Batchelor. I984. "Downward migration of shearing in jointed rock during hydraulic injections.” Int. J. of Rock Mechanics Mining Sciences and Geomechanical Abstracts, 2I(5): $249-263$.

Pruess, K. and M. Azaroual. 2006. "On the Feasibility of Using Supercritical $\mathrm{CO}_{2}$ as Heat Transmission Fluid in an Engineered Hot Dry Rock Geothermal System," Proc. 30 ${ }^{\text {th }}$ Workshop on Geothermal Reservoir Engineering, Stanford University, Calif.

Schroeder, R., D. Swenson, N. Shinohara, T. Okabe, S. Takasugi, and K. Hayashi. I998. "Strategies for the Hijiori Long Term Flow Test." Proc. $23^{\text {rd }}$ Workshop on Geothermal Reservoir Engineering, Stanford University, Calif.

Shin, K., H. Ito, and Y. Oikawa. 2000. "Stress state at the Ogachi site." Proc. World Geothermal Congress 2000, Kyushu-Tohoku, Japan.

Smith, M. C., R. L. Aamodt, R. M. Potter, and D. W. Brown. I975. "Man-made geothermal reservoirs." Proc. UN Geothermal Symp., 3:I,78I-I,787, San Francisco, Calif.

Swenson, D., R. Schroeder, N. Shinohara, and T. Okabe. I999. "Analyses of the Hijiori Long Term Circulation Test," Proc. 24th Workshop on Geothermal Reservoir Engineering, Stanford University, Stanford, California, Jan. 25-27, Paper No. SGP-TR-I62.

Tenma, N., T. Yamaguchi, K. Tezuka, and H. Karasawa. 2000. "A Study of the Pressure-Flow Response of the Hijiori Reservoir at the Hijiori HDR Test Site." Proc. World Geothermal Congress 2000, Kyushu-Tohoku, Japan.

Tenma, N., T. Yamaguchi, Y. Oikawa, and G. Zyvoloski. 200I. "Comparison of the Deep and the Shallow Reservoirs at the Hijiori HDR Test Site using FEHM Code.” Proc. $26^{\text {th }}$ Stanford Geothermal Workshop, CA.

Tenzer, H. 200I. "Development of hot dry rock technology." Bulletin Geo-Heat Center, 32(4): I4-22.

Tester, J. W. and J. N. Albright, eds. I979. "Hot Dry Rock Energy Extraction Field Test: 75 Days of Operation of a Prototype Reservoir at Fenton Hill, Segment 2 of Phase I," Informal Rep. No. LA-777IMS, Los Alamos Scientific Laboratory, Los Alamos, NM.

Tester, J. W., H. D. Murphy, C.O. Grigsby, R.M. Potter, and B.A. Robinson. I989. "Fractured Geothermal Reservoir Growth Induced by Heat Extraction." SPE J. Reservoir Engineering, 3:97-IO4.

Vuatarez, F-D. 2000. "Review of the Papers on HDR and Enhanced Geothermal Systems." Proc. World Geothermal Congress 2000, Kyushu-Tohoku, Japan.

Yamaguchi, S., S. Akibayashi, S. Rokugawa, Y. Fujinaga, N. Tenma, and Y. Sato. 2000. "The numerical modeling study of the Hijiori HDR test site.” Proc. World Geothermal Congress 2000, pp. 3975-3980, Kyushu-Tohoku, Japan. 


\section{CHAPTER 5}

\section{Subsurface System Design Issues and Approaches}

5.1 Scope and Approach: EGS vs. Hydrothermal Reservoirs

5.2 Formation Characteristics-Porosity, Permeability, Fracture Distribution, Density and Orientation, and Connectivity _ _-_-_-_-_-__-_ 5-3

5.3 Rock-Fluid Interactions

5.4 Temperature Variation with Depth $\ldots \ldots \ldots \ldots \ldots \ldots$

5.5 Geology

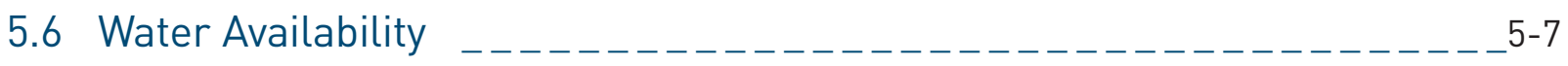

5.7 Susceptibility to Induced Seismicity

5.8 Remaining Issues for Successful Stimulation

5.8.1 Site selection

5.8.2 Instrumentation

5.8.3 Downhole pumps _.

5.8.4 High-temperature packers or other well-interval isolation systems _ _- _ _ 5-9

5.8.5 Short-circuit prevention and repair

5.8.6 Fracture design models

5.8.7 Rock property quantification

5.8.8 Fracturing fluid loss

5.8.9 Fracture mapping methods

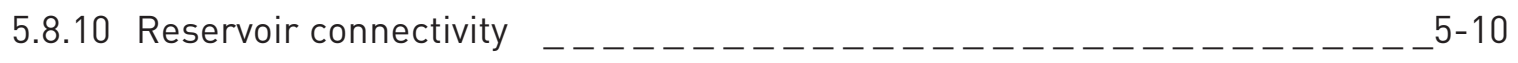

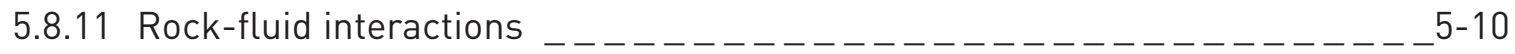

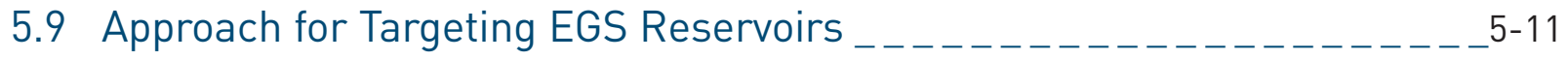

5.10 Diagnostics for EGS Reservoir Characterization _ $\ldots \ldots \ldots \ldots-\ldots \ldots \ldots-\ldots 5-12$

5.11 Reservoir Stimulation Methods _

5.11.1 Geologic case studies _ _ _ - _

5.12 Long-Term Reservoir Management _ _ _ _ _ _

5.13 Conclusions - Stimulation Technologies and Estimated Costs _ _ _ _ 5-19

References _.

Appendices _- 


\subsection{Scope and Approach: EGS vs. Hydrothermal Reservoirs}

Geothermal electric power and heat production from hydrothermal resources has been commercialized since I904, leading to a large body of experience on what constitutes a good hotwater resource. In terms of thermal energy, a kilogram of hot water at temperatures of $\mathrm{I} 50^{\circ} \mathrm{C}$ to $300^{\circ} \mathrm{C}$ has a low energy content compared to a kilogram of hydrocarbon liquid. This occurs because only the sensible and latent enthalpy of the geofluid can be used, rather than the stored chemical energy released during combustion of a hydrocarbon fuel. Therefore, for a producing geothermal well to be comparable in energy content to an oil well, high mass flow rates of hot water are needed. Typically, 50 to $150 \mathrm{~kg} / \mathrm{s}$ or more per production well, depending on its temperature, are required to make a geothermal project economical. Resource temperature and flow per well are the primary factors in defining the economics of a geothermal resource. The increasing cost of drilling deeper wells trades off against the increased thermodynamic efficiency of higher temperature. Eventually, an Enhanced Geothermal System (EGS) will reach an optimum depth after which drilling deeper wells will not be more economical. However, studies by Tester and Herzog (I99I) have shown that the optimal depth for minimum costs is on a fairly flat cost-versus-depth surface for most geothermal gradients. The insensitivity of project cost to depth, in the neighborhood of the optimal point, permits a range of economically acceptable depths.

Hydrothermal projects are based on resources with naturally high well productivity and high temperatures. They rely on having high flow per well to compensate for the capital cost of drilling and completing the system at depth, and they need very high permeability to meet required production and injection flow rates. Typically, in a successful hydrothermal reservoir, wells produce $5 \mathrm{MW}$ or more of net electric power through a combination of temperature and flow rate (see Chapter 7). For instance, a well in a shallow hydrothermal reservoir producing water at $150^{\circ} \mathrm{C}$ would need to flow at about $\mathrm{I} 25 \mathrm{~kg} / \mathrm{s}(2,000 \mathrm{gpm})$ to generate about $4.7 \mathrm{MW}$ of net electric power to the grid. Thus, as a starting target for EGS, we assume that the fluid temperature and production flow-rate ranges will need to emulate those in existing hydrothermal systems.

\subsection{Formation Characteristics - Porosity, Permeability, Fracture Distribution, Density and Orientation, and Connectivity}

A number of resource-related properties - temperature gradient, natural porosity and permeability of the rock, rock physical properties, stresses in the rock, water stored in the rock, and susceptibility to seismicity - control the amount of the heat resource in the earth's crust that can be extracted. These factors, taken together, not only control the physical process of extracting the heat, but also ultimately play a major role in determining the economics of producing energy (see Chapter 9 for details).

In the example above, to determine the economics of the hydrothermal project, the well depth, the temperature, and the flow rate need to be defined. While it is clear that the flow rate of the fluid and its temperature control the rate of energy produced, it is not evident what controls the reservoir production rate. In a natural system, wells flow due to pressure drop at the well, caused either by 
density changes due to boiling or by downhole pumping. The amount of possible pressure drop is controlled by the natural permeability and other properties of the rock that make up the reservoir. The permeability, or ability to conduct water to the well, may result from cracks in the rock or from connected pore spaces; but, from whatever cause, in a hydrothermal system the permeability is high. While permeability is a property of the rock only (related to the interconnectedness and size of cracks or pores), the transmissivity, which includes the cross-sectional area that the fluid flows through on its way to the well, can be influenced by well design. Measured transmissivities in geothermal systems are very high (greater than roo darcy-meters is common), compared to oil and gas reservoirs with transmissivities often around Ioo millidarcy-meters.

In an EGS system, the natural permeability is enhanced - or created when none exists - through stimulation. Stimulation can be hydraulic, through injecting fluids with or without controlling the viscosity at higher or lower rates and pressures; or chemical, by injecting acids or other chemicals that will remove the rock or the material filling the fractures. The stresses on the rocks and the elastic and thermal properties of the rocks in the potential reservoir, along with the design of the stimulation, control the extent of the enhanced or created fractures and their ultimate transmissivity. The natural rock properties and stresses on the rocks then become metrics for the formation of an EGS reservoir.

The economics of hydrothermal systems let us know that we need to target very high flow rates. High flow rates are only possible if the reservoir has high transmissivity. However, high transmissivity can come from a single fracture with a large aperture, or from a large number of fractures with small apertures. We could have both high flow rates and low pressure drop, if a large number of fractures with small fracture apertures gave high transmissivity.

We need to understand how the type of rocks, the stresses on those rocks, and the design of the stimulation interact to develop a connected fracture system. Rocks that are critically stressed to the point where they will fail, shear, and movement during stimulation should produce fractures that will stay open and allow for fluid circulation. Rocks with at least some connected permeability through either fractures or pore spaces are more likely to result in a connected circulation system after stimulation. If there is some significant porosity in the rocks before stimulation, there will be some water stored in the reservoir for future production. Taken together, all of these metrics define the outcome of stimulation and, thus, the economics of the project.

The fracture system not only needs to be connected and have high transmissivity, but it also must allow injected cool water to have sufficient residence time to contact the hot rock, so that it will be produced from the production wells at or close to the formation temperature. The amount of temperature drop in the production fluid that can be tolerated by different power plant equipment then will determine the life of that part of the reservoir for a particular conversion technology. Under given flow conditions, the longer the life of the reservoir, the better the economics.

At the best sites for developing a reservoir, the rocks will be stressed so that when they are stimulated, open fractures will be created. However, if there is too much pre-existing permeability or if the stimulation produces a preferred pathway of very open cracks that the injected fluid can take to the production wells, the created or enhanced fractures may allow water to move too quickly, or short circuit, from the injection wells to the production wells without heating up enough to be economic. 
While permeability of a fractured reservoir can be improved by increasing the injection pressure, there are two negative effects of increasing the throughput in this way: (i) fractures at higher pressures may be "jacked" open, allowing a few paths to dominate and short circuits to occur, and (ii) the critical pressure beyond which fracture growth occurs may be exceeded, extending the reservoir, allowing water to be lost to noncirculating parts of the reservoir and reducing the proportion of effective heat-transfer area.

At Fenton Hill, high-injection pressures were used to maintain open fractures and improve permeability (Brown, I988) However, the fractured volume continued to grow, water was lost from the circulating system, and new fractured volume was created that was not accessed by the wells. At Rosemanowes, trying to improve fracture permeability by increasing injection pressures resulted in growth of the fracture system but away from the inter-well region, exacerbating the water loss without improving the connectivity (see Figure 5.I).

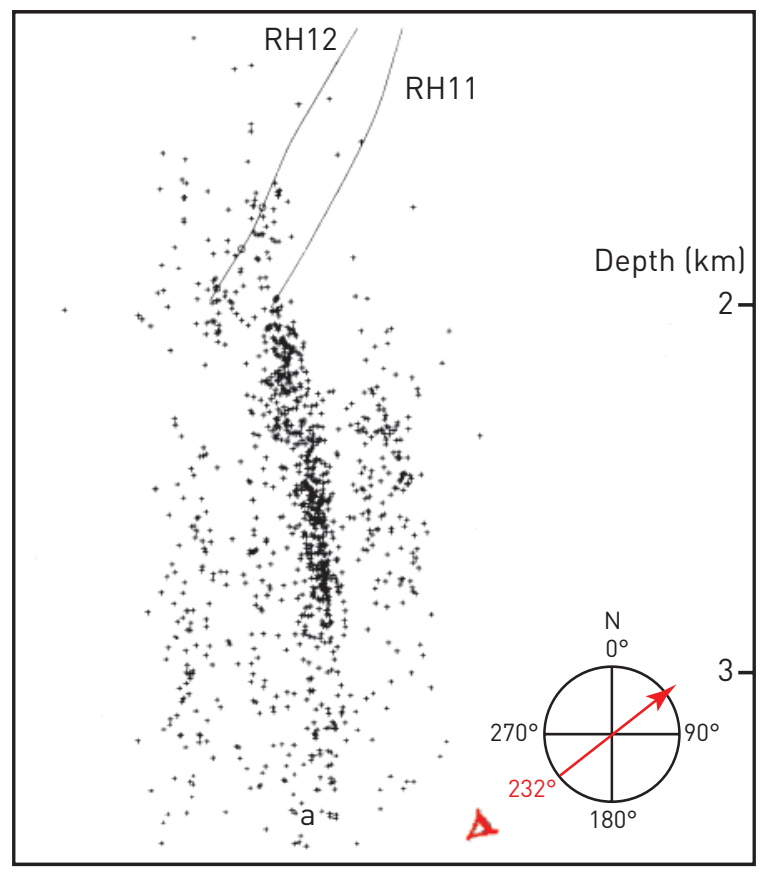

Figure 5.1 Vertical section viewed from the southwest showing downward growth of fractures (microseismic events) at Rosemanowes (Pine and Batchelor, 1983).

\subsection{Rock-Fluid Interactions}

One of the big risk areas in the long-term operation of an EGS system is the potential change in the permeability and connectivity of the stimulated reservoir with time. The fluid injected may be a combination of water from surface or shallow ground water and water naturally occurring in the geothermal reservoir. It will be cooled by the energy conversion system. As a result, the circulated water will not be in equilibrium with the minerals in the rock. With time, these minerals may dissolve or minerals dissolved in the water may precipitate, changing the permeability of the rock over time. In enhanced oil-recovery projects, rock-fluid interactions have been of great importance over the life 
of the project in determining the project economics and the ultimate amount of oil that can be recovered. On the other hand, hydrothermal geothermal projects have dealt with some of the most severe geochemical conditions on Earth and found economic methods to control scale and corrosion.

Because geothermal companies are trying to operate a complex power-generation plant attached to an even more complex natural system - while solving ongoing problems - there are few data available in the literature about their efforts to deal with the geochemistry of geothermal fluids under production. Furthermore, in the competitive marketplace, solutions to such problems are usually deemed proprietary.

Government-sponsored research in this area has quickly been absorbed by the private sector and commercialized. For instance, calcium carbonate scale in geothermal production wells, surface equipment, and in the injection wells has been controlled very successfully by use of scale inhibitors such as polymaleic acid in very small quantities. Silica scale has been more difficult to deal with. Despite research leading to several potential silica-scale inhibitors, the least expensive method of controlling silica scale has been modification of $\mathrm{pH}$. Acidification of the spent brine has worked to some extent, but it causes corrosion in surface equipment that then needs to be dealt with. Lowering $\mathrm{pH}$ probably also impacts the subsurface, but there is not much research on how the acidified fluid reacts with the rock in hydrothermal reservoirs. In some situations, high silica acidified fluids appear to reduce permeability of sedimentary geothermal reservoirs, perhaps by changing the cementation of the grains. In other projects using $\mathrm{pH}$ lowering to control silica scale, injectivity appears to have improved over time in wells receiving the acidified fluid.

At Hijiori, during the long-term flow test, boiling in the wellbore and in the reservoir caused highpressure drop in the production wells that led to scale deposition and required that the wells be cleaned. At Rosemanowes, long-term circulation appeared to improve permeability in one fracture set, but it decreased heat-transfer area and residence time so that a short circuit might have developed.

Circulating fluid that is not in geochemical equilibrium with the rock forming the heat exchange system will have long-term impacts, both on the properties of the reservoir and on the economics of the project. Models exist to predict some aspects of rock-fluid interaction. However, no EGS system has operated long enough yet to test whether the predicted behavior is observed. This is one of the areas with greatest uncertainty for EGS feasibility. Ongoing laboratory studies should help shed light on this issue, but long-term testing will be needed in several different real reservoirs to verify laboratory-scale results.

\subsection{Temperature Variation with Depth}

The temperature gradient determines the depth of wells needed to reach specific temperatures (see also Chapter 2). Knowledge of the temperature is essential to determining the amount of heat in place and the conversion efficiency with which it can be used to generate power. The depth to the resource is a primary factor in determining the cost of the wells. To some extent, the extra cost of drilling deeper wells trades off against the benefit of reaching higher temperatures because higher temperatures result in higher conversion efficiency. Well-field cost in hydrothermal power projects generally accounts for about $25 \%-50 \%$ of the total project capital cost. EGS projects are associated with 
somewhat lower flow rates, lower conversion efficiencies (because of lower temperatures), and greater depths (required to encounter economic temperatures). These factors often bring the well-field cost up to more than $50 \%$ of the total cost of the project, at least in the early stages of project development.

\subsection{Geology}

Other factors affecting well cost include lithology, grain or crystal size, and degree of weathering. These influence the rate of penetration and the life of the drill bit, as well as the mechanical and thermal properties of the rock and, thus, the results of the stimulation. Other geologic factors influence hole stability, ease of maintaining directional control, and drilling fluid circulation loss.

However, drilling cost is not the only cost element of the EGS affected by rock properties. Rock, in general, does not make a very good heat exchanger. While rocks have a high heat capacity and can, therefore, store a large amount of thermal energy per unit of volume, they do not have very high thermal conductivities. This means that water we inject into our enhanced or created reservoir must reside in the fractures or pore spaces long enough to heat up, and that only the rock surface area close to the fluid flow path will give up its heat to the fluid.

There are two ways to increase the residence time of the water in the rock: (i) increase the path length and (ii) slow the flow rate. The second method seems in direct contrast to our goal of having very high flow rates per well. However, we can slow the flow rate in a given fracture or part of the porous system by exposing the fluid to more fractures or a larger porous matrix contact area. This conforms to our other option of increasing the path length, because a longer path length will also allow more contact area. A larger number of fractures in combination with larger well spacing and a more complex fracture or porous pathway should accomplish the goal of a longer residence time for the fluid, and should also result in higher transmissivity.

To accomplish the two goals of long residence time and high transmissivity, a large number of complex fractures - none of them with very large apertures - would work the best. If the natural fractures in place are closely spaced, stimulating them to produce more connected and more conductive pathways should yield an ideal EGS reservoir. However, if fractures are fewer and widely separated, then a much larger well spacing will be needed.

\subsection{Water Availability}

Creation and operation of an EGS require that water be available at the site for a reasonable cost. In the absence of a nearby river, major lake, or the sea as a cooling source, the most efficient powergeneration systems require evaporative cooling, which means that an average of about $15 \%$ of the water requirements for the cooling system are lost to evaporation and need to be replaced. During creation of an extensive and connected fractured system, large quantities of water are needed for stimulation and growth of the reservoir. While most systems probably can be maintained without adding much water through management of pressure in the reservoir, some water will need to be replaced in the reservoir. The size of the reservoir may need to be expanded periodically to maintain the heat-exchange area, requiring the addition of more water. A site with water available in large quantities, in close proximity, will improve project economics. 


\subsection{Susceptibility to Induced Seismicity}

One of the other aspects of project economics and of project feasibility is the potential of the site for induced acoustic emissions (Batchelor et al., I983). At the best potential EGS sites, rocks are critically stressed for shear failure, so there is always the potential for induced seismicity that may be sufficiently intense to be felt on the surface. With current technology, it appears feasible that the number and magnitude of these induced events can be managed. In fact, based on substantial evidence collected so far, the probability of a damaging seismic event is low, and the issue - though real - is often one more of public perception. Nonetheless, there is some risk that, particularly in seismically quiet areas, operation of an EGS reservoir under pressure for sustained periods may trigger a felt earthquake. As a result, the potential for seismicity becomes an environmental factor for determining the economics of EGS project development. This and other environmental factors that would control siting of potential EGS projects are discussed in Chapter 8.

\subsection{Remaining Issues for Successful Stimulation}

At our current level of understanding and with the technology available for stimulating potential geothermal reservoirs, pre-existing fractures with some connectivity in the far field are needed to develop a connected system that can be circulated. The fractures need to be oriented with respect to the stress field in such a way that they will fail in shear; this is the case over a wide range of geologic and tectonic conditions. We can stimulate connected fractures and improve permeability.

\subsubsection{Site selection}

Exploration methods that can effectively tell us the stress field at depth from the surface are not currently available. We can use GPS and satellite imaging to locate and map more regional stress regimes, but it is very difficult to predict the downhole stress patterns and how they will vary with depth. Few wells have been drilled to deep depths in the areas of highest heat flow. Those wells that have been drilled to deep depths are generally oil and gas wells, and the stress data are proprietary for the most part.

The heat flow data we have are limited and not very detailed. Unless an area has been extensively explored for geothermal energy, the detailed temperature-with-depth information that we need for siting EGS exploratory wells is not available. While oil and gas wells are often logged for temperature as part of the normal assessment process, these data are again proprietary and not available.

\subsubsection{Instrumentation}

Evaluation of the geothermal system requires drilling, stimulation, mapping of the stimulated area, and then drilling into the stimulated area. Borehole imaging prior to and post stimulation is a necessity for understanding and assessing the potential system, and for design of the stimulation. Once we have drilled a well, if the rock temperature is above $225^{\circ} \mathrm{C}$, the use of borehole imaging tools for characterizing natural fractures and the stress regime will require precooling of the borehole. Instrumentation for borehole imaging is difficult to protect from borehole temperatures because data pass-throughs permit too much heat gain from the hot borehole environment. High-temperature electronics that would extend the temperature range for all kinds of instrumentation for use in geothermal situations need to be developed and applied to downhole logging tools and drilling 
information systems as well as to seismic-monitoring tools. There is a strong need for hightemperature instrumentation in other technologies such as internal combustion engine monitoring, generators and power generation systems, nuclear power generation monitoring, and hightemperature oil and gas well drilling and logging. These industries can support some of the developments to extend the temperature range for these components. However, geothermal temperatures can far exceed the highest temperatures in oil and gas wells. So, while we can piggyback to some extent on the oil and gas industry, there is still a need for a focused geothermal instrumentation program.

\subsubsection{Downhole pumps}

Experience has shown that downhole pumping of the production well is essential for long-term production management of the EGS reservoir system. However, only line-shaft pumps are currently capable of long-term operation in temperatures above $175^{\circ} \mathrm{C}$. Line-shaft pumps are of limited usefulness for EGS development, because they cannot be set at depths greater than about $600 \mathrm{~m}$. In principle, there is no limitation on the setting depth of electric submersible pumps; but these are not widely used in the geothermal industry.

\subsubsection{High-temperature packers or other well-interval isolation systems}

We know from experience that when we pump from the surface, we preferentially stimulate those fractures that accepted fluid before the stimulation. If we want to stimulate pre-existing fractures that do not accept fluid or create fractures where none exist, we would need to isolate sections of the borehole for separate stimulation. At present, we do not have packers that will accomplish this reliably. Most packers use elastomer elements that are limited in temperature to about $225^{\circ} \mathrm{C}$. Allmetal packers have been developed, but because there is not much demand for packers that function at high temperatures, these have not been tested widely or made routinely available. There is the potential for setting cemented strings of expanded casing with sealable sections in the open-hole section of the well, but this has not been tested either. Inflatable cement packers have been used in certain oil-field applications. They were tried at Fenton Hill unsuccessfully but later implemented successfully at Soultz using cement inflatable aluminum packers. In general, they have not yet been used in hydrothermal wells.

\subsubsection{Short-circuit prevention and repair}

Short circuiting, the development of preferred pathways in stimulated reservoirs, is one of the major problems for EGS economics. Short circuits may develop as part of the initial fracturing process, or during long-term circulation. Either way, we need a suite of methods to repair the situation, or be forced to abandon large sections of the stimulated volume.

\subsubsection{Fracture design models}

Credible hydraulic-fracturing simulation models capable of addressing the propagation of clusters of shear fractures in crystalline rock are not available. Developments must include incorporating dynamic (pressure, time, and temperature) poroelastic and thermoelastic effects in the formations penetrated by the fractures and in the regions of the fracture perimeter - as well as consideration of using explosive and intermediate strain rate stimulation methods. 


\subsubsection{Rock property quantification}

Although some data are available (Batchelor, I984), and some logging/coring analysis methods and numerical models have been developed, we still need better methods for quantifying formation properties pertinent to hydraulic fracturing and post-frac circulation. Methods are needed that include not just the near-wellbore region, but extend out as far as possible from the wells. The methods developed need to be cost-effective as well as reliable. We also need to use data, gathered both in the laboratory and in the field, to validate numerical models for fluid/rock geochemical interaction. The results from current models can vary immensely.

\subsubsection{Fracturing fluid loss}

The behavior of the reservoir during fracturing fluid injection and during circulation - and its relationship to fluid loss - is not well understood. The nature of dynamic fluid loss, and the effects of both poroelastic and thermoelastic behavior remain as issues. Specifically, it is largely unknown how thermal contraction caused by local cooling of the rock at and near fracture channels affects fluid losses and dynamic fracture propagation.

\subsubsection{Fracture mapping methods}

While microseismic event monitoring gives us 3-D, time-resolved pictures of event location and magnitude from which we infer the fractured rock volume, we do not have a quantitative understanding of how the event map relates to the flow paths that define the extent of the underground heat exchanger. More credible methods for mapping tensile fracture and shear fracture cluster geometry resulting from hydraulic stimulation are needed. Also, it may be possible to use the focal mechanisms for the events to determine which events are correlated with fluid flow.

\subsubsection{Reservoir connectivity}

While the fractured volume may be mapped using microearthquake data, there are still issues with ensuring that production wells connect adequately with injectors through the fractured volume. Some portions of the volume may be isolated from the injector. Boundaries due to pre-existing faults, fractures, and lithology changes may prevent connection or make too strong a connection with parts of the reservoir. It may be possible to improve reservoir connectivity through pressuremanagement methods such as producing one well while injecting into another or injecting into two wells simultaneously.

\subsubsection{Rock-fluid interactions}

Geochemistry at low temperatures can be a benign factor, but as the salinity and temperature increase, it may pose difficult engineering challenges. Considerable effort is now going into the numerical modeling of coupled geochemical processes, but generally there is still a lack of data to support the verification of the models. Dissolution and precipitation problems in very hightemperature EGS fields are not well understood. Conventional means of overcoming these problems by controlling $\mathrm{pH}$, pressure, temperature, and the use of additives are widely known from experience at hydrothermal fields. Some laboratory studies may shed light on the processes involved; however, solutions to specific geochemical problems will have to be devised when the first commercial fields come into operation. 


\subsection{Approach for Targeting EGS Reservoirs}

Exploring for hydrothermal geothermal systems is a high-risk proposition. Not only must the resource have a high temperature at a drillable depth, it must also be very permeable with fluid in place and sufficient recharge available to sustain long-term operation. With EGS resources, the exploration effort is not as demanding because, ultimately, only high temperature at drillable depth is really necessary. The temperature-at-depth maps of Chapter 2 provide us with the basic information we need to assess a project site. However, the economics of the project can be greatly improved by selecting a site with the right geological characteristics.

The criteria that make one site more economical to develop than another are fairly obvious. Most will be discussed in detail in the chapter on economics (Chapter 9). Here, we will address the resource characteristics that improve the project economics and reduce project risk.

Proximity to load centers. Where possible, sites relatively close to a load center with existing infrastructure (roads, power lines, water supply, etc.) are preferred.

Temperature gradient. Depth, number of wells, etc., will be set by the required temperature and by economic optimization. Obviously, higher-temperature gradients allow high-temperature rock to be reached at shallower depths, which reduces drilling costs.

Structural information. Because EGS reservoir depths are likely to exceed 3,000 $\mathrm{m}$ (I0,000 ft), structural information on the target formations is likely to be limited. Geophysical techniques should be considered with a view to identifying fault zones, major fractures, and possible convection cells.

Regional stress regime. Some regional stress data are available, but we do not have the ability to estimate stress regimes at depths of interest (see 5.8.I). The type of stress regime is largely unimportant; successful reservoir stimulation usually can be achieved if there is some existing and/or historical differential stress of any kind. The first well should be directionally drilled to maximize the intersection with critically oriented joints in the target region.

Large rock volume. A site with a large volume of fairly homogeneous rock is preferred, which allows extension of information from the first wells to the rest of the area and reduces risk.

Thick sedimentary cover. A thick sedimentary cover, but without overpressure, above basement rock can insulate the crystalline rock, resulting in higher average temperature gradients, thereby reducing drilling cost.

Water availability and storage. Sites in sedimentary rock have the advantage of having water stored in place and will probably exhibit permeability. The matrix porosity may allow for better heat exchange. Sedimentary formations, however, may allow leak-off of injected fluids outside the stimulated reservoir volume.

Microseismic monitoring network wells. For early systems, a microseismic monitoring network will be required (Cornet, I997). Its design will depend on the nature of the superficial formations and the depth and geometry of the target reservoir zone. Wells drilled for exploration, for oil and gas 
production, or for mining, can be used to install microseismic monitoring equipment. Sites that already have these holes can save money on installing the equipment. A site where such a monitoring system is already in place would provide baseline background data as well as reduce cost.

Understanding of lithology and pre-existing fractures. Data on lithology from other exploration efforts, such as oil and gas or an existing well of opportunity, can greatly reduce the risk of the project. The well should be logged and tested to obtain as much information as possible about the undisturbed fracture network. Vertical seismic profiling (VSP) or resistivity surveys may be helpful in identifying major structures.

\subsection{Diagnostics for EGS Reservoir Characterization}

Compared to typical oil and gas field data, there is scant information pertinent to geothermal prospects in crystalline rock. Information collection and diagnostic programs are essential to enhancing understanding, insight and knowledge of the behavior of geothermal granites. Although such programs can be costly, the oil and gas industry learned that the cost of ignorance far exceeds the cost of knowledge when trying to develop low-permeability gas formations. Hence, information collection and diagnostic programs are strongly recommended to accelerate the economical development of EGS. Appendix A.5.3 describes, in detail, the tests recommended to be conducted on the first well to be drilled into a prospective EGS reservoir.

\subsection{Reservoir Stimulation Methods}

In developing a methodology for creating EGS reservoirs, the primary goal of R\&D in field testing is to improve the repeatability and reliability of stimulation methods. Because the cost of drilling the wells and generating the fractured volume is high, correcting problems such as short circuiting and high near-wellbore pressure drop should be a primary goal of any research efforts.

There are two general methods for creating a geothermal reservoir: (i) hydraulic fracturing through successive isolation and stimulation of sections of the wellbore (for details see Gidley et al., I989), and (ii) stimulation of pre-existing fractures at pressures just high enough to cause shear failure.

The original concept developed in the I970s of improving the residual permeability of the in situ rock mass at depth by injecting fluid under high pressure in successive sections of the wellbore has not yet been tested adequately because of technical difficulties. To overcome the problem of thermal drawdown, the concept of parallel stimulations evolved to enhance the total stimulated rock volume (Parker, I989). Supporting this concept are the following ideas:

i. Stronger planned growth of microseismicity following stimulation of short packed-off zones.

ii. The apparent lack of microseismic overlap and the limited hydraulic connection between neighboring stimulated segments. 
iii. The belief that a large open-hole length improves the chance of good connections to natural hydraulic features, which could be enhanced further by bulk stimulation with little development of the rest of the potential EGS reservoir.

iv. Increased engineering confidence in an ability to satisfactorily conduct stimulations of small zones with near planar spread of stimulated regions. The observed pressure/microseismic response of each small stimulation might be used to tailor the stimulation for each zone to the requirements of a uniform reservoir.

For example, at Rosemanowes, U.K., it was found that the impedance to flow between wells was too high, that the reservoir volume was too low, and that this had resulted in significant thermal drawdown. The use of gels with varying degrees of viscosity was tested to overcome the impedance problem by jacking the joints apart farther into the reservoir. However, it is probable that these methods resulted in the development of some fracture paths with much higher permeability shortcircuiting to the other wells.

Attempts to fracture successive parts of the wellbore at Fenton Hill ran into problems with setting packers in deep, high-temperature rocks. Although some packers held, and hydraulic fracturing was attempted with the packer in place, it is likely that fracturing around the packer occurred. A segment of casing cemented in place was an effective way to place a seal and isolate the section of the wellbore for treatment. However, this is costly, decreases the size of the wellbore, and must be planned carefully to avoid the need to go back in different segments or shut off potentially productive zones.

The multisegment concept is an attractive one; however, it may be difficult to engineer because each reservoir segment has to be progressively stimulated, circulated, and tested in isolation, without causing a cross-flow. The concept has not been tried, and achieving hydraulic separation between reservoir segments may represent a difficult engineering feat. Otherwise, certain paths (short circuits) could dominate, thus reducing the overall sustainable life of the reservoir. The separate stimulation of isolated zones at great depth and temperature also may need extensive engineering development to occur. However, with a drillable inflatable packer now available for high-temperature use, the concept of successively fracturing different zones should be revisited.

Hydraulic stimulation has been effective in overcoming local difficulties of fulfilling economic reservoir creation targets. Reservoir development at the current state of the art will need to target rock with existing fractures and a stress state that promotes fractures to shear. A large volume of rock with similar conditions should be found for a large-scale project to be possible. Generally speaking, from experience to-date and in conjunction with previous developments from other projects, the basic steps for reservoir creation can be described as follows:

I. Drill the first deep well (injection) with the casing set at appropriate depth to give the required mean reservoir temperature.

2. Obtain basic fundamental properties of the underground such as stress field, joint characteristics, in situ fluid characteristics, mechanical properties of the rock mass, and the identification of flowing /open zones where appropriate.

3. Having established the best positions for the sensors of the microseismic sensor array, install an appropriate instrumentation system to yield the best possible quality of microseismic event locations, not only during the first stimulations but for all events likely during the reservoir's lifetime. 
4. Conduct stepped flow-rate injections until the pressure for each injection step becomes steady. The maximum injection pressure should exceed the minimum formation stress at the point of injection.

5. Maintain high flow-rate injection until the seismicity migrates to the distance necessary for targeting the second well.

6. Depending on the relationship of the in situ stress and the density of in situ fluid, it may be possible to influence the vertical direction of reservoir growth by selecting an appropriate density of the stimulation fluid.

7. Perform a shut-in test to assess the size of the reservoir.

8. Carry out flow logs in the injection well to identify the main flowing zones.

9. Let the reservoir deflate and then make injection tests at lower flow rates to assess the permanent residual enhancement of permeability i.e., flow against injection pressure.

Io. Target the second well (production) into the periphery of the seismically activated structure, with the separation of the wells appropriate to suit economic targets. At the same time, ensure that the well has a downhole pumping chamber incorporated in its completion plan.

II. Stimulate the second well in a stepped manner as described above to improve access to the previous stimulated zone and eventually permit the recovery of the mobile in situ fluid (carry out diagnostic technique as in steps 3 and 8).

I2. Conduct short-circulation tests to assess the connectivity between the injector and the producer.

13. Perform tracer tests to evaluate reservoir flow-through volume, to characterize the residence time distribution, and to identify any short-circuit paths.

I4. Repeat steps Io to I4 for the third well, i.e., the second production well, and for a fourth and even fifth, if the system warrants this.

This process can then be repeated to create a large enough system to support a commercial power generation or heat and power installation. Although the steps described above are very rudimentary and perhaps oversimplify the overall approach, the general trend remains and the procedure fits with our understanding of the reservoir creation process. Each area or region will have its own specific properties and these will have to be taken into account in the general reservoir stimulation concept described.

Channeling or short circuiting of circulation fluids has been a nemesis in conductive heat transfer efforts. The feasibility of altering injection/producing patterns may be worth further investigation.

\subsubsection{Geologic case studies}

To demonstrate how this process might work in specific areas, and how costs might vary for different geologic conditions, some specific geologic cases were chosen (Table 5.I). These sites cover a wide geographical area and represent a diverse set of geological characteristics that are appropriate for a nationwide deployment of EGS technology.

\section{i. Winnie, Texas}

A deep, overpressured sedimentary basin with moderate geothermal gradient on the Gulf of Mexico. The area is actively producing oil and gas from both shallow and deep depths. The target 
formation for an EGS would be the Cotton Valley Formation, a tight sand encountered at between $4.6 \mathrm{~km}(\mathrm{I} 5,000 \mathrm{ft})$ and $5.2 \mathrm{~km}(\mathrm{I7}, 000 \mathrm{ft})$. In this area, temperature gradients are about $40^{\circ} \mathrm{C} / \mathrm{km}$, and the temperature at the completion depth of $5.75 \mathrm{~km}(\mathrm{I} 8,900 \mathrm{ft})$ is $200^{\circ} \mathrm{C}$. Rates of penetration (ROP) for this area are high except for soft shales at shallow depths. However, well costs are affected by overpressure encountered in some formations, so extra casing strings may be needed.

\section{ii. Nampa, Idaho}

This location in southwest Idaho is in the Snake River Plain with basalt to a depth of about $1.5 \mathrm{~km}$ and granitic basement below that. Basalt is hard and abrasive with fractures and loss zones. The temperature gradient is $43^{\circ} \mathrm{C} / \mathrm{km}$ on average, but is higher below the basalt, so that the completion temperature at the target depth of $5.5 \mathrm{~km}$ is $265^{\circ} \mathrm{C}$.

\section{iii. Three Sisters, Oregon}

The area immediately around the Three Sisters volcanoes is a national park and is, therefore, offlimits for drilling. However, a large caldera complex with high heat flow extends to the east toward Bend. Faults trending northeast-southwest, possibly tensional, pass through the caldera area and make this a potential target. Volcanics with potentially large lost circulation zones overlie granitic basement. The target temperature is $250^{\circ} \mathrm{C}$ at $4.6 \mathrm{~km}$, due to a geothermal gradient of about $50^{\circ} \mathrm{C} / \mathrm{km}$. However, shallow groundwater circulation may obscure a much higher gradient, and no deep well data are available to determine this.

\section{iv. Poplar, Montana}

Plentiful data and ongoing oil and gas production from the Poplar Dome oil field in the Madison limestone make this site of interest. There are two targets: (i) the shallow, known-temperature oil field with temperatures of about $135^{\circ} \mathrm{C}$ at $2.2 \mathrm{~km}$ and (ii) the deep, granitic basement at $250^{\circ} \mathrm{C}$ at $6.5 \mathrm{~km}$ or possibly shallower. There has been little deep exploration in this area because production in the upper zones has been sufficient. However, as production has declined, deeper wells have been drilled in neighboring fields. Unfortunately, few temperature data are publicly available. The example addressed below is completed at shallow depth and low temperature in the Madison limestone because there are available data on this resource. The area generally is normally pressured. The location on a Sioux reservation with a casino, development, and increasing demand for power make this site somewhat more attractive.

\section{v. Kelseyville, California}

The Clear Lake volcanic field has very high temperature gradients and a great deal of data from both mining and geothermal exploration. Although tailings piles from mercury mining drain into the lake in some areas, making the environmental aspects of this site challenging, the location was chosen away from old mines but outside the city of Kelseyville. The target temperature is $4 \mathrm{I} 5^{\circ} \mathrm{C}$ at a depth of $6 \mathrm{~km}$. The high temperature warrants the deep depth. Altered and potentially unstable meta-sedimentary rocks overlie granite, which starts at variable depth of around 3-4 km.

\section{vi. Conway, New Hampshire}

This site is in the East, with a somewhat elevated temperature gradient (for the East Coast) of $24^{\circ} \mathrm{C} / \mathrm{km}$. The completion depth is $7 \mathrm{~km}$ to reach $200^{\circ} \mathrm{C}$, with drilling through granite to total depth. The stress regime in this area is not well known, but is likely to be strike slip. 
Table 5.1 Example of site-fracturing information.

\begin{tabular}{|c|c|c|c|c|c|c|}
\hline & $\begin{array}{l}\text { E. Texas } \\
\text { Basin }\end{array}$ & Nampa & $\begin{array}{l}\text { Sisters } \\
\text { Area }\end{array}$ & $\begin{array}{l}\text { Poplar } \\
\text { Dome }\end{array}$ & $\begin{array}{l}\text { Clear } \\
\text { Lake }\end{array}$ & $\begin{array}{l}\text { Conway } \\
\text { Granite }\end{array}$ \\
\hline $\begin{array}{l}\text { Average } \\
\text { temperature gradient } \\
\text { to } 250^{\circ} \mathrm{C},{ }^{\circ} \mathrm{C} / \mathrm{km}\end{array}$ & 40 & 43 & 50 & 37 & 76 & 24 \\
\hline Depth to $250^{\circ} \mathrm{C}, \mathrm{km}$ & 5.75 & 5.5 & 4.6 & 6.5 & 3 & 10 \\
\hline $\begin{array}{l}\text { Completion } \\
\text { temperature, }{ }^{\circ} \mathrm{C}\end{array}$ & 200 & 265 & 250 & 135 & 415 & 200 \\
\hline $\begin{array}{l}\text { Depth to top of } \\
\text { granite, } \mathrm{km}\end{array}$ & 5 & 4.5 & 3.5 & 4 & 3 & 0 \\
\hline $\begin{array}{l}\text { Completion } \\
\text { depth, km }\end{array}$ & 5 & 5 & 5 & 2.2 & 6 & 7 \\
\hline Stress type & Tension & Tension & Tension & Strike slip & Tension & Strike slip \\
\hline $\begin{array}{l}\text { Completion } \\
\text { formation (bedrock) }\end{array}$ & $\begin{array}{l}\text { Sandstone, } \\
\text { silicified }\end{array}$ & Granite & Granite & $\begin{array}{l}\text { Madison } \\
\text { limestone }\end{array}$ & Granite & Granite \\
\hline $\begin{array}{l}\text { Overlying } \\
\text { formations }\end{array}$ & $\begin{array}{l}\text { Soft grading } \\
\text { to harder } \\
\text { cements }\end{array}$ & $\begin{array}{l}\text { Basalt to } \\
\text { about } 1.5 \mathrm{~km}\end{array}$ & $\begin{array}{l}\text { Tuffs, } \\
\text { andesite/ } \\
\text { basaltic } \\
\text { lavas, } \\
\text { andesite }\end{array}$ & $\begin{array}{l}\text { Sandstone/ } \\
\text { limestone/ } \\
\text { shale }\end{array}$ & $\begin{array}{l}\text { Rhyolite/ } \\
\text { hydro- } \\
\text { thermally } \\
\text { altered } \\
\text { meta- } \\
\text { sediments }\end{array}$ & None \\
\hline
\end{tabular}

The sites with crystalline basement will be similar to many of the EGS sites studied so far for research purposes. All of these sites have significant stress histories that should have produced pre-existing fractures. The two sites in sedimentary basins are routinely fractured for oil and gas production and resemble the situation at Horstberg. Water is available from oil and gas production for fracturing and for circulation makeup. Water costs for the other sites assumed purchase from the local water utility, although the New Hampshire site is very close to a river, and there should be ample water available in the long term for cooling and makeup, as well as fracturing, because the run of the river water law is followed in the east. 
Cost estimates were based on the assumption that commercial fracturing service companies would perform the hydraulic-fracture stimulation. Portions (some significant) of the above costs depend on: (i) equipment mileage from the nearest pumping service company office to the site, and (ii) service company on-site personnel time charges.

For these cases, the results from two hydraulic-fracturing models, Perkins Kern Nordgren (PKN) and Geertsama de Klerk (GDK), were used for volume, pumping power, and pumping time requirements. The PKN and GDK models yield close, but not exact, results for these. Because no direct link between cost and any property of the reservoir could be found, an average of the results from each was used in the analysis.

All cases were for a vertically oriented fracture (or shear fracture cluster), penetrating radially outward and downward as well as up, (centered at the casing shoe), with a fracture radius of $900 \mathrm{~m}$ to provide $5 \mathrm{XIO}^{6} \mathrm{~m}^{2}$ of fracture face exposure. The in situ stresses in the fracture regions were based on a stress gradient of $0.136 \mathrm{MPa} / \mathrm{m}$. The injection fracturing pipe string was consistent with the drilling-casing programs for the site for calculating surface injection power requirements.

The effective rock mechanical properties (elastic moduli and Poisson's ratios), and fluid efficiency parameters for the designs, were based on relative percentages of granite to non-granite formation penetrated by the fracture (shear fracture cluster).

The costs for all project wells include tailing (placing) in relatively small, but sufficient, proppant quantities to mitigate high-pressure drop (skin) effects in the near wellbore vicinity. Table 5.2 shows the estimated cost for two average injection rates. Detailed step rate injection histories were not used for this analysis.

It was assumed that each well would need two fracture treatments. Experience would determine whether this is the best strategy or whether one longer fracture treatment would be more effective, so that in out years, the cost might be cut in half. These costs can be lowered further for later stimulations - once the project is determined to be feasible - by using purchased pumps that would be used for long-term site operations. For large-scale projects, there would be on-site fracturing pumps, designed for long-term operation, to stimulate new reservoirs without a service company. This represents a cost benefit in developing a large volume of relatively uniform rock.

Table 5.2 Cost estimates for wells at example sites, for two average injection rates.

\begin{tabular}{l|l|l|l}
\hline Project site & $\begin{array}{l}\text { Percentage of } \\
\text { fracture in granite }\end{array}$ & \multicolumn{2}{l}{ Hydraulic fracturing costs, \$ } \\
\cline { 3 - 4 } & & @ 93 kg/s & @ 180 kg/s \\
\hline Winnie, TX & $0 \%$ & 145,000 & 171,000 \\
\hline Nampa, ID & $39 \%$ & 260,000 & 356,000 \\
\hline Sisters, OR & $83 \%$ & 348,000 & 450,000 \\
\hline Poplar, MT & $0 \%$ & 152,000 & 179,000 \\
\hline Kelseyville, CA & $56 \%$ & 450,000 & 491,000 \\
\hline Conway, NH & $100 \%$ & 502,000 & 580,000
\end{tabular}




\subsection{Long-term Reservoir Management}

Because no resource of commercial size has been tested for more than a few months, there are few data to make conclusions about the long-term management of an EGS resource. Flow rate per production well, temperature, and pressure drop through the reservoir and wells govern the energy that can be extracted from a well system. The nature of the fractured reservoir controls the reservoir life and the amount of heat that can ultimately be recovered from the rock volume. The pressure drop and wellhead temperature are both controlled by the nature of the fracture system, the surface area that the fluid is in contact with, and the fracture aperture and path length. While a long path length is desirable for a long reservoir life, a long path length would be likely to result in higher pressure drop. On the other hand, if there are many paths for the fluid to take, high flow rates and high fracture surface area can both be achieved with lower pressure drop, better heat exchange, and higher total heat recovered from the rock volume.

The amount of temperature drop in the active reservoir that can be tolerated by any given system is largely a matter of project economics. If there is no temperature decline, then the heat is not being efficiently removed from the rock. If there is too much temperature decline, either the reservoir must be replaced by drilling and fracturing new rock volume, or the efficiency of the surface equipment will be reduced and project economics will suffer. The amount of decline in circulating fluid temperature that power-generation equipment can tolerate is a matter of economics. While a given plant may be able to run with temperatures as much as 50\% lower than the initial design temperature (in degrees Celsius), the net power output may fall below zero if there is not enough power to operate the pumps for the circulation system. With current technology, there are a number of options for operating the reservoir that might work to manage the reservoir long term. For the purpose of economics, a I०\% drop in temperature means that the system can still operate without too extreme a reduction in efficiency, while extracting heat from the rock and maintaining some rock temperature for future heat mining. Sanyal and Butler (2005) use a drop of $15 \%$ in their analysis of recoverable heat from EGS systems, so a Io\% drop is probably conservative. The temperature drop at East Mesa exceeded I०\% in some parts of the field, and changes to the wellfield system were able to restore some of this without huge expense. This amount of temperature drop would be significant enough to trigger some intervention.

Long-term reservoir management demands that models predicting long-term temperature, pressure, and fluid chemistry behavior be validated with data collected from operating the reservoir (for example, see Dash et al., I989). These models can be used to predict the reservoir behavior prior to operation and then make changes in well pressures, flow rates, and in the reservoir fractured volume to maintain the produced fluid temperature.

The circulation system consists of injection pumps, production pumps, the surface conversion system, the wells, the fractured reservoir, and the piping to move the fluid around. Each of these elements involves frictional pressure drop, which needs to be accounted for in the economics of the project because it represents an energy loss to the system. The wellbore size must be planned to accommodate the lowest pressure drop, while also controlling the cost of the well. The production wells most likely will be pumped using downhole pumps and so must be designed to accommodate the pump diameter needed for the pumps and motors - usually about $24 \mathrm{~cm}(9.5)$ - and maintain a sufficient-diameter downhole to reduce pressure drop for the high flow rates. 
Buoyancy effects due to the density difference between the hot production and colder injection wells work to reduce the pumping work required for fluid circulation. Given that many EGS systems will involve deep reservoirs, this effect can have a significant impact on overall system performance. Buoyancy causes a pressure gain which, in principle, can be large enough to cause the system to "selfpump" as a result of a thermal siphon effect. For example, for a $250^{\circ} \mathrm{C}$ reservoir at $6 \mathrm{~km}$, the net buoyancy gain could be as large as Io MPa (I450 psi). Therefore, if the pressure drop in the circulating system - due to frictional losses in the wells and impedance within the fractured formation - was less than io MPa, the system would self-pump.

The life of the reservoir is largely controlled by the effective surface area and the total volume of rock that the circulating fluid accesses. However, other factors affecting the lifetime of the system include the amount of short circuiting of fluid between injection and production wells, the quantity of water permanently lost to the surrounding rock, and the amount and severity of seismic activity generated during reservoir operation (if any). The development of preferred pathways in the reservoir through which fluids can bypass portions of the fracture rock mass (termed "short circuiting") is one of the major challenges facing EGS system development. To measure short circuiting, tracer testing with numerical modeling will probably yield the best metric, but more research work needs to be done in this area. The metric adopted here is the ratio of the volume of tracer-doped water before breakthrough to a producer to the total reservoir effective volume. The larger this ratio is, and the closer it is to the reservoir porosity (usually I\% to 7\% for fractured hard rocks), the less the short circuiting.

Loss of fluid to the reservoir determines how much cold fluid must be added as the system is produced. Because makeup water may be expensive, low fluid loss is desirable. Minimal loss is also desirable from other considerations. Fluid that has circulated repeatedly through the reservoir will eventually come to chemical equilibrium with the reservoir rocks, neither dissolving nor depositing minerals. Also, makeup water will be colder than water injected directly from the surface plant, so addition of large amounts of makeup water will hasten the cooling of the rock volume.

\subsection{Conclusions - Stimulation Technologies and Estimated Costs}

The analysis presented in Chapter 2 indicates that the heat stored in the earth to depths that are accessible with today's technology is truly vast. However, the fraction of this resource base that can be economically recovered is dependent on increased understanding of reservoir behavior and, therefore, is directly connected to current research and testing of EGS. Here, we present some of the pressing needs to advance the state of the art in EGS reservoir technology.

- Assessing the size of the stimulated volume and heat-transfer area. Being able to determine the heatexchange area and the volume of the fractured rock in an EGS reservoir is an important part of stimulation design and operation. Conservative tracers, thermally and chemically reactive tracers, natural fluid tracers, microseismic monitoring, active seismic measurement, and advanced forms of reservoir tomography such as muon tomography are areas with potential for determining the size of the resource accessed, and for targeting and drilling further production and injection wells. 
- Development of high-temperature downhole tools. While downhole tools have been developed that can be used to measure temperature, pressure, flow, and natural gamma emissions on a short-term basis, these instruments cannot be left in the well for long-term monitoring. In addition, tools for microearthquake monitoring are limited to temperatures below $120^{\circ} \mathrm{C}$. New generation downhole tools need to withstand temperatures of more than $200^{\circ} \mathrm{C}$ for extended time periods to be useful for monitoring over the lifetime of the reservoir.

- Better understanding of rock/water interactions. One important area of ongoing research is prediction and monitoring of rock/water interactions (for example, see Moller et al., 2006). Although our understanding of the chemistry of rock/water systems has improved, we are still working on predictive models of long-term behavior in an EGS operation. Past EGS field experiments have yielded only scant information on rock/water interaction because of their limited duration. Data are available from deep petroleum industry wells, but these data have not been collected and analyzed for their relevance to EGS development. Control of scale formation and rock dissolution in the reservoir are areas for technology enhancement through research. Whereas scale and corrosion in wells and surface equipment can be controlled using methods developed by the hydrothermal industry, this has not been attempted in the reservoir itself.

- Methods for coping with flow short circuits. An important area for engineering research is the development of methods for dealing with flow short circuits that may develop during operation of the EGS reservoir. A better understanding of this will allow fluids to be directed to specified parts of the reservoir, and will prevent excessive water loss. The oil and gas industry uses fluids with controlled viscosity to accomplish some of this. Currently, the temperature limit for fluid additives to control rheology is about $175^{\circ} \mathrm{C}\left(350^{\circ} \mathrm{F}\right)$, well below the target temperature of $200^{\circ} \mathrm{C}$ for high-grade EGS projects. Increasing oil prices have resulted in renewed interest in extending the temperature limits for these fluid additives as higher-temperature oil and gas fields become economical to produce. As a result, maximum temperatures for fluid additives have been increased through research by the petroleum industry. There may be other areas of research that can result in reduced risk of short circuiting, or in managing sections of the wellbore to shut off preferred pathways. Pressure management of the reservoir may be useful for long-term control of both fluid loss and tooshort fluid pathways causing excessive cooling.

- Strategy for dealing with formation temperature decline. The current strategy for coping with temperature drop in the system is to replace the cooled fracture volume with new fractured rock. This can be accomplished by drilling new wells into previously unfractured rock or by drilling legs from existing wells into rock previously fractured but not accessed by circulation. In large-scale, commercial systems, the well spacing and pattern would be designed to take advantage of as much of the created or enhanced reservoir as possible, so that no upfront fracturing cost would be wasted. However, there is bound to be some volume that is not swept on the edges of the system, which could be accessed either by redrilling wells, or by drilling new wells. The ongoing reservoir maintenance of a commercial-size system with many well groups and circulation cells would require adding new reservoir fracture area at regular intervals to maintain temperature and flow rate to the plant. This becomes part of the cost of maintaining the reservoir. 
- Methods to control growth of fractured volume. It is clear from experiences at Soultz and other EGS sites that reservoirs can continue to grow during circulation, unless pressures are controlled and balanced to avoid expansion. Strategies for controlling operating pressures could be developed empirically by tracking the reservoir growth with seismic monitoring equipment. New wells, or new legs to existing wells, could then be drilled to access this new portion of the reservoir. This type of reservoir management would require validated numerical models that accurately predict reservoir behavior. Thermal hydraulic models currently can handle heat transfer, but they do not quantitatively predict changes in fracture surface area or permeability with pressure and temperature. Geochemically induced changes in permeability may be modeled in the future, but presently are not included in most models.

- Improved reservoir modeling. The future of EGS is extremely dependent on our understanding of the natural, unstimulated rock fracture system and on our ability to predict how the reservoir will behave under stimulation and production (for example, see DuTeaux et al., I996). So far, we have not operated a commercial-sized EGS reservoir long enough to be able to use the data to validate a model. Until we do this, it is difficult to estimate the actual operating cost of one of these systems. At this early stage, we have based estimated EGS stimulation costs on variations of oil and gas field practice (see Chapter 9 for details). As more data become available, these costs will be refined.

To sum up, a robust R\&D program will be needed to realize the ultimate potential of EGS. More specifically, to extend the predictive capabilities of reservoir performance modeling will require validation with extensive flow testing at a number of EGS field sites (e.g. see Figure 5.2).

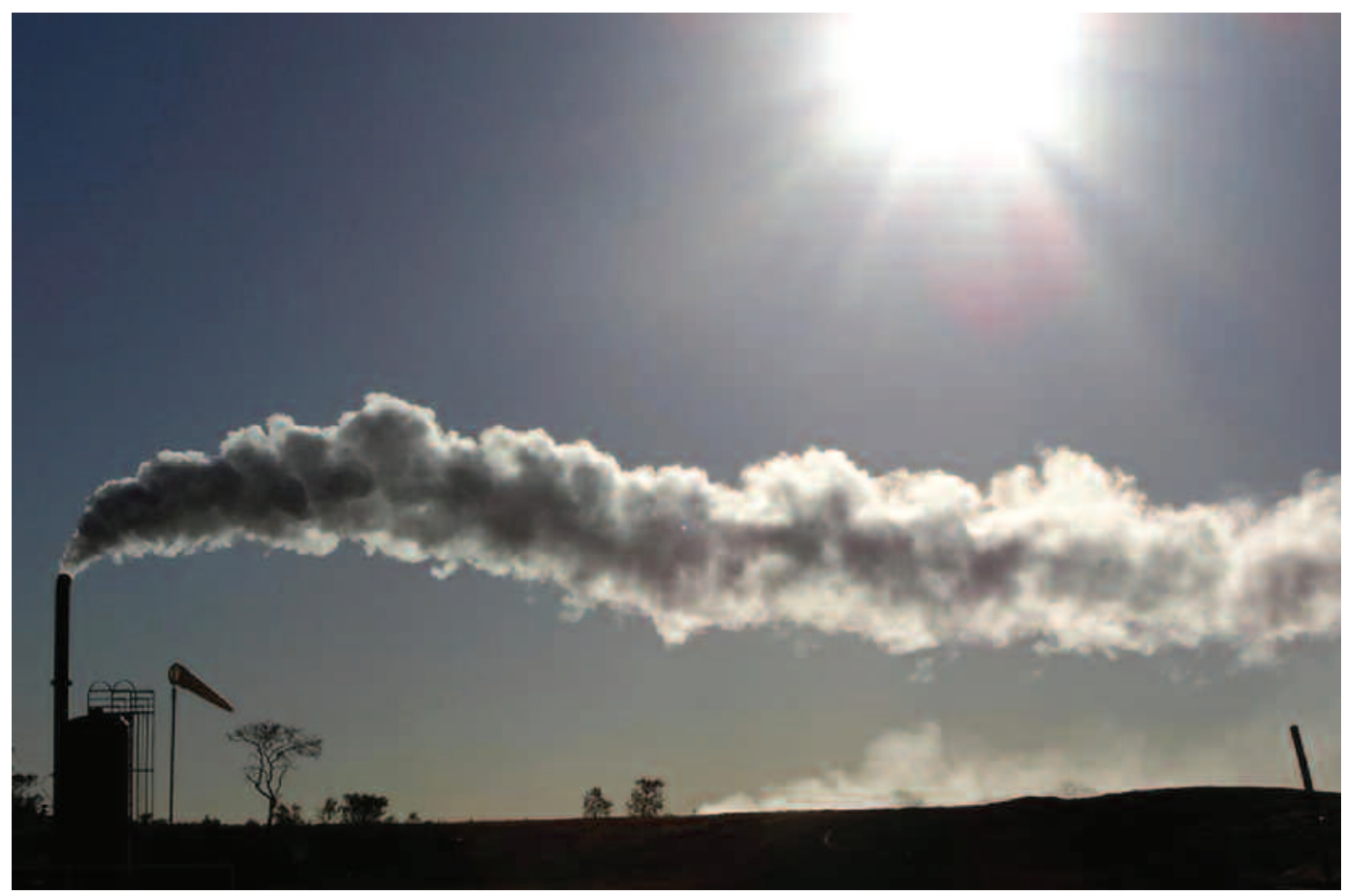

Figure 5.2 Flow tests at Cooper Basin EGS site, Australia (Geodynamics, 2005). 


\section{References}

Batchelor, A. S. I984. "Mechanical properties of the Carnmenellis granite." Internal Report 2-46, Camborne School of Mines Geothermal Energy Project, UK, Group III, Part 3, Volume I.

Batchelor, A. S., R. Baria, and K. Hearn. I983. "Monitoring the effects of hydraulic stimulation by microseismic event locations: A case study." SPE Paper 12109, Presented at the SPE $58^{\text {th }}$ ATCE, San Francisco, Calif.

Brown, D. W. I988. "Anomalous earth stress measurements during a six-year sequence of pumping tests at Fenton Hill, New Mexico.” Los Alamos National Laboratory report, LA-UR-88-3985.

Cornet, F. H. I997. "Proceedings of the Ist workshop on the development of a multiborehole observatory at the Gulf of Corinth." International Continental Drilling Program, Athens.

Dash, Z. V., R. G. Aguilar, B. R. Dennis, D. S. Dreesen, M. C. Fehler, R. H. Hendron, L. S. House, H. Ito, S. M. Kelkar, M. V. Malzahn, J. R. Miller, H. D. Murphy, W. S. Phillips, S. B. Restine, P. M. Roberts, B. A. Robinson, and W. R. Romero. I989. "ICFT: An initial closed-loop flow test of the Fenton Hill Phase III HDR reservoir.” Los Alamos National Laboratory report, LA-II498-HDR, DE89007286.

DuTeaux R., D. Swenson, and B. Hardeman. I996. "Insight from modeling discrete fractures with GEOCRACK, a geothermal reservoir model," Proceedings Twenty-First Workshop on Geothermal Reservoir Engineering, Stanford University, Calif.

Geodynamics. 2005. "Quarterly Report, Period ending 30 June 2005," Geodynamics, Ltd., Milton, Queensland, Australia.

Gidley, J. L., S. A. Holditch, D. E. Nierode, and R. W. Veatch Jr. I989. "Recent advances in hydraulic fracturing." Soc. Petr. Eng. Monograph, I2.

Mansure, A. J. and L. J. Westmoreland. 2000. "Plugging lost-circulation zones with polyurethane: Controlling the process." Geothermal Resources Council Transactions, 24.

Moller, N., C. Christov, and J. Weare. 2006. "Thermodynamic models of aluminum silicate mineral solubility for application to enhanced geothermal systems." Proceedings of the 31st Stanford Workshop on Geothermal Reservoir Engineering, Calif.

Parker, R. H. (Ed). I989. Hot Dry Rock Geothermal Energy, Phase 2B Final report of the Camborne School of Mines Project, Two Volumes, Pub Pergamon Press, ISBN o-08-037929-X.

Pine, R.J. and A. S. Batchelor. I983. "Downward growth of hydraulic stimulation by shearing in jointed rock." Submitted to the international Journal of Rock Mechanics and Mining Sciences.

Sanyal, S. K. and S. J. Butler. 2005. "An analysis of power generation prospects from enhanced geothermal systems." Proceedings Geothermal Resources Council 2005.

Sarian, S. and A. Gibson. 2005. "Wireline technology in HPHT wells." SPEE Paper 97571, Presented at the SPE High Pressure High Temperature Sour Well Design Applied Technology Workshop, The Woodlands, TX.

Tester, J. W. and H. J. Herzog. I991. "The economics of heat mining: an analysis of design options and performance requirements for hot dry rock (HDR) geothermal power systems." Energy Systems and Policy, 25:33-63. 


\section{Appendices}

\section{A.5.1 Current State of Technology}

\section{A.5.I.I Logging tools}

Temperature, pressure, spinner, and gamma tools are available for use on logging cable for up to about $300^{\circ} \mathrm{C}$. For temperatures exceeding this, the tools should be used as memory tools run on slick line. Resistivity, sonic, gamma, and density neutron tools are available for use at or above $260^{\circ} \mathrm{C}$ and $20 \mathrm{MPa}$ pressures (Sarian and Gibson, 2005). Borehole imaging can be done by cooling the hole and using Formation Micro-imaging (micro resistivity) or by using a high-temperature $\left(225^{\circ} \mathrm{C}\right.$ limit) ultrasonic borehole televiewer.

\section{A.5.I.2 Downhole mechanical tools}

Downhole mechanical tools (packers, etc.) can be equipped for reliable service up to about $250^{\circ} \mathrm{C}$. However, open-hole packers that can be set and released reliably are not readily available for these temperatures. Sandia (Mansure and Westmoreland, 2000) has contributed to the development of a drillable inflatable packer by Weatherford that can be used at high temperatures. Although the packer is not retrievable, it is drillable after the stimulation is finished. Similar noncommercial packers have been used successfully at Soultz.

\section{A.5.I.3 Hydraulic-fracturing materials}

Propping agents: Manufactured chemically stable proppants can provide acceptable long-term fracture conductivities at $8,000+$ meters and temperatures of $250^{\circ} \mathrm{C}$.

Fracturing fluids: Although water is the fluid of choice from an economic standpoint, there are alternatives that can provide adequate proppant transport rheology for periods of 72 hours at temperatures of $220^{\circ} \mathrm{C}$. However, viscosity begins to decrease at about $175^{\circ} \mathrm{C}$ for most hightemperature fluids. Planning for this is necessary, if alternative fluids are to be used.

\section{A.5.I.4 Downhole electric submersible pumps}

Downhole electric submersible pumps are available for temperatures up to $175^{\circ} \mathrm{C}$. High-volume flow rates of up to about I25 $1 / \mathrm{s}$ can be produced at this temperature, but there is little testing at temperatures higher than this. Line-shaft pumps can produce fluids at higher temperatures, but these cannot be set at depths greater than about $600 \mathrm{~m}$. They also require the use of oil lubrication of the rotating driveshaft. This oil leaks to the reservoir and is injected, causing long-term environmental risk and possible clogging or fouling of the heat exchangers in binary plants.

\section{A.5.I.5 Numerical models}

Numerical models are available for flow in fractures with heat exchange and changing pressure. However, the effect of thermal and pressure changes on permeability in fractures along with heat exchange has not been adequately modeled in such a way that fracture growth can be predicted. Fully coupled models that take geochemical effects into account are far from being perfected. Much more work is needed on the correlations required for these models, if they are to be used successfully. 


\section{A.5.2 Oil and Gas Developments Relevant to EGS}

The oil and gas industry continues its pursuit of technology and tools applicable to high-pressure, high-temperature conditions. The temperatures that are currently being encountered for oil and gas development generally are on the lower end of the geothermal temperature spectrum. However, as the price of oil and gas increases, the search for new U.S.-based reserves will extend into deeper formations with higher temperatures and pressures.

Capability limits (both temperature and pressure) have increased significantly during the past decade for oil and gas wire-line logging equipment, downhole mechanical tools, and hydraulicfracturing materials. These limits are expected to continue increasing to serve the needs of the oil and gas explorers and producers as they progress into more severe environments. As a result, the technology and tools that will emerge in the oil and gas industry also will be useful for developing geothermal applications.

\section{A.5.3 Tests for the First Well in an EGS Project}

The following lists specific tests and logs that are recommended for EGS wells:

I. Collection of full-hole, oriented core samples (one core barrel) at Ioo $\mathrm{m}$ intervals throughout the prospective portion of the formation where fracture penetration is expected.

2. Comprehensive laboratory core analysis to ascertain:

- Rock properties (via both mechanical and acoustical tests) for elastic modulii, Poisson's ratios, compressive and tensile and shear strengths, directional attributes, point-load behavior, densities, thermoelastic properties, etc.

- Mineralogical compositions

- Descriptive formation structure - fracture, fissure, joint, fault patterns

3. Comprehensive wire-line log suites, including:

- Radioactive - Gamma ray, neutron

- Acoustic wave train - Compression/shear wave

- Resistivity - micro, intermediate, deep

- Wellbore caliper

- Wellbore image

4. Tests at selected points or intervals in the wellbore, in accordance with analyses of core and log information:

- Micro-frac in situ stress breakdown

- Mini-frac shut-in/pressure decline (for fluid leak-off)

- Tri-axial borehole seismic in concert with mini-frac tests made during drilling each interval

- Fluid injectivity/pressure fall-off (for both virgin, and induced fracture intervals) 
5. Comprehensive mapping of the fracture or shear fracture cluster during hydraulic fracturing through monitoring of microearthquakes. This requires installation of a network of threecomponent seismometers in boreholes drilled into fairly solid rock and, if possible, into the basement rock.

Prior to drilling the second well in the prospect, the above collection of information should be thoroughly analyzed. Tests that obviously do not yield worthwhile information should be discarded. Test procedures that yield questionable information should be revised. In cases where information requirements emerge by virtue of the existing test results, additional test procedures should be developed to obtain such information. A test program should then be developed for the second prospective well. This process should be repeated for subsequent wells in the project. Once a deep well is completed, geophysical logs will be required to quantify the temperature profile, joint network data, in situ stress profile, sonic log, etc. In a high-temperature environment, the well may need to be circulated and cooled before these logs (except for a temperature log) can be carried out. The only useful temperature information obtained during drilling, or just after drilling, is the bottom-hole temperature, as the temperature profile higher in the well will be affected by the cooling caused by the drilling. Even the bottom-hole temperature may have some cooling if there is permeability on the bottom. It may take up to three months after the drilling is completed for the temperature to reach the natural equilibrium.

Following the assessment of the in situ conditions from geophysical logs, small-scale injection tests (as seen at Cooper Basin in Figure 5.2) will be required to assess undisturbed hydraulic properties of the open section of the well. The quantity of water and the pressure required will depend on the state of existing flowing joints and tightness of the formation. Estimation will be made on the requirement of the water for these tests. The following tests are appropriate for evaluating the natural state of the reservoir for permeability/transmissivity and other hydrologic properties:

\section{i. Slug test}

A slug test involves an impulse excitation, such as a sudden withdrawal/injection of a weighted float, or a rapid injection of a small volume of water. The response of a well-aquifer to that change in water level is then measured. The slug test will also give information required to design the subsequent lowrate injection test. The total amount of water used is negligible i.e., in the range of $2-5 \mathrm{~m}^{3}$.

\section{ii. Production test}

Producing formation fluid will yield important information for the future heat exchanger about the $P-T$ conditions in the reservoir. Furthermore, the fluid chemistry and the gas content are important parameters in designing the pilot plant to minimize scaling and corrosion. These are two good reasons to perform a production test at a time when the fluid surrounding the well is not yet disturbed by a major injection. A well can be produced by using a buoyancy effect or a down-hole pump. It is preferable to use a down-hole submersible pump where possible. A submersible pump can be deployed at a depth of about IOO-I50 $\mathrm{m}$. Depending on the outcome of the slug test, it is probable that the well could produce nearly I $\mathrm{m}^{3} / \mathrm{hr}$, which may be sufficient to get several wellbore volumes of fluid in a reasonable time of a few weeks. Additionally, a down-hole pressure gauge, gas sampling (or gas trap) at the wellhead, and a surface flow meter, would add further information on the draw-down characteristic of the well. 


\section{iii. Low-rate injection tests}

The main objective of the low-rate injection test is to determine the hydraulic properties of the unstimulated open-hole section of the well. The derived values will be used as inputs for numeric models, planning of the stimulation (pressure required for a stimulation), and subsequently for the assessment of the stimulation and identification of predominant flowing zones using a temperature or flow log.

\section{iv. Pre-stimulation test}

This test consists of injecting nearly $400-600 \mathrm{~m}^{3}$ of fluid at a constant flow rate of about 5-7 kg/s. Fresh water, or saturated brine, can be used. Saturated brine can be very useful in helping stimulation near the bottom of the well, but this depends on the state of the in situ stress. After the pre-stimulation test, the wellhead is shut in to see how the pressure declines. This will give some indication of the natural transmissivity, leak-off, or far-field connectivity.

\section{v. Main stimulation of the first well}

During the main stimulation, fresh water is injected in steps with increasing flow rates. Three to four flow-rate steps are normally used. The flow-rate steps may vary depending on the leak-off, and on whether it is a closed system or open system. Flow-rate steps of about $30,40,50$, and maybe $70 \mathrm{~kg} / \mathrm{s}$ are not unreasonable. Normally, the selected step of injected flow rate is continued until the wellhead or downhole pressure reaches an asymptote showing that the far-field leak-off is balanced by the injected flow. This is feasible in a relatively open system, but most observed EGS systems have poor far-field connectivity and, therefore, the wellhead pressure is likely to continue increasing. In this case, injection may be carried out at $30 \mathrm{~kg} / \mathrm{s}$ for $24-30 \mathrm{hrs}, 40 \mathrm{~kg} / \mathrm{s}$ for $24-30 \mathrm{hrs}, 50 \mathrm{~kg} / \mathrm{s}$ for 24 $30 \mathrm{hrs}$, and $70 \mathrm{~kg} / \mathrm{s}$ for 3 days. The injected volume may vary between $28,000 \mathrm{~m}^{3}$ to $3 \mathrm{I}, 000 \mathrm{~m}^{3}$, depending on the flow and the injection period.

\section{vi. Post-stimulation test}

A post-stimulation test is conducted to evaluate the enhancement in the permeability obtained during the main stimulation of the reservoir. Possible injection flow rates would be around 7, 30, 40 and $50 \mathrm{~kg} / \mathrm{s}$ for about I2, I2, 24 and I2 hrs. The apparent reduction in the injection pressure, compared to the injection pressure required pre-stimulation for the same flow rate, will give quantitative indication of the improvement in the permeability of the stimulated rock mass. The total volume of water used for this test would be about $7,200 \mathrm{~m}^{3}$.

\section{vii. Drilling of the second well and follow-on testing}

Results of the testing of the first well and the stimulated reservoir are used to target the drilling of the second well. Following drilling of the second well, the same wellbore characterization diagnostics recommended for the first well should be run on the second well. A suite of flow tests (similar to those for the first well) also should be carried out, but this time the goal of the testing is to establish the connection between the first and second well. If the connection is not good or needs improvement, the second well may need to be stimulated one or more times.

\section{viii. Short-term circulation test between the first and second wells}

Once a hydraulic link between the two wells has been established, a small-scale circulation loop 
between the wells will need to be established. Wells with a separation of $600 \mathrm{~m}$ and a good hydraulic link between the wells would show a breakthrough time for a tracer of about 4 to 6 days. The storage volume of the reservoir may increase to accommodate increased injection rates through the system. An initial starting step of $20 \mathrm{~kg} / \mathrm{s}$ is considered reasonable and, if possible, the rate should be stepped up until the microseismicity suggests reservoir growth is taking place - which would suggest that about $2,600 \mathrm{~m}^{3}$ will be required to initiate a circulation test. Taking a worst-case scenario of losing I0\% in the formation via leak-off, this will bring the figure up to $3,600 \mathrm{~m}^{3}$ for a three-week circulation test. A separator, a heat exchanger, a heat load, and water-storage facility will be required to implement this test.

\section{ix. Evaluate and refracture or stimulate near wellbore}

If the wellbore has skin damage (high-pressure drop near the wellbore), the near-wellbore area is very susceptible to improvement. Acidizing, emplacing proppants, short high-pressure stimulation, or other methods can help eliminate near-wellbore pressure drop.

\section{x. Long-term test circulation at or near commercial scale (about $50-100 \mathrm{~kg} / \mathrm{s}$ )}

No one has reached flow rates in the region of 70-100 kg/s. This stage will depend on the result of the earlier circulation test. Evaluating the reservoir using pressure and temperature response, tracers, and microseismic data will help analysts understand what is happening in the reservoir and its surroundings.

About 4,000 $\mathrm{m}^{3}$ would be required to charge the system. An acceptable worst-case scenario for water loss during circulation is $10 \%$, which brings the figure up to $\mathrm{I} 3,000 \mathrm{~m}^{3}$ for a three-week test. 


\section{CHAPTER 6}

\section{Drilling Technology and Costs}

6.1 Scope and Approach

6.2 Review of Geothermal Drilling Technology _

6.2.1 Early geothermal/EGS drilling development $\ldots \ldots \ldots \ldots \ldots \ldots \ldots-\ldots \ldots \ldots-\ldots-4$

6.2.2 Current EGS drilling technology _._.

6.3 Historical Well-Cost Data $\ldots \ldots-\ldots-\ldots$

6.3.1 General trends in oil and gas well-completion costs $\ldots \ldots \ldots \ldots \ldots \ldots-\ldots-\ldots$

6.3.2 MIT Depth Dependent (MITDD) drilling-cost index _

6.3.3 Updated geothermal well costs _ _ _

6.4 Predicting Geothermal Well Costs with the Wellcost Lite Model _ _-_ _- 6-18

6.4.1 History of the Wellcost Lite model

6.4.2 Wellcost Lite model description _ _ _ -

6.5 Drilling-Cost Model Validation _

6.5.1 Base-case geothermal wells _._.

6.5.2 Comparison with geothermal wells

6.5.3 Comparison with oil and gas wells $\ldots \ldots \ldots \ldots \ldots \ldots \ldots \ldots \ldots \ldots-\ldots-22$

6.5.4 Model input parameter sensitivities and drilling-cost breakdown $\ldots \ldots-\ldots \ldots-6-23$

6.6 Emerging Drilling Technologies _

6.6.1 Current oil and gas drilling technologies adaptable to EGS _ _ _ _ _- _ 6-27

6.6.2 Revolutionary drilling technologies $\ldots-\ldots-\ldots-\ldots-\ldots-\ldots-\ldots-\ldots-\ldots-\ldots 6-28$

6.7 Conclusions _

References _.

Appendices _._.

A.6.1 Well-Cost Data

A.6.2 Wellcost Lite Model $\ldots \ldots-\ldots \ldots-\ldots-\ldots-\ldots$

A.6.2.1 Background and brief history of the development of Wellcost Lite

A.6.2.2 Wellcost Lite - How does the cost model work? _ _ _ _ _ _ _ _ _ _ _ 6-37

A.6.3 Model Results for Specific Areas and Depths _ _ _ _ _ _ _ _ _ _ _ _ _ _ 6- 69

A.6.4 Model Results for Reworked Wells

A.6.4.1 Rig on drilling/deepening $460 \mathrm{~m}(1,500 \mathrm{ft}) / \mathrm{rig}$ still on the well $\ldots \ldots \ldots-\ldots-\ldots-51$

A.6.4.2 Rig on drilling/sidetracked lateral/as a planned part of the well design _ _ 6-51

A.6.4.3 Reworks/rig has to be mobilized/add a lateral for

production maintenance/a work-over _ _ _ _

A.6.4.4 Redrills to enhance production/a work-over/rig to be mobilized _ _ _ _ _ $6-51$ 


\subsection{Scope and Approach}

Exploration, production, and injection well drilling are major cost components of any geothermal project (Petty et al., I992; Pierce and Livesay, I994; Pierce and Livesay, I993a; Pierce and Livesay, I993b). Even for high-grade resources, they can account for $30 \%$ of the total capital investment; and with low-grade resources, the percentage increases to $60 \%$ or more of the total. Economic forecasting of thermal energy recovery by Enhanced Geothermal System (EGS) technologies requires reliable estimates of well drilling and completion costs. For this assessment, a cost model - flexible enough to accommodate variations in well-design parameters such as depth, production diameter, drilling angle, etc. - is needed to estimate drilling costs of EGS wells for depths up to Io,000 m (32,800 ft).

Although existing geothermal well-cost data provide guidance useful in predicting these costs, there are insufficient numbers of geothermal well records, of any kind, to supply the kind of parametric variation needed for accurate analysis. Currently, there are fewer than soo geothermal wells drilled per year in the United States, few or none of which are deep enough to be of interest. Very few geothermal wells in the United States are deeper than 2,750 $\mathrm{m}(9,000 \mathrm{ft})$, making predictions of deep EGS wells especially difficult. Although there are clear differences between drilling geothermal and oil and gas wells, many insights can be gained by examining technology and cost trends from the extensive oil and gas well drilling experience.

Thousands of oil/gas wells are drilled each year in the United States, and data on the well costs are readily available (American Petroleum Institute, JAS, I976-2004). Because the process of drilling oil and gas wells is very similar to drilling geothermal wells, it can be assumed that trends in the oil and gas industry also will apply to geothermal wells. Additionally, the similarity between oil and gas wells and geothermal wells makes it possible to develop a drilling cost index that can be used to normalize the sparse data on geothermal well costs from the past three decades to current currency values, so that the wells can be compared on a common dollar basis. Oil and gas trends can then be combined with existing geothermal well costs to make rough estimates of EGS drilling costs as a function of depth.

Oil and gas well completion costs were studied to determine general trends in drilling costs. These trends were used to analyze and update historical geothermal well costs. The historical data were used to validate a drilling cost model called Wellcost Lite, developed by Bill Livesay and coworkers. The model estimates the cost of a well of a specific depth, casing design, diameter, and geological environment. A series of base-case geothermal well designs was generated using the model, and costs for these wells were compared to costs for both existing geothermal wells and oil and gas wells over a range of depths. Knowledge of the specific components of drilling costs was also used to determine how emerging and revolutionary technologies would impact geothermal drilling costs in the future. 


\subsection{Review of Geothermal Drilling Technology}

\subsubsection{Early geothermal/EGS drilling development}

The technology of U.S. geothermal drilling evolved from its beginning in the early I970s with a flurry of activity in The Geysers field - a vapor-dominated steam field - in Northern California. Although international geothermal development began before the ig6os in places such as Italy at Lardarello, New Zealand, and Iceland, the development of The Geysers field in northern California was the first big U.S project. Problems encountered during drilling at The Geysers, such as fractured hard and abrasive formations, extreme lost circulation, and the higher temperatures were overcome by adaptation and innovation of existing oil and gas technology to the demanding downhole environment in geothermal wells. The drilling at The Geysers resulted in the reconfiguration of rigs specially outfitted for drilling in that environment.

These early geothermal wells at The Geysers were perceived to lie in a category somewhere between "deep, hot, water wells" and "shallow oil/gas wells." Later, other U.S. geothermal drilling activities started in the hydrothermal environments of Imperial Valley in California, the Coso field in East Central California, and Dixie Valley in Northern Nevada. Imperial Valley has a "layer-cake" arrangement of formations, very similar to a sedimentary oil and gas field. Here, geothermal fluids are produced in the boundaries of an area that has subsided due to the action of a major fault (San Andreas). The Salton Sea reservoir is in the Imperial Valley about 25 miles from El Centro, California. Some extremely productive wells have been drilled and are producing today at this site, including Vonderahe I, which is the most productive well in the continental United States. An extension of the same type of resource crosses over into Northern Mexico near Cierro Prieto. Approximately $300 \mathrm{MW}_{\mathrm{e}}$ are generated from the Salton Sea reservoir and more than $720 \mathrm{MW}_{\mathrm{e}}$ from Ciero Prieto. Northern Nevada has numerous power producing fields. Dixie Valley is a relatively deep field (> 3,000 $\mathrm{m}$ or 9,000 ft) near a fault line.

In parallel with these U.S. efforts, geothermal developments in the Philippines and Indonesia spurred on the supply and service industries. There was continual feedback from these overseas operations, because, in many cases, the same companies were involved - notably Unocal Geothermal, Phillips Petroleum (now part of ConocoPhillips), Chevron, and others.

Similar to conventional geothermal drilling technology, drilling in Enhanced Geothermal Systems (EGS) - in which adequate rock permeability and/or sufficient naturally occurring fluid for heat extraction are lacking and must be engineered - originated in the I970s with the Los Alamos-led hot dry rock (HDR) project at Fenton Hill. Drilling efforts in EGS continued with the British effort at Rosemanowes in the I980s, and the Japanese developments at Hijiori and Ogachi in the I990s. Research and development in EGS continues today with an EGS European Union project at Soultz, France, and an Australian venture at Cooper Basin (see Chapter 4 for details of these and other projects). First-generation EGS experiments are also ongoing at Desert Peak in Nevada and Coso in southern California, which is considered to be a young volcanic field. Experience at these sites has significantly improved EGS drilling technology. For example, rigs used to drill shallow geothermal wells rarely include a top-drive, which has proven to be beneficial. However, there is still much that can be improved in terms of reducing EGS drilling costs.

As a result of field experience at conventional hydrothermal and EGS sites, drilling technology has matured during the past 30 years. To a large degree, geothermal drilling technology has been adapted 
from oil, gas, mining, and water-well drilling practices - and generally has incorporated engineering expertise, uses, equipment, and materials common to these other forms of drilling. Nonetheless, some modification of traditional materials and methods was necessary, particularly with regard to muds and mud coolers, bit design, and bit selection. Initially, there were problems with rapid bit wear, especially in the heel-row (or gauge) of the bit, corrosion of the drill pipe during the air drilling effort, and general corrosion problems with well heads and valves. Major problems with wear of the bit bearing and cutting structure have been almost completely overcome with tougher and more robust, tungsten carbide roller cone journal bearing bits. Rapid wear of the cutting structure, especially the heel row, has been overcome by the development of more wear-resistant tungsten carbide cutters, and the occasional use of polycrystalline surfaced inserts to improve wear-resistance. Alternative designs were needed for geothermal applications, such as for casing and cementing to accommodate thermal expansion and to provide corrosion protection. Drilling engineers and rig-site drilling supervisors used their experience and background to develop these methods to safely drill and complete the geothermal wells in The Geysers, Imperial Valley, the Philippines, Indonesia, Northern Nevada, and other hydrothermal resource areas.

\subsubsection{Current EGS drilling technology}

The current state of the art in geothermal drilling is essentially that of oil and gas drilling, incorporating engineering solutions to problems that are associated with geothermal environments, i.e., temperature effects on instrumentation, thermal expansion of casing strings, drilling hardness, and lost circulation. The DOE has supported a range of R\&D activities in this area at Sandia National Laboratories and elsewhere. Advances in overcoming the problems encountered in drilling in geothermal environments have been made on several fronts:

High-temperature instrumentation and seals. Geothermal wells expose drilling fluid and downhole equipment to higher temperatures than are common in oil and gas drilling. However, as hydrocarbon reserves are depleted, the oil and gas industry is continually being forced to drill to greater depths, exposing equipment to temperatures comparable with those in geothermal wells. High-temperature problems are most frequently associated with the instrumentation used to measure and control the drilling direction and with logging equipment. Until recently, electronics have had temperature limitations of about $150^{\circ} \mathrm{C}\left(300^{\circ} \mathrm{F}\right)$. Heat-shielded instruments, which have been in use successfully for a number of years, are used to protect downhole instrumentation for a period of time. However, even when heat shields are used, internal temperatures will continue to increase until the threshold for operation of the electronic components is breached. Batteries are affected in a similar manner when used in electronic instruments. Recent success with "bare" high-temperature electronics has been very promising, but more improvements are needed.

Temperature effects on downhole drilling tools and muds have been largely overcome by refinement of seals and thermal-expansion processes. Fluid temperatures in excess of $190^{\circ} \mathrm{C}\left(370^{\circ} \mathrm{F}\right)$ may damage components such as seals and elastomeric insulators. Bit-bearing seals, cable insulations, surface well-control equipment, and sealing elements are some of the items that must be designed and manufactured with these temperatures in mind. Elastomeric seals are very common in the tools and fixtures that are exposed to the downhole temperatures.

Logging. The use of well logs is an important diagnostic tool that is not yet fully developed in the geothermal industry. For oil and gas drilling, electric logging provides a great deal of information 
about the formation, even before field testing. Logs that identify key formation characteristics other than temperature, flow, and fractures are not widely used for geothermal resources. Logging trucks equipped with high-temperature cables are now more common, but not without additional costs. Geothermal logging units require wirelines that can withstand much higher temperatures than those encountered in everyday oil and gas applications. This has encouraged the growth of smaller logging companies that are dedicated to geothermal applications in California and Nevada.

Thermal expansion of casing. Thermal expansion can cause buckling of the casing and casing collapse, which can be costly. Also, thermal contraction due to cooling in injection wells, or thermal cycling in general, can also lead to damage and eventual tensile failure of casing. It is customary in U.S. geothermal drilling to provide a complete cement sheath from the shoe to surface on all casing strings. This provides support and stability to the casing during thermal expansion as the well heats up during production - and shields against corrosion on the outside of the casing. In contrast, thermal expansion is much less of an issue in oil and gas completions. Oil and gas casings and liners are often only tagged at the bottom with 150 to $300 \mathrm{~m} \mathrm{(500} \mathrm{to} \mathrm{I,000} \mathrm{ft)} \mathrm{of} \mathrm{cement} \mathrm{to} \mathrm{"isolate"} \mathrm{zones,}$ and do not require a complete sheath from shoe to the surface. The oil and gas liner laps are also squeeze-cemented for isolation purposes. Thermal expansion and contraction of casing and liners is an issue that has been adequately addressed for wells with production temperatures below $260^{\circ} \mathrm{C}$ $\left(500^{\circ} \mathrm{F}\right)$. Full-sheath cementing and surface-expansion spools can be employed in this temperature range with confidence. Above operating temperatures of $260^{\circ} \mathrm{C}\left(500^{\circ} \mathrm{F}\right)$, greater care must be taken to accommodate thermal expansion or contraction effects.

Drilling fluids/"mud" coolers. Surface "mud coolers" are commonly used to reduce the temperature of the drilling fluid before it is pumped back down the hole. Regulations usually require that mud coolers be used whenever the return temperature exceeds $75^{\circ} \mathrm{C}\left(\mathrm{I} 70^{\circ} \mathrm{F}\right)$, because the high temperature of the mud is a burn hazard to rig personnel. The drilling fluid temperature at the bottom of the well will always be higher than the temperature of the fluid returning to the surface through the annulus, because it is partly cooled on its way upward by the fluid in the drill pipe. High drilling fluid temperatures in the well can cause drilling delays after a bit change. "Staging" back into the well may be required to prevent bringing to the surface fluid that may be above its boiling temperature under atmospheric conditions.

Drill bits and increased rate of penetration. While many oil and gas wells are in sedimentary column formations, geothermal operations tend to be in harder, more fractured crystalline or granitic formations, thus rendering drilling more difficult. In addition to being harder, geothermal formations are prone to being more fractured and abrasive due to the presence of fractured quartz crystals. Many EGS resources are in formations that are igneous, influenced by volcanic activity, or that have been altered by high temperatures and/or hot fluids. Drilling in these formations is generally more difficult. However, not all geothermal formations are slow to drill. Many are drilled relatively easily overall, with isolated pockets of hard, crystalline rock. In these conditions, drill bit selection is critical.

Bits used in geothermal environments are often identical to those used in oil and gas environments, except that they are more likely to come from the harder end of the specification class range. The oil and gas industry tends to set the market price of drill bits. Hard tungsten carbide-based roller cone bits, the most commonly used type for geothermal applications, comprise less than I०\% of this market. Hard formation bits from the oil and gas industry generally do not provide sufficient cutting 
structure hardness or heel row (the outer row of cutters on a rock bit) protection for geothermal drilling applications. The hard, abrasive rocks encountered in geothermal drilling causes severe wear on the heel row and the rest of the cutting structure. This sometimes results in problems with maintenance of the hole diameter and protection of the bearing seals. In some instances, mining insert bits have been used (especially in air drilling applications) because they were often manufactured with harder and tougher insert material.

Problems with drilling through hard formations has been greatly improved by new bearings, improved design of the heel row, better carbides, and polycrystalline diamond coatings. Bitmanufacturing companies have made good progress in improving the performance of hardformation drill bits through research on the metallurgy of tungsten carbide used in the insert bits and through innovative design of the bit geometry. Journal bearing roller cone bits are also proving to be quite effective. However, cutting structure wear-rates in fractured, abrasive formations can still be a problem, and bit-life in deep geothermal drilling is still limited to less than 50 hours in many applications. When crystalline rocks (such as granite) are encountered, the rate of advance can be quite slow, and impregnated diamond bits may be required.

Polycrystalline diamond compact (PDC) bits have had a major impact on oil and gas drilling since their introduction in the late I970s, but did not have a similar effect on geothermal drilling. Although PDC bits and downhole mud motors, when combined, have made tremendous progress in drilling sedimentary formations, PDC-based small element drag bits are not used in hard fractured rock.

Lost circulation. Lost circulation is a drilling problem that arises when the circulation of the drilling fluid is interrupted and it does not return to the surface. The return flow in the annulus is laden with cuttings cleaned from the well. The sudden loss of fluid return causes the cuttings to be suspended in the annulus and/or to fall back down the well, clogging the drill pipe. With a total loss of fluid return, the drilling fluid must be mixed and pumped fast enough to sustain flow and keep the bit clean, which can be an expensive process. Lost circulation exists in oil and gas drilling, mining, and in water-well drilling as well, but is much more prevalent in geothermal well drilling.

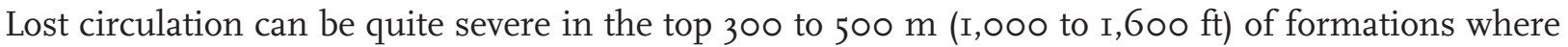
sub-hydrostatic conditions exist, leading to standing fluid levels substantially below the surface. Top sections are often weathered and disturbed and may allow leakage into the formation. Lost circulation in geothermal projects tends to be near the surface, while lost circulation generally occurs at greater depths in oil and gas drilling, which can have a greater impact on overall drilling costs.

Fluid flow from the hole into the loss zone may also remove cement, preventing completion of a sheath around the casing from the shoe to the surface, or from the shoe to the liner hanger.

Problems with lost circulation during drilling have been reduced somewhat by the greater use of aerated drilling fluids or air drilling. Air drilling is another technology that has been adapted from the oil/gas and mining industries. Geothermal reservoirs are quite often under-pressured and prone to lost circulation, which can make for very difficult casing and cementing procedures. Air or aerated drilling fluids reduce the effective density of the fluid column and therefore may permit drilling without loss of circulation. Aerated drilling fluids are most common, but there are various ways in which air is introduced to affect density reduction. One form of air drilling, utilizing dual-tube 
reverse-circulation drilling (and tremmie tube cementing), is being tested as a solution to severe lost circulation in the tophole interval of some wells. The dual-tube process provides a path for fluids to flow down the outer annulus and air to be injected in the annulus between inner tube and the outer tube. The combined effect is to airlift the cuttings and fluids inside the inner tube. The use of tremmie tubes to place cement at the shoe of a shallow (or not so shallow) casing shoe is borrowed from waterwell and mining drilling technology. This technique is helpful in cementing tophole zones, where severe lost circulation has occurred.

Another solution to cementing problems in the presence of lost circulation is to drill beyond, or bypass, the loss zone and to cement using a technique that can prevent excessive loss. Lightweight cement, foamed cement, reverse circulation cement, and lightweight/foamed cement are developments that enable this approach to be taken. However, only lightweight cement has found widespread use. Selection of an appropriate cement is critical, because a failed cement job is extremely difficult to fix.

Directional drilling. Directionally drilled wells reach out in different directions and permit production from multiple zones that cover a greater portion of the resource and intersect more fractures through a single casing. An EGS power plant typically requires more than one production well. In terms of the plant design, and to reduce the overall plant "footprint," it is preferable to have the wellheads close to each other. Directional drilling permits this while allowing production well bottom-spacings of 3,००० ft. $(900 \mathrm{~m})$ or more. Selective bottom-hole location of production and injection wells will be critical to EGS development as highlighted in Chapters 4 and 5.

The tools and technology of directional drilling were developed by the oil and gas industry and adapted for geothermal use. Since the I960s, the ability to directionally drill to a target has improved immensely but still contains some inherent limitations and risks for geothermal applications. In the I970s, directional equipment was not well-suited to the high-temperature downhole environment. High temperatures, especially during air drilling, caused problems with directional steering tools and mud motors, both of which were new to oil and gas directional drilling. However, multilateral completions using directional drilling are now common practice for both oil and gas and geothermal applications. The development of a positive displacement downhole motor, combined with a real-time steering tool, allowed targets to be reached with more confidence and less risk and cost than ever before. Technology for re-entering the individual laterals for stimulation, repair, and work-overs is now in place. Directional tools, steering tools, and measurement-while-drilling tools have been improved for use at higher temperatures and are in everyday use in geothermal drilling; however, there are still some limitations on temperatures.

\subsection{Historical Well-Cost Data}

In order to make comparisons between geothermal well costs and oil and gas well costs, a drilling cost index is needed to update the costs of drilling hydrothermal and EGS or HDR wells from their original completion dates to current values. There are insufficient geothermal well-cost data to create an index based on geothermal wells alone. The oil and gas well drilling industry, however, is a large and well established industry with thousands of wells drilled each year. Because the drilling process is essentially the same for oil, gas, and geothermal wells, the Joint Association Survey (JAS) database provides a good basis for comparison and extrapolation. Therefore, data from the JAS (API, I976- 
2004) were used to create a drilling index, and this index was used to normalize geothermal well costs to year 2004 U.S. \$. Oil and gas well costs were analyzed based on data from the 2004 JAS for completed onshore U.S. oil and gas wells. A new, more accurate drilling cost index, called the MIT Depth Dependent (MITDD) drilling index, which takes into consideration both the depth of a completed well and the year it was drilled, was developed using the JAS database (1976-2004) (Augustine et al., 2006). The MITDD index was used to normalize predicted and actual completed well costs for both HDR or EGS and hydrothermal systems from various sources to year 2004 U.S. \$, and then compare and contrast these costs with oil and gas well costs.

\subsubsection{General trends in oil and gas well-completion costs}

Tabulated data of average costs for drilling oil and gas wells in the United States from the Joint Association Survey (JAS) on Drilling Costs (I976-2004) illustrate how drilling costs increase nonlinearly with depth. Completed well data in the JAS report are broken down by well type, well location, and the depth interval to which the well was drilled. The wells considered in this study were limited to onshore oil and gas wells drilled in the United States. The JAS does not publish individual well costs due to the proprietary nature of the data. The well-cost data are presented in aggregate, and average values from these data are used to show trends. Ideally, a correlation to determine how well costs vary with depth would use individual well-cost data. Because this is not possible, average values from each depth interval were used. However, each depth interval was comprised of data from between hundreds and thousands of completed wells. Assuming the well costs are normally distributed, the resulting averages should reflect an accurate value of the typical well depth and cost for wells from a given interval to be used in the correlation.

In plotting the JAS data, the average cost per well of oil and gas wells for a given year was calculated by dividing the total cost of all onshore oil and gas wells in the United States by the total number of oil and gas wells drilled for each depth interval listed in the JAS report. These average costs are tabulated in Table A.6.I (in the Appendices) and shown in Figure 6.I as the "JAS Oil and Gas Average" points and trend line. Wells in the o-I,249 $\mathrm{ft}(0-380 \mathrm{~m})$ and $20,000+\mathrm{ft}(6 \mathrm{IOO}+\mathrm{m})$ depth intervals were not included, because wells under $\mathrm{I}, 250 \mathrm{ft}(380 \mathrm{~m})$ are too shallow to be of importance in this study, and not enough wells over $20,000 \mathrm{ft}(6,100 \mathrm{~m})$ are drilled in a year to give an accurate average cost per well.

A cursory analysis quickly shows that well costs are not a linear function of depth. A high order polynomial, such as:

$$
\Phi_{\text {well }}=c_{0}+c_{1} z+c_{2} z^{2}+c_{3} z^{3}+\ldots
$$

where $\Phi_{\text {well }}$ is the completed well cost, $z$ is the depth of the well, and $c_{i}$ are fitted parameters, can be used to express well costs as a function of depth. However, it is not obvious what order polynomial would best fit the data, and any decent fit will require at least four parameters, if not more. By noting that an exponential function can be expanded as an infinite series of polynomial terms:

$$
e^{x}=1+x+\frac{x^{2}}{2 !}+\frac{x^{3}}{3 !}+\ldots
$$


one might be able to describe the well-cost data as a function of depth using only a few parameters. As Figure 6.I shows, the average costs of completed oil and gas wells for the depth intervals from I,250 feet $(380 \mathrm{~m})$ to 19,999 feet $(6,100 \mathrm{~m})$ can be described as an exponential function of depth, that is:

$$
\Phi_{\text {well }}=a \cdot \exp \left(b_{1} \cdot \operatorname{depth}\right)=a \cdot \exp \left(b_{l} z\right)
$$

where only two fitted parameters, $a$ and $b_{1}$, are needed. Thus, a plot of $\log _{10}$ (well cost) vs. depth results in a straight line:

$$
\log _{10}\left(\Phi_{\text {well }}\right)=\log _{10}(a)+b_{2} z
$$

Although there is no fundamental economic reason for an exponential dependence, the "Oil and Gas Average" trend line in Figure 6.I shows that a two-parameter exponential function adequately describes year 2004 JAS average completed well costs as a function of depth for the depth intervals considered. The correlation coefficient $\left(R^{2}\right)$ value for the year 2004 JAS data, when fit to Eq. (6-4), was 0.968 . This indicates a high degree of correlation between the log of the completed well costs and depth. Similar plots for each year of JAS report data from the years 1976-2003 also show high levels of correlation between the $\log _{10}$ of well costs and depth, with all years having an $\mathrm{R}^{2}$ value of 0.984 or higher.

An insufficient number of ultra-deep wells, with depths of $20,000+\mathrm{ft}(6,100+\mathrm{m})$, were drilled in 2004 to give an accurate average. Instead, a number of ultra-deep well costs from I994-2002 were corrected to year 2004 U.S. \$ using MITDD index values (see Section 6.3.2) for the 17,500-19,999 feet (5,3006,I00 $\mathrm{m}$ ) depth interval and plotted in Figure 6.I. Most of the data points represent individual well costs that happened to be the only reported well drilled in the $20,000+$ feet $(6,100 \mathrm{~m})$ depth interval in a region during a given year, while others are an average of several (two or three) ultra-deep wells. Extrapolation of the average JAS line beyond 20,000 feet $(6,100 \mathrm{~m})$, indicated by the dashed line in Figure 6.I, is generally above the scatter of costs for these individual ultra-deep wells. The ultra-deep well data demonstrate how much well costs can vary depending on factors other than the depth of the well. It is easy to assume that all the depth intervals would contain similar scatter in the completed well costs.

Another possible reason for scatter in the drilling cost data is that drilling cost records are often missing important details, or the reported drilling costs are inaccurate. The available cost data are usually provided in the form of an authorization for expenditures (AFE), which gives the estimated and actual expenditures for wells drilled by a company. For example, it is not uncommon for a company to cover some of the personnel and services required in the drilling of the well in the overhead labor pool, or for materials purchased for several wells to be listed as expenses on the AFE of only one of the wells. The lack of records and concern for completeness is an incentive to have a logical method to develop a model of detailed well drilling-cost expectations. Such a well-cost model attempts to account for all costs that would relate to the individual well, estimated in a manner similar to a small company's accounting. 


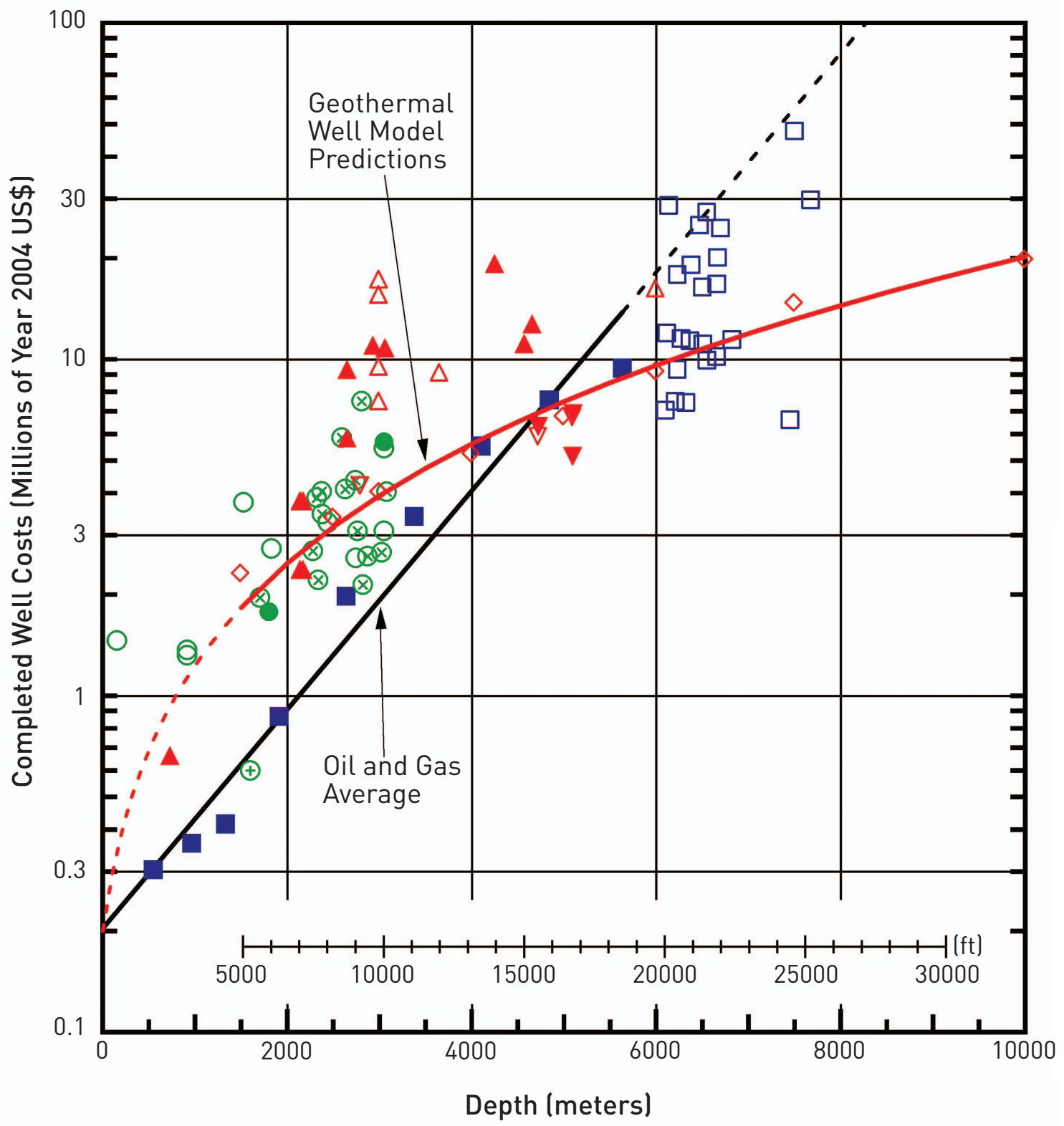

\begin{tabular}{|c|c|c|}
\hline JAS Oil and Gas Average & $\boldsymbol{\Delta}$ & HDR/EGS Actual \\
\hline JAS Ultra Deep Oil and Gas & $\Delta$ & HDR/EGS Predicted \\
\hline The Geysers Actual & $\boldsymbol{\nabla}$ & Soultz/Cooper Basin \\
\hline$\oplus$ Imperial Valley Actual & & Wellcost Lite Model \\
\hline$\otimes$ Other Hydrothermal Actual & & $\diamond$ Wellcost Lite Base Case \\
\hline Hydrothermal Predicted & & $\nabla$ Wellcost Lite Specific Wells \\
\hline
\end{tabular}

1. JAS $=$ Joint Association Survey on Drilling Costs.

2. Well costs updated to US\$ (yr. 2004) using index made from 3-year moving average for each depth interval listed in JAS (1976-2004) for onshore, completed US oil and gas wells. A 17\% inflation rate was assumed for years pre-1976.

3. Ultra deep well data points for depths greater than $6 \mathrm{~km}$ are either individual wells or averages from a small number of wells listed in JAS (1994-2000).

4. “Other Hydrothermal Actual” data include some non-US wells (Source: Mansure 2004).

Figure 6.1 Completed geothermal and oil and gas well costs as a function of depth in year 2004 U.S. \$, including estimated costs from Wellcost Lite model. 


\subsubsection{MIT Depth Dependent (MITDD) drilling-cost index}

To make comparisons between geothermal well costs and oil and gas well costs, a drilling cost index is needed to update the costs of drilling hydrothermal and HDR/EGS wells from their original completion dates to current values. The MIT Depth Dependent (MITDD) drilling cost index (Augustine et al., 2006) was used to normalize geothermal well costs from the past 30 years to year 2004 U.S. \$. The average cost per well at each depth interval in the JAS reports (1976-2004) was used to create the drilling index, because the drilling process is essentially the same for oil, gas, and geothermal wells. A I7\% inflation rate was assumed for pre-I976 index points. Only onshore, completed oil and gas wells in the United States were considered, because all hydrothermal and HDR wells to-date have been drilled onshore. A three-year moving average was used to smooth out shortterm fluctuations in price. The index was referenced to I977, which is the first year for which a moving average could be calculated using data reported by JAS from the previous and following years. Previous indices condense all information from the various depth intervals into a single index number for each year. This biases the indices toward the cost of shallower wells, which are normally drilled in much larger numbers each year, and also makes them prone to error in years where a disproportionate number of either deep or shallow wells are drilled. The MITDD drilling index was chosen because it avoids these pitfalls by incorporating both depth and year information into the index. Although this method requires slightly more information and more work, it results in superior estimates of normalized drilling costs.

The MIT Depth Dependent drilling cost index is tabulated in Table A.6.2 and shown in Figure 6.2, which clearly illustrates how widely the drilling indices vary among the different depth intervals. Before I986, the drilling cost index rose more quickly for deeper wells than shallower wells. By I982, the index for the deepest wells is almost double the index for shallow wells. After I986, the index for shallow wells began to rise more quickly than the index for deeper wells. By 2004, the index for wells in the $\mathrm{I}, 250-2,499 \mathrm{ft}(380-760 \mathrm{~m})$ range is $25 \%-50 \%$ greater than all other intervals. Although it has the same general trend as the MITDD index, the composite index (MIT Composite) - made by calculating the average cost per well per year as in previous indices - does not capture these subtleties. Instead, it incorrectly over- or under-predicts well-cost updates, depending on the year and depth interval. For example, using the previous method, the index would incorrectly over-predict the cost of a deep well drilled in 1982 by more than $20 \%$ when normalized to year 2004 U.S. \$. The MITDD indices are up to $35 \%$ lower for wells over $4 \mathrm{~km}$ ( $\mathrm{I3}, 000 \mathrm{ft}$ ) deep in 2004 than the previous index. The often drastic difference between index values of the MIT Composite index - based on average costs and the new MITDD index shown in Figure 6.2 from two given years - demonstrates the superiority of the new MITDD index as a means for more accurately updating well costs. 


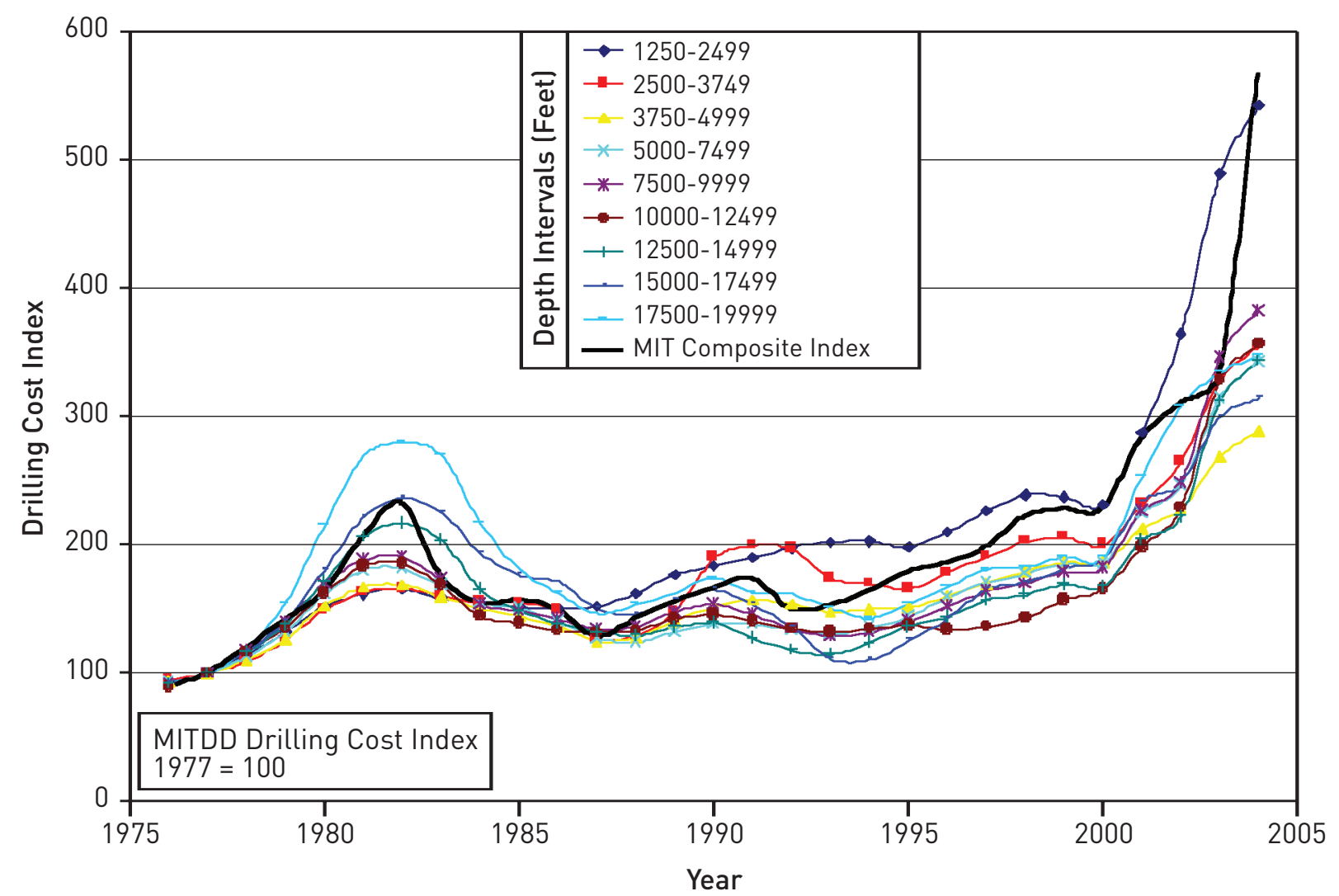

Figure 6.2 MITDD drilling cost index made using average cost per well for each depth interval from Joint Association Survey on Drilling Costs (1976-2004), with data smoothed using a three-year moving average (1977 = 100 for all depth intervals). Note: $1 \mathrm{ft}=0.3048 \mathrm{~m}$.

Although the drilling cost index correlates how drilling costs vary with depth and time, it does not provide any insights into the root causes for these variations. An effort was made to determine what factors influence the drilling cost index and to explain the sometimes erratic changes that occurred in the index. The large spikes in the drilling index appearing in I982 can be explained by reviewing the price of crude oil imports to the United States and wellhead natural gas prices compared to the drilling cost index, as shown in Figures 6.3 and 6.4. The MIT Composite drilling index was used for simplicity. Figures 6.3 and 6.4 show a strong correlation between crude oil prices and drilling costs. This correlation is likely due to the effect of crude oil prices on the average number of rotary drilling rigs in operation in the United States and worldwide each year, shown in Figure 6.5. Therefore, the drilling cost index maximum in 1982 was in response to the drastic increase in the price of crude oil, which resulted in increased oil and gas exploration and drilling activity, and a decrease in drilling rig availability. By simple supply-and-demand arguments, this led to an increase in the costs of rig rental and drilling equipment. The increase in drilling costs in recent years, especially for shallow wells, is also due to decreases in rig availability. This effect is not apparent in Figure 6.5, however, because very few new drilling rigs have been built since the mid I980s. Instead, rig availability is dependent, in part, on the ability to salvage parts from older rigs to keep working rigs operational. As the supply of salvageable parts has decreased, drilling rig rental rates have increased. Because most new rigs are constructed for intermediate or deep wells, shallow well costs have increased the most. This line of reasoning is supported by Bloomfield and Laney (2005), who used similar arguments to relate rig availability to drilling costs. Rig availability, along with the nonlinearity of well costs with depth, can account for most of the differences between the previous MIT index and the new depth-dependent indices. 


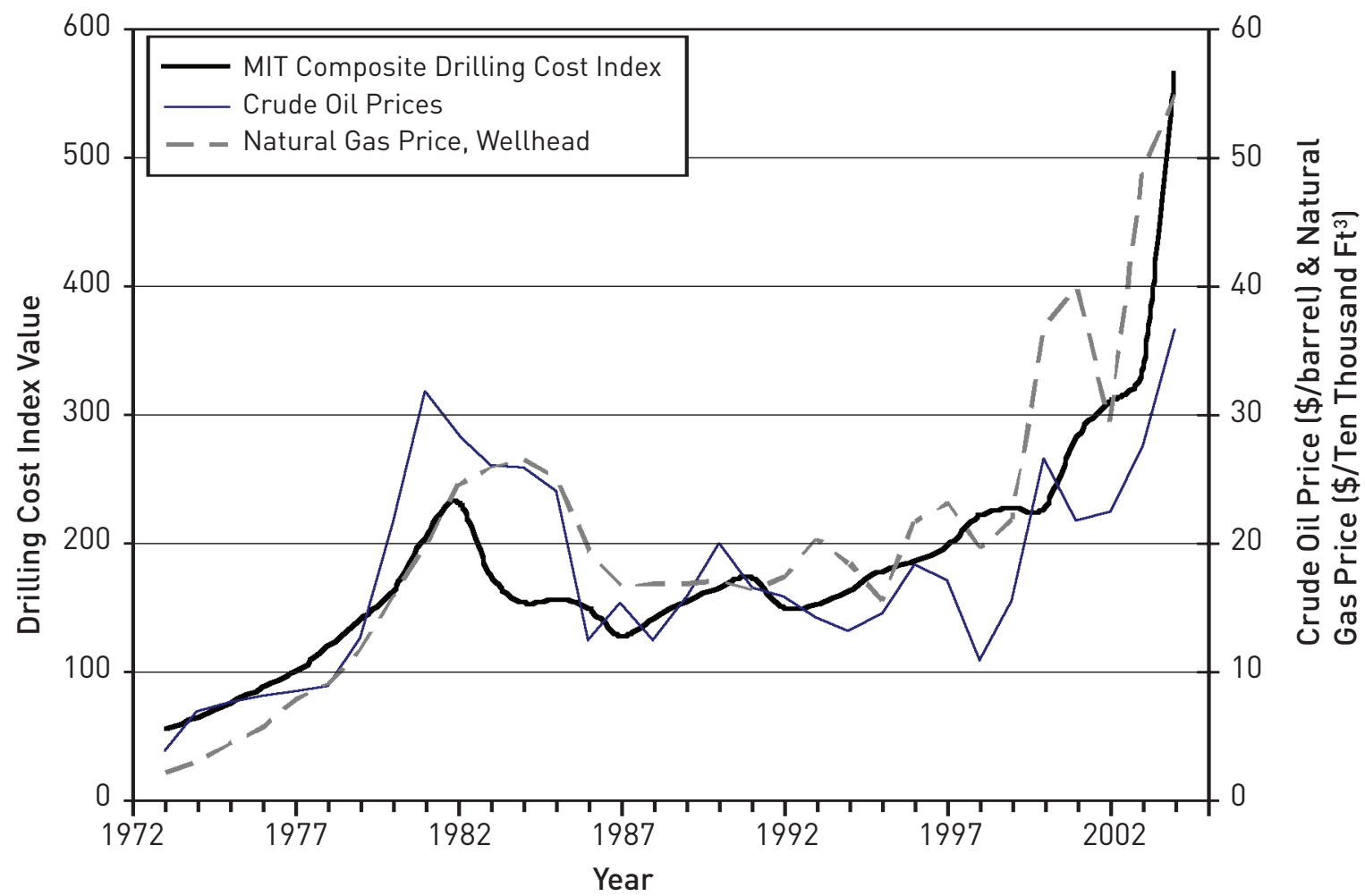

Figure 6.3 Crude oil and natural gas prices, unadjusted for inflation (Energy Information Administration, 2005) compared to MIT Composite Drilling Index.

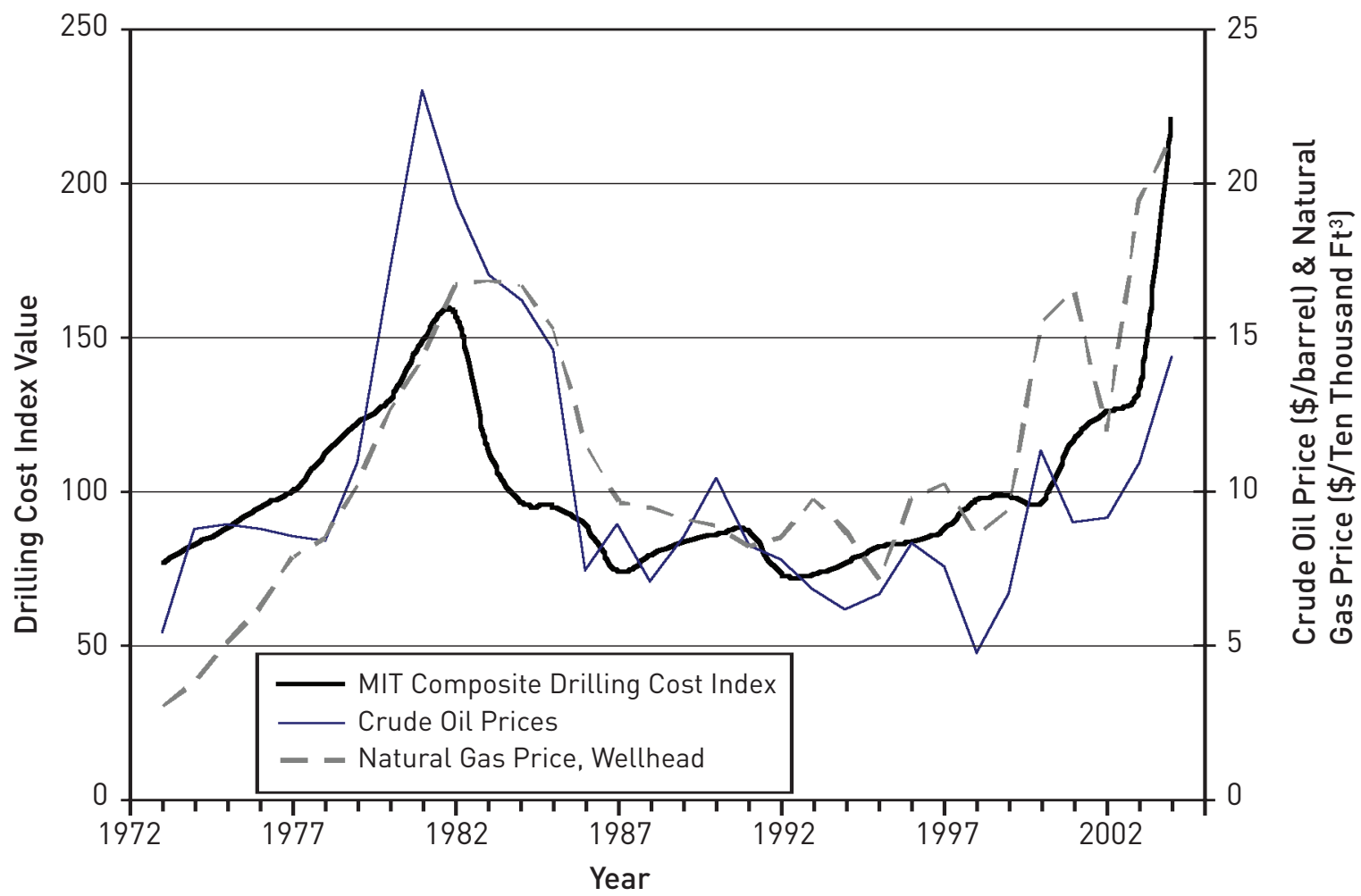

Figure 6.4 Crude oil and natural gas prices, adjusted for inflation (Energy Information Administration, 2005) compared to MIT Composite Drilling Index. 


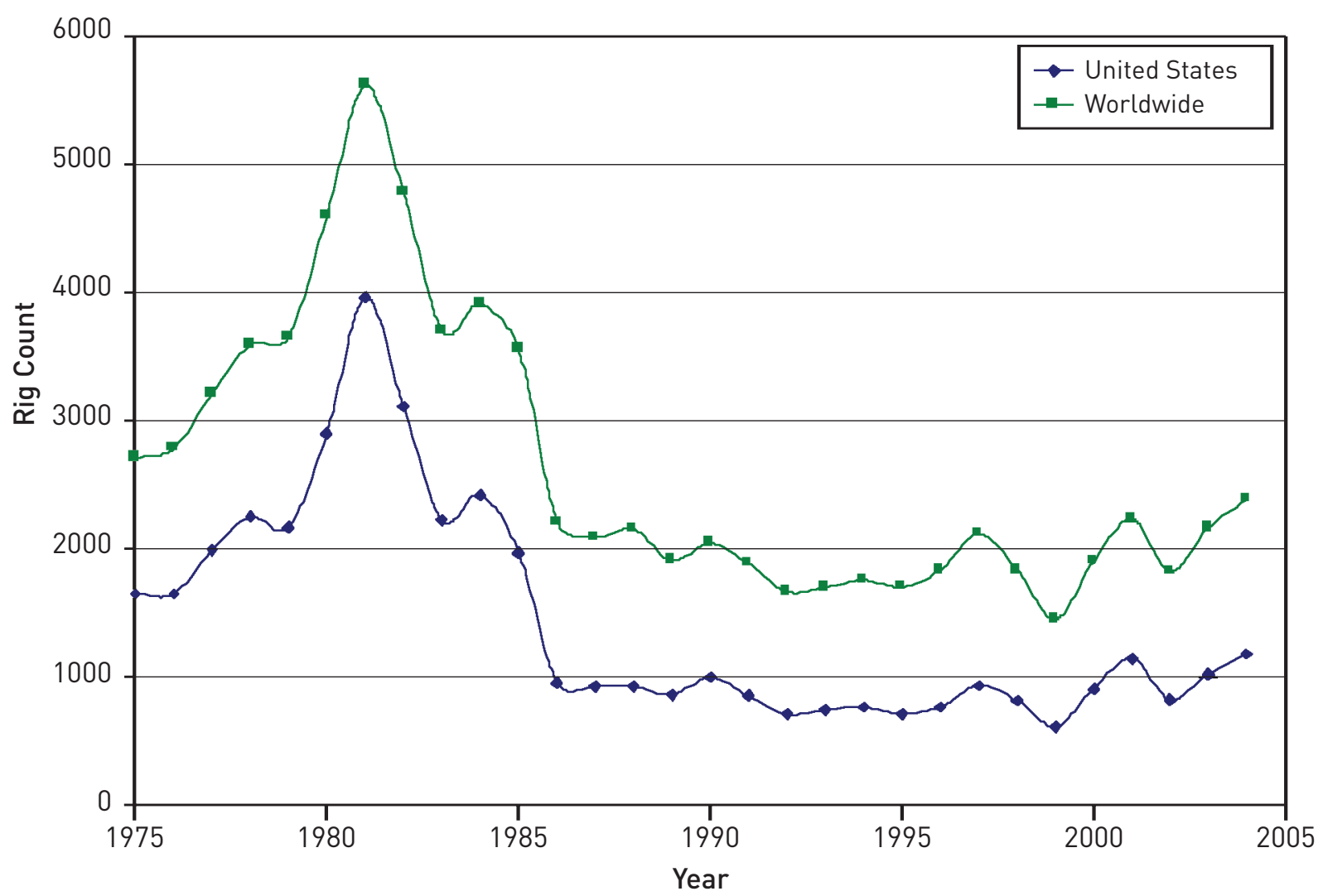

Figure 6.5 Average operating rotary drilling rig count by year, 1975-2004 (Baker Hughes, 2005).

The effect of inflation on drilling costs was also considered. Figure 6.6 shows the gross domestic product (GDP) deflator index (U.S. Office of Management and Budget, 2006), which is often used to adjust costs from year to year due to inflation, compared to the MITDD drilling cost index. Figure 6.6 shows that inflation has been steadily increasing, eroding the purchasing power of the dollar. For the majority of depth intervals, the drilling cost index has only recently increased above the highs of I982, despite the significant decrease in average purchasing power. Because the MITDD index does not account for inflation, this means the actual cost of drilling in terms of present U.S. dollars had actually decreased in the past two decades until recently. This point is illustrated in Figure 6.7, which shows the drilling index adjusted for inflation, so that all drilling costs are in year 2004 U.S. \$. For most depth intervals shown in Figure 6.7, the actual cost of drilling in year 2004 U.S. \$ has dropped significantly since I98I. Only shallower wells (I,250-2,499 feet) (380-760 m) do not follow this trend, possibly due to rig availability issues discussed above. This decrease is likely due to technological advances in drilling wells - such as better drill bits, more robust bearings, and expandable tubulars as well as overall increased experience in drilling wells. 


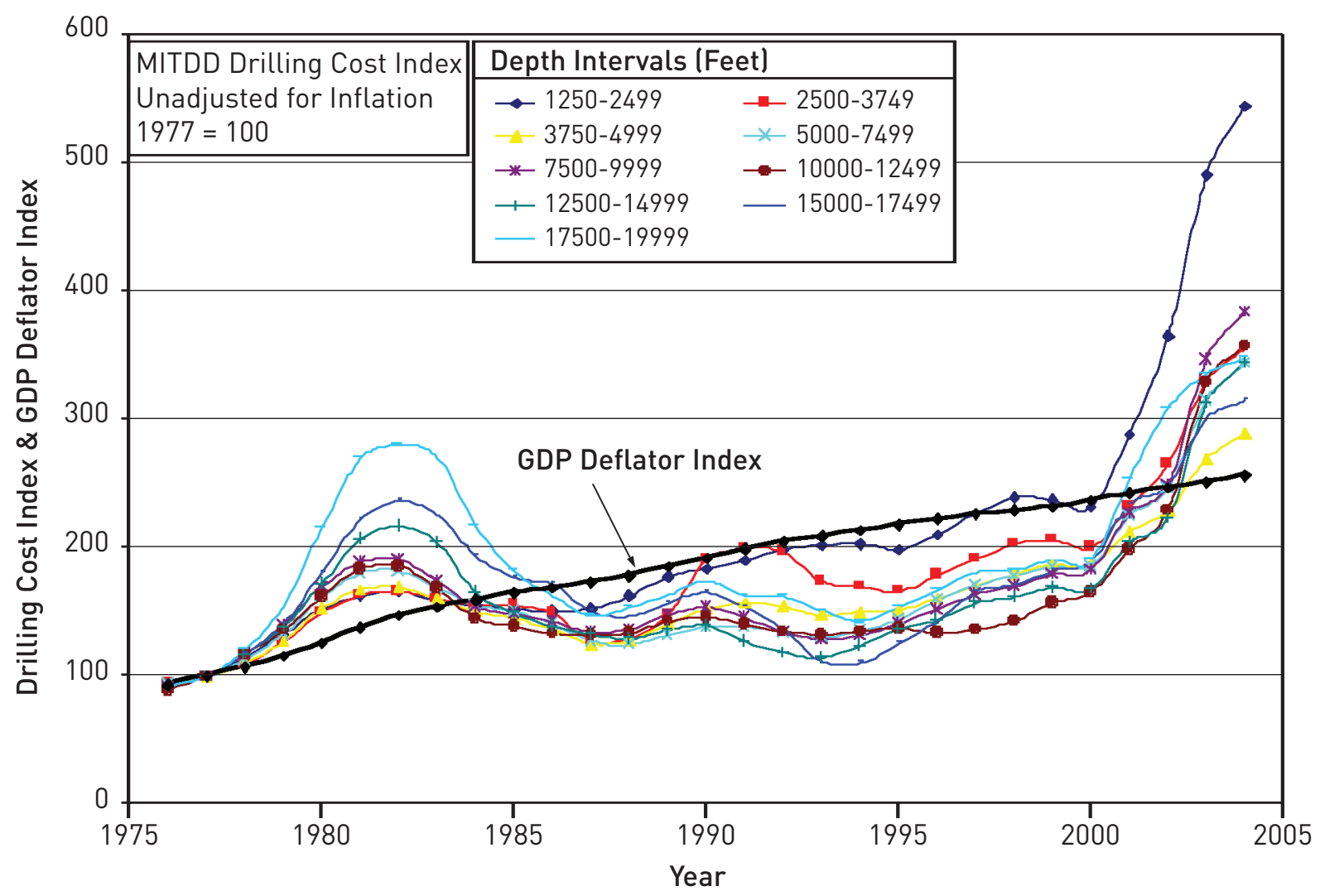

Figure 6.6 MITDD drilling cost index compared to GDP deflator index for 1977-2004 (U.S. Office of Management and Budget, 2006). Note: $1 \mathrm{ft}=0.3048 \mathrm{~m}$.

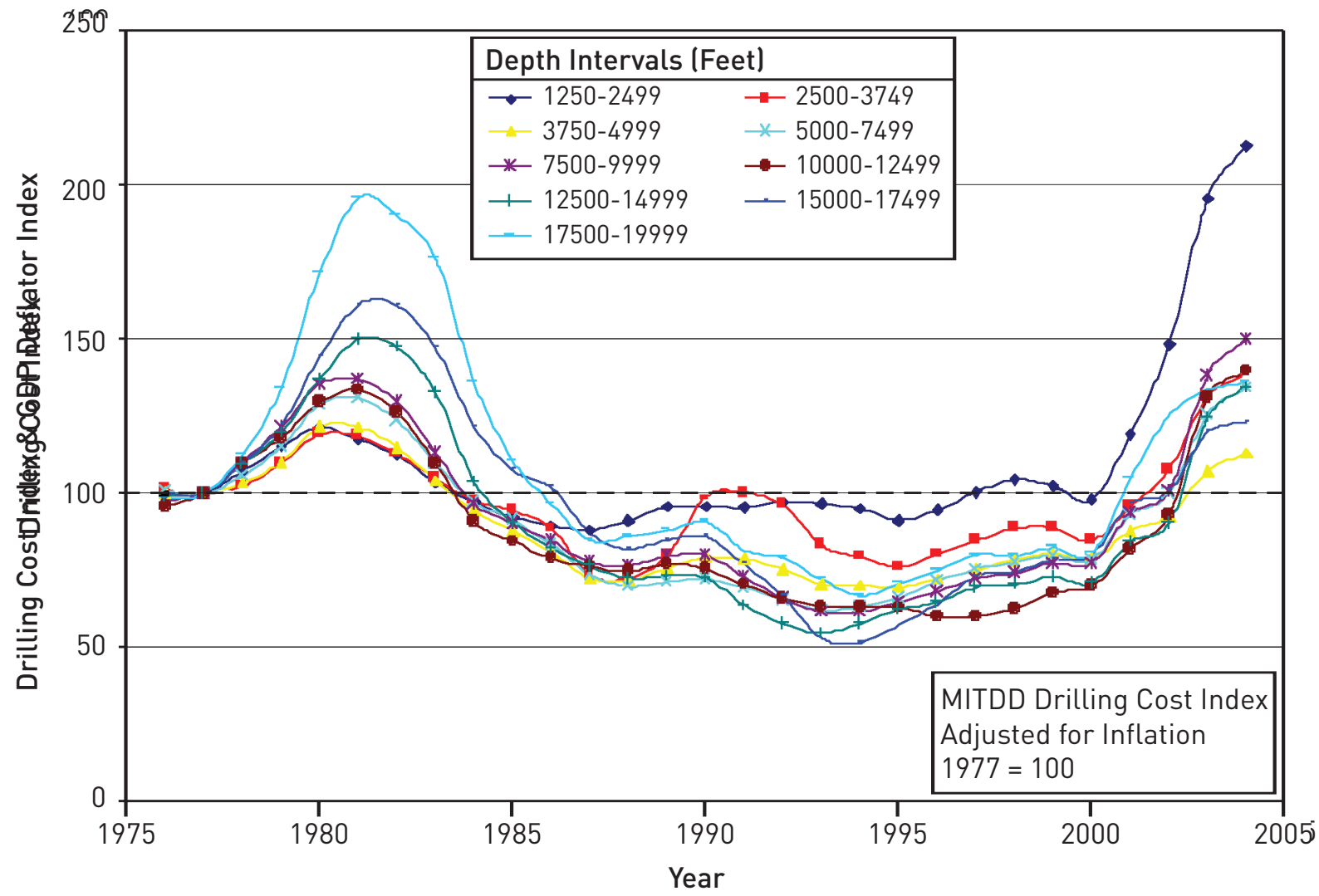

Figure 6.7 MITDD drilling cost index made using new method, adjusted for inflation to year 2004 U.S. \$. Adjustment for inflation made using GDP Deflator index $(1977=100)$. Note: $1 \mathrm{ft}=0.3048 \mathrm{~m}$. 


\subsubsection{Updated geothermal well costs}

The MITDD drilling cost index was used to update completed well costs to year 2004 U.S. \$ for a number of actual and predicted EGS/HDR and hydrothermal wells.

Table A.6.3 (see appendix) lists and updates the costs of geothermal wells originally listed in Tester and Herzog (I990), as well as geothermal wells completed more recently. Actual and predicted costs for completed EGS and hydrothermal wells were plotted and compared to completed JAS oil and gas wells for the year 2004 in Figure 6.I. Actual and predicted geothermal well costs vs. depth are clearly nonlinear. No attempt has been made to add a trend line to this data, due to the inadequate number of data points.

Similar to oil and gas wells, geothermal well costs appear to increase nonlinearly with depth (Figure 6.I). However, EGS and hydrothermal well costs are considerably higher than oil and gas well costs often two to five times greater than oil and gas wells of comparable depth. It should be noted that several of the deeper geothermal wells approach the JAS Oil and Gas Average. The geothermal well costs show a lot of scatter in the data, much like the individual ultra-deep JAS wells, but appear to be generally in good agreement, despite being drilled at various times during the past 30 years. This indicates that the MITDD index properly normalized the well costs.

Typically, oil and gas wells are completed using a $63 / 4$ " or 6 I/4" bit, lined or cased with 4 I/2" or 5 " casing that is almost always cemented in place, then shot perforated. Geothermal wells are usually completed with io $3 / 4$ " or 8 I/2" bits and $95 / 8$ " or 7 " casing or liner, which is generally slotted or perforated, not cemented. The upper casing strings in geothermal wells are usually cemented all the way to the surface to prevent undue casing growth during heat up of the well, or shrinkage during cooling from injection. Oil wells, on the other hand, only have the casing cemented at the bottom and are allowed to move freely at the surface through slips. The higher costs for larger completion diameters and cement volumes may explain why, in Figure 6.I, well costs for many of the geothermal wells considered - especially at depths below 5,000 $\mathrm{m}$ - are 2-5 times higher than typical oil and gas well costs.

Large-diameter production casings are needed to accommodate the greater production fluid flow rates that characterize geothermal systems. These larger casings lead to larger rig sizes, bits, wellhead, and bottom-hole assembly equipment, and greater volumes of cement, muds, etc. This results in a well cost that is higher than a similar-depth oil or gas well where the completed hole diameter will be much smaller. For example, the final casing in a 4,000 $\mathrm{m}$ oil and gas well might be drilled with a $63 / 4$ " bit and fitted with 5" casing; while, in a geothermal well, a 10 5/8" bit run might be used into the bottom-hole production region, passing through a II 3/4" production casing diameter in a drilled I4 3/4" wellbore.

This trend of higher costs for geothermal wells vs. oil and gas wells at comparable depths may not hold for wells beyond 5,000 $\mathrm{m}$ in depth. In oil and gas drilling, one of the largest variables related to cost is well control. Pressures in oil and gas drilling situations are controlled by three methods: drilling fluid density, well-head pressure control equipment, and well design. The well design change that is most significant when comparing geothermal costs to oil and gas costs is that extra casing strings are added to shut off high-pressure zones in oil and gas wells. While over-pressure is common in oil and gas drilling, geothermal wells are most commonly hydrostatic or under-pressured. The 
primary well-control issue is temperature. If the pressure in the well is reduced suddenly and very high temperatures are present, the water in the hole will boil, accelerating the fluid above it upward. The saturation pressure, along with significant water hammer, can be seen at the wellhead. Thus, the most common method for controlling pressure in geothermal wells is by cooling through circulation. The need for extra casing strings in oil wells, as depth and the risk of over-pressure increases, may cause the crossover between JAS oil and gas well average costs and predicted geothermal well costs seen in Figure 6.I at 6,000 m. Because no known geothermal wells have been drilled to this depth, a cost comparison of actual wells cannot be made.

The completed well-cost data (JAS) show that an exponential fit adequately describes completed oil and gas well costs as a function of depth over the intervals considered using only two parameters. The correlation in Figure 6.I provides a good basis for estimating drilling costs, based on the depth of a completed well alone. However, as the scatter in the ultra-deep well-cost data shows, there are many factors affecting well costs that must be taken into consideration to accurately estimate the cost of a particular well. The correlation shown in Figure 6.I has been validated using all available EGS drilling cost data and, as such, serves as a starting point or base case for our economic analysis. Once more specific design details about a well are known, a more accurate estimate can be made. In any case, sensitivity analyses were used to explore the effect of variations in drilling costs from this base case on the levelized cost of energy (see Section 9.IO.5).

\subsection{Predicting Geothermal Well Costs with the Wellcost Lite Model}

There is insufficient detailed cost history of geothermal well drilling to develop a statistically based cost estimate for predicting well costs where parametric variations are needed. Without enough statistical information, it is very difficult to account for changes in the production interval bit diameter and the diameter, weight, and grade of the tubulars used in the well, as well as the depths in a given geological setting. Although the correlation from the JAS data and drilling cost index discussed above allow one to make a general estimate of drilling costs based on depth, they do not explain what drives drilling costs or allows one to make an accurate estimate of drilling costs once more information about a drilling site is known. To do this, a detailed model of drilling costs is necessary. Such a model, called the Wellcost Lite model, was developed by B. J. Livesay and coworkers (Mansure et al., 2005) to estimate well costs based on a wide array of factors. This model was used to determine the most important driving factors behind drilling costs for geothermal wells.

\subsubsection{History of the Wellcost Lite model}

The development of a well-cost prediction model began at Sandia in I979 with the first well-cost analysis being done by hand. This resulted in the Carson-Livesay-Linn SAND 8I-2202 report (Carson, I983). The eight generic wells examined in the model represented geothermal areas of interest at the

time. The hand-calculated models were used to determine well costs for the eight geothermal drilling areas. This effort developed an early objective look at the major cost categories of well construction.

The initial effort was followed by a series of efforts in support of DOE well-cost analysis and cost-ofpower supply curves. About I990, a computer-based program known as IMGEO (Petty, Entingh, and Livesay, I988; Entingh and McLarty, I99I), which contained a well-cost predictive model, was 
developed for DOE and was used to evaluate research and development needs. The IMGEO model included cost components for geological studies, exploration, development drilling, gathering systems, power facilities, and power-online. IMGEO led to the development of the Wellcost-I996 model. As a part of the Advanced Drilling Study (Pierce et al., I996), a more comprehensive costing model was developed, which could be used to evaluate advanced drilling concepts. That model has been simplified to the current Wellcost Lite model.

\subsubsection{Wellcost Lite model description}

Wellcost Lite is a sequential event- and direct cost-based model. This means that time and costs are computed sequentially for all events that occur in the drilling of the well. The well drilling sequence is divided into intervals, which are usually defined by the casing intervals, but can be used where a significant change in formation drilling hardness occurs. Current models are for 4, 5, and 6 intervals - more intervals can be added as required.

The model calculates the cost of drilling by casing intervals. The model is EXCEL spreadsheet-based and allows the input of a casing design program, rate of penetration, bit life, and trouble map for each casing interval. The model calculates the time to drill each interval including rotating time, trip time, mud, and related costs and end-of-interval costs such as casing and cementing and well evaluation. The cost for materials and the time required to complete each interval is calculated. The time is then multiplied by the hourly cost for all rig time-related cost elements such as tool rental, blowout preventers (BOP), supervision, etc. Each interval is then summed to obtain a total cost. The cost components of the well are presented in a descriptive breakdown and on the typical authorization for expenditures (AFE) form used by many companies to estimate drilling costs.

\subsection{Drilling-Cost Model Validation}

\subsubsection{Base-case geothermal wells}

The cost of drilling geothermal wells, including enhanced geothermal wells and hot dry rock wells exclusive of well stimulation costs, was modeled for similar geologic conditions and with the same completion diameter for depths between I,500 and I0,000 m. The geology was assumed to be an interval of sedimentary overburden on top of hard, abrasive granitic rock with a bottom-hole temperature of $200^{\circ} \mathrm{C}$. The rates of penetration and bit life for each well correspond to drilling through typical poorly lithified basin fill sediments to a depth of I,००० $\mathrm{m}$ above the completion interval, below which granitic basement conditions are assumed. The completion interval varies from $250 \mathrm{~m}$ for a I,500 $\mathrm{m}$ well to I,000 $\mathrm{m}$ for wells 5,000 $\mathrm{m}$ and deeper. The casing programs used assumed hydrostatic conditions typical for geothermal environments. All the well plans for determining base costs with depth assume a completion interval drilled with a Io 5/8" bit. The wells are not optimized for production and are largely trouble free. For the base-case wells at each depth, the assumed contingency is I०\%, which includes noncatastrophic costs for troubles during drilling.

The well costs that are developed for the EGS consideration are for both injectors and producers. The upper portion of the cased production hole may need to accommodate some form of artificial lift or pumping. This would mean that the production casing would be run as a liner back up to the point at which the larger diameter is needed. Current technology for shaft drive pumps limits the setting

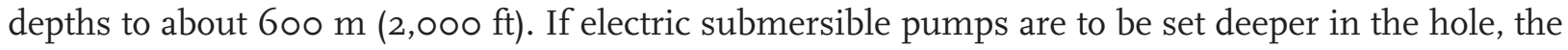
required diameter will have to be accommodated by completing the well with liners, leaving greater 
clearance deeper into the hole. The pump cavity can be developed to the necessary depth. The estimates are for an injection well that has a production casing from the top of the injection zone to the surface.

EGS well depths beyond 4,000 $\mathrm{m}$ (13,100 ft) may require casing weights and grades that are not widely available to provide the required collapse and tensile ratings. The larger diameters needed for high-volume injection and production are also not standard in the oil and gas industry - this will cause further cost increases. Both threaded and welded connections between casing lengths will be used for EGS applications and, depending on water chemistry, special corrosion-resistant materials may be needed.

An appropriately sized drilling rig is selected for each depth using the mast capacity and rig horsepower as a measure of the needed size. A rig rental rate, as estimated in the third quarter of 2004, is used in determining the daily operating expense. It is assumed that all well-control equipment is rented for use in the appropriate interval. Freight charges are charged against mobilization and demobilization of the blowout-preventer equipment.

The rates of penetration (ROP) selected in the base case are those of medium-hardness sedimentary formations to the production casing setting depth. An expected reduction in ROP is used through the production interval. For other lithology columns, it is only necessary to select and insert the price and performance expectations to derive the well cost. These bit-performance values are slightly conservative.

The I,500 $\mathrm{m}(4,900 \mathrm{ft}), 2,500 \mathrm{~m}(8,200 \mathrm{ft})$, and 3,000 $\mathrm{m}(9,800 \mathrm{ft})$ well-cost estimates from the model compare favorably with actual geothermal drilling costs for those depths. The deeper wells at depths of 4,000 $\mathrm{m}$ (I3,100 ft), 5,000 $\mathrm{m}(\mathrm{I} 6,400 \mathrm{ft})$, and 6,000 $\mathrm{m}$ (I9,700 ft) have been compared to costs from the JAS oil and gas well database. The length of open hole for the 7,500 $\mathrm{m}$ - and ro,o00 m-deep wells was assumed limited to between 2,I00 $\mathrm{m}(6,900 \mathrm{ft})$ and 2,600km $(8,500 \mathrm{ft})$.

All wells should have at least one interval with significant directional activity to permit access to varied targets downhole. This directional interval would be either in the production casing interval or the interval just above. The amount and type of directional well design can be accommodated in the model. The well-cost estimates are initially based on drilling hardness, similar to those used in the Basin and Range geothermal region. It is assumed that the EGS production zone is crystalline. The well should penetrate into the desired temperature far enough so that any upward fracturing does not enter into a lower temperature formation. Also, each well is assumed to penetrate some specific depth into the granitic formation. In the deeper wells, a production interval of $1,000 \mathrm{~m}(3,300 \mathrm{ft})$ is assumed. It is reduced for the shallower wells and is noted in the Wellcost Lite output record

Well costs were estimated for depths ranging from I,500 $\mathrm{m}$ to I0,000 $\mathrm{m}$. The resulting curves indicate drilling costs that grow nonlinearly with depth. The estimated costs for each of these wells are given in Table 6.I. 
Table 6.1 EGS well drilling-cost estimates from the Wellcost Lite model (in 2004 U.S. \$)

\begin{tabular}{|c|c|c|c|c|c|c|c|c|}
\hline \multicolumn{3}{|c|}{ Shallow } & \multicolumn{3}{|c|}{ Mid Range } & \multicolumn{3}{|c|}{ Deep } \\
\hline $\begin{array}{l}\text { Depth, m } \\
\text { (ft) }\end{array}$ & $\begin{array}{l}\text { No. of } \\
\text { Casing } \\
\text { Strings }\end{array}$ & $\begin{array}{l}\text { Cost, } \\
\text { million \$ }\end{array}$ & $\begin{array}{l}\text { Depth, m } \\
\text { (ft) }\end{array}$ & $\begin{array}{l}\text { No. of } \\
\text { Casing } \\
\text { Strings }\end{array}$ & $\begin{array}{l}\text { Cost, } \\
\text { million \$ }\end{array}$ & $\begin{array}{l}\text { Depth, m } \\
\text { (ft) }\end{array}$ & $\begin{array}{l}\text { No. of } \\
\text { Casing } \\
\text { Strings }\end{array}$ & $\begin{array}{l}\text { Cost, } \\
\text { million \$ }\end{array}$ \\
\hline $\begin{array}{l}1,500 \\
(4,900)\end{array}$ & 4 & 2.3 & $\begin{array}{l}4,000 \\
(13,100)\end{array}$ & 4 & 5.2 & $\begin{array}{l}6,000 \\
(19,700)\end{array}$ & 5 & 9.7 \\
\hline $\begin{array}{l}2,500 \\
(8,200)\end{array}$ & 4 & 3.4 & $\begin{array}{l}5,000 \\
(16,400)\end{array}$ & 4 & 7.0 & $\begin{array}{l}6,000 \\
(19,700)\end{array}$ & 6 & 12.3 \\
\hline \multirow[t]{2}{*}{$\begin{array}{l}3,000 \\
(9,800)\end{array}$} & 4 & 4.0 & $\begin{array}{l}5,000 \\
(16,400)\end{array}$ & 5 & 8.3 & $\begin{array}{l}7,500 \\
(24,600)\end{array}$ & 6 & 14.4 \\
\hline & & & & & & $\begin{array}{l}10,000 \\
(32,800)\end{array}$ & 6 & 20.0 \\
\hline
\end{tabular}

Shallow EGS wells. For the shallow wells (I,500 m, 2,500 m, and 3,000 m), the well-cost predictions are supported by actual geothermal drilling costs from the Western U.S. states. Due to the confidential nature of these actual costs, the level of validation with the model is far from precise, because only the depth and cost were provided. No specific formation characteristics or well/casing design information was used in this modeling effort, but it was assumed that bit performance in the model was similar to current geothermal well experience.

Mid-range EGS wells. For the mid-range of depths, 4,000 $\mathrm{m}$ and 5,000 $\mathrm{m}$, the cost estimates have been made by extending the same well design and drilling approaches used in the shallow group.

The 5,000 $\mathrm{m}$ well is first modeled as a 4-casing interval model (surface casing, intermediate liner, production casing into the heat, production zone lined with perforated liner). Another $5 \mathrm{~km}$-deep well has 5 casing intervals (surface casing, intermediate liner, intermediate liner 2, production casing into the heat, production zone lined with perforated liner). The cost impact of the additional liner is significant. For the same diameter in the production zone, all casings and liners above that zone are notably larger in diameter.

Deep EGS wells. The 6,000 $\mathrm{m}$ well is the first in a number of modeled well designs with very large upper casing sections and higher cost. The $6,000 \mathrm{~m}$ well uses 5 - and 6-casing interval cost models to better accommodate the greater casing diameters needed and reduce the length of the intervals. The change results in an increase in cost, due to the additional casing and cementing charges as well as the other end-of-interval activities that occur. The cost of a 6-casing, 6,000 $\mathrm{m}$ (I9,700 ft) geothermal well compares satisfactorily with a limited number of oil and gas wells from the JAS database. The estimated cost of the $6,000 \mathrm{~km}$ EGS well is \$I2.28 million vs. an average JAS oil and gas well cost of \$18 million.

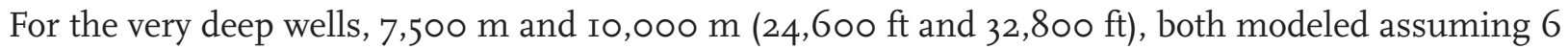
casing intervals, the developed estimates reflect the extreme size of the surface casing when the amount of open hole is limited to $2, \mathrm{I} 30$ to $2,440 \mathrm{~m}$ (7,000 to 8,000 ft). The well designs were based on oil and gas experience at these depths. Well-cost models have been developed for numerous 
geothermal fields and other specific examples. They are in reasonable agreement with current welldrilling practice. For example, costs for wells at The Geysers and in Northern Nevada and the Imperial Valley are in good agreement with the cost models developed in this study.

\subsubsection{Comparison with geothermal wells}

Predicted EGS well costs (from the Wellcost Lite model) are shown in Figure 6.I, alongside JAS oil/gas well costs and historical geothermal well-cost data. For depths of up to about 4,000 m, predicted well costs exceed the oil and gas average but agree with the higher geothermal well-cost data. Beyond depths of $6,000 \mathrm{~m}$, predictions drop below the oil and gas average but agree with costs for ultra-deep oil and gas wells within uncertainty, given the considerable scatter of the data. The Wellcost Lite predictions accurately capture a trend of nonlinearly increasing costs with depth, exhibited by historical well costs.

Figure 6.8 shows predicted costs for hypothetical wells at completion depths between I,500 $\mathrm{m}$ and I0,000 $\mathrm{m}$. Cost predictions for three actual existing wells are also shown, for which real rates-ofpenetration and casing configurations were used in the analysis. These wells correspond to RHI5 at Rosemanowes, GPK4 at Soultz, and Habanero-2 at Cooper Basin. It should be noted that conventional U.S. cementing methods were assumed, which does not reflect the actual procedure used at GPK4. Two cost predictions were made for this particular well: one (shown in Figure 6.8) based on actual recorded bit run averages, and a second (not shown) that took the best available technology into consideration. Use of the best available technology resulted in expected savings of $17.6 \%$ compared to a predicted cost of $\$ 6.7$ million when the recorded bit run averages were used to calculate the estimated well cost. Figure 6.8 also includes the actual trouble-free costs from GPK4 and Habanero-2, which agree with the model results within uncertainty. For example, the predicted cost of U.S. \$ 5.87 million for Habanero-2 is quite close to the reported actual well cost of U.S. \$ 6.3 million (AUS \$8.7 million). Both estimated and actual costs shown in Figure 6.8 are tabulated in Table A.6.3. The agreement between the Wellcost Lite predictions and the historical records demonstrate that the model is a useful tool for predicting actual drilling costs with reasonable confidence.

\subsubsection{Comparison with oil and gas wells}

Comparisons between cost estimates of the base-case geothermal wells to oil and gas well-cost averages are inconclusive and are not expected to yield valuable information. Oil and gas well costs over the various depth intervals range from less expensive to more expensive than the geothermal well costs developed from Wellcost Lite. However, an example well-cost estimate was developed for a 2,500 $\mathrm{m}(8,200 \mathrm{ft})$ oil and gas well with casing diameters that are more representative of those used in oil and gas drilling (the comparison is shown in Table 6.2). These costs are within the scatter of the JAS cost information for California. A 2,500 $\mathrm{m}$ well is a deep geothermal well but a shallow West Texas oil or gas well. This comparison shows the effect of well diameter on drilling costs and demonstrates why geothermal wells at shallow depths tend to be considerably more expensive than oil and gas wells of comparable depth. 


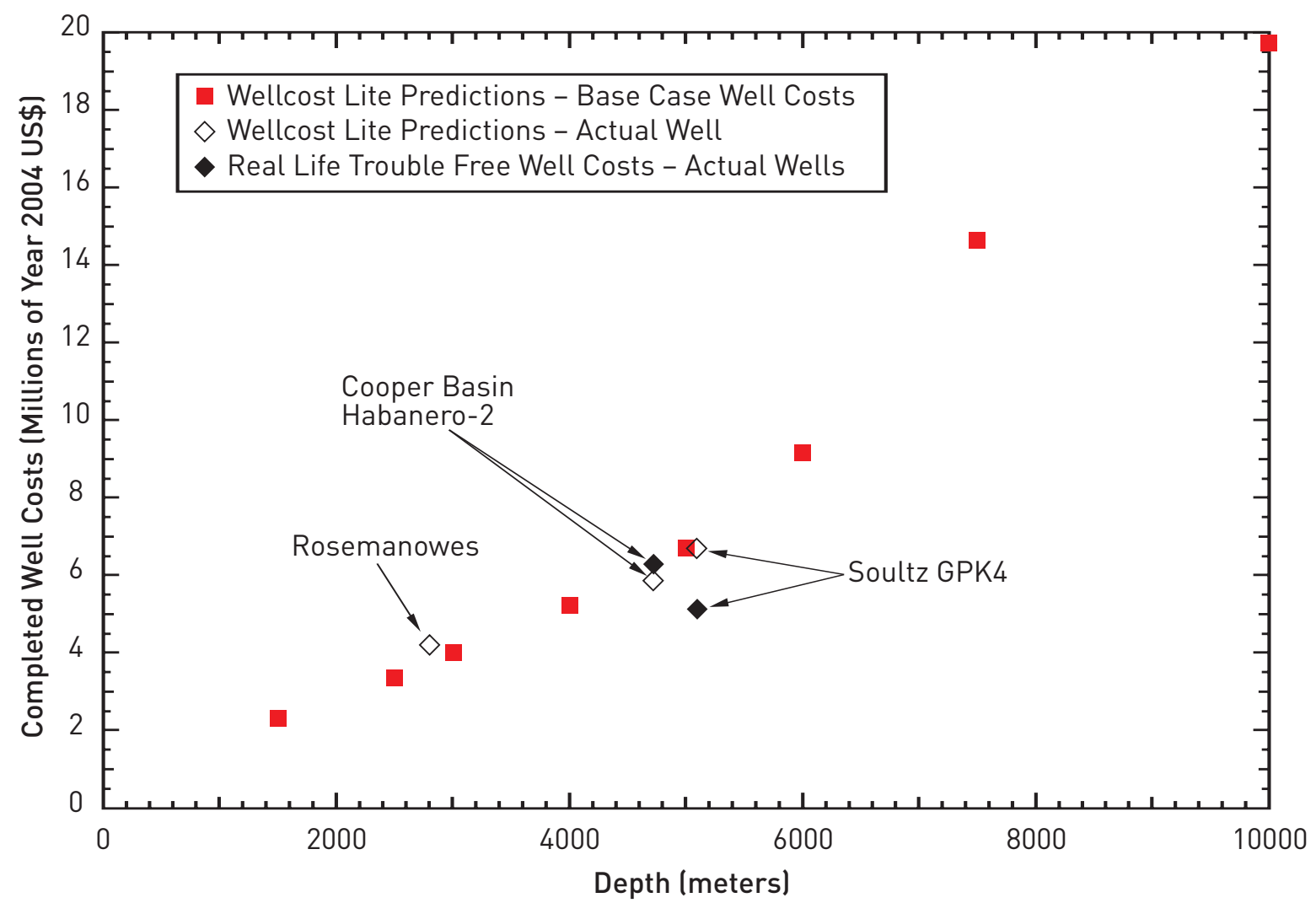

Figure 6.8 EGS well-cost predictions from the Wellcost Lite model and historical geothermal well costs, at various depths.

Table 6.2 Well-cost comparison of EGS with oil and gas. Costs shown are for completed through/perforated in-place casing.

\begin{tabular}{l|l|l|l|l}
\hline Well type & Depth & Production casing size & Final bit diameter & Cost/days of drilling \\
\hline EGS & $2,500 \mathrm{~m}(8,200 \mathrm{ft})$ & $113 / 4^{\prime \prime}$ & $105 / 8^{\prime \prime}$ & $\$ 3,400 \mathrm{~m} / 43$ \\
\hline Oil / Gas average & $2,500 \mathrm{~m}(8,200 \mathrm{ft})$ & $85 / 8^{\prime \prime}$ & $63 / 4^{\prime \prime}$ & $\$ 1,800 \mathrm{~m} / 29$ \\
\hline Oil / Gas Slim Hole & $2,500 \mathrm{~m}(8,200 \mathrm{ft})$ & $51 / 2^{\prime \prime}$ & $63 / 4^{\prime \prime}$ & $\$ 1,400 \mathrm{~m} / 21$ \\
\hline
\end{tabular}

\subsubsection{Model input parameter sensitivities and drilling-cost breakdown}

The Wellcost Lite model was used to perform a parametric study to investigate the sensitivities of model inputs such as casing configuration, rate-of-penetration, and bit life. Well-drilling costs for oil, gas, and geothermal wells are subdivided into five elements: (i) pre-spud costs, (ii) casing and cementing costs, (iii) drilling-rotating costs, (iv) drilling-nonrotating costs, and (v) trouble costs. Prespud costs include move-in and move-out costs, site preparation, and well design. Casing and cementing costs include those for materials and those for running casing and cementing it in place. Drilling-rotating costs are incurred when the bit is rotating, including all costs related to the rate-ofpenetration, such as bits and mud costs. Drilling-nonrotating costs are those costs incurred when the bit is not rotating, and include tripping, well control, waiting, directional control, supervision, and well evaluation. Unforeseen trouble costs include stuck pipe, twist-offs, fishing, lost circulation, holestability problems, well-control problems, casing and cementing problems, and directional problems. 
The contribution of each major drilling cost component is shown in Figure 6.9 over a range of depths. Rotating-drilling costs and casing/cementing costs dominate well costs at all depths. Drilling-rotating, drilling-nonrotating, and pre-spud expenses show linear growth with depth. Casing/cementing costs and trouble costs increase considerably at a depth of about $6,000 \mathrm{~m}$, coinciding with the point where a change from three to four casing strings is required. All of these trends are consistent with the generally higher risks and more uncertain costs that accompany ultra-deep drilling.

All costs are heavily affected by the geology of the site, the depth of the well, and to a lesser degree, the well diameter. Casing and cementing costs also depend on the fluid pressures encountered during drilling. Well depth and geology are the primary factors that influence drilling nonrotating costs, because they affect bit life and therefore tripping time. Pre-spud costs are related to the rig size, which is a function of the well diameter, the length of the longest casing string, and the completed well depth.

Geology/Rate-of-Penetration. Rate-of-penetration (ROP), which is controlled by geology and bit selection, governs rotating-drilling costs. EGS wells will typically be drilled in hard, abrasive, hightemperature formations that reduce ROP and bit life. This also affects drilling nonrotating costs, because lower bit life creates an increased need for trips. However, most EGS sites will have at least some softer sedimentary rock overlying a crystalline basement formation. In the past I5 to 20 years, dramatic improvements in bit design have led to much faster rates-of-penetration in hard, hightemperature environments.

The degree to which the formation geology affects total drilling costs was investigated by using the model to make well-cost predictions under four different assumed geologic settings. Rate-ofpenetration (ROP) and bit-life input values to the model were adjusted to simulate different drilling environments, which ranged from very fast/nonabrasive to very hard/abrasive. The medium ROP represents sedimentary basin conditions (e.g., at Dixie Valley), whereas the very low ROP would be more representative of crystalline formations such as those found at Rosemanowes. In all cases, the best available bit technology was assumed. A 4,000 m-deep well was modeled to study the impact of increasing ROP on total well cost. An 83\% increase in ROP from "very low" to "medium" values resulted in a $20 \%$ cost savings. 


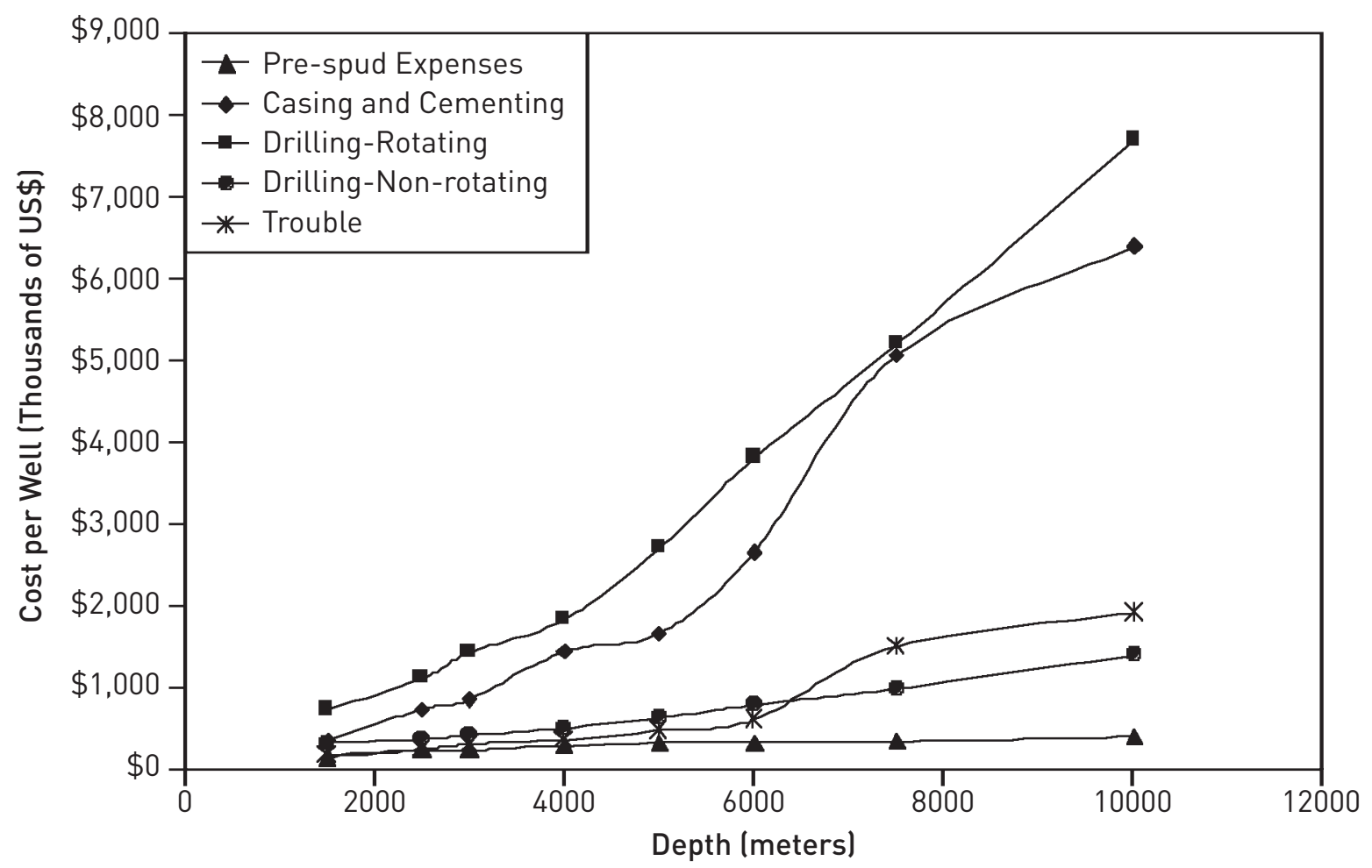

Figure 6.9 Breakdown of drilling cost elements as a function of depth from Wellcost Lite model results.

Number of Casing Strings. A greater number of casing strings results in higher predicted drilling costs. It is not just the direct cost of additional strings that has an effect; there are also costs that occur because of well-diameter constraints. For example, to maintain a 9 5/8" completion diameter - which may be required to achieve flow rates suitable for electric power production - the surface casing in a IO,000 m-deep EGS well must have a diameter of 42 ". The ability to handle this large casing size requires more expensive rigs, tools, pumps, compressors, and wellhead control equipment.

The relationship between the number of casing strings and completed well costs is shown in Figure 6.Io. Increasing the number of casing strings from four to five in the 5,000 m-deep well results in an $18.5 \%$ increase in the total predicted well cost. An increase in the number of casing strings from five to six in the 6,000 m-deep well results in a $24 \%$ increase in total cost. As the number of casing strings increases, the rate at which drilling costs increase with depth also increases. 


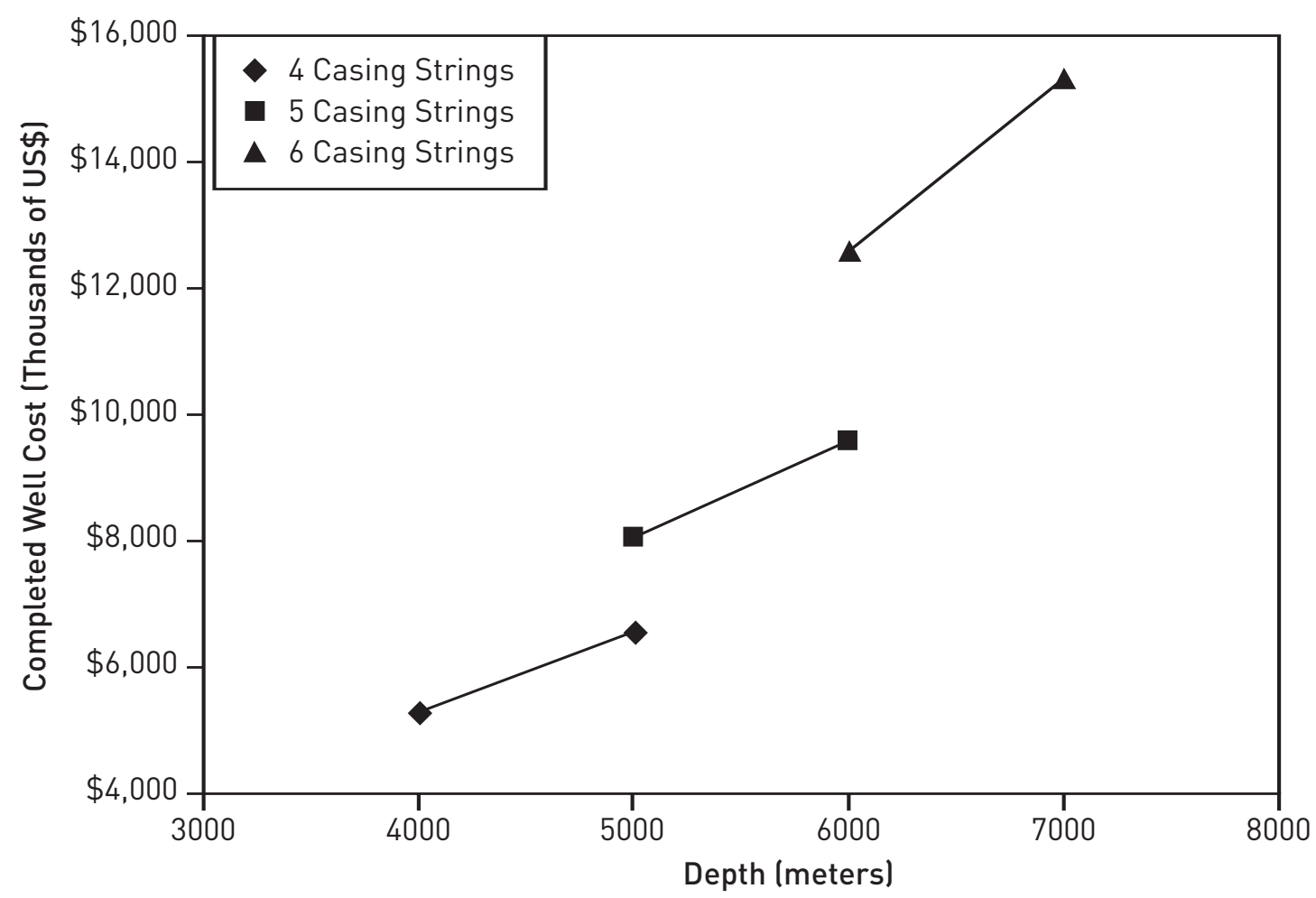

Figure 6.10 Change in Wellcost Lite model predictions as a function of depth and number of casing intervals.

Figure 6.II compares rotating time with tripping time for different depths of completion, using the Wellcost Lite model. Both grow almost linearly with depth, assuming ROP and bit life remain constant. However, these may not be appropriate assumptions at greater depths.

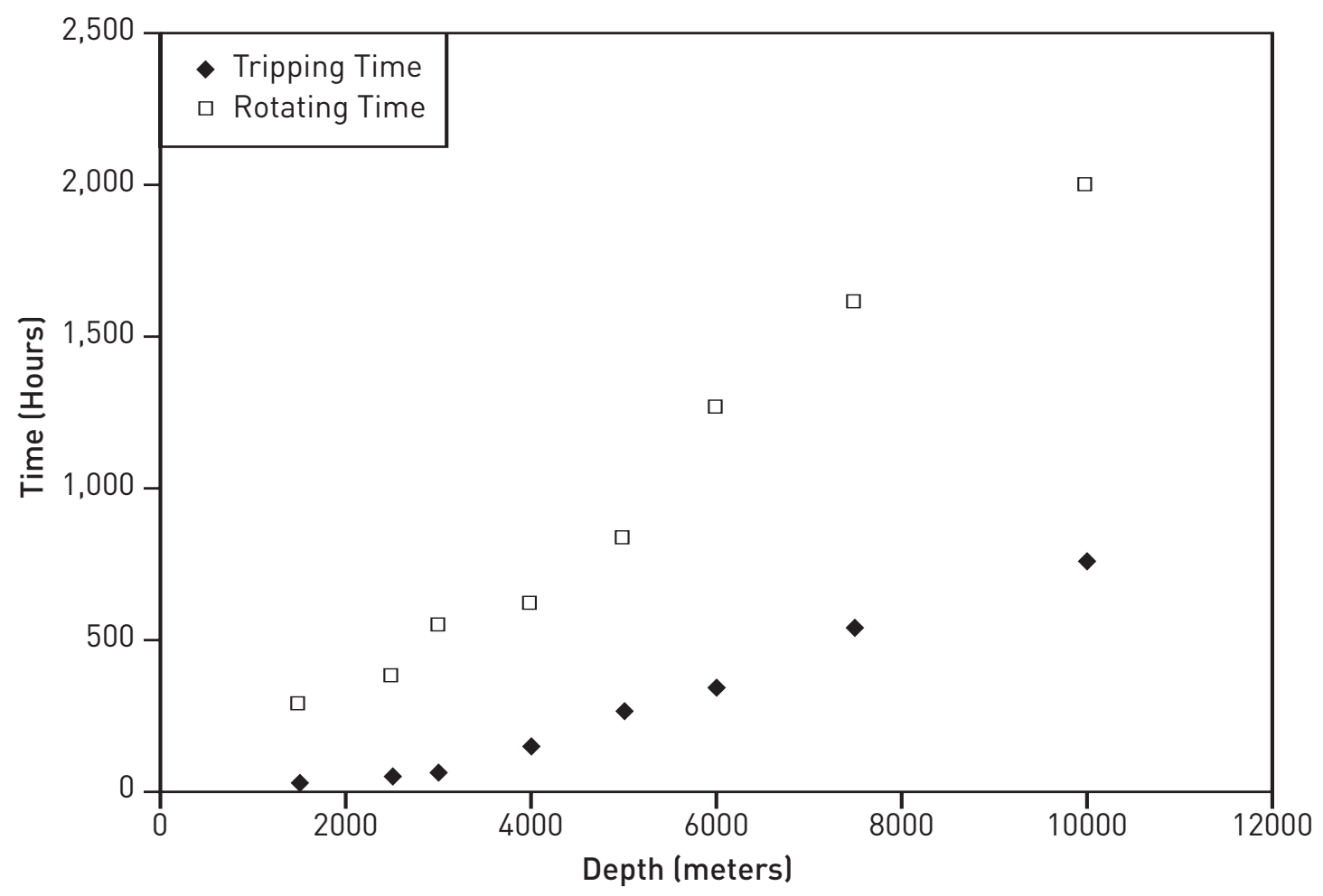

Figure 6.11 Comparison of rotating and tripping hours as a function of well depth from Wellcost Lite model. 


\subsection{Emerging Drilling Technologies}

Given the importance of drilling costs to the economic viability of EGS, particularly for mid- to lowgrade resources where wells deeper than $4 \mathrm{~km}$ will be required, it is imperative that new technologies are developed to maximize drilling capabilities (Petty et al., I988; Petty et al., I991; Petty et al., I992; Pierce and Livesay, I994; Pierce and Livesay, I993a; Pierce and Livesay, I993b). Two categories of emerging technologies that would be adaptable to EGS are considered: (i) evolutionary oil and gas well-drilling technologies available now that are adaptable to drilling EGS wells, and (ii) revolutionary technologies not yet available commercially.

\subsubsection{Current oil and gas drilling technologies adaptable to EGS}

There are a number of approaches that can be taken to reduce the costs of casing and cementing deep EGS wells: expandable tubular casings, low-clearance well casing designs, casing while drilling, multilaterals, and improved rates-of-penetration are developments that will dramatically improve the economics of deep EGS wells. The first three concepts, which relate to casing design, are widely used in the oil and gas industry and can easily be adapted for EGS needs. The use of multilaterals to reduce the cost of access to the reservoir has also become common practice for hydrothermal and oil/gas operations. Adaptation, analysis, and testing of new technologies are required to reduce deep EGS well costs.

Expandable tubulars casing. Casing and cementing costs are high for deep wells due to the number of casing strings and the volume of cement required. A commercially available alternative is to use expandable tubulars to line the well. Further development and testing is still needed to ensure the reliability of expandable tubular casing in wells where significant thermal expansion is expected. Efforts are underway to expand the range of available casing sizes and to develop effective tools and specialized equipment for use with expandable tubulars (Benzie et al., 2000; Dupai et al., 200I; Fillipov et al., I999).

The expandable tubing casing process utilizes a product, patented by Shell Development (Lohbeck, I993), which allows in situ plastic deformation of the tubular casing. The interval is drilled using a bit just small enough to pass through the deepest casing string. There is an under-reamer behind the lead bit. The under-reamer is used to widen the bottom of the well and allow cementing of the casing, after running and expanding. The result is that the inner surfaces of adjacent casings are flush (i.e., the inner diameter is constant with depth). This allows two possible approaches to be taken: (i) the resulting casing may be used as the production string; and (ii) a liner may be run and cemented in the well after progress through the production interval is completed. Technology improvements are needed if this approach is to be taken in deep, large-diameter EGS wells.

Under-reamers. Monobore designs that use expandable tubulars require under-reamers. The use of under-reamers is common in oil and gas drilling through sediments, and provides cementing clearance for casing strings that would not otherwise be available. However, high-quality underreamers for hard rock environments are not common, with expansion arms often being subject to failure. Currently, under-reaming in oil and gas operations utilizes bi-center bits and PDC-type cutters. Unfortunately, the success of PDC cutters in geothermal environments has not yet been established. More robust under-reamers are required for EGS applications. 
Low-clearance casing design. An alternative approach to using expandable tubulars is to accept reduced clearances. A well design using smaller casing and less clearance between casing strings may be appropriate (Barker, I997). This may also require the use of an under-reamer to establish clearance between the casing and the borehole for cementing. Although closer tolerances may cause problems with cementing operations, this can usually be remedied by the use of under-reamers before cementing.

Drilling-with-casing is an emerging technology that has the potential to reduce cost. This approach may permit longer casing intervals, meaning fewer strings - and, therefore, reduced costs (Gill et al., I995). Research is needed to improve our understanding of cementing practices that apply to the drilling-with-casing technique. As with expandable tubulars, the development of reliable underreamers is key to the advancement of this technology.

Multilateral completions/stimulating through sidetracks and laterals. Tremendous progress has been made in multilateral drilling and completions during the past Io years. However, pressure-based stimulation of EGS reservoirs may still prove difficult, unless the most sophisticated (Class 5 and Class 6) completion branch connections are used. The successful development of reliable re-entry schemes and innovative ways to sequentially stimulate EGS development sets may be necessary, if the additional cost of such sophisticated completion practices is to be avoided.

Well design variations. Considerable savings are possible if the length of casing intervals is extended. This will reduce the number of casing strings, and therefore, the diameter of the surface and first intermediate casings. The success of this approach depends on the ability to maintain wellbore stability of the drilled interval and to install a good cement sheath. There may be isolated intervals where this technique will be appropriate.

\subsubsection{Revolutionary drilling technologies}

Rate-of-penetration issues can significantly affect drilling costs in crystalline formations. ROP problems can cause well-cost increases by as much as $15 \%$ to $20 \%$ above those for more easily drilled Basin and Range formations.

Although we have not formally analyzed the potential cost reductions of revolutionary drilling technologies as a part of this assessment, it is clear that they could have a profound long-term impact on making the lower-grade EGS resource commercially accessible. New drilling concepts could allow much higher rates of penetration and longer bit lifetimes, thereby reducing rig rental time, and lighter, lower-cost rigs that could result in markedly reduced drilling cost. Such techniques include projectile drilling, spallation drilling, laser drilling, and chemical drilling. Projectile drilling consists of projecting steel balls at high velocity using pressurized water to fracture and remove the rock surface. The projectiles are separated and recovered from the drilling mud and rock chips (Geddes and Curlett, 2006). Spallation drilling uses high-temperature flames to rapidly heat the rock surface, causing it to fracture or "spall." Such a system could also be used to melt non-spallable rock (Potter and Tester, I998). Laser drilling uses the same mechanism to remove rock, but relies on pulses of laser to heat the rock surface. Chemical drilling involves the use of strong acids to break down the rock, and has the potential to be used in conjunction with conventional drilling techniques (Polizzotti et al., 2003). These drilling techniques are in various stages of development but are not yet commercially available. However, successful development of any of these technologies could cause a major change in drilling practices, dramatically lower drilling costs - and, even more important, allow deeper drilling capabilities to be realized. 


\subsection{Conclusions}

Wellcost Lite is a detailed accounting code for estimating drilling costs, developed by B. J. Livesay and Sandia National Laboratories over the past 20 years. Wellcost Lite, which has been used to evaluate technology impacts and project EGS well costs, was used to estimate costs covering a range of depths from I,500 $\mathrm{m}$ to $10,000 \mathrm{~m}$. Three depth categories have been examined in some detail in this study: shallow wells (I,500-3,000 $\mathrm{m}$ depths), mid-range wells (4,000-5,000 $\mathrm{m}$ depths), and deep wells (5,000-10,000 $\mathrm{m}$ depths).

The shallow set of wells at depths of I,500 m (4,900 ft), 2,500 m (8,200 ft), and 3,000 m (9,800 ft) is representative of current hydrothermal well depths. The predicted costs from the Wellcost Lite model were compared to actual EGS and hydrothermal shallow well drilling-cost records that were available. The agreement is satisfactory, although actual cost data are relatively scarce, making a direct comparison not entirely appropriate.

The same well-design concepts used for the shallow set of wells was also adopted for the mid-range

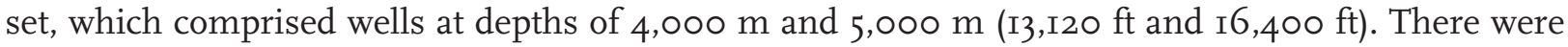
no detailed geothermal or EGS well-cost records at these depths available for comparison with model results. Nonetheless, we believe our predicted well-cost modeling approach is conservative and, as such, produces reasonable estimates of the costs of EGS wells for 4 and $5 \mathrm{~km}$ drilling depths.

A similar approach was taken for the deepest set of wells at depths of 6,000 m, 7,500 m, and 10,000 $\mathrm{m}$ $(19,700 \mathrm{ft}, 24,600 \mathrm{ft}$, and 32,800 ft). These deeper well designs and costs are naturally more speculative than estimates for the shallower wells. There have been only two or three wells drilled close to depths of $10,000 \mathrm{~m}$ in the United States, so a conservative well design was used to reflect higher uncertainty.

The estimated costs for the EGS wells are shown in Table 6.I, which shows that the number of casing strings is a critical parameter in determining the well costs. Well-drilling costs have been estimated for 4-, 5-, and 6-casing well designs. For example, Table 6.I shows that two 5,000 $\mathrm{m}$ deep wells were modeled, one with 4 casing intervals and another with 5 casing intervals. The former requires fewer casing intervals but increased lengths of individual sections may raise concerns about wellbore stability. This is less of a problem if more casing strings are used, but costs will be affected by an increase in the diameter of the upper casing strings, the size of rig required, and a number of other parameters. The $6,000 \mathrm{~m}$ well was modeled with both 5 - and 6 - casing intervals. Costs for the 7,500 $\mathrm{m}$ and Io,००० $\mathrm{m}$ wells were estimated using 6 casing intervals.

Figure 6.I shows the actual costs of geothermal wells, including some for EGS wells. The specific costs predicted by the Wellcost Lite model are plotted in hollow red diamonds $(\diamond)$. The modeled costs show reasonable agreement with actual geothermal well costs in the mid- to deep-depth ranges, within expected ranges of variation. The agreement is not as good for shallow well costs. Also shown in Figure 6.I are average costs for completed oil and gas wells drilled onshore in the United States, where we see an exponential dependence of cost on depth.

Emerging technologies, which have yet to be demonstrated in geothermal applications and are still going through development and commercialization, can be expected to significantly reduce the cost 
of these wells, especially those at 4,000 $\mathrm{m}$ depths and deeper. The technologies include those that are focused on increasing overall drill effectiveness and rates, as well as stabilizing the hole with casing, e.g., expanded tubulars, drilling while casing, enhanced under-reaming, and improved drill bit design and materials. Revolutionary technologies involving a completely different mechanism of drilling and/or casing boreholes were also identified, which could ultimately have a large impact on lowering drilling costs and enabling economic access to low-grade EGS resources. 


\section{References}

American Petroleum Institute (API). I976-2004. "Joint Association Survey (JAS) on Drilling Costs." Washington, D.C.

Armstead, H. C. H. and J. W. Tester. I987. Heat Mining. E.F. Spon, London.

Augustine, C., B. Anderson, J. W. Tester, S. Petty, and W. Livesay. 2006. "A comparison of geothermal with oil and gas drilling costs." Proc. $31^{\text {st }}$ Workshop on Geothermal Reservoir Engineering, Stanford University, Stanford, Calif.

Baker Hughes. 2005. "Worldwide Right Count." Online Posting, December.

$<$ http://www.bakerhughes.com/investor/rig>

Baria, R. 2005. Mil-Tech UK Limited, Personal Communication, November II.

Barker, J.W. I997. "Wellbore Design With Reduced Clearance Between Casing Strings." Proc. SPE/IADC Drilling Conference, SPE/IADC 376I5, Amsterdam.

Batchelor, A. S. I989. Geoscience Ltd., Falmouth, U.K., Personal Communication, December I2, I989.

Bechtel National Inc. I988. "Hot Dry Rock Venture Risks and Investigation," Final report for the U.S. Department of Energy, under contract DE-ACo3-86SFi6385, San Francisco, CA.

Benzie, S., P. Burge, and A. Dobson. 2000. “Towards a Mono-Diameter Well - Advances in Expanding Tubular Technology.” Proc. SPE European Petroleum Conference 2000, SPE 65164, Paris.

Bloomfield, K. K. and P. T. Laney. 2005. "Estimating Well Costs for Enhanced Geothermal System Applications." Report for the U.S. Department of Energy, INL/EXT-05-00660, under contract DEAC07-05iDi45I7, Idaho National Laboratory, Idaho Falls, Idaho.

Carson, C. C., Y. T. Lin, and B. J. Livesay. I983. "Representative Well Models for Eight Geothermal Resource Areas.” Sandia National Laboratories report, SAND8I-2202.

Dupai, K. K., D. B. Campo, J. E. Lofton, D. Weisinger, R. L. Cook, M. D. Bullock, T. P. Grant, and P. L. York. 200I. "Solid Expandable Tubular Technology - A Year of Case Histories in the Drilling Environment.” Proc. SPE/IADC Drilling Conference 2001, SPE/IADC 67770.

Energy Information Administration, U.S. Department of Energy. 2005. "Section 9 - Energy Prices, Tables 9.I and 9.II," Monthly Energy Review, September.

Entingh, D. I987. "Historical and Future Cost of Electricity from Hydrothermal Binary and Hot Dry Rock Reservoirs, I975-2000.” Meridian Corp. report 240-GG, Alexandria, Va., October.

Entingh, D. 1989. Meridian Corporation, Alexandria, Va., Personal Communication, November.

Entingh, D. and L. McLarty. I991. “Geothermal Cost of Power Model IM-GEO Version 3.05: User's Manual." Meridian Corporation.

Filippov, A., R. Mack, L. Cook, P. York, L. Ring, and T. McCoy. I999. “Expandable Tubular Solutions.” SPE Annual Conference and Exhibition, SPE 56500, Houston.

Geddes, C. J. and H. B. Curlett. 2006. "Leveraging a new energy source to enhance oil and oil sands production.” GRC Bulletin, January/February, pp. 32-36.

Gill, D. S., W. C. M. Lohbeck, R. B. Stewart, and J. P. M van Viet. I995. "Method of creating a casing in a borehole." Patent No. PCT / EP 96/0000265, Filing date: I6 January I995. 
Hori, Y. et al. 1986. "On Economics of Hot Dry Rock Geothermal Power Station" and related documents. Corporate Foundation Central Research Institute for Electric Power, Hot Dry Rock Geothermal Power Station Cost study Committee Report 38500I, Japan.

Lohbeck, W. C. M. I993. "Method of completing an uncased section of a borehole."

Patent publication date: 23 December I993.

Mansure, A. J. 2004. Sandia National Laboratories, Personal Communication, April I2.

Mansure, A. J., S. J. Bauer, and B. J. Livesay. 2005. "Geothermal Well Cost Analyses 2005." Geothermal Resources Council Transactions, 29:515-519.

Milora, S. L. and J. W. Tester. 1976. Geothermal Energy as a Source of Electric Power. MIT Press, Cambridge, Mass.

Petty, S., D. Entingh, and B. J. Livesay. I988. "Impact of R\&D on Cost of Geothermal Power, Documentation of IMGEO Model Version 2.09." Contractor Report, Sandia National Laboratories, SAND87-70I8

Petty, S., B. J. Livesay, and W. P. Long. I99I. "Supply of Geothermal Power from Hydrothermal Sources." Contractor Report, Sandia National Laboratory.

Petty, S., B.J. Livesay, W. P. Long, and J. Geyer. I992. "Supply of Geothermal Power from Hydrothermal Sources: A Study of the Cost of Power in 20 and 40 years." Contractor Report, Sandia National Laboratory, SAND 92-7302.

Pierce, K. G. and B.J. Livesay. I994. "A Study of Geothermal Drilling and the Production of Electricity from Geothermal Energy." Contractor Report, DOE-GET and Sandia National Laboratory, SAND 92I728.

Pierce, K.G. and B. J. Livesay. I993a. "An Estimate of the Cost of Electricity Production from Hot-Dry Rock." SAND93-0866J.

Pierce, K. G. and B. J. Livesay. I993b. "An Estimate of the Cost of Electricity Production from Hot-Dry Rock." Geothermal Resources Council Bulletin, 22(8).

Pierce, K. G., B. J. Livesay, and J. T. Finger. I996. “Advanced Drilling Systems Study.” Sandia National Laboratories, SAND95-033I.

Polizzotti, R. S., L. L. Hirsch, A. B. Herhold, and M. D. Ertas. 2003. "Hydrothermal Drilling Method and System." United States Patent No. 6.742,603, July 3.

Potter, R. M. and J. W. Tester. I998. "Continuous Drilling of Vertical Boreholes by Thermal Processes: Including Rock Spallation and Fusion.” United States Patent No. 5,77I,984, June 30.

Shock, R. A. W. I986. “An Economic Assessment of Hot Dry Rocks as an Energy Source for the U.K.” Energy Technology Support Unit Report ETSU-R-34, U.K. Department of Energy, Oxfordshire, U.K.

Tester, J. W. and H. Herzog. I990. "Economic Predictions for Heat Mining: A Review and Analysis of Hot Dry Rock (HDR) Geothermal Energy Technology.” Final Report for the U.S. Department of Energy, Geothermal Technology Division, MIT-EL 90-०oI, Cambridge, Mass.

United States Office of Management and Budget (U.S. OMB). 2006. "Section Io - Gross Domestic Product and Implicit Outlay Deflators - Table Io.I." Budget of the United States Government, Washington, D.C.

Wyborn, D. 2005. Chief Scientific Officer, Geodynamics, Ltd., Queensland, Australia, Personal Communication, November II. 


\section{Appendices}

\section{A.6.1 Well-Cost Data}

Table A.6.1 Average costs of oil and gas onshore wells drilled in the United States in 2004, from JAS data for listed depth intervals.

\begin{tabular}{l|l|l|l}
\hline Drilling Interval (feet) & $\begin{array}{l}\text { Average Depth } \\
\text { (meters) }\end{array}$ & $\begin{array}{l}\text { Average Depth } \\
\text { (feet) }\end{array}$ & $\begin{array}{l}\text { Average Cost } \\
\text { (Year 2004 U.S. M\$) }\end{array}$ \\
\hline $\mathbf{1 , 2 5 0 - 2 , 4 9 9}$ & 549 & 1,801 & 0.304 \\
\hline $\mathbf{2 , 5 0 0 - 3 , 7 4 9}$ & 965 & 3,165 & 0.364 \\
\hline $\mathbf{3 , 7 5 0 - 4 , 9 9 9}$ & 1,331 & 4,367 & 0.416 \\
\hline $\mathbf{5 , 0 0 0 - 7 , 4 9 9}$ & 1,913 & 6,275 & 0.868 \\
\hline $\mathbf{7 , 5 0 0 - 9 , 9 9 9}$ & 2,636 & 8,649 & 1.975 \\
\hline $10,000-12,499$ & 3,375 & 11,074 & 3.412 \\
\hline $12,500-14,999$ & 4,103 & 13,463 & 5.527 \\
\hline $15,000-17,499$ & 4,842 & 15,886 & 7.570 \\
\hline $17,500-19,999$ & 5,629 & 18,468 & 9.414
\end{tabular}


Table A.6.2 Values of MIT Depth Dependent (MITDD) drilling cost index made using average cost per well for each depth interval from Joint Association Survey on Drilling Costs (1976-2004), with data smoothed using a three-year moving average. MIT Composite drilling cost index included for comparison.

\begin{tabular}{|c|c|c|c|c|c|c|c|c|c|c|}
\hline \multirow{5}{*}{ Year } & \multirow{5}{*}{$\begin{array}{l}\text { MIT Composite } \\
\text { Drilling Cost } \\
\text { Index }\end{array}$} & \multicolumn{9}{|c|}{ MITDD Drilling Cost Index } \\
\hline & & \multicolumn{9}{|c|}{ Depth Interval (Feet) } \\
\hline & & $\begin{array}{l}1250- \\
2499\end{array}$ & $\begin{array}{l}2500- \\
3749\end{array}$ & $\begin{array}{l}3750- \\
4999\end{array}$ & $\begin{array}{l}5000- \\
7499\end{array}$ & $\begin{array}{l}7500- \\
9999\end{array}$ & $\begin{array}{l}10000- \\
12499\end{array}$ & $\begin{array}{l}12500- \\
14999\end{array}$ & \begin{tabular}{|l|}
$15000-$ \\
17499
\end{tabular} & $\begin{array}{l}17500- \\
19999\end{array}$ \\
\hline & & \multicolumn{9}{|c|}{ Depth Interval (Meters) } \\
\hline & & $\begin{array}{l}381- \\
761\end{array}$ & $\begin{array}{l}762- \\
1142\end{array}$ & $\begin{array}{l}1143- \\
1523\end{array}$ & $\begin{array}{l}1524- \\
2285\end{array}$ & $\begin{array}{l}2286- \\
3047\end{array}$ & $\begin{array}{l}3048- \\
3809\end{array}$ & $\begin{array}{l}3810- \\
4571\end{array}$ & $\begin{array}{l}4572- \\
5333\end{array}$ & $\begin{array}{l}5334- \\
6096\end{array}$ \\
\hline 1972 & 47.3 & 49.4 & 50.3 & 49.8 & 50.0 & 48.5 & 47.5 & 49.1 & 49.5 & 48.9 \\
\hline 1973 & 55.4 & 57.8 & 58.8 & 58.2 & 58.5 & 56.8 & 55.6 & 57.4 & 58.0 & 57.2 \\
\hline 1974 & 64.8 & 67.6 & 68.8 & 68.1 & 68.4 & 66.4 & 65.0 & 67.2 & 67.8 & 67.0 \\
\hline 1975 & 75.8 & 79.1 & 80.5 & 79.7 & 80.1 & 77.7 & 76.1 & 78.6 & 79.3 & 78.4 \\
\hline 1976 & 88.7 & 92.5 & 94.2 & 93.3 & 93.7 & 91.0 & 89.0 & 92.0 & 92.8 & 91.7 \\
\hline 1977 & 100.0 & 100.0 & 100.0 & 100.0 & 100.0 & 100.0 & 100.0 & 100.0 & 100.0 & 100.0 \\
\hline 1978 & 119.7 & 114.3 & 109.1 & 110.2 & 112.9 & 117.4 & 117.0 & 116.9 & 117.1 & 119.9 \\
\hline 1979 & 141.2 & 132.8 & 126.4 & 127.0 & 132.6 & 139.9 & 136.0 & 138.0 & 140.4 & 154.4 \\
\hline 1980 & 163.3 & 152.1 & 149.3 & 152.4 & 161.3 & 169.7 & 162.3 & 171.7 & 180.6 & 214.8 \\
\hline 1981 & 205.4 & 161.7 & 163.1 & 167.1 & 180.1 & 188.3 & 183.7 & 206.3 & 221.4 & 269.0 \\
\hline 1982 & 232.2 & 165.5 & 165.6 & 169.0 & 181.6 & 190.5 & 185.5 & 216.5 & 236.4 & 279.1 \\
\hline 1983 & 175.3 & 158.9 & 160.7 & 160.0 & 168.5 & 173.6 & 168.6 & 203.6 & 225.5 & 270.2 \\
\hline 1984 & 154.1 & 155.1 & 155.3 & 150.4 & 154.9 & 153.7 & 144.8 & 165.1 & 193.6 & 216.6 \\
\hline 1985 & 156.8 & 151.7 & 155.1 & 144.8 & 150.6 & 148.3 & 139.0 & 149.0 & 176.7 & 181.3 \\
\hline 1986 & 149.7 & 150.8 & 149.1 & 136.3 & 140.5 & 142.3 & 133.1 & 138.8 & 171.4 & 162.6 \\
\hline 1987 & 128.1 & 152.3 & 127.4 & 125.1 & 127.4 & 134.4 & 131.9 & 132.4 & 150.4 & 146.5 \\
\hline 1988 & 141.5 & 162.4 & 129.3 & 127.8 & 124.5 & 136.5 & 133.5 & 129.2 & 146.2 & 153.4 \\
\hline 1989 & 155.3 & 177.3 & 148.0 & 140.3 & 132.1 & 147.6 & 142.6 & 135.8 & 157.2 & 162.9 \\
\hline 1990 & 165.6 & 183.7 & 190.0 & 152.2 & 138.6 & 153.7 & 145.3 & 139.3 & 164.9 & 174.3 \\
\hline 1991 & 173.6 & 190.1 & 199.3 & 157.0 & 138.5 & 145.4 & 140.5 & 127.1 & 153.3 & 162.5 \\
\hline 1992 & 149.6 & 198.3 & 196.6 & 154.0 & 133.9 & 134.9 & 134.9 & 118.2 & 136.3 & 161.5 \\
\hline 1993 & 152.6 & 201.7 & 173.7 & 147.4 & 129.8 & 128.9 & 132.4 & 114.5 & 111.3 & 150.8 \\
\hline 1994 & 164.1 & 202.7 & 169.4 & 149.9 & 135.4 & 131.4 & 134.7 & 123.7 & 110.3 & 142.7 \\
\hline 1995 & 178.6 & 198.6 & 165.8 & 151.2 & 144.2 & 141.0 & 137.4 & 136.2 & 125.2 & 153.9 \\
\hline 1996 & 186.1 & 210.0 & 178.2 & 160.5 & 159.3 & 151.8 & 133.7 & 143.7 & 142.7 & 167.1 \\
\hline 1997 & 198.1 & 226.6 & 191.0 & 170.0 & 170.4 & 163.6 & 136.3 & 157.3 & 165.4 & 180.9 \\
\hline 1998 & 221.7 & 238.8 & 202.7 & 179.2 & 177.9 & 169.8 & 142.8 & 161.3 & 170.8 & 182.3 \\
\hline 1999 & 227.9 & 237.1 & 205.7 & 186.5 & 185.0 & 179.2 & 157.3 & 169.1 & 181.8 & 190.8 \\
\hline 2000 & 227.9 & 231.5 & 200.0 & 186.0 & 185.7 & 182.5 & 165.6 & 167.8 & 189.4 & 189.9 \\
\hline 2001 & 282.8 & 287.8 & 231.4 & 212.8 & 224.8 & 226.6 & 198.4 & 203.9 & 233.7 & 253.2 \\
\hline 2002 & 310.3 & 364.6 & 265.0 & 228.3 & 220.3 & 248.4 & 229.0 & 222.4 & 247.8 & 307.9 \\
\hline 2003 & 489.4 & 328.6 & 268.8 & 314.6 & 346.2 & 328.7 & 312.2 & 300.1 & 334.5 & 489.4 \\
\hline 2004 & 542.7 & 354.8 & 288.9 & 343.2 & 382.8 & 356.5 & 343.7 & 314.0 & 347.2 & 542.7 \\
\hline
\end{tabular}


Table A.6.3a Actual and predicted geothermal well drilling and completion costs (2004 U.S. \$).

\begin{tabular}{|c|c|c|c|c|c|c|}
\hline Well ID & $\begin{array}{l}\text { Depth } \\
\text { (meters) }\end{array}$ & $\begin{array}{l}\text { Depth } \\
\text { (feet) }\end{array}$ & $\begin{array}{l}\text { Cost When } \\
\text { Drilled (M\$) }\end{array}$ & $\begin{array}{l}\text { Year } \\
\text { Drilled }\end{array}$ & $\begin{array}{l}\text { Cost Year } \\
2004(M \$)\end{array}$ & Comments \\
\hline GT-1 & 732 & 2402 & 0.060 & 1972 & 0.66 & \multirow{6}{*}{$\begin{array}{l}\text { Fenton Hill Site, } \\
\text { New Mexico, USA. Actual Costs } \\
\text { (Tester and Herzog, 1990) }\end{array}$} \\
\hline GT-2 & 2932 & 9619 & 1.900 & 1974 & 10.95 & \\
\hline EE-1 & 3064 & 10052 & 2.300 & 1975 & 10.78 & \\
\hline $\mathrm{EE}-2$ & 4660 & 15289 & 7.300 & 1980 & 12.69 & \\
\hline EE-3 & 4250 & 13944 & 11.500 & 1981 & 19.16 & \\
\hline EE-3a & 4572 & 15000 & 5.160 & 1988 & 11.08 & \\
\hline RH-11 (low) & 2175 & 7136 & 1.240 & 1981 & 2.36 & \multirow{6}{*}{$\begin{array}{l}\text { Rosemanowes Site, Cornwall, UK. } \\
\text { Actual Costs. (Tester and Herzog, 1990) } \\
\text { Low: } \$ 1=1 € \text { GBP }\end{array}$} \\
\hline RH-11 (high) & 2175 & 7136 & 1.984 & 1981 & 3.78 & \\
\hline RH-12 (low) & 2143 & 7031 & 1.240 & 1981 & 2.36 & \\
\hline RH-12 (high) & 2143 & 7031 & 1.984 & 1981 & 3.78 & \\
\hline RH-15 (low) & 2652 & 8701 & 2.250 & 1985 & 5.81 & \\
\hline $\mathrm{RH}-15$ (high) & 2652 & 8701 & 3.600 & 1985 & 9.29 & \\
\hline UK (Shock, 1987) & 6000 & 19685 & 8.424 & 1985 & 16.13 & Camborne School of Mines( $\$ 1=1 \mathrm{E}$ GBP) \\
\hline Bechtel (1988) & 3657 & 11998 & 3.359 & 1987 & 9.08 & Predict. for Roosevelt Hot Springs, UT \\
\hline Hori et al. (1986) & 3000 & 9843 & 6.000 & 1985 & 15.49 & Predicted Costs \\
\hline Entingh (1987) I & 3000 & 9843 & 6.900 & 1984 & 17.18 & \multirow{3}{*}{$\begin{array}{l}\text { Predicted Costs based on } \\
\text { Heat Mining }\end{array}$} \\
\hline Entingh (1987) II & 3000 & 9843 & 3.800 & 1984 & 9.46 & \\
\hline Entingh (1987) III & 3000 & 9843 & 3.000 & 1984 & 7.47 & \\
\hline Heat Mining & 3000 & 9843 & 3.000 & 1984 & 7.47 & Predicted Costs - Armstead \& Tester (1987) \\
\hline The Geysers & 1800 & 5906 & 0.486 & 1976 & 1.78 & Actual costs - Milora \& Tester (1976) \\
\hline The Geysers & 3048 & 10000 & 2.275 & 1989 & 5.69 & Actual costs - Batchelor (1989) \\
\hline Imperial Valley & 1600 & 5249 & 0.165 & 1976 & 0.60 & Actual costs - Milora \& Tester (1976) \\
\hline IM-GEO IV-FL & 1829 & 6001 & 1.123 & 1986 & 2.74 & \multirow{9}{*}{$\begin{array}{l}\text { Meridian predictions of hydrothermal } \\
\text { wells from IMGEO database (Entingh, } \\
\text { 1989). Only base well costs shown. }\end{array}$} \\
\hline IM-GEO IV-BI & 2743 & 8999 & 0.956 & 1986 & 2.57 & \\
\hline IM-GEO BR-FL & 2438 & 7999 & 1.217 & 1986 & 3.27 & \\
\hline IM-GEO BR-BI & 914 & 2999 & 0.556 & 1986 & 1.32 & \\
\hline IM-GEO CS-FL & 3048 & 10000 & 2.032 & 1986 & 5.44 & \\
\hline IM-GEO CS-BI & 914 & 2999 & 0.576 & 1986 & 1.37 & \\
\hline IM-GEO YV-FL & 1524 & 5000 & 0.906 & 1986 & 3.76 & \\
\hline IM-GEO YV-BI & 152 & 499 & 0.406 & 1986 & 1.46 & \\
\hline IM-GEO GY-DS & 3048 & 10000 & 1.155 & 1986 & 3.09 & \\
\hline
\end{tabular}


Table A.6.3a (continued)

\begin{tabular}{|c|c|c|c|c|c|c|}
\hline SNL - Non-US & 2317 & 7603 & 1.539 & 1996 & 3.88 & \multirow{15}{*}{$\begin{array}{l}\text { Actual geothermal well costs from } \\
\text { Sandia National Laboratories } \\
\text { (SNL) (Mansure, 2004) }\end{array}$} \\
\hline SNL - Non-US & 2374 & 7789 & 1.729 & 1997 & 4.05 & \\
\hline SNL - Non-US & 2377 & 7800 & 1.377 & 1996 & 3.47 & \\
\hline SNL - Non-US & 2739 & 8986 & 1.867 & 1997 & 4.37 & \\
\hline SNL - Non-US & 2760 & 9055 & 1.320 & 1997 & 3.09 & \\
\hline SNL - Non-US & 2807 & 9210 & 2.979 & 1996 & 7.51 & \\
\hline SNL - Non-US & 2819 & 9249 & 0.915 & 1997 & 2.14 & \\
\hline SNL - Non-US & 2869 & 9414 & 1.030 & 1996 & 2.60 & \\
\hline SNL - Non-US & 3021 & 9912 & 1.060 & 1996 & 2.67 & \\
\hline SNL - Non-US & 3077 & 10096 & 1.514 & 1996 & 4.04 & \\
\hline SNL - US & 2277 & 7471 & 1.186 & 1985 & 2.70 & \\
\hline SNL - US & 2334 & 7658 & 0.822 & 1986 & 2.21 & \\
\hline SNL - US & 1703 & 5588 & 0.804 & 1986 & 1.96 & \\
\hline SNL - US & 2590 & 8496 & 2.220 & 1991 & 5.85 & \\
\hline SNL - US & 2627 & 8618 & 1.760 & 1997 & 4.12 & \\
\hline GPK3 & 5101 & 16731 & 6.571 & 2003 & 6.88 & \multirow{2}{*}{$\begin{array}{l}\text { Soultz, France. Trouble costs excluded. } \\
\text { (1 USD = } 1.13 \text { EUD) (Baria, 2005) }\end{array}$} \\
\hline GPK4 & 5100 & 16728 & 5.14 & 2004 & 5.14 & \\
\hline $\begin{array}{l}\text { Cooper Basin, } \\
\text { Australia } \\
\text {-Habanero } 2\end{array}$ & 4725 & 15498 & 6.3 & 2004 & 6.3 & $\begin{array}{l}\text { Trouble costs excluded. } \\
\text { ( } 1 \text { USD = } 0.724 \text { AUD) (Wyborn, 2005) }\end{array}$ \\
\hline
\end{tabular}

1. $M \$$ = millions of U.S. $\$$.

2. A listing and discussion of the origins of many of the actual and predicted well costs is given in Tester and Herzog (1990).

3. Currency conversions based on yearly average of Interbank conversion rate.

Table A.6.3b Predicted geothermal well drilling and completion costs from Wellcost Lite model (in year 2004 U.S. \$).

\begin{tabular}{|c|c|c|c|c|}
\hline Well ID & $\begin{array}{l}\text { Depth } \\
\text { (meters) }\end{array}$ & $\begin{array}{l}\text { Depth } \\
\text { (feet) }\end{array}$ & $\begin{array}{l}\text { Estimated } \\
\text { Cost (2004 M\$) }\end{array}$ & Comments \\
\hline WCL Base Case Well & 1500 & 4921 & 2.303 & \multirow{8}{*}{$\begin{array}{l}\text { Wellcost Lite (WCL) Base } \\
\text { Case Wells } \\
\text { Assume } 10 \% \text { Contingency } \\
\text { Costs }\end{array}$} \\
\hline WCL Base Case Well & 2500 & 8202 & 3.372 & \\
\hline WCL Base Case Well & 3000 & 9842 & 4.022 & \\
\hline WCL Base Case Well & 4000 & 13123 & 5.223 & \\
\hline WCL Base Case Well & 5000 & 16404 & 6.740 & \\
\hline WCL Base Case Well & 6000 & 19685 & 9.172 & \\
\hline WCL Base Case Well & 7500 & 24606 & 14.645 & \\
\hline WCL Base Case Well & 10000 & 32808 & 19.731 & \\
\hline Rosemanowes & 2800 & 9200 & 4.195 & \multirow{3}{*}{$\begin{array}{l}\text { Estimates made using } \\
\text { actual casing program for } \\
\text { specific individual wells }\end{array}$} \\
\hline Soultz GPK4 & 5100 & 16750 & 6.705 & \\
\hline Cooper Basin - Habanero-2 & 4725 & 15500 & 5.872 & \\
\hline
\end{tabular}




\section{A.6.2 Wellcost Lite Model}

\section{A.6.2.1 Background and brief history of the development of Wellcost Lite}

A more robust, yet easier-to-use costing model, Wellcost Lite, was developed to more readily accommodate changes in the drilling system.

The Wellcost Lite model has been qualified by offering the cost estimate to someone involved in drilling that area, for their comment, agreement or disagreement. This was especially true of the earlier models. Well costs were not normally made public by the companies and, to some degree, still are not. Recently, agreements have been made between Sandia and operators to access some records. Some of these records had been kept on a RimBase format. RimBase is a cost and time-accounting system for use on the drill rig. Records that were not initially on RimBase were hand-entered into the RimBase format. Reasonable agreement has been made from those records to Wellcost Lite model results.

But even with those records, an estimate for a well to be drilled with a different depth, final diameter, casing design, etc. is still needed. Comparison between Wellcost Lite modeled cost and field-drilling numbers is an ongoing effort through Sandia.

\section{A.6.2.2 Wellcost Lite - How does the cost model work?}

Wellcost Lite is a sequential, event-based and item cost-based estimate for drilling. The model approach takes into account the time and materials cost for each action relating to the drilling of the well. The Input field acts as a reminder for each step of drilling and the cost and time involved. The Cost Information Spreadsheet retains an estimate of the cost and performance of materials and services.

Well design/well planning. Each cost model is constructed by developing a well design profile. Sequentially, as the well is drilled, details for each interval are entered in the Input Section and are summed into the Wellcost Section, and subsequently presented on an AFE output format or other format.

Well design is the initial step in developing the cost of an EGS well. The well design schematic and casing information is provided or developed by the modeler. The downhole geology sets (or estimates) the array of formations to be drilled in a particular well. A performance map for the well is created for bits and hole openers. With the tectonically jumbled regions, geothermal wells are very likely to vary even when close to one another. The expected downhole geological conditions are estimated from the experience of geologists and engineers familiar with the areas in question.

Well control is considered in well design, especially in the top intervals of the hole. Geothermal wellcontrol pressures are mostly determined based on the temperatures expected in the well and occasionally for artesian pressures as well. The fracture tolerance gradient of the formations is used to determine the safe depths for the surface casing and subsequent casing strings.

Experience has taught how much "open hole" can be exposed during drilling before it is necessary to run and cement casing to protect the integrity of the well. Wellbore stability can be a mechanical problem, where weak and ratty formations exist; or it can be a chemically based problem where the clays in the shales and other formations are weakened when exposed to the drilling fluid. The amount of open hole puts limits on how long an interval can be and how long it may be safe to expose the formations to the drilling fluids. 
Well depth and final drill bit diameter come into play in designing the well schematic. The schematic is a representation of the selected diameters, weights of the casing, and the grade of material used in the manufacture of the pipe. The productive interval bit diameter sets the diameters from the bottom to the surface. Geothermal wells tend to use larger-diameter casing than are used in oil and gas well completions. For the most part, K-55, L-80, and T-95 casing grades are used in making the estimates. Available sizes and weights are determined by contacting the casing vendors.

Modeling the well cost also considers the requirements presented by the geologic stratigraphy to be drilled, the desired depth, and the final production interval bit diameter. Using these requirements, the well is designed. The traditional, casing-within-a-casing design can be estimated based on the available sizes, desired clearance for cementing, and accepted risk of the amount of open hole. Normal wellbore to casing clearances in use in the geothermal drilling industry are applied wherever possible. There is some leeway in the well design where multiple casing strings are to be run.

The geothermal industry has to depend on the oil and gas drilling industry to set the available supply of casing sizes, and weights and grades of steel available for geothermal completions. Geothermal drilling has little or no impact on the available inventory. Onshore oil and gas wells tend to be smaller in diameter than geothermal wells. This sometimes puts a limitation of the availability of casing sizes, weights, and grades.

CIS $3^{\text {rd }}$ Quarter 2004. The Cost Information Spreadsheet (CIS $3^{\text {rd }} / 2004$ ) is used to set the costs of goods and services at a particular date (or period of time) and to set guidelines to be used in materials, equipment and services, time lines, performance, and cost. A file for casing cost is maintained for the different casing sizes, weights and grades, and connections. The CIS also provides for collapse calculations and costs for large-diameter welded pipe used in the tophole section of the well (20" casing is the largest seamless casing normally manufactured and threaded).

Drilling costs are subjected to considerable volatility. The rig rental rate, material costs, and services are all subjected to supply-and-demand cycles that are not necessarily tied to the Consumer Price Index. There is, however, a Drilling Cost Index that reflects changes in drilling cost. But this is an annualized record and of little help if costing a current well. Unfortunately, the variations occur on a monthly rather than an annual basis. Because geothermal wells use a slightly larger selection of casing diameters, weights, and grades, the supply for geothermal may be limited. Each cost information spreadsheet (for example, CIS $3^{\text {rd }}$ Quarter 2004) has a date stamp. Models have been used for 1979, I996, 2000, third quarter 2004, and fourth quarter 2005.

Information will be entered for all drilling intervals and each subsequent "end of interval time and cost" and for the initial completion of the well.

Pre-spud. Pre-spud expenses are listed and accounted. These are expenses that are incurred before the hole is actually started (spudded). Pre-spud cost for the cost of mobilizing and demobilizing the rig, setting up a water supply, the drill site construction, conductor hole drilling and cementing, the well cellar, etc. are all estimated and appear in the Pre-spud subsection of the Input Section.

Daily operating expenses. A cost for the daily (and, therefore, hourly) cost of operations is developed by making daily cost entries for each item listed. The rig daily rental rate and the other running costs such as insurance, overhead, management, drilling engineering charges, rig supervision, and other miscellaneous time-based charges (daily or hourly operating cost) are entered for the overall 
operation. There is an hourly cost for the rig, for fuel for the rig (computed from horsepower rating of the rig), for a drilling supervisor, a drilling management activity, charges for insurance, power, water, etc. Some of these categories of costs are often omitted from drilling-cost records. The level of detail necessary for parametric changes to the well design are often missing.

Table A.6.4 Input section, top page.

Cost Information Field

EGS 5000 m 16400 ft E Rev7 10-5/8 12/3/2005

\begin{tabular}{|c|c|c|c|c|c|c|c|c|}
\hline Well Configuration & Hole Dia & Depths & Casing & & Cost/ft & Interval & ROP & Bit Life \\
\hline Conductor Pipe/Line Pipe & 26" bit/36"HO & 80 & $30 " 0.375$ Wall welded $118 \mathrm{lb} / \mathrm{ft}$ & & $\$ 90.00$ & Conductor & & \\
\hline Surface CSG & $28 "$ & 1,250 & 22"0.625 Wall welded & & $\$ 107.00$ & 1 Casing & 25 & 90 \\
\hline Intermediate CSG & $20 "$ & 5,000 & 16"109lb K-55 Premium & & $\$ 70.86$ & 2 Liner & 25 & 80 \\
\hline Intermediate CSG 2 & 14-3/4" & 13,120 & 11-3/4"73.6lb T-95 Premium & & $\$ 78.24$ & 3 Casing & 18 & 65 \\
\hline Production Zone & 10-3/8"special & 16,400 & 8-5/8"36lb K-55 slotted Butt & & $\$ 29.80$ & 4 perf Liner & 15 & 45 \\
\hline Prespud and Mobilization & & & Depths & $\begin{array}{l}\text { Casing } \\
\text { Critical psi }\end{array}$ & $\begin{array}{l}\text { Frac Gradient } \\
\text { psi/ft }\end{array}$ & $\begin{array}{l}\text { Mud Shoe } \\
\text { Pressure }\end{array}$ & & \\
\hline
\end{tabular}

\begin{tabular}{|c|c|c|c|c|c|c|c|}
\hline 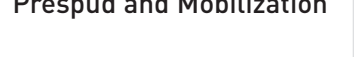 & & & Deptis & Critical psi & $\mathrm{psi} / \mathrm{ft}$ & Pressure & \\
\hline & & & & & 0.8 & 9.6 & Csg String \\
\hline & Activity Cost & & 80 & 112 psi & 64 & 40 & \\
\hline Mobilization & $\$ 132,000$ & & 1,250 & 570 psi & 1000 & 624 & $22 " 0.625 \mathrm{lb}$ \\
\hline Mobilization Labor & $\$ 16,500$ & & 5,000 & 3180 psi & 4000 & 2496 & $16 " 109 l b$ \\
\hline Demobilization & $\$ 66,000$ & & 13,120 & 5920 psi & 10496 & 6550 & $11-3 / 4 " 73.6 l b$ \\
\hline Demobilization Labor & $\$ 16,500$ & & 16,400 & 9320 psi & 13120 & 8187 & $8-5 / 8 " 36 l b$ \\
\hline \multirow[t]{2}{*}{ Waste Disposal \& Cleanup } & $\$ 30,000$ & & 0 & $\mathrm{~N} / \mathrm{A}$ & & 0 & \\
\hline & & $\$ 261,000.00$ & & & & & \\
\hline \multicolumn{8}{|l|}{ Location Cost } \\
\hline Site Expense & $\$ 32,000$ & & & & & & \\
\hline Cellar & $\$ 25,000$ & & & & & & \\
\hline Drill Conductor Hole & $\$ 8,000$ & & & & & & \\
\hline Water Supply & $\$ 10,000$ & & & & & & \\
\hline Initial Mud Cost & $\$ 10,000$ & & & & & & \\
\hline \multirow[t]{3}{*}{ Prespud Cost Total } & & $\$ 85,000.00$ & & & & & \\
\hline & & $\$ 346,000.00$ & & & & & \\
\hline & & & & Description & & & \\
\hline Daily Operating Cost & $\$ 1,040.65$ & $\$ 24,975.60$ & & & & & \\
\hline Rig Day Rate & $\$ 687.50$ & $\$ 16,500.00$ & & 2,000 & hp & $1,200,000$ mast & \\
\hline Fuel & & $\$ 1,425.60$ & & \multicolumn{2}{|c|}{$0.45 \times h p \times 0.06 \times$ cost per gal $\times 24$} & \multicolumn{2}{|l|}{ Cost Per Gallon } \\
\hline Water & & $\$ 400.00$ & & \multicolumn{2}{|c|}{ Estimated } & & \\
\hline Electric Power & & $\$ 50.00$ & & \multicolumn{2}{|c|}{ Estimated } & $\$ 1.10$ & \\
\hline Camp Expense & & $\$ 200.00$ & & \multicolumn{2}{|c|}{ Estimated } & & \\
\hline Drilling Supervision & & $\$ 1,200.00$ & & \multicolumn{2}{|c|}{$\$ 1000 /$ day 1 man } & & \\
\hline DRLG Engr \& Management & & $\$ 1,000.00$ & & \multicolumn{2}{|c|}{ Estimated } & & \\
\hline Mud Logging & & $\$ 1,800.00$ & & \multicolumn{2}{|c|}{ Current Rate } & & \\
\hline Hole Insurance & & $\$ 250.00$ & & \multicolumn{2}{|c|}{ Estimated } & & \\
\hline Administrative Overhead & & $\$ 500.00$ & & \multicolumn{2}{|c|}{ Estimated } & & \\
\hline Misc Transportation & & $\$ 500.00$ & & \multicolumn{2}{|c|}{ Estimated } & & \\
\hline Site Maintenance & & $\$ 200.00$ & & \multicolumn{2}{|c|}{ Estimated } & & \\
\hline Waste Disposal and Cleanup & & $\$ 200.00$ & & \multicolumn{2}{|c|}{ Estimated } & & \\
\hline Misc Services & & $\$ 750.00$ & & \multicolumn{2}{|c|}{ Estimated } & & \\
\hline
\end{tabular}


Table A.6.5 Input section, Interval 3 example. EGS 5000 m $16400 \mathrm{ft}$ E Rev 7 10-5/8

\begin{tabular}{|c|c|c|c|c|c|c|}
\hline \multirow{3}{*}{$\begin{array}{l}\text { Production Casing } \\
\text { Depth of Interval } 3\end{array}$} & & \multicolumn{2}{|c|}{ Input Information Interval 3} & & & \multirow{3}{*}{$\$ 78.24$} \\
\hline & & 14-3/4" & Casing & \multicolumn{2}{|c|}{ 11-3/4" 73.6lb T-95 Premium } & \\
\hline & & 13120 & Shoe Depth & 13,120 & Casing Length & \\
\hline \multirow[t]{2}{*}{ Interval Length } & & 8120 & Interval Length & & & \\
\hline & & $\mathrm{ROP} \mathrm{ft} / \mathrm{hr}$ & Bit Life Hrs & No.of Bits & & \\
\hline \multirow[t]{2}{*}{ Bit Performance } & 14-3/4"bit & 18.00 & 65.00 & 7 & & \\
\hline & Hourly Rates & Rig Time & $\begin{array}{l}\text { Charge Time- } \\
\text { Not Rig Time }\end{array}$ & $\begin{array}{r}\text { Misc. Hourly } \\
\text { Expense }\end{array}$ & $\begin{array}{l}\text { One Time } \\
\text { Expenses }\end{array}$ & $\begin{array}{l}\text { Explanation of Charges and } \\
\text { source of Information }\end{array}$ \\
\hline Delta Time Hrs & & 451.11 & & & & Computed Drilling Hours \\
\hline \multicolumn{7}{|l|}{ Technical Changes Hrs \& \$ } \\
\hline \multicolumn{7}{|l|}{ Drilling Fluids } \\
\hline Mud Cost $\$ / \mathrm{Hr}$ & $\$ 100.00$ & $x$ & & $\$ 45,111.11$ & $\$ 4000.00$ & Hourly Mud Expense \\
\hline Mud Treatment Equip & $\$ 25.00$ & $\mathrm{x}$ & 451.11 & $\$ 11,277.78$ & $\$ 1000.00$ & $\begin{array}{l}\text { Mud Treatment } \\
\text { Equipment }\end{array}$ \\
\hline Mud Cooling Equip & $\$ 20.00$ & $x$ & 451.11 & $\$ 9,022.22$ & $\$ 1000.00$ & Mud Coolers \\
\hline Air Service Hrs \& \$ & $\$ 150.00$ & & 20.00 & $\$ 3,000.00$ & $\$ 2,000.00$ & Air Drilling Services \\
\hline \multicolumn{7}{|l|}{ D/H Tools and Times } \\
\hline BHA Changes Hrs & 2 & 14.00 & & & & Hours to Change BHA \\
\hline BIT Trips Hrs & & 63.42 & & & & Total Interval Trip Time \\
\hline BITS & $\$ 18,970.00$ & $x$ & & & $\$ 132,790.00$ & $14-3 / 4 " \$ 17,000$ each \\
\hline Stab, Reamers, HO & & $x$ & & & $\$ 26,558.00$ & \\
\hline DRLG Tools. Jars, Shocks & & $x$ & & & $\$ 19,918.50$ & \\
\hline D/H Rentals, DP, DC, Motor & & $x$ & & & $\$ 17,000.00$ & \\
\hline Drill String Inspections & & $x$ & & & $\$ 3,000.00$ & \\
\hline Small Tools and Supplies & & $x$ & & & $\$ 5,000.00$ & \\
\hline Reaming Hrs \& \$ & $\$ 0.00$ & & 12.00 & $\$ 0.00$ & $\$ 4,000.00$ & Reaming Hrs \& \$ \\
\hline Hole Opening Hrs \& \$ & $\$ 0.00$ & & 0.00 & $\$ 0.00$ & $\$ 0.00$ & Hole Opening Hrs \& \$ \\
\hline \multicolumn{7}{|l|}{ Directional } \\
\hline Dir Engr Services Hrs \& \$ & $\$ 40.00$ & 10.00 & 451.11 & $\$ 18,044.44$ & $\$ 1,200.00$ & Directional Drilling Expense \\
\hline Dir Tools Hrs \& \$ & $\$ 10.00$ & $\mathrm{x}$ & 451.11 & $\$ 4,511.11$ & $\$ 4,000.00$ & Directional Drilling Tools \\
\hline Mud Motors Hrs \& \$ & $\$ 200.00$ & $x$ & 451.11 & $\$ 90,222.22$ & $\$ 1,000.00$ & Mud Motor Charges \\
\hline Steering/MWD Equip Hrs \& \$ & $\$ 100.00$ & $\mathrm{x}$ & 451.11 & $\$ 45,111.11$ & $\$ 1,000.00$ & MWD Charges \\
\hline \multicolumn{7}{|l|}{ Trouble } \\
\hline Fishing Hrs \& \$ & $\$ 10.00$ & 0.00 & 0.00 & $\$ 0.00$ & $\$ 1,000.00$ & $\begin{array}{l}\text { Fishing Standby and } \\
\text { Expenses }\end{array}$ \\
\hline Lost Circulation Hrs \& \$ & & 0.00 & 0.00 & & 0.00 & Lost Circulation Estimated \\
\hline MISC Trouble Hrs \& \$ & & 12.00 & & & & Misc Trouble Cost \\
\hline
\end{tabular}


Table A.6.5 (continued)

\begin{tabular}{|c|c|c|c|c|c|c|}
\hline End of interval & & & & & & \\
\hline Logging Hrs \& \$ & & 18.00 & & & $\$ 36,000.00$ & $\begin{array}{l}\text { Logging Time and } \\
\text { Expense }\end{array}$ \\
\hline Casing Services \$ & & $x$ & & & $\$ 40,350.00$ & $\begin{array}{l}\text { Casing Service, or } \\
\text { Welding, and Mob. }\end{array}$ \\
\hline CSG/Liner Hrs \& \$ & & 48.00 & & & $\$ 1,026,508.80$ & Casing Time and Cost \\
\hline Casing Cementing Equipment & & $x$ & & & $\$ 8,000.00$ & \\
\hline Liner Hanger and Packers & & 0.00 & & & $\$ 0.00$ & Liner Hanger if used \\
\hline Cementing Hrs \& \$ & $30 \%$ excess & 22.00 & $\$ 40 / \mathrm{ft}^{3}$ & & $\$ 270,000.00$ & $\begin{array}{l}\text { Cementing time, WOC } \\
\text { and expense }\end{array}$ \\
\hline End of Interval Hrs \& \$ & & 12.00 & & & $\$ 20,000.00$ & End of Interval \\
\hline Wellhead \$ & & 8.00 & & & $\$ 15,000.00$ & Well Head Cost \\
\hline Welding and Heat Treat & & 24.00 & Rental 16-3/4" & & $\$ 25,000.00$ & Welding and Heat Treat \\
\hline BOPE Hrs \& \$ & $\$ 1,212.00$ & 12.00 & BOPE & $\$ 22,781.11$ & $\$ 3,000.00$ & $\begin{array}{l}\text { BOPE Rental, Change } \\
\text { out Time, Testing }\end{array}$ \\
\hline Test and Completion & & & Install 11" BOPE & & & \\
\hline Location Cost & & $\mathrm{x}$ & & & $\$ 0.00$ & \\
\hline Testing Coring Sampling & & 0.00 & & & $\$ 0.00$ & \\
\hline Well Testing Hrs \& \$ & & 0.00 & & & $\$ 0.00$ & Well Testing Expenses \\
\hline Completion Hrs \& \$ & & 12.00 & & & $\$ 20,000.00$ & Valves \\
\hline \multirow[t]{2}{*}{ Production Tree and Valves } & & 0.00 & & & $\$ 84,000.00$ & $\begin{array}{l}\text { Master Valves and exp } \\
\text { Spool }\end{array}$ \\
\hline & & & & $\$ 249,081.11$ & & \\
\hline \multirow[t]{2}{*}{ Total Interval Rig Hours } & & 706.53 & Daily Operating & $\$ 735,251.60$ & & \\
\hline & & & & & $\$ 1,772,325.30$ & $\$ 2,756,658.01$ \\
\hline
\end{tabular}


Input Section. The Input Section acts as a reminder of each event within each interval to be accounted. A time and cost for each activity in an interval are entered. For all activities that affect the hours for the rig, the hourly operating rate is charged and tracked in the interval. All direct costs are also entered. For charges that do not affect rig hours, a charge time is developed and multiplied by the number of hours that would be charged for the rental or service. There is a running cost based on the additional equipment that is on the "clock" during drilling operations. Some of these events and equipment also require freight charges, mobilization charges (or initiation cost), and demobilization charges. Each event or equipment selection may also result in a direct cost for materials such as bits or packers or wellheads. With this degree of detail, the model can be altered to account for changes in procedures and for differences in service and equipment performances. The model can also be adapted to develop costs for alternative drilling methods and technologies. The costing process is adaptable and flexible.

At the end of these interval steps, there are a series of end-of-interval activities that are listed and a cost and time recorded for each activity. That includes circulating and conditioning drilling fluid, logging the well, running casing, cementing the casing, and changing out the well-control equipment to accommodate the new diameter of drilling to occur next.

The model is developed for a particular well by accounting for each time and each cost during the drilling of a well. At each step along the way, an account is kept of the amount of time required of the rig, the amount and cost of materials, and the time and cost of services to develop the well to completion.

Wellcost Section. The Wellcost Section sums the costs and times into an account for each interval. The amount of time and dollars can be determined from the Wellcost Section for each activity in each interval. It is possible to track the interval costs from beginning to end. At the end of each interval, a sum of the interval cost is available.

AFE Section. All of the costs and times are then transferred or summed to an AFE Sheet. The AFE Sheet was chosen as the primary form of output because most available information is recorded in that format. The total well cost, the time, and the cost for each major type of expense is listed in the authorization for expenditures (AFE) spreadsheet. 
Table A.6.6 AFE Section, Page 1.

EGS $5000 \mathrm{~m} 16400 \mathrm{ft} E \operatorname{Rev} 7$ 10-5/8

BJL

No Entry Point

Tangible Drilling Costs

Casing

Cond $\quad 30 " 0.375$ Wall Welded

Int $1 \quad 22 " 0.625$ Wall Welded

Int $2 \quad 16 " 109 \mathrm{lb}$ L80 Premium

Int $3 \quad 11-3 / 4 " 73.61 b$ K-55 Premium

Int 4 8-5/8"40lb K-55 Slotted

Other Well Equipment

Wellhead Assembly

Production Tree and Valves

Liner Hangers and Packers

Total of Tangible Drilling Costs

Intangible Drilling Costs

\begin{tabular}{l|l|r}
\hline ok & Drilling Engineering & $\$ 75,619.70$ \\
\hline ok & Direct Supervision & $\$ 90,743.64$ \\
\hline ok & Mobilization and Demobilization & $\$ 346,000.00$ \\
\hline ok & Drilling Contractor & $\$ 1,247,725.03$ \\
\hline
\end{tabular}

Bits, Tools, Stabilizers, Reamers etc

Bit Totals

\begin{tabular}{|c|c|c|c|}
\hline Int 1 & $0^{\prime}$ to $1250^{\prime}$ Interval $28^{\prime \prime}$ & & $\$ 43,190.00$ \\
\hline Int 2 & $1250^{\prime}$ to $5000^{\prime}$ Interval $20^{\prime \prime}$ & & $\$ 53,480.00$ \\
\hline Int 3 & $5000^{\prime}$ to $12000^{\prime}$ Interval $14-3 / 4^{\prime \prime}$ & & $\$ 132,790.00$ \\
\hline Int 4 & $12000^{\prime}$ to $16000^{\prime}$ Interval $10-3 / 8^{\prime \prime}$ & & $\$ 92,187.50$ \\
\hline ok & Stabilizers, Reamers and Hole Openers & $\$ 64,329.50$ & \\
\hline Int 1 & $0^{\prime}$ to $1250^{\prime}$ Interval $28^{\prime \prime}$ & & $\$ 8,638.00$ \\
\hline Int 2 & $1250^{\prime}$ to $5000^{\prime}$ Interval $20^{\prime \prime}$ & & $\$ 10,696.00$ \\
\hline Int 3 & $5000^{\prime}$ to $12000^{\prime}$ Interval $14-3 / 4^{\prime \prime}$ & & $\$ 26,558.00$ \\
\hline Int 4 & $12000^{\prime}$ to $16000^{\prime}$ Interval $10-3 / 8^{\prime \prime}$ & & $\$ 18,437.50$ \\
\hline \multicolumn{4}{|c|}{ EGS $5000 \mathrm{~m} 16400 \mathrm{ft}$ E Rev 7 10-5/8 } \\
\hline & Other Drilling Tools, Jars, Shock Subs, etc & $\$ 48,247.13$ & \\
\hline Int 1 & $0^{\prime}$ to $1250^{\prime}$ Interval $28^{\prime \prime}$ & & $\$ 6,478.50$ \\
\hline Int 2 & $1250^{\prime}$ to $5000^{\prime}$ Interval $20^{\prime \prime}$ & & $\$ 8,022.00$ \\
\hline Int 3 & $5000^{\prime}$ to $12000^{\prime}$ Interval $14-3 / 4^{\prime \prime}$ & & $\$ 19,918.50$ \\
\hline \multirow[t]{6}{*}{ Int 4} & $12000^{\prime}$ to $16000^{\prime}$ Interval $10-3 / 8^{\prime \prime}$ & & $\$ 13,828.13$ \\
\hline & D/H Rentals DP, DC, Motors etc & $\$ 72,000.00$ & \\
\hline & Drill String Inspections & $\$ 12,500.00$ & \\
\hline & Small Tools, Services, Supplies & $\$ 20,000.00$ & \\
\hline & Reaming & $\$ 7,500.00$ & \\
\hline & Hole Opening & $\$-$ & \\
\hline
\end{tabular}

$12 / 3 / 2005$

AFE Days:

AFE Amount

$\$ 1,577,155.80$

$\$ 6,600,809.43$

$\$ 35,000.00$

$\$ 104,000.00$

$\$ 52,000.00$

$\$ 1,768,155.80$

\section{$\$ 7,200.0080 \mathrm{ft}$}

$\$ 139,750.001250 \mathrm{ft}-28 " \mathrm{bit}$

$\$ 287,897.005000 \mathrm{ft}-20 "$ bit

$\$ 1,034,508.8013120 \mathrm{ft}-14.75 "$ bit

$\$ 107,800.0016400 \mathrm{ft}-10.375$ "bit

$\$ 107,800.0016400$ ft-10.375"bit

$\$ 321,647.50$

$\$ 43,190.00$

$\$ 132,790.00$ 
Table A.6.7 AFE section, Page 2.

\begin{tabular}{|c|c|c|c|c|}
\hline & Directional Services and Equipment & & & \\
\hline & Directional & $\$ 272,975.56$ & & \\
\hline & Directional Engineering Service & & $\$ 36,451.11$ & \\
\hline & Directional Tools & & $\$ 23,191.11$ & \\
\hline & Mud Motors & & $\$ 140,222.22$ & \\
\hline & Steering/MWD Equipment & & $\$ 73,111.11$ & \\
\hline & Trouble & & & \\
\hline & Fishing Tools and Services & $\$ 5,000.00$ & & \\
\hline & Lost Circulation & $\$ 40,000.00$ & & \\
\hline & Misc. Trouble Cost & $\$-$ & & \\
\hline & Drilling Fluids Related & & & \\
\hline & Drilling Muds, Additives \& Service & $\$ 104,227.78$ & & \\
\hline & Mud Cleaning Equipment & $\$ 25,744.44$ & & \\
\hline & Mud Coolers & $\$ 19,395.56$ & & \\
\hline & Air Drilling Services and Equipment & $\$ 45,500.00$ & & \\
\hline & Casing Cementing and EOI & & & \\
\hline & Casing Tools and Services & $\$ 127,060.00$ & & \\
\hline & Welding and Heat Treat & $\$ 49,000.00$ & & \\
\hline & Cement and Cement Services & $\$ 554,000.00$ & & \\
\hline & Mob/Demob Cementing Equipment & & $\$-$ & \\
\hline Int 1 & 0’ to $1250^{\prime}$ Interval $28 " x 22 "$ & Casing & $\$ 122,000.00$ & \\
\hline Int 2 & $1250^{\prime}$ to $5000^{\prime}$ Interval $20^{\prime \prime} \times 16^{\prime \prime}$ & Casing & $\$ 162,000.00$ & \\
\hline Int 3 & 5000 to $12000^{\prime}$ Interval $14-3 / 4 " x$ 11-3/4" & Shoe to Surface & $\$ 270,000.00$ & \\
\hline \multirow[t]{3}{*}{ Int 4} & No Cement Perforated Liner & Perforated Liner & $\$-$ & \\
\hline & Well Control Equipment & & & \\
\hline & Blow out Preventer Rentals & $\$ 48,546.67$ & & \\
\hline Int 1 & Diverter & & $\$ 3,500.00$ & $26^{\prime \prime}$ to $1,000^{\prime}$ \\
\hline Int 2 & 21-1/4"2000 Stack & & $\$ 10,750.00$ & $20^{\prime \prime}$ to $5,000^{\prime}$ \\
\hline Int 3 & 16-3/4"3000 Stack & & $\$ 25,781.11$ & $14-3 / 4 "$ to 10,000 \\
\hline Int 4 & 13-5/8"3000 Stack & & $\$ 8,515.56$ & $10-3 / 8 "$ to 15,000 \\
\hline Int 5 & 13-5/8"3000 Stack & & $\$-$ & $7-7 / 8 "$ to 20,000 \\
\hline
\end{tabular}


Table A.6.8 AFE section, Page 3.

\begin{tabular}{|c|c|c|c|}
\hline \multicolumn{4}{|c|}{ EGS $5000 \mathrm{~m} 16400 \mathrm{ft}$ E Rev 7 10-5/8 } \\
\hline & Logging and Testing & & \\
\hline \multirow[t]{2}{*}{ ok } & Mud Logging and H2S Monitoring \& Equip. & $\$ 136,115.46$ & \\
\hline & Electrical Logging & $\$ 94,000.00$ & \\
\hline Int 1 & $0^{\prime}$ to $1250^{\prime}$ Interval & & $\$-$ \\
\hline Int 2 & $1250^{\prime}$ to $5000^{\prime}$ Interval & & $\$ 18,000.00$ \\
\hline Int 3 & $5000^{\prime}$ to $12000^{\prime}$ Interval & & $\$ 36,000.00$ \\
\hline Int 4 & $12000^{\prime}$ to $16000^{\prime}$ Interval & & $\$ 40,000.00$ \\
\hline \multirow[t]{5}{*}{ Int 5} & $16000^{\prime}$ to $20000^{\prime}$ Production Interval & & $\$-$ \\
\hline & Testing, Sampling \& Coring & $\$ 2,000.00$ & \\
\hline & Well Test & $\$ 130,000.00$ & \\
\hline & Completion Costs & $\$ 95,000.00$ & \\
\hline & Misc Expenses & & \\
\hline ok & Transportation and Cranes & $\$ 37,809.85$ & \\
\hline ok & Fuel & $\$ 107,803.44$ & \\
\hline ok & Water and System & $\$ 30,247.88$ & \\
\hline \multirow[t]{2}{*}{ ok } & Electric Power & $\$ 3,780.98$ & \\
\hline & Location Cost & & \\
\hline ok & Camp Cost and Living Expenses & $\$ 15,123.94$ & \\
\hline \multirow[t]{12}{*}{ ok } & Site Cleanup, Repair, Waste Disposal & $\$ 15,123.94$ & \\
\hline & Site Maintenance & $\$ 15,123.94$ & \\
\hline & Location Costs & $\$-$ & \\
\hline & Misc Administrative and Overhead & & \\
\hline & Administrative Overhead & $\$ 37,809.85$ & \\
\hline & Well Insurance & $\$ 18,904.92$ & \\
\hline & Miscellaneious Services & $\$ 56,714.77$ & \\
\hline & Total Intangible Drilling Costs & $\$ 4,393,321.48$ & 75.620 days \\
\hline & Total Tangible Drilling Costs & $\$ 1,768,155.80$ & \\
\hline & Total Tangible and Intangible Costs & $\$ 6,161,477.28$ & \\
\hline & Contingencies $10 \%$ of Intangibles & $\$ 439,332.15$ & \\
\hline & Total Drilling Costs & $\$ 6,600,809.43$ & \\
\hline
\end{tabular}


Trouble costs. Time and costs for troubles are entered into the Input Sections as expected. Some companies do not permit trouble cost expectations to be entered in the originating cost estimate. Separate costing modules can be created for trouble events such as lost circulation, stuck pipe, failed cement, etc. The frequency of these occurrences is more difficult to establish, because there are not enough examples to establish a statistical frequency. When trouble is to be included, interviews with individuals with knowledge of the area have been used to establish the likelihood of these trouble events. A "trouble event" time and direct cost can then be entered into Wellcost Lite Input Sheet in the appropriate interval. In many geothermal areas, for the tophole, it is common to have severe lost circulation especially above the water table. The number of events in the interval is estimated from interviews and what records are available. The degree of the trouble is also estimated. Lost circulation, stuck pipe, twist-offs, and the resulting fishing, instrumentation temperature limitations, and failed cement jobs can be significant cost items. Failed cementing jobs and collapsed casing are more complicated and difficult to properly include. For geothermal drilling records, only the identifiable troubles are listed. Trouble event times and costs can be estimated for each type and severity of problem.

Output of well costs. The output of the cost model can take a number of useful forms. The information entered into the Input Section is automatically summed in the Wellcost Section. The cost summary for each interval is available from the Wellcost Section. At the end of each interval, a total time and cost are summed and listed.

Because most drilling authorizations are put in an authorization for expenditures (AFE) format, it is used as one of the output formats for Wellcost Lite. Other formats have evolved for specific uses. The variations needed for the EGS Cost of Geothermal Power consideration were reduced to a representative curve, a simplification, for ease of use. There will be a unique curve for different geological areas. 
Table A.6.9 Description section, Page 1.

EGS 5000 m 16400 ft E Rev 7 10-5/8 12/3/2005

\begin{tabular}{|c|c|c|}
\hline$\$ 6,600,809$ & \multicolumn{2}{|c|}{ Total Well Cost w/cont } \\
\hline$\$ 6,161,477$ & \multicolumn{2}{|c|}{ Total Well Cost wo/cont } \\
\hline$\$ 346,000$ & \multicolumn{2}{|l|}{ Prespud } \\
\hline$\$ 2,593,216$ & \multicolumn{2}{|c|}{ Well Construction } \\
\hline$\$ 1,768,156$ & \multicolumn{2}{|l|}{ Tangible } \\
\hline$\$ 825,060$ & \multicolumn{2}{|c|}{ Non Tangible Well Construction Expenses } \\
\hline$\$ 3,222,261$ & \multicolumn{2}{|l|}{ Drilling } \\
\hline$\$ 2,508,886$ & \multicolumn{2}{|c|}{ Drilling Hole Making Related } \\
\hline$\$ 223,078$ & \multicolumn{2}{|c|}{ Mgmt and Overhead } \\
\hline$\$ 83,182$ & \multicolumn{2}{|l|}{ Site Related } \\
\hline$\$ 45,000$ & \multicolumn{2}{|l|}{ Trouble Cost } \\
\hline$\$ 362,115$ & \multicolumn{2}{|l|}{ Evaluation } \\
\hline$\$ 6,161,477$ & \multicolumn{2}{|c|}{ Chk Sum should Equal Total wo/cont } \\
\hline$\$ 391$ & \multicolumn{2}{|c|}{ Total w/cont-prespud/depth } \\
\hline$\$ 162$ & \multicolumn{2}{|c|}{ Well Construction/depth } \\
\hline$\$ 363$ & \multicolumn{2}{|c|}{ Total wo/cont-prespud/depth } \\
\hline$\$ 229$ & \multicolumn{2}{|c|}{ Drilling+Contingency/depth } \\
\hline$\$ 229$ & \multicolumn{2}{|c|}{ Total w/cont-prespud-construction/depth } \\
\hline 1,815 & Total Hours & \\
\hline 76 & Days & \\
\hline 870 & Rotating Hours & $47.9 \%$ \\
\hline 179 & Tripping Hours & $9.9 \%$ \\
\hline
\end{tabular}




\section{$5000 \mathrm{~m} / 4$ casing $\quad 5000 \mathrm{~m} / 5$ casing}

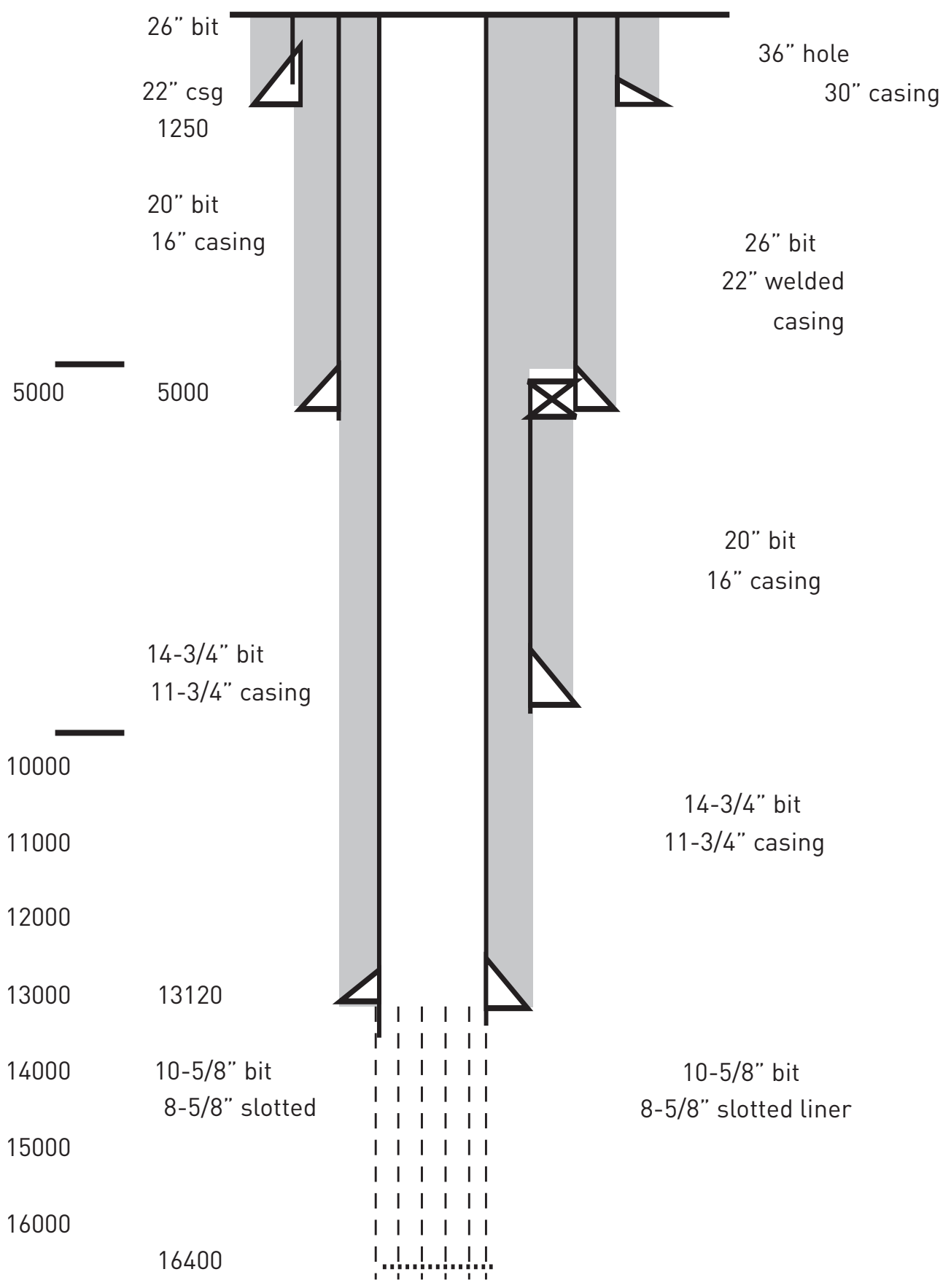

Figure A.6.1 4- and 5-interval 5,000 m casing 


\section{A.6.3 Model Results for Specific Areas and Depths}

Wells selected to represent potential U.S. EGS sites have been cost estimated using the Wellcost Lite modeling technique with the same performance parameters and cost values from earlier work reported. The variations in depth and bit performance have been an input for each model. The list of U.S. EGS sites is preliminary, but well cost can be estimated for any site that is chosen. The specific U.S. EGS sites well costs are as follows:

a. East Texas - NW LA / E Texas Basin

Well cost

Well design reservoir temperature

Formations

Bit performance

Casing shoe

TD

Open-hole interval
$\$ 7,665,032$ / 69 days of drilling

$200^{\circ} \mathrm{C}$

Sandstone grading to harder sediments

Sediment to the hot zone, then altered sediments

$\mathrm{I} 3,350 \mathrm{ft}$

$\mathrm{I} 6,400 \mathrm{ft}$

$3,050 \mathrm{ft}$

b. SE Idaho - N Utah / Ore Ida

Well cost

Well design reservoir temperature

Formations

Bit performance

Casing shoe

TD

Open-hole interval
$\$ 6,993,136 / 8$ I days of drilling

$265^{\circ} \mathrm{C}$

Basalt to I,500 m

Crystalline to $4,500 \mathrm{ft}(\mathrm{I}, 500 \mathrm{~m})$, then altered sediments, followed by crystalline

$\mathrm{I} 4, \mathrm{I} 00 \mathrm{ft}$

$\mathrm{I} 6,400 \mathrm{ft}, 5,000-4$

$2,300 \mathrm{ft}$

The Ore Ida well is estimated using the 5,000-4 well, since it is thought that wellbore stability will not be a significant problem in that area. If wellbore stability is a perceived problem, then the cost would be greater.

\section{c. NE Montana / Poplar Dome}

Well cost

Well design reservoir temperature

Formations

Bit performance

Casing shoe

TD

Open-hole interval
\$3,I66,027 / 37 days of drilling

$\mathrm{I} 35^{\circ} \mathrm{C}$

Madison limestone, sandstone, limestone and shale

Altered sediment throughout

$6,200 \mathrm{ft}$

$7,200 \mathrm{ft}$

$\mathrm{I}, 000 \mathrm{ft}$ 


\section{d. Northern California / Clear Lake}

\begin{tabular}{|c|c|}
\hline Well cost & $\begin{array}{l}\text { \$10,670,I25 / II5 days of drilling } \\
5 \text { intervals / no stability problems }\end{array}$ \\
\hline Well cost & $\begin{array}{l}\text { \$13,305,073 / I2 } 6 \text { days of drilling } \\
6 \text { intervals / concern for stability problems }\end{array}$ \\
\hline Well design reservoir temperature & $4 \mathrm{I} 5^{\circ} \mathrm{C}$ \\
\hline Formations & Granite, rhyolite, hydrothermally altered metasediments \\
\hline Bit performance & $\begin{array}{l}\text { Altered sediment for top } 5,000 \mathrm{ft} \text { to } 9,000 \mathrm{ft} \text {, then } \\
\text { granite }\end{array}$ \\
\hline Casing shoe & $\mathrm{I} 5,800 \mathrm{ft}$ \\
\hline TD & $\mathrm{I} 9,700 \mathrm{ft}$ \\
\hline Open-hole interval & $3,900 \mathrm{ft}$ \\
\hline
\end{tabular}

The Clear Lake prospective site will differ by almost \$3 million, depending on the amount of ash or unstable zones that are encountered. For an unstable geology, the greater cost should be used.

\section{e. SE Oregon / Sisters Area}

Well cost

$\$ 7,243,690 / 87$ days of drilling

Well design reservoir temperature

$225^{\circ} \mathrm{C}$

Formations

Granite, tuffs, andesite, andesite/basaltic lavas

Bit performance

Use altered sediment and crystalline ROP and hrs

Casing shoe

I3, I2O ft

TD

$\mathrm{I} 6,400 \mathrm{ft}$

Open-hole interval

$3,280 \mathrm{ft}$

\section{f. New Hampshire / Conway Granite}

Well cost

Well design reservoir temperature

Formations

Bit performance

Casing shoe

TD

Open-hole interval
\$I5,570,743 / I54 days of drilling

$200^{\circ} \mathrm{C}$

Granite from surface down

Use crystalline ROP and hrs

$\mathrm{I} 8,400 \mathrm{ft}$

23,000 ft

$4,600 \mathrm{ft}$

The bit performance values used in the EGS wells have been assumed to be slower and with fewer hours due to the depth of drilling. The bit performance map used for the New Hampshire well assumes crystalline formations from the surface down. 


\section{A.6.4 Model Results for Reworked Wells}

The least expensive rework will be to extend the depth of the well while the rig is still mobilized over the hole, and before the perforated liner has been run in the shorter interval.

A planned multilateral would mean sidetracking out of the well from a zone shallower than the original leg of the well. If it is necessary to sidetrack from a shallower point in search of promising fractures, then the cost to cement, pull back, and sidetrack the well will be more significant. This effort is a remedial operation to enhance the production. This cost would be similar to a multilateral additional cost. The rig on reworks and remedial operations will be cost-estimated for the 5,000 $\mathrm{m}$ (I6,400 ft) wells using the 4- and 5-interval models.

\section{A.6.4.1 Rig on drilling / deepening $460 \mathrm{~m}(1,500 \mathrm{ft}) /$ rig still on the well}

The cost increment for drilling an additional $460 \mathrm{~m}(\mathrm{I}, 500 \mathrm{ft})$ is $\$ 375,000$ (5,000 $\mathrm{m}$ well). This is a simple extension of the final interval, using the same ROP/hrs performance numbers and addition length to the perforated liner. The rig is over the hole, so there is no mobilization charge. Procuring and having the extra length of perforated liner would not be a significant planning issue.

\section{A.6.4.2 Rig on drilling / sidetracked lateral / as a planned part of the well design}

To sidetrack the well as a planned part of the well, the kickoff point would be $645 \mathrm{~m}(2, \mathrm{I} 20 \mathrm{ft})$ above the last casing point of 4,000 $\mathrm{m}$ (I3,I20 ft for a 5,000 m /I6,400 ft well) at 3,355 $\mathrm{m}$ (II,000 ft). With

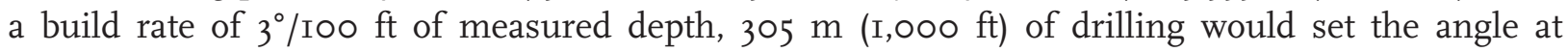
30 degrees. Drilling another I,I45 $\mathrm{m}(3,754 \mathrm{ft})$ would be the middle of the I, 000 $\mathrm{m}(3,280 \mathrm{ft})$ hot zone. Drilling would proceed to a total measured depth of 5,380 $\mathrm{m}$ (I7,648 ft). The sidetracked lateral would have penetrated completely through the hot zone. The Total Vertical Depth at the 5,380 m (I7,648 ft)

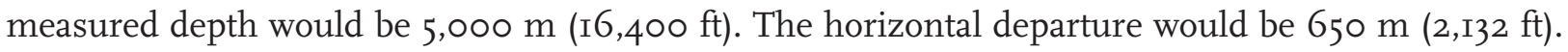
The planned lateral will be used to develop a second production (or injection) leg to the well.

Using the 5,000-4 model without the sidetrack was $\$ 6,989,859$, which took I,960 hours in 82 days. The total well cost with the additional sidetracked interval would cost $\$ 8,972,859$, done in 2,827 hours in II 8 days. This is an additional cost of $\$ 1,983,000$ and 36 days.

\section{A.6.4.3 Reworks / rig has to be mobilized / add a lateral for production maintenance / a work-over}

A well recompletion, which requires a lateral to restore production flow or temperature, would then require an additional $\$ 400,000$ for mobilization/demobilization, blowout preventer equipment (BOPE) rental, and setup. Due to the depth, the rig would need to be of a similar size and specification. The configuration of the well would be the same as the sidetracked lateral noted above. There would be an additional cost of $\$ 90,000$ for a bridge plug and cement. The whipstock is covered in the above cost model. The total for the lateral, as a remedial operation, would cost $\$ 2,473,000$ and take approximately 40 days. It is assumed that the formations being drilled are mostly crystalline.

\section{A.6.4.4 Redrills to enhance production / a work-over / rig to be mobilized}

To deepen a 5,000 $\mathrm{m}(\mathrm{I} 6,400 \mathrm{ft})$ well by $\mathrm{I}, 500 \mathrm{ft}$ to $\mathrm{I7}, 900 \mathrm{ft}$, which requires the mobilization of a rig, is considerably more expensive. There will be a cost of $\$ 500,000$ for mobilization/demobilization,

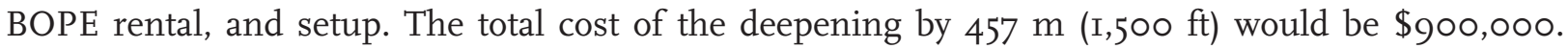


Almost any work-over that requires mobilizing a rig will run between \$700,000 and \$I million, depending on the depth of the well being reworked. The cost of a coiled tubing rig for this operation is only marginally less expensive, because coiled tubing rigs have gotten quite expensive.

Maintenance reworks for acidizing, casing scraping, logging, etc. will be in the same range of $\$ 600,000$ to \$I million per well event. 
CHAPTER 7

\section{Energy Conversion Systems - Options and Issues}

7.1 Introduction $----------------------------------{ }^{7-3}$

7.2 Electric Power Generation $--------------------------{ }^{7-3}$

7.2.1 Electricity from coproduced oil and gas operations _

7.2.2 Electricity from high-temperature EGS resources _ _ _ $\ldots-\ldots-\ldots-\ldots-\ldots$ 7-11

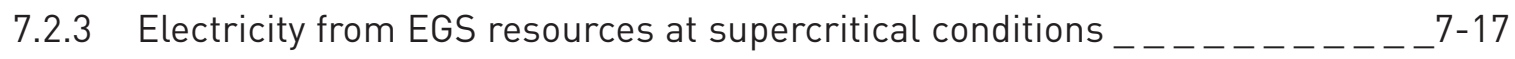

7.3 Cogeneration of Electricity and Thermal Energy _ _ _ _ _ _ _ _ _ _ _ $7-23$

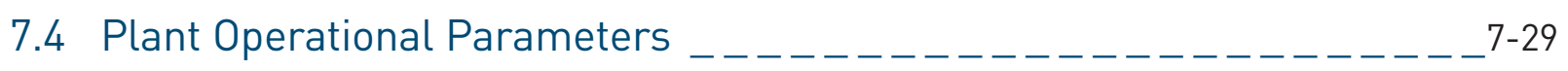

7.5 Summary and Conclusions _ $------------------------\_7-29$

References _- - - - - - - - - - - - - - - - - - - - - - - - - - - - - - - ${ }^{7-31}$ 


\subsection{Introduction}

This section presents energy conversion (EC) systems appropriate for fluids obtained from Enhanced Geothermal Systems (EGS). A series of EC systems are given for a variety of EGS fluid conditions; temperature is the primary variable and pressure is the secondary variable.

The EC systems used here are either directly adapted from conventional hydrothermal geothermal power plants or involve appropriate modifications. In certain cases, ideas have been borrowed from the fossil-fuel power industry to cope with special conditions that may be encountered in EGS fluids.

Several applications are considered. These range from existing "targets-of-opportunity" associated with the coproduction of hot aqueous fluids from oil and gas wells to very hot, ultra-high-pressure geofluids produced from very deep EGS reservoirs. Although electricity generation is our principal goal, we also discuss direct-heat applications and cogeneration systems, which use the available energy in the EGS fluid for electricity generation and direct heat.

Thermodynamic analyses are carried out, sample plant-flow diagrams and layouts are presented for typical applications at both actual and hypothetical sites, and estimates are made for the capital cost of installing the power plants.

\subsection{Electric Power Generation}

To cover a wide range of EGS fluids, we consider five cases of a geofluid at the following temperatures:
(I) $100^{\circ} \mathrm{C}$;
(2) $150^{\circ} \mathrm{C}$;
(3) $200^{\circ} \mathrm{C}$;
(4) $250^{\circ} \mathrm{C}$;
(5) $400^{\circ} \mathrm{C}$.

In most - but not all - cases, pressures are assumed sufficient to maintain the geofluid as a compressed liquid (or dense, supercritical fluid) through the EGS reservoir and well system, and up to the entry to the power-generating facility.

For each case, we have:

(a) Identified the most appropriate energy conversion system.

(b) Determined the expected net power per unit mass flow in $\mathrm{kW} /(\mathrm{kg} / \mathrm{s})$.

(c) Determined the mass flow required for I, IO, and $50 \mathrm{MW}$ plants.

(d) Estimated the installed cost of the power plants.

Table 7.I summarizes the preferred energy conversion systems for the five cases. Note that the first two cases are relatively low-temperature applications, which may not apply to a high-temperature EGS system, but would apply instead to one of the "targets-of-opportunity" - namely, coproduced aqueous fluids from oil and gas operations. The last case is that of a supercritical dense fluid that could present engineering and economic challenges owing to the high pressures involved, necessitating expensive heavy-duty piping and other materials. 
Although we suggest using a binary cycle with a recuperator for the $150^{\circ} \mathrm{C}$ resource, we did not incorporate a regenerator in the cycles we examined. It may be more beneficial to allow the geofluid to cool to as low a temperature as possible, if the binary plant is to be used with an EGS reservoir. This will enhance the gravity head through the well-reservoir system and improve the natural circulation.

The $200^{\circ} \mathrm{C}$ case lies on the border between the binary and flash systems, and we show both as possibilities. If a binary cycle is chosen, the working fluid should be operated at supercritical pressure to obtain the optimum performance.

Table 7.1 Summary of energy conversion systems.

\begin{tabular}{|c|c|c|c|c|}
\hline $\begin{array}{l}\text { Geofluid } \\
\text { temperature, }{ }^{\circ} \mathrm{C}\end{array}$ & $\begin{array}{l}\text { Energy conversion } \\
\text { system }\end{array}$ & $\begin{array}{l}\text { Typical } \\
\text { application }\end{array}$ & $\begin{array}{l}\text { Working } \\
\text { fluid }\end{array}$ & $\begin{array}{l}\text { Cooling } \\
\text { system }\end{array}$ \\
\hline 100 & Basic binary & O\&G waters & R-134a & $\begin{array}{l}\text { Water (evaporative } \\
\text { condenser) }\end{array}$ \\
\hline 150 & $\begin{array}{l}\text { Binary } \\
\text { w/recuperator }\end{array}$ & O\&G waters & Isobutane & Air \\
\hline 200 & $\begin{array}{l}\text { Binary or } \\
\text { Single-flash }\end{array}$ & EGS & $\begin{array}{l}\text { Isobutane or } \\
\text { Geofluid }\end{array}$ & Air or water \\
\hline 250 & Double-flash & EGS & Geofluid & Water \\
\hline 400 & $\begin{array}{l}\text { Single or } \\
\text { triple expansion }\end{array}$ & $\begin{array}{l}\text { Supercritical } \\
\text { EGS }\end{array}$ & Geofluid & Water \\
\hline
\end{tabular}

\subsubsection{Electricity from coproduced oil and gas operations}

It has been suggested recently that there is an enormous untapped hydrothermal energy resource associated with coproduced hot waters from oil and gas operations (McKenna and Blackwell, 2005; McKenna et al., 2005). Those authors estimated that the resource potential could range from about 985 to $5,300 \mathrm{MW}_{\mathrm{e}}$ (depending on the water temperature), using the fluids currently being produced in seven Gulf Coast states.

Binary power plants are a well-established technology for utilizing low- to moderate-temperature geothermal fluids (DiPippo, 2004; DiPippo, 2005). Figure 7.I shows a typical binary plant in simplified form. This type of plant is ideally suited for energy recovery from coproduced fluids. 


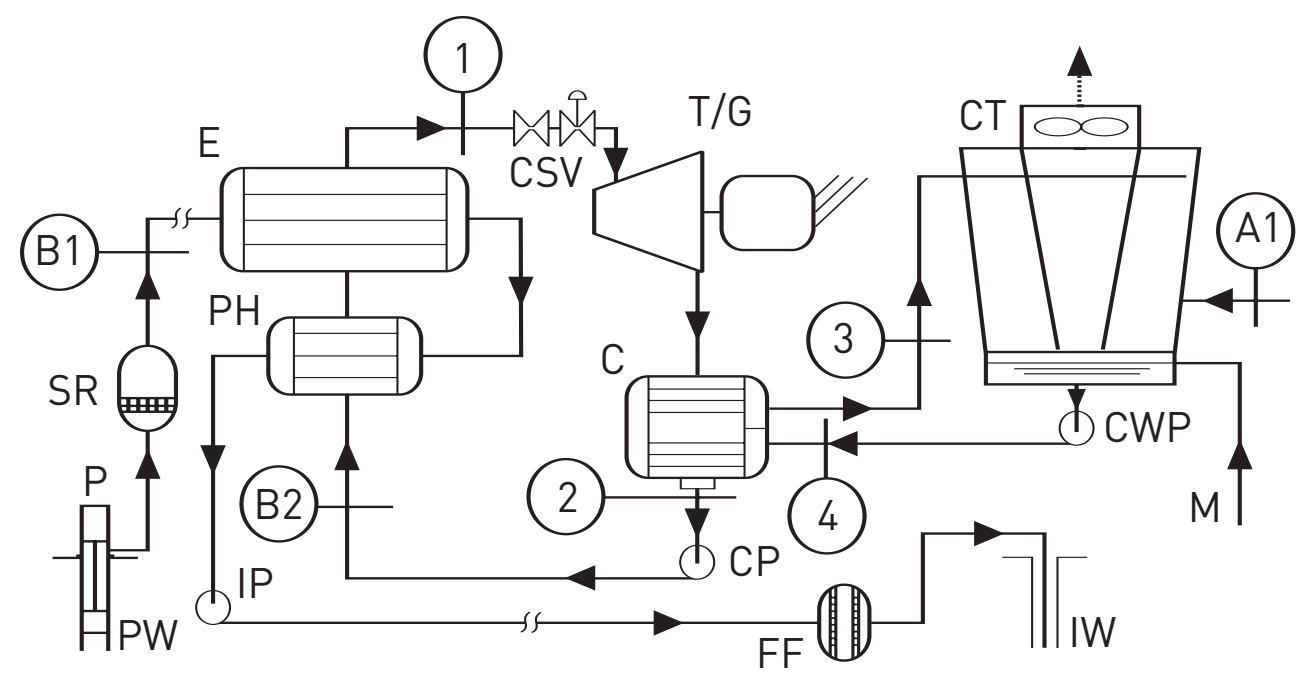

Figure 7.1 Basic binary power plant in simplified schematic form (DiPippo, 2005).

For this study, we examined this resource, beginning with a survey of current binary power plant performance, to determine the effect that geofluid temperature has on the cycle thermal efficiency. Once we found this dependency, we applied it parametrically to the known coproduced fluids in the seven Gulf Coast states included in McKenna et al. (2005), plus California. The results are presented as a function of fluid temperature because the coproduced fluids vary in temperature from field to field. Once the flow rate and the temperature are known for any site, our analysis allows an easy calculation of the electric power that can be installed. Thus, for each state, we have calculated the expected total power potential, in MW, as a function of the fluid temperature.

This analysis is based on a correlation for the thermal efficiency derived from several actual binary plants. The thermal efficiency is defined in the standard way as the ratio of the net power output to the rate of heat input, i.e., input thermal power (Moran and Shapiro, 2004). The plants used in the correlation are shown in Table 7.2, and the data are plotted in Figure 7.2 with the correlation equation for thermal efficiency as a function of geofluid temperature. All of the plants are organic Rankine cycles (ORCs), with the Húsavík plant being a Kalina-type plant using a water-ammonia mixture as the working fluid. The data used for the efficiencies come from various sources and may be found in DiPippo (2004).

There is considerable scatter in the efficiency data because of the variety of plant configurations represented by the data. The pinch-point temperature difference in the brine-working fluid heat exchangers is an important factor in determining the plant thermal efficiency, and this value is not reported in the literature. However, for the purposes of this study, the efficiency correlation is considered accurate enough to show the dependence of binary plant efficiency on the geofluid temperature. 
Table 7.2 Cycle thermal efficiencies for several binary power plants.

\begin{tabular}{l|r|r|r}
\hline Plant name & Location & Brine inlet temperature, ${ }^{\circ}$ C & Efficiency, $\%$ \\
\hline Amedee & CA & 103 & 5.8 \\
\hline Wabuska & NV & 105 & 8 \\
\hline Brady & NV & 109 & 7 \\
\hline Húsavík & Iceland & 122 & 10.6 \\
\hline Otake & Japan & 130 & 12.9 \\
\hline Nigorikawa & Japan & 140 & 9.8 \\
\hline Steamboat SB-2 \& SB-3 & NV & 152 & 8.2 \\
\hline Ormesa II & CA & 157 & 13.5 \\
\hline Heber SIGC & CA & 165 & 13.2 \\
\hline Miravalles Unit 5 & Costa Rica & 166 & 13.8 \\
\hline
\end{tabular}

The cycle net thermal efficiency is found from the temperature of the coproduced fluid using the correlation equation shown in Figure 7.2, namely

$$
\eta_{t h}=0.0935 T-2.3266
$$

where $T$ is in ${ }^{\circ} \mathrm{C}$ and the efficiency is in percent. Then, the net power output can be calculated from the geofluid inlet temperature, the geofluid outlet temperature, and the geofluid mass flow rate.

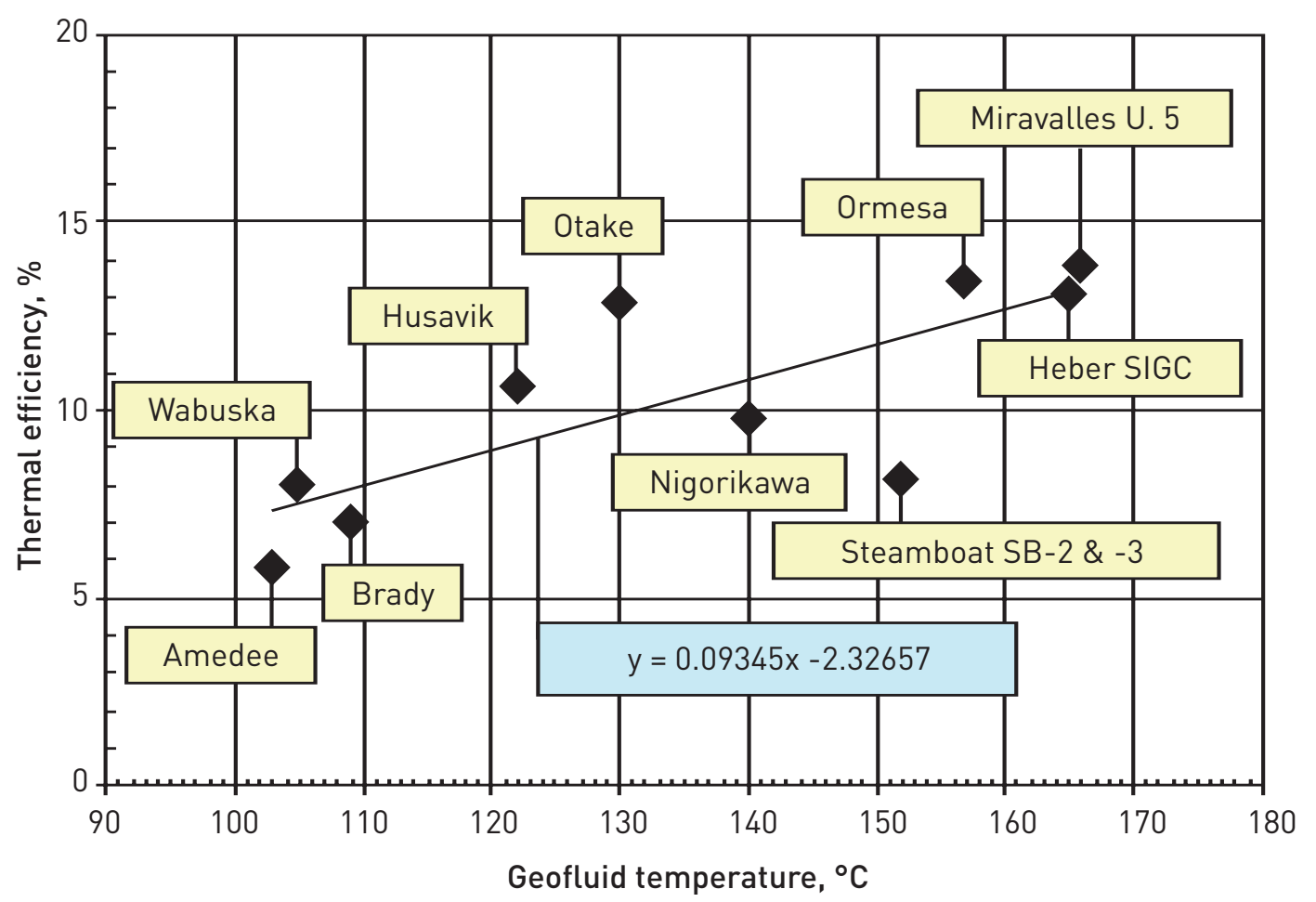

Figure 7.2 Correlation of binary plant cycle thermal efficiency with geofluid temperature in degrees Celsius $\left({ }^{\circ} \mathrm{C}\right)$ 
The results are presented in the form shown in Figure 7.3, where $T_{2}$ is the geofluid temperature leaving the plant. If one knows the inlet $\left(T_{1}\right)$ and outlet $\left(T_{2}\right)$ geofluid temperatures, the power output (in $\mathrm{kW}$ ) for a unit mass flow rate of one $\mathrm{kg} / \mathrm{s}$ can be read from the graph. The total power output can then be obtained simply by multiplying this by the actual mass flow rate in $\mathrm{kg} / \mathrm{s}$. For example, a flow of $20 \mathrm{~kg} / \mathrm{s}$ of a geofluid at $130^{\circ} \mathrm{C}$ that is discharged at $35^{\circ} \mathrm{C}$ can be estimated to yield a power output of $800 \mathrm{~kW}$ (i.e., $40 \mathrm{~kW} /(\mathrm{kg} / \mathrm{s})$ times $20 \mathrm{~kg} / \mathrm{s})$.

Finally, using the data from McKenna and Blackwell (2005) for the flow rates of waste water from petroleum production wells in the Gulf Coast states, plus the data for California (DOGGR, 2005), we can estimate the power that might be obtained if all the waste water were used in binary plants. The results are shown in Table 7.3 for an assumed outlet temperature of $40^{\circ} \mathrm{C}$. To correct the power $(\dot{W})$ totals for an outlet temperature other than $40^{\circ} \mathrm{C}$, one can use the following equation:

$$
\frac{\Delta \dot{W}}{\Delta T_{2}}=0.098701-0.0039645 T_{1}
$$

This equation was obtained from a simple fit to the calculated data and gives the change in the power output per degree Celsius change in outlet temperature as a function of the inlet temperature. Then the actual power output can be found from:

$$
\dot{W}_{\text {actual }}=\dot{W}_{T 2=40 C}+\frac{\Delta \dot{W}}{\Delta T_{2}} \times\left(T_{2}-40\right)
$$

As an example, let $T_{1}=100^{\circ} \mathrm{C}$. From Table 7.3, the estimated power from Alabama's waste water is I6.6 MW at $T_{2}=40^{\circ} \mathrm{C}$. If $T_{2}=50^{\circ} \mathrm{C}$, then from Eq. $(7-2)$, the power gradient is negative 0.29775 , and from Eq. (7-3), the actual power would be reduced to I3.6 MW. If the outlet temperature were $25^{\circ} \mathrm{C}$, the power gradient would be the same, but the actual power would be increased to 2I.I MW. 


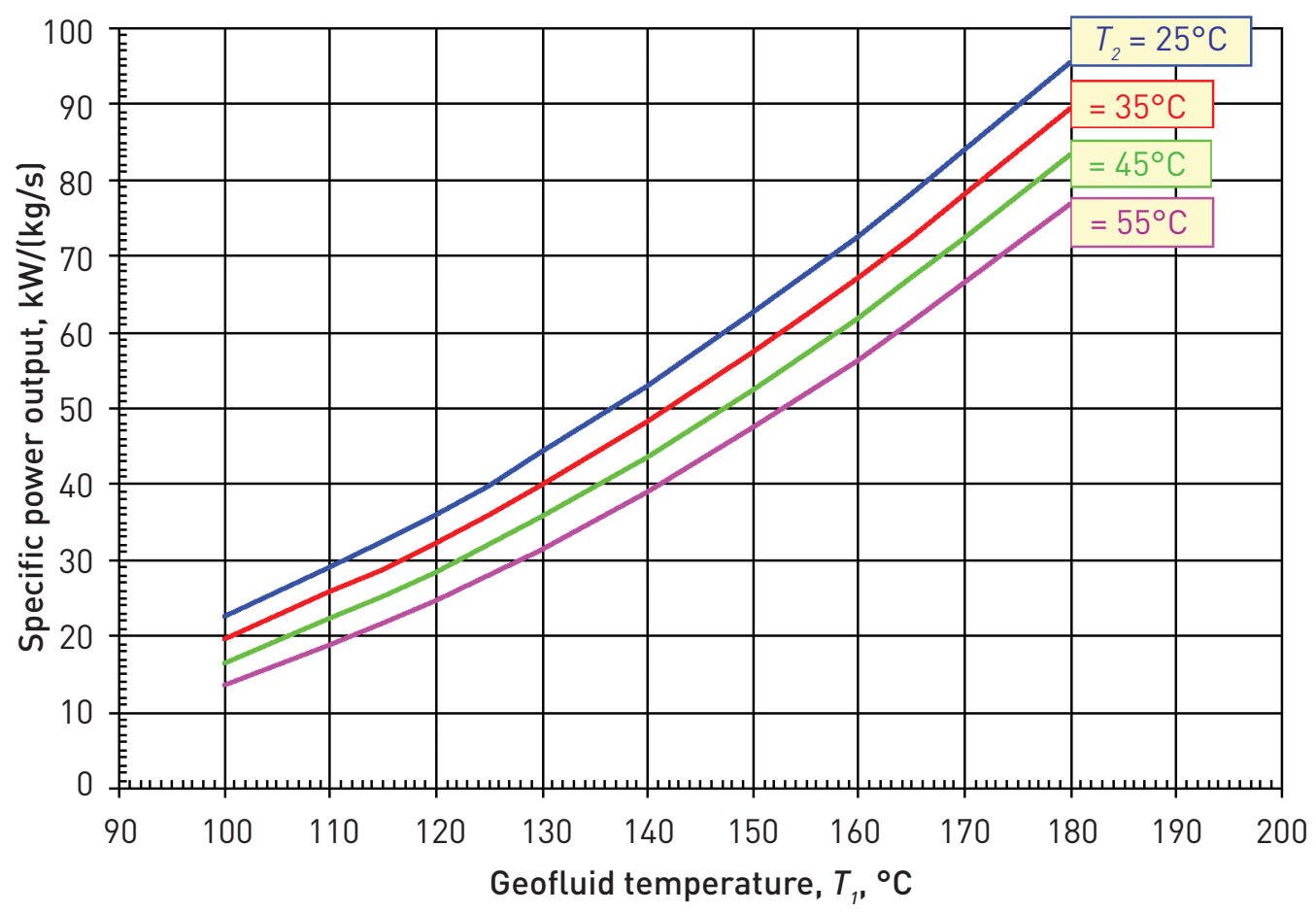

Figure 7.3 Specific power output (in $\mathrm{kW} /(\mathrm{kg} / \mathrm{s})$ ) for low- to moderate-temperature geofluids as a function of inlet $\left(T_{1}\right)$ and outlet temperatures $\left(T_{2}\right)$ shown in degrees Celsius $\left({ }^{\circ} \mathrm{C}\right)$.

Adopting the middle of the temperature range, we see that about 6,000 MW might be obtained today using standard binary-cycle technology from hot waters that are currently being reinjected without any energy recovery. This estimate could very well be higher because there are several other states with coproduced fluids, but we do not have sufficiently reliable data that allows us to include them in our survey.

Finally, another case of combined use of petroleum and geothermal energy resources may be considered. The use of so-called geopressured geothermal resources was extensively studied beginning in the I970s by the U.S. Department of Energy (DOE), the Electric Power Research Institute (EPRI), and others (see, for example, DiPippo, 2005; Swanson, I980; and Campbell and Hatter, I99I).

A nominal I MW pilot plant was installed to exploit the very high-pressure, high-temperature, methane-saturated fluids that were obtained along the Gulf Coast. The plant ran from I989-I990, and generated 3,445 MWh of electricity over I2I days of operation. This came to an average power output of $\mathrm{I}, 200 \mathrm{~kW}$. The plant captured the thermal energy in the geofluid using a binary cycle, and the chemical energy in the dissolved methane by burning it in a gas engine equipped with a waste heatrecovery system. The hydraulic energy represented by the high-pressure geofluid was not recovered for power generation. 
Table 7.3 Estimated power from California and Gulf states coproduced waters; outlet temperature assumed to be $40^{\circ} \mathrm{C}$.

\begin{tabular}{l|r|r|r|r}
\hline State & Flow rate, $\mathrm{kg} / \mathrm{s}$ & $\mathrm{MW} @ 100^{\circ} \mathrm{C}$ & $\mathrm{MW} @ 140^{\circ} \mathrm{C}$ & $\mathrm{MW} @ 180^{\circ} \mathrm{C}$ \\
\hline Alabama & 927 & 16.6 & 42.3 & 79.9 \\
Arkansas & 1,204 & 21.6 & 54.9 & 103.7 \\
California & 2,120 & 37.9 & 96.7 & 182.5 \\
Florida & 753 & 13.4 & 34.3 & 64.8 \\
Louisiana & 9,786 & 175.2 & 446.3 & 842.6 \\
Mississippi & 2,758 & 49.4 & 125.8 & 237.5 \\
Oklahoma & 59,417 & 1,064 & 2,709 & 5,116 \\
Texas & 56,315 & 1,008 & 2,568 & 4,849 \\
\hline TOTALS & 131,162 & 2,348 & 5,981 & 11,293 \\
\hline
\end{tabular}

Although the plant performed well, such plants were not economical at the time. Recently, Griggs (2004) re-examined this subject and concluded that the time is still not appropriate for this resource to become economic, but that under the right conditions of prices for competing fuels, geopressured resources might once again be considered for power production. In 50 years, when conventional petroleum resources may be close to exhaustion, the economic conditions should be favorable for the exploitation of geopressured resources.

Coproduction from the Naval Petroleum Reserve No. 3. As an example of a resource that is currently under production for oil, we consider the case of the Naval Petroleum Reserve (NPR) No. 3, and develop a binary plant that could operate with the hot water that is now being discharged to the surface. The flow diagram is represented in Figure 7.I. The plant has been designed to conform to the resource conditions as given by Myers et al. (200I). The most appropriate cycle working fluid is Ri34a. The key state-point parameters for a nominal I MW (net) power plant using a $100^{\circ} \mathrm{C}$ fluid are listed in Table 7.4. The actual coproduced fluid temperature is not known with certainty but may be as low as $82-93^{\circ} \mathrm{C}$. In such a case, the required flow rate to achieve the nominal I MW would be greater than the $88 \mathrm{~kg} / \mathrm{s}(48,000 \mathrm{bbl} /$ day) shown in the table. We estimate that the flow rate would range from I6o $\mathrm{kg} / \mathrm{s}\left(87,000 \mathrm{bbl} /\right.$ day) for the $82^{\circ} \mathrm{C}$ temperature to $103 \mathrm{~kg} / \mathrm{s}\left(56,000 \mathrm{bbl} /\right.$ day) for the $93^{\circ} \mathrm{C}$ temperature. We estimate the installed cost for this plant would range from $\$ 2,180 / \mathrm{kW}$ (for $100^{\circ} \mathrm{C}$ ) to $\$ 2,326 / \mathrm{kW}\left(\right.$ for $93^{\circ} \mathrm{C}$ ) and $\$ 2,540 / \mathrm{kW}$ (for $82^{\circ} \mathrm{C}$ ). 
Table 7.4 Cycle parameters for 1 MW binary plant at NPR No. 3 (see Figure 7.1).

\begin{tabular}{l|r|r}
\hline State-point (description) & Temperature, ${ }^{\circ} \mathrm{C}$ & Mass flow rate, kg/s \\
\hline B1 (brine inlet) & 100 & 88 \\
\hline B2 (brine outlet) & 60 & 88 \\
\hline 1 (turbine inlet) & 71 & 77 \\
\hline 2 (condenser outlet) & 26 & 77 \\
\hline 3 (cooling water outlet) & 21 & 380 \\
\hline 4 (cooling water inlet) & 13 & 380 \\
\hline A1 (air wet-bulb) & 7.2 & -- \\
\hline
\end{tabular}

Design of $1 \mathrm{MW}$ binary plants for low-to-moderate temperatures. The results of an engineering design exercise for a series of binary plants operating on low- to moderate-temperature geofluids are presented in Figure 7.4. Shown are two curves as a function of the geofluid temperature: (I) the specific installed plant cost in $\$ / \mathrm{kW}$ and (2) the specific power output in $\mathrm{kW} /(\mathrm{kg} / \mathrm{s})$. All the systems represented by the points on these curves have been designed as nominal I MW power plants, but we think that the results would apply reasonably well to units up to $5 \mathrm{MW}$ in capacity. The working fluid is Ri34a for the three low temperatures, and they are subcritical cycles. Isobutane is the working fluid for the two higher-temperature cases. The $150^{\circ} \mathrm{C}$ case is slightly subcritical, while the $200^{\circ} \mathrm{C}$ case is supercritical. The geofluid discharge temperature is $60^{\circ} \mathrm{C}$ for all the cases, except for the $200^{\circ} \mathrm{C}$ supercritical case. For the lower-temperature cases, $60^{\circ} \mathrm{C}$ is necessary to maintain reasonable pinchpoint temperature differences in the heat exchangers. The supercritical case does not experience a sharp pinch point between the preheater, and the vaporizer and the fluid can be cooled to $50^{\circ} \mathrm{C}$.

Notice that the specific plant cost approaches $\$ \mathrm{I}, 500 / \mathrm{kW}$ at the highest temperatures considered, and that the specific power or utilization effectiveness increases dramatically as the geofluid temperature increases. 


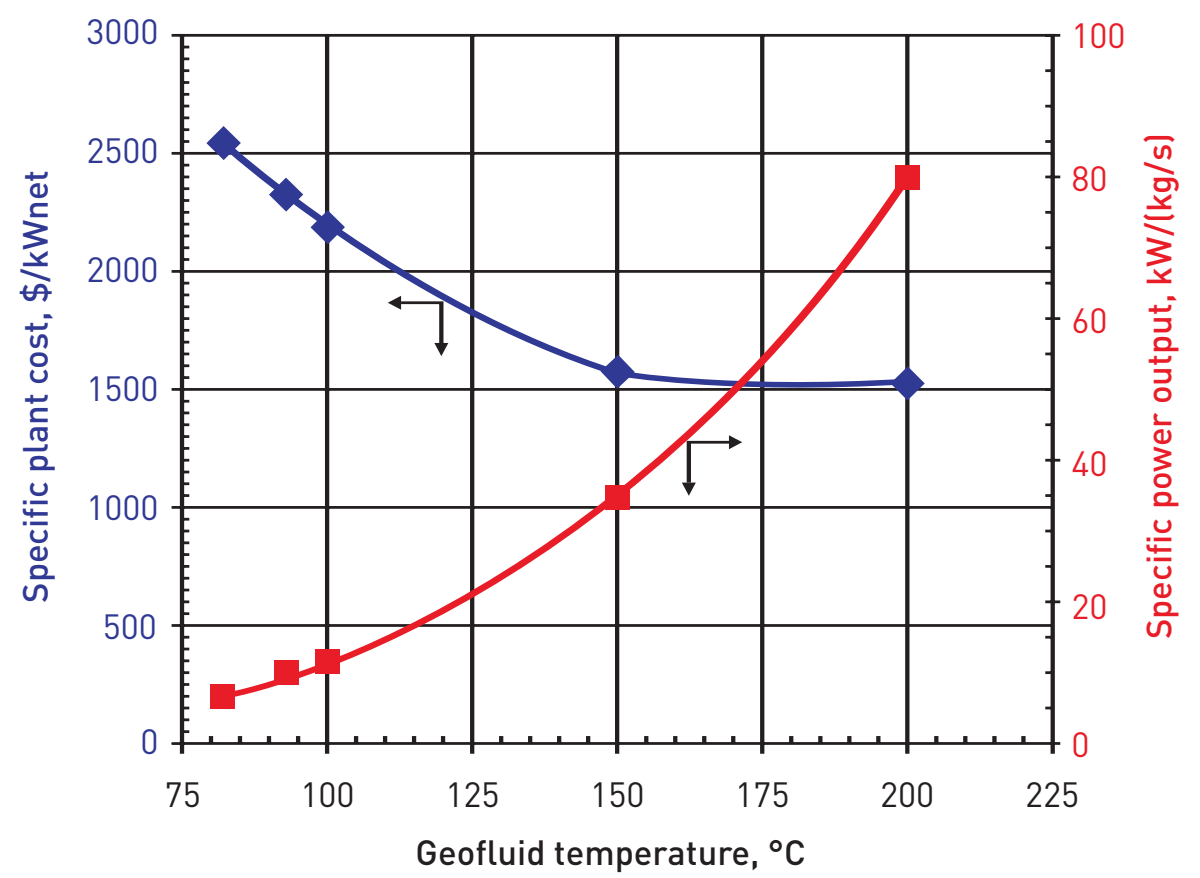

Figure 7.4 Cost and performance of $1 \mathrm{MW}$ binary power plants as a function of geofluid temperature in degrees Celsius $\left({ }^{\circ} \mathrm{C}\right)$.

\subsubsection{Electricity from high-temperature EGS resources}

It is expected that EGS reservoirs will be created in deep granitic basement rocks where the in situ temperatures will range from about $250^{\circ} \mathrm{C}$ to more than $500^{\circ} \mathrm{C}$ in special circumstances such as near magma intrusions. The fluids produced from such reservoirs may range in temperature from about $200^{\circ} \mathrm{C}$ to values well in excess of the critical temperature for pure water, i.e., $374^{\circ} \mathrm{C}$.

In this section, we consider energy conversion systems for fluids at the subcritical temperatures of $200^{\circ} \mathrm{C}$ and $250^{\circ} \mathrm{C}$; in the next section, we treat the supercritical case at $400^{\circ} \mathrm{C}$. As shown in Table 7.I, we selected a single-flash plant for the $200^{\circ} \mathrm{C}$ case and a double-flash plant for the $250^{\circ} \mathrm{C}$ case. Figures 7.5 and 7.6 show these plants in simplified schematic form (DiPippo, 2005).

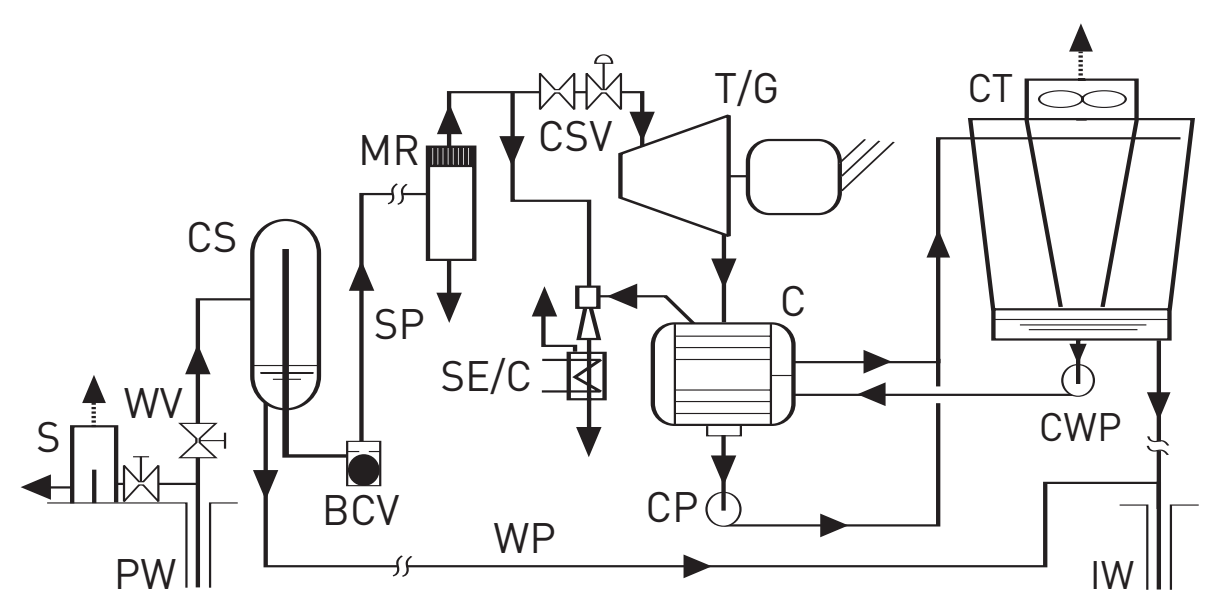

Figure 7.5 Single-flash power plant in simplified schematic form (DiPippo, 2005). 


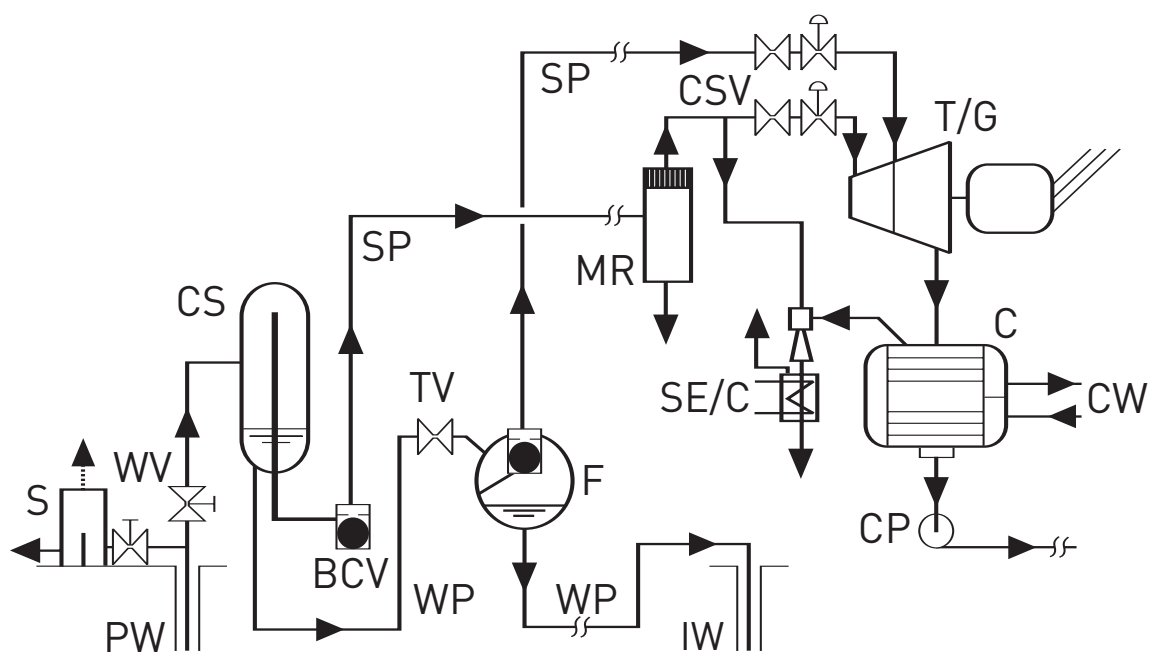

Figure 7.6 Double-flash power plant in simplified schematic form (DiPippo, 2005).

Note that a water cooling tower is shown in Figure 7.5, but that air-cooled condensers could be used in all of the systems, both flash and binary, allowing I00\% reinjection into the EGS reservoir. The latter option would increase the plant capital cost and reduce the net power, all other factors being the same.

If the EGS fluids are kept in the liquid state by the application of high pressure, these cases are similar thermodynamically to the typical hydrothermal situations encountered in many fields around the world. The fluid pressures may be higher than normally found in natural reservoirs, but the systems analysis is the same. Whether the geofluids are allowed to flash into two-phase liquid-vapor flow in the production wells, or at the surface separator, it makes no difference in the thermodynamic analysis, but may have practical importance from a chemical scaling standpoint.

The two plants were analyzed to determine the thermodynamic optimum conditions, i.e., the highest specific power output for each geofluid temperature, for a fixed condensing temperature of $50^{\circ} \mathrm{C}$. Turbine efficiency was downgraded to account for moisture in the lowest-pressure stages using the Baumann rule (DiPippo, 2005). The parasitic power requirements have been assumed to be $5 \%$ of the gross turbine power. That is, in arriving at the mass flow rates needed for a specified MW power output, the specific turbine power was first multiplied by 0.95 .

The final optimized performance results are shown in Table 7.5. The utilization efficiency, i.e., the ratio of the power output to the rate of exergy supplied by the geofluid, is $31.2 \%$ for the $200^{\circ} \mathrm{C}$ singleflash case, and $45.8 \%$ for the $250^{\circ} \mathrm{C}$ double-flash case. 
Table 7.5 Results for thermodynamically optimized single- and double-flash plants.

\begin{tabular}{|c|c|c|c|c|c|c|c|}
\hline \multirow{2}{*}{$\begin{array}{l}\text { Geofluid } \\
\text { temp., } \\
{ }^{\circ} \mathrm{C}\end{array}$} & \multirow{2}{*}{$\begin{array}{r}\text { Energy } \\
\text { conversion } \\
\text { system }\end{array}$} & \multirow[t]{2}{*}{$\begin{array}{r}\text { Separator } \\
\text { temp., }{ }^{\circ} \mathrm{C}\end{array}$} & \multirow[t]{2}{*}{$\begin{array}{r}\text { Flash } \\
\text { temp., }{ }^{\circ} \mathrm{C}\end{array}$} & \multirow[t]{2}{*}{$\begin{array}{r}\text { Specific turbine } \\
\text { power, kW/(kg/s) }\end{array}$} & \multicolumn{3}{|c|}{ Mass flow rate in $\mathrm{kg} / \mathrm{s}$ needed for } \\
\hline & & & & & $\begin{array}{c}1 \\
M W\end{array}$ & $\begin{array}{c}10 \\
\mathrm{MW}\end{array}$ & $\begin{array}{c}50 \\
\mathrm{MW}\end{array}$ \\
\hline 200 & Single-flash & 121 & N.A. & 53.9 & 19.5 & 195.2 & 975.9 \\
\hline 250 & Double-flash & 185 & 122 & 123.5 & 8.52 & 85.2 & 426.2 \\
\hline
\end{tabular}

It should be recognized that the maximum reasonably sustainable mass flow rates from EGS reservoirs to-date have been in the neighborhood of $20-22 \mathrm{~kg} / \mathrm{s}$. This would be sufficient to generate I $\mathrm{MW}$ from a $200^{\circ} \mathrm{C}$ fluid, and about $2.4 \mathrm{MW}$ from a $250^{\circ} \mathrm{C}$ fluid.

Estimated power plant costs for 1- and 2-flash systems. In this section, we estimate the cost to install plants of the I- and 2-flash type for use at EGS resources. The costs are based on the work of Sanyal (2005). He postulated that the cost of a power plant (including the cost of the initial wells and associated piping gathering system, but not replacement wells) would follow an exponentially declining curve as the capacity of the power unit increases. His cost equation is:

$$
C=2500 \times \exp (-0.003(\dot{W}-5))
$$

where $C$ is in $\$ / \mathrm{kW}$ and $\dot{W}$ is the unit capacity in MW. This formula was calibrated at $\$ 2,500 / \mathrm{kW}$ for a 5 MW plant and \$I,6I8/kW for a I50 MW plant, the largest size considered in Sanyal's study.

Our purpose is somewhat different in that we want to estimate the cost of power units when several of them will be constructed in a large EGS field. Thus, we need to account for both economy of scale (i.e., larger-size plants will be less expensive, per $\mathrm{kW}$, than smaller ones) and a learning curve (i.e., the unit cost of many units of identical design will be less than a one-off designed plant). We expect that a lower cost limit will be reached, for which the cost of a plant will remain constant no matter the size of a given unit or the number of common units constructed.

One other important difference exists in our case: We need the cost of the power plant alone because the well and field costs to create an EGS reservoir will be estimated separately in this report. To this end, we have assumed that $75 \%$ of the total cost from Eq. (7-4) is for the plant itself. Given the current uncertainty in estimating the cost to create an EGS reservoir, we believe this percentage is a reasonable estimate for the present purpose. 
Thus, we adapted Sanyal's equation to suit the present needs and used the following formulation:

$$
C=0.75 \times[1000+1500 \times \exp (-0.006115(\dot{W}-5))]
$$

or

$$
C=750+1125 \times \exp (-0.006115(\dot{W}-5))]
$$

This equation gives $\$ \mathrm{I}, 875 / \mathrm{kW}$ for the plant cost, exclusive of initial wells, for a $5 \mathrm{MW}$ plant; and $\$ \mathrm{I}, 2 \mathrm{I} 3 / \mathrm{kW}$ for a I50 MW plant (the same as Sanyal's equation), but includes an asymptotic plant cost of $\$ 750 / \mathrm{kW}$ for large units or for very large numbers of common units. This limit cost is our judgment, based on experience with actual, recently constructed plants.

We want to show how the temperature of the EGS resource affects the cost of the plant. For this purpose, we calculated the exergy of the geofluid coming from the EGS reservoir at any temperature. This value was multiplied by the utilization efficiency for optimized 1- and 2-flash plants to obtain the power output that should be attainable from the geofluid. This power was then used in Eq. (7-6) to obtain the estimated cost of the power unit.

The results are shown in Figures 7.7 to 7.10, which cover the range of temperatures expected from EGS systems. Figures 7.7 and 7.9 show the optimized power output, and Figures 7.8 and 7.I0 show the plant costs, for I-and 2-flash plants, respectively. The dramatic reductions in cost per $\mathrm{kW}$ for the higher flow rates are evident, which, of course, mean higher power ratings.

A nominal $50 \mathrm{MW}$ plant can be obtained from $\mathrm{I}, 000 \mathrm{~kg} / \mathrm{s}$ at $200^{\circ} \mathrm{C}$ using a $\mathrm{I}$-flash plant at an estimated cost of $\$ \mathrm{I}, 600 / \mathrm{kW}$. The same power output can be obtained from a 2 -flash plant using I, $000 \mathrm{~kg} / \mathrm{s}$ at $\mathrm{I} 80^{\circ} \mathrm{C}$ for $\$ \mathrm{I}, 650 / \mathrm{kW}$. 


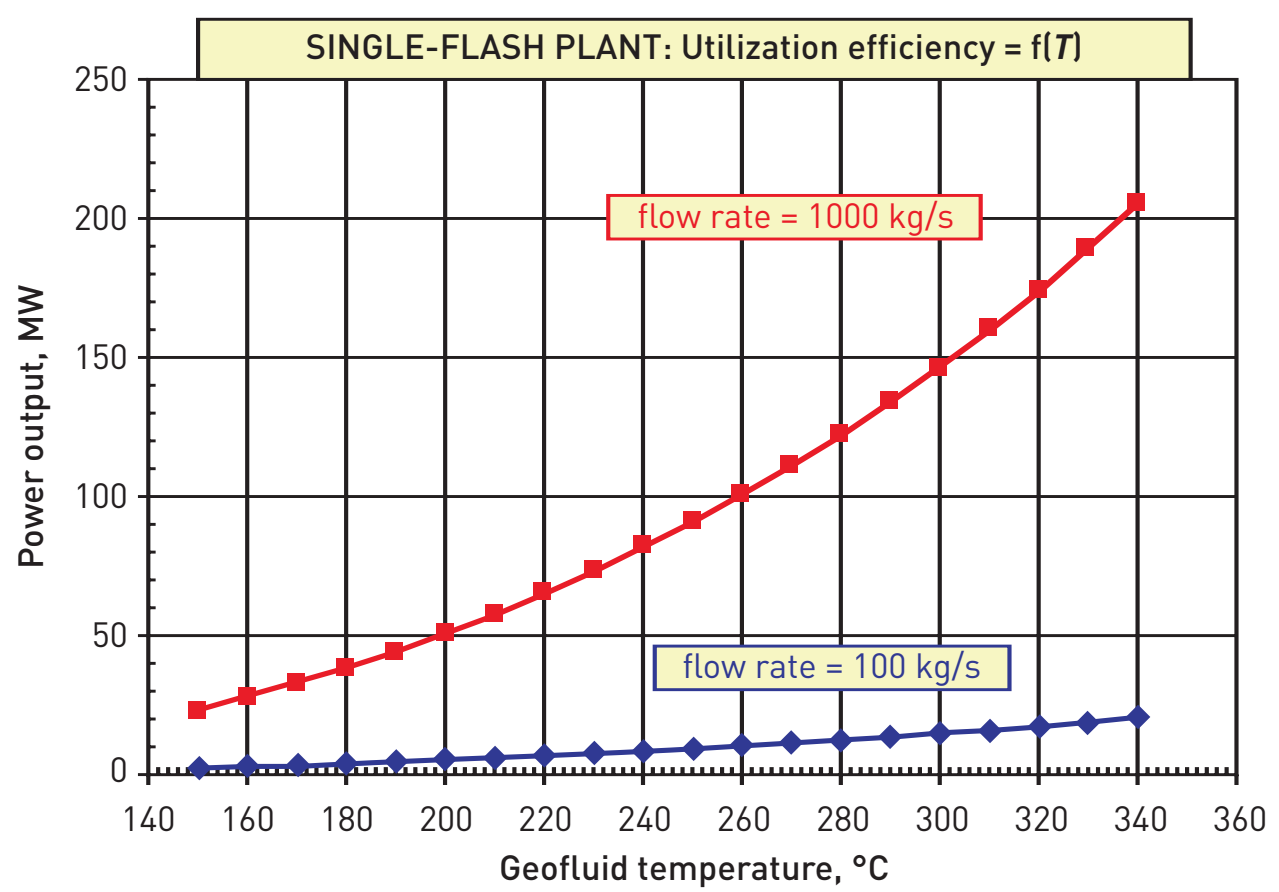

Figure 7.7 Optimized power output for a 1-flash plant as a function of geofluid temperature in degrees Celsius $\left({ }^{\circ} \mathrm{C}\right)$ for geofluid flow rates of 100 and $1,000 \mathrm{~kg} / \mathrm{s}$.

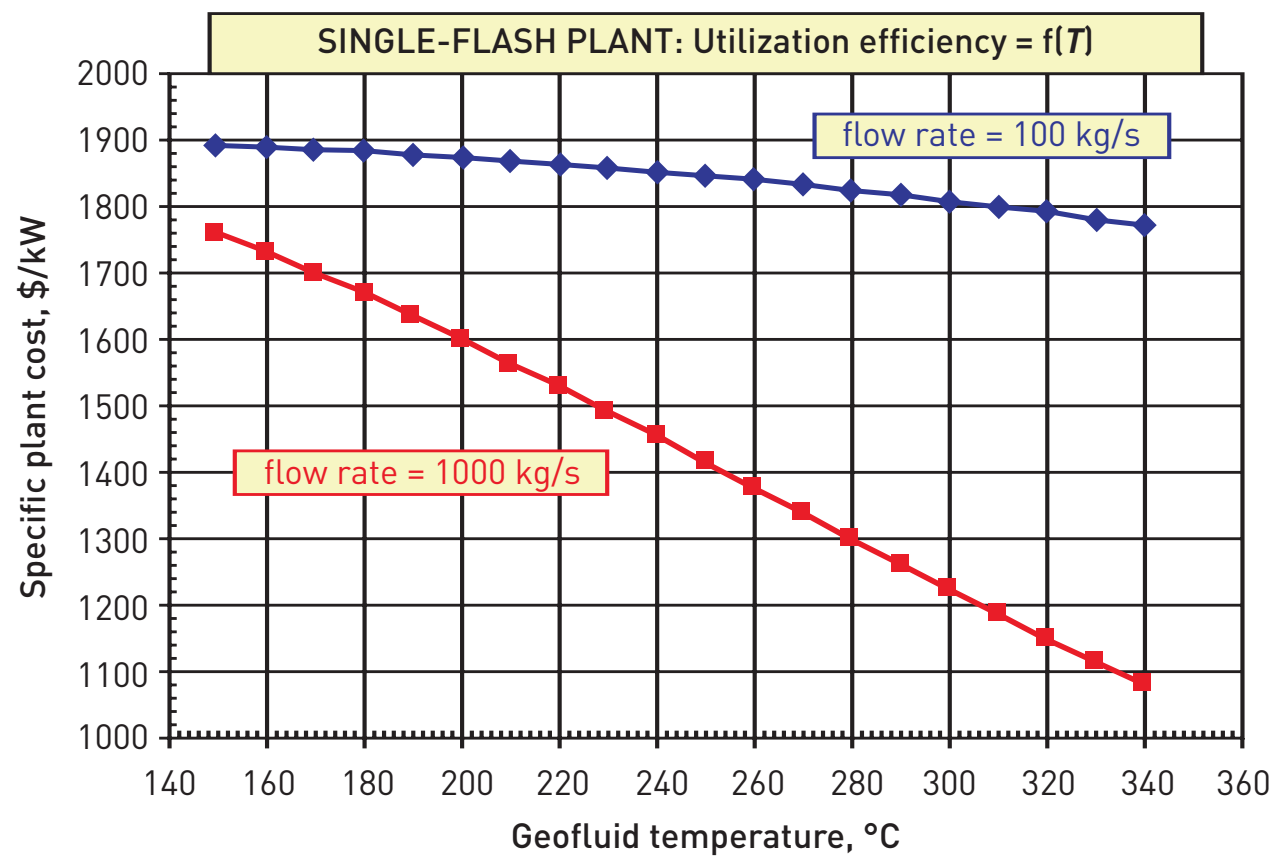

Figure 7.8 Estimated plant cost $(\$ / \mathrm{kW})$ for a 1 -flash plant as a function of geofluid temperature in degrees Celsius $\left({ }^{\circ} \mathrm{C}\right)$ for geofluid flow rates of 100 and $1,000 \mathrm{~kg} / \mathrm{s}$. 


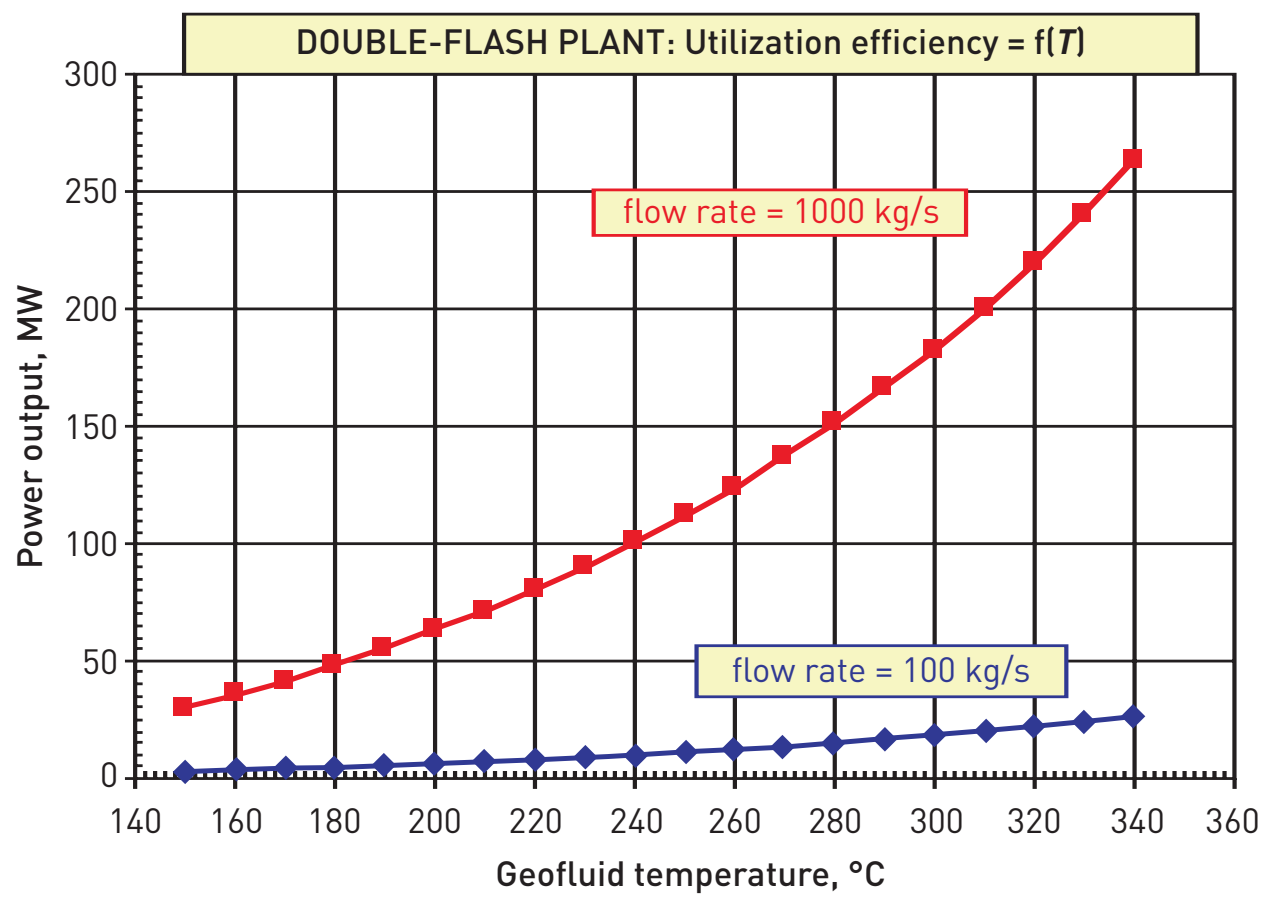

Figure 7.9 Optimized power output for a 2-flash plant as a function of geofluid temperature in degrees Celsius $\left({ }^{\circ} \mathrm{C}\right)$ for geofluid flow rates of 100 and $1,000 \mathrm{~kg} / \mathrm{s}$.

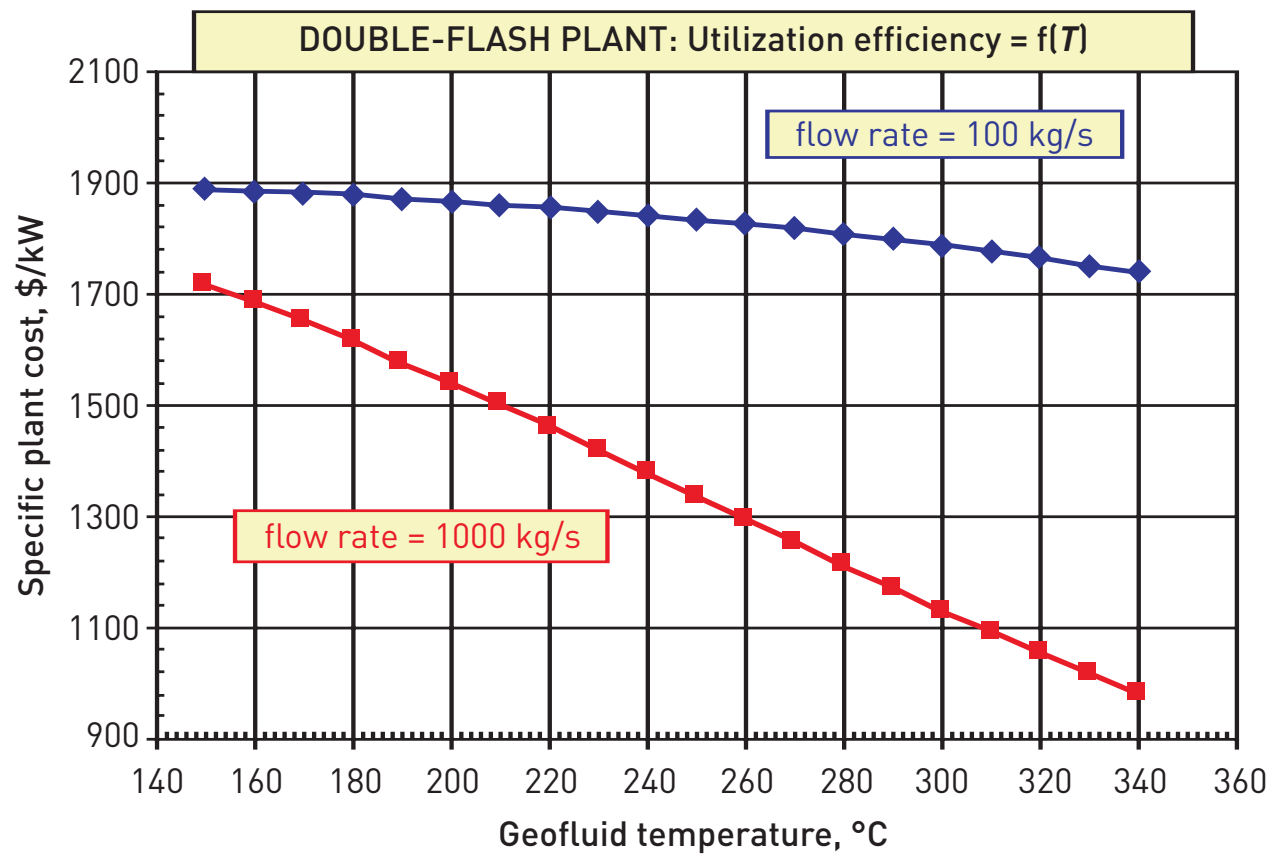

Figure 7.10 Estimated plant cost $(\$ / \mathrm{kW})$ for a 2 -flash plant as a function of geofluid temperature in degrees Celsius $\left({ }^{\circ} \mathrm{C}\right)$ for geofluid flow rates of 100 and $1,000 \mathrm{~kg} / \mathrm{s}$. 


\subsubsection{Electricity from EGS resources at supercritical conditions}

A novel energy conversion system was developed to handle the cases when the EGS geofluid arrives at the plant at supercritical conditions, i.e., at a temperature greater than $374^{\circ} \mathrm{C}$ and a pressure greater than $22 \mathrm{MPa}$. For all situations studied, the temperature was taken as constant at $400^{\circ} \mathrm{C}$. The plant is called the "triple-expansion" system; it is shown in simplified schematic form in Figure 7.II, and the thermodynamic processes are shown in the temperature-entropy diagram in Figure 7.I2.

The triple-expansion system is a variation on the conventional double-flash system, with the addition of a "topping" dense-fluid, back-pressure turbine, shown as item SPT in Figure 7.II. The turbine is designed to handle the very high pressures postulated for the EGS geofluid, in much the same manner as a "superpressure" turbine in a fossil-fueled supercritical double-reheat power plant (El Wakil, I984). However, in this case, we impose a limit on the steam quality leaving the SPT to avoid excessive moisture and blade erosion.

The analysis was based on the following assumptions:

- Geofluid inlet temperature, $T_{1}=400^{\circ} \mathrm{C}$.

- Geofluid pressure, $P_{1}>22 \mathrm{MPa}$.

- Condenser temperature and pressure: $T_{10}=50^{\circ} \mathrm{C}$ and $P_{10}=0.123$ bar $=0.0123 \mathrm{MPa}$.

- All turbine and pump isentropic efficiencies are $80 \%$.

- Steam quality at SPT exit, state $2=0.90$.

- HPT- and LPT-turbine outlet steam qualities (states 8 and ro) are unconstrained.

To determine the "optimum" performance, we selected the temperature at the outlet of the flash vessel (state-point 5) as the average between the temperature at the SPT outlet (state 2) and the condenser (state Io), in accordance with the approximate rule-of-thumb for optimizing geothermal double-flash plants (DiPippo, 2005). No claim is made, however, that this will yield the true optimum tripleexpansion design, but it should not be far off.

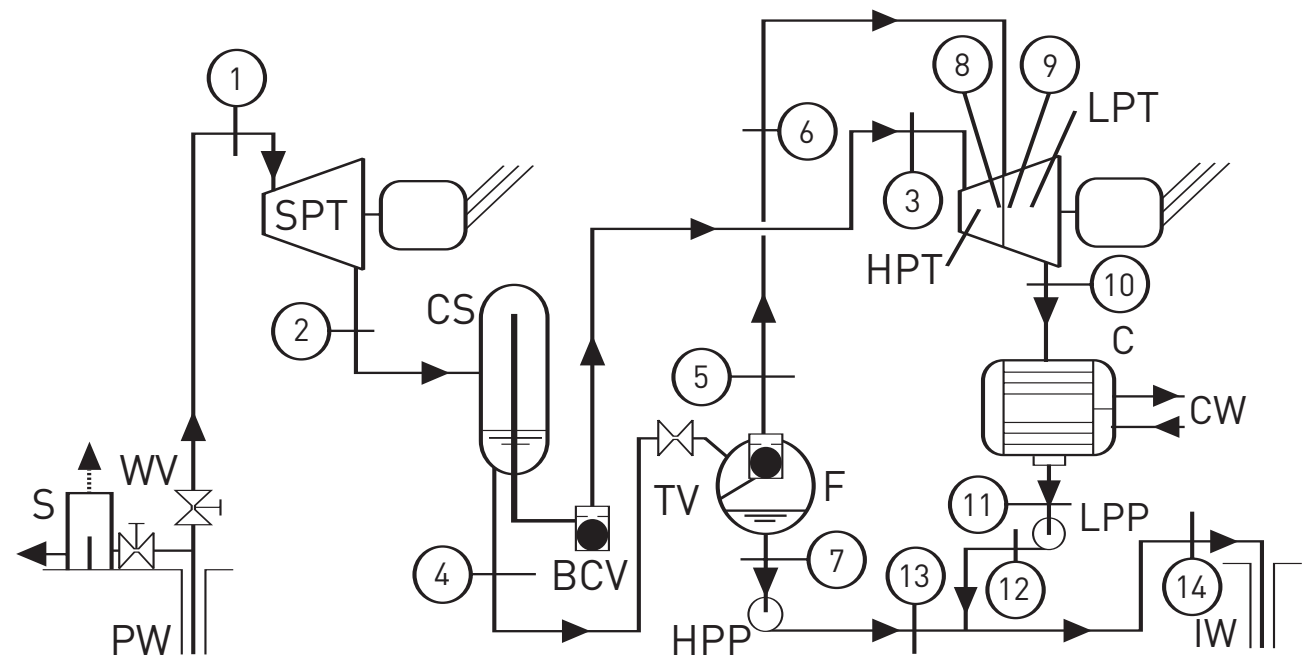

Figure 7.11 Triple-expansion power plant for supercritical EGS fluids. 


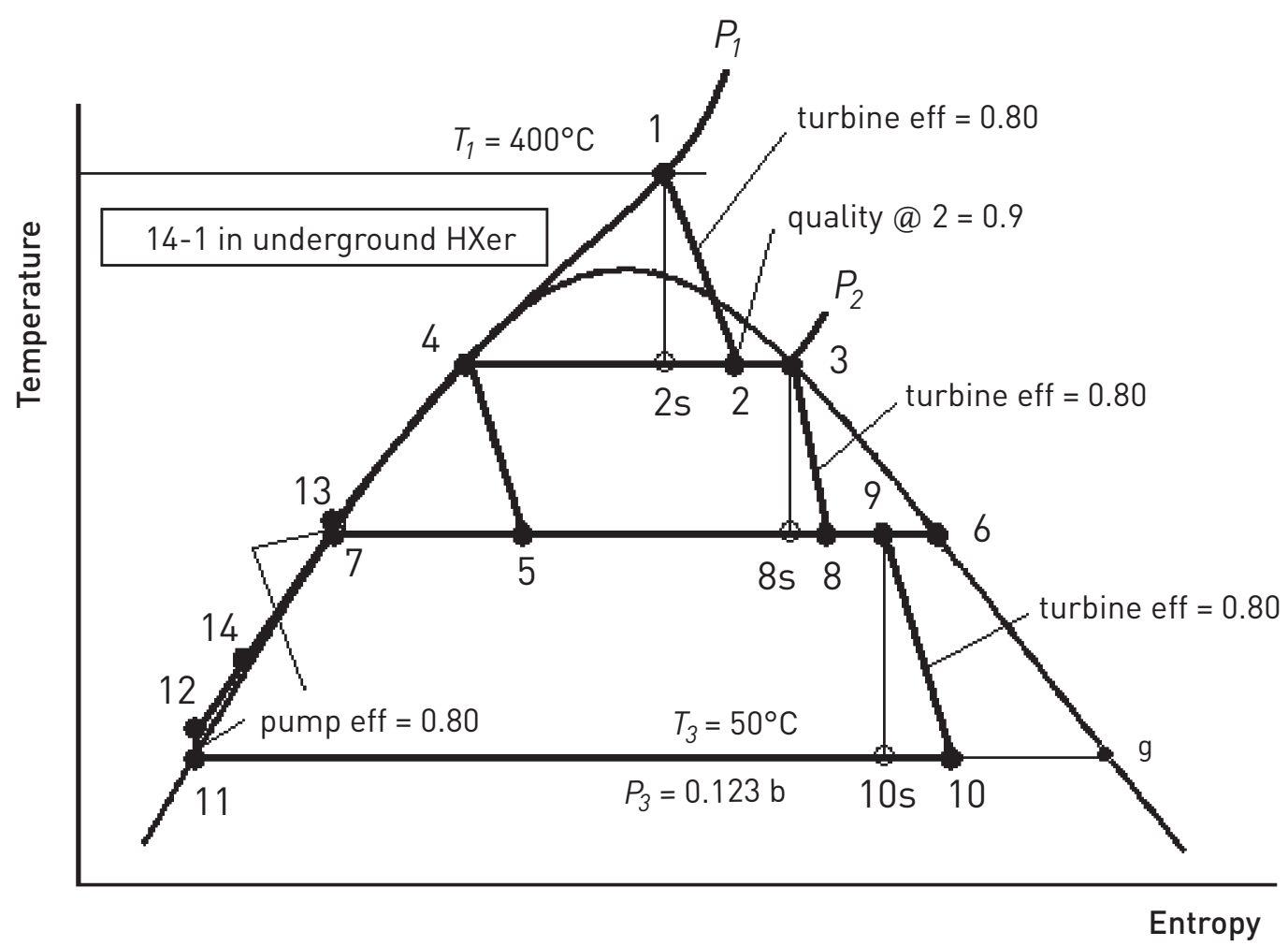

Figure 7.12 Processes for triple-expansion power plant (see Figure 7.11 for location of state points).

The results for the triple-expansion system are shown in Tables 7.6 and 7.7. It is evident that this is a very efficient means of generating electricity. The utilization efficiency is about $67 \%$, and the thermal efficiency is about 31\%. Given the high specific net power, it would take only about $15 \mathrm{~kg} / \mathrm{s}$ of EGS fluid flow to produce ro MW in either case. Such flow rates have already been demonstrated at EGS reservoirs in Europe. For inlet pressures above $27 \mathrm{MPa}$, there are no solutions that satisfy our constraints with the triple-expansion system. Even the solution at $27 \mathrm{MPa}$ requires the cyclone separator to operate close to the critical point, thereby diminishing its effectiveness. The density difference between the liquid and vapor phases is not as pronounced as at separator conditions found in a typical geothermal flash plant: Here, the liquid-to-vapor density ratio is only 3.5 as compared with I72.5 in a I MPa separator.

Table 7.6 Results of triple-expansion analysis for an inlet temperature of $400^{\circ} \mathrm{C}$.

\begin{tabular}{l|l|l|l|l|l|l|l}
\hline $\begin{array}{l}P_{1} \\
\mathrm{MPa}\end{array}$ & $\begin{array}{l}P_{2} \\
\mathrm{MPa}\end{array}$ & $\begin{array}{l}T_{2} \\
{ }^{\circ} \mathrm{C}\end{array}$ & $\begin{array}{l}\Sigma \mathrm{w}_{T} \\
\mathrm{~kJ} / \mathrm{kg}\end{array}$ & $\begin{array}{l}\Sigma \mathrm{w}_{P} \\
\mathrm{~kJ} / \mathrm{kg}\end{array}$ & $\begin{array}{l}\mathrm{w}_{\text {net }} \\
\mathrm{kW} /(\mathrm{kg} / \mathrm{s})\end{array}$ & $\begin{array}{l}\mathrm{q}_{\text {IN }} \\
\mathrm{kW} /(\mathrm{kg} / \mathrm{s})\end{array}$ & $\begin{array}{l}\eta_{\text {th }} \\
\%\end{array}$ \\
\hline 25 & 14.6 & 340.0 & 759.1 & 31.8 & 727.3 & 2301.3 & 31.6 \\
\hline 27 & 19.05 & 361.6 & 699.3 & 34.3 & 665.0 & 2149.0 & 30.9 \\
\hline
\end{tabular}


Table 7.7 Further results for triple-expansion analysis at $400^{\circ} \mathrm{C}$.

\begin{tabular}{l|l|c|c|c}
\hline$P_{1}$ & $\eta_{u}$ & \multicolumn{3}{|c}{ Mass flow rate in kg/s needed for } \\
MPa & $\%$ & $1 \mathrm{MW}$ & $10 \mathrm{MW}$ & $50 \mathrm{MW}$ \\
\cline { 3 - 5 } & & 1.37 & 13.8 & 68.8 \\
\hline 25 & 67.6 & 1.50 & 15.0 & 75.2 \\
\hline
\end{tabular}

Thus, for very high inlet pressures - greater than about $28 \mathrm{MPa}$ - a different form of energy conversion system must be found. A binary plant might be considered which allows the EGS fluid to be sent directly to the heat exchangers, but the extremely high pressures would necessitate very thickwalled piping and tubes in the heat exchangers. The cost of such elements would be prohibitively high, and the overall heat-transfer coefficients would be quite low. These two factors taken together would seem to rule out a simple binary plant, in spite of its inherent simplicity.

An alternative system would simply eliminate the superpressure turbine shown in Figure 7.II, and incorporate a flash-separation process that would reduce the EGS fluid pressure while generating steam for use in a conventional steam turbine. The residual liquid from the separator might then be used in a binary plant because the fluid pressure would then be manageable, or it might be flashed a second time, or most simply reinjected. The first option is what is called a flash-binary plant; the second option would be equivalent to using a double-flash plant, albeit with a very high pressure at the throttle inlet; and the last option would result in a single-flash plant or what we call a "singleexpansion" plant.

We examined the last case in detail. Figures 7.I3 and 7.I4 show the plant in schematic form and the processes in temperature-entropy coordinates.

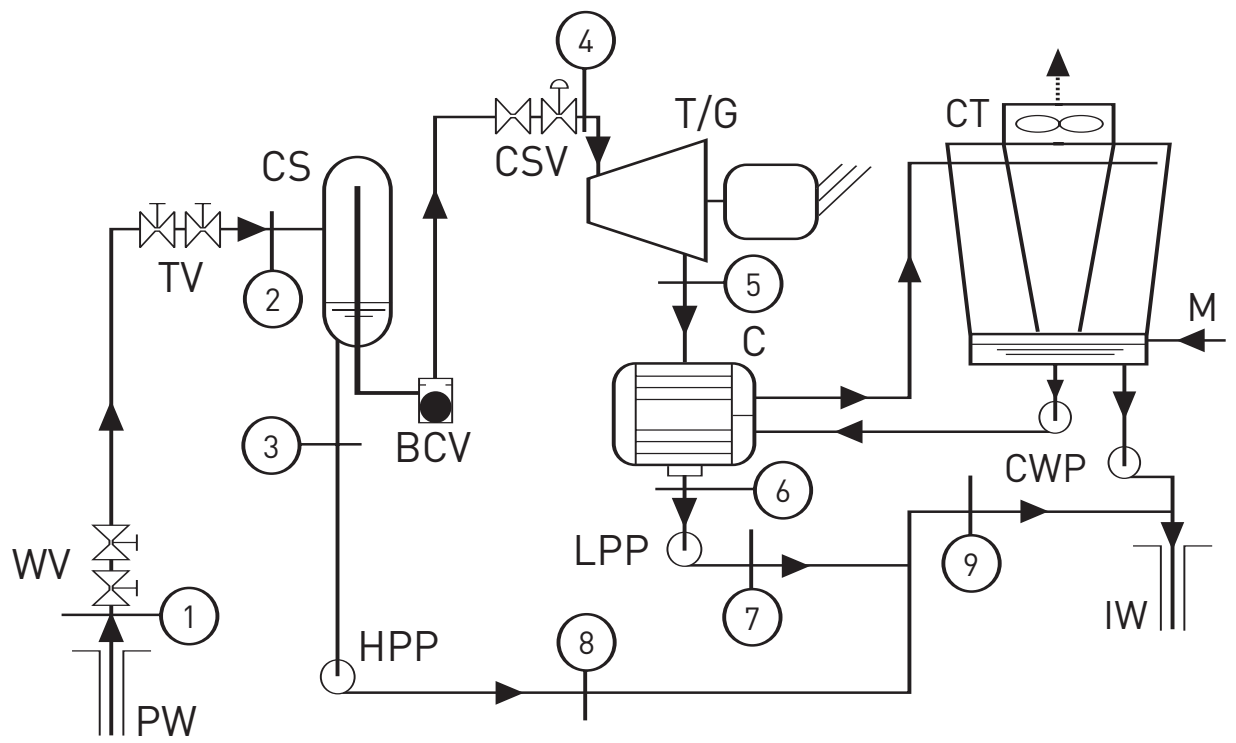

Figure 7.13 Supercritical single-expansion plant with ultra-high inlet pressures. 


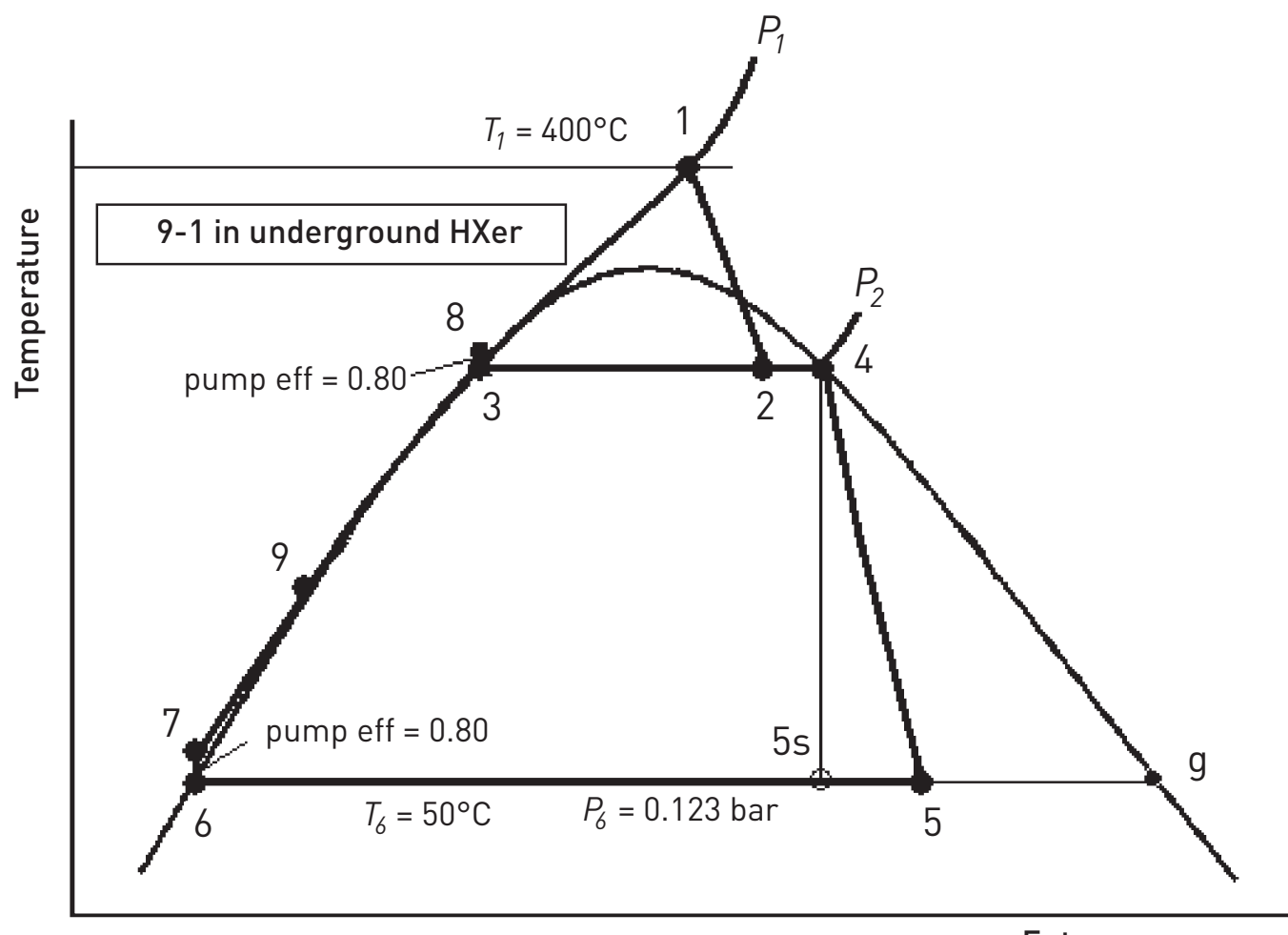

Entropy

Figure 7.14 Fluid processes for supercritical single-expansion plant with ultra-high inlet pressures (see Figure 7.13 for location of state points).

The analysis was based on the following assumptions:

- Geofluid inlet temperature, $T_{1}=400^{\circ} \mathrm{C}$.

- Geofluid pressure, $P_{1} \geq 28 \mathrm{MPa}$.

- Condenser temperature and pressure: $T_{10}=50^{\circ} \mathrm{C}$ and $P_{10}=0.123$ bar $=0.0123 \mathrm{MPa}$.

- Turbine efficiency found from Baumann rule with $85 \%$ dry expansion efficiency.

- All pump isentropic efficiencies are $80 \%$.

Tables 7.8 and 7.9 show the results for optimized single-expansion plants. By comparing these results with those in Tables 7.6 and 7.7, it is clear that this system produces far less output than the tripleexpansion system. This plant, however, is much simpler, and should be significantly less expensive to install and operate. 
Table 7.8 Results of thermodynamically optimized single-expansion plants with supercritical EGS fluids at $400^{\circ} \mathrm{C}$ and various pressures greater than $27 \mathrm{MPa}$.

\begin{tabular}{|c|c|c|c|c|c|c|c|}
\hline \multirow[t]{2}{*}{$\begin{array}{l}\text { Inlet } \\
\text { pressure } \\
\mathrm{MPa}\end{array}$} & \multirow[t]{2}{*}{$\begin{array}{l}\text { Separator } \\
\text { pressure } \\
\text { MPa }\end{array}$} & \multirow[t]{2}{*}{$\begin{array}{l}\text { Separator } \\
\text { temperature } \\
{ }^{\circ} \mathrm{C}\end{array}$} & \multirow{2}{*}{$\begin{array}{l}\text { Specific } \\
\text { turbine } \\
\text { power } \\
\mathrm{kW} /(\mathrm{kg} / \mathrm{s})\end{array}$} & \multirow[t]{2}{*}{$\begin{array}{l}\text { Specific net } \\
\text { power } \\
\mathrm{kW} /(\mathrm{kg} / \mathrm{s})\end{array}$} & \multicolumn{3}{|c|}{$\begin{array}{l}\text { Mass flow rate in } \mathrm{kg} / \mathrm{s} \\
\text { needed for }\end{array}$} \\
\hline & & & & & $\begin{array}{c}1 \\
\mathrm{MW}\end{array}$ & $\begin{array}{c}10 \\
\mathrm{MW}\end{array}$ & $\begin{array}{c}50 \\
\mathrm{MW}\end{array}$ \\
\hline 28 & 8.22 & 297 & 488.89 & 453.8 & 2.20 & 22.0 & 110.2 \\
\hline 29 & 5.94 & 275 & 443.82 & 406.7 & 2.46 & 24.6 & 122.9 \\
\hline 30 & 4.84 & 262 & 410.35 & 371.5 & 2.69 & 26.9 & 134.6 \\
\hline 31 & 4.25 & 254 & 388.02 & 347.6 & 2.88 & 28.8 & 143.9 \\
\hline 32 & 3.91 & 249 & 372.93 & 331.0 & 3.02 & 30.2 & 151.1 \\
\hline 35 & 3.34 & 240 & 347.46 & 301.2 & 3.32 & 33.2 & 166.0 \\
\hline
\end{tabular}

Table 7.9 Efficiencies of optimized single-expansion plants (see Table 7.7).

\begin{tabular}{l|l|l|l|l|l}
\hline $\begin{array}{l}P_{1} \\
\mathrm{MPa}\end{array}$ & $\begin{array}{l}\text { Exergy, } \mathrm{e}_{1} \\
\mathrm{~kW} /(\mathrm{kg} / \mathrm{s})\end{array}$ & $\begin{array}{l}\mathrm{w}_{\text {net }} \\
\mathrm{kW} /(\mathrm{kg} / \mathrm{s})\end{array}$ & $\begin{array}{l}\mathrm{q}_{\text {IN }} \\
\mathrm{kW} /(\mathrm{kg} / \mathrm{s})\end{array}$ & $\begin{array}{l}\eta_{t h} \\
\%\end{array}$ & $\begin{array}{l}\eta_{u} \\
\%\end{array}$ \\
\hline 28 & 941.4 & 453.8 & $1,754.3$ & 25.9 & 48.2 \\
\hline 29 & 886.7 & 406.7 & $1,632.7$ & 24.9 & 45.9 \\
\hline 30 & 842.9 & 371.5 & $1,538.0$ & 24.2 & 44.1 \\
\hline 31 & 812.4 & 347.6 & $1,472.8$ & 23.6 & 42.8 \\
\hline 32 & 791.3 & 331.0 & $1,427.1$ & 23.2 & 41.8 \\
\hline 35 & 755.7 & 301.2 & $1,349.4$ & 22.3 & 39.9 \\
\hline
\end{tabular}

The optimum separator temperature and the best specific power output are plotted in Figure 7.I5 as a function of the inlet EGS fluid pressure. Figure 7.I6 gives the thermal and utilization efficiencies. The optimization process maximized the net power (and, therefore, the utilization efficiency) so that the thermal efficiency is not necessarily at its peak value for the conditions shown. 


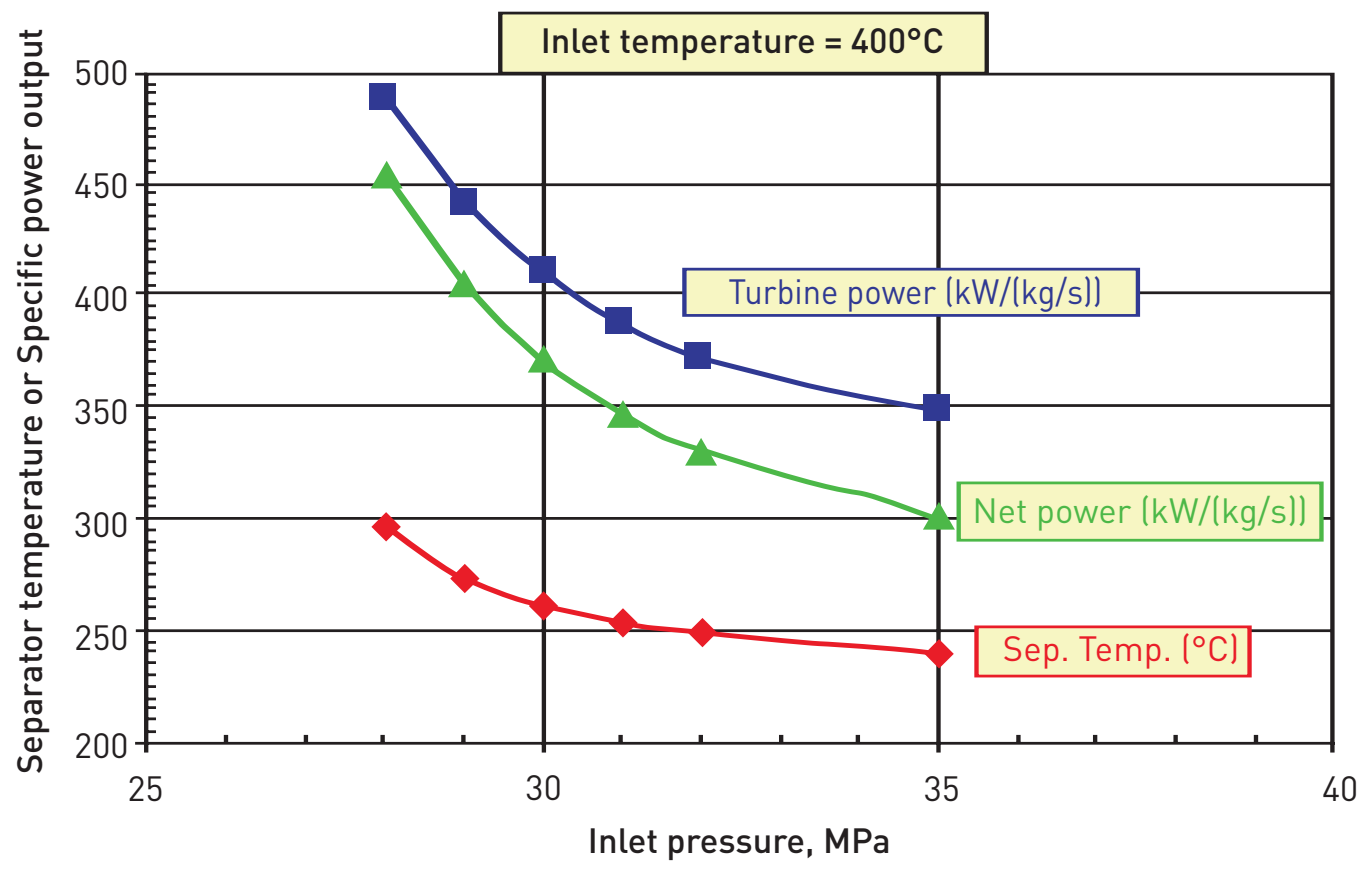

Figure 7.15 Optimum single-expansion plant performance for EGS fluid inlet temperature of $400^{\circ} \mathrm{C}$ and pressures greater than $27 \mathrm{MPa}$.

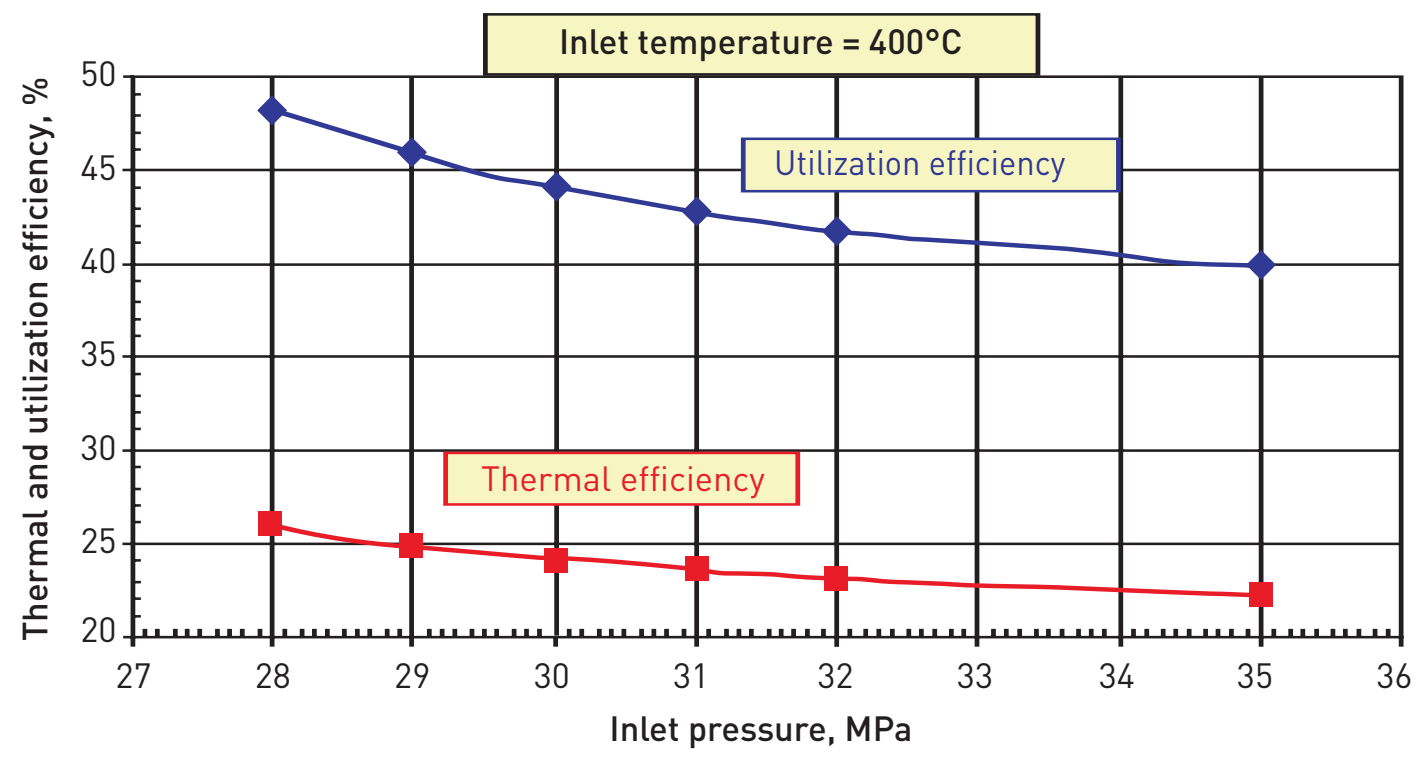

Figure 7.16 Thermal and utilization efficiencies for the supercritical single-expansion plant shown in Figure 7.13 and for the conditions shown in Figure 7.14.

It might be noted that the power needed to pump the geofluid back into the reservoir is significant, ranging from about $9 \%-13 \%$ of the turbine gross power. Also, the currently achievable EGS flow rates of about $20 \mathrm{~kg} / \mathrm{s}$ could generate roughly IO-I5 MW with this type of power plant under the fluid conditions postulated. 
Thus, for supercritical geofluids from EGS reservoirs, we conclude that for those cases where the geofluid is supplied to the plant at a temperature of $400^{\circ} \mathrm{C}$, and at pressures greater than $22 \mathrm{MPa}$ but less than $28 \mathrm{MPa}$, the preferred energy conversion system is a relatively complex, triple-expansion system. Cycle thermal efficiencies of about 31\% and utilization efficiencies of $67 \%$ can be expected.

For cases where the geofluid is supplied to the plant at a temperature of $400^{\circ} \mathrm{C}$ and at pressures greater than $28 \mathrm{MPa}$, the preferred energy conversion system is a single-expansion system. Cycle thermal efficiencies of about $24 \%$ and utilization efficiencies of $40 \%-45 \%$ can be expected.

The analysis presented here does not account for pressure losses through any piping or heat exchangers, including the manufactured one in the underground reservoir. Once the reservoir performance has been determined in the field, this can easily be taken into account by adjusting the required pump work.

We are left to speculate what geofluid pressures are reasonable for the EGS environment. For the simpler energy conversion system (i.e., the single-expansion cycle), the higher the pressure, the poorer the performance of the power cycle. The best performance occurs at pressures that may be too low to provide sufficient throughput of geofluid. For the more complex, triple-expansion system, it is not known whether the very high pressures postulated, requiring expensive thick-walled piping and vessels, may render this system uneconomic. Finally, at this stage of our understanding, we have no idea what geofluid flow rates will accompany any particular geofluid pressure because of the great uncertainty regarding the flow in the manufactured underground reservoir. More fieldwork is needed to shed light on this issue.

\subsection{Cogeneration of Electricity and Thermal Energy}

One of the possible uses of EGS-produced fluids is to provide both electricity and heat to residential, commercial, industrial, or institutional users. In this section, we consider the case of the MIT cogeneration system (MIT-COGEN) as a typical application.

Our tasks for the cogeneration case are:

(a) Identify the most appropriate energy conversion system using hot geofluid from an EGS resource that will supply all the required energy flows of the current system, i.e., electricity, heating, and air conditioning.

(b) Calculate the required flow rate of the geofluid.

MIT-COGEN employs a gas turbine with a waste heat-recovery steam generator (HRSG) to meet nearly all of the electrical and heating/cooling needs of the campus - Tables 7.Io and 7.II give HRSG a snapshot of the energy outputs for November I8, 2005. Also, on November I8, 2005, the steam generated from the HRSG was at I.46 MPa and $227^{\circ} \mathrm{C}$, with $30^{\circ} \mathrm{C}$ of superheat. Figure 7.I7 shows the energy flow diagram for the plant (Cooper, 2005), and Figure 7.I8 is a highly simplified flow diagram for the main components of the system. It is important to note that the chiller plant is powered mainly by steam turbines that drive the compressors, the steam being raised in the HRSG of the gas turbine plant. Two of the chillers have electric motor-driven compressors. 
The actual performance data for the MIT-COGEN plant were obtained from the plant engineers (Cooper, 2005). Table 7.12 shows the minimum, maximum, and average monthly demands for electricity, chiller cooling, and steam. Table 7.I3 gives the annual amounts for these quantities, and Table 7.I4 converts these values to instantaneous power requirements based on monthly averages.

Table 7.10 Electrical demand and supply at MIT - November 18, 2005.

\begin{tabular}{l|l|l}
\hline Demand load, kWe & Cogen power, kWe & NSTAR power, kWe \\
\hline 24,087 & 22,100 & 2,060 \\
\hline
\end{tabular}

Table 7.11 Steam demand and supply at MIT - November 18, 2005.

\begin{tabular}{l|l|l|l}
\hline Demand load, lbm/h & HRSG output, lbm/h & Demand load, kg/s & HRSG output, kg/s \\
\hline 135,059 & 135,059 & 17.017 & 17.017 \\
\hline
\end{tabular}

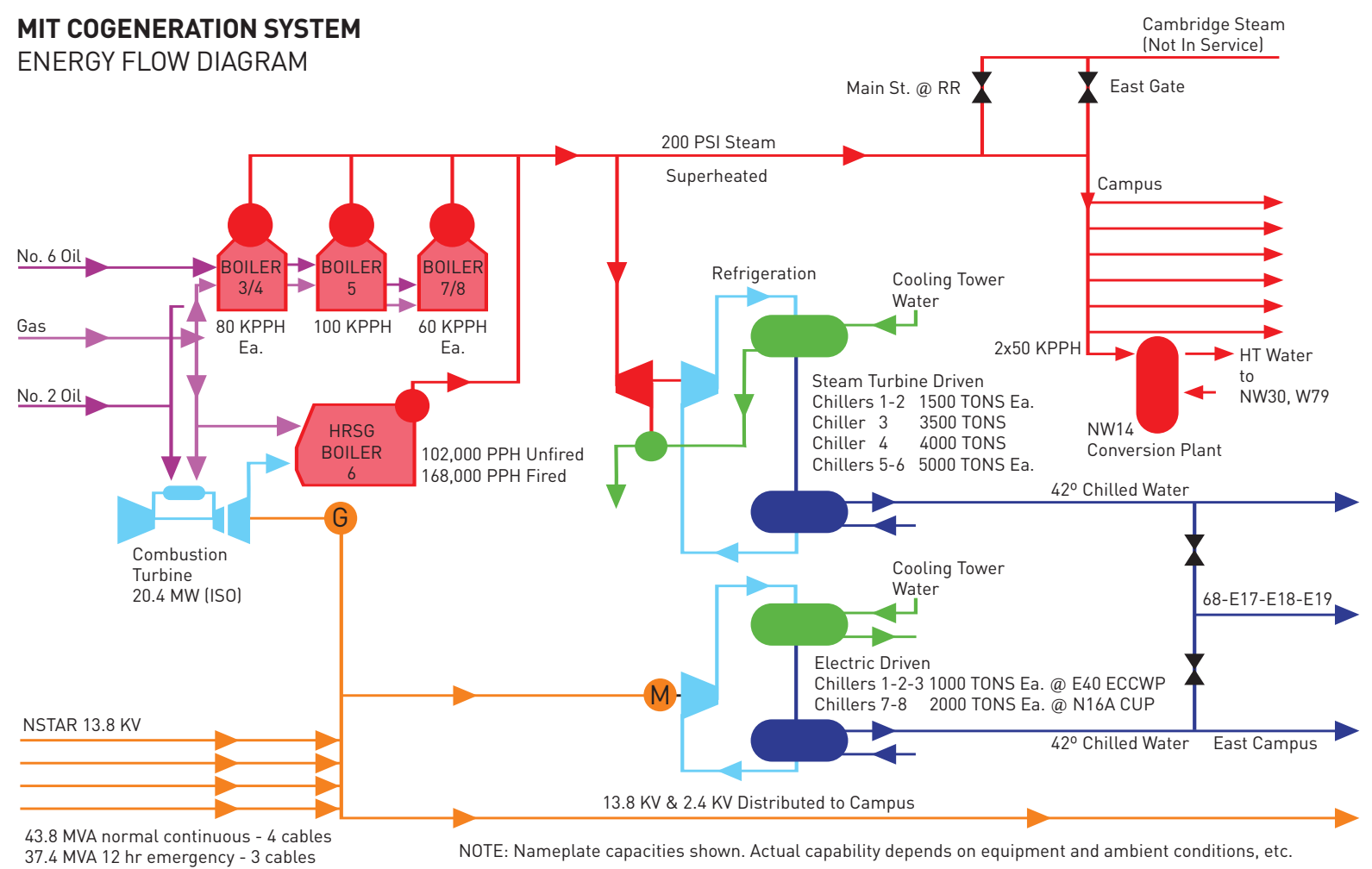

Figure 7.17 Energy-flow diagram for MIT-COGEN system. 


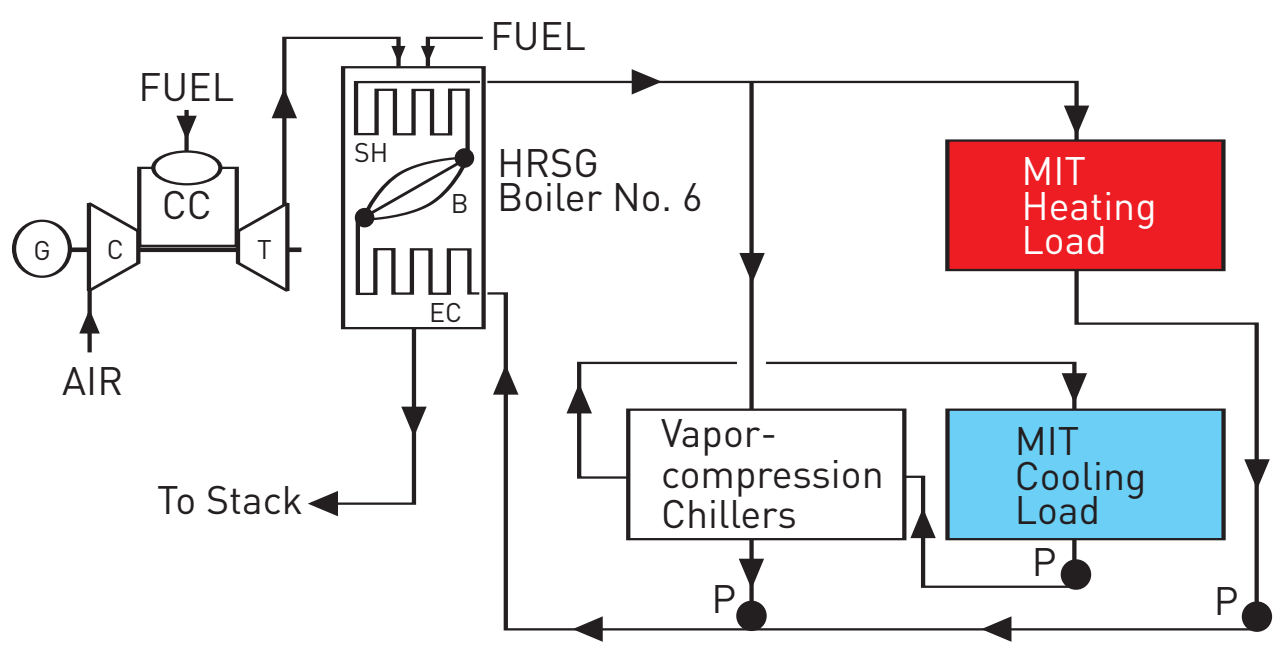

Figure 7.18 Highly simplified flow diagram for MIT-COGEN system.

Table 7.12 Monthly requirements for MIT-COGEN system, June 2004-May 2005.

\begin{tabular}{l|r|r|r}
\hline Item & Minimum & Maximum & Average \\
\hline Electricity demand, kWh & $14,300,000$ (Jan.) & $19,600,000$ (May) & $16,500,000$ \\
\hline Steam production, lbm & $93,400,000$ (Sep.) & $169,400,000$ (Jan.) & $120,000,000$ \\
\hline Chiller cooling, ton·h & $2,000,000$ (Feb.) & $7,200,000$ (Aug.) & $3,600,000$ \\
\hline
\end{tabular}

Table 7.13 Annual requirements for MIT-COGEN system, June 2004-May 2005.

\begin{tabular}{l|r}
\hline Item & Amount \\
\hline Electricity demand, kWh & $197,500,000$ \\
\hline Steam production, lbm & $1,440,000,000$ \\
\hline Chiller cooling, ton $\cdot h$ & $43,000,000$ \\
\hline
\end{tabular}


Table 7.14 Average power needs for MIT-COGEN system, June 2004-May 2005.

\begin{tabular}{lr}
\hline Item & Amount \\
\hline Electricity demand, $\mathrm{kW}$ & 22,900 \\
\hline Steam production, $\mathrm{lbm} / \mathrm{h}$ & 167,000 \\
\hline Steam production, $\mathrm{kg} / \mathrm{s}$ & 21 \\
\hline Chiller cooling, ton & 5,000 \\
\hline Chiller cooling, Btu/h & $60,000,000$ \\
\hline Chiller cooling, kWth & 17,500 \\
\hline
\end{tabular}

Figure 7.I9 is a flow diagram in which an EGS wellfield replaces the fossil energy input to the existing MIT-COGEN plant and supplies all of the current energy requirements.

The current gas turbine generator set is rated at $20 \mathrm{MW}$ but usually puts out more than that, typically $22 \mathrm{MW}$; the remainder of the electrical load must be supplied by the local utility. The power requirements will have to be produced by a new steam turbine driven by EGS-produced steam. We have selected a single-flash system with a back-pressure steam turbine. The exhaust steam from the turbine will be condensed against part of the heating load, thereby providing a portion of the total load for the moderate- to lower-temperature applications. The separated liquid from the cyclone separators may also be used to supply some of the needs of the heating system.

If the EGS system were to replicate the existing chiller plant, a side stream of the separated steam generated in the cyclone separator would be needed to drive the steam turbine-compressor sets. However, we think it is more practical for the EGS system to provide sufficient electricity from its steam turbine-generator to supply electric motors to power the chiller compressors.

Another innovation that fits the new EGS system is to retrofit the campus to meet the heating and space cooling needs with ground-source heat pumps (GSHP). In the long-range view of this assessment, it will be beneficial to use GSHPs for space conditioning and to use electricity to drive the compressors. 


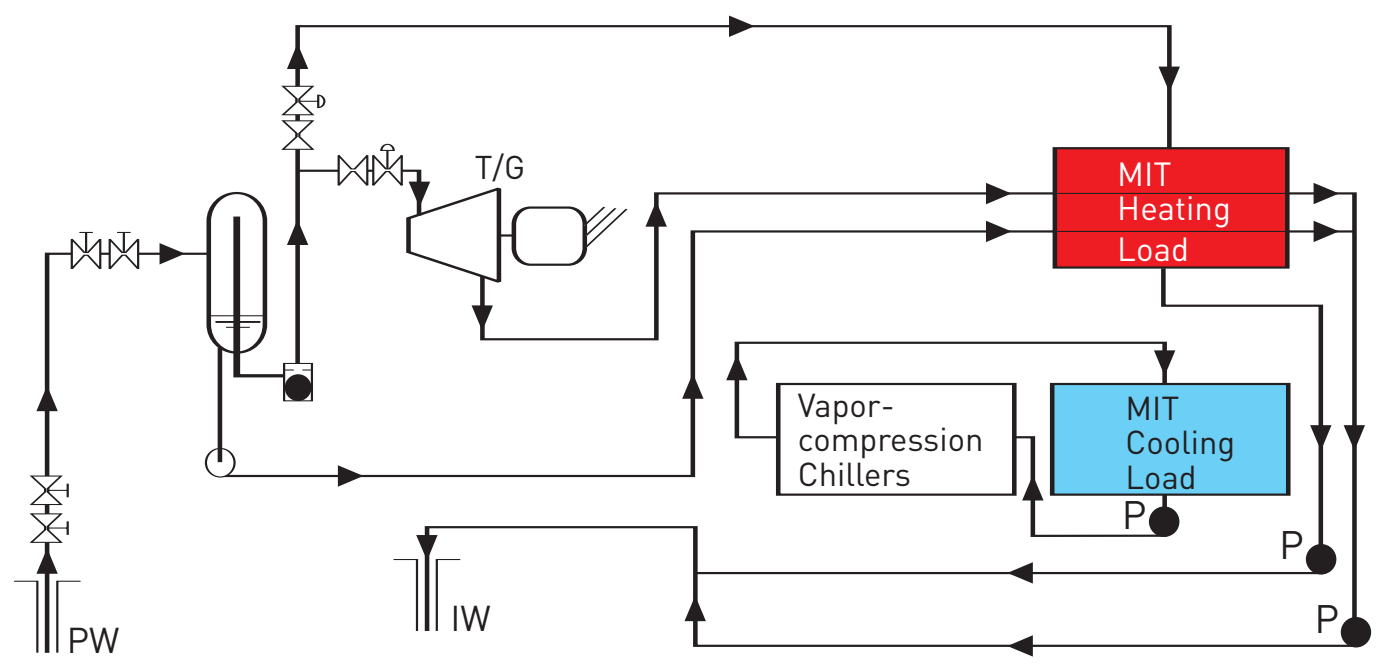

Figure 7.19 EGS system to supply MIT-COGEN energy requirements.

Switzerland, a non-hydrothermal country that is using GSHPs very extensively and effectively, is an example of what can be done with this technology. In 2004, Switzerland had 585 MWth of direct geothermal heating and cooling installed. Most of this, 91.I\%, is in GSHPs, either earth- or watercoupled and geostructures, e.g., building foundation piles. The country produced I,I9O GWh of energy from their geothermal energy, enough to displace ı००,००० toe (tonnes of oil equivalent) and 300,000 tonnes of carbon dioxide (Rybach and Gorhan, 2005). With more than 25,000 GSHP units installed and an annual growth of about $15 \%$ (Curtis et al., 2005), it is evident that GSHPs are an attractive and economic method of providing indoor climate control in a country not endowed with conventional high-temperature hydrothermal resources.

In the case of the MIT campus, the EGS system may be used in conjunction with ground-source heat pumps to provide all the heating and cooling needs (see Figure 7.20). The EGS system shown still allows for some direct heating using the back-pressure exhaust steam from the main turbine for those applications where steam is essential. In practice, these heating needs might be taken care of using steam bled from an appropriate stage of the turbine. Furthermore, because it is highly desirable to return the spent geofluid to the injection wells as cold as possible (to enhance the gravity-head flow effect), we still will use the liquid from the cyclone separator to meet some campus heating needs. 


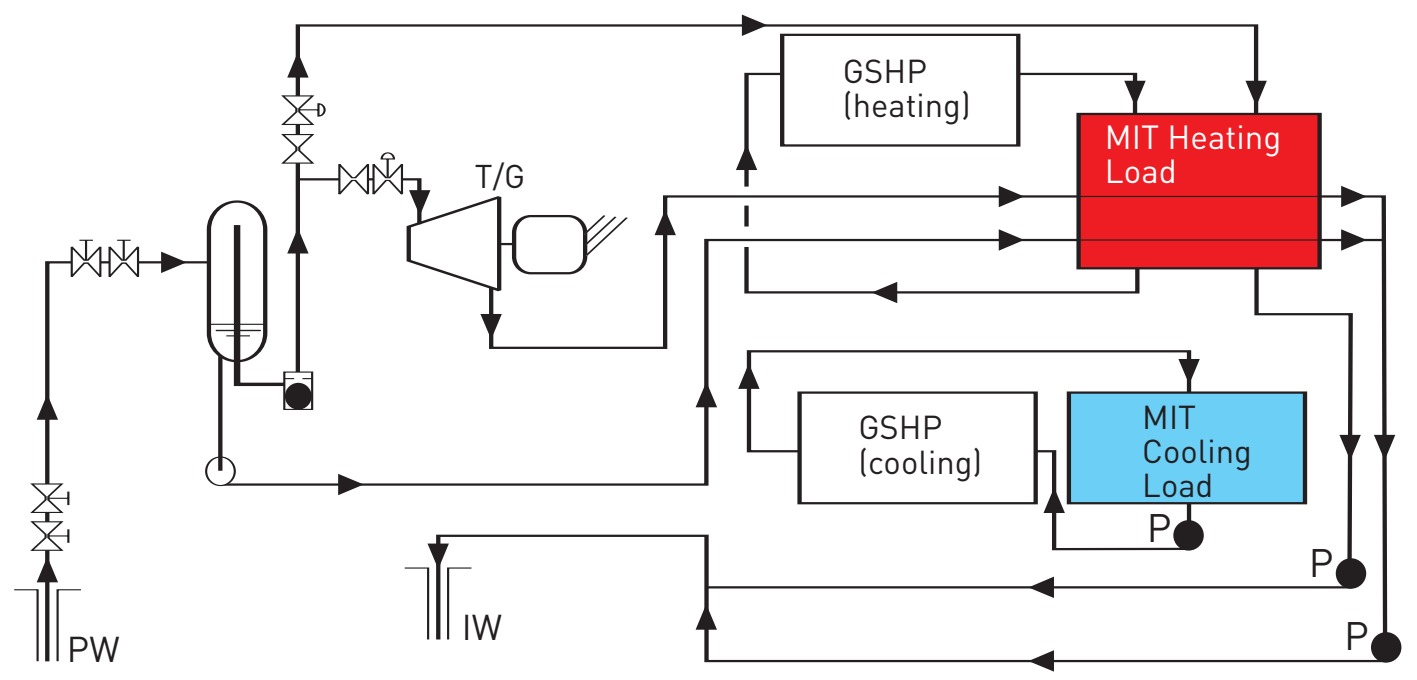

Figure 7.20 EGS system to supply MIT-COGEN energy requirements using ground-source heat pumps.

The EGS version of the COGEN plant will be as flexible as possible to accommodate varying electrical, heating, and cooling loads. However, for this analysis, it is assumed that the electrical load is a nominal $22 \mathrm{MW}$ - the total heating load requires $2 \mathrm{I} \mathrm{kg} / \mathrm{s}$ of steam at $\mathrm{I} .48 \mathrm{MPa}$ and $227^{\circ} \mathrm{C}$, and the cooling load is 5,000 tons of refrigeration or $17,500 \mathrm{kWth}$. The steam condensate returns saturated at about $109^{\circ} \mathrm{C}$; thus, the heating load is roughly $50,700 \mathrm{kWth}$.

To find the electricity needed to drive the compressors of the GSHPs, we assumed that the COP is 5.0 in the heating mode and 7.3 in the cooling mode (U.S. DOE, 2005). Thus, on these bases, the electrical input would be IO,I40 kWe to power the GSHP heating system, and 2,400 kWe to power the cooling plant. The base electric power requirement of $22 \mathrm{MW}$ must be added to these, giving a total electrical output from the EGS-driven turbine-generator of 32.I MW. This would require a mass flow rate of about $470 \mathrm{~kg} / \mathrm{s}$ from an EGS reservoir having a temperature of $250^{\circ} \mathrm{C}$, assuming a backpressure turbine is used with a double-flash system. The required fluid flow rate might be somewhat lower if a condensing, extraction turbine is used, but we did not perform the engineering analysis to assess this possibility.

The type of system described here for the MIT situation can be used as a model for other similar applications. It can accommodate other direct-heat uses such as the processing of agricultural products such as foodstuffs and biomass, or in aquaculture, because only low- to moderate-temperature fluids are needed. Applications of this kind are common at existing hydrothermal plants around the world (Lund, 2005), and would make sense for power plants operating on EGS-derived fluids. 


\subsection{Plant Operational Parameters}

Power plants operating on EGS-derived geofluids will be subject to the same kind of operating and performance metrics as those at conventional hydrothermal resources. However, because the EGS fluids are "pure" water to start with at the injection wells, and are recirculated after production, it is expected that they will be far less aggressive than typical hydrothermal fluids. This should minimize the problems often seen regarding chemical scaling, corrosion, and noncondensable gases found in some natural hydrothermal power plants where methods already exist for coping with all of these potential problems. Nevertheless, the EGS fluids may have much higher pressures than those seen at hydrothermal plants, even supercritical pressures, which already have been discussed. These

conditions, when combined with very high temperatures, will need to be accounted for in the field piping and plant design.

The analysis presented here presumes that the properties of the EGS circulating fluid remain constant. Because this is unlikely to be true over the expected lifetime of a plant, it may be necessary to modify the plant components to maintain the power output, unless replacement wells are able to restore the initial fluid conditions. This problem is routinely encountered in current geothermal plants, both flash-steam and binary, and the methods used would apply to the EGS plants.

The general finding is that no insurmountable difficulties are expected on the power-generation side of an EGS operation.

\subsection{Summary and Conclusions}

In this section, we have shown that:

- Energy conversion systems exist for use with fluids derived from EGS reservoirs.

- Conventional geothermal power plant techniques are available to cope with changing properties of the fluids derived from EGS reservoirs.

- It is possible to generate roughly 6,000 MW of electricity from fluids that are currently being coproduced from oil and gas operations in the United States by using standard binary-cycle technology.

- Power plant capital costs for coproduced fluids range from about $\$ \mathrm{I}, 500-2,300 / \mathrm{kW}$, depending on the temperature of the coproduced fluids.

- If a mass flow rate of $20 \mathrm{~kg} / \mathrm{s}$ can be sustained from a $200^{\circ} \mathrm{C}$ EGS reservoir, approximately I MW of power can be produced; the same power can be achieved from a $250^{\circ} \mathrm{C}$ EGS reservoir, with only about $8.5 \mathrm{~kg} / \mathrm{s}$.

- Supercritical fluids from an EGS reservoir can be used in a triple-expansion power plant. About I5 kg/s will yield about Io MW of power from fluids at $400^{\circ} \mathrm{C}$ and pressures in the range of 25$27 \mathrm{MPa}$; power plant thermal efficiencies will be about 31\%.

- Supercritical fluids from an EGS reservoir at very high pressures up to $35 \mathrm{MPa}$ and $400^{\circ} \mathrm{C}$ can be used in a single-expansion power plant to generate Io MW of power from flow rates of $2 \mathrm{I}-30 \mathrm{~kg} / \mathrm{s}$, depending on the fluid pressure. 
- Fluids derived from EGS reservoirs can be used in innovative cogeneration systems to provide electricity, heating, and cooling in conjunction with ground-source heat pumps. For example, the current MIT energy needs could be met with an EGS power plant with a $32 \mathrm{MW}$ rating; this could be achieved with a flow rate of $1,760 \mathrm{~kg} / \mathrm{s}$ from a $200^{\circ} \mathrm{C}$ EGS reservoir using a single-flash system - or a $470 \mathrm{~kg} / \mathrm{s}$ flow rate from a $250^{\circ} \mathrm{C}$ EGS reservoir using a double-flash system - and backpressure turbines.

- The installed specific cost $(\$ / \mathrm{kW})$ for either a conventional I- or 2 -flash power plant at EGS reservoirs is inversely dependent on the fluid temperature and mass flow rate. Over the range from $150-340^{\circ} \mathrm{C}$ : For a mass flow rate of $100 \mathrm{~kg} / \mathrm{s}$, the specific cost varies from $\$ 1,894-\mathrm{I}, 773 / \mathrm{kW}$ (I-flash) and from $\$ \mathrm{I}, 889$-I,737/kW (2-flash); for a flow rate of I,000 kg/s, the cost varies from \$I,760-I,080/kW (I-flash) and from \$I,7I8-98I/kW (2-flash).

- The total plant cost, exclusive of wells, for a 2 -flash plant receiving I,000 kg/s from an EGS reservoir would vary from $\$ 50$ million to $\$ 260$ million, with a fluid temperature ranging from $150-340^{\circ} \mathrm{C}$; the corresponding power rating would vary from about $30-265 \mathrm{MW}$. If the reservoir were able to supply only roo $\mathrm{kg} / \mathrm{s}$, the plant cost would vary from $\$ 5.6$ million to $\$ 45.8$ million over the same temperature range; the corresponding power rating would vary from 3-26.4 MW.

It should be noted that the possibility of using supercritical-pressure carbon dioxide as the circulating fluid in the EGS reservoir, alluded to in other parts of this report, has not been analyzed in this chapter. The use of $\mathrm{CO}_{2}$ as the heat-transfer medium raises a number of complex questions, the resolution of which lies beyond the scope of this report. The reader may consult Brown (2000) for an excellent discussion of this concept. 


\section{References}

Brown, D.W. 2000. "A Hot Dry Rock Geothermal Energy Concept Utilizing Supercritical CO2 Instead of Water," Proc. Twenty-Fifth Workshop on Geothermal Reservoir Engineering, Stanford University, Stanford, Calif., Jan. 24-26, 2000, SGP-TR-165.

Campbell, R.G. and M.M. Hatter. I99I. "Design and Operation of a Geopressured-Geothermal Hybrid Cycle Power Plant,” Final Report Vol. I, I8o pp. and Vol. II, I72 pp.; Eaton Operating Company Inc. and United States Department of Energy, The Ben Holt Co., DOE contract DE-ACO7-85IDi2578.

Cooper, P. 2005. Peter Cooper, Manager of Sustainable Engineering/Utility Planning, MIT, personal communication, December 8.

Curtis, R., J. Lund, B. Sanner, L. Rybach, and G. Hellstrom. 2005. "Ground Source Heat Pumps Geothermal Energy for Anyone, Anywhere: Current Worldwide Activity," Proc. World Geothermal Congress, Antalya, Turkey, April 24-29.

DiPippo, R. 2004. "Second Law Assessment of Binary Plants for Power Generation from LowTemperature Geothermal Fluids," Geothermics, V. 33, pp. 565-586.

DiPippo, R. 2005. Geothermal Power Plants: Principles, Applications and Case Studies, Elsevier Advanced Technology, Oxford, England.

DOGGR. 2005. 2004 Annual Report of the State Oil \& Gas Supervisor, California Department of Conservation, Div. of Oil, Gas, and Geothermal Resources, Sacramento, p. I97.

El Wakil, M.M. I984. Powerplant Technology, McGraw-Hill, New York, pp. 7I-72.

Griggs, J. 2004. "A Re-Evaluation of Geopressured-Geothermal Aquifers as an Energy Resource," Masters Thesis, Louisiana State University, The Craft and Hawkins Dept. of Petroleum Engineering, Baton Rouge, La., August 2004.

Lund, J.W. 2005. "Worldwide Utilization of Geothermal Energy - 2005," GRC Transactions, V. 29, pp. $83 \mathrm{I}-836$.

McKenna, J.R. and D.D. Blackwell. 2005. "Geothermal Electric Power From Texas Hydrocarbon Fields,” GRC BULLETIN, May/June, pp. I2I-I28.

McKenna, J.R., D.D. Blackwell, C. Moyes, and P.D. Patterson. 2005. "Geothermal Electric Power Supply Possible From Gulf Coast, Midcontinent Oil Field Waters,” Oil a Gas Journal, Sept. 5, pp. 34-40.

Moran, M.J. and H.N. Shapiro. 2004. Fundamentals of Engineering Thermodynamics, 5th Ed., John Wiley \& Sons, Hoboken, NJ.

Myers, J.E., L.M. Jackson, R.F. Bernier, and D.A. Miles. 200I. "An Evaluation of the Department of Energy Naval Petroleum Reserve No. 3 Produced Water Bio-Treatment Facility," SPA/EPA/DOE Exploration and Production Environmental Conference, Paper No. SPE 66522, San Antonio, Texas, February 200I.

Rybach, L. and H.L. Gorhan. 2005. "2005 Update for Switzerland,” Proc. World Geothermal Congress, Antalya, Turkey, April 24-29. 
Sanyal, S.K. 2005. "Levelized Cost of Geothermal Power - How Sensitive Is It?" GRC Transactions, V. 29, pp. 459-465.

Swanson, R.K. I980. “Geopressured Energy Availability,” Final Report, EPRI AP-I457, Electric Power Research Institute, Palo Alto, Calif.

U.S. DOE, 2005. "How to Buy an Energy-Efficient Ground Source Heat Pump," http://www.eere.energy.gov/femp/technologies/eep_groundsource_heatpumps.cfm.

\section{Nomenclature (as used in figures)}

B Boiler

BCV Ball check valve

C Condenser; compressor (Fig. 7.I8); Celsius (throughout)

CC Combustion chamber

CP Condensate pump

CS Cyclone separator

CSV Control and stop valves

CT Cooling tower

CW Cooling water

CWP Cooling water pump

E Evaporator

EC Economizer

F Flash vessel

FF Final filter

G Generator

HPP High-pressure pump

HPT High-pressure turbine

HRSG Heat-recovery steam generator

$7-32$

IP Injection pump

IW Injection well

LPP Low-pressure pump

LPT Low-pressure turbine

M Make-up water

MR Moisture remover

P Pump

PH Preheater

PW Production well

S Silencer

SE/C Steam ejector/condenser

SH Superheater

SP Steam piping

SPT Super-pressure turbine

SR Sand remover

$\mathrm{T}$ Turbine

T/G Turbine/generator

TV Throttle valve

WP Water piping

WV Wellhead valve 


\section{CHAPTER 8}

\section{Environmental Impacts, Attributes, and Feasibility Criteria}

8.1 Scope and Approach to Geothermal Environmental Effects _

8.2 Potential Environmental Impacts from Geothermal Development

8.2.1 Gaseous emissions _-_-

8.2.2 Water pollution

8.2.3 Solids emissions

8.2.4 Noise pollution

8.2.5 Land use

8.2.6 Land subsidence

8.2.7 Induced seismicity

8.2.8 Induced landslides

8.2.9 Water use

8.2.10 Disturbance of natural hydrothermal manifestations _

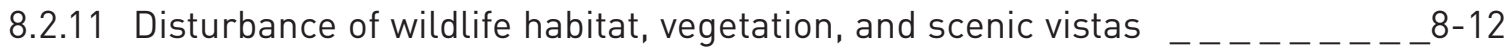

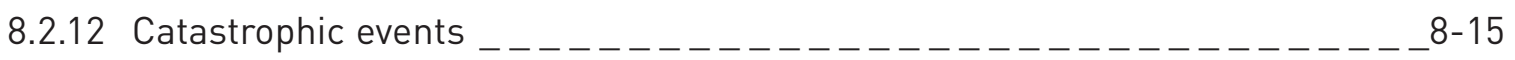

8.2.13 Thermal pollution

8.3 Environmental Attributes of EGS Power Projects _ _ _ _ _ _ _ _ _ _ _ $8-16$

8.3.1 No greenhouse gas emissions during operations _ $\ldots \ldots \ldots \ldots \ldots \ldots \ldots-\ldots-16$

8.3.2 Modest use of land

8.3.3 Possible sequestration of carbon dioxide _.

8.3.4 Low overall environment impact

8.4 Environmental Criteria for Project Feasibility _

8.5 Concluding Remarks _

References 


\subsection{Scope and Approach to Geothermal Environmental Effects}

In the United States, the environmental impact of any type of power project is subject to many forms of regulation. All of the following laws and regulations play a role before any geothermal development project can be brought to fruition (Kagel et al., 2005):

- Clean Air Act

- National Environmental Policy Act

- National Pollutant Discharge Elimination System Permitting Program

- Safe Drinking Water Act

- Resource Conservation and Recovery Act

- Toxic Substance Control Act

- Noise Control Act

- Endangered Species Act

- Archaeological Resources Protection Act

- Hazardous Waste and Materials Regulations

- Occupational Health and Safety Act

- Indian Religious Freedom Act.

Thus, it is highly unlikely that any geothermal power plant will be a threat to the environment anywhere in the United States, given the comprehensive spectrum of regulations that must be satisfied.

The potential environmental impacts of conventional hydrothermal power generation are widely known. Several articles and reports have documented the various potential impacts from geothermal dry-steam, flash-steam, and binary energy conversion systems. The general conclusion from all studies is that emissions and other impacts from geothermal plants are dramatically lower than other forms of electrical generation. The following references, chosen from among many possible ones, provide detailed discussions: Armstead, I983; Armstead and Tester, I987; Burnham et al., I993; DiPippo, I99ıа; DiPippo, I99ıb; Kagel et al., 2005; Mock et al., I997; Pasqualetti, I980; and Tester et al., 2005.

Thus, the lessons learned from the hundreds of existing geothermal power plants can be used to ensure that future EGS systems will have similar or even lower environmental impacts.

Our focus in this report is on systems to generate electricity. Ground-source heat pumps are another means of utilizing geothermal energy on a distributed basis for space heating and cooling of buildings (see Section 7.3). The environmental impact of such systems is quite limited because they are usually installed during building construction and normally utilize a subsurface heat exchanger, buried well below the frost line. The environmental impacts of geothermal heat pumps are not addressed further, because they are beyond the scope of this study (see Mock et al., I997.) 
There are several potential environmental impacts from any geothermal power development. These include:

- Gaseous emissions

- Water pollution

- Solids emissions

- Noise pollution

- Land use

- Land subsidence

- Induced seismicity

- Induced landslides

- Water use

- Disturbance of natural hydrothermal manifestations

- Disturbance of wildlife habitat and vegetation

- Altering natural vistas

- Catastrophic events.

Despite this long list, current and near-term geothermal energy technologies generally present much lower overall environmental impact than do conventional fossil-fueled and nuclear power plants. For example, the power plant is located above the geothermal energy resource eliminating the need (a) to physically mine the energy source (the "fuel") in the conventional sense and, in the process, to disturb the Earth's surface, and (b) to process the fuel and then use additional energy to transport the fuel over great distances while incurring additional environmental impacts. Furthermore, the geothermal energy conversion equipment is relatively compact, making the overall footprint of the entire system small. With geothermal energy, there are no atmospheric discharges of nitrogen oxides or particulate matter, and no need to dispose of radioactive waste materials.

There are, however, certain impacts that must be considered and managed if geothermal energy, including EGS, is to be developed as a larger part of a more environmentally sound, sustainable energy portfolio for the future. Most of the potentially important environmental impacts of geothermal power plant development are associated with ground water use and contamination, and with related concerns about land subsidence and induced seismicity as a result of water injection and production into and out of a fractured reservoir formation. Issues of air pollution, noise, safety, and land use also merit consideration.

The next section presents a comprehensive overview of environmental issues, summarizes the body of experience from hydrothermal plants, contrasts geothermal operations with alternative systems, and estimates the impact from EGS operations. 


\subsection{Potential Environmental Impacts from Geothermal Development}

\subsubsection{Gaseous emissions}

Gaseous emissions result from the discharge of noncondensable gases (NCGs) that are carried in the source stream to the power plant. For hydrothermal installations, the most common NCGs are carbon dioxide $\left(\mathrm{CO}_{2}\right)$ and hydrogen sulfide $\left(\mathrm{H}_{2} \mathrm{~S}\right)$, although species such as methane, hydrogen, sulfur dioxide, and ammonia are often encountered in low concentrations. In the United States, emissions of $\mathrm{H}_{2} \mathrm{~S}$ - distinguished by its "rotten egg" odor and detectable at 30 parts per billion - are strictly regulated by the Environmental Protection Agency (EPA) to avoid adverse impacts on plant and human life. We expect that for most EGS installations, there will be lower amounts of dissolved gases than are commonly found in hydrothermal fluids. Consequently, impacts would be lower and may not even require active treatment and control. Nonetheless, for completeness, we review here the situation encountered today for managing gaseous emissions from hydrothermal plants.

Emissions are managed through process design. In steam and flash plants, naturally occurring NCGs in the production fluid must be removed to avoid the buildup of pressure in the condenser and the resultant loss in power from the steam turbine (see Figures 7.5 and 7.6). The vent stream of NCGs can be chemically treated and/or scrubbed to remove $\mathrm{H}_{2} \mathrm{~S}$, or the NCGs can be recompressed and injected back into the subsurface with the spent liquid stream from the power plant. Both of these solutions require power, thereby increasing the parasitic load and reducing the plant output and efficiency. Binary plants avoid this problem because such plants only recover heat from the source fluid stream by means of a secondary working fluid stream. The source geofluid stream is reinjected without releasing any of the noncondensables.

The selection of a particular $\mathrm{H}_{2} \mathrm{~S}$ cleanup process from many commercially available ones will depend on the specific amounts of contaminants in the geofluid stream and on the established gaseous emissions standards at the plant site.

So far in the United States, there are no standards to be met for the emission of $\mathrm{CO}_{2}$ because the United States has not signed the Kyoto agreement. Nevertheless, geothermal steam and flash plants emit much less $\mathrm{CO}_{2}$ on an electrical generation basis (per megawatt-hour) than fossil-fueled power plants, and binary plants emit essentially none. The concentrations of regulated pollutants - nitrogen oxide (NOx) and sulfur dioxide $\left(\mathrm{SO}_{2}\right)$ - in the gaseous discharge streams from geothermal steam and flash plants are extremely minute. Table 8. I shows a comparison of typical geothermal plants with other types of power plants (Kagel et al., 2005).

The data indicate that geothermal plants are far more environmentally benign than the other conventional plants. It should be noted that the NOx at The Geysers comes from the combustion process used to abate $\mathrm{H}_{2} \mathrm{~S}$ in some of the plants; most geothermal steam plants do not rely on combustion for $\mathrm{H}_{2} \mathrm{~S}$ abatement and therefore emit no NOx at all. 
Table 8.1 Gaseous emissions from various power plants.

\begin{tabular}{|c|c|c|c|c|}
\hline Plant type & $\begin{array}{l}\mathrm{CO}_{2} \\
\mathrm{~kg} / \mathrm{MWh}\end{array}$ & $\begin{array}{l}\mathrm{SO}_{2} \\
\mathrm{~kg} / \mathrm{MWh}\end{array}$ & $\begin{array}{l}\mathrm{NO}_{\mathrm{x}} \\
\mathrm{kg} / \mathrm{MWh}\end{array}$ & $\begin{array}{l}\text { Particulates } \\
\mathrm{kg} / \mathrm{MWh}\end{array}$ \\
\hline Coal-fired & 994 & 4.71 & 1.955 & 1.012 \\
\hline Oil-fired & 758 & 5.44 & 1.814 & N.A. \\
\hline Gas-fired & 550 & 0.0998 & 1.343 & 0.0635 \\
\hline $\begin{array}{l}\text { Hydrothermal - flash-steam, } \\
\text { liquid dominated }\end{array}$ & 27.2 & 0.1588 & 0 & 0 \\
\hline $\begin{array}{l}\text { Hydrothermal - The Geysers dry } \\
\text { steam field }\end{array}$ & 40.3 & 0.000098 & 0.000458 & negligible \\
\hline Hydrothermal - closed-loop binary & 0 & 0 & 0 & negligible \\
\hline EPA average, all U.S. plants & 631.6 & 2.734 & 1.343 & N.A. \\
\hline
\end{tabular}

N.A. = not available

\subsubsection{Water pollution}

Liquid streams from well drilling, stimulation, and production may contain a variety of dissolved minerals, especially for high-temperature reservoirs $\left(>230^{\circ} \mathrm{C}\right)$. The amount of dissolved solids increases significantly with temperature. Some of these dissolved minerals (e.g., boron and arsenic) could poison surface or ground waters and also harm local vegetation. Liquid streams may enter the environment through surface runoff or through breaks in the well casing. Surface runoff is controlled by directing fluids to impermeable holding ponds and by injection of all waste streams deep underground. To guard against fluids leaking into shallow fresh-water aquifers, well casings are designed with multiple strings to provide redundant barriers between the inside of the well and the adjacent formation. Nevertheless, it is important to monitor wells during drilling and subsequent operation, so that any leakage through casing failures can be rapidly detected and managed.

In principle, EGS operations are subject to the same possibility for subsurface contamination through casing defects, but there is little chance for surface contamination during plant operation because all the produced fluid is reinjected. Of course, a catastrophic failure of a surface pipeline could lead to contamination of a limited area until isolation valves are activated and seal off the affected pipeline.

\subsubsection{Solids emissions}

There is practically no chance for contamination of surface facilities or the surrounding area by the discharge of solids per se from the geofluid. The only conceivable situation would be an accident associated with a fluid treatment or minerals recovery system that somehow failed in a catastrophic manner and spewed removed solids onto the area. There are no functioning mineral recovery facilities of this type at any geothermal plant - although one was piloted for a short time near the Salton Sea in southern California - and it is not envisioned that any such facility would be associated with an EGS plant. Precautions, however, would need to be in place should the EGS circulating fluid require chemical treatment to remove dissolved solids, which could be toxic and subject to regulated disposal and could plug pathways in the reservoir. 


\subsubsection{Noise pollution}

Noise from geothermal operations is typical of many industrial activities (DiPippo, I99Ia). The highest noise levels are usually produced during the well drilling, stimulation, and testing phases when noise levels ranging from about 80 to II5 decibels A-weighted (dBA) may occur at the plant fence boundary. During normal operations of a geothermal power plant, noise levels are in the 7I to 83 decibel range at a distance of $900 \mathrm{~m}$ (DiPippo, 2005). Noise levels drop rapidly with distance from the source, so that if a plant is sited within a large geothermal reservoir area, boundary noise should not be objectionable. If necessary, noise levels could be reduced further by the addition of mufflers or other soundproofing means but at added cost. For comparison, congested urban areas typically have noise levels of about 70 to 85 decibels, and noise levels next to a major freeway are around 90 decibels. A jet plane just after takeoff produces noise levels of about i2o to I30 decibels.

During normal operations, there are three main sources of noise: the transformer, the power house, and the cooling tower. Because the latter is a relatively tall structure and the noise emanates from the fans that are located at the top, these can be the primary source of noise during routine operation. Aircooled condensers employ numerous cells, each fitted with a fan, and are worse from a noise perspective than water cooling towers, which are smaller and use far fewer cells for a given plant rating.

Because EGS plants will likely be located in regions where water may be in short supply, they may require air-cooling, and proper attention may be needed to muffle the sound from their air-cooled condensers.

\subsubsection{Land use}

Land footprints for hydrothermal power plants vary considerably by site because the properties of the geothermal reservoir fluid and the best options for waste stream discharge (usually reinjection) are highly site-specific. Typically, the power plant is built at or near the geothermal reservoir because long transmission lines degrade the pressure and temperature of the geofluid. Although well fields can cover a considerable area, typically 5 to Io $\mathrm{km}^{2}$ or more, the well pads themselves will only cover about $2 \%$ of the area. With directional-drilling techniques, multiple wells can be drilled from a single pad to minimize the total wellhead area.

Gathering pipelines are usually mounted on stanchions, so that most of the area could be used for farming, pasture, or other compatible use (see Figure 8.I). The footprint of the power plant, cooling towers, and auxiliary buildings and substation is relatively modest. Holding ponds for temporary discharges (during drilling or well stimulation) can be sizeable but represent only a small fraction of the total well field. 


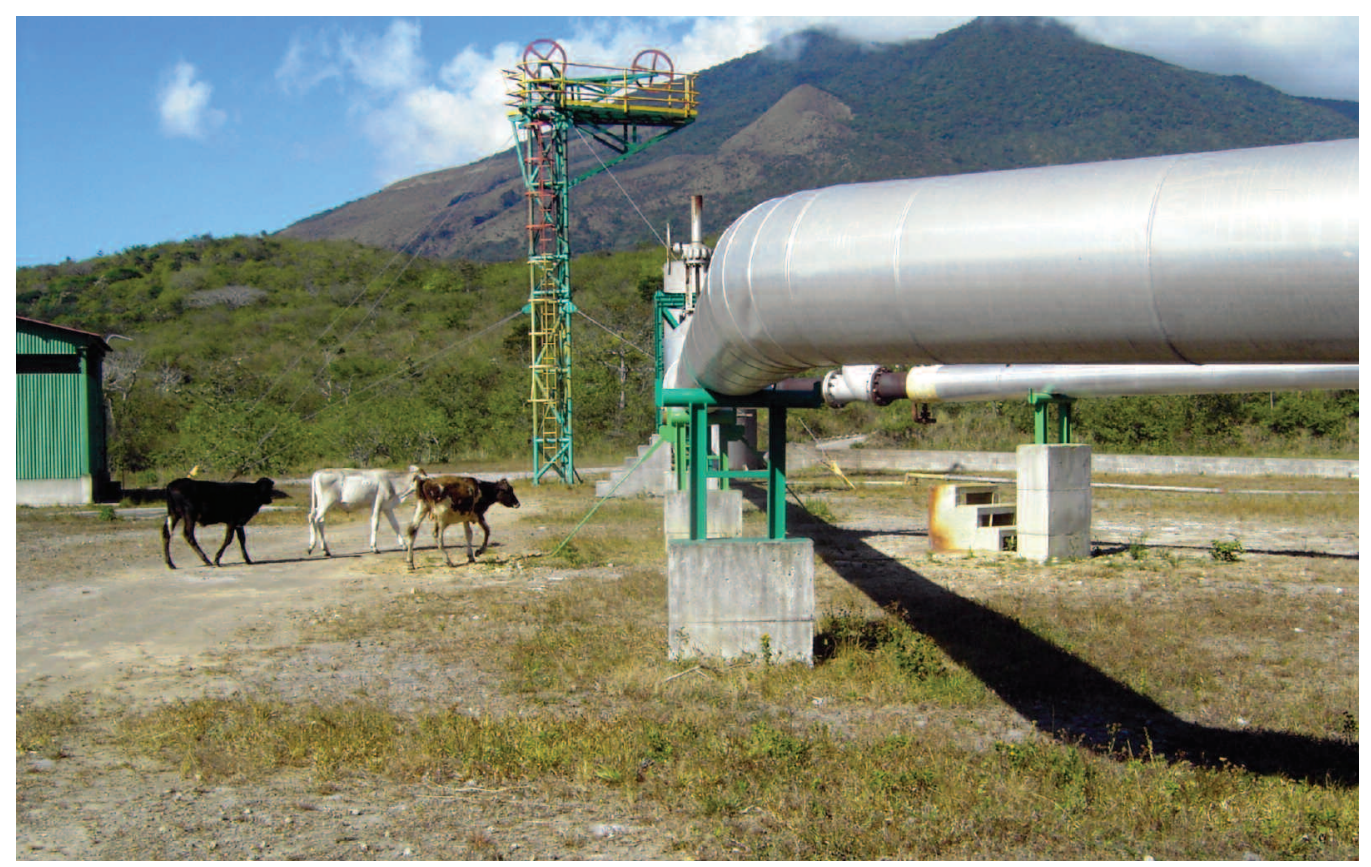

Figure 8.1 Typical pipeline at Miravalles geothermal power plant, Costa Rica (photo by R. DiPippo).

A comparison of land uses for typical geothermal flash and binary plants with those of coal and solar photovoltaic plants is presented in Table 8.2 using data from DiPippo (I99rb).

Table 8.2 Comparison of land requirements for typical power generation options.

\begin{tabular}{l|r|r}
\hline Technology & $\begin{array}{r}\text { Land use } \\
\mathrm{m}^{2} / \mathrm{MW}\end{array}$ & $\begin{array}{r}\text { Land use } \\
\mathrm{m}^{2} / \mathrm{GWh}\end{array}$ \\
\hline $110 \mathrm{MW}$ geothermal flash plant (excluding wells) & 1,260 & 160 \\
\hline $20 \mathrm{MW}$ geothermal binary plant (excluding wells) & 1,415 & 170 \\
\hline $49 \mathrm{MW}$ geothermal FC-RC plant ${ }^{(1)}$ (excluding wells) & 2,290 & 290 \\
\hline $56 \mathrm{MW}$ geothermal flash plant (including wells, ${ }^{(2)}$ pipes, etc.) & 7,460 & 900 \\
\hline $2,258 \mathrm{MW}$ coal plant (including strip mining) & 40,000 & 5,700 \\
\hline $670 \mathrm{MW}$ nuclear plant (plant site only) & 10,000 & 1,200 \\
\hline $47 \mathrm{MW}$ lavg) solar thermal plant (Mojave Desert, CA) & 28,000 & 3,200 \\
\hline $10 \mathrm{MW}$ lavg) solar PV plant ${ }^{(3)}$ (Southwestern US) & 66,000 & 7,500 \\
\hline
\end{tabular}

(1) Typical Flash-Crystallizer/Reactor-Clarifier plant at Salton Sea, Calif.

(2) Wells are directionally drilled from a few well pads.

(3) New land would not be needed if, for example, rooftop panels were deployed in an urban setting.

These data incorporate realistic capacity factors for each technology. Note that average power outputs, not rated values, were used for the solar plants. A solar-thermal plant requires about 20 times more area than a geothermal flash or binary plant; and a solar photovoltaic plant (in the best insolation area in the United States) requires about 50 times more area than a flash or binary plant per MW. The ratios are similar on a per MWh basis. The coal plant, including 30 years of strip mining, requires 
between 30-35 times the surface area for a flash or binary plant, on either a per MW or MWh basis. The nuclear plant occupies about seven times the area of a flash or binary plant. The land use for geothermal plants having hypersaline brines is about $75 \%$ greater than either simple flash or binary because of the large vessels needed to process the brine.

EGS plants are expected to conform more closely to the conventional geothermal flash and binary plants because of the relatively benign chemical nature of the circulating fluids. See Section 8.2.II for further discussion of land use.

\subsubsection{Land subsidence}

If geothermal fluid production rates are much greater than recharge rates, the formation may experience consolidation, which will manifest itself as a lowering of the surface elevation, i.e., this may lead to surface subsidence. This was observed early in the history of geothermal power at the Wairakei field in New Zealand where reinjection was not used. Subsidence rates in one part of the field were as high as $0.45 \mathrm{~m}$ per year (Allis, I990). Wairakei used shallow wells in a sedimentary basin. Subsidence in this case is very similar to mining activities at shallow depths where raw minerals are extracted, leaving a void that can manifest itself as subsidence on the surface. After this experience, other geothermal developments adopted actively planned reservoir management to avoid this risk.

Most of EGS geothermal developments are likely to be in granitic-type rock formations at great depth, which may contain some water-filled fractures within the local stress regime at this depth. After a geothermal well is drilled, the reservoir is stimulated by pumping high-pressure water down the well to open up existing fractures (joints) and keep them open by relying on the rough surface of the fractures. Because the reservoir is kept under pressure continuously, and the amount of fluid in the formation is maintained essentially constant during the operation of the plant, the usual mechanism causing subsidence in hydrothermal systems is absent and, therefore, subsidence impacts are not expected for EGS systems.

\subsubsection{Induced seismicity}

Induced seismicity in normal hydrothermal settings has not been a problem because the injection of waste fluids does not require very high pressures. However, the situation in the case of many EGS reservoirs will be different and requires serious attention. Induced seismicity continues to be under active review and evaluation by researchers worldwide. Annual workshops have been held recently to discuss current results (see, e.g., Majer and Baria, 2006).

The process of opening fractures can occur in a sliding manner by shear failure or in extensional manner by tensile failure. In either case, acoustic noise is generated during this process. This acoustic noise is referred to as microseismic noise or events. The acoustic noise is monitored during the stimulation process as an EGS reservoir management tool to see how far the stimulation has opened the reservoir in three dimensions (Batchelor et al., I983; Baria et al., I985; Baria and Green, I989; Baria et al., I995; Baria, I990; Baria et al., 2005; Baria et al., 2006). This is analogous to tracking a submarine through acoustic noise patterns. The microseismic monitoring pinpoints how the pressure waves are migrating in the rock mass during the reservoir creation process. In the EGS systems studied to date (see Chapter 4) shear failure has been the dominant mechanism. 
Signatures of the microseismic events also can be used to quantify the energy radiated from the shearing of fractures, the size of the fractures, the orientation of fractures, dilation and slip of fractures, etc. This is a unique method and serves as a remote sensing technique to observe changes in the reservoir properties (stress), not just during the development of the reservoir but also during the long-term energy-extraction phase.

Typically, natural fractures vary in length on a scale of I to Io meters. Seismic energy radiated during the shearing process depends on the length of the fracture or the stress release from the constraining natural forces. A majority of the observed data from existing EGS projects suggest that the higher energy radiated from the shearing is caused by a high stress release from relatively small joint lengths (Michelet et al., 2004). This would suggest that if there were some perceived events on the surface, the frequency content would be too high to generate any seismic risk, but minor events may still raise concerns among local inhabitants.

Experience to-date suggests that an appropriate infrastructure needs to be set up to inform local residents about the program prior to the implementation of an EGS project. Planning needs to include a system where local residents are briefed on the project and are encouraged to contact a specified person on the program whose duties include answering questions and dealing responsively and sympathetically to any concerns of the local residents. Regular public meetings and arranged visits to the site from schools and interested parties are a way of enhancing acceptance of the program by local residents.

The collection of baseline data at the selected site prior to the onset of drilling is useful in separating natural from induced events. Additionally, it is prudent to instrument the site for any unexpected natural or induced felt microseismic events. A procedure also needs to be in effect to assess any effects on the public and local infrastructure. Lastly, sound geological and tectonic investigations must be carried out prior to the selection of the site to avoid the inadvertent lubrication of a major fault that could cause a significant seismic event.

\subsubsection{Induced landslides}

There have been instances of landslides at geothermal fields. The cause of the landslides is often unclear. Many geothermal fields are in rugged terrain that is prone to natural landslides, and some fields actually have been developed atop ancient landslides. Some landslides can be triggered by large earthquakes, but it is highly unlikely that geothermal production and injection could lead to such a massive event. Badly sited wells, particularly shallow injection wells, may interact with faults and cause slippage similar to what has been described in the preceding section.

Under these circumstances, it is possible for a section of a slope to give way initiating a landslide. However, such events at hydrothermal fields are rare, and proper geological characterization of the field should eliminate the possibility of such a catastrophe. EGS reservoir development should avoid areas of high landslide risk even though the chance of a catastrophic event is extremely low.

\subsubsection{Water use}

Geothermal projects, in general, require access to water during several stages of development and operation. Water use can be managed in most cases to minimize environmental impacts. Various aspects of water use in EGS projects are described below. 
Well drilling, reservoir stimulation, and circulation. Water is required during well drilling to provide bit cooling and rock chip removal. This water (actually a mixture of water and chemicals) is recirculated after being cooled and strained. Makeup water is required to compensate for evaporation losses during cooling.

It is expected that in most advanced EGS applications, surface water will be needed to both stimulate and operate the reservoir (i.e., the underground heat exchanger) and produce the circulation patterns needed. The quantity of hydrothermal fluids naturally contained in the formation is likely to be very limited, particularly in formations with low natural permeability and porosity. In the western part of the United States, where water resources are in high demand, water use for geothermal applications will require careful management and conservation practice. The water may be taken from a nearby high-flow stream or river, if available, or collected in a temporary surface reservoir during the rainy season. Sometimes, local streams may be dammed and diverted. In some EGS resource areas, water treatment will be needed to ensure sufficient quality for reinjection and reuse or to remove potentially hazardous contaminants that might be dissolved or suspended in the circulating geofluid or cooling water. It is necessary to coordinate water use during field development with other local water demands for agricultural or other purposes.

Fluids produced from the reservoir. Production of geofluids from a hydrothermal reservoir for use in power or thermal energy generation can lower the water table, adversely affect nearby geothermal natural features (e.g., geysers, springs, and spas), create hydrothermal (phreatic) eruptions, increase the steam zone, allow saline intrusions, or cause subsidence. EGS systems are designed to avoid these impacts by balancing fluid production with recharge. In principle, EGS systems may be approximated as "closed-loop" systems whereby energy is extracted from the hot fluid produced by production wells (namely, a heat exchanger for binary plants) and cooled fluid is reinjected through injection wells. However, the circulation system is not exactly closed because water is lost to the formation; this lost water must be made up from surface water supplies.

Cooling water for heat rejection. Cooling water is generally used for condensation of the plant working fluid. The waste heat can be dissipated to the atmosphere through cooling towers if makeup water is available. Water from a nearby river or other water supply can also serve as a heat sink. There are opportunities for recovering heat from these waste fluids (and possibly from the brine stream) in associated activities such as fish farms or greenhouses.

An alternative to water-cooling is the technique of air-cooling using electric motor-driven fans and heat exchangers. This approach is particularly useful where the supply of fresh water is limited, and is currently used mainly for binary power plants (see Chapter 7). While air-cooled condensers eliminate the need for fresh makeup water that would be required for wet cooling towers, they occupy large tracts of land owing to the poor heat transfer properties of air vs. water. This greatly increases the land area needed for heat rejection compared to a plant of the same power rating that uses a wet cooling tower. For example, in the case of the I5.5 MW bottoming binary plant at the Miravalles field in Costa Rica, a design comparison between a water-cooling tower and an air-cooled condenser showed that the air-cooled condenser would cost more than three times as much, weigh more than two-and-a-half times as much, cover about three times as much surface area, and consume about three times more fan power than a water-cooling tower (Moya and DiPippo, 2006). 
The environmental impacts of waste heat rejection into the atmosphere or water bodies can be minimized through intelligent design and the use of well-developed technologies; but the amount of heat that must be dissipated is controlled by the laws of thermodynamics.

\subsubsection{Disturbance of natural hydrothermal manifestations}

Although numerous cases can be cited of the compromising or total destruction of natural hydrothermal manifestations such as geysers, hot springs, mud pots, etc. by geothermal developments (Jones, 2006; Keam et al., 2005), EGS projects will generally be sited in nonhydrothermal areas and will not have the opportunity to interfere with such manifestations. For EGS facilities sited at the margins of existing hydrothermal plants where manifestations might be present, reservoir simulations should be performed to gauge the possible effects on those surface thermal features of drilling new wells and operating the EGS plant. However, because there is no "drawdown" in the traditional sense of an existing water table for an EGS system, it is unlikely that normal operations will have a significant effect on them.

\subsubsection{Disturbance of wildlife habitat, vegetation, and scenic vistas}

Problems related to loss of habitat or disturbance of vegetation are relatively minor or nonexistent at hydrothermal projects in the United States. Given the relatively small area taken out of the environment for geothermal operations, these potential impacts can be minimized with proper planning and engineering. It is difficult to imagine an EGS development causing more of an impact on wildlife and vegetation than a hydrothermal project. Furthermore, an Environmental Impact Statement must be filed before any permits can be granted for a geothermal project, and any potential impact in this area would have to be addressed.

It is undeniable that any power generation facility constructed where none previously existed will alter the view of the landscape. Urban plants, while objectionable to many for other reasons, do not stand out as abruptly as a plant in a flat agricultural region or one on the flank of a volcano. Many geothermal plants are in these types of areas, but with care and creativity can be designed to blend into the surroundings. Avoiding locations of particular natural beauty is also important, whether or not the land is nationally or locally protected. EGS developments will be no different than conventional hydrothermal plant developments, in that the design of the facility must comply with all local siting requirements.

The development of a geothermal field can involve the removal of trees and brush to facilitate the installation of the power house, substation, well pads, piping, emergency holding ponds, etc. However, once a geothermal plant is built, reforestation and plantings can restore the area to a semblance of its original natural appearance, and can serve to mask the presence of buildings and other structures. For example, Figures 8.2 and 8.3 show the Ahuachapán geothermal facility in El Salvador, soon after commissioning around I977 (DiPippo, 1978), and then after regrowth of trees and vegetation in 2005 (LaGeo, 2005). 


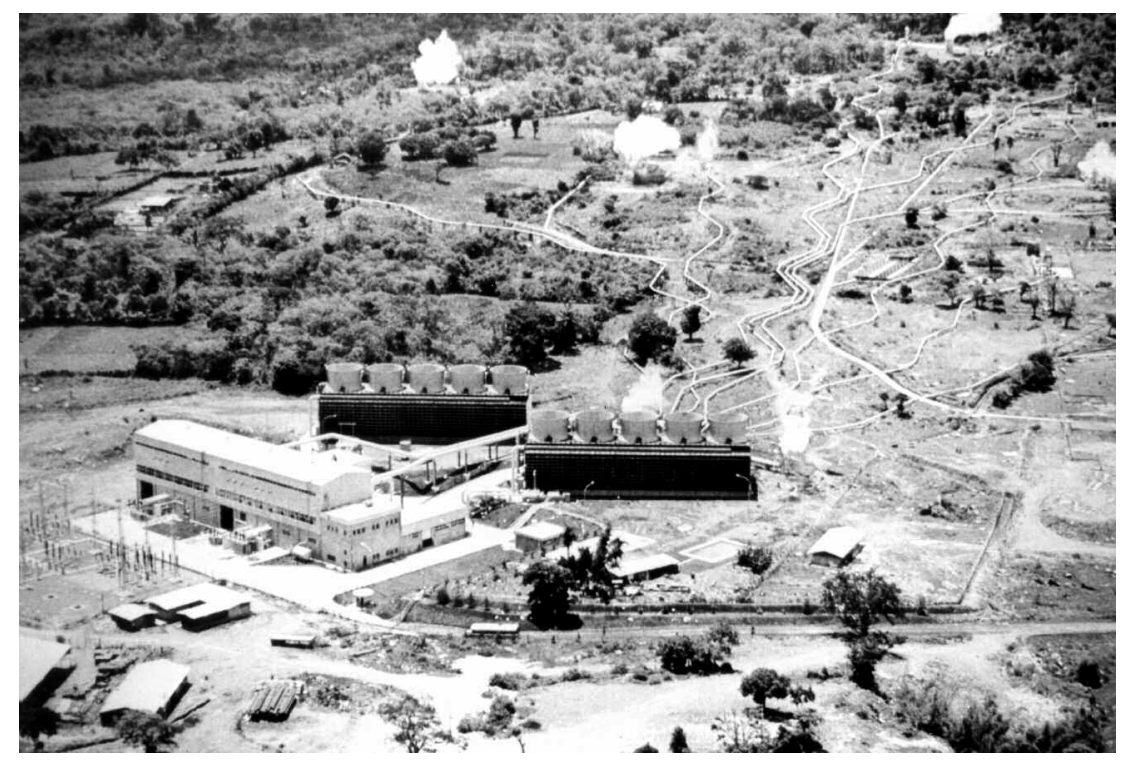

Figure 8.2 Ahuachapan geothermal facility after commissioning around 1977 (DiPippo, 1978).

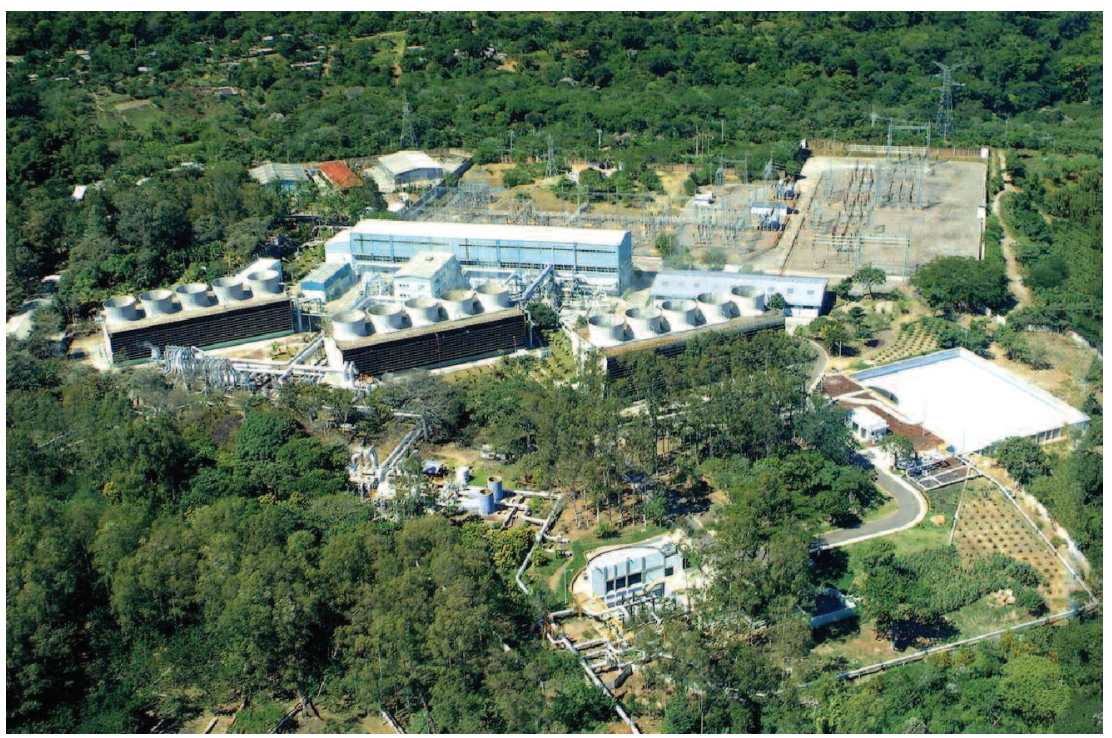

Figure 8.3 Ahuachapan geothermal facility after revegetation, circa 2005 (LaGeo, 2005).

Geothermal plants generally have a low profile and are much less conspicuous than, for example, wind turbines, solar power towers, or coal plants with chimneys as tall as I50-200 m. Buildings and pipelines can be painted appropriate colors to help conceal them from a distance. While it is impossible to conceal steam being vented from flash plants - a periodic occurrence during normal operation - most people do not object to the sight of white steam clouds in the distance. Binary plants during normal operation have no emissions whatsoever. 
There are several geothermal power plants in the Imperial Valley of California that coexist harmoniously with various agricultural activities. Figure 8.4 shows an aerial view of the 40 MW SIGC Heber binary plant amid fields of alfalfa in California's Imperial Valley (Google Earth, 2006). Notice that the plant site, including the main production well pad, covers about $0.12 \mathrm{~km}^{2}$ or about $3,000 \mathrm{~m}^{2} / \mathrm{MW}$. The power plant proper, excluding the wells, covers only $0.04 \mathrm{I} \mathrm{km}^{2}$ or about $\mathrm{I}, 020 \mathrm{~m}^{2} / \mathrm{MW}$. The barren land to the south of the plant site was the location of an older experimental binary plant that has been decommissioned (DiPippo, 2005).

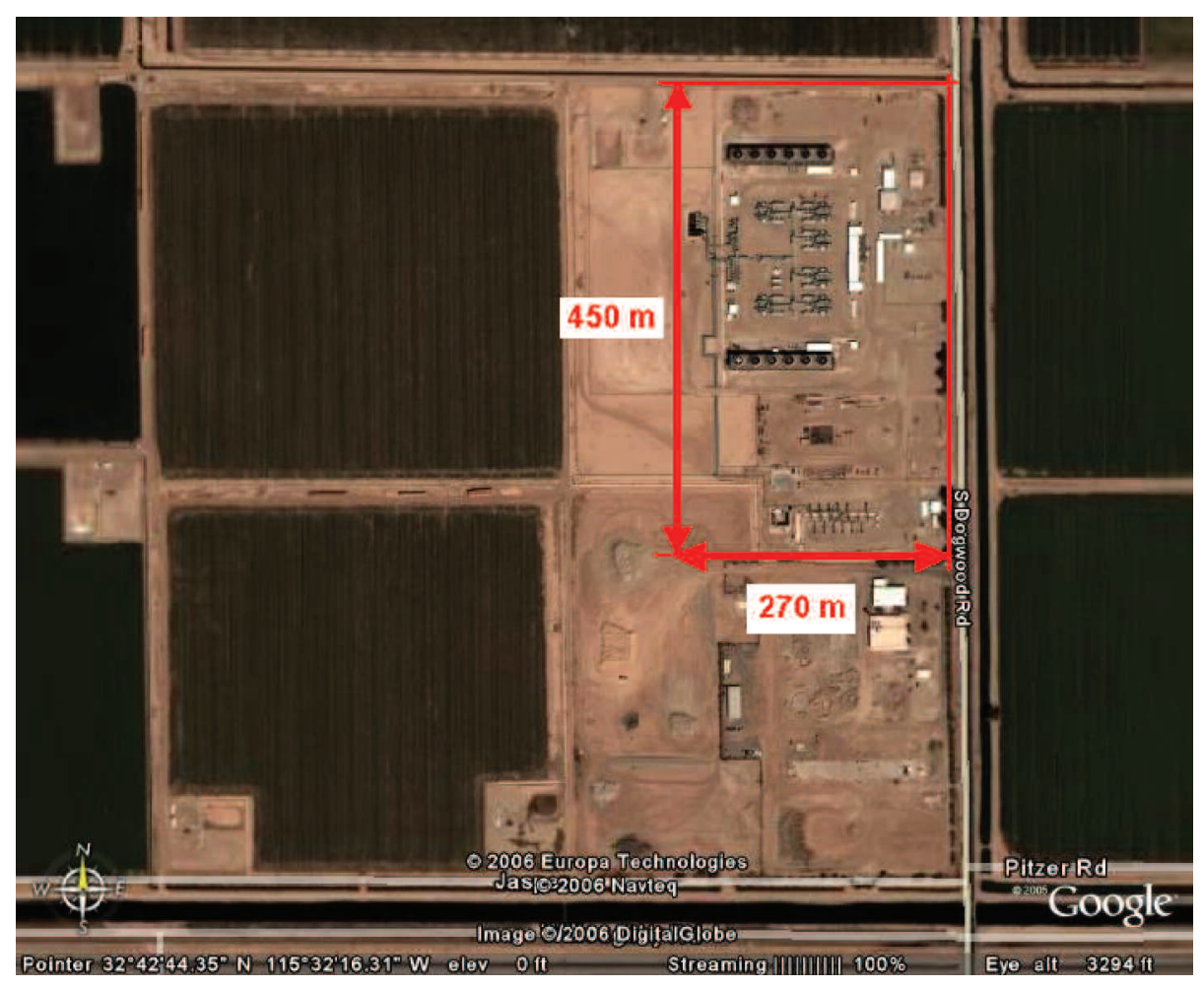

Figure 8.4 Aerial view of the SIGC binary plant near Heber, Calif. (Google Earth, 2006).

Figure 8.5 is a view of the 47 MW Heber Double-Flash plant that is located just to the east of the SIGC plant. The area occupied by this plant and all well pads and holding ponds is about $0.095 \mathrm{~km}^{2}$ or about $2,000 \mathrm{~m}^{2} / \mathrm{MW}$. Both of these plants illustrate how geothermal plants, flash and binary, can operate compatibly within an agricultural environment and be economical of land space.

With regard to the construction of an EGS facility, it can be expected that similar impacts will take place on the land surface and result in a facility having a central power plant with a network of aboveground pipelines connecting the power station to a set of production and injection wells. However, the land can be at least partially restored to its natural condition through the same reclamation techniques practiced at hydrothermal plants. 


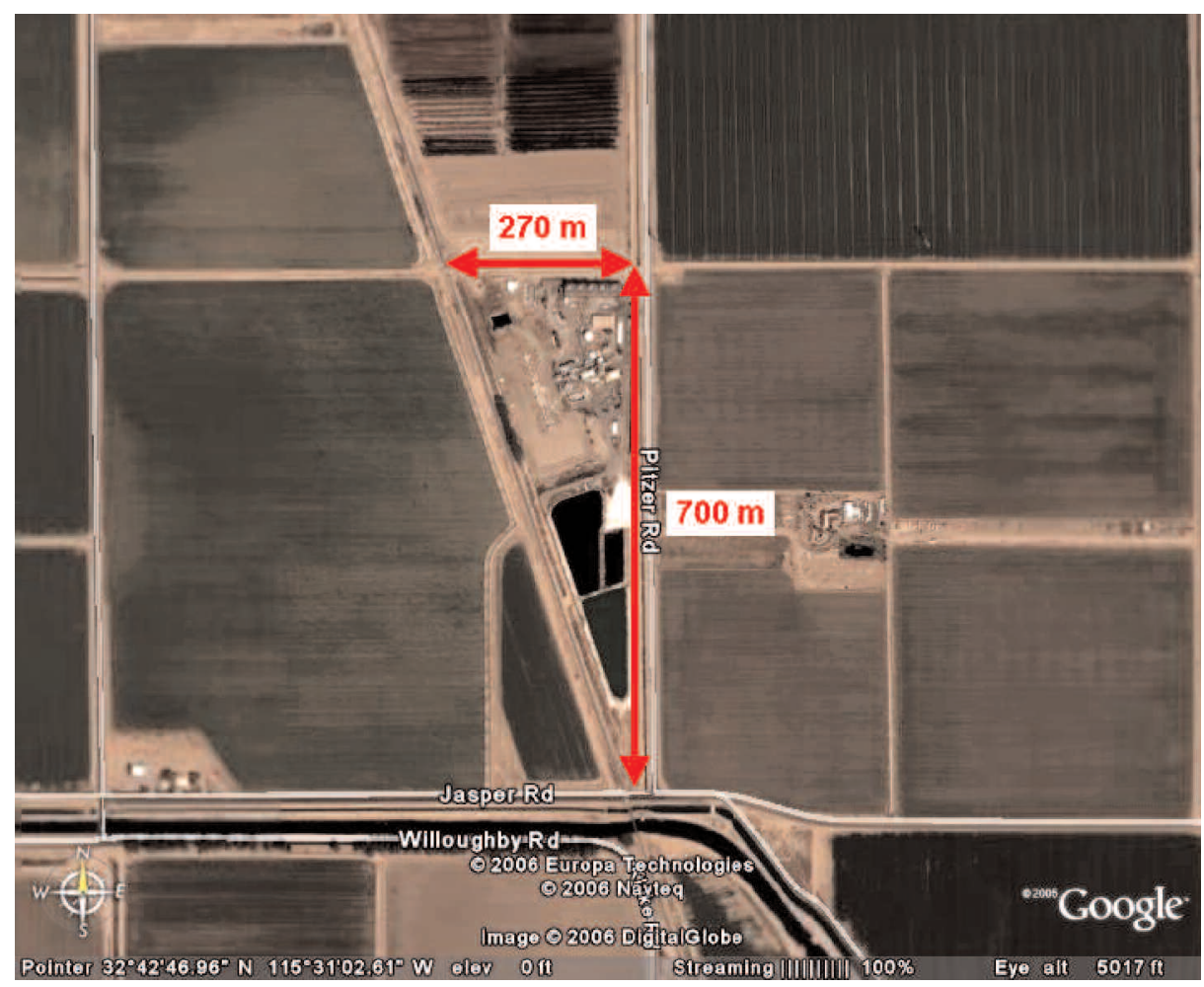

Figure 8.5 Aerial view of the Heber Double-Flash plant, Calif. (Google Earth, 2006).

\subsubsection{Catastrophic events}

Accidents can occur during various phases of geothermal activity including well blowouts, ruptured steam pipes, turbine failures, fires, etc. This is no different from any other power generation facility where industrial accidents unfortunately can and do happen. The ones that are unique to geothermal power plants involve well drilling and testing. In the early days of geothermal energy exploitation, well blowouts were a fairly common occurrence; but, nowadays, the use of sophisticated and fast-acting blowout preventers have practically eliminated this potentially lifethreatening problem. Furthermore, geothermal prospects are now more carefully studied using modern geoscientific methods before well drilling commences.

In the case of EGS projects, it will be critical to study and characterize the nature of any potential site before any development begins. This will minimize the chances for a catastrophic event related to the drilling phase. Proper engineering and adherence to standard design codes should also minimize, if not completely eliminate, any chance of a mechanical or electrical failure that could cause serious injury to plant personnel or local inhabitants.

\subsubsection{Thermal pollution}

Although thermal pollution is currently not a specifically regulated quantity, it does represent an environmental impact for all power plants that rely on a heat source for their motive force. Heat rejection from geothermal plants is higher per unit of electricity production than for fossil fuel plants or nuclear plants, because the temperature of the geothermal stream that supplies the input thermal energy is much lower for geothermal power plants. Considering only thermal discharges at the plant site, a geothermal plant is two to three times worse than a nuclear power plant with respect to thermal 
pollution, and the size of the waste heat rejection system for a Ioo MW geothermal plant will be about the same as for a $500 \mathrm{MW}$ gas turbine combined cycle (DiPippo, I991a). Therefore, cooling towers or air-cooled condensers are much larger than those in conventional power plants of the same electric power rating. The power conversion systems for EGS plants will be subject to the same laws of thermodynamics as other geothermal plants, but if higher temperature fluids can be generated, this waste heat problem will be proportionally mitigated.

\subsection{Environmental Attributes of EGS Power Projects}

\subsubsection{No greenhouse gas emissions during operations}

Geothermal power plants built on EGS reservoirs and using "closed-loop" cycles will emit no carbon dioxide $\left(\mathrm{CO}_{2}\right)$, one of the principal greenhouse gases (GHGs) implicated in global warming. Although not currently a signatory to the Kyoto agreement, the United States may find itself forced to address this problem soon. A decision by the U.S. Supreme Court is expected by June 2007, which could lead to a new posture by the government on $\mathrm{CO}_{2}$ emissions. If a "carbon tax" were to be implemented, the cost to generate a kilowatt-hour of electricity from fossil-fueled plants would increase relative to other less-polluting technologies. EGS plants would not be penalized and could gain an economic advantage over all plants using carbon-based fuels. If a program of "carbon credits" were to be established, EGS plants would gain an additional revenue stream by selling such credits on the carbon-credit trading market.

\subsubsection{Modest use of land}

In comparison with fossil-fueled, nuclear, or solar-electric power plants, EGS plants require much less land area per MW installed or per MWh delivered. In fact, the land required is not completely occupied by the plant and the wells, and can be used, for example, for farming and cattle-raising. The practice of directionally drilling multiple wells from a few well pads will keep the land use to a minimum. Furthermore, because EGS plants are not necessarily tied to hydrothermal areas, it may be possible to site them within populated and industrial districts, a clear advantage over fossil or nuclear plants.

\subsubsection{Possible sequestration of carbon dioxide}

Although not analyzed in this assessment, a proposal has been put forth to use $\mathrm{CO}_{2}$ as the EGS reservoir heat-transfer fluid. Brown (2000) has developed a conceptual model for such a system based on the Fenton Hill Hot Dry Rock reservoir. The argument is made that $\mathrm{CO}_{2}$ holds certain thermodynamic advantages over water in EGS applications. Based on the case study in his paper, a single EGS reservoir having a pore space of $0.5 \mathrm{~km}^{3}$ could hold in circulation some $260 \mathrm{x} \mathrm{I0}{ }^{9} \mathrm{~kg}$ of $\mathrm{CO}_{2}$, the equivalent of 70 years of $\mathrm{CO}_{2}$ emissions from a $500 \mathrm{MW}$ coal power plant having a capacity factor of $85 \%$. EGS plants then could conceivably play a valuable symbiotic role in controlling $\mathrm{CO}_{2}$ emissions while allowing the exploitation of the abundant supply of coal in the United States without contributing $\mathrm{CO}_{2}$ to the atmosphere. 


\subsubsection{Low overall environment impact}

In all aspects, with the exception of possible effects caused by induced seismicity, geothermal plants are the most environmentally benign means of generating base-load electricity. Overall, EGS plants would have comparable impact to hydrothermal binary plants operating with closed-loop circulation. The only potential area of concern, induced seismicity (which is somewhat unique to EGS), can be mitigated, if not overcome, using modern geoscientific methods to thoroughly characterize potential reservoir target areas before drilling and stimulation begin. Continuous monitoring of microseismic noise will serve not only as a vital tool for estimating the extent of the reservoir, but also as a warning system to alert scientists and engineers of the possible onset of a significant seismic event. On balance, considering all the technologies available for generating large amounts of electric power and their associated environmental impacts, EGS is clearly the best choice.

\subsection{Environmental Criteria for Project Feasibility}

In determining the feasibility of an EGS project at a particular location, there are a number of technical criteria that carry direct or indirect environmental implications:

- Electricity and/or heat demand in the region

- Proximity to transmission and distribution infrastructure

- Volume and surface expression of a high-quality EGS reservoir

- Reservoir life and replacement wells

- Circulating fluid chemistry

- Flash vs. binary technology

- Cost/installed $\mathrm{MW}_{\mathrm{e}}$ and cost/MWh delivered to a local or regional market

- Load-following vs. base-load capability

- Plant reliability and safety.

In addition, as with any energy supply system, there are environmental criteria that need to be considered before moving forward with a commercial EGS project. These include:

- Geologic formations that are not prone to large seismic events, devastating landslides, or excessive subsidence

- Compatible land use

- Drinking water and aquatic life protection

- Air quality standards

- Noise standards

- GHG emissions/MWh

- Solid waste disposal standards

- Reuse of spent fluid and waste heat 
- Acceptable local effects of heat rejection

- Compliance with all applicable federal, state, and local laws.

All of these will influence the acceptability and the cost of a project, and, ultimately, whether or not a project will go forward.

\subsection{Concluding Remarks}

Although there certainly are environmental impacts associated with EGS developments, they are generally more benign than those associated with other power generation technologies, particularly fossil and nuclear.

With more than Ioo years of worldwide experience in geothermal operations including

- the design and operation of hydrothermal power plants, especially flash-steam and binary plants the likely systems of choice for EGS power projects,

- geothermal well drilling,

- reservoir engineering and management, and

- abatement systems to mitigate environmental impacts,

future EGS power plant facilities can be designed and operated to have relatively small impacts on the local and regional environment. In fact, because EGS plants have a small footprint and can operate essentially emissions-free, the overall environmental impact of EGS power facilities is likely to be positive, reducing the growth of greenhouse gas emissions while providing a reliable and safe source of electricity. 


\section{References}

Allis, R. G. I990. "Subsidence at Wairakei field, New Zealand," Trans. Geothermal Resources Council, I4: IO8I-I087.

Armstead, H. C. H. I983. Geothermal Energy, $2^{\text {nd }}$ Ed., E. and F. N. Spon, London.

Armstead, H. C. H. and J. W. Tester. I987. Heat Mining, E. and F. N. Spon, London.

Baria, R., K. C. Hearn, and A. S. Batchelor. I985. "Induced seismicity during the hydraulic stimulation of the potential Hot Dry Rock geothermal reservoir," Proc. Fourth Conference on Acoustic Emission/Microseismic Activity in Geology Structures and Materials, Pennsylvania State University.

Baria, R. and A. S. P. Green. I989. "Microseismics: A Key to Understanding Reservoir Growth," in Hot Dry Rock Geothermal Energy, Proc. Camborne School of Mines International Hot Dry Rock Conference, Ed. Roy Baria, Camborne School of Mines Redruth, Robertson Scientific Publications, London, pp. 363-377.

Baria, R. (ed.). I990. “Hot Dry Rock Geothermal Energy,” Proc. Camborne School of Mines International HDR Conference, Robertson Scientific Publications, London, pp. 6rз3.

Baria, R., J. Garnish, J. Baumgartner, A. Gerard, and R. Jung. I995. "Recent development in the European HDR research programme at Soultz-Sous-Foret (France)," Proc. World Geothermal Congress, International Geothermal Association, Vol. 4, pp. 2,63I-2,637, Florence, Italy. ISBN 0-473-03I23-X.

Baria, R., S. Michelet, J. Baumgartner, B. Dyer, A. Gerard, T. Hettkamp, D. Teza, N. Soma, H. Asanuma, and J. Garnish. 2005. "A $5000 \mathrm{~m}$ deep reservoir development at the European HDR site at Soultz," Proc. World Geothermal Conference 2005, Antalya, Turkey, 24-29 April 2005, Paper No. I627.

Baria, R., R. Jung, T. Tischner, J. Nicholls, S. Michelet, B. Sanjuan, N. Soma, H. Asanuma, B. Dyer, and J. Garnish. 2006. "Creation of a HDR reservoir at $5000 \mathrm{~m}$ depth at the European HDR project," Proc. Thirty-First Workshop on Geothermal Reservoir Engineering, Stanford University, Calif.

Batchelor, A. S., R. Baria, and K. Hearn. 1983. "Microseismic detection for Camborne Geothermal Project," The Institution of Mining and Metallurgy in association with the Institution of Mining Engineers, London.

Brown, D.W. 2000. "A Hot Dry Rock Geothermal Energy Concept Utilizing Supercritical $\mathrm{CO}_{2}$ Instead of Water," Proc. Twenty-Fifth Workshop on Geothermal Reservoir Engineering, Stanford University, Stanford, Calif, Jan. 24-26, 2000, Paper SGP-TR-I65.

Burnham, L. (exec. ed.), T. B. Johansson, H. Kelly, A. K. N. Reddy, and R. H. Williams. I993. Renewable Energy: Sources for Fuels and Electricity, Island Press, Washington D.C.

DiPippo, R. I978. “The Geothermal Power Station at Ahuachapan, El Salvador," Geothermal Energy Magazine, 6, pp. II-22.

DiPippo, R. I99га. "Geothermal Energy: Electricity Production and Environmental Impact, A Worldwide Perspective," Energy and Environment in the $21^{\text {st }}$ Century, pp. 74I-754, MIT Press, Cambridge.

DiPippo, R. I99ıb. “Geothermal Energy: Electricity Generation and Environmental Impact,” Energy Policy, I9, pp. 798-807.

DiPippo, R. 2005. Geothermal Power Plants: Principles, Applications and Case Studies, Elsevier, Oxford, U.K. 
Jones, G.L. 2006. "Geysers/Hot Springs Damaged or Destroyed by Man,"

http://www.wyojones.com/destroye.htm

Kagel, A., D. Bates, and K. Gawell. 2005. "A Guide to Geothermal Energy and the Environment," Geothermal Energy Association, Washington, D.C.

Keam, R.F., K.M. Luketina, and L.Z. Pipe. 2005. "Definition and Listing of Significant Geothermal Feature Types in the Waikato Region, New Zealand," Proc. World Geothermal Congress 2005, Antalya, Turkey, 24-29 April 2005, Paper 0209.

LaGeo. 2005. Historia de la Energía Geotérmica en El Salvador, San Salvador, El Salvador.

Majer, E. and R. Baria. 2006. "Induced seismicity associated with Enhanced Geothermal Systems: State of knowledge and recommendations for successful mitigation," Working paper presented at the Stanford Geothermal Workshop, Stanford University, Calif.

Michelet, S., R. Baria, J. Baumgartner, A. Gérard, S. Oates, T. Hettkamp, and D. Teza. 2004. "Seismic source parameter evaluation and its importance in the development of an HDR/EGS system," Proc. Twenty-Ninth Workshop on Geothermal Reservoir Engineering, Stanford University, Calif.

Mock, J. E., J. W. Tester, and P. M. Wright. I997. "Geothermal energy from the earth: Its potential impact as an environmentally sustainable resource," Annual Review of Energy and the Environment, 22: $305-356$.

Moya, P.R. and R. DiPippo, 2006. "Miravalles Unit 5: Planning and Design," Trans. Geothermal Resources Council, V. 30, pp. 76I-766.

Pasqualetti, M.J. I980. "Geothermal Energy and the Environment - The Global Experience," Energy (UK), 5: III-I65.

Tester, J.W., E.M. Drake, M.W. Golay, M.J. Driscoll, and W.A. Peters. 2005. Sustainable Energy: Choosing Among Options, The MIT Press, Cambridge, Mass. 
CHAPTER 9

\section{Energy-Sector Fundamentals: Economic Analysis, Projections, and Supply Curves}

9.1 EGS in the Energy Sector

9.2 Base-load Electricity Options _

9.3 Transmission Access

9.4 Forecasting Base-load Needs _.__

9.5 Forecast Demand and Supply Calculations

9.6 Risk _

9.7 Economics and Cost of Energy _

9.8 Using Levelized Costs for Comparison

9.8.1 Fixed costs _.

9.8.2 Variable costs of operation

9.8.3 Levelized cost projections

9.8.4 Supply and capacity

9.8.5 The aggregate industry supply curve

9.8.6 Geothermal supply characteristics _ _ _

9.9 EGS Economic Models _

9.9.1 GETEM model description

9.9.2 Updated MIT EGS model

9.9.3 Base case and sensitivity

9.10 Supply Curves and Model Results _ _ _ _ _ _ _ _ _ _ $\ldots \ldots \ldots \ldots \ldots-\ldots 9-24$

9.10.1 Supply of EGS power on the edges of existing hydrothermal systems

9.10.2 Supply of EGS power from conductive heating _ _ _ _ _ _ _ _ _ _ _ _ $9-27$

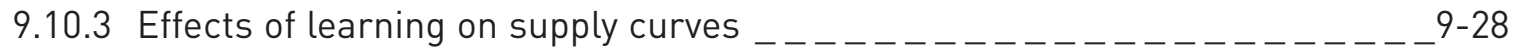

9.10.4 Supply curve for EGS _ _-

9.10.5 EGS well characteristics _

9.11 Learning Curves and Supply Curves _ _

9.12 Forecast Supply of Geothermal Energy _

9.12.1 The role of technology

9.12.2 Variable debt/equity rates vs. fixed charge rates (FCRs)

9.12.3 Deriving cost and supply curves

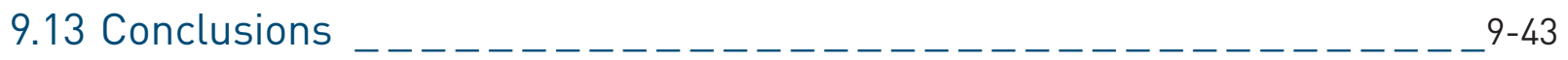

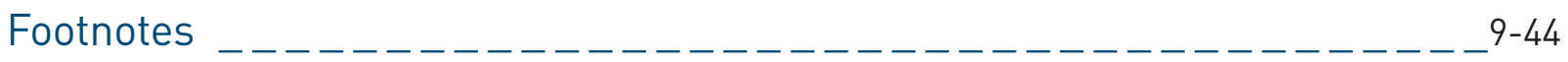

References _- - - - - - - - - - - - - - - - - - - - - - - - - - $---9-47$

Appendices _- - - - - - - - - - - - - - - - - - - - - - - - - - - - - 9 9-49 


\subsection{EGS in the Energy Sector}

Geothermal operations have been in place with varying degrees of complexity and use of technology since the turn of the previous century. These operations occupy a range of technologies from geothermal heat pumps through advanced binary and flash plant facilities that produce electric power. Costs of operation for existing plants are well-documented (see references) and reflect the conditions of drilling and operation for primarily hydrothermal wells at depths that do not exceed $4 \mathrm{~km}$ for typically electric utilities that are commercially operated.

High-grade hydrothermal systems exist because natural permeability allows naturally present water to circulate to shallow depths. The circulating hot water heats surrounding rock to some distance away from the permeability anomaly, according to the length of time the system has been in existence. These systems rely primarily on convective heating rather than the conductive heating from the resource base. In hydrothermal systems, the thermal energy accessible for recovery is limited to the thermodynamic availability of the fluids in the natural system consisting of the convective cell. Such systems require (I) abnormally high heat flow, (2) significant permeability to compensate for the low thermal conductivity of rock, (3) the presence of significant storage porosity for containing the fluid, and (4) the fluid itself. The exploitation of hydrothermal systems requires the fortuitous collocation of these four conditions.

Enhanced Geothermal Systems (EGS) differ fundamentally from these hydrothermal systems. EGS engineering technology provides means for mining heat from a portion of the universally present stored thermal energy contained in rock at depths of interest, by designing and stimulating a reservoir whose production characteristics would be similar to a commercial hydrothermal system. For high-grade EGS resources, the high heat flow requirement (I) is met, while lower EGS grades are also generally accessible using EGS technology, albeit at higher cost. EGS provides engineering options for satisfying the remaining requirements - (2)-(4). Consequently, the number of potential sites suitable for EGS is significantly greater than for hydrothermal. Ultimately, the EGS approach may be universally applicable, assuming continued, longer-term R\&D support for advanced exploration, reservoir stimulation and drilling, and technologies.

Electric utilities are defined as either privately owned companies or publicly owned agencies that engage in the supply (including generation, transmission, and/or distribution) of electric power. Nonutilities are privately owned companies that generate power for their own use and/or for sale to utilities and others.

The generating units operated by an electric utility vary by intended use, that is, by the three major types of load requirements the utility must meet, generally categorized as base, intermediate, and peak. A base-load generating unit is normally used to satisfy all or part of the minimum or base demand of the system and, as a consequence, produces electricity essentially at a constant rate and runs continuously. Base-load units are generally the largest of the three types of units, but they cannot be brought online or taken off-line quickly. Peak-load generating units can be brought online quickly and are used to meet requirements during the periods of greatest load on the system. They are normally smaller plants using gas turbines, and/or combined cycle steam and gas turbines. Intermediate-load generating units meet system requirements that are greater than base load but less than peak load. Intermediate-load units are used during the transition between base-load and peakload requirements (EIA, 2005; Stoft, 2002). 
The history of electricity generation in the United States and projections to 2020 are shown in Figure 9.I for all resources. It is important to note that the projected demand for electricity assumes that there are no major policy initiatives to offset current demand growth trends. Even if policies were put in place to reduce demand by improving efficiency in all forms of energy use, a growing U.S. population will eventually lead to some growth in demand that could be met by further development of renewables, including new forms such as environmentally friendly EGS.

A key characteristic of renewable hydrothermal geothermal power is the long-term stability of the resource and characteristic power curve. This power curve is valued by utility or grid operators for base-load conditions where load following or rapidly changing load operations do not need to be met. Geothermal plants run at all times through the year except in the case of repairs or scheduled maintenance.

A base-load power plant is one that provides a steady flow of power regardless of total power demand by the grid. ${ }^{* *}$ Power generation units are designated base-load according to their efficiency and safety at set designed outputs. Base-load power plants do not change production to match power consumption demands. Generally, these plants are massive enough, usually greater than $250 \mathrm{MW}_{\mathrm{e}}$, to provide a significant portion of the power used by a grid in everyday operations with consequent long ramp-up and ramp-down times. Capacity factors are typically in excess of $90 \%$. Fluctuations in power supply demand, the peak power demand, or spikes in customer demand are handled by smaller and more responsive types of power plants.

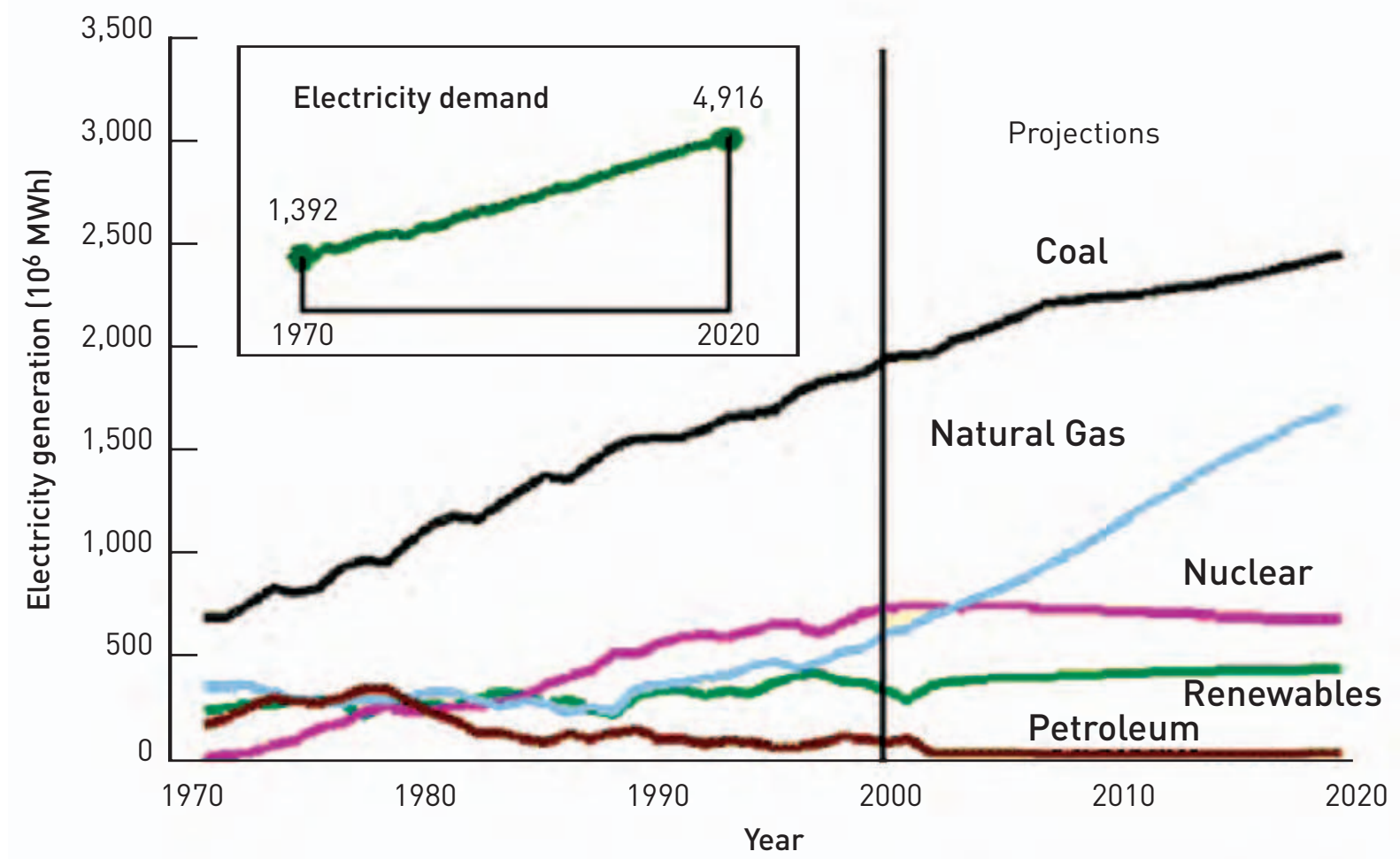

Figure 9.1 U.S. electricity generation by energy source, 1970-2020 (million megawatt-hours) (EIA, 2004).

* Numbered footnotes are located before the references at the end of this chapter. 


\subsection{Base-load Electricity Options}

Steam-electric (thermal) generating units are the typical source of base-load power. A significant fraction of North American base-load power is provided by fossil fuels such as coal, which are burned in a boiler to produce steam. Nuclear plants use nuclear fission as the heat source to make steam. Geothermal or solar-thermal energy can also be used to produce steam. The expected thermal efficiency of fossil-fueled steam-electric plants is about $33 \%$ to $35 \%$. In the case of fossil-fired plants, waste heat is emitted from the plant either directly into the atmosphere, through a cooling tower, or into water bodies for cooling where a pump brings the residual water from the condenser back to the boiler. In the case of geothermal power, condensed geofluid is used for cooling water makeup and the residual water is reinjected into the well system.

Because geothermal power plants are usually operated as base-load units, we include a detailed assessment of the state of U.S. electrical supply and demand to illustrate how EGS plants would complement the existing and projected supply system. This discussion is found in Appendix A.9.I.

\subsection{Transmission Access}

Access to the electricity grid and, ultimately, the market is a key cost consideration for geothermal projects. ${ }^{9}$ The necessary power transmission system involves the transportation of large blocks of power over relatively long distances from a central generating station to main substations close to major load centers, or from one central station to another for load sharing.

High-voltage transmission lines are used because they require less surface area for a given carrying power capacity, and result in less line loss. According to the Energy Information Administration (EIA), in the United States, investor-owned utilities (IOUs) own $73 \%$ of the transmission lines, federally owned utilities own $13 \%$, and public utilities and cooperative utilities own $14 \%$. Not all utilities own transmission lines (i.e., they are not vertically integrated), and no independent power producers or power marketers own transmission lines. Over the years, these transmission lines have evolved into three major networks (power grids), which include smaller groupings or power pools. The major networks consist of extra-high-voltage connections between individual utilities, designed to permit the transfer of electrical energy from one part of the network to another. These transfers are restricted, on occasion, because of a lack of contractual arrangements or because of inadequate transmission capability.

Power generated from geothermal plants of all kinds is delivered as alternating current (AC) power, ${ }^{10}$ which is suitable for dispatch by grid operators or for wheeling to other demand locations. Bulk transmission is also an option when costs of power are low enough, to distant markets via direct current $^{11}$ (DC) transmission facilities. Distances of more than I, 000 miles combined with a threshold of $\mathrm{I}, 000 \mathrm{MW}_{\mathrm{e}}$ are typically necessary to justify the costs of service obtained by using DC lines.

\subsection{Forecasting Base-load Needs}

Forecasting demand for an electric utility is critical for delivering reliable power, for estimating future costs, and for encouraging new investment. In the past, power system operators relied on straight-line extrapolations of historical energy consumption trends. However, given inflation with 
rapidly rising energy prices, emergence of alternative fuels and technologies, demographics, and industrial technologies, more sophisticated demand models have been employed by utilities and government agencies.

Penalties for underestimation have been overcome in the past, typically by resorting to rapid construction of plants such as simple or combined-cycle gas turbines ${ }^{12}$ to meet emerging short-term demand. This technique was successful in large measure because of the relatively low price and easy access to fuels such as natural gas.

Historically, overestimates were eventually corrected by growth in demand, with the assumption that excess capacity could be sustained by the rate base and would be absorbed by naturally occurring increases. In the current market climate, an underestimate is likely to lead to under capacity, resulting in diminished quality of service including localized brownouts, blackouts, and distortion in capacity investment needs. Overestimates could lead to the authorization of excess capacity, which might not be sustainable in the rate base. Given the interest in deregulation, with associated unbundling of electricity supply services, tariff reforms, and increasing reliance on private-sector providers such as energy service providers (ESPs), accurate demand forecasting is of ever-greater importance.

Power plant construction periods, including needs assessments, financing, approvals, and physical construction, may vary from four to I2 years for thermal and fossil plants. Shorter construction periods occur for gas-fired generation, which may be needed for peak demand and load following. In the case of geothermal plants, the time to build and install the power plant can be less than two years, once the well field has been developed. As a result, utilities typically forecast demand and load profiles for 20 years into the future, adjusting annually.

For the industrial and manufacturing sectors, including public utilities, many factors such as available technologies, market share, and location will drive their long-term forecast. Forecasts, in turn, will further influence investment plans for industry and associated industries as well as demandmanagement plans for regulators and utilities. The system load shape is important for organizing future construction planning and tariff design. For instance, demand forecasting models can provide an assessment of the impact of new technology on overall energy consumption, a fact that may allow technologies such as geothermal power to seek rent in the form of attribute values, which could trade on a separate market ${ }^{13}$ and increase returns on the base investment. For instance, demand forecasts are often done for each consumer category and voltage level. Charging the commercial, industrial, and large consumers a higher charge, which is then used to subsidize social reform programs, optimizes revenues while keeping social objectives in mind. The forecast may also indicate a relative category of higher willingness or ability to pay vs. those needing subsidy.

\subsection{Forecast Demand and Supply Calculations}

In electricity markets, electricity demand forecasts are of interest to suppliers (responsible for meeting demand), grid operators (responsible for dispatch and system security), and generators. Generators use forecasts to estimate delivered power prices and to calculate imbalance charges, which are particularly important for volatile fuel costs and some renewable technologies. Energy and peak demand growth rates generally hover around $2 \%$ a year. 
New demand for base-load power is determined by a wide variety of factors including growth in overall demand for power by sector, retirement of existing generation units, operator costs, and cost of transmission access. Competitive access to the grid will always be a function of location, competitive power prices, reliability of delivered power supplies, and the ongoing demand structure of the region into which the power is delivered.

Demand is generally a function of population growth, housing demand, and energy intensity of operations in both the industrial and commercial sectors of the economy. In the case of electricity demand, changes in overall demand generally reflect the ability of individuals or businesses in a particular sector to monitor and adjust activities in response to changes in delivered energy prices. Thus, applications of energy-saving or energy efficiency technologies will have an immediate impact on lowering demand, and may reduce the overall slope of the demand for the future. This demand will be driven by growth in population and more reliance on electric-intensive appliances, devices, computers, and, eventually, electric or hybrid vehicles.

Base-load power is competitively acquired by system operators, generally in long-term contracts. As a consequence, price for delivered energy does not vary significantly over time, although the price may vary between regions. The growth in energy services reflects an increase in population and economic activity, tempered by improved efficiency of equipment and buildings.

However, the present coincidence of domestic petroleum reserve issues and international politics, the failure to keep up with energy infrastructure requirements, the slow rebirth of the nuclear option due to continued public resistance and nonsupportive regulatory/permitting policies, growing pressure to limit the environmental costs of coal production and utilization, and the pervasive pressure for reduction of $\mathrm{CO}_{2}$ emissions all will work against the traditional ability of technology to match demand growth. As current energy contracts expire and societal/cultural impediments affect expanded use of nuclear and coal, upward price trends for electricity should result over the near to long term.

\subsection{Risk}

The level of risk for the project must account for all potential sources of risk: technology, scheduling, finances, politics, and exchange rate. The level of risk generally will define whether or not a project can be financed and at what rates of return.

Current hydrothermal projects or future EGS projects will, in the near term, carry considerable risk as viewed in the power generation and financial community. Risk can be expressed in a variety of ways including cost of construction, construction delays, or drilling cost and/or reservoir production uncertainty. In terms of "fuel" supply (i.e., the reliable supply of produced geofluids with specified flow rates and heat content, or enthalpy), a critical variable in geothermal power delivery, risks initially are high but become very low once the resource has been identified and developed to some degree, reflecting the attraction of this as a dependable base-load resource.

Table 9.I lists the costs and risks associated with the stages of geothermal power development. The risks are qualitative assessments, based on our understanding of the facets of each of the diverse project activities. 
Table 9.1 Stages of EGS development: costs and risk

Geologic assessment and permits

\begin{tabular}{|c|c|c|c|}
\hline Category & Duration & Cost & Risk \\
\hline Define areas of potential development & $1-2$ years & Moderate & Low \\
\hline $\begin{array}{l}\text { Exclude areas of public protection, high environmental } \\
\text { impact, or protected zones }\end{array}$ & $1-2$ years & Moderate & Low \\
\hline Determine regional high- to low-heat gradient zones & $1-2$ years & Moderate & Low \\
\hline $\begin{array}{l}\text { Correlate with areas of forecast demand growth or } \\
\text { base-load retirement }\end{array}$ & 1 year & Low & Moderate \\
\hline $\begin{array}{l}\text { Determine regional variations in drilling costs, labor costs, } \\
\text { grid integration }\end{array}$ & $<1$ year & Low & Moderate \\
\hline Determine need for voltage and VARS ${ }^{14}$ support & $<1$ year & Low & Moderate \\
\hline Determine regulation constraints & $<1$ year & Low & Moderate \\
\hline Determine taxation policies & $<1$ year & Low & Moderate \\
\hline Estimate market or government subsidies & $<1$ year & Low & Moderate \\
\hline Estimate costs & 1 year & Low & Moderate \\
\hline File for permit and mitigate environmental externalities & $3+$ years & High & High \\
\hline Apply for transmission interconnect & $<1$ year & Moderate & High \\
\hline Acquire permit and begin drilling & 1 month & Moderate & Low \\
\hline
\end{tabular}

Exploratory drilling

\begin{tabular}{|c|c|c|c|}
\hline Category & Duration & Cost & Risk \\
\hline Site improvement & 1 month & Moderate & Moderate \\
\hline $\begin{array}{l}\text { Determine reservoir characteristics (rock type, gradient, } \\
\text { stimulation properties, etc.) }\end{array}$ & 6 months & High & High \\
\hline $\begin{array}{l}\text { Performance/productivity (flow rate, temperature, fluid } \\
\text { quality, etc.) }\end{array}$ & 6 months & High & High \\
\hline $\begin{array}{l}\text { Apply and test advances in drilling and fracturing } \\
\text { technology }\end{array}$ & 6 months & High & High \\
\hline $\begin{array}{l}\text { Achieve cost reductions as function of recent research and } \\
\text { past learning curve }\end{array}$ & 6 months & High & High \\
\hline
\end{tabular}

Production drilling and reservoir stimulation

\begin{tabular}{l|l|l|l}
\hline Category & Duration & Cost & Risk \\
\hline Apply best practices and further develop site & 1 year & High & Moderate \\
\hline Construct transmission interconnection & 2 months & Moderate & Moderate \\
\hline Construct power transmission facility & 2 months & High & Moderate \\
\hline Construct power conversion system & 2 years & High & Low
\end{tabular}


Power production and market performance

\begin{tabular}{l|l|l|l}
\hline Category & Duration & Cost & Risk \\
\hline $\begin{array}{l}\text { Bid long based on expected delivery costs } \\
\begin{array}{l}\text { Routine and } \\
\text { recurring }\end{array}\end{array}$ & Low & High \\
\hline $\begin{array}{l}\text { base-load power } \\
\text { Enter power purchase agreement }\end{array}$ & $\begin{array}{l}\text { Routine and } \\
\text { recurring }\end{array}$ & Low & High \\
\hline
\end{tabular}

\subsection{Economics and Cost of Energy}

Geothermal energy - which is transformed into delivered energy (electricity or direct heat) - is an extremely capital-intensive and technology-dependent industry. The capital investment may be characterized in three distinct phases:

a) Exploration and drilling of test and production wells

b) Construction of power conversion facilities

c) Discounted future redrilling and well stimulation.

Previous estimates of capital cost by the California Energy Commission (CEC, 2006), showed that capital reimbursement and interest charges accounted for $65 \%$ of the total cost of geothermal power. The remainder covers fuel (water), parasitic pumping loads, labor and access charges, and variable costs. By way of contrast, the capital costs of combined-cycle natural gas plants are estimated to represent only about $22 \%$ of the levelized cost of energy produced, with fuel accounting for up to $75 \%$ of the delivered cost of energy.

Given the high initial capital cost, most EGS facilities will deliver base-load power to grid operations under a long-term power purchase agreement (typically greater than Io years) in order to acquire funding for the capital investment. We have assumed that loan life will typically be 30 years, and that the life span of surface capital facilities will be 70 years with incremental improvements or repairs to the installed technology during that period. We assume that the life of the well field will be 30 years with periodic (approximately seven to Io years) redrilling, fracturing, and hydraulic stimulation during that period. At the end of a 30-year cycle, the well complex is assumed to be abandoned, but the surface facilities can service new well complexes through extension of piping and delivery systems with no appreciable loss. Delivered cost of energy is, thus, a function of this stream of capital investment and refurbishment, and ongoing operations and delivery costs.

The upshot of this analytical technique is to allow comparison with existing fossil and other renewable technologies such as wind and hydroelectric, where similar capital facility life span can be expected.

\subsection{Using Levelized Costs for Comparison}

The delivered cost of electricity is the primary criterion for any electric power generation technology. The levelized cost of energy (or levelized electricity cost, LEC) is the most common approach used for 
comparing the cost of power from competing technologies. The levelized cost of energy is found from the present value of the total cost of building and operating a generating plant over its expected economic life. Costs are levelized in real dollars, i.e., adjusted to remove the impact of inflation.

There are two common approaches for calculating the LEC. The first, a simplified approach, calculates a total annualized cost using a fixed charge rate applied to invested capital, adds an annualized operating cost, and divides the sum by the annual electric generation. The second approach uses a full financial cash-flow model to perform a similar calculation. The latter approach is usually preferred because it takes into account a wide range of cost parameters that any project must face. As pointed out by the EIA, the cost of power must be competitive with other power generation options after taking into account any special incentives available to the technology. This could include green-pricing production incentives, grants (such as those from the California Energy Commission to improve drilling techniques), subsidies or required purchases through renewable energy portfolio standards, or special tax incentives.

\subsubsection{Fixed costs}

Any power production facility is subject to a range of fixed and variable costs. Comparing power development opportunities requires like units of measure, typically capitalized costs of fixed assets and the levelized costs of operation.

The capitalized construction cost takes into account both drilling and construction activities as well as accumulated interest during construction. We assume that construction (other than in test facilities, which will involve research and/or grant funds) is financed by a mixture of debt and equity, and that the ratio of debt to equity remains constant during the construction period. Under these circumstances, the rate of return (ROR) for both debt and equity is constant. If the rate of return on debt is $r_{b}$, the rate of return on equity is $r_{e}$, and the ratio of debt to total capital is $f$, then the capitalized cost of debt at the start of plant operation is:

$$
L(0)=\sum_{m=1}^{M} f C_{m}\left(1+r_{b}\right)^{M-m}
$$

where $M$ is the time period in months and $C_{m}$ is the overnight capital cost. The capitalized cost of equity investment is:

$$
E(0)=(1-f) \sum_{m=1}^{M} C_{m}\left(1+r_{e}\right)^{M-m}
$$

Revenue, $R(n)$, received by the owners of the generating plant in time period $n$ will be equal to the amount of electricity, $Q(n)$, produced in that period, times the price of the electricity, $p(n)$ :

$$
R(n)[\$ / \mathrm{yr}]=Q(n)\left[\mathrm{kW}_{e} \mathrm{~h} / \mathrm{yr}\right] \times p(n)\left[\phi / \mathrm{kW}_{e} \mathrm{~h}\right] \times 10^{-2}[\$ / \phi]
$$


where

$$
Q(n)\left[\mathrm{kW}_{e} \mathrm{~h} / \mathrm{yr}\right]=365[\text { days } / \mathrm{yr}] \times 24[\mathrm{~h} / \text { day }] \times C F(n) \times K\left[\mathrm{MW}_{e}\right] \times 1000\left[\mathrm{~kW}_{e} / \mathrm{MW}_{e}\right]
$$

We assume $K$ is the rated capacity (in $\mathrm{MW}_{\mathrm{e}}$ ) of the plant ${ }^{15}$ and $C F(n)$ is the capacity factor of the plant in time period $n$. The capacity factor will gradually decline over time, but for the assumed period of this analysis, is taken as constant. Thus,

$$
Q(n)=8760 \times 10^{3} \times C F(n) \times K \text {. }
$$

\subsubsection{Variable costs of operation}

Costs of operation consist of fuels (water for injection, electricity for parasitic power pumping load), operations and maintenance (excluding the cost of redrilling or stimulation, which are assumed in capital cost calculations), interest and principal repayments, taxes, and depreciation. In addition, shareholder returns on equity, $r_{e}$, are counted when a project is commercial, as opposed to experimental.

$$
T V c=T x+F+O m+D q
$$

where:

$T V c=$ Total annual variable cost

$T x=$ Tax payment on income and property

$F=$ Annual fuel cost

$$
F=C_{\text {fuel }}(n)=Q(n) \cdot c_{\text {fuel }}(n)
$$

where:

$c_{\text {fuel }}(n)=$ the fuel cost expressed in $\$ / \mathrm{kWh}$ in year $n$

$O m=$ Annual Operations and Maintenance

$$
O m=C_{O \& M}(n)=Q(n) \cdot c_{O \& M}(n)
$$

where:

$c_{O \& M}(n)=$ the unit O\&M cost expressed in $\$ / \mathrm{kWh}$. The fixed cost component of O\&M is ignored.

$D q=$ combined debt and equity service in equal annual installments over a term of $N$ years.

The term $D q$ reflects not only market cost but risk (for example, the higher risk of equity versus borrowed capital) when $r_{e}>r_{b}$. This places a relative premium on payments over the project lifetime. 


\subsubsection{Levelized cost projections}

The EIA has estimated the cost of future energy supplies out to 2020 in the latest Annual Energy Outlook (EIA, 2005). As shown in Figure 9.2, the base-load cost of coal is projected to fall due to decreases led by savings in capital costs, and nuclear energy costs are also projected to decrease during the same period. However, historically, the costs of both technologies have been showing a tendency to increase when technology improvements to meet air quality standards and mitigate other environmental externalities or safety issues are taken into account. Also, fuel costs for both technologies are increasing in commodity markets: coal due to the transportation costs for "clean" varieties, and nuclear because of increases in the costs due to a decrease in supply of uranium.

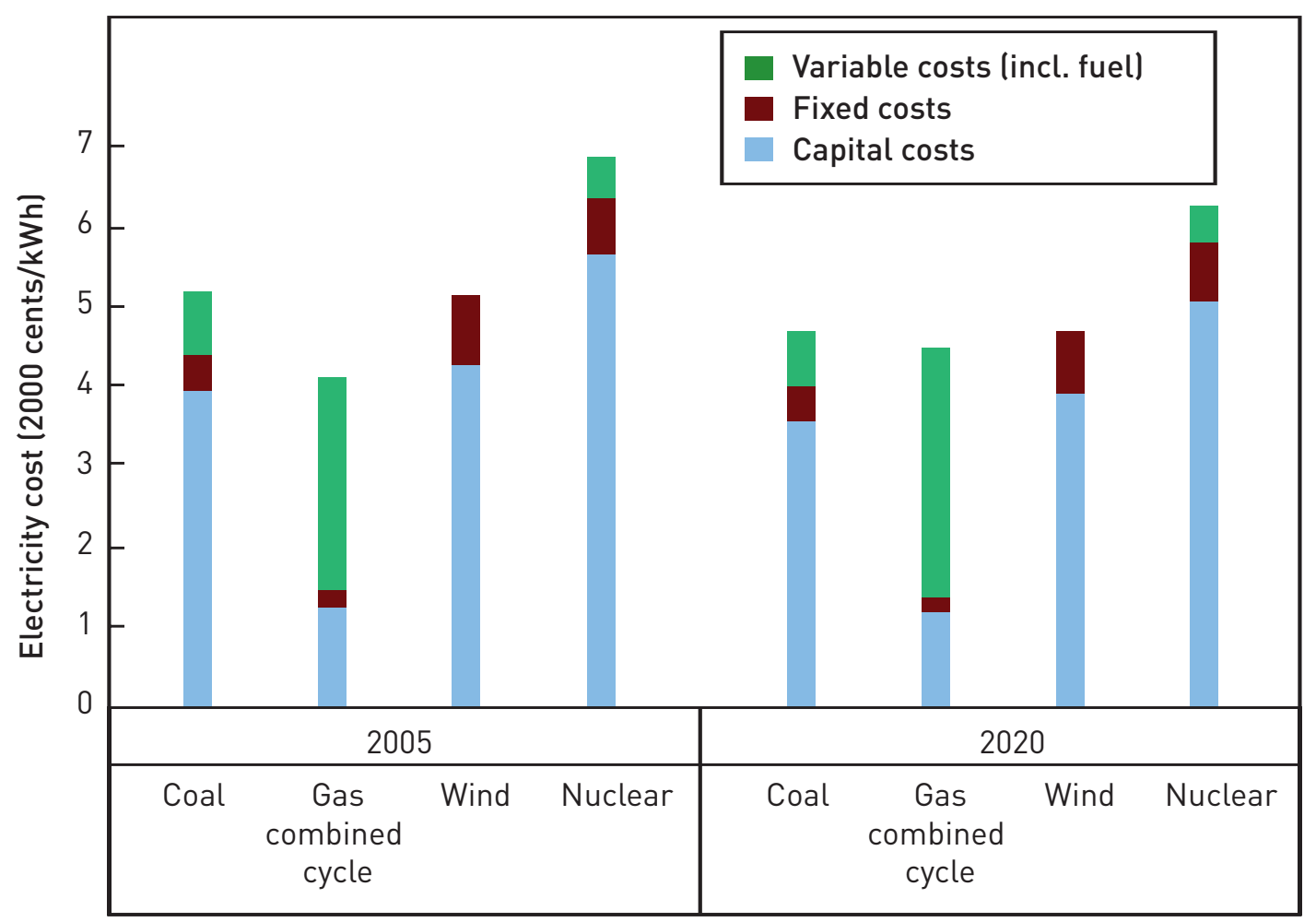

Figure 9.2 Projected levelized electricity generating costs, 2005 and 2020. 


\subsubsection{Supply and capacity}

The supply or stock of energy-generating capacity is fixed over short periods of time, while the capacity called on or utilized may vary widely in that same period, depending on competitive energy prices, maintenance schedules, fuel prices, transportation costs, or line charges. Capital expenditures on new supply are not continuous and require, in addition to market signals, regulatory and siting approvals as well as investor interest before proceeding. The length of time for capital investment from inception to generation varies by region and jurisdiction. It can be described, generally, as shown in Table 9.2.

These constraints suggest, in the current quasi-deregulated market, that obtaining surplus capacity is difficult without specific authorization by the regulator. As a result, the capital supply curve typically lags demand; and once new capacity is brought online, it can be expected to be used up to its maximum capacity factor (allowing for maintenance outages). For existing technologies, this translates to a relatively elastic supply curve matched to a time-sensitive series of relatively inelastic demand curves.

For base-load power, new additions to existing supplies can be added at relatively high cost in the short term. Generation and consequent fuel substitution is usually available to accomplish this (i.e., the substitution of gas-fired combined-cycle plants usually reserved for load following can be brought in to satisfy base-load needs but at higher cost). This can represent a significant opportunity cost when the technology is more expensive at the margin.

As shown in Figure 9.3, for the installed base, the supply curve is elastic to the point where the operating capacity is fully utilized. Meeting additional demand will force new generation to come online. Where the new generation operates with base-load characteristics, it establishes a new elastic supply curve (slope b). Where the replacement is higher-cost load-following technology, the supply curve is likely to assume normal market coefficients (slope b').

Table 9.2 Permitting, siting, and construction relationships.

\begin{tabular}{l|c|c}
\hline Generation Type & Permitting, years & Construction, years \\
\hline Gas turbine & $1-2$ & $1-2$ \\
\hline Renewable energy (wind, solar) & $1-2$ & $1-2$ \\
\hline Renewable (biomass, MSW) & $2-4$ & $1-2$ \\
\hline Renewable (geothermal) & $1-2$ & $2-3$ \\
\hline Coal & $2-3$ & $2-3$ \\
\hline Hydroelectric & $5-6$ & $6-10$ \\
\hline Nuclear & $4-10$ & $2-10$ \\
\hline
\end{tabular}




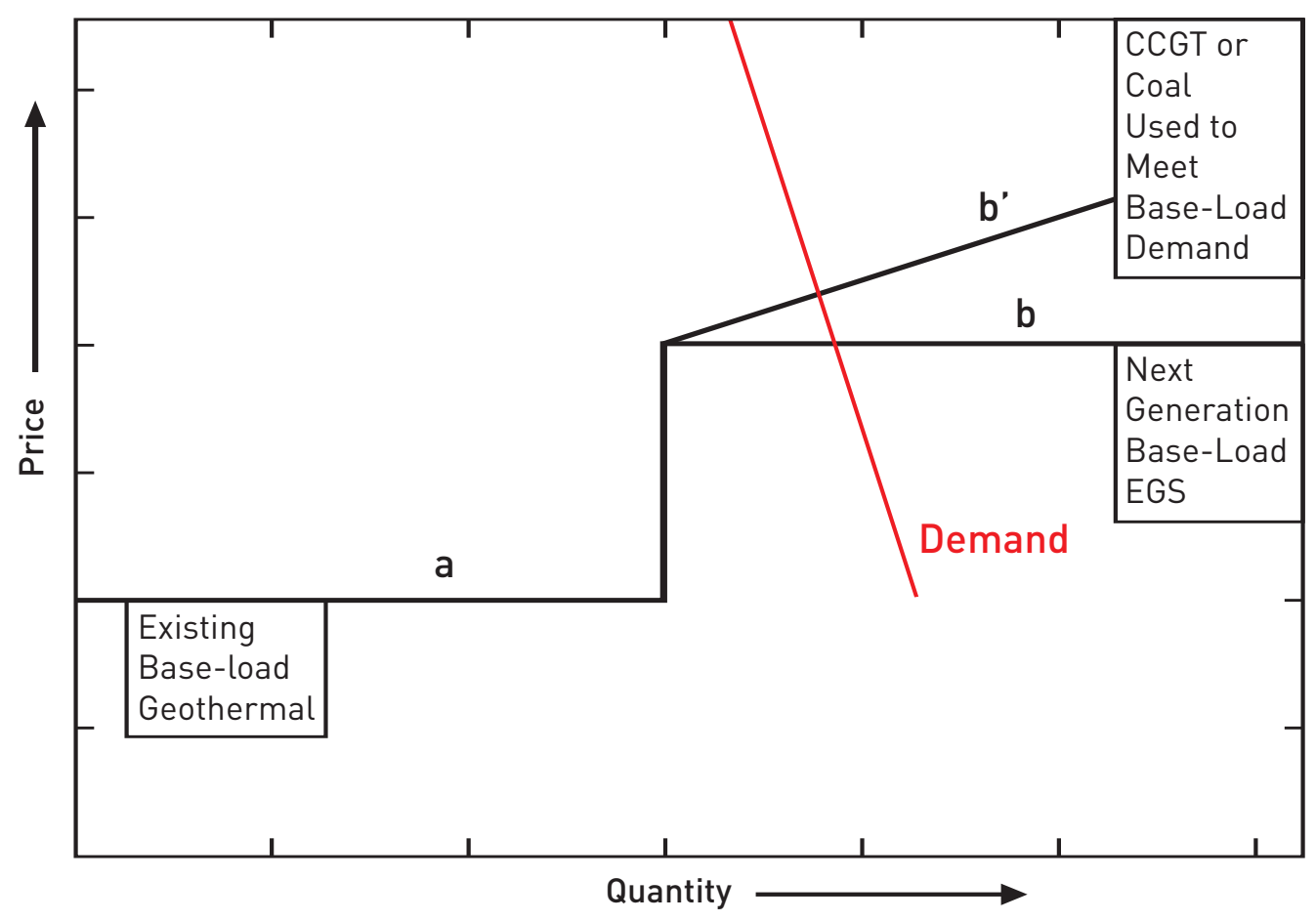

Figure 9.3 Price trends for meeting base-load electricity demand.

\subsubsection{The aggregate industry supply curve}

Generally, supply to meet base-load power requirements is available at different price levels depending on region, available installed capacity, and fuel cost. When looked at from the standpoint of delivered energy in $\$ / \mathrm{MWh}$, and operating characteristics that match the system operations demand (i.e., for base load, peak load following, etc.), the substitution from conventional pulverized coal to supercritical generation will reflect continuously higher-cost options (assuming all operators bid marginal cost).

In addition, each technology has a replacement technology supply curve that is a proxy for efficiency or equivalent substitution in grid operations. The best example of this replacement supply curve is in the area of coal plants (see Figure 9.4). With it, we also have a rough approximation of time of installation and potential capacity factor, each increasing over time and adding to the aggregate supply.

Geothermal plants also exhibit a replacement substitution based on technology of surface conversion, depth to resource, and resource recovery. 


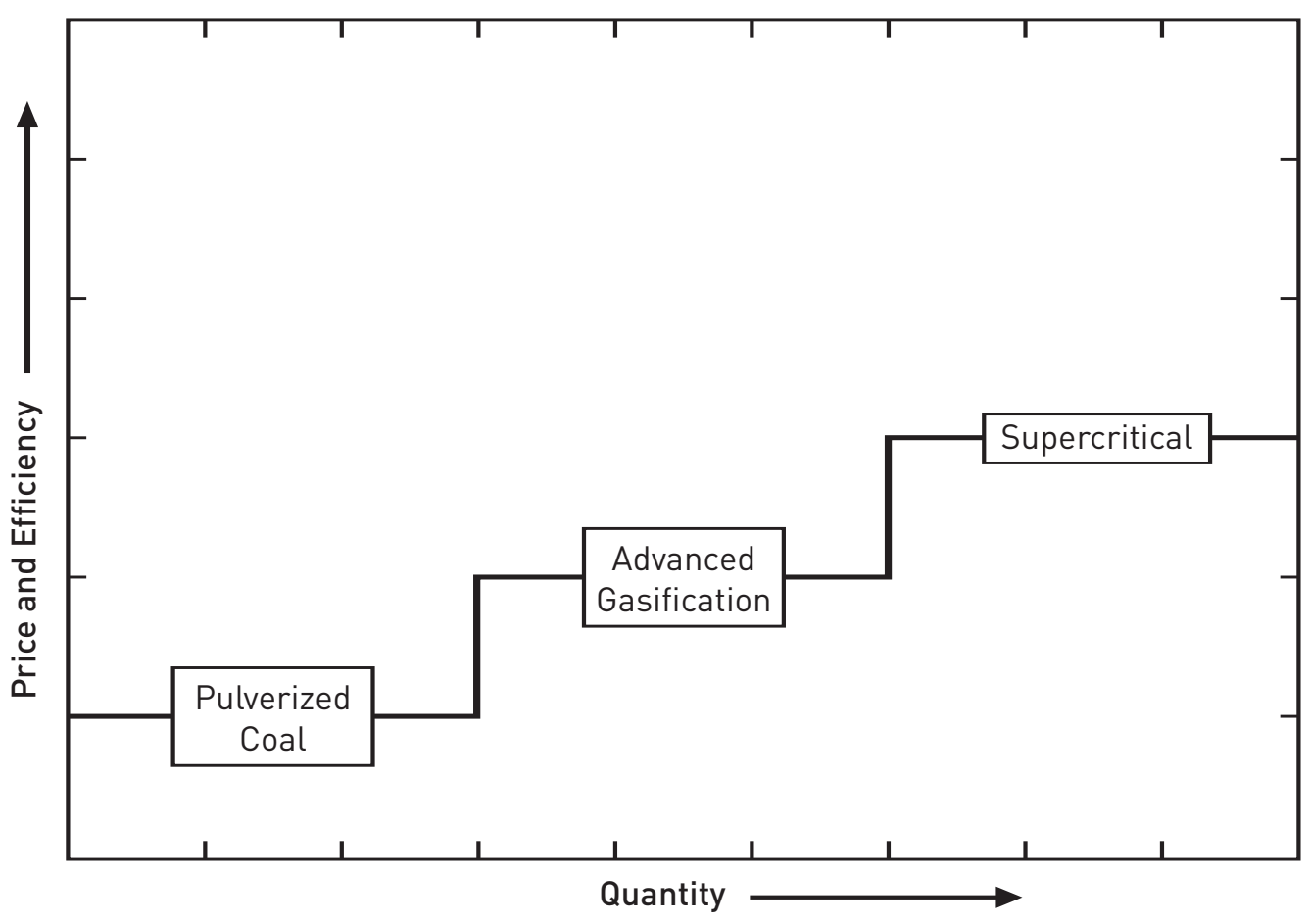

Figure 9.4 Schematic of replacement technology supply curve for coal plants.

\subsubsection{Geothermal supply curve characteristics}

By definition, the supply curve is a relation between each possible price of a given good and the quantity of that good that would be supplied for market sale at that price. This is typically represented as a graph showing the hypothetical supply of a product or service that would be available at different price points. The supply curve usually exhibits a positive slope, reflecting that higher prices give producers an incentive to supply more, in the hope of making greater revenue.

The supply of a "good" such as energy, either in the form of direct heat output or electricity, is dependent on the quality and quantity of the resource available, the technology used to extract it, and the cost of transforming it into a consumable product. Thus, the delivered cost of energy becomes a combination of capital (fixed) and fuel (variable) costs. When levelized over a period assumed to cover fixed costs and increased costs of operation, these technologies vary in terms of characteristics and delivered cost of energy as shown in Table 9.3.

Geothermal energy provides critical value to overall grid operations. While initial capital costs are high, reliability and capacity factors are correspondingly high, with minimal downtime for maintenance and minimal fuel cost through replenishment of lost water in operations. The supply curve for energy from a geothermal system represents a combined range of production that is not traditional from the point of view of a normal economic good, where a price continuum represents the available supplies offered to the market. In this case, a single-well complex represents a "system" of heat delivery and energy transformation. Essentially, the complex is "tuned" to "mine" a given heat resource through a range of depth represented by the well system, the fractured rock strata, and the amount of water that can be injected into the system to extract an optimal level of heat without degradation of the reservoir. 
Base-load needs are typically met by procuring the most inexpensive, nonvolatile, high-capacity-factor energy available. While this can vary by region or by time of day, in general, the most competitive fuel/technology combinations available to satisfy this demand include coal, hydroelectric, nuclear, and geothermal power. Dispatchability means that power can be generated when it is needed to meet peak-system power loads. The primary metrics for dispatchability are the time when the peak load occurs, the length of the peak-load period, and the capacity factor the system must maintain during these periods, exclusive of maintenance periods.

The use of geothermal energy in grid operations adds capacity to existing stock. In terms of capacity available for dispatch, the capacity factor is high. The primary responsibility of hydrothermal geothermal power is in base-load power delivery with very limited load-following capability. However, power plants operating on EGS reservoirs should be much more flexible in following load because the circulation of the fluid through the hot rocks is controlled by pumping. 
Table 9.3 Energy technology characteristics.

\begin{tabular}{|c|c|c|c|c|c|c|}
\hline Technology & $\begin{array}{r}\text { Overnight } \\
\text { cost, } \\
\$ / \mathrm{kW}\end{array}$ & $\begin{array}{r}\text { Total } \\
\text { overnight } \\
\text { (w/ variable } \\
\text { 0\&M) costs, } \\
\$ / \mathrm{kW}\end{array}$ & $\begin{array}{r}\text { Variable } \\
\text { costs, } \\
\text { \$/MWh }\end{array}$ & $\begin{array}{r}\text { Fixed } \\
\text { costs, } \\
\$ / M W h\end{array}$ & $\begin{array}{r}2001 \\
\text { Heat } \\
\text { rate, } \\
\text { Btu/kWh }\end{array}$ & $\begin{array}{c}2010 \\
\text { Heat } \\
\text { rate, } \\
\text { Btu/kWh }\end{array}$ \\
\hline $\begin{array}{l}\text { Conventional } \\
\text { Pulverized Coal }\end{array}$ & 1,046 & 1,119 & 3.38 & 23.41 & 9,386 & 9,087 \\
\hline $\begin{array}{l}\text { Integrated Coal } \\
\text { Gasification }\end{array}$ & 1,250 & 1,338 & 0.8 & 32.67 & 7,869 & 6,968 \\
\hline $\begin{array}{l}\text { Conventional Gas/Oil } \\
\mathrm{CC}\end{array}$ & 435 & 456 & 0.52 & 15.61 & 7,618 & 7,000 \\
\hline Advanced Gas/Oil CC & 546 & 590 & 0.52 & 14.46 & 6,870 & 6,350 \\
\hline $\begin{array}{l}\text { Conventional Gas } \\
\text { Turbine }\end{array}$ & 323 & 339 & 0.1 & 6.45 & 11,380 & 10,600 \\
\hline Advanced Gas Turbine & 451 & 474 & 0.1 & 9.16 & 9,020 & 8,000 \\
\hline Fuel Oil & 1,810 & 2,091 & 2.08 & 14.98 & 5,744 & 5,361 \\
\hline Advanced Nuclear & 1,772 & 2,144 & 0.42 & 57.23 & 10,400 & 10,400 \\
\hline Biomass & 1,536 & 1,725 & 2.9 & 44.95 & 8,911 & 8,911 \\
\hline MSW-Landfill Gas & 1,336 & 1,429 & 0.01 & 96.31 & 13,648 & 13,648 \\
\hline Geothermal & 1,663 & 1,746 & 0 & 70.07 & $32,173^{a}$ & $32,173^{\mathrm{a}}$ \\
\hline Wind $^{\mathrm{b}}$ & 918 & 962 & 0 & 25.54 & N.A. & N.A. \\
\hline Solar Thermal ${ }^{\mathrm{b}}$ & 2,157 & 2,539 & 0 & 47.87 & N.A. & N.A. \\
\hline Solar PV & 3,317 & 3,831 & 0 & 9.85 & N.A. & N.A. \\
\hline
\end{tabular}

${ }^{a}$ Assumes a binary-cycle power plant with $10.6 \%$ net thermal efficiency; flash plants cannot be characterized by a heat rate.

${ }^{b}$ Capacity and availability factors are adjusted for these technologies by each systems operator, reducing available output. 


\subsection{EGS Economic Models}

\subsubsection{GETEM model description}

The Geothermal Electric Technology Evaluation Model (GETEM) is a macro-model that estimates levelized cost of geothermal electric power in a commercial context. This model and its documentation were prepared as required work under a subcontract from the National Renewable Energy Laboratory (Golden, Colo.) to Princeton Energy Resources International (Rockville, Md.). Developed for the U.S. DOE Geothermal Technology Program, GETEM is coded in an Excel spreadsheet and simulates the economics of major components of geothermal systems and commercial-development projects. The model uses a matrix of about 80 user-defined input variables to assign values to technical and economic parameters of a geothermal power project. In general categories, the variables account for geothermal resource characteristics, drilling and well-field construction, power plant technologies, and development of geothermal power projects.

A key feature of the model is that GETEM uses a subset of the input matrix to apply change factors to model components. These factors are targeted to enable a user to investigate the impacts of diverse combinations of changes - ostensibly, improvements - in the performance and unit costs of a project. The impacts are quantified as net levelized energy costs.

GETEM accounts for the gamut of factors that comprise electric power costs - not prices - commonly referred to as "bus-bar costs." GETEM applies documented and expert-interpreted conditions such as reservoir performance, drilling and construction costs, energy conversion factors, and competitive financial frameworks. It uses empirical, industry-based reference data. It is a good tool for evaluating case-specific costs, technology trends, cost sensitivities, and probabilistic values of technology goals. Thus, GETEM enables DOE to quantify the effectiveness of research program elements, using measures that reflect power industry practices.

\subsubsection{Updated MIT EGS model}

"EGS Modeling for Windows" is a tool for economic analysis of geothermal systems. The software was based on work by Tester and Herzog (Tester et al., I990; Tester and Herzog, I99I; Herzog et al., I997) as enhanced by the MIT Energy Laboratory as part of its research into EGS systems sponsored by the Geothermal Technologies Office of the U.S. Department of Energy and further modified by Anderson (2006) as part of the assessment.

This model has been updated using the results of this study with regard to the cost of drilling, plant costs, stimulation costs, and the learning-curve analysis.

\subsubsection{Base case and sensitivity}

Table 9.4 lists the base-case parameters used in the evaluation of the levelized cost of electricity (LCOE) for three different stages of EGS technology: initial (today's technology), midterm, and commercially mature. The plant capital costs, the well drilling and completion costs, and the stimulation costs are based on the results of the earlier chapters on those individual topics. 
Due to the uncertainty of the various rock drawdown models and the variations in rock characteristics across the United States, a drawdown parameter model (Armstead and Tester, I987) was chosen to simulate the drawdown of the reservoir. The impedance per well is based on results from the Rosemanowes, Hijiori, and Soultz circulation tests. The debt and equity rates of return are based on the 1997 EERE Renewable Energy Technology Characterizations report (DOE, I997).

Table 9.5 shows the base case and optimized LCOE for the six sites selected in Chapter 4. The optimization was performed on the completion depth only, and the resulting electricity costs are at base-case conditions. Figures 9.5 and 9.6 illustrate the sensitivity of the levelized electricity costs to eight important reservoir, capital cost, and financial parameters in the MIT EGS model. Figure 9.6 depicts a high-grade prospect, whereas Figure 9.5 shows a low-grade one. As one can discern from the sensitivity analysis, the cost of electricity is most sensitive to the geofluid flow rate, the drilling and completion costs, the thermal drawdown rate, as well as the economic parameters, debt/equity ratio, and the equity rate of return. The nonlinearity of the sensitivity of costs to drawdown rate is a result of the fixed plant lifetime of 30 years and the variability of the interval for reservoir rework/redrilling. Because a small fraction of the total capital cost is in the surface plant (in relation to the drilling cost), the LCOE is relatively insensitive to the surface plant costs for lower-grade resources (Figure 9.5), but the sensitivity increases for higher-grade resources. Although sensitivity plots are shown here for the two extremes in geothermal gradient, the sensitivity at all six sites is shown in Appendix A.9.3. 
Table 9.4 Parameter values for the base case EGS economic models.

\begin{tabular}{|c|c|c|c|}
\hline Parameter description & $\begin{array}{r}\text { Initial Values } \\
\text { (today's technology, } \\
\text { years } 1-5 \text { ) }\end{array}$ & $\begin{array}{r}\text { Midterm Values } \\
\text { (years 5-11) }\end{array}$ & $\begin{array}{r}\text { Commercially } \\
\text { Mature Values } \\
\text { (years 20+] }\end{array}$ \\
\hline Geofluid flow rate per producer & $20 \mathrm{~kg} / \mathrm{s}$ & $40 \mathrm{~kg} / \mathrm{s}$ & $80 \mathrm{~kg} / \mathrm{s}$ \\
\hline Thermal drawdown rate & $3 \% / y r$ & $3 \% / y r$ & $3 \% / y r$ \\
\hline $\begin{array}{l}\text { Number of production wells per } \\
\text { injection well }\end{array}$ & 2 & $2-3$ & 3 \\
\hline $\begin{array}{l}\text { Maximum allowable bottom hole } \\
\text { temperature }\end{array}$ & $350^{\circ} \mathrm{C}$ & $350^{\circ} \mathrm{C}$ & $400^{\circ} \mathrm{C}$ \\
\hline Average surface temperature & $15^{\circ} \mathrm{C}$ & $15^{\circ} \mathrm{C}$ & $15^{\circ} \mathrm{C}$ \\
\hline Impedance per well & $0.15 \mathrm{MPa} s / \mathrm{L}$ & $0.15 \mathrm{MPa} \mathrm{s} / \mathrm{L}$ & $<0.15 \mathrm{MPa} s / \mathrm{L}$ \\
\hline Temperature loss in production well & $15^{\circ} \mathrm{C}$ & $15^{\circ} \mathrm{C}$ & $15^{\circ} \mathrm{C}$ \\
\hline Water loss/total injected & $2 \%$ & $2 \%$ & $1 \%$ \\
\hline $\begin{array}{l}\text { Drawdown parameter } \\
\text { (Armstead and Tester, 1987) }\end{array}$ & $0.000119 \mathrm{~kg} / \mathrm{s} \cdot \mathrm{m}^{2}$ & $0.000119 \mathrm{~kg} / \mathrm{s}^{\cdot} \mathrm{m}^{2}$ & $0.000119 \mathrm{~kg} / \mathrm{s}^{\cdot \mathrm{m}^{2}}$ \\
\hline Well deviation from vertical & $0^{\circ}$ & $0^{\circ}$ & $0^{\circ}$ \\
\hline Well separation & $500 \mathrm{~m}$ & $500 \mathrm{~m}$ & $500 \mathrm{~m}$ \\
\hline Geofluid pump efficiency & $80 \%$ & $80 \%$ & $80 \%$ \\
\hline Capacity factor & $95 \%$ & $95 \%$ & $95 \%$ \\
\hline $\begin{array}{l}\text { Fluid thermal availability drawdown } \\
\text { threshold before rework }\end{array}$ & $20 \%$ & $20 \%$ & $20 \%$ \\
\hline Injection temperature & $40^{\circ} \mathrm{C}$ & $40^{\circ} \mathrm{C}$ & $40^{\circ} \mathrm{C}$ \\
\hline Well casing inner diameter & $7 "$ & 7" & 7" \\
\hline Inflation rate & $3 \%$ & $3 \%$ & $3 \%$ \\
\hline Debt rate of return & $5.5 \%$ & $6.4 \%$ & $8.0 \%$ \\
\hline Equity rate of return & $\mathrm{N} / \mathrm{A}$ & $17 \%$ & $17 \%$ \\
\hline Fraction of debt/equity & $100 / 0$ & $80 / 20$ & $60 / 40$ \\
\hline Plant lifetime & 30 years & 30 years & 30 years \\
\hline Property tax rate & $2 \%$ & $2 \%$ & $2 \%$ \\
\hline Sales tax & $6.5 \%$ & $6.5 \%$ & $6.5 \%$ \\
\hline Drilling contingency factor & $20 \%$ & $20 \%$ & $20 \%$ \\
\hline
\end{tabular}


Table 9.5 Levelized cost of electricity (LCOE) for six selected sites for development.

\begin{tabular}{|c|c|c|c|c|c|c|c|c|c|c|}
\hline \multirow[t]{2}{*}{$\begin{array}{l}\text { Site } \\
\text { Name }\end{array}$} & \multirow[t]{2}{*}{$\begin{array}{c}\partial \mathrm{T} / \partial \mathrm{z} \\
\left({ }^{\circ} \mathrm{C} / \mathrm{km}\right)\end{array}$} & \multirow[t]{2}{*}{$\begin{array}{l}\text { Depth to } \\
\text { Granite } \\
\text { (km) }\end{array}$} & \multirow[t]{2}{*}{$\begin{array}{l}\text { Completion } \\
\text { Depth } \\
\text { I(km) }\end{array}$} & \multicolumn{2}{|c|}{$\begin{array}{l}\text { Fracture Costs } \\
\qquad(\$ \mathrm{~K})\end{array}$} & \multicolumn{2}{|c|}{$\begin{array}{l}\text { LCOE Using Initial } \\
\text { Values for Base Case } \\
\text { [\$/kWh] }\end{array}$} & \multicolumn{3}{|c|}{$\begin{array}{c}\text { Optimized LCOE Using } \\
\text { Commercially Mature } \\
\text { Values ( } \$ / \mathrm{kWh})\end{array}$} \\
\hline & & & & $\stackrel{@}{9} \mathrm{l} / \mathrm{s}$ & $180 \mathrm{l} / \mathrm{s}$ & MIT EGS & GETEM & MIT EGS & GETEM & $\begin{array}{c}\text { Depth } \\
(\mathrm{km})\end{array}$ \\
\hline $\begin{array}{l}\text { East } \\
\text { Texas } \\
\text { Basin }\end{array}$ & 40 & 5 & 5 & 145 & 171 & 29.5 & 21.7 & 6.2 & 5.8 & 7.1 \\
\hline Nampa & 43 & 4.5 & 5 & 260 & 356 & 24.5 & 19.5 & 5.9 & 5.5 & 6.6 \\
\hline $\begin{array}{l}\text { Three } \\
\text { Sisters } \\
\text { Area }\end{array}$ & 50 & 3.5 & 5 & 348 & 450 & 17.5 & 15.7 & 5.2 & 4.9 & 5.1 \\
\hline $\begin{array}{l}\text { Poplar } \\
\text { Dome a }\end{array}$ & 55 & 4 & 2.2 & 152 & 179 & 74.7 & 104.9 & 5.9 & 4.1 & 4.0 \\
\hline $\begin{array}{l}\text { Poplar } \\
\text { Dome b }\end{array}$ & 37 & 4 & 6.5 & 152 & 179 & 26.9 & 22.3 & 5.9 & 4.1 & 4.0 \\
\hline $\begin{array}{l}\text { Clear } \\
\text { Lake }\end{array}$ & 67 & 3 & 5 & 450 & 491 & 10.3 & 12.7 & 3.6 & 4.1 & 5.1 \\
\hline $\begin{array}{l}\text { Conway } \\
\text { Granite }\end{array}$ & 26 & 0 & 7 & 502 & 580 & 68.0 & 34.0 & 9.2 & 8.3 & $10^{*}$ \\
\hline
\end{tabular}

*10 km limit put on drilling depth - MITEGS LCOE reaches $7.3 \$ / \mathrm{kWh}$ at $12.7 \mathrm{~km}$ and $350^{\circ} \mathrm{C}$ geofluid temperature.

We have created a series of sensitivity graphs to illustrate the sensitivity of the levelized electricity costs to eight important reservoir, capital cost, and financial parameters in the MIT EGS model. The first graph illustrates the base case itself, and the following tables illustrate the range of difference both by location and by changes in the key characteristic of flow rates. 
Initial Base-Case Values (see Table 9.4)

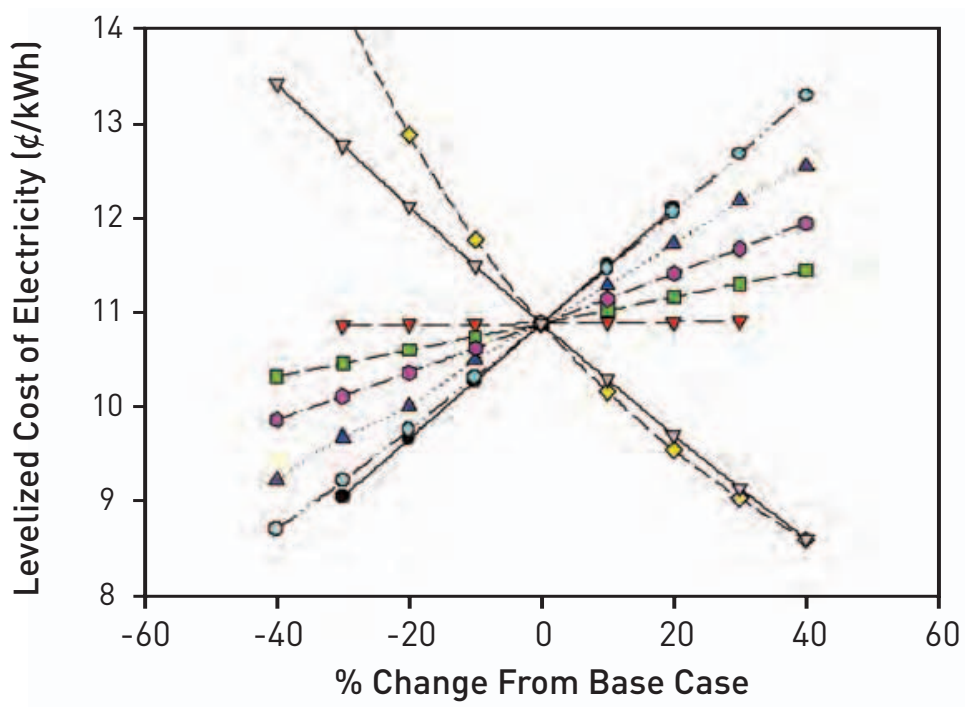

\begin{tabular}{|c|c|c|}
\hline $\begin{array}{c}\longrightarrow \\
-\rightarrow-\end{array}$ & $\begin{array}{l}\text { Drilling \& Completion Cost } \\
\text { Stimulation Cost } \\
\text { Surface Plant Capital Cost } \\
\text { Flow Rate/Production Well }\end{array}$ & 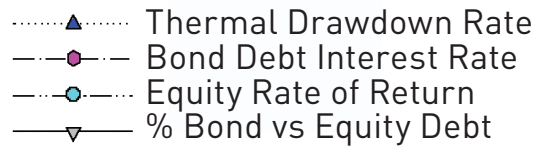 \\
\hline
\end{tabular}

Commercially Mature Values (see Table 9.4)

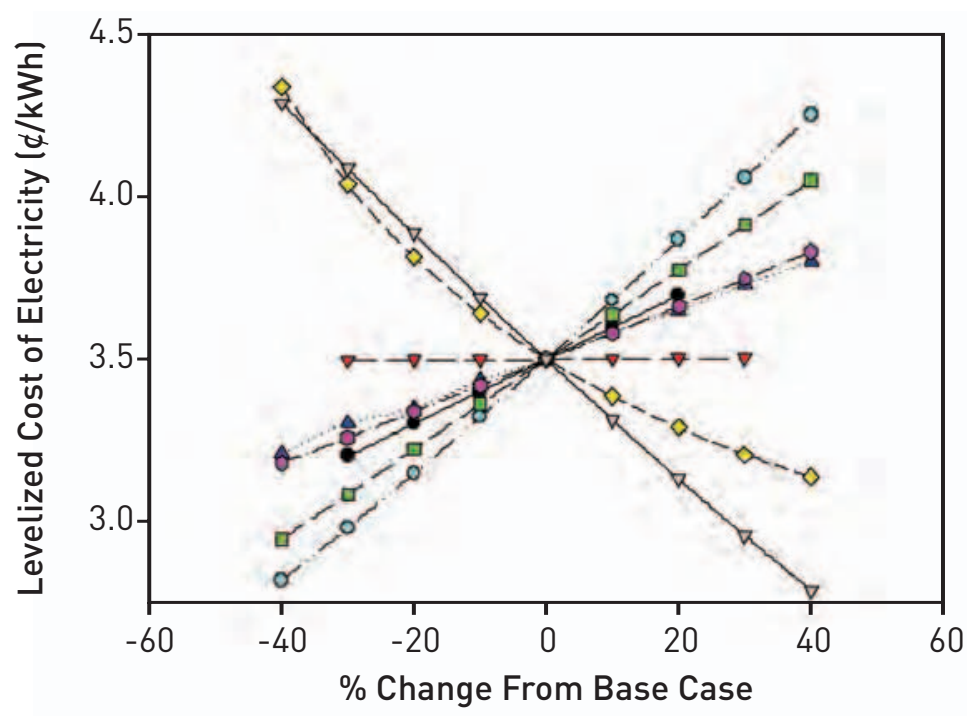
$\longrightarrow$ Drilling \& Completion Cost
$\rightarrow-$ Stimulation Cost
$-\rightarrow-$ Surface Plant Capital Cost
$--\diamond--$ Flow Rate/Production Well
…......... Thermal Drawdown Rate
-.- Bond Debt Interest Rate
-..-o.... Equity Rate of Return
$\longrightarrow$ \% Bond vs Equity Debt

Figure 9.5 Sensitivity of EGS LCOE for the Clear Lake (Kelseyville, Calif.) scenario using: (a) initial base-case values, and (b) commercially mature values. 
Initial Base-Case Values (see Table 9.4)
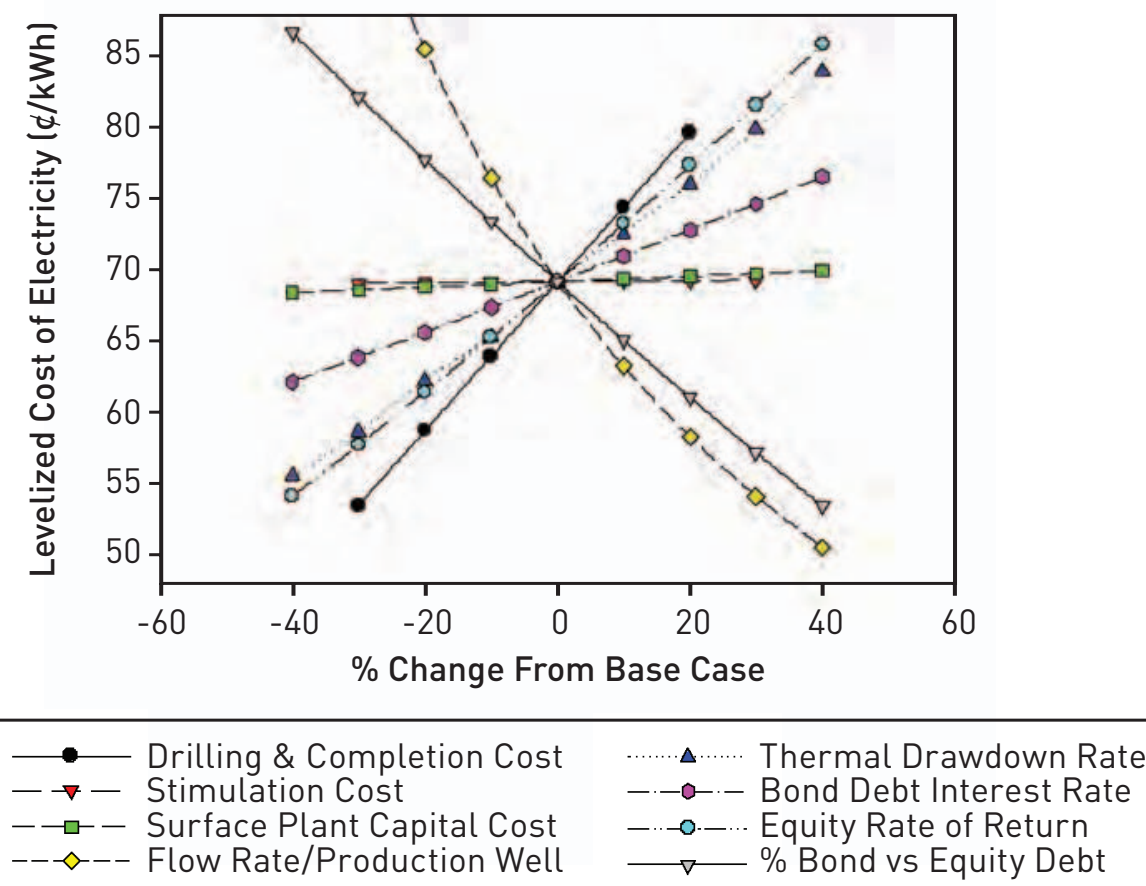

…......... Thermal Drawdown Rate

- - - - Bond Debt Interest Rate

-...-.... Equity Rate of Return

$\longrightarrow$ \% Bond vs Equity Debt

Commercially Mature Values (see Table 9.4)

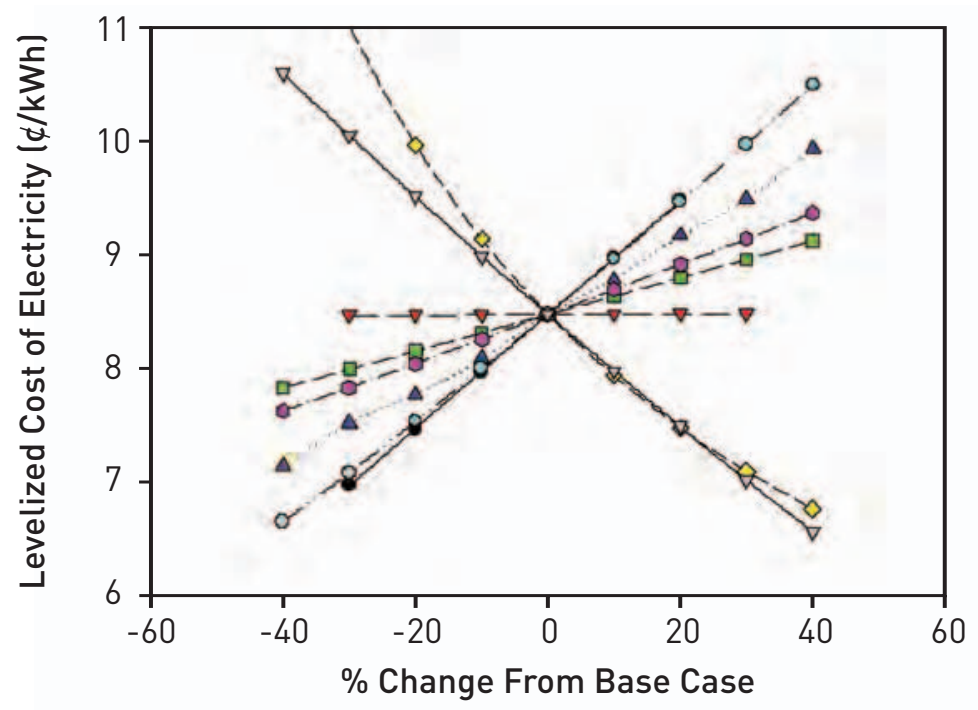

$$
\begin{aligned}
& \longrightarrow \text { Drilling \& Completion Cost } \\
& -\rightarrow-\text { Stimulation Cost } \\
& -\rightarrow-\text { Surface Plant Capital Cost } \\
& --\diamond-- \text { Flow Rate/Production Well }
\end{aligned}
$$

Figure 9.6 Sensitivity of EGS LCOE for the Conway, N.H., scenario using: (a) initial base-case values, and (b) commercially mature values. 


\subsection{Supply Curves and Model Results}

Today, geothermal power is considered base-load capacity because it is fully available year-round, 24 hours a day. A utility could use a base-load supply curve for planning purposes in one of two ways. They can determine how much renewable base-load capacity they might buy for a certain price, and they can see what they would have to pay for capacity equal to their needs.

The supply of power available from current and future generating facilities is, by definition, a reflection of access to heat reserves. The heat reserves, in turn, are accessible only as drilling and fracturing techniques are improved and demonstrated to be economically competitive.

The North American continent and, by definition, the United States, is underlain by a vast heat resource varying in heat and consequent power potential as a function of depth and transmissivity. The supply of energy available can be portrayed in a variety of ways, each reflecting technology and access over time.

The ultimate resource is virtually infinite, but inaccessible. That is, if it were possible to drill to depths where $>350^{\circ} \mathrm{C}$ heat stores were available, fracture the rock at that depth, and gain access to reservoirs created as a result, then all basement rock on the continent would be a source of EGS. As a practical matter, this is not likely to occur within the next 50 years, so we have arbitrarily limited the estimates of available energy by assuming aggressive, but historically proven, learning and technology application scenarios.

Modeling a resource with infinite capacity requires arbitrary assumptions on the resource recovery. We can access relatively shallow resources with hydrothermal electric technologies and drilling techniques, which effectively defines current technology. Expansion and exploration into new land areas with these technologies offers the first example of a long-term supply curve, which expands to satisfy demand as a function of applying new capital with existing technology and expands the supply curve outward.

As technology and drilling techniques improve, access to deeper and more productive reserves become available. ${ }^{16}$ This can be described by dividing the total resource available at depths shallower than $3 \mathrm{~km}$ for near-term development and the remaining much-larger resource at depths greater than $3 \mathrm{~km}$ for long-term development.

Technically, it is impossible to know how large the unidentified EGS resource might be. Muffler and Guffanti (I979) and Renner et al. (I975) speculate that this unidentified hydrothermal resource could be anything from twice to five times the identified resource. An ongoing study by Petty and others (Petty and Porro, 2006) also estimates the EGS portion of the geothermal supply.

The result can be illustrated by a set of supply curves that describe the available resource over time. These curves demonstrate how the available EGS resource is being utilized with incremental access to it, starting as an expansion of existing, high-grade hydrothermal resources and ending with lowgrade conduction-dominated basement rock EGS resources at depths greater than $3 \mathrm{~km}$. 
The cumulative or ultimate supply of EGS available represents the resource as a function of expected and competitive advances in technology over the time horizon of approximately 50 years. Here, we assume that technology is employed in increments to satisfy increased demand for base-load power, and price is not a limiting factor. That is to say, in this scenario, technology is available as needed and only the supply of the resource matters; the result is a traditional supply curve as shown in Figure 9.7. We also assume that in this period, a conservative estimate of the available resource is accessed. This figure is limited to $2 \%$ of the total resource available and yields in excess of $70,000 \mathrm{GW}_{\mathrm{e}}$ in the planning horizon.

This type of supply curve illustrates how much power from a particular resource is available at or below a certain price. This curve suggests that access to available power is solely a function of price and effectively assumes that capacity is, thus, available for economic dispatch as needed. This type of curve, which is used by the electric power industry for long-term resource planning, is developed for a fixed point in time based on the cost of generating that power and the amount of power available at that time at that price.

For emerging technologies such as concentrating solar power, integrated coal gasification, residual cellulosic biomass to ethanol, and EGS, there are no data available on how large-scale commercial systems will perform, how many of these there might be, and how the price will change with time. The supply curves must be developed based on the future improvement in technology that is likely to occur, as well as the cost of constructing the plant and ancillary systems.

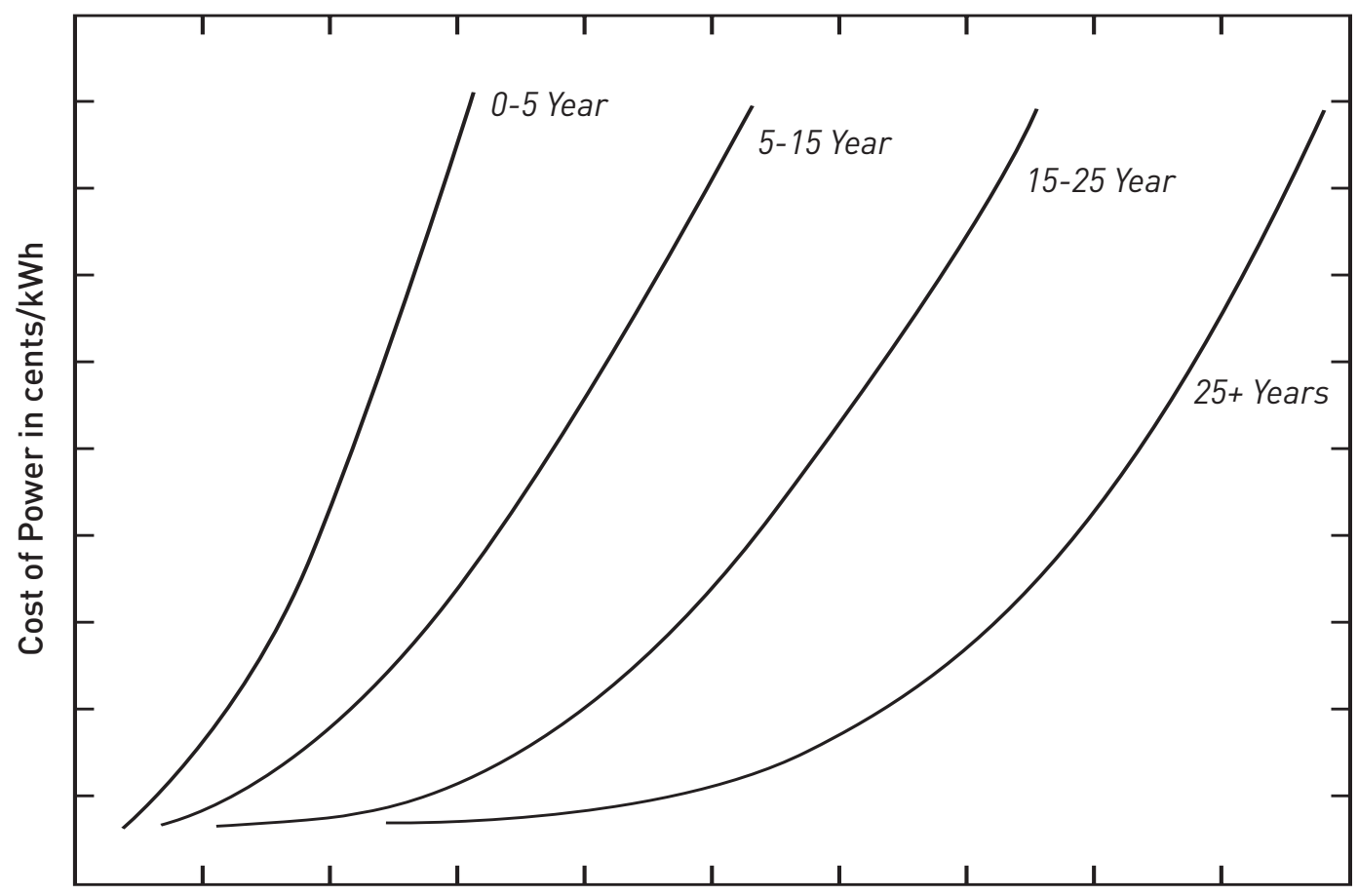

Power Available at or Below Cost in $\mathrm{MW}_{\mathrm{e}}$

Figure 9.7 Traditional form of an electricity supply curve. 


\subsubsection{Supply of EGS power on the edges of existing hydrothermal systems}

As geothermal developers drill outward away from the best and most permeable parts of current highgrade hydrothermal fields, they often encounter rock that has high temperatures at similar or deeper depths than the main field, but with lower natural permeability. It is becoming routine for geothermal developers to stimulate these lower permeability wells to increase fluid production rates up to commercial levels. Pumping large volumes of cold water at high rates over a short period, treating with acid, or injecting cold water at lower rates for a long period all are regularly used to try to improve well productivity on the edges of hydrothermal systems. However, this is most successful when the stimulated wells are in hydrologic connection with the wells in the main part of the reservoir. When the lower permeability well is not connected to the main reservoir, it and the associated hightemperature rock reservoir can be treated as a separate EGS project. For instance, Well 23-I at Desert Peak in Nevada is of this type and is currently part of a U.S. DOE-sponsored EGS research study. It may be possible to stimulate the Desert Peak well, drill production wells around it, and create a viable EGS reservoir.

In other areas, a hydrothermal resource has been identified, but it is not permeable enough to be commercial, and so is not being developed. The EGS resources in these low-permeability hydrothermal areas and on the edges of identified hydrothermal systems could be considered "identified" EGS systems. They are likely to be developed earlier than the deeper EGS systems because they tend to be associated with high conductive gradients instead of convective temperature anomalies. Because the hydrothermal sites have been identified in USGS Circular 790 (Muffler and Guffanti, I979) with updates by Petty et al., (I991), the associated EGS resource could be calculated by subtracting the fraction of the hydrothermal resource deemed commercial in the near term from the totals found as part of these earlier studies. It is assumed that these noncommercial resources will require stimulation to produce at commercial rates before they can be considered EGS resources.

While the reserves of recoverable energy in these identified EGS resources can be assessed in the same way that a hydrothermal system is assessed - by a volumetric heat calculation - there is probably an equal or greater "unidentified" EGS resource associated with convective temperature anomalies that have not been discovered yet. Because the resource-base estimates in our study start at a depth of $3 \mathrm{~km}$, the identified and unidentified EGS resource associated with existing hydrothermal resources are not included in this calculated reserve. For this reason, the identified and unidentified EGS resource was calculated separately.

Using a costing code (GETEM) (see Section 9.9.I), the forecast cost of power was calculated based on current capabilities in EGS technology with the specific temperatures and depths for each identified resource. Each of these identified EGS resources has a depth and temperature based on the data available from the hydrothermal resource associated with it, or one similar to it, if there is no associated resource. Flow rates were based on the current best-available flow from the longest test at the Soultz projects, which has produced the highest observed sustained production flow rates from an EGS reservoir. The available power was then ranked by cost and a cumulative amount of power plotted against the associated cost of power. The result is a forecast total supply curve shown in Figure 9.8. This supply curve assumes that technology is applied as needed, in response to competitive market signals to deliver power for dispatch in the existing system. It is simplistic in the assumption that there are no limits to transmission or available land sites beyond the restrictions of public parks, military, or existing urban facilities. 


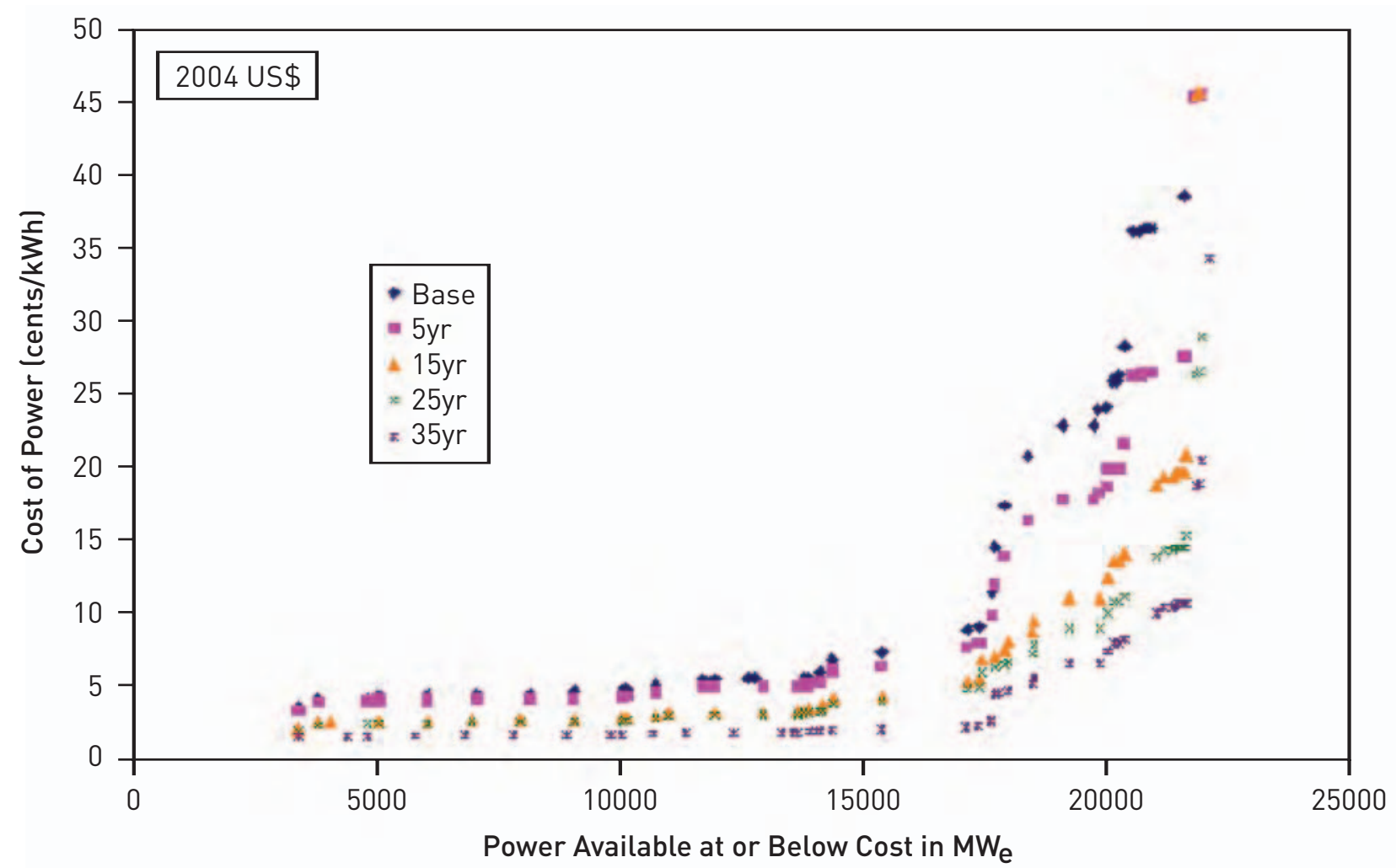

Figure 9.8 Predicted supply curves using the GETEM model for identified EGS sites associated with hydrothermal resources at depths shallower than $3 \mathrm{~km}$. The base case corresponds to today's technology and the 5-, 15-, 25-, and 35-year values correspond to the state of technology at that number of years into the future.

The GETEM code also allows the user to change cost multipliers to calculate the impact of technology improvement. To look at the future cost of power from the identified EGS resources, the research targets from drilling, conversion, and EGS research sponsored by the federal government were used as multipliers in the GETEM code. The future cost of power was also calculated based on both the learning experience expected from the long-term test upcoming at Soultz, Cooper Basin, and other EGS projects, as well as on the projected improvements from the DOE Geothermal strategic plan and the multiyear program plan. These cost multipliers were entered into the GETEM code to calculate a 5-, I5-, 25-, and 35-year cost of power. Of course, the magnitude of cost improvements in the long term are highly speculative and depend on achievements from a continuing aggressive R\&D program, both in the United States and in other countries.

\subsubsection{Supply of EGS power from conductive heating}

The EGS thermal resource described in Chapter 2 is due primarily to conduction-dominated effects at depths below $3 \mathrm{~km}$. This resource is more evenly distributed throughout the United States than geothermal resources that are naturally correlated with hydrothermal anomalies. Starting from the heat-in-place calculations described in Chapter 2, the accessible and recoverable heat were calculated and converted to electric power for each depth and average temperature. This allows us to use the GETEM costing code with the depth and temperature as input with current technology and the cost for fracturing determined for this study to produce a supply curve for the entire United States (Figure 9.9). The assumption used for the flow rate in the current supply curve is based on the flow rate 
achieved during the longest flow test at the Soultz project. The fracturing cost used in the model runs is twice the average of the costs shown in Table 5.2 (Chapter 5), approximately $\$ 700,000$. The other inputs for GETEM were assumed to be similar to current technology as demonstrated at the Soultz project. For the five-year costs, the goals of the U.S. DOE Geothermal Technology Program MYPP were used, along with the assumption that the Soultz long-term test will be successful at maintaining $50 \mathrm{~kg} / \mathrm{s}$ flow for an extended time period.

The supply curve shown in Figure 9.9 provides an estimate of the electric power capacity potentially available assuming a 30-year project life (x-axis), at or below a cost in third-quarter 2004 dollars shown on the y-axis. It illustrates the shift likely from small increases in base-load power contract prices. Figure 9.9 shows the dramatic influence on the price expected, given improvements in technology and more extensive field experience.

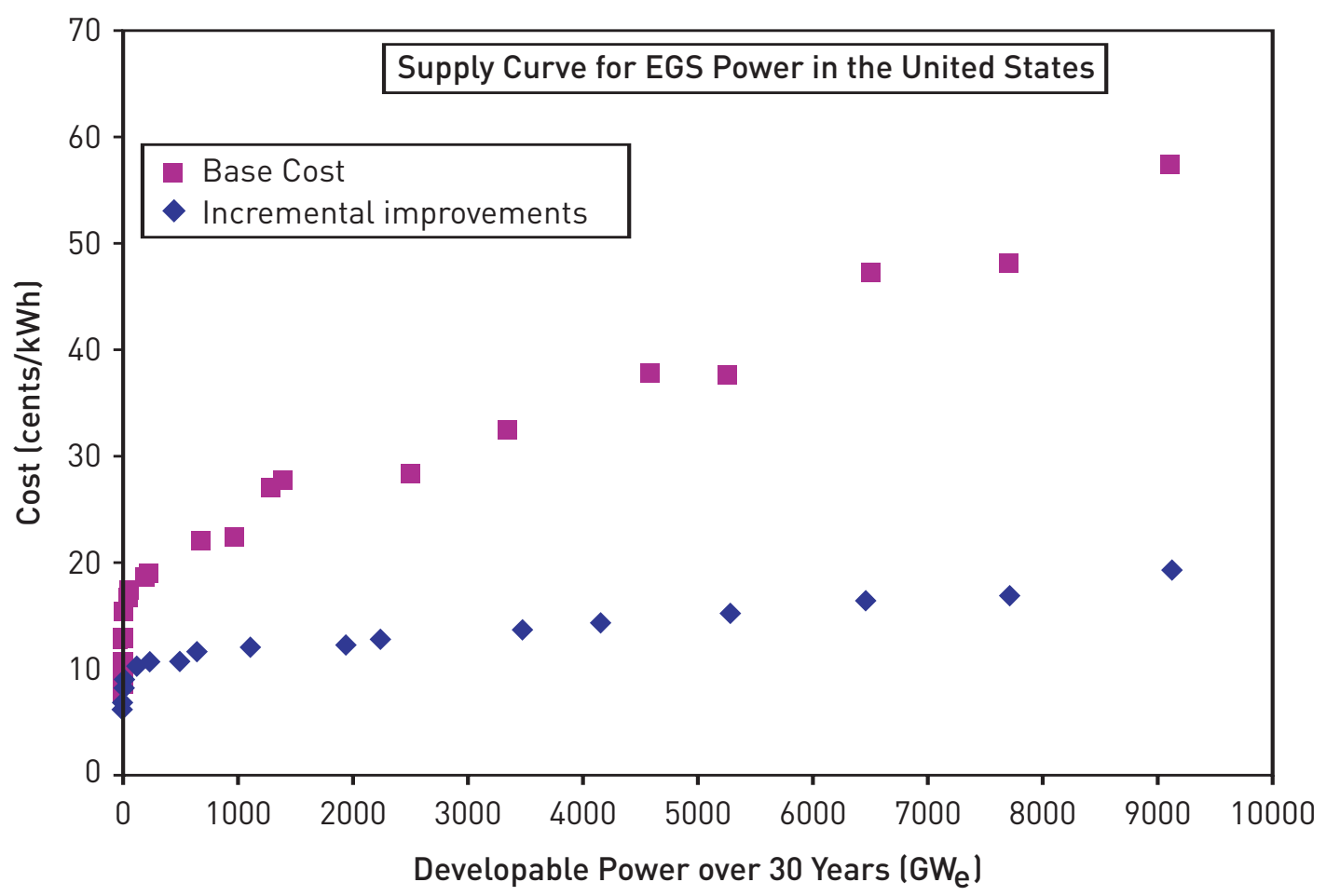

Figure 9.9 Supply of developable power from conductive EGS sources at depths greater than $3 \mathrm{~km}$ at cost of energy calculated using GETEM model for base case as shown in Table 9.4. This includes incremental improvements only from DOE Geothermal Technology Program Multiyear Plan.

\subsubsection{Effects of learning on supply curves}

A second type of supply curve illustrates the effect of increased knowledge of the resource and applications of technology needed to recover it. The learning curve process is illustrated in Figure 9.IO, showing the increased efficiency on a field-by-field basis (field learning) and the cumulative effect on the installed base of power systems (technology learning) capacity.

Applying this learning curve to satisfy market demand assumes access to land and transmission facilities where power can be delivered to markets. For analytic purposes, we assume that this can be modeled as a dynamic but orderly increase in available supplies when the resource is competitively 
priced. This supply relationship is shown in Figure 9.II and demonstrates the dynamic effects of field information and drilling experience, as well as the benefits of applying new technologies as power projects are developed. Here, the combination of increased drilling depth, diminished drilling cost, increased fracture, and consequent flow rate enable increased cumulative installed capacity.

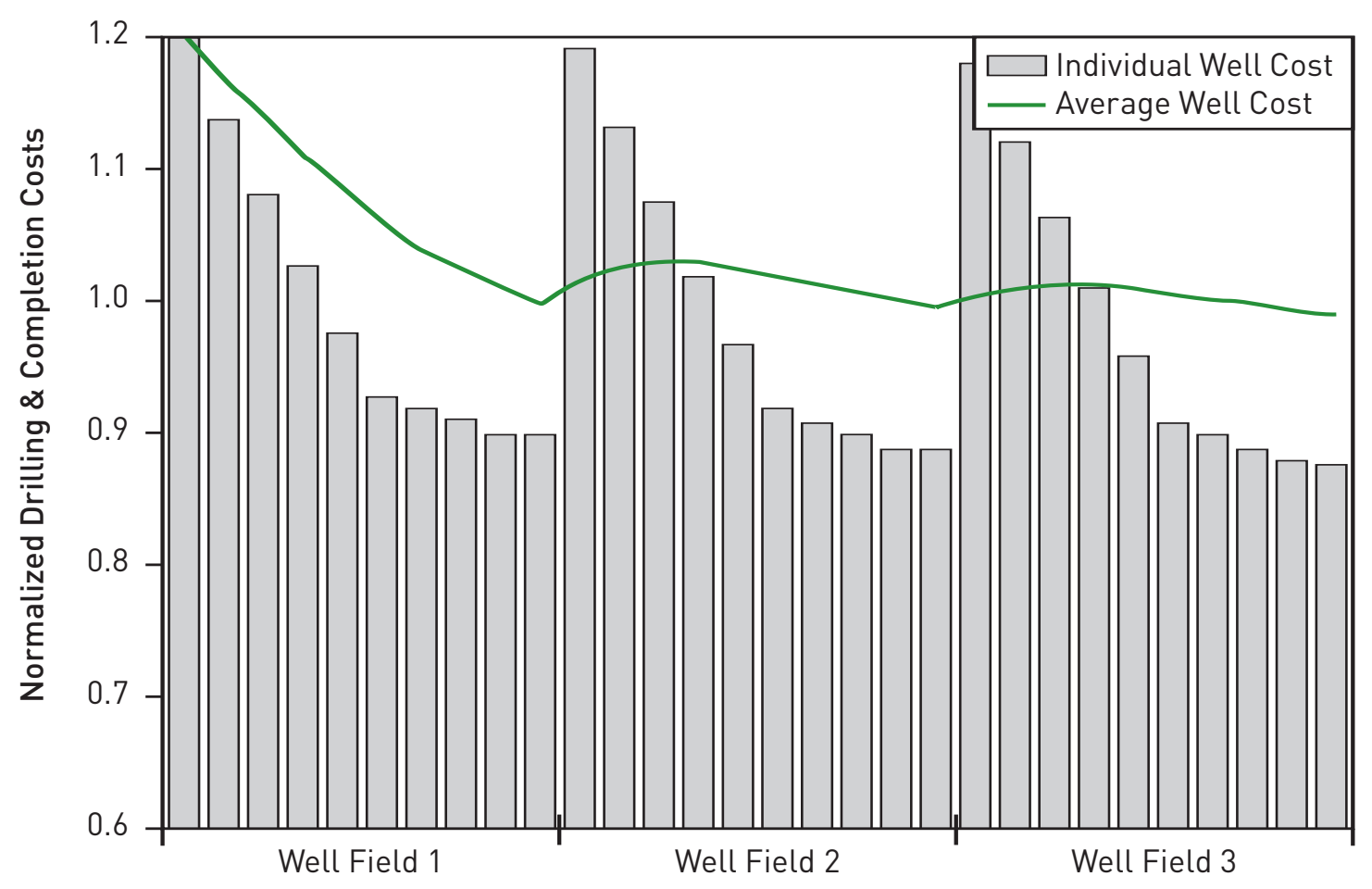

Figure 9.10 Drilling-cost learning curve illustrating the learning process that occurs within each well field. Base case includes a $20 \%$ contingency factor to account for nonrotating costs. 


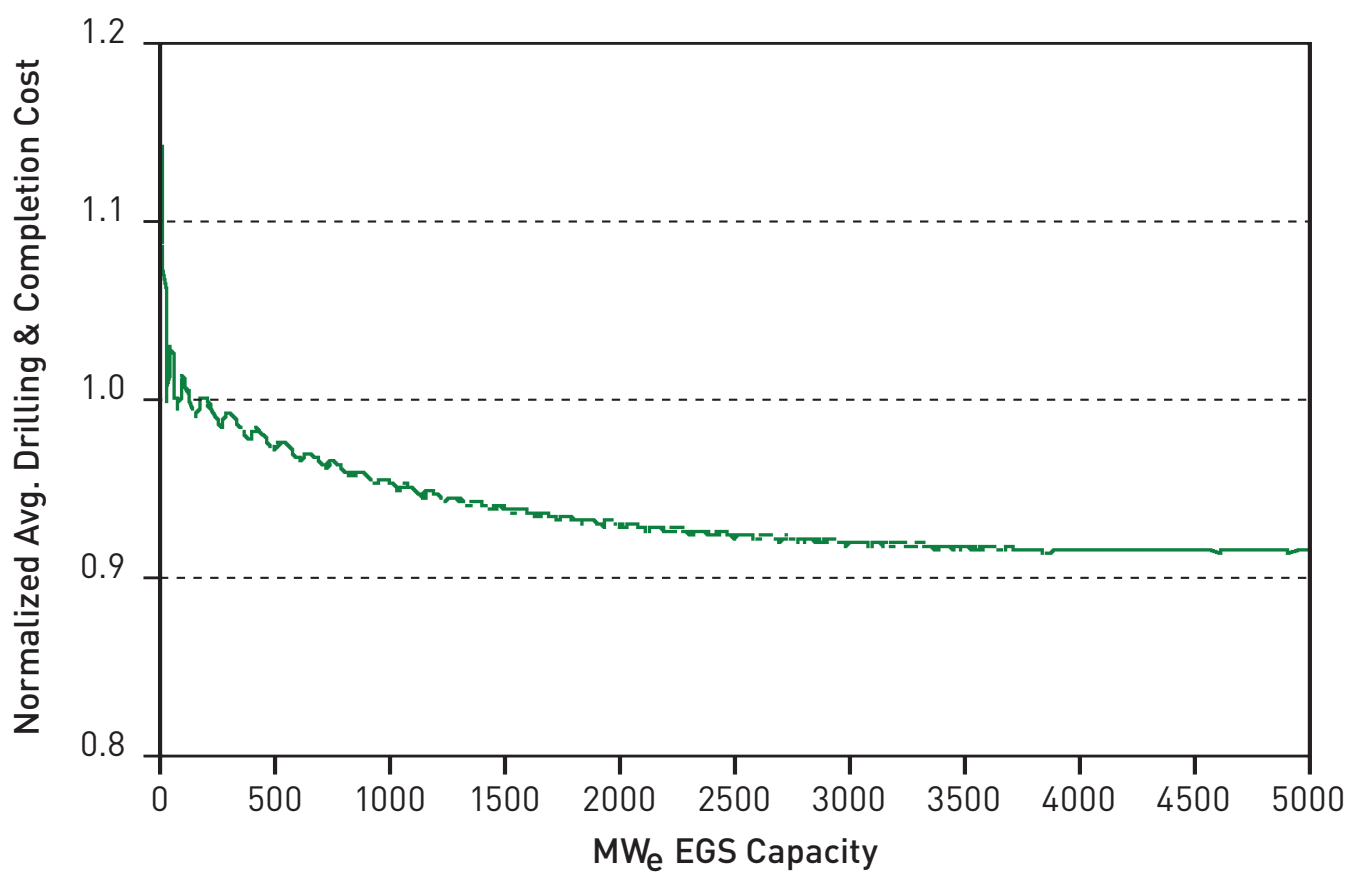

Figure 9.11 Drilling-cost reduction curve illustrating the effects of R\&D-driven technology improvement on the initial well cost in a given well field. Base case includes a $20 \%$ contingency factor to account for nonrotating costs.

\subsubsection{Supply curve for EGS}

The supply curve for EGS has been derived as a function of depth to resource, estimated temperature at depth, the assumed flow, and drawdown rate for the reservoir. Rock at depth must either possess fracture characteristics that allow hydraulic flow or can be fractured to allow flow of sufficient volume to provide an adequate heat source and sustain a drawdown that maintains economic conditions for a reasonable period of time. These criteria can be met in a variety of geographic areas, at different depths depending on the underlying geologic formations and structural characteristics. We have used other limiting conditions to create aggregate estimates of supply, including an estimate of the gross potential of the resource available for each temperature/depth regime, and limited to a recovery factor of $2 \%$ and a power delivery per well field complex of $50 \mathrm{MW}_{\mathrm{e}}$. This definition is arbitrary but convenient in terms of power generation facilities and surface heat-collection systems.

Each well complex is based on a system of wells (I injector, and 3 producers) that are arrayed to maximize access to the underground resource while minimizing the surface footprint (see Figure 9.I2). Access to the resource is assumed to be completed in sequence, matching drilling experience. We assumed that more efficient techniques and growing confidence in fracturing and reservoir stimulation will allow access to continually deeper resources. Thus, the supply curves are time sensitive, with the highest near-term resource development and access occurring in areas with the highest geothermal temperature gradient. These areas have rock temperatures that reach $300^{\circ} \mathrm{C}$ at depths between 3 and $5 \mathrm{~km}$. The higher costs for accessing and stimulating the resource at greater depths is ultimately offset in the modeling of the supply curve by greater yields in terms of heat recovery over longer periods of time (productivity and reliability), leading to lower unit costs of electricity generation over time. 


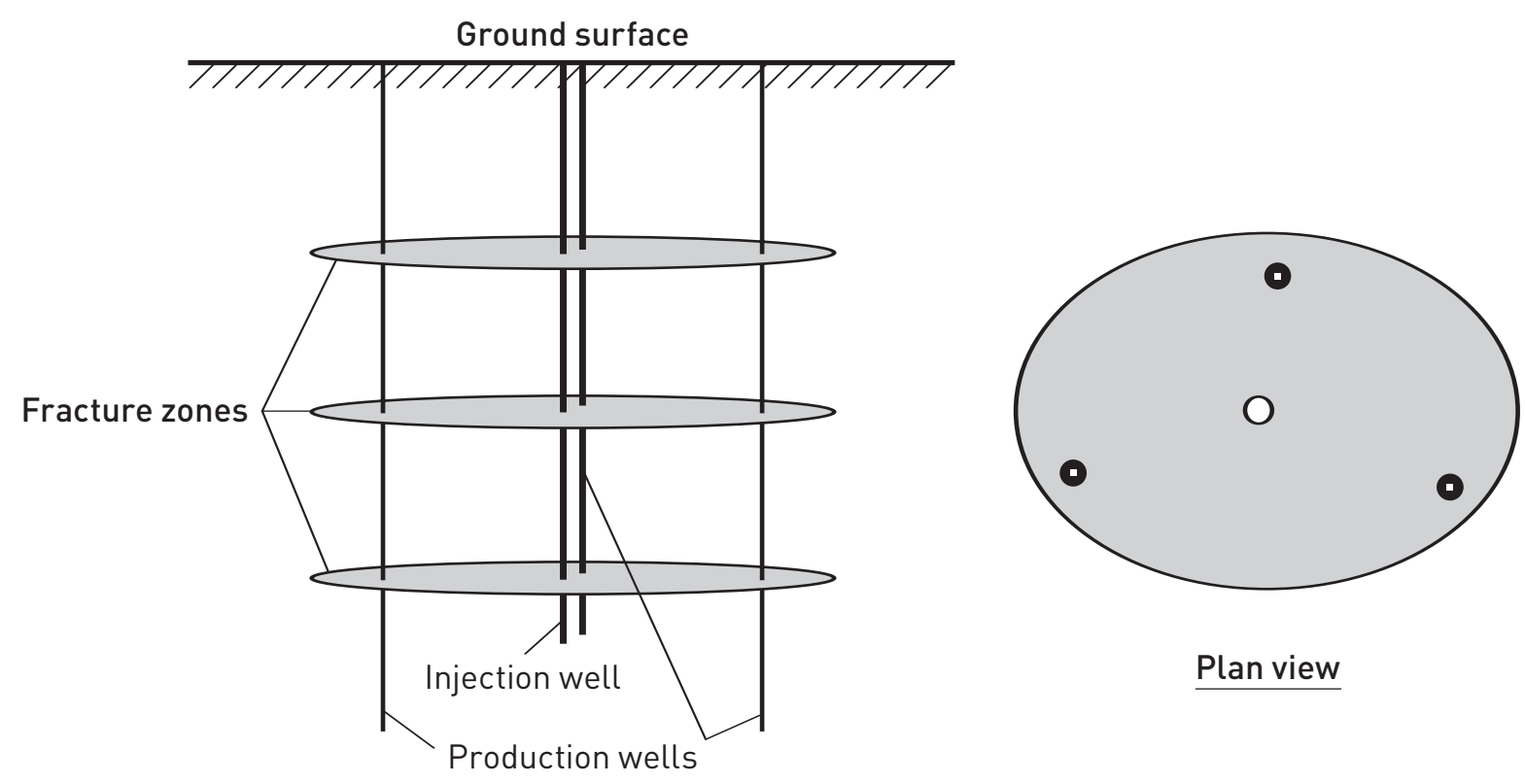

\section{Elevation view}

Figure 9.12 Schematic of the quartet well-field complex and expected fracture stimulation zones at intervals.

\subsubsection{EGS well characteristics}

For development of the supply curves, we have assumed that production wells are drilled in triplets and complexes that yield approximately $50 \mathrm{MW}_{\mathrm{e}}$ of base-load power and are arrayed in modules that optimize yield from the entire resource base as a function of depth and temperature. We have assumed fracture and stimulation of zones around the corresponding well depth that have an average radius of 500 meters and a swept area of $5,000 \mathrm{~m}^{2}$ per fracture zone. This is illustrated in Figure 9.I2 for a quartet configuration. A well complex producing $50 \mathrm{MW}_{\mathrm{e}}$ would have between 30 and 40 wells, depending on subsurface conditions.

\subsection{Learning Curves and Supply Curves}

Assuming that sufficient R\&D funds have supported a successful deployment of several firstgeneration EGS plants, the stage is set for commercial development of EGS, where learning effects will influence costs. Accessing proportionally larger amounts of the EGS resource base is expected to result in greater economies of scale for delivered power. This will translate into lower average costs per well as a function not only of wells drilled per field, but wells drilled regionally as well. This learning curve concept has been assessed and applied for almost three decades in oil and gas drilling (Ikoku, I978; Brett and Millheim, I986) as well as across a number of energy conversion technologies (McDonald and Schrattenholzer, 200I). We have assumed a cost reduction of $5 \%$ per well through the first five wells in a complex, with $\mathrm{I} \%$ per well for the next five wells, and constant drilling costs beyond that point - a cost reduction realized through the decrease in "trouble" (Kravis et al., 2004) (see Figure 9.13). This sequence is likely to be repeated in new complexes with a maximum reduction in expected drilling costs of $25 \%$ overall through the life of the well complex. Because each well is 
expected to be redrilled or improved three times during its lifetime, the cost reduction applies to the total capital cost of the well through the lifetime, because knowledge gained in the initial drilling will be transferred to future exploration.

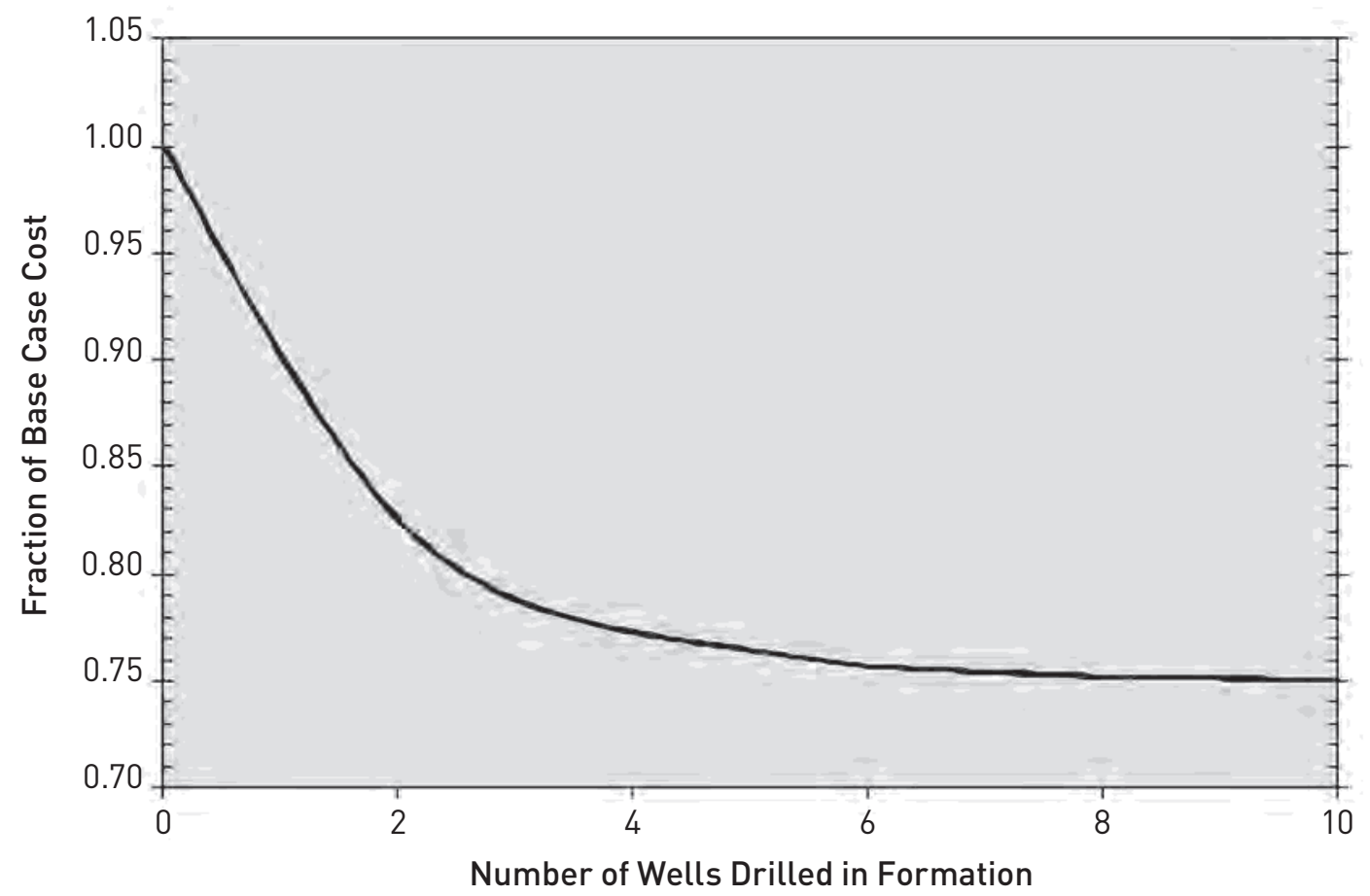

Figure 9.13 Learning curve influence on drilling cost.

A similar learning curve is expected for fracturing and stimulation costs, plant capital expenditures, plant and wellfield O\&M costs, and exploration success (see Table 9.6 and Figure 9.I4). Learning curves are modeled using the following functional form:

$$
\operatorname{Cost}\left(M W_{c u m}\right)=C_{1}+C_{2} \exp \left[-C_{3}\left(M W_{c u m}-M W_{r e f}\right)\right]
$$

where

$M W_{\text {cum }}=$ Cumulative EGS capacity installed under various supply scenarios $M W_{r e f}=$ Reference installed capacity for which cost is reliably known

$C_{i}=$ empirical fitted parameters in Eq. (9-12) that are correlated to specific learning curve behavior

$C_{1}=$ Technical limit achievable

$C_{2}=$ Learning potential

$C_{3}=$ Learning rate. 
Table 9.6 Learning curve parameters.

\begin{tabular}{l|l|l|l|l|l|l|l}
\hline Variable & $\begin{array}{l}\text { O\&M } \\
\text { plant }\end{array}$ & $\begin{array}{l}\text { O\&M } \\
\text { well field }\end{array}$ & $\begin{array}{l}\text { O\&M } \\
\text { staff }\end{array}$ & $\begin{array}{l}\text { Exploration } \\
\text { Success }\end{array}$ & $\begin{array}{l}\text { Well } \\
\text { Cost }\end{array}$ & $\begin{array}{l}\text { Plant } \\
\text { Capital } \\
\text { Costs }\end{array}$ & $\begin{array}{l}\text { Well Casing inside } \\
\text { Diameter ID (in) }\end{array}$ \\
\hline$C_{1}$ & 0.5 & 0.65 & 0.8 & 1.1 & 0.75 & 0.7 & 12 \\
\hline$C_{2}$ & 0.5 & 0.35 & 0.2 & -0.1 & 0.25 & 0.3 & 5 \\
\hline$C_{3}$ & 0.003 & 0.002 & 0.004 & 0.004 & 0.060 & 0.0002 & 0.003 \\
\hline
\end{tabular}

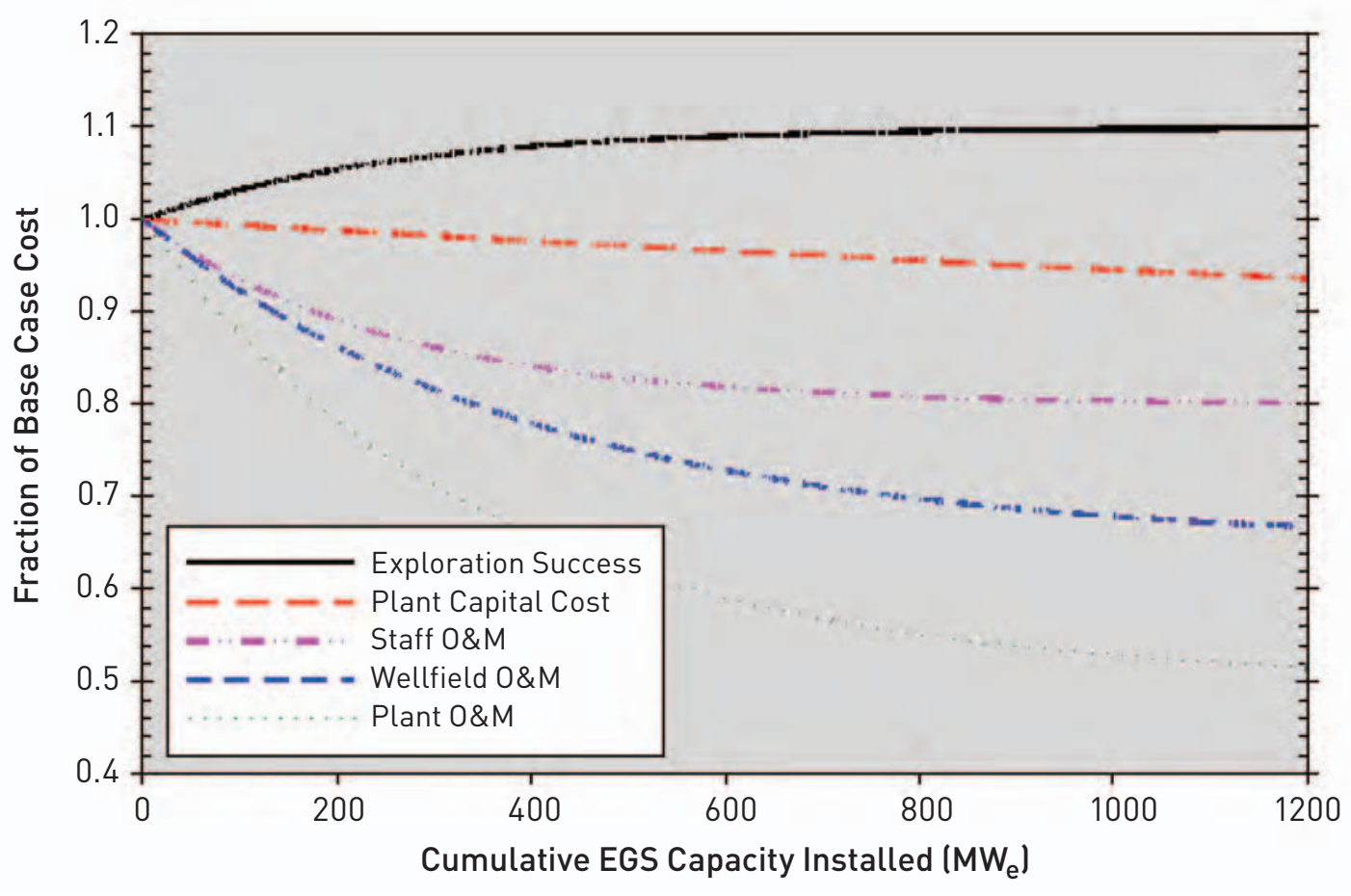

Figure 9.14 Learning curves for various EGS LEC parameters.

The learning curve for well drilling and stimulation translates into increased access to overall resource expressed as supply available at depth. The plant capital cost learning curve is based on the existing hydrothermal capacity and learning parameters from turbine technology cost improvements (MacGregor et al., I99I; Nakićenović et al., I998; McDonald and Schrattenholzer, 200I). The O\&M learning curves are based on economies of scale considerations and plant automation techniques.

As discussed earlier, the geothermal LEC is highly sensitive to the flow rate achieved from each production well. This parameter is also highly uncertain and unproven. Circulations of greater than $20 \mathrm{~kg} / \mathrm{s}$ have been accomplished in EGS reservoirs, and up to Ioo kg/s is ultimately possible. We have chosen to present four different flow-rate scenarios to illustrate the actual needs that must be met to warrant large-scale EGS penetration into the base-load market. These four different flow learning scenarios are illustrated in Figure 9.I5. 


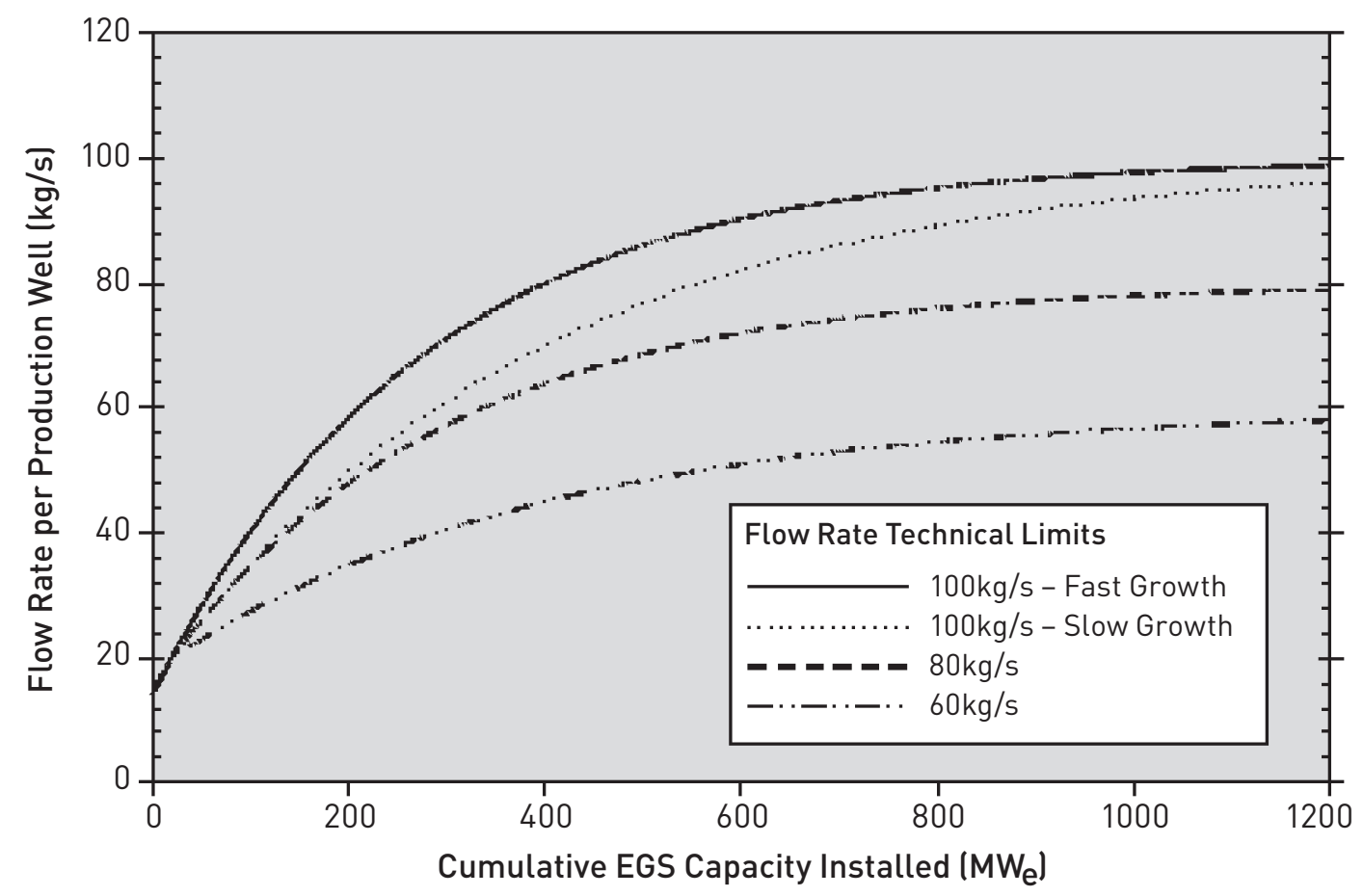

Figure 9.15 Learning curves for production well flow rates.

Power generation is extremely capital-intensive at inception and tends to be fuel- or variable-cost sensitive over time. Once a power system is organized around a suite of technologies, such as fossilbased generation, it becomes difficult to shift or redesign the system. Key reasons for this can be found in the nature of the support facilities, including fuel acquisition and transformation, transportation pipes and wires, storage facilities, and delivery systems - which also entail long-lived capital-intensive facilities. As a consequence, improvements of existing systems tend to occur at the margin, in the form of advanced technologies for a particular fuel source.

Geothermal power technologies are no exception to this trend. The learning curve involved in extending drilling capability, and in more efficient fracture and stimulation of rock, leads directly to higher rates of heat recovery. The three phases of expected improvement demonstrate the application of the learning curve thesis in terms of more efficient power generation and lower costs. The fact that the delivered cost of power remains effectively level over time after taking advantage of installation economies, e.g., larger-size plants, demonstrates the benefits of continuous improvement in techniques and technology. Renewable energy technologies, in particular, have shown great benefit from focused research and development programs, which can significantly shorten the time of successful market penetration and adoption (Moore and Arent, 2006). 


\subsection{Forecast Supply of Geothermal Energy}

"Getting a new idea adopted, even when it has obvious advantages, is difficult. Many innovations require a lengthy period of many years from the time when they become available to the time when they are widely adopted. Therefore, a common problem for many individuals and organizations is how to speed up the rate of diffusion of an innovation." (Rogers, 2003)

In this section, we describe the forecast of supply as a function of resource and market price in various scenarios and sensitivity ranges. The basis of all of the learning curve benefits described earlier is the actual installation of EGS power. Therefore, we must establish a market-penetration plan that would allow for these benefits to be realized. Diffusion of an innovation follows a normal bell distribution (Rogers, 2003):

$$
f\left(t, t_{\max }, \sigma\right)=\frac{1}{\sigma \sqrt{2 \pi}} \exp \left(-\frac{\left(t-t_{\max }\right)^{2}}{2 \sigma^{2}}\right)
$$

This normal distribution gives the installation rate for EGS in our evaluation. Equation (9-I3) is centered on time $t_{\max }$, where the EGS installation rate would be at a maximum. According to the Rogers diffusion theory, the standard deviation, $\sigma$, categorizes the adopters into: (i) innovators $\left(t_{\max }-3 \sigma \leq t \leq t_{\max }-2 \sigma\right)$, (ii) early adopters $\left(t_{\max }-2 \sigma \leq t \leq t_{\max }-\sigma\right)$, (iii) early majority $\left(t_{\max }-\sigma \leq t \leq\right.$ $\left.t_{\text {max }}\right)$, (iv) late majority $\left(t_{\max } \leq t \leq t_{\max }+\sigma\right)$, and (v) laggards $\left(t_{\max }+\sigma \leq t\right){ }^{17}$. We must also normalize Eq. (9-13) by the total possible installed EGS capacity, $M W_{\text {tot,EGS }}$ to scale up to the desired installed capacity. When Eq. (9-13) is integrated with respect to time, we get the cumulative capacity of EGS. Both the total capacity and $t_{\max }$ are determined iteratively, depending on the base-load market and the EGS LEC. The parameters $t_{\max }$ and $\sigma$ were determined iteratively considering the economics of the innovation. The categorical divisions, given by $\sigma$, were found to be Io years, $t_{\max }=40$ years, and $M W_{t o t, E G S}(t=50 y r s)=100,000 \mathrm{MW}_{\mathrm{e}}$, per the scope of this project. Using these parameters, we plot the distribution of installation rate and the cumulative EGS capacity in Figure 9.I6. This distribution is used throughout the remaining analysis and is verified with the market considerations in the sections to follow. Using this scenario, one can see that the innovators enter the market at year io, the early adopters at year 20 , and the early majority at year 30 . As will be seen in the following sections, the innovators enter the market once parity with market base-load price is reached, while the late majority adopt the technology following the period of highest profitability. 


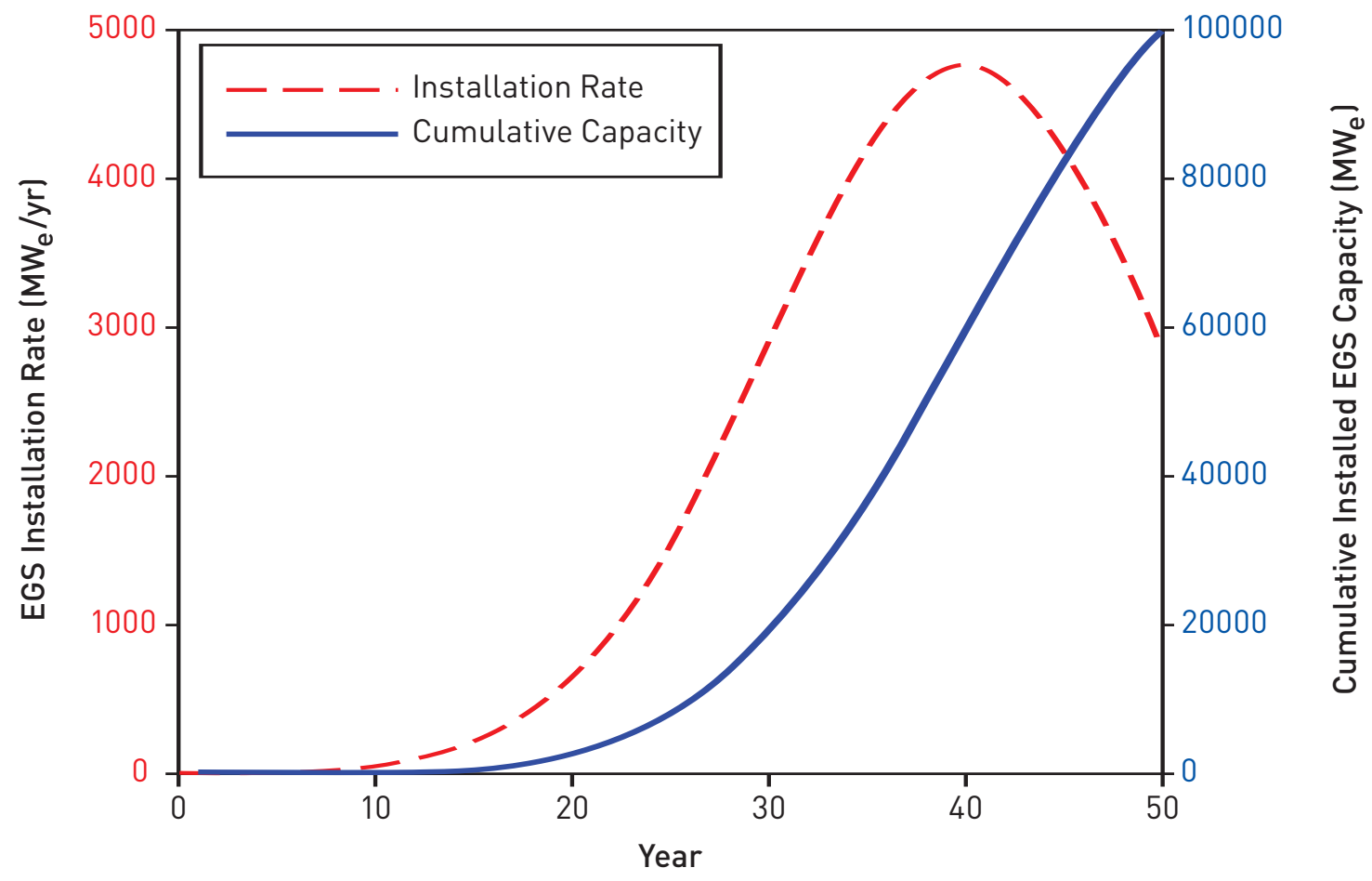

Figure 9.16 Diffusion of technology scenario - 100,000 $\mathrm{MW}_{\mathrm{e}}$ after 50 years.

\subsubsection{The role of technology}

Because technology improvements will improve the ability to access new and deeper areas with predictably higher heat content (Armstead and Tester, I987), we can develop a proxy for new supply curve(s), represented by access to the deeper resources. We expect technology improvements in surface plants to decrease the delivered cost of energy (COE), by allowing higher efficiency energy conversion from heat to electricity, effectively utilizing lower-grade heat content areas that are accessible at shallower depths.

Using both the GETEM and the MIT EGS models, we have forecast the relationship of new energy supplies to the COE delivered to the expected base-load power market. The price of energy falls predictably with higher volumes of installed capacity, finally approaching a break-even price at approximately II years from inception; this is shown in section 9.I2.2. The effect of technology and subsequent price levels is sensitive to assumptions in the models regarding fixed rates of return vs. variable rates in ultimately achieving performance goals. We have illustrated both approaches in this research and they are reflected in the graphs shown later in this chapter.

The key to decreasing installed costs is an investment in key areas identified above, including drilling techniques, subsurface analysis, rock fracture, flow control, well-field monitoring, and injection mechanics. This implies an ongoing investment in research and development, including a proof-ofconcept design to access deeper resources and higher heat regimes. The R\&D equivalent commitment can be measured as "absorbed cost," which is a proxy for the subsidy that would represent industry investment in capital, land, and support facilities needed to produce the first 240 $\mathrm{MW}_{\mathrm{e}}$ of delivered power. 
We have estimated the penetration of geothermal capacity into the overall North American market as a function of the variables cited in the model description above. This is shown later in this chapter with graphs that present such penetration both in terms of $\mathrm{MW}_{\mathrm{e}}$ of installed capacity as a function of price or delivered cost, as well as the relative value of subsidizing technology development and deployment at the early stage of the process.

Table 9.7 Debt capital structure for the variable rate of return (VRR) model, based on DOE (1997).

\begin{tabular}{|c|c|c|c|}
\hline Year & $\%$ Debt & Debt Annual Rate of Return & Equity Annual Rate of Return \\
\hline $1-5$ & 100 & $5.5 \%^{a}$ & $\mathrm{n} / \mathrm{a}$ \\
\hline $5-11$ & 80 & $6.4375 \%^{b}$ & $17 \%$ \\
\hline $11-50$ & 60 & $8.0 \%$ & $17 \%$ \\
\hline \multicolumn{4}{|c|}{$\begin{array}{l}\text { Not typical of competitive market conditions, but reflect primarily public-sector sponsored research } \\
\text { with little commercial penetration into the energy market. }\end{array}$} \\
\hline \multicolumn{4}{|c|}{$\begin{array}{l}0.5 \times 100+0.5 \times 60=80 \% \text { debt rate of return calculated as hybrid between } \\
\text { govt. share }(5 / 8 @ 5.5 \%) \text { and IPP share }(3 / 8 @ 8.0 \%)=3.4375 \%+3 \%\end{array}$} \\
\hline
\end{tabular}

Figure 9.I7 illustrates the expected change in aggregate supply of EGS technology available for baseload energy as calculated by the MIT EGS VRR model. This model is built on variable rate of return (VRR) assumptions that, in turn, reflect the quartet well configuration (3 production, I injector) and per-well flow rates at $80 \mathrm{~kg} / \mathrm{s}$. The value of this curve lies in its ability to show the relationship of "start-up" in the new industry profile ${ }^{18}$ to a heat resource that is currently technically and economically beyond reach. This zone of "deficit" in installed capacity lays the groundwork for learning new drilling techniques and locating higher-density power delivery regions. It also demonstrates the "break-even" price of delivered power to grid operations given forecast increases in technology performance, drilling techniques, and reservoir stimulation and management where the area utilization (fraction of utilized thermal resource within a given temperature and depth regime) is limited to $2 \%^{19}$ of capacity.

Subsequent supply curves shown in this study were calculated using a break-even price minimization algorithm that assumes that any resource at the lowest possible break-even price would be exploited up to the area utilization fraction before developing thermal resources that would result in a higher break-even price (i.e., deeper and/or cooler resources). This covers the available resource range as presented in Chapters 2 and 3 of this report and uses either the MIT EGS model or the GETEM model to calculate the break-even price, according to the learning curves for the technologies combined with the resource characteristics that are available across the United States, and allows for estimation of break-even price as a function of technology penetration. 


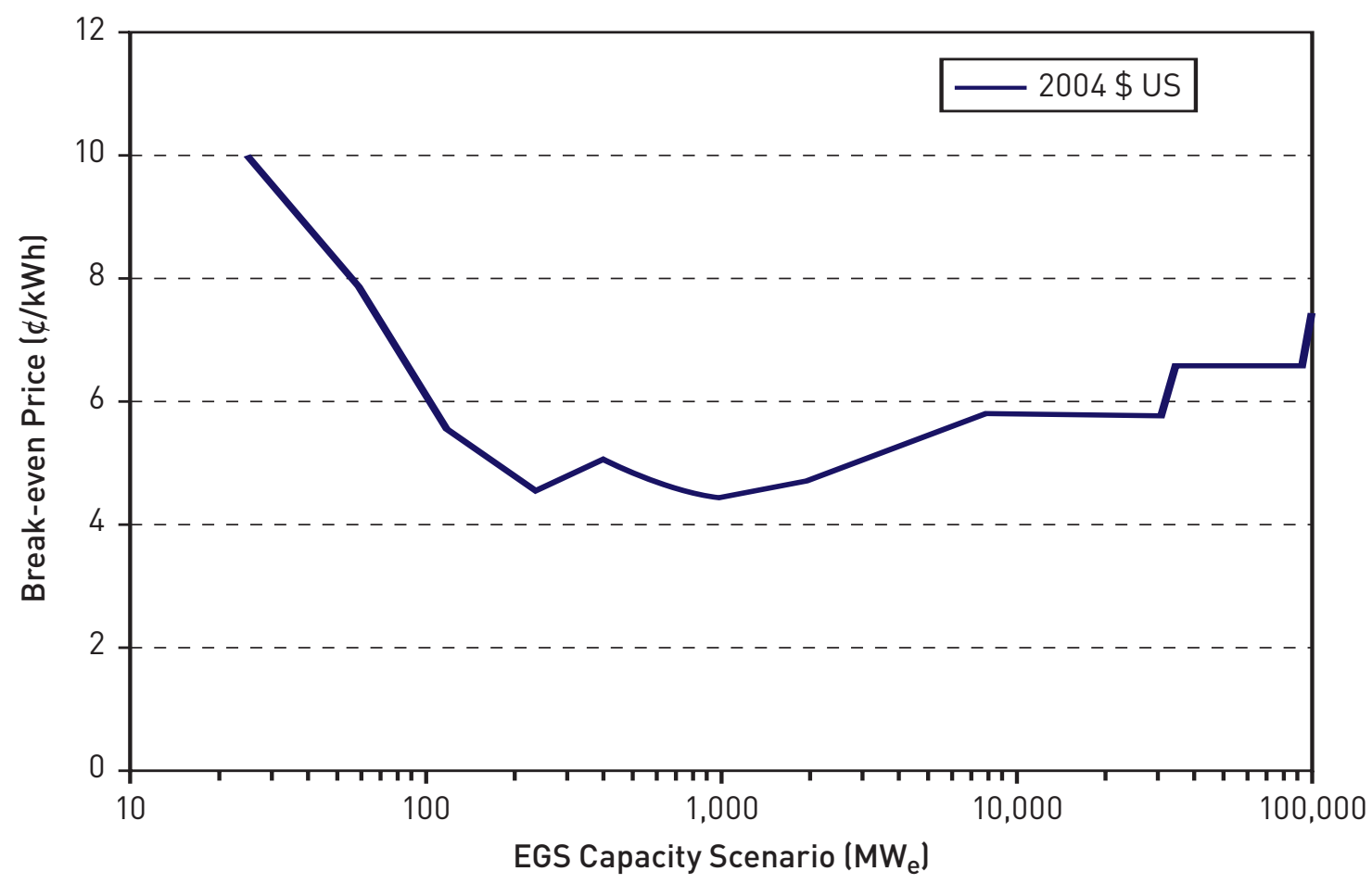

Figure 9.17 Capacity and price relationships for EGS: predicted aggregate supply of base-load power from EGS resources using the MIT EGS, variable rate of return (VRR) model with quartet well configurations (3 producers +1 injector), and a commercially mature flow rate of $80 \mathrm{~kg} / \mathrm{s}$ per well.

These analytical results show EGS technology becomes increasingly cost-competitive, relative to other renewable energy technologies, in three distinct and sequential phases.

The first phase is an extension of capacity by improved drilling and fracturing techniques at existing sites or known resource-rich areas. This critical phase demonstrates the cost-effectiveness of the new techniques, and extracts a higher fraction of the heat-in-place as a function of greater rates of flow in stimulated areas and more efficient heat conversion at the surface.

The second phase involves further extension of the new drilling techniques and power conversion into areas with heat resources outside the limits of current technology and, therefore, left unexploited in the past two decades. Extracting power and heat from this resource will significantly increase the contribution to the power grid, because it will involve expansion to areas in close proximity to power transmission facilities.

The third phase will exploit the full potential of geothermal resources in virtually every region of the United States. This phase will reach areas that will necessitate new drilling technologies, new fracturing and stimulation techniques, new control technologies, and a new generation of power conversion systems for power extraction. 


\subsubsection{Variable debt/equity rates vs. fixed charge rates (FCRs)}

Most energy models adopt either fixed or variable charge rate-based scenarios. Fixed charge rates include a range of factors such as construction financing, financing fees, return on debt and equity, depreciation, income tax, property tax, and insurance. The fixed charge rate, when multiplied by the cost of a new construction project, yields the annual "fixed charges." Thus, the fixed charges are the annual interest expenses of the money borrowed to build, plus the annual costs to operate and maintain a new construction project. This is in contrast to the variable cost rate charge, which shows what any given loan fund needs to yield to cover variable costs. Here,

$$
\frac{\text { Total costs }- \text { Fixed costs }}{\text { Average amount outstanding }}=\text { Fixed charge rate }
$$

Fixed charge rate comparison for renewable technologies is a common procedure and allows comparison across technologies. We have adopted the $12.8 \%$ fixed charged rate cited in the National Energy Modeling System (NEMS) model, sponsored by DOE, as our fixed charge rate for calculations. This is used consistently in both the GETEM and MIT EGS models.

Although all results from either the GETEM or the MIT EGS model show the cost of energy declining to a point below competitive alternatives and are in general agreement in terms of overall cumulative supply, the use of VRR in MIT EGS offers what we believe is a closer approximation of market conditions when used in the case of developing technologies as opposed to commercially mature, established technologies.

A comparison of the two approaches will illustrate this effect. The results can be dramatic as shown in Figure 9.I8. In Figure 9.I8b, the levelized energy costs are significantly lower when using a fixed charge rate opposed to using a variable rate of return as in Figure 9.I8a, holding other model parameters constant.

A key result that emerged between the use of variable cost and fixed cost models is illustrated by comparing Figure 9.I8a and Figure 9.I9a. Here, both scenarios achieve I00,000 $\mathrm{MW}_{\mathrm{e}}$ from EGS with a vertical reservoir spacing of I $\mathrm{km}$. Using the VRR method requires $80 \mathrm{~kg} / \mathrm{s}$ with a quartet (one injector to three production) well field, while the fixed charge method requires only $60 \mathrm{~kg} / \mathrm{s}$ for a triplet in order to deliver economic power.

If one compares the results from the GETEM model in Figure 9.Igb to the results from the MIT EGS model using a fixed charge rate in Figure 9.I9a, it is evident that the two models agree relatively well. 


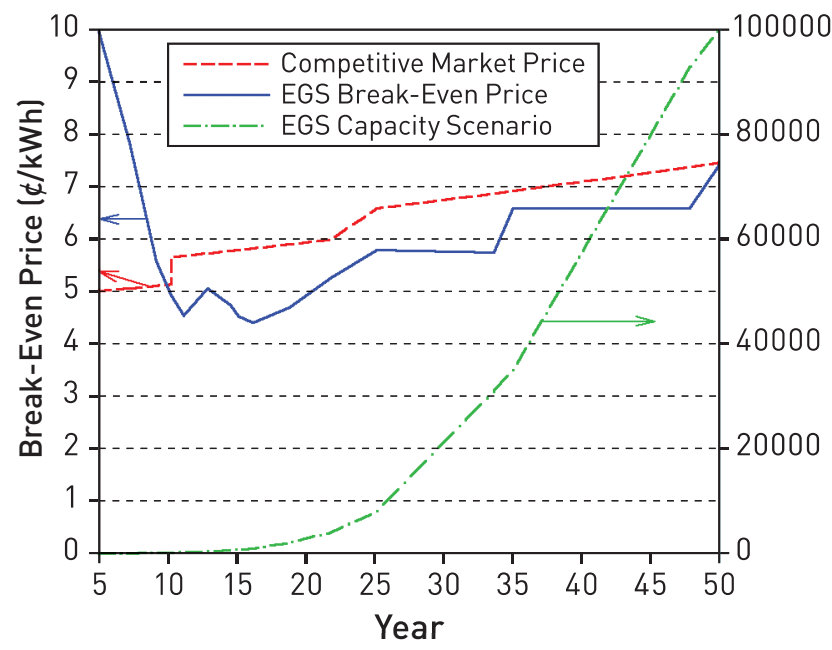

(a)

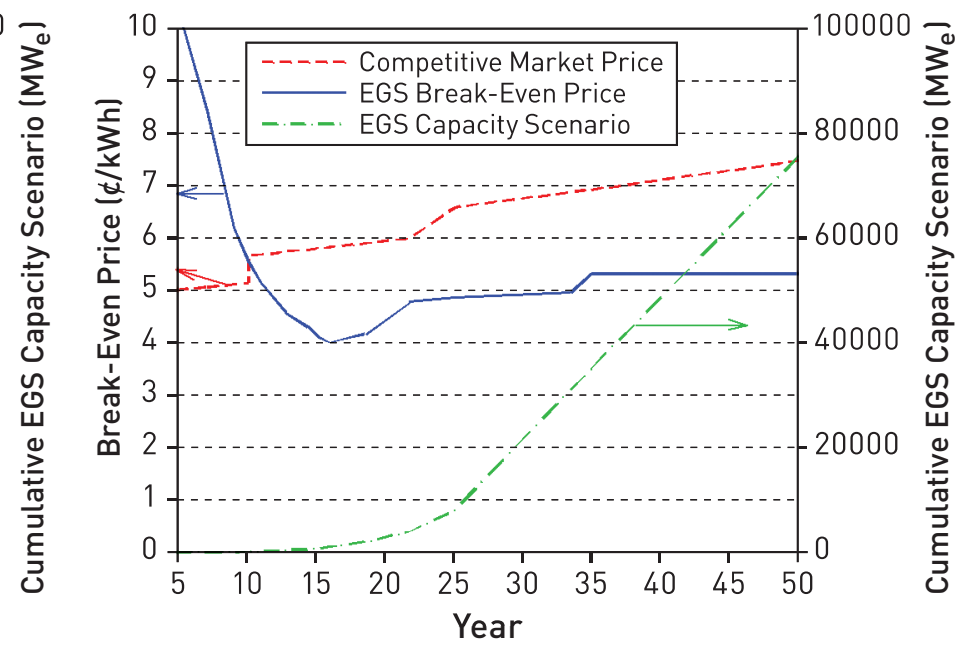

(b)

Figure 9.18 Levelized break-even COE using the MIT EGS model for the 100,000 $\mathrm{MW}_{\mathrm{e}}-50$ year scenario using (a) variable debt and equity rates (VRR) shown in Table 9.7 and (b) fixed charge rate of $12.8 \%$ per the NEMS model. Flow rate per production well (in a quartet configuration -1 injector, 3 producers) follows the $80 \mathrm{~kg} / \mathrm{s}$ learning curve. Thermal drawdown is $3 \% / \mathrm{yr}$ resulting in well-field rework after $\sim 6$ years and the vertical spacing between stacked reservoirs is $1 \mathrm{~km}$. Resulting absorbed technology deployment costs are (a) $\$ 216$ and (b) $\$ 262$ million U.S. (2004).

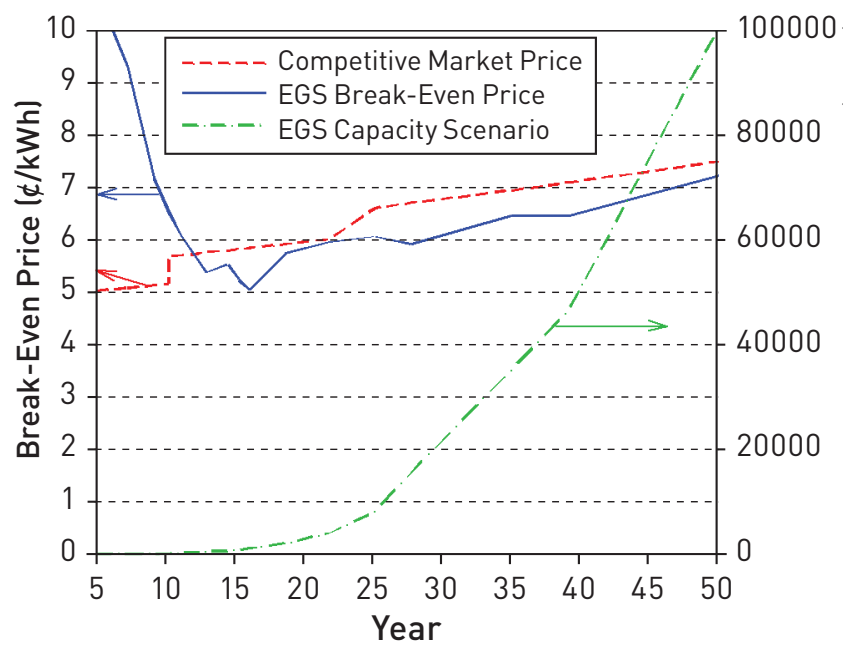

(a)

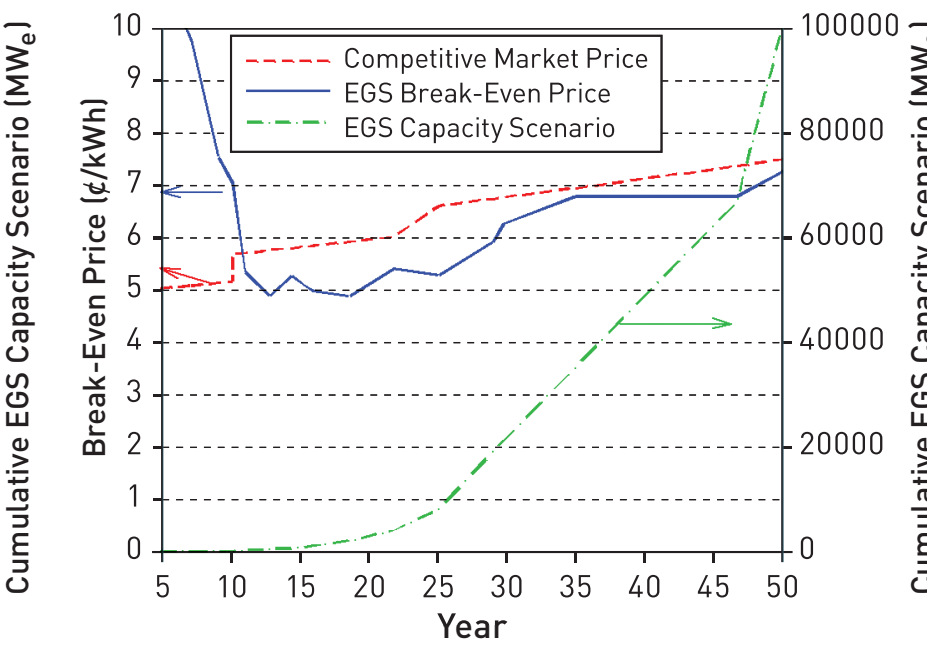

(b)

Figure 9.19 Levelized break-even COE using (a) MIT EGS and (b) GETEM for the $100,000 \mathrm{MW}_{\mathrm{e}}-50$ year scenario using a fixed charge rate of $12.8 \%$ per the NEMS model. Flow rate per production well lin a triplet configuration - 1 injector, 2 producers) follows the $60 \mathrm{~kg} / \mathrm{s}$ learning curve. Thermal drawdown is $3 \% / y r$ resulting in well-field rework after $\sim 6$ years and the vertical spacing between stacked reservoirs is $1 \mathrm{~km}$. Resulting absorbed technology deployment costs are (a) \$368 and (b) \$394 million U.S. (2004). 


\subsubsection{Deriving cost and supply curves}

Both the GETEM and MIT EGS model results suggest a favorable outcome from investments in EGS for base-load power. Figure 9.20 provides a demonstration of the impact of new applied technology and field learning. It demonstrates that as new phases of technology are developed and used in the field, the delivered cost of energy is forecast to fall below competitive base-load energy prices.

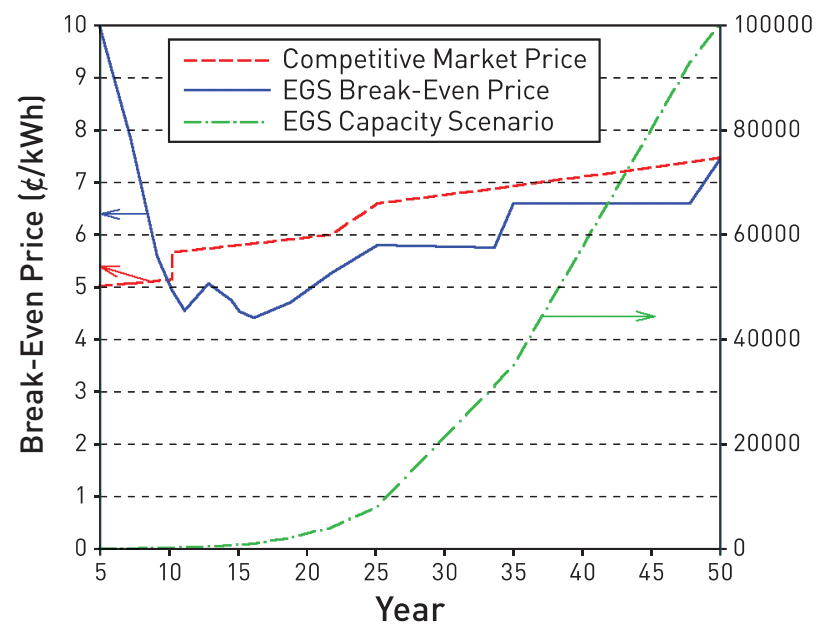

(a)

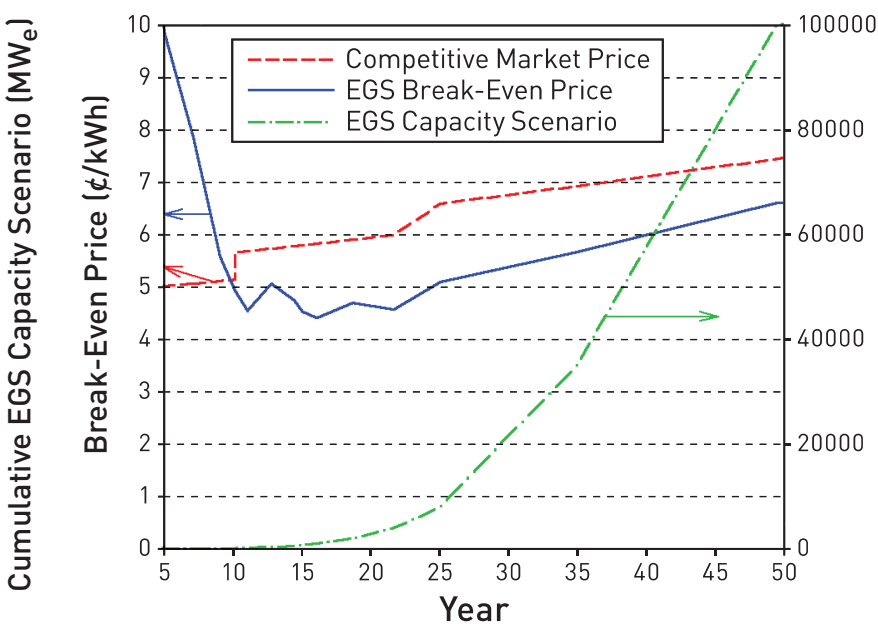

(b)

Figure 9.20 Levelized break-even COE using MIT EGS for the $100,000 \mathrm{MW}_{\mathrm{e}}-50$ year scenario using variable debt and equity rates (VRR) shown in Table 9.7. Flow rate per production well (in a quartet configuration - 1 injector, 3 producers) follows the $80 \mathrm{~kg} / \mathrm{s}$ learning curve. Thermal drawdown is $3 \% / \mathrm{yr}$ resulting in well-field rework after $\sim 6$ years and the vertical spacing between stacked reservoirs are (a) $1 \mathrm{~km}$ and (b) $500 \mathrm{~m}$. Resulting absorbed technology deployment cost is $\$ 216$ million U.S. (2004).

Figure 9.2I illustrates the effect of investments in EGS research and market adoption of new technology and drilling techniques. The figures show cumulative EGS capacity at I००,००० $\mathrm{MW}_{\mathrm{e}}$, and assume flow rate per production well in quartet configuration of $80 \mathrm{~kg} / \mathrm{s}$ with vertical spacing between stacked reservoirs is I $\mathrm{km}$. Thermal drawdown is assumed to be $3 \% /$ year and well-field rework and restimulation occurs approximately every six years.

In this scenario, variable debt and equity rates (VRR) are employed to gauge the impact on the breakeven price of EGS and the resultant cumulative supply additions while assuming the trend in competitive market price. The time period in which competitive prices can be achieved is estimated to be approximately II years after inception of significant efforts to expand research. Here the levelized energy cost (LEC), including forecast costs of redrilling and stimulation, approaches parity with market prices. When viewed through the full 50-year scenario, the analysis suggests that the competitive price of EGS remains below the price for other base-load power.

Continued expansion of facilities beyond that point will ultimately displace older coal- and oil-fired generation and forestall construction of other less-competitive base-load facilities including coal and nuclear power. This is apparent as cumulative additions to the supply curve extend it through the forecast period of 2050. During this period, beyond year II, the market price of delivered EGS electricity is expected to be below competitive technologies. 
The result of this pricing position is positive on several levels. First, this level of competition will tend to put pressure on competitive energy sources to become more efficient, effectively driving down their costs over time. Second, the attraction of geothermal energy as a source of base-load power will be high, leading to higher use over time. Third, the demonstrated reliability and cost effectiveness will lead to greater investment opportunities with higher corresponding economic development potential as a result.

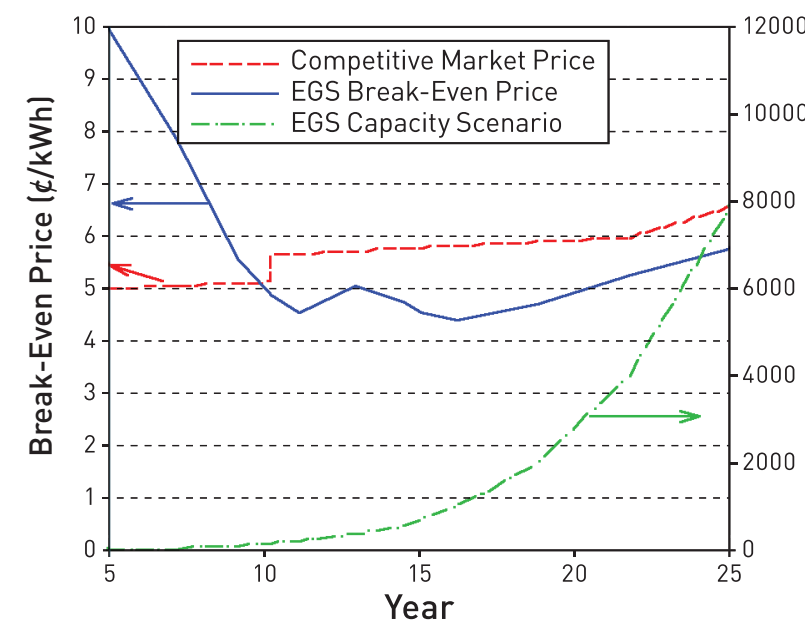

(a)

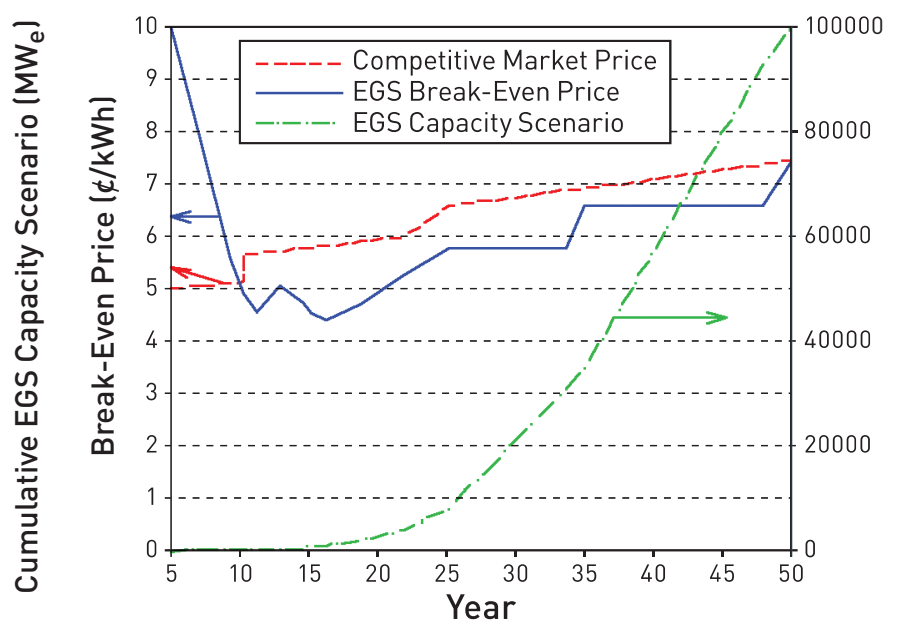

(b)

Figure 9.21 Levelized break-even COE using MIT EGS for the 100,000 $\mathrm{MW}_{\mathrm{e}}-50$ year scenario using variable debt and equity rates (VRR) shown in Table 9.7. Flow rate per production well (in a quartet configuration - 1 injector, 3 producers) follows the $80 \mathrm{~kg} / \mathrm{s}$ learning curve. Thermal drawdown is $3 \% / \mathrm{yr}$ resulting in well-field rework after $\sim 6$ years and the vertical spacing between stacked reservoirs is $1 \mathrm{~km}$. Resulting absorbed technology deployment cost is $\$ 216$ million U.S. (2004).

The cost equivalency shown in Figure 9.2I is a function of the assumed market price for base-load energy, essentially a proxy for the delivered price of coal as the lowest-cost alternative. Once the breakeven point is reached at approximately year II, any added capacity is expected to reflect the needs for expansion of the existing base-load portfolio. A singular advantage to investing continuously in this technology is the match of new demand to supply with minimal disruption to the system and avoidance of price spikes. The estimate of costs to achieve this breakthrough is shown in Table 9.8 as approximately \$2I6 million U.S., with most of that expenditure occurring in the early years (I-8) of such an effort. 
Table 9.8 Relationship of year, output, cost and cost deficit - $80 \mathrm{~kg} / \mathrm{s}$ learning curve, quartet configuration, $3 \%$ thermal drawdown, $1 \mathrm{~km}$ vertical reservoir spacing.

\begin{tabular}{|c|c|c|c|c|c|c|}
\hline Year & $\begin{array}{r}\text { EGS } \\
\text { capacity } \\
\left(\mathrm{MW}_{\mathrm{e}}\right)\end{array}$ & $\begin{array}{r}\text { EGS COE } \\
\text { (\$/kWh) }\end{array}$ & $\begin{array}{r}\text { Base-load } \\
\text { market } \\
(\$ / \mathrm{kWh})\end{array}$ & $\begin{array}{l}\text { EGS deficit } \\
(\$ / \mathrm{kWh})\end{array}$ & Total Cost & $\begin{array}{r}\text { Absorbed } \\
\text { cost }\end{array}$ \\
\hline 5 & 25 & 9.99 & 5.00 & 4.99 & $\$ 229,539,800$ & $\$ 114,612,500$ \\
\hline 7 & 60 & 7.82 & 5.06 & 2.77 & $\$ 251,051,400$ & $\$ 88,766,000$ \\
\hline 9 & 120 & 5.56 & 5.11 & 0.45 & $\$ 152,024,900$ & $\$ 12,401,900$ \\
\hline 10 & 180 & 4.92 & 5.65 & 0.00 & & \\
\hline 11 & 240 & 4.52 & 5.67 & 0.00 & & \\
\hline 13 & 400 & 5.06 & 5.72 & & & \\
\hline 14 & 550 & 4.75 & 5.77 & & & \\
\hline 15 & 750 & 4.53 & 5.78 & & & \\
\hline 16 & 1,000 & 4.40 & 5.82 & & & \\
\hline 19 & 2,000 & 4.69 & 5.89 & & & \\
\hline 22 & 4,000 & 5.24 & 5.98 & & & \\
\hline 25 & 8,000 & 5.78 & 6.58 & & & \\
\hline 34 & 30,982 & 5.74 & 6.86 & & & \\
\hline 35 & 35,000 & 6.59 & 6.91 & & & \\
\hline 48 & 92,778 & 6.58 & 7.38 & & & \\
\hline \multirow[t]{2}{*}{50} & 100,000 & 7.43 & 7.45 & & & \\
\hline & & & & Total & $\$ 632,616,100$ & $\$ 215,780,400$ \\
\hline
\end{tabular}

The diffusion of technology scenario (100,000 $\mathrm{MW}_{\mathrm{e}}$ over 50 years) employed in this analysis is validated by Figure 9.2Ia and Table 9.8. Using the VRR-based MIT EGS model with the supply algorithm, we find a maximum cost differential at 35 years where EGS technology offers a premium source of energy for dispatch and has achieved sustained levels of capacity. Assuming a five-year lag period for permitting and construction, the point of maximum differential may occur more providently in year 40. The advantage (although, in reality, the supply of energy available is effectively infinite) lies in the fact that approximately I००,००० $\mathrm{MW}_{\mathrm{e}}$ are developed during the first phase of development.

\subsection{Conclusions}

We have found a positive correlation between the development of new EGS fields and continued declines in delivered costs of energy. This finding reflects not only the economies from new techniques and access to higher value resources, but also the inevitable cost of competitive power sources. Analysis suggests that, with significant initial investment, installed capacity of EGS could reach I00,000 $\mathrm{MW}_{\mathrm{e}}$ within 50 years, with levelized energy costs at parity with market prices after II 
years. It is projected that the total cost, including costs for research, development, demonstration, and deployment, required to reach this level of EGS generation capacity ranges from approximately $\$ 600$-\$900 million with an absorbed cost of \$200-\$350 million.

In this period, we expect that the development of new EGS resources will occur at a critical time when grid stabilization with base-load power will be needed to avoid redirecting expensive natural gas facilities when they are most in demand worldwide.

EGS power lacks a demonstration of its capability at the present time. As pointed out in this report, this can be accomplished with a proven application of R\&D support. We expect that the cost of power potential demonstrated in this chapter warrants a comprehensive research and demonstration effort to begin moving toward the period when replacement of retiring fossil and nuclear units and new capacity growth will most affect the U.S. electrical supply.

\section{Footnotes}

I. A power transmission system is commonly referred to as a "grid." However, for reasons of economy, the network is rarely a grid (a fully connected network) in the mathematical sense. Redundant paths and lines are provided so that power can be routed from any power plant to any load center, through a variety of routes, based on the economics of the transmission path and the cost of power. Much analysis is done by transmission companies to determine the maximum reliable capacity of each line, which, due to system stability considerations, may be less than the physical limit of the line.

2. The revival of the FutureGen program at DOE underscores this trend.

3. In the IEO2005 reference case, coal continues to be the dominant fuel for generation of electricity and combined heat and power (district heat). In 2025 , coal is projected to fuel $38 \%$ of the world's electricity generation, compared with a $24 \%$ share for natural gas. Coal-fired capacity is expected to grow by I.5\% per year, from $987 \mathrm{GW}_{\mathrm{e}}$ in 2002 to $\mathrm{I}, 403 \mathrm{GW}_{\mathrm{e}}$ in 2025 . Installed coal-fired capacity, as a share of total world capacity, declines from $30 \%$ to $26 \%$ over the forecast.

By country, the United States and China currently are the leaders in terms of installed coal-fired capacity, at $3 \mathrm{II}$ and $204 \mathrm{GW}_{\mathrm{e}}$, respectively. In China, strong growth in natural-gas-fired capacity is projected to push coal's share down from $65 \%$ to $52 \%$ of total generating capacity. In the United States, coal-fired power plants are expected to continue supplying most of the country's electricity through 2025. In 2002, coal-fired plants in the United States (including utilities, independent power producers, and end-use combined heat and power) accounted for $51 \%$ of all electricity generation. While the output from U.S. coal-fired power plants increases in the forecast, from $\mathrm{I}, 88 \mathrm{I}$ billion $\mathrm{kWh}$ in 2002 to 2,890 billion $\mathrm{kWh}$ in 2025 , their share of total generation decreases slightly, to $50 \%$, as a result of a rapid increase in natural-gas-fired generation.

4. The source for declining transportation costs is not cited by the EIA.

5. According to the EIA, U.S. nuclear capacity is projected to increase from $99 \mathrm{GW}_{\mathrm{e}}$ in 2002 to I03 $\mathrm{GW}_{\mathrm{e}}$ in 2025, in part because of the return of the Browns Ferry reactor, scheduled for 2007. 
6. For the mature market economies, the IEO (2005) reference case assumes that, in the long term, retirements of existing plants as they reach the end of their operating lives will not be balanced by the construction of new nuclear power capacity, and there will be a slight decline in installed nuclear capacity toward the end of the forecast.

7. Load firming is the acquisition of supply to fill a real or expected gap in guaranteed delivery of power to customers. Firm power is power or power-producing capacity intended to be available at all times during the period covered by a guaranteed commitment to deliver, even under adverse conditions.

8. According to the EIA in 2004, retail sales of electricity increased to 3,548 billion $\mathrm{kWh}$ in 2004 , a I.7\% increase from 2003 and a pace close to the historical growth rate. Revenue, however, increased to more than $\$ 270$ billion in 2004 , a $4.5 \%$ increase from 2003 and the second straight year of strong growth. All customer classes except transportation faced higher average retail prices in 2004 , as the national average price across all sectors was 7.62 cents per $\mathrm{kWh}$, up from 7.42 cents in 2003 .

The average retail price in the residential sector increased to $8.97 \propto / \mathrm{kWh}$, a $3.1 \%$ increase from 2003. In the commercial and industrial sectors, average price increases were $2.0 \%$ and $2.9 \%$, respectively. Higher fossil fuel prices to electricity generators led to higher wholesale power costs. Average end-use prices increased dramatically in states where natural gas fuels significant portions of base-load generating capacity - Texas, Mississippi, Louisiana, and Florida.

9. For instance, in 2002, MidAmerica Energy dropped a project in the Salton Sea area of California, due to constraints on transmission access and capacity, (M. Masri, chief of Renewable Programs, California Energy Commission, personal communication).

IO. Power is defined as the rate of flow of energy past a given point. In "alternating current" circuits, energy storage elements such as inductance and capacitance may result in periodic reversals of the direction of energy flow. The portion of power flow that, averaged over a complete cycle of the AC waveform, results in net transfer of energy in one direction is known as real power. That portion of power flow due to stored energy, which returns to the source in each cycle, is known as reactive power.

II. Direct current (DC or "continuous current") is the continuous flow of electric charge through a conductor such as a wire from high to low potential.

I2. See California Energy Commission emergency siting process for 2000.

I3. The energy attribute may be considered as a separate value, which is not purchased directly but which may be priced, such as renewable attributes, reliability, "cleanness," etc.

I4. Reactive energy (VARs) is defined as the imaginary component of the vector product of the voltage and current, each expressed as a vector and used to provide line stability.

I5. Each surface complex is assumed to be composed of power turbines nominally rated at $60 \mathrm{MW}_{\mathrm{e}}$, and combined in modules dependent on the resource being accessed. 
I6. Supply curves for EGS power in selected specific states are given in Appendix A.9.4. An example of a state in an area with no operating hydrothermal geothermal plants is Texas, shown in Figure A.9.I5. High-temperature gradients in the Gulf Coast area have been discovered during drilling for oil and gas. The hot water coproduced with oil and gas production is discussed in Chapters 2 and 7. The EGS resource base for these fluids could also be developed on its own. While the costs for developing geothermal resources in Texas are currently higher than market, the amount of power available is significant and, with incremental improvements in cost, could represent a significant base-load resource. Colorado (Figure A.9.I6) is a state with both identified hydrothermal resources and identified EGS resources at depths shallower than $3 \mathrm{~km}$ - there is also a significant EGS resource at depths greater than $3 \mathrm{~km}$. About $42 \mathrm{GW}_{\mathrm{e}}$ could be available by 2 III at a cost of less than IOC/kWh based on the continued success of the Soultz project or other EGS field projects if drilling cost improvements and conversion technology improvements continue to be made.

I7. For a normal distribution, $95.45 \%$ of the area is within two standard deviations. Therefore, after more than two standard deviations on both sides of the distribution (40 years), about $95 \%$ of the EGS capacity would be installed.

I8. The technologies described in this paper are an extension of existing geothermal drilling and fracturing techniques, only to the extent that drilling and fracturing are taking place at depth. The techniques are assumed to be more precise and capable of delivering higher rates of power over longer periods of time than previous hydrothermal systems. Thus, although these systems may be collocated in existing geothermal fields, the depth and accessed heat resource are beyond current established technology and power conversion.

I9. A $2 \%$ area utilization is a conservative estimate of potential resources at depth. We have chosen this level to find coincident break-even points for the cost of capital, which is assumed to be borne by the private sector after the initial $6,000 \mathrm{MW}_{\mathrm{e}}$. 


\section{References}

Anderson, B.J. 2006. Personal communication, West Virginia University, Department of Chemical Engineering, Morgantown, W.V.

Armstead, H. C. H. and J. W. Tester. I987. Heat mining: a new source of energy. E. \& F.N. Spon, London.

Brett, J. F. and K. K. Millheim. I986. “The Drilling Performance Curve: A Yardstick for Judging Drilling Performance - SPE I5362." SPE Annual Technical Conference and Exhibition, October 5-8, New Orleans, Louisiana.

CEC. 2006. California Energy Commission Web site. Accessed March 9, 2006. http://energy.ca.gov/geothermal/index.html

DOE. I997. "Renewable Energy Technology Characterizations.” TR-I09496. EERE Office of Utility Technologies, U.S. Department of Energy.

EIA. 2002. "Inventory of Electric Utility Power Plants in the United States 2000." Energy Information Administration, U.S. Department of Energy.

EIA. 2004. "Annual Electric Power Industry Report." Form EIA-86I, Energy Information Administration, U.S. Department of Energy.

EIA. 2005. "Annual Energy Outlook 2005: Electricity Supply." AEO2005. Energy Information Administration, U.S. Department of Energy.

GEA. 2006. Figures released by Geothermal Energy Association, Washington, DC.

Herzog, H. J., J. W. Tester, et al. I997. “Economic analysis of heat mining.” Energy Sources, I9(I): I9-33.

Ikoku, C. U. I978. "Application of Learning Curve Models to Oil and Gas Well Drilling - SPE 7II9." SPE California Regional Meeting, April I2-I4, San Francisco, California.

Kravis, S., R. Irrgang, et al. 2004. "The Trouble Probability Plot: A New Measure of Drilling Maturity - SPE 89959." SPE Annual Technical Conference and Exhibition, September 26-29, Houston, Texas.

MacGregor, P. R., C. E. Maslak, et al. I99I. "The Market Outlook for Integrated Gasification Combined Cycle Technology.” New York, General Electric Company.

McDonald, A. and L. Schrattenholzer. 200I. "Learning rates for energy technologies." Energy Policy, 29(4): 255-26I.

Moore, M.C. and D.J. Arent, 2006. "R\&D Advancement, Technology Diffusion, and the Impact on Evaluation of Public R\&D," Energy Policy.

Muffler, L. J. P. and M. Guffanti (eds.), I979. "Assessment of geothermal resources in the United States - I978." US Geol. Surv. Circ. 790.

Nakićenović, N., A. Grübler, et al. I998. Global energy perspectives. Cambridge University Press, Cambridge, New York.

Petty, S., B. J. Livesay, and W. P. Long. I99I. "Supply of Geothermal Power from Hydrothermal Sources.” Contractor Report, Sandia National Laboratory.

Petty, S. and G. Porro. 2006. Personal communications. 
Renner, J. L., D. E. White, and D. L. Williams. I975. "Hydrothermal Convection Systems," in White, D. E. and D. L. Williams, (Eds.), Assessment of Geothermal Resources of the United States - I975. US Geol. Surv. Circ. 726.

Rogers, E. M. 2003. Diffusion of innovations. New York, Free Press.

Stoft, S. 2002. Power System Economics: Designing Markets for Electricity. IEEE Press.

Tester, J. W., H. J. Herzog, et al. I990. “Economic predictions for heat mining: a review and analysis of hot dry rock (HDR) geothermal energy technology.” Energy Laboratory, Massachusetts Institute of Technology, Cambridge, Mass.

Tester, J. W. and H. J. Herzog. I99I. “The Economics of Heat Mining: An Analysis of Design Options and Performance Requirements of Hot Dry Rock (HDR) Geothermal Power Systems." Sixteenth Workshop on Geothermal Reservoir Engineering, January 23-25, Stanford University, Stanford, California. 


\section{Appendices}

\section{A.9.1 Base-load Power in Grid Operations}

Base-load plants tend to be older than gas-fired combustion turbine units and are usually powered by coal, oil, or nuclear fuel - they also can be hydroelectric. In contrast, most peak-load plants, called "peaking units," are fueled by natural gas. Intermediate-load - or mid-range load-following plants are often smaller, older, coal-fueled plants that have been modified to allow them to ramp up and down without damage.

As system loads have grown, new generation has been built to supply that load. However, there have been relatively few new base-load plants completed in the United States since the I990s. Thus, the base-load units tend to be older than the gas-fired combustion turbine units and are usually powered by nuclear, coal, and, to a very small extent, oil. The new plants have either been of the mid-range loadfollowing or peak varieties. Peaking plants may only run for Io० to 200 hours a year and, at most, a few hours in any given day. Mid-range load-following plants may serve load in key daytime hours by following load changes during the day.

Therefore, there has been a small and gradual shift in the percentage of the system load served from base-load plants to mid-range plants. The amount of load served by peaking plants grew somewhat during the I990s, but has leveled off during the past decade. Natural gas-fired plants, originally deployed for peaking capacity, are now increasingly being used for base-load power. This has tended to increase prices of delivered energy in many urban markets in the United States. Furthermore, the dramatic increase in the price of natural gas has resulted in many stranded combined-cycle units, unable to produce economical electricity in the current market.

As a result of some older power plants being taken out of service and because of the types of new plants that have been built, the amount of natural gas-fueled generation to serve overall load has increased. At the same time, the amount of generation fueled by coal has remained relatively constant.

During the past decade, a move to install new gas-fired combined-cycle plants has displaced some of the new demand for coal power generation. This phenomenon seems to be abating in the face of sustained and expected high prices for natural gas in domestic, Canadian, and imported markets. As a consequence, future use of natural gas for base-load power generation is likely to be constrained by price and, ultimately, by supply. Simultaneously, expansion of coal-based power generation is constrained by environmental and air quality regulations that have slowed new permitting and suggest stricter plant design criteria in the future. ${ }^{2}$

The base-load requirements of most regions are served by a combination of coal-fired generation, nuclear steam generation, and hydroelectric facilities. There are several features of this combination of resources that suggest higher prices and tightened supplies in the future. These include:
a. fuel prices
b. additions of new generating capacity and capacity constraints
c. transmission capacity
d. retirements of existing stock
e. environmental regulations and future $\mathrm{CO}_{2}$ emissions costs. 


\section{A.9.1.1 Coal-fired generation in base load}

Coal prices have been climbing at a rate of approximately $0.5 \%$ per year (without indexing for inflation) for the past decade, although not consistently year-to-year. Some of this increase reflects the preference for low-sulphur coal available from the Powder River Basin, which entails higher demand on an already constrained railroad capacity resulting in higher transportation costs. Also, simple supply/demand balances show steady pressure on existing sources. A lack of new transmission capacity, a limited ability to expand existing coal facilities near urban areas, and compliance with tighter environmental standards makes delivered power slightly more expensive. In addition, retirement of existing facility stock, which was largely constructed in the mid-Igoos and is less efficient than modern units, has contributed to the increase in overall costs. Finally, the demand for coal used in metallurgical operations (such as coking) is in competition for coal demanded for energy generation; this may be exacerbated when newer coal gasification and liquefaction facilities become more economical to construct in the future. ${ }^{3}$

Coal plays an important and, in some regions, dominant role in base-load power delivery. Coal consumption in the United States as a share of fuels used for electricity generation is expected to increase from $52 \%$ to $53 \%$ over the forecast. In terms of installed capacity, coal's share of the total will hold steady at $35 \%$. Coal is used for base-load generation, which explains why it accounts for only $35 \%$ of U.S. capacity but generates more than one-half of the country's electricity. In Figure A.9.I, the significance of that role is graphically illustrated.

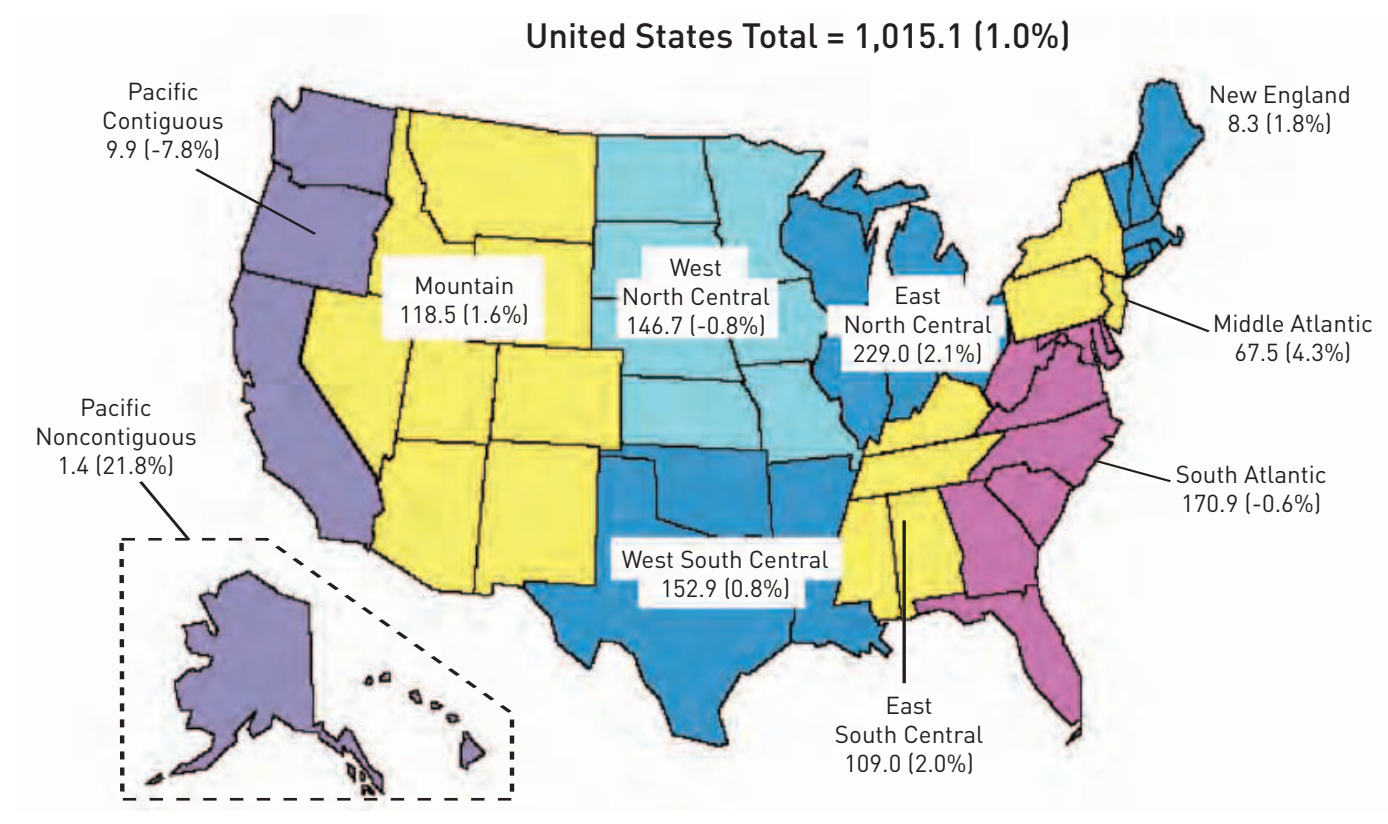

Figure A.9.1 Electric power-sector consumption of coal by Census region, 2004 (million short tons and percent change from 2003) (EIA, 2005).

According to the EIA, to a large extent, the projections of increasing prices for natural gas after 2010 - combined with projections of relatively stable coal prices and slightly declining rates for domestic transportation of $\mathrm{coal}^{4}$ - have been the key factors helping coal compete as a fuel for U.S. power generation. Increases in coal-fired generation are projected to result from both greater utilization of 
existing U.S. coal-fired generating capacity and an additional $89,500 \mathrm{MW}_{\mathrm{e}}$ of new coal-fired capacity by $2025\left(3,600 \mathrm{MW}_{\mathrm{e}}\right.$ of older coal-fired capacity is projected to be retired). The average utilization rate of coal-fired generating capacity is projected to increase from $70 \%$ in 2002 to $83 \%$ in 2025 . A coalfired plant produces the lowest-cost electricity when gas prices are higher than $\$ 2.80$ per million (MMBtu).

\section{A.9.1.2 Nuclear steam generation}

The price of nuclear-sourced electricity has remained relatively constant during the past decade, a reflection of better management and ongoing maintenance of facilities compared to earlier periods. Spent fuel continues to be stored on-site in most facilities and could be a source of long-term price increases in the future as spent fuel becomes increasingly difficult to manage on-site. Although there are new facilities in design, no recent construction has taken place in the United States, which would augment the existing stock of nuclear facilities. The earliest, currently operating commercial nuclear facilities were constructed in I969-1970, with a large fraction of the generation base constructed in the I980s. Assuming the design life of a nuclear plant is 25 years, with regulatory extensions available to 40 years before retirement, $46 \mathrm{GW}_{\mathrm{e}}$ of capacity can be expected to retire in the period to 2020 . $^{5}$ This represents about $46 \%$ of the nearly $99 \mathrm{GW}_{\mathrm{e}}$ of current base-load power from this source. Environmental regulations, public concerns over safety, uncertainty over the storage of spent fuel, and investor concerns over financial risk combine to make expansion and replacement of this source of power problematic. Assuming 50\% of the retired stock is replaced during the next I5 years, the resulting gap in base-load capacity could approach $25 \mathrm{GW}_{\mathrm{e}}{ }^{6}$

\section{A.9.1.3 Hydroelectric facilities}

Hydroelectric facilities continue to provide a critical backbone of the base-load capacity for U.S. power networks in areas served by the Western Area Power Administration (WAPA) or the Bonneville Power Administration (BPA). A proven technology, hydroelectric plants are dispatchable efficiently for both base-load and load firming, ${ }^{7}$ and are the core of operations for federal agencies such as BPA and WAPA, underpinning the transmission facilities built to transmit power from the large hydroelectric project areas. Increased environmental concerns over the use of water, reduced capacity due to siltation, and changes in rainfall patterns have created some uncertainty in the availability of this power source. Because no new hydroelectric facilities are planned or are likely in the next decade, this source of power should be considered static or in slight decline.

\section{A.9.1.4 Base-load power prices and electricity supply sources}

Prices for base-load power do not generally change rapidly, due, in part, to the fact that most are controlled through long-term contracts. Given all the factors cited above, however, we expect the competitive price for base-load power bid into system operations to increase from about 4-5 cents/kWh to 6-7 cents/kWh during the next ro years. ${ }^{8}$ Figure A.9.2 shows the price of electricity on a state-by-state basis across the United States. 


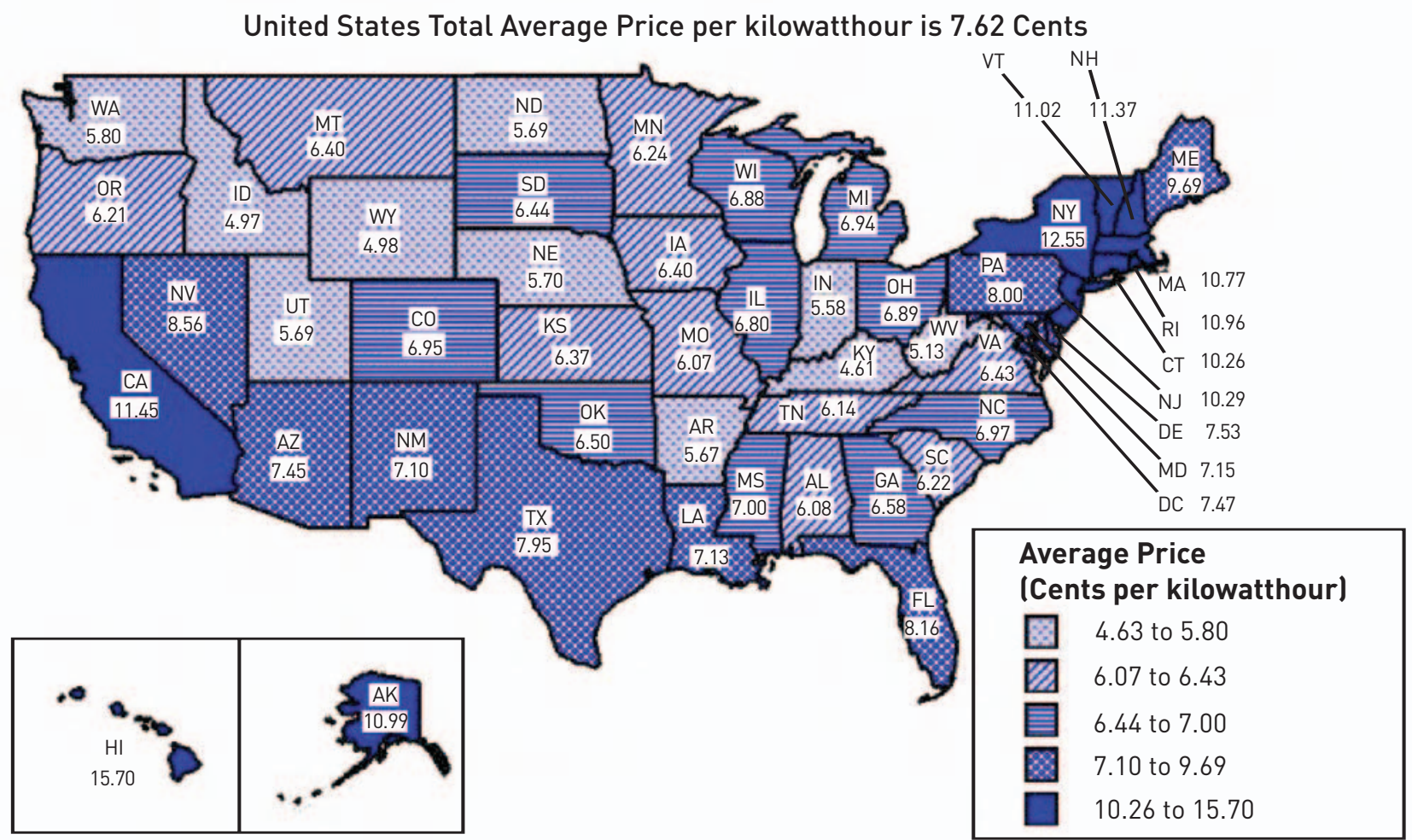

Note: Figure information is shown by 5 groupings of 10 States and The District of Columbia. The presented range moves from the values for the lowest 10 States to the top 10 States. Source: Energy Information Administration, Form EIA-861, “Annual Electric Power Industry Report."

Figure A.9.2 Average retail electricity price by state, 2004 (in $\$ / k W h$ or cents per kilowatt hour) (EIA, 2004).

A look at the U.S. electricity generation base (see Table A.9.I) shows that the available power supplies are increasing, but are offset by planned retirements of existing facilities reflecting a high concentration of use for base-load operations.

We have summed the highest-capacity energy generating sources in Figure A.9.3. It shows the disproportionate share borne by fossil facilities in the current energy mix.

DOE had estimated (see Table A.9.2) that there would be significant additions to the existing generating stock during 200I-2005, based on anticipated applications for new siting licenses. The list is notable for the absence of any new nuclear or hydroelectric facilities.

During this same period, the grid in the United States experienced significant retirement of existing capacity, mainly in older petroleum (oil)-fired generation and simple-cycle gas turbines (see Table A.9.3). The DOE has suggested that there will be a significant amount of new generation sited in coming decades as shown in Figure A.9.4, relative to expected retirements. Our projections of nuclear plant retirements, as well as older coal facilities, would cause this projection to increase slightly during $202 \mathrm{I}-2030$. 
Table A.9.1 Existing U.S. generation base (EIA, 2005; and GEA, 2006).

\begin{tabular}{|c|c|c|c|c|}
\hline & $\begin{array}{r}\text { Existing No. } \\
\text { of Units }\end{array}$ & $\begin{array}{r}\text { Generator } \\
\text { Nameplate } \mathrm{MW}_{\mathrm{e}}\end{array}$ & $\begin{array}{l}\text { Net Summer } \\
\qquad \mathrm{MW}_{\mathrm{e}}\end{array}$ & $\begin{array}{r}\text { Net Winter } \\
\mathrm{MW}_{\mathrm{e}}\end{array}$ \\
\hline U.S. Total & 16,770 & $1,049,615$ & 962,942 & 999,749 \\
\hline Geothermal & 212 & 3,119 & 2,170 & 2,311 \\
\hline Coal & 1,526 & 335,243 & 313,020 & 315,364 \\
\hline Petroleum & 3,175 & 37,970 & 33,702 & 37,339 \\
\hline Natural Gas & 3,048 & 256,627 & 224,257 & 241,391 \\
\hline Dual-fired & 3,003 & 193,115 & 172,170 & 184,399 \\
\hline Other Gases & 119 & 2,535 & 2,296 & 2,259 \\
\hline Nuclear & 104 & 105,560 & 99,628 & 101,377 \\
\hline Hydroelectric Conventional & 3,995 & 77,130 & 77,641 & 77,227 \\
\hline Pumped Storage & 150 & 19,569 & 20,764 & 20,676 \\
\hline Wind & 246 & 6,552 & 6,456 & 6,456 \\
\hline Wood/Wood Waste & 171 & 2,864 & 2,583 & 2,582 \\
\hline Municipal Solid Waste & 98 & 2,677 & 2,196 & 2,217 \\
\hline Biomass gas & 90 & 243 & 200 & 232 \\
\hline Solar (photovoltaic, thermal) & 17 & 404 & 398 & 366 \\
\hline Landfill gas & 582 & 934 & 859 & 879 \\
\hline Agricultural by-product & 26 & 289 & 274 & 268 \\
\hline Black liquor (biomass) & Not available & $\sim 4,000$ & $\sim 4,000$ & $\sim 4,000$ \\
\hline Other & 42 & 754 & 700 & 716 \\
\hline
\end{tabular}




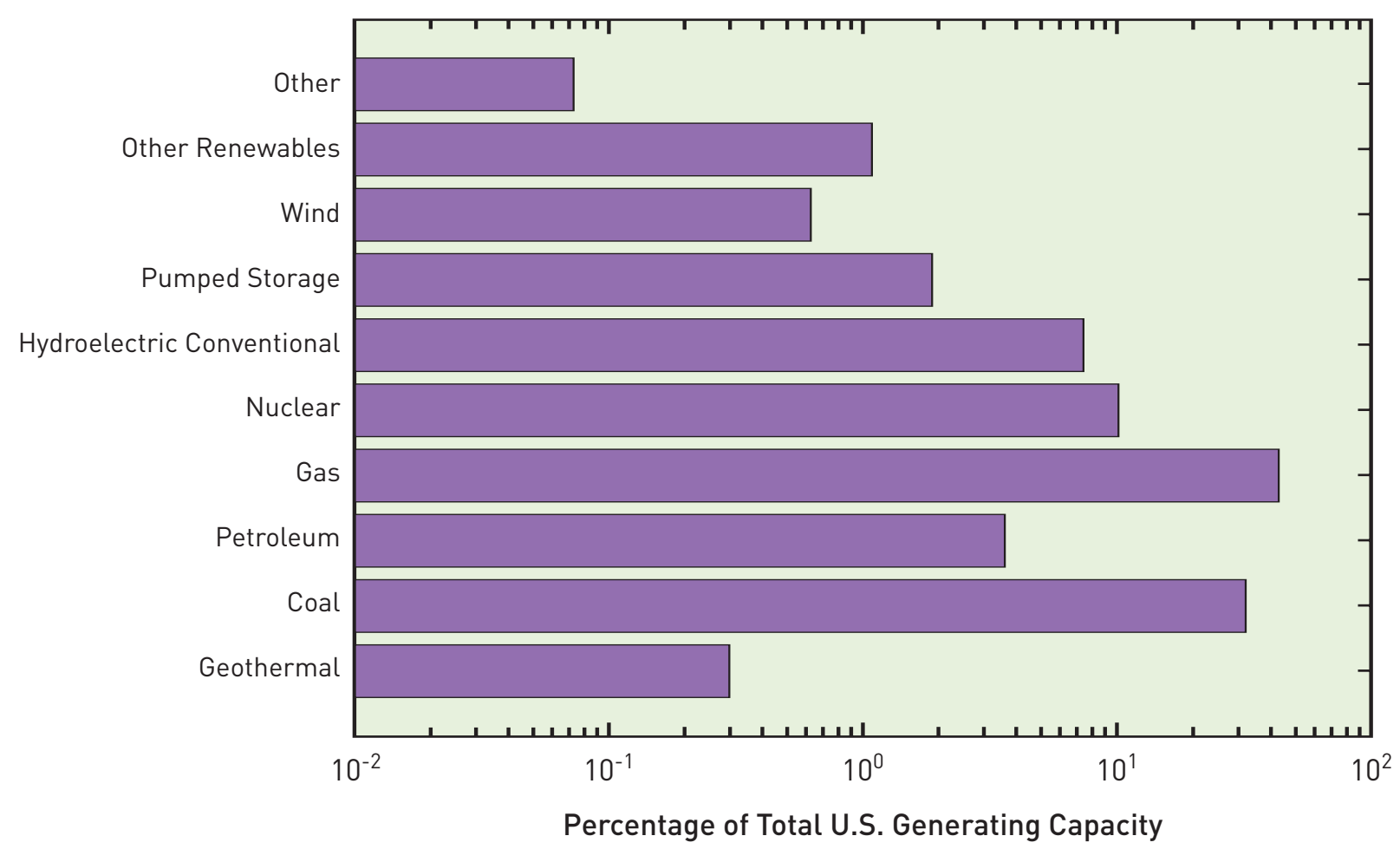

Figure A.9.3 Energy shares by technology in the United States (EIA, 2004).

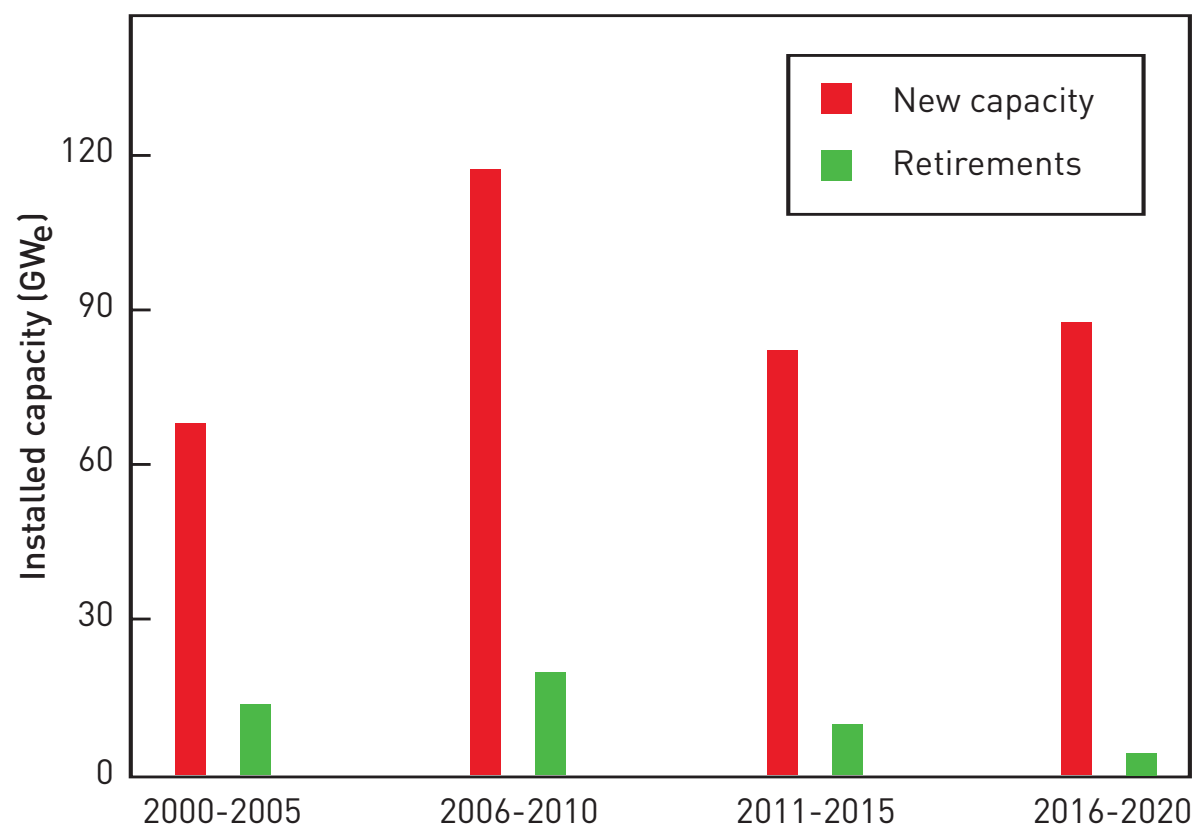

Figure A.9.4 Projected new generating capacity and retirements, 2000-2020 (EIA, 2004). 
Table A.9.2 Additions to the existing power generation base (2001-2005). (EIA, 2005).

\begin{tabular}{l|r|r|r|r}
\hline & No. of units & $\begin{array}{r}\text { Generator } \\
\text { nameplate } \text { MW }_{\mathrm{e}}\end{array}$ & $\begin{array}{r}\text { Net summer } \\
\mathrm{MW}_{\mathrm{e}}\end{array}$ & $\begin{array}{r}\text { Net winter } \\
\mathrm{MW}_{\mathrm{e}}\end{array}$ \\
\hline U.S. Total & 244 & 9,528 & 7,993 & 9,041 \\
\hline Coal & 1 & 18 & 16 & 18 \\
\hline Petroleum & 156 & 448 & 407 & 424 \\
\hline Gas & 74 & 8,062 & 6,680 & 7,655 \\
\hline Water/Pump Storage & & & & \\
\hline Nuclear & & & & \\
\hline Waste Heat & 6 & 994 & 683 & 937 \\
\hline Renewables & 7 & 6 & 6 & 6 \\
\hline
\end{tabular}

Table A.9.3 Retirement of capacity (2001-2005). (EIA, 2005).

\begin{tabular}{l|r|r|r|r}
\hline & No. of units & $\begin{array}{r}\text { Generator } \\
\text { nameplate } \mathbf{M W}_{\mathrm{e}}\end{array}$ & $\begin{array}{r}\text { Net summer } \\
\mathbf{M W}_{\mathrm{e}}\end{array}$ & $\begin{array}{r}\text { Net winter } \\
\mathrm{MW}_{\mathrm{e}}\end{array}$ \\
\hline U.S. Total & 63 & 303 & 248 & 248 \\
\hline Coal & 3 & 37 & 40 & 39 \\
\hline Petroleum & 42 & 193 & 138 & 139 \\
\hline Gas & 11 & 71 & 68 & 69 \\
\hline
\end{tabular}

Water/Pump Storage

Nuclear

Waste Heat

Renewables

7

2

1 


\section{A.9.2 Forecast Break-Even Prices of EGS}
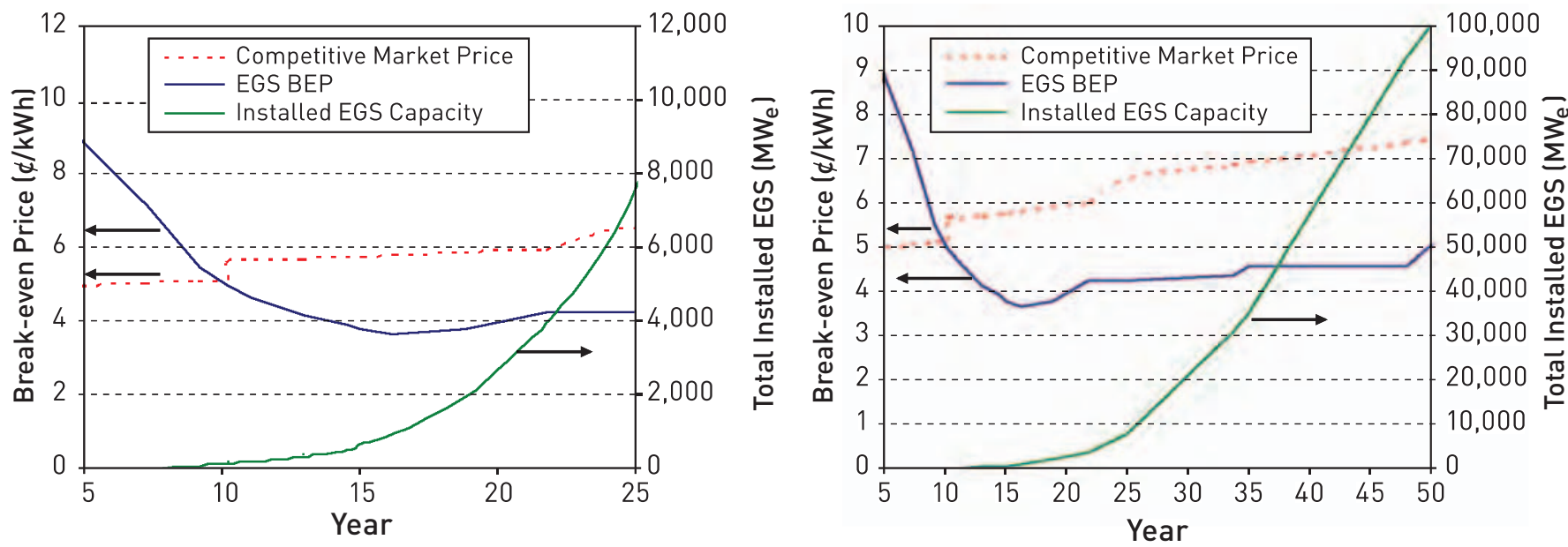

Figure A.9.5 Levelized break-even COE using MIT EGS for the $100,000 \mathrm{MW}_{\mathrm{e}}$ - 50 year scenario using a fixed charge rate of $12.8 \%$ per the NEMS model. Flow rate per production well lin a quartet configuration - 1 injector, 3 producers) follows the $80 \mathrm{~kg} / \mathrm{s}$ learning curve. Thermal drawdown is $3 \% / \mathrm{yr}$ resulting in well-field rework after $\sim 6$ years. Resulting absorbed technology deployment cost is \$262MM U.S. (2004).
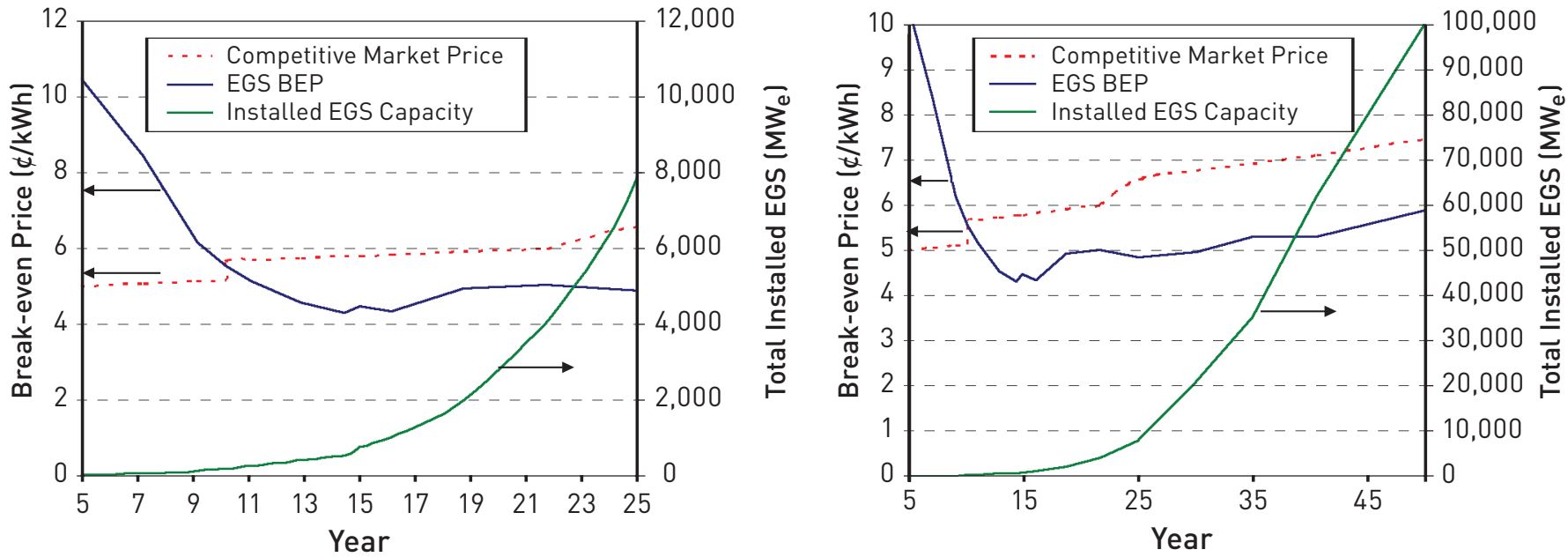

Figure A.9.6 Levelized break-even COE using MIT EGS for the $100,000 \mathrm{MW}_{\mathrm{e}}-50$ year scenario using a fixed charge rate of $12.8 \%$ per the NEMS model. Flow rate per production well (in a triplet configuration 1 injector, 2 producers) follows the $80 \mathrm{~kg} / \mathrm{s}$ learning curve. Thermal drawdown is $3 \% / \mathrm{yr}$ resulting in wellfield rework after $\sim 6$ years. Resulting absorbed technology deployment cost is \$344MM U.S. (2004). 

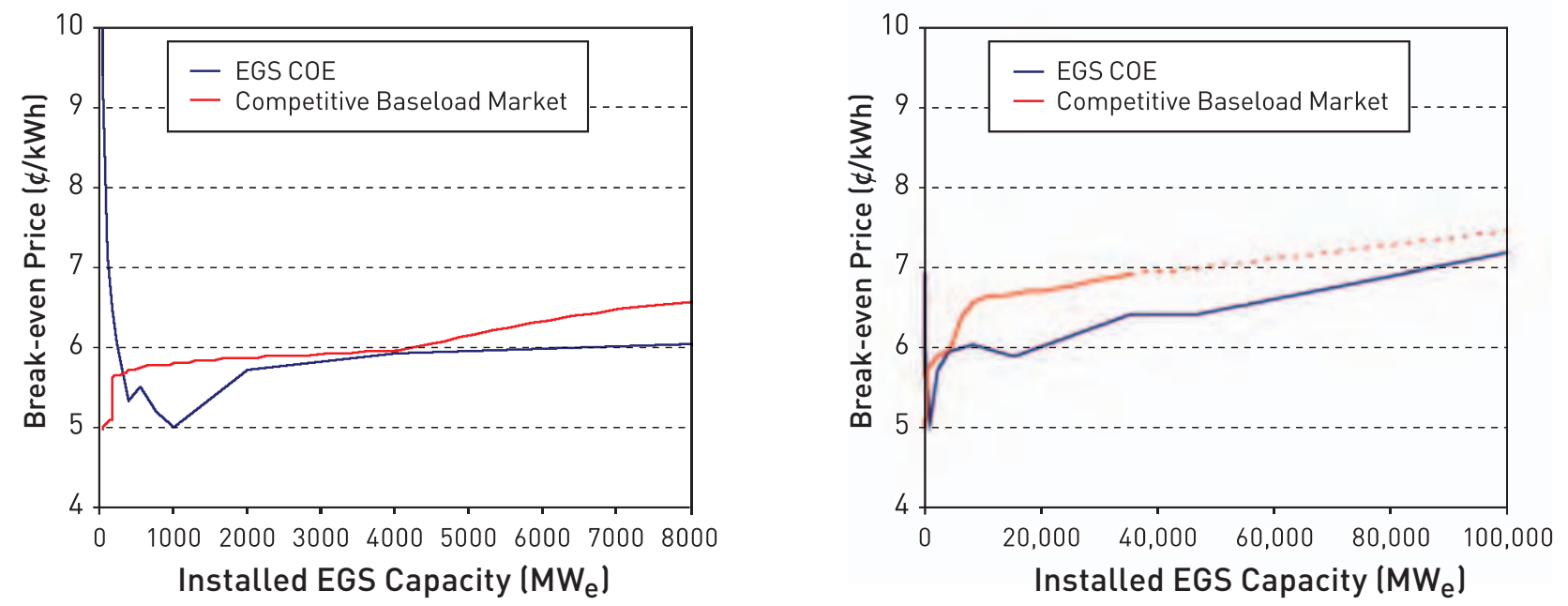

Figure A.9.7 Levelized break-even COE using MIT EGS for the $100,000 \mathrm{MW}_{\mathrm{e}}-50$ year scenario using a fixed charge rate of $12.8 \%$ per the NEMS model. Flow rate per production well (in a triplet configuration 1 injector, 2 producers) follows the $60 \mathrm{~kg} / \mathrm{s}$ learning curve. Thermal drawdown is $3 \% / \mathrm{yr}$ resulting in wellfield rework after $\sim 6$ years. Resulting absorbed technology deployment cost is \$368MM U.S. (2004).
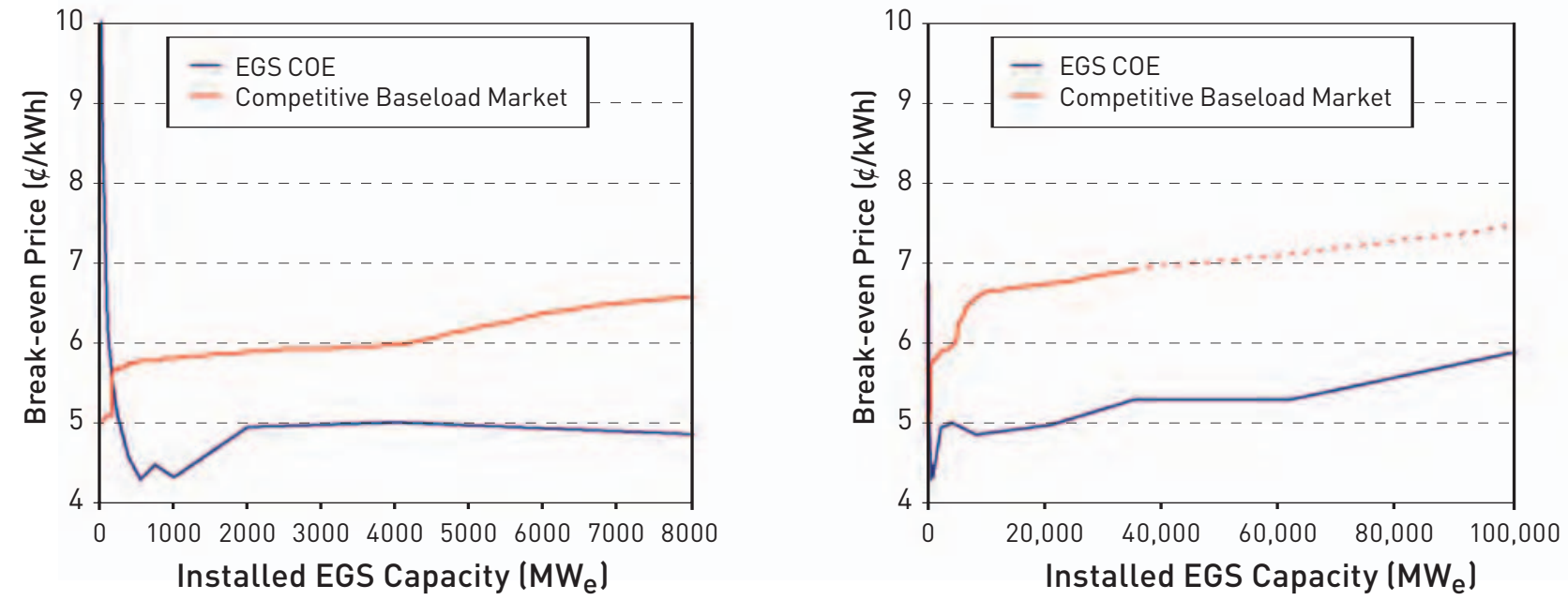

Figure A.9.8 Levelized break-even COE using MIT EGS for the $100,000 \mathrm{MW}_{\mathrm{e}}-50$ year scenario using a Fixed Charge Rate of $12.8 \%$ per the NEMS model. Flow rate per production well (in a triplet configuration - 1 injector, 2 producers) follows the $80 \mathrm{~kg} / \mathrm{s}$ learning curve. Thermal drawdown is $3 \% / \mathrm{yr}$ resulting in well-field rework after $\sim 6$ years. Resulting absorbed technology deployment cost is \$262MM U.S. (2004). 


\title{
A.9.3 Cost Sensitivities
}

\author{
Clear Lake
}

(a) $40 \mathrm{~kg} / \mathrm{s}$ production well flow rate

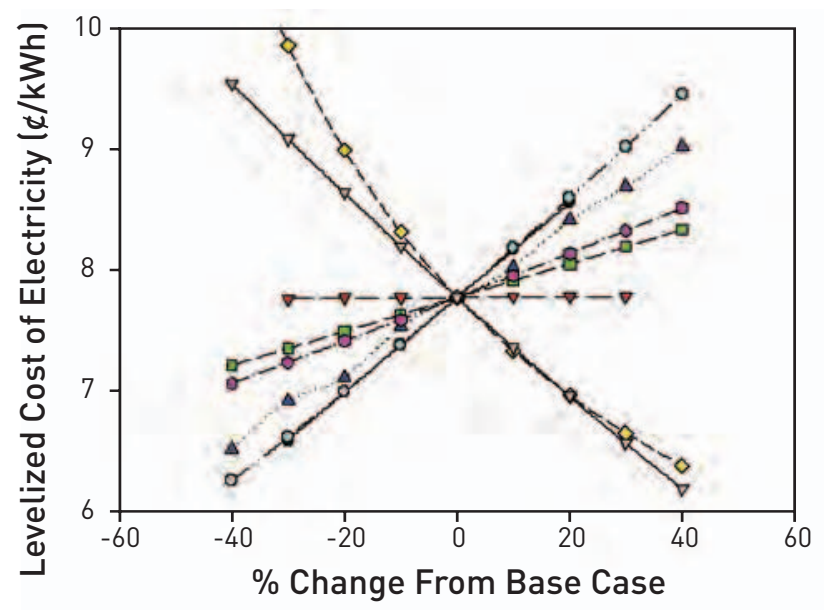

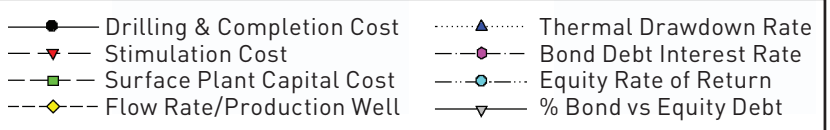

(b) $20 \mathrm{~kg} / \mathrm{s}$ production well flow rate

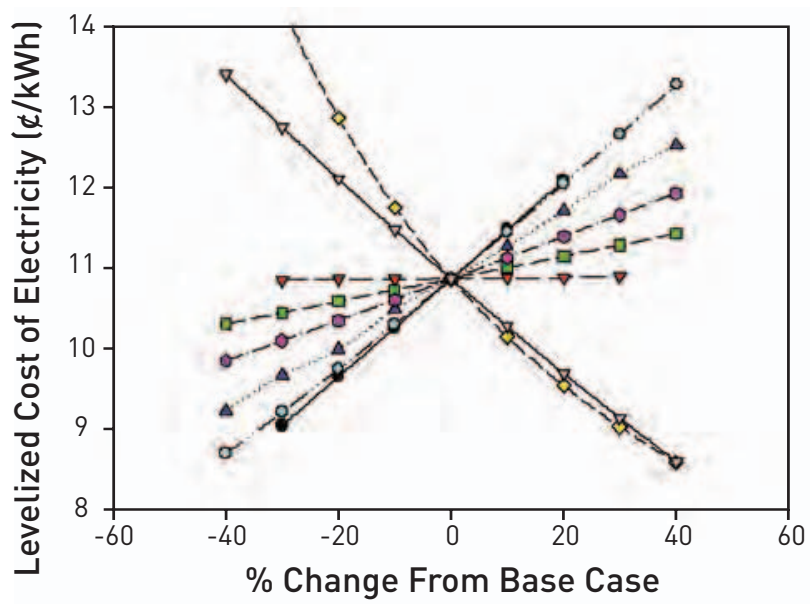

(c) Mature technology: $80 \mathrm{~kg} / \mathrm{s}$ production well flow rate, quartet configuration
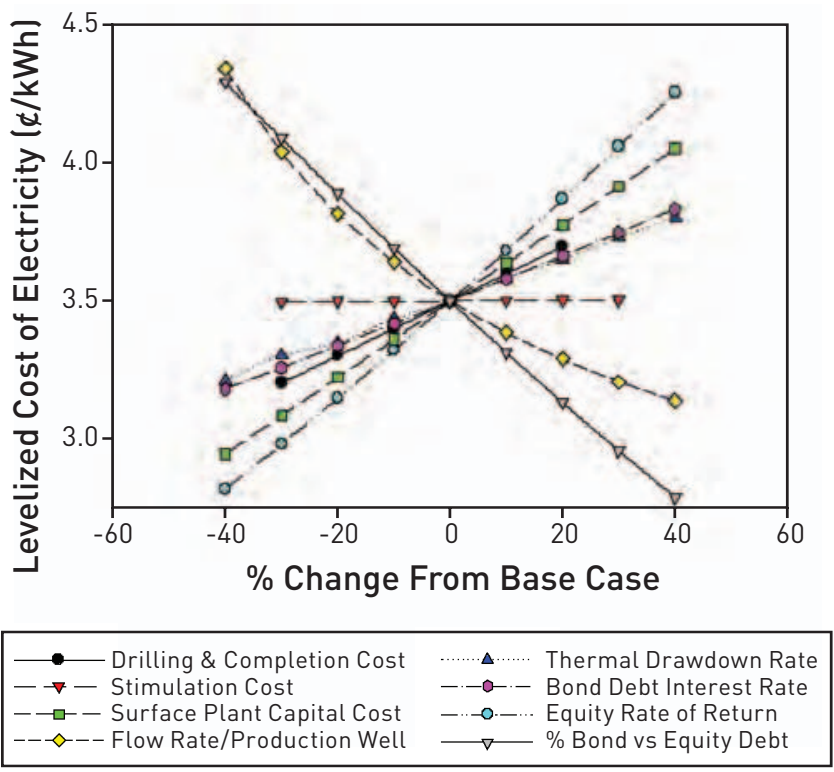

Figure A.9.9 Sensitivity of base case EGS LEC for the Clear Lake (Kelseyville, Calif.) scenario, showing levelized cost of electricity in $\$ / \mathrm{kWh}$ for three different production well flow rates. 


\section{Conway}

(a) $40 \mathrm{~kg} / \mathrm{s}$ production well flow rate

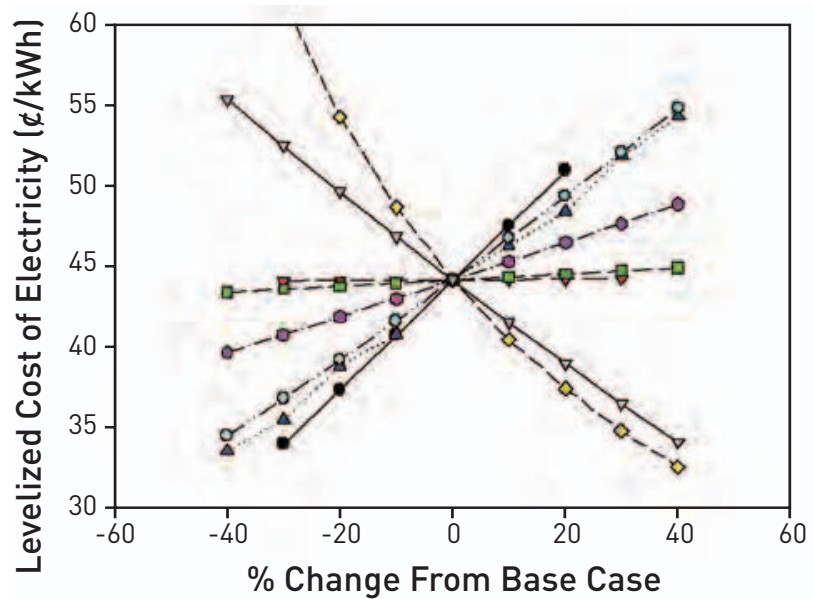

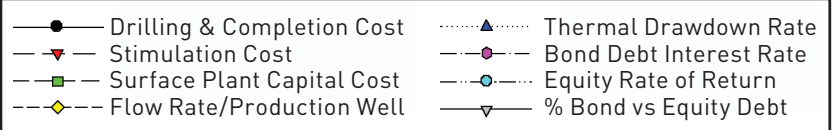

(b) $20 \mathrm{~kg} / \mathrm{s}$ production well flow rate

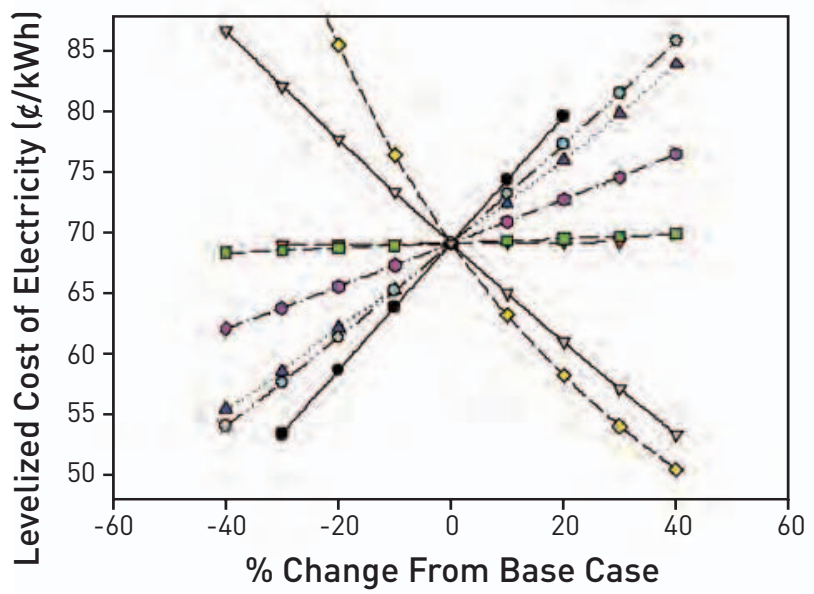

$\longrightarrow$ Drilling \& Completion Cost $\quad \cdots \cdots \cdot . \cdots \cdots \cdot . .$. Thermal Drawdown Rate $-\rightarrow-$ Stimulation Cost - - - - - Bond Debt Interest Rate - $\square-$ - Surface Plant Capital Cost _ _. - o.... Equity Rate of Return $--\diamond--$ Flow Rate/Production Well $\longrightarrow \longrightarrow$ Bond vs Equity Debt

(c) Mature technology: $80 \mathrm{~kg} / \mathrm{s}$ production well flow rate, quartet configuration

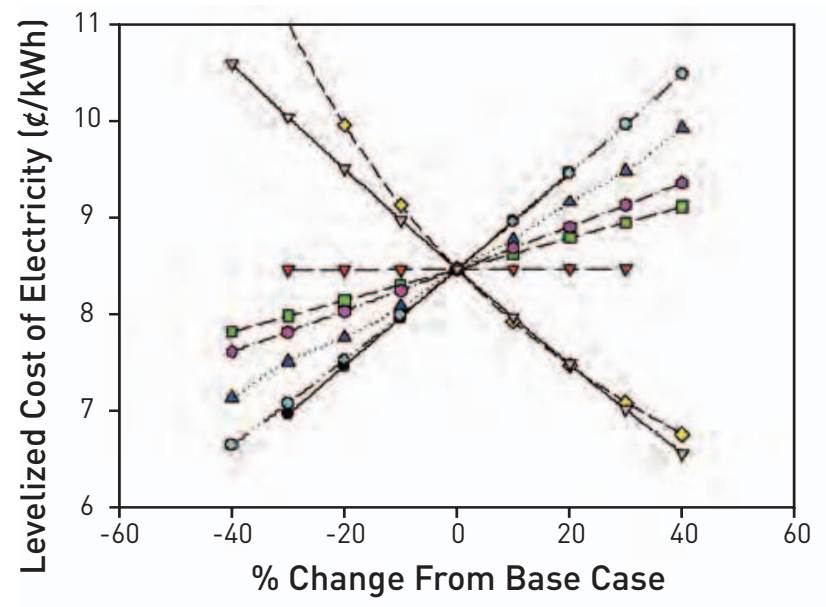

\begin{tabular}{|c|c|}
\hline $\begin{array}{l}\longrightarrow-\text { Drilling \& Completion Cost } \\
-\square-\text { Stimulation Cost } \\
-\rightarrow-- \text { Surface Plant Capital Cost } \\
--\diamond-- \text { Flow Rate/Production Well }\end{array}$ & $\begin{array}{l}\text { T.... Thermal Drawdown Rate } \\
--0-\text { Bond Debt Interest Rate } \\
-\ldots-\cdots \text { Equity Rate of Return } \\
\square \quad \text { \% Bond vs Equity Debt }\end{array}$ \\
\hline
\end{tabular}

Figure A.9.10 Sensitivity of base case EGS LEC for the Conway, N.H., scenario, showing levelized cost of electricity in $\$ / \mathrm{kWh}$ for three different production well flow rates. 


\section{Winnie, Texas, in the East Texas Basin}

(a) $40 \mathrm{~kg} / \mathrm{s}$ production well flow rate

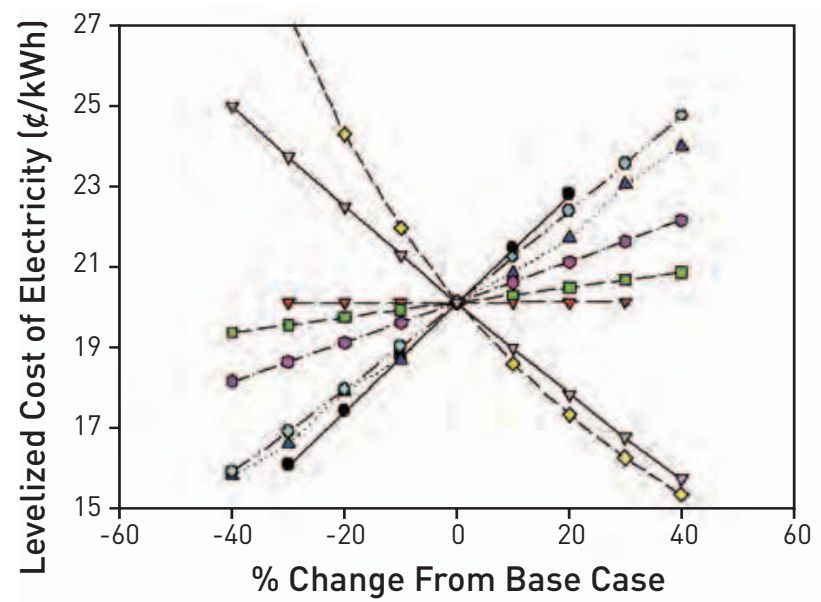

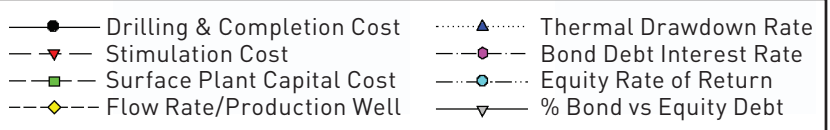

(b) $20 \mathrm{~kg} / \mathrm{s}$ production well flow rate

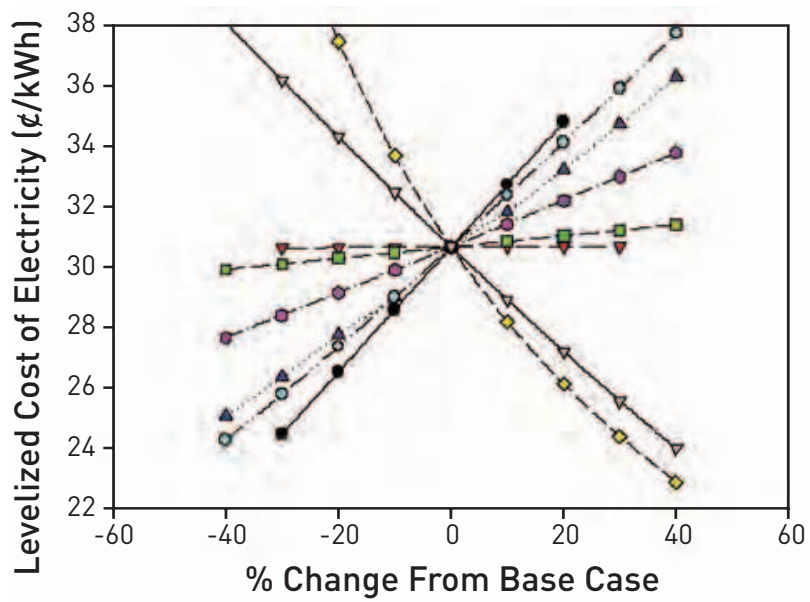

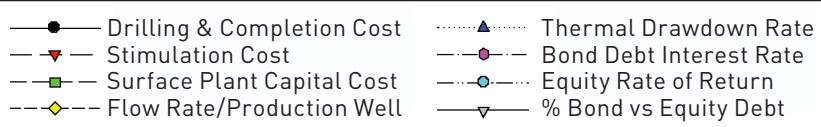

(c) Mature technology: $80 \mathrm{~kg} / \mathrm{s}$ production well flow rate, quartet configuration

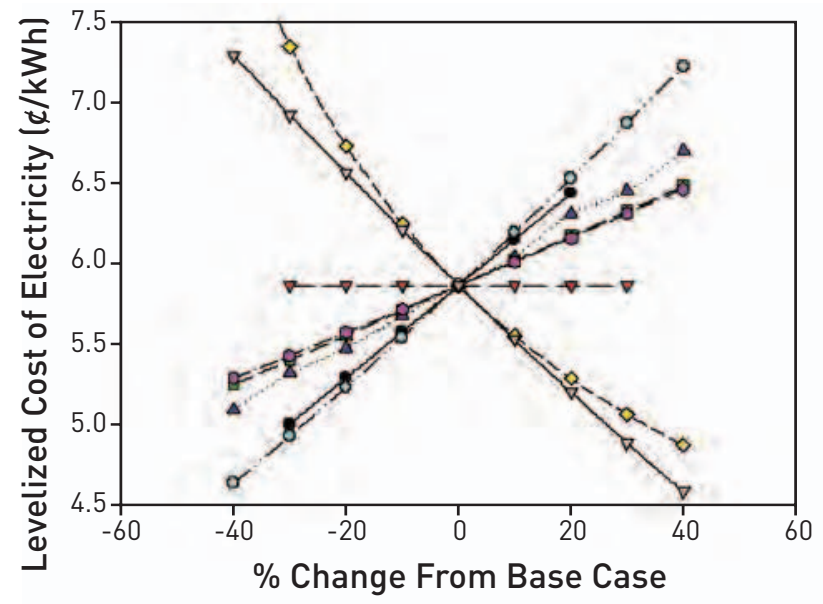

$9-60$

\begin{tabular}{|c|c|}
\hline $\begin{array}{l}\longrightarrow \text { Drilling \& Completion Cost } \\
-\square-\text { Stimulation Cost } \\
--\square-\text { Surface Plant Capital Cost } \\
-\diamond-- \text { Flow Rate/Production Well }\end{array}$ & 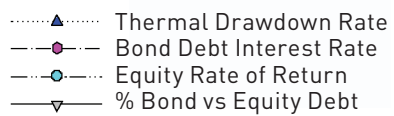 \\
\hline
\end{tabular}

Figure A.9.11 Sensitivity of base case EGS LEC for the East Texas Basin (Winnie, Texas) scenario, showing levelized cost of electricity in $\$ / \mathrm{kWh}$ for three different production well flow rates. 


\section{Nampa}

(a) $40 \mathrm{~kg} / \mathrm{s}$ production well flow rate

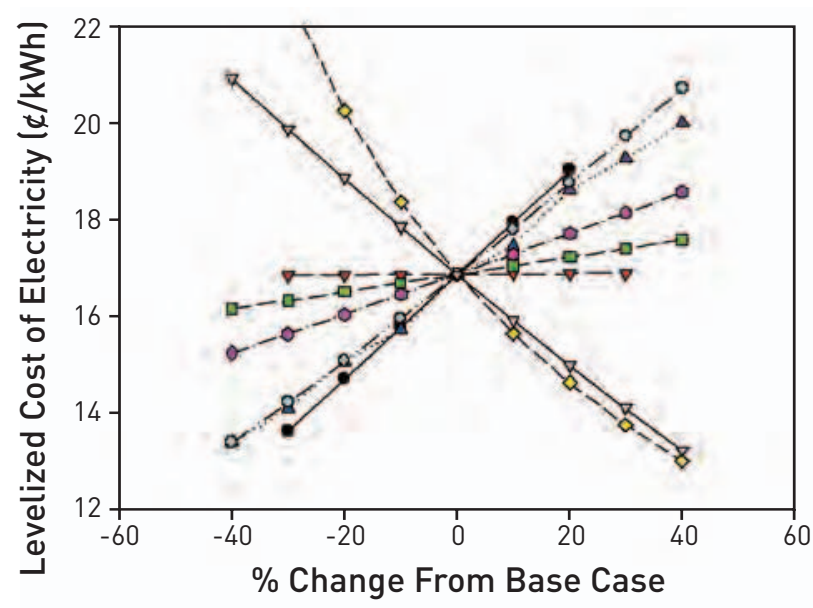

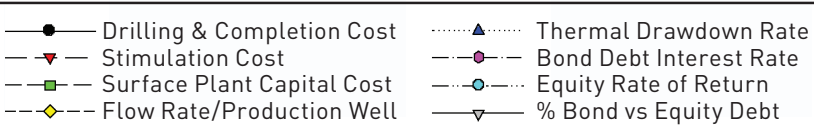

(b) $20 \mathrm{~kg} / \mathrm{s}$ production well flow rate

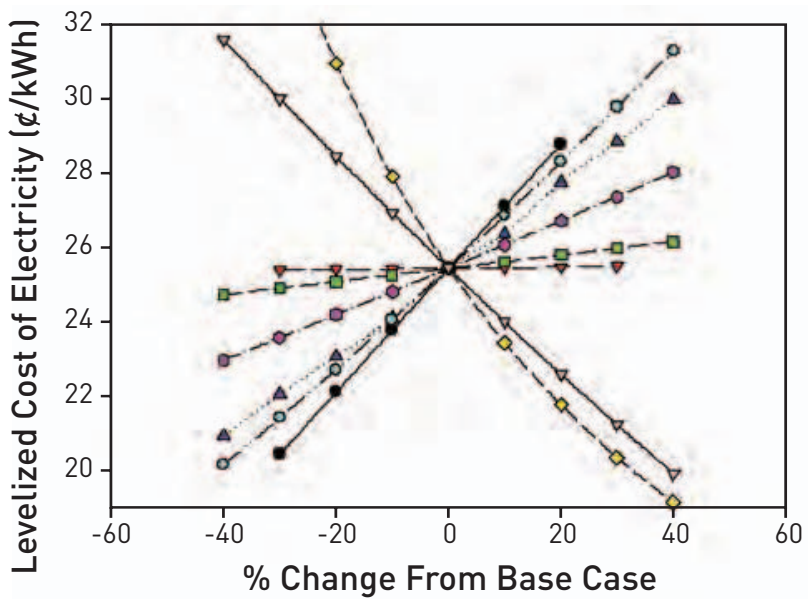

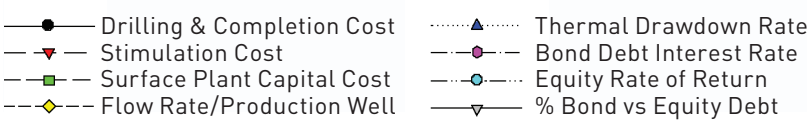

(c) Mature technology: $80 \mathrm{~kg} / \mathrm{s}$ production well flow rate, quartet configuration

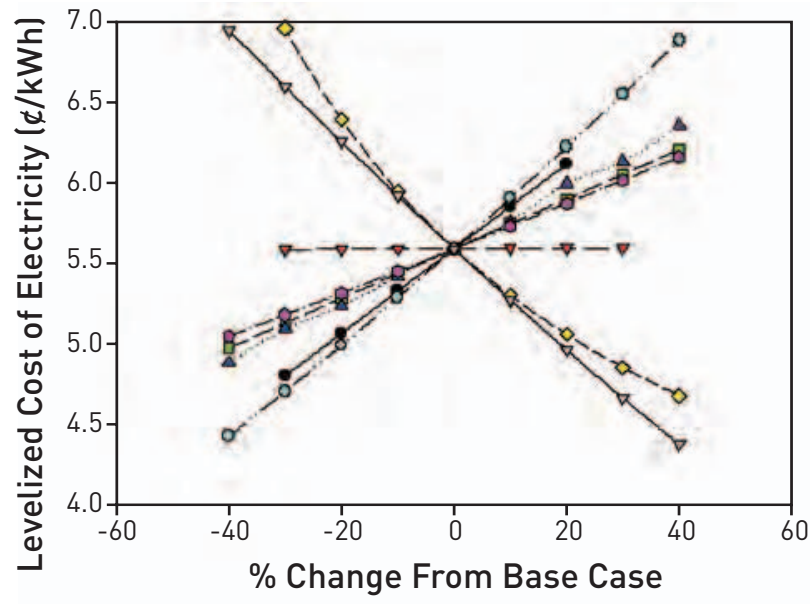

$$
\begin{aligned}
& \longrightarrow \text { Drilling \& Completion Cost } \quad \text { …........... Thermal Drawdown Rate } \\
& -\rightarrow-\text { Stimulation Cost } \quad-\text { - - - - Bond Debt Interest Rate } \\
& \text { - }- \text { - - Surface Plant Capital Cost } \quad \text {-....... Equity Rate of Return } \\
& --\diamond-- \text { Flow Rate/Production Well } \longrightarrow \text { \% Bond vs Equity Debt }
\end{aligned}
$$

Figure A.9.12 Sensitivity of base case EGS LEC for the Nampa, Idaho, scenario, showing (a) levelized cost of electricity in $\$ / \mathrm{kWh}$ for three different production well flow rates. 


\section{Sisters}

(a) $40 \mathrm{~kg} / \mathrm{s}$ production well flow rate

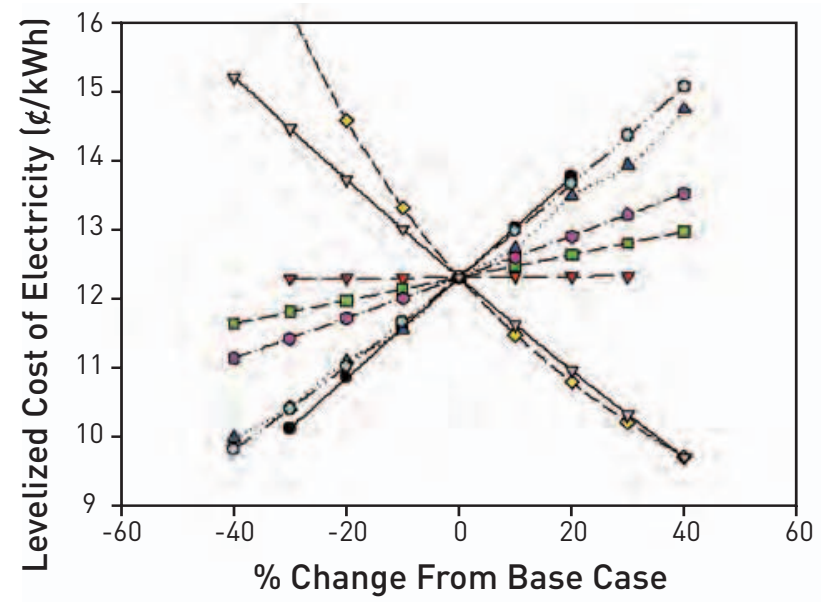

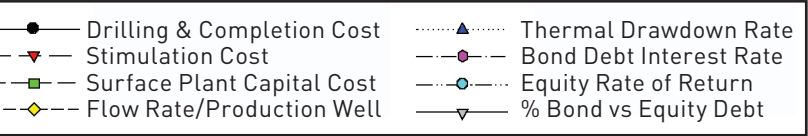

(b) $20 \mathrm{~kg} / \mathrm{s}$ production well flow rate

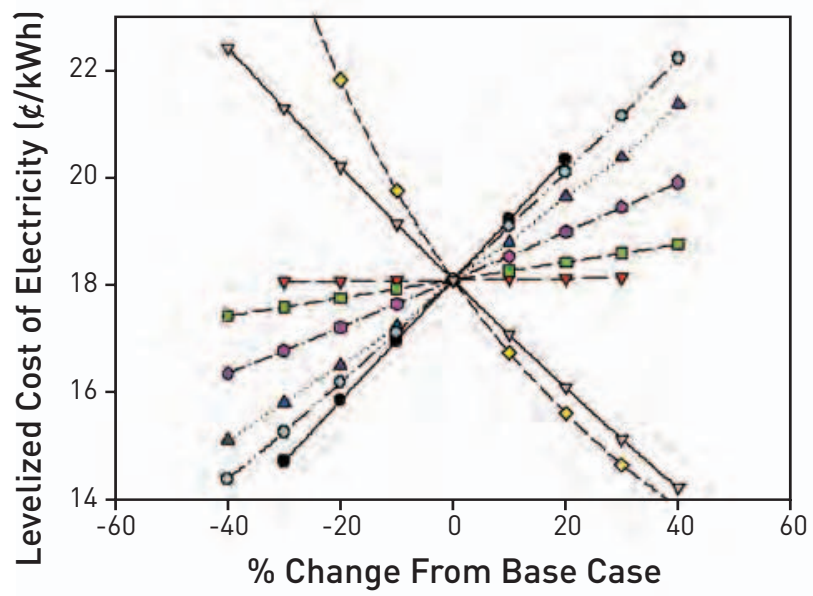

(c) Mature technology: $80 \mathrm{~kg} / \mathrm{s}$ production well flow rate, quartet configuration

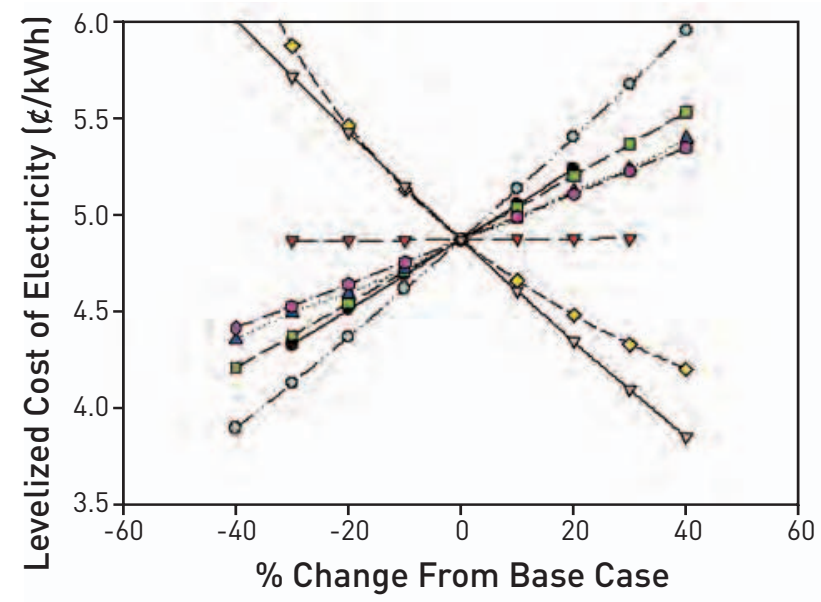

\begin{tabular}{|c|c|}
\hline $\begin{array}{l}\longrightarrow-\text { Drilling \& Completion Cost } \\
-\rightarrow-\text { Stimulation Cost } \\
-\rightarrow-\text { Surface Plant Capital Cost } \\
-\diamond-- \text { Flow Rate/Production Well }\end{array}$ & 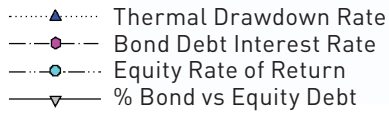 \\
\hline
\end{tabular}

Figure A.9.13 Sensitivity of base case EGS LEC for the Sisters, Ore., scenario showing levelized cost of electricity in $\$ / \mathrm{kWh}$ for three different production well flow rates. 


\section{Poplar Dome}

(a) $40 \mathrm{~kg} / \mathrm{s}$ production well flow rate

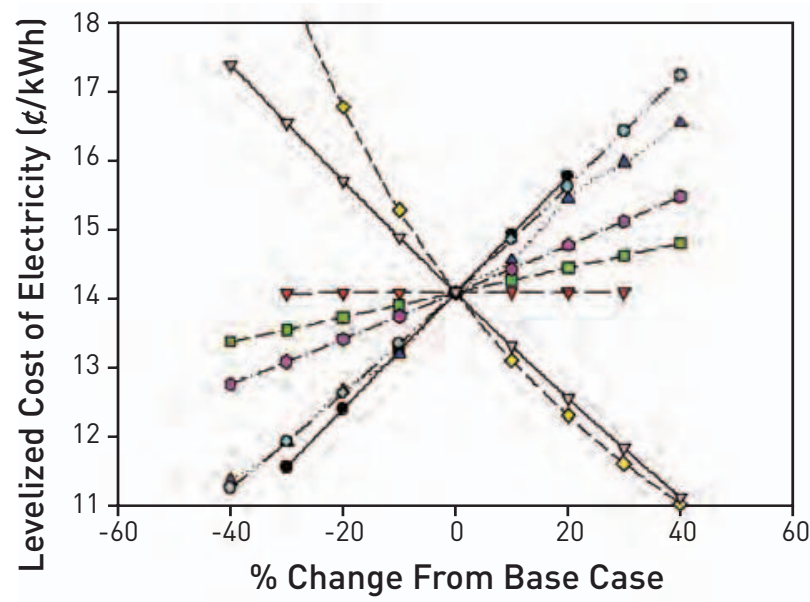

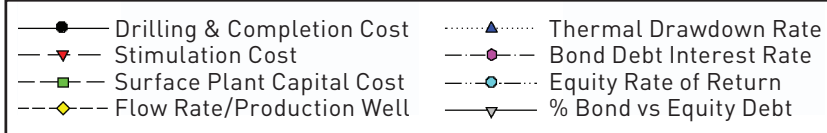

(b) $20 \mathrm{~kg} / \mathrm{s}$ production well flow rate

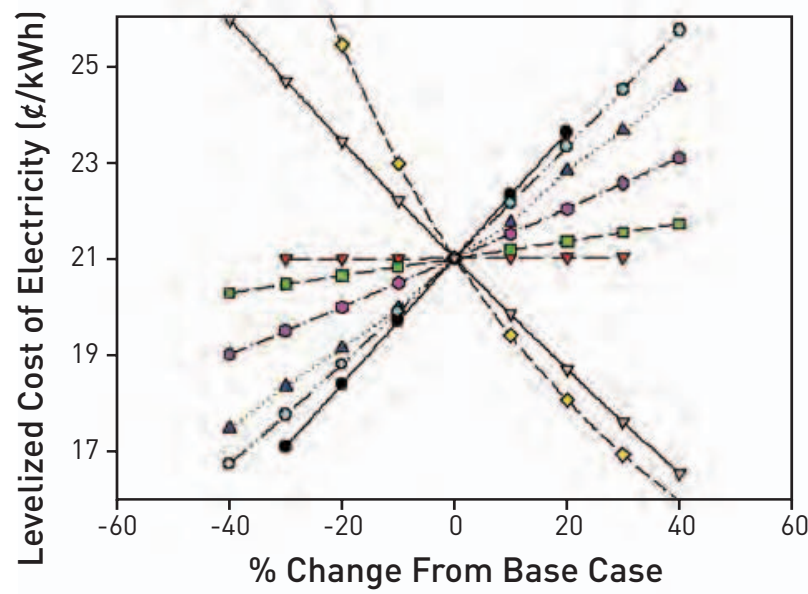

$\begin{array}{lll}\longrightarrow-\text { Drilling \& Completion Cost } & \ldots . . . . . . . . . & \text { Thermal Drawdown Rate } \\ -\rightarrow-\text { Stimulation Cost } & --0-\text { Bond Debt Interest Rate } \\ -\rightarrow-- \text { Surface Plant Capital Cost } & -\cdots-\ldots \text { Equity Rate of Return } \\ --\diamond-- \text { Flow Rate/Production Well } & \longrightarrow-\text { \% Bond vs Equity Debt }\end{array}$

(c) Mature technology: $80 \mathrm{~kg} / \mathrm{s}$ production well flow rate, quartet configuration
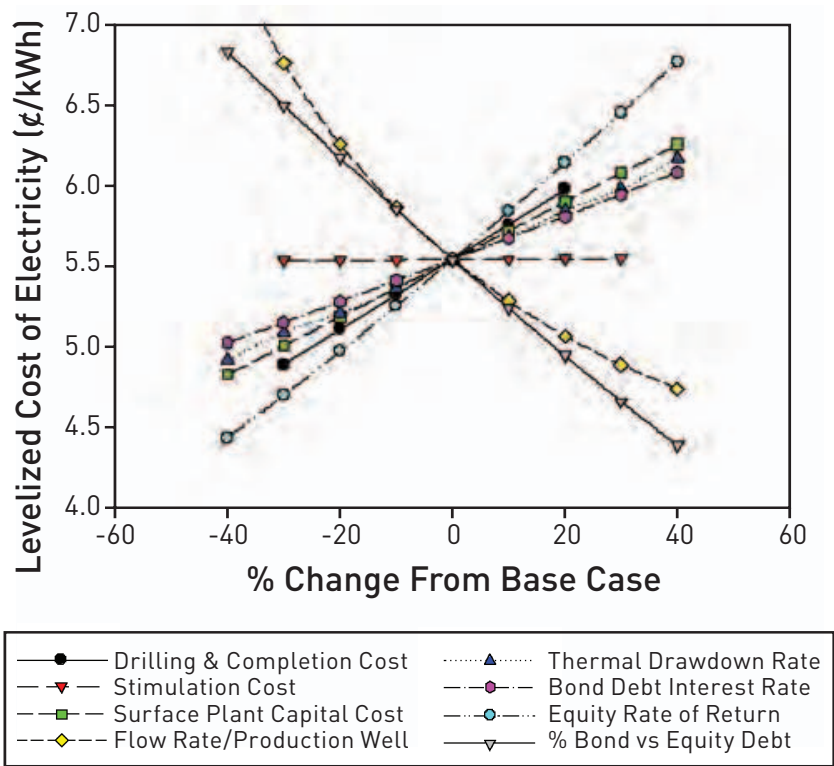

Figure A.9.14 Sensitivity of base case EGS LEC for the Poplar Dome (Poplar, Mont.) scenario, showing levelized cost of electricity in $₫ / \mathrm{kWh}$ for three different production well flow rates. 


\section{A.9.4 EGS Supply Curves for Selected States}

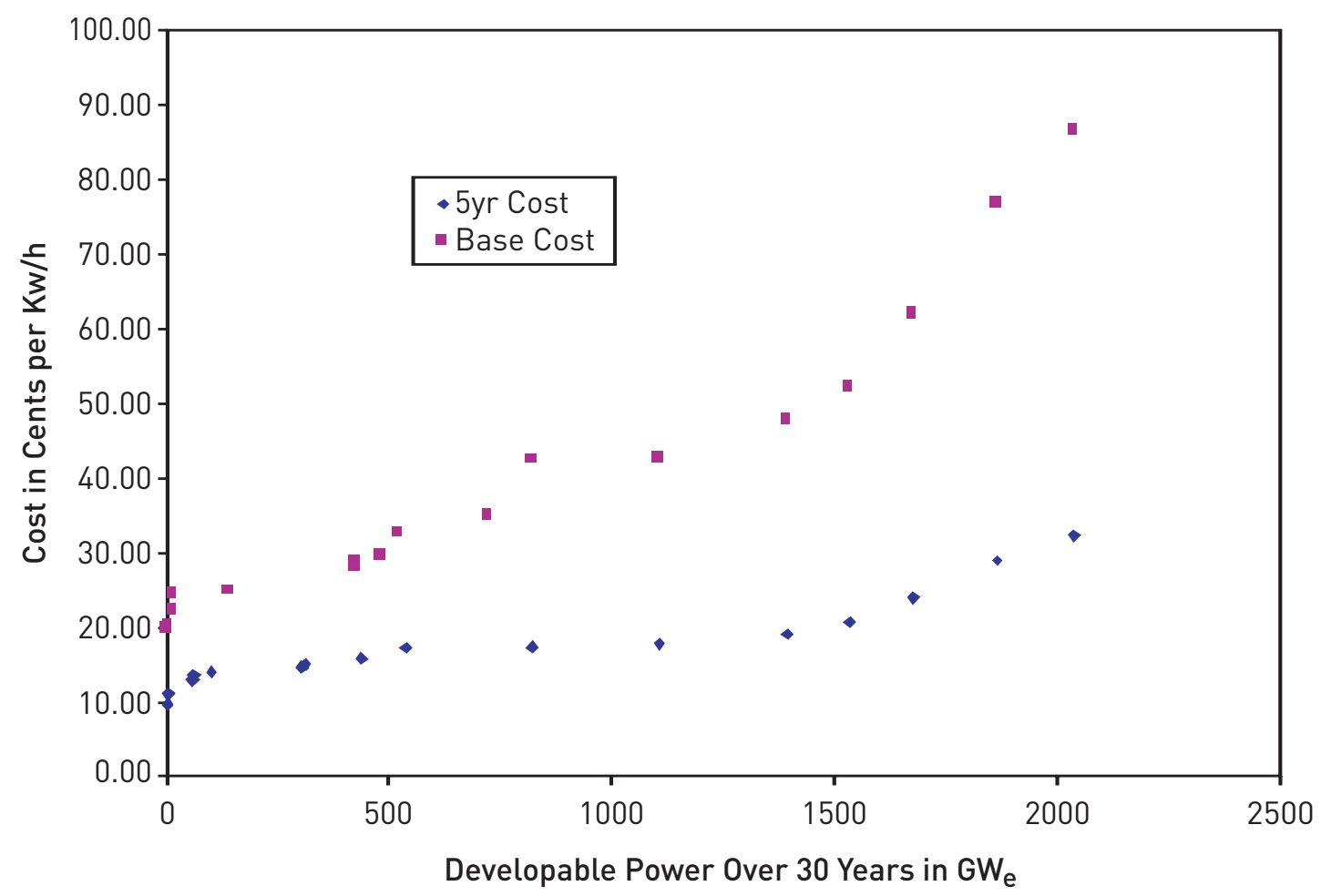

Figure A.9.15 Supply curve for EGS power at greater than $3 \mathrm{~km}$ in Texas, with current technology and in 5 years.

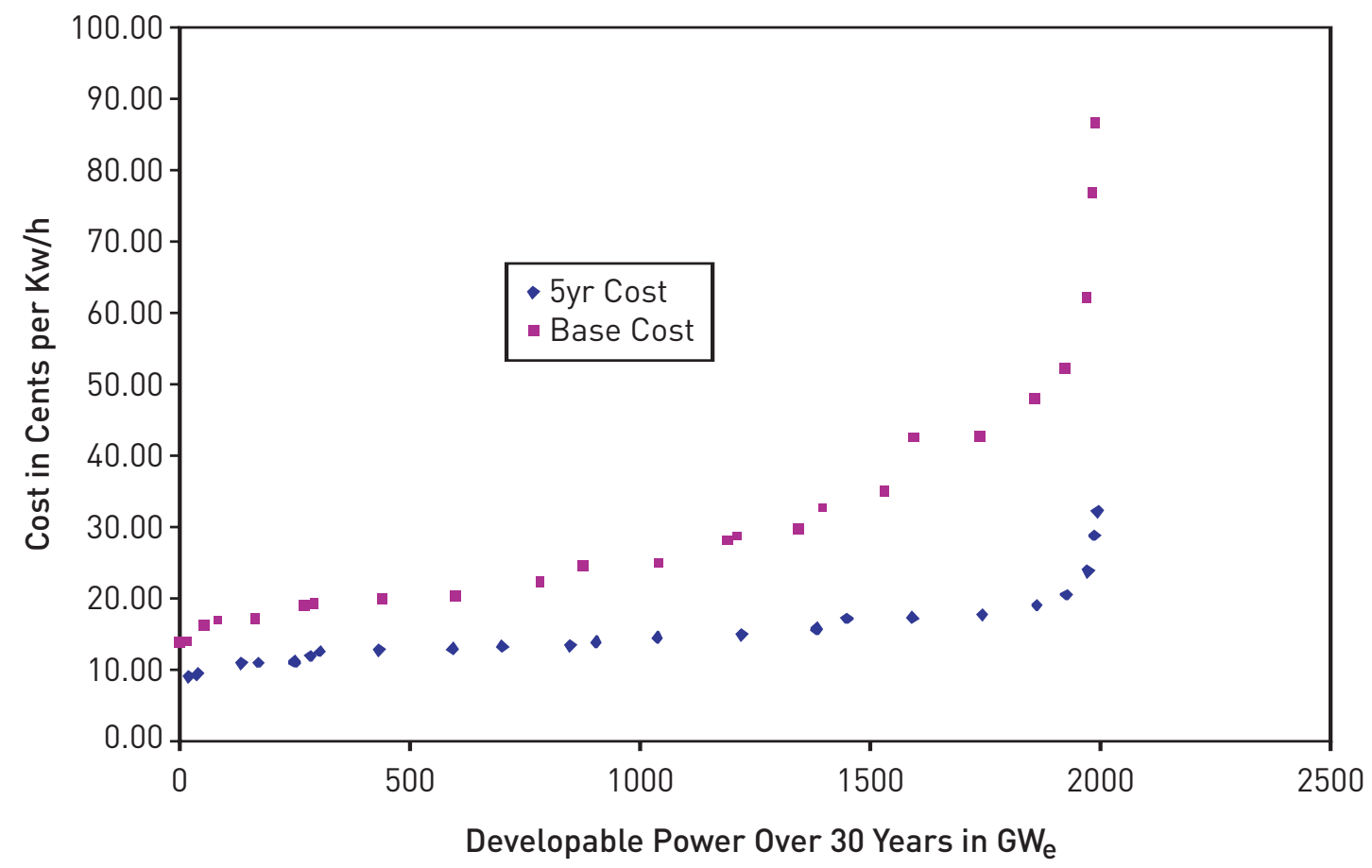

Figure A.9.16 Supply curve for EGS power at greater than $3 \mathrm{~km}$ in Colorado, with current technology and in 5 years. 


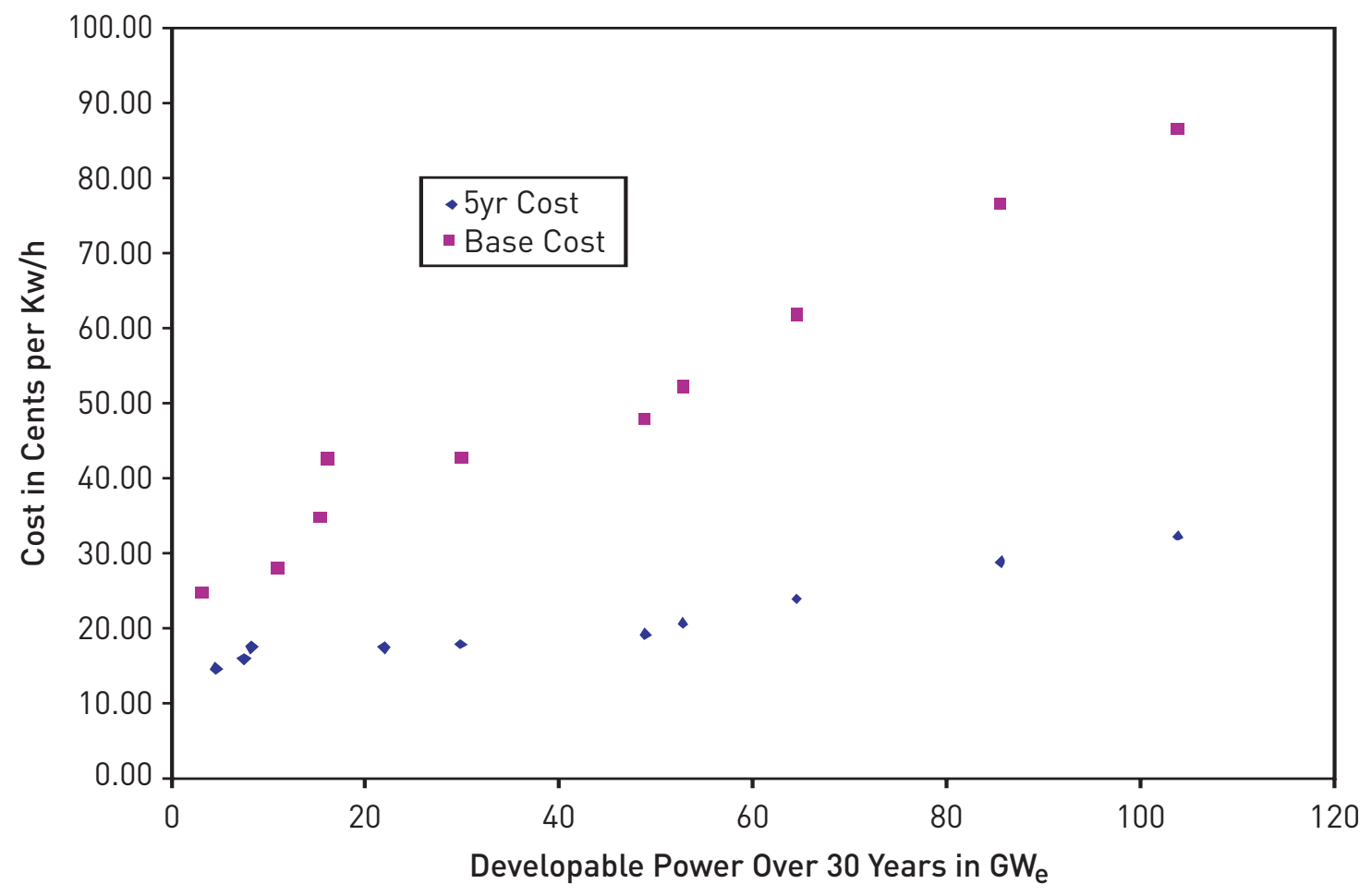

Figure A.9.17 Supply curve for EGS power at greater than $3 \mathrm{~km}$ in West Virginia, with current technology and in 5 years. 


\section{Appendix A}

\section{Table A.1 Energy Conversion Factors}

\begin{tabular}{lllllll}
\hline & Btus & quads & calories & $\mathrm{kWh}$ & $\mathrm{MWy}$ \\
\hline Btus & 1 & $10^{-15}$ & 252 & $2.93 \times 10^{-4}$ & $3.35 \times 10^{-11}$ \\
\hline quads & $10^{15}$ & 1 & $2.52 \times 10^{17}$ & $2.93 \times 10^{11}$ & $3.35 \times 10^{4}$ \\
\hline calories & $3.97 \times 10^{-3}$ & $3.97 \times 10^{-18}$ & 1 & $1.16 \times 10^{-6}$ & $1.33 \times 10^{-13}$ \\
\hline $\mathrm{kWh}$ & 3412 & $3.41 \times 10^{-12}$ & $8.60 \times 10^{5}$ & 1 & $1.14 \times 10^{-7}$ \\
\hline MWy & $2.99 \times 10^{10}$ & $2.99 \times 10^{-5}$ & $7.53 \times 10^{12}$ & $8.76 \times 10^{6}$ & 1 \\
\hline bbls oil & $5.50 \times 10^{6}$ & $5.50 \times 10^{-9}$ & $1.38 \times 10^{9}$ & 1612 & $1.84 \times 10^{-4}$ \\
\hline tonnes oil & $4.04 \times 10^{7}$ & $4.04 \times 10^{-8}$ & $1.02 \times 10^{10}$ & $1.18 \times 10^{4}$ & $1.35 \times 10^{-3}$ \\
\hline kg coal & $2.78 \times 10^{4}$ & $2.78 \times 10^{-11}$ & $7 \times 10^{6}$ & 8.14 & $9.29 \times 10^{-7}$ \\
\hline tonnes coal & $2.78 \times 10^{7}$ & $2.78 \times 10^{-8}$ & $7 \times 10^{9}$ & 8139 & $9.29 \times 10^{-4}$ \\
\hline MCF gas & $10^{6}$ & $10^{-9}$ & $2.52 \times 10^{8}$ & 293 & $3.35 \times 10^{-5}$ \\
\hline joules & $9.48 \times 10^{-4}$ & $9.48 \times 10^{-19}$ & 0.239 & $2.78 \times 10^{-7}$ & $3.17 \times 10^{-14}$ \\
\hline EJ & $9.48 \times 10^{14}$ & 0.948 & $2.39 \times 10^{17}$ & $2.78 \times 10^{11}$ & $3.17 \times 10^{4}$ \\
\hline
\end{tabular}

\begin{tabular}{l|l|l|l|l|l|l|l}
\hline & $\begin{array}{l}\text { bbls oil } \\
\text { equiv. }\end{array}$ & $\begin{array}{l}\text { tonnes oil } \\
\text { equiv. }\end{array}$ & $\begin{array}{l}\text { kg coal } \\
\text { equiv. }\end{array}$ & $\begin{array}{l}\text { tonnes } \\
\text { coal equiv. }\end{array}$ & $\begin{array}{l}\text { MCF gas } \\
\text { equiv. }\end{array}$ & joules & EJ \\
\hline Btus & $1.82 \times 10^{-7}$ & $2.48 \times 10^{-8}$ & $3.6 \times 10^{-5}$ & $3.6 \times 10^{-8}$ & $10^{-6}$ & 1055 & $1.06 \times 10^{-15}$ \\
\hline quads & $1.82 \times 10^{8}$ & $2.48 \times 10^{7}$ & $3.6 \times 10^{10}$ & $3.6 \times 10^{7}$ & $10^{9}$ & $1.06 \times 10^{18}$ & 1.06 \\
\hline calories & $7.21 \times 10^{-10}$ & $9.82 \times 10^{-11}$ & $1.43 \times 10^{-7}$ & $1.43 \times 10^{-10}$ & $3.97 \times 10^{-9}$ & 4.19 & $4.19 \times 10^{-18}$ \\
\hline kWh & $6.20 \times 10^{-4}$ & $8.45 \times 10^{-5}$ & 0.123 & $1.23 \times 10^{-4}$ & $3.41 \times 10^{-3}$ & $3.6 \times 10^{6}$ & $3.6 \times 10^{-12}$ \\
\hline MWy & 5435 & 740 & $1.08 \times 10^{6}$ & 1076 & $2.99 \times 10^{4}$ & $3.15 \times 10^{13}$ & $3.15 \times 10^{-5}$ \\
\hline bbls oil & 1 & 0.136 & 198 & 0.198 & 5.50 & $5.80 \times 10^{9}$ & $5.80 \times 10^{-9}$ \\
\hline tonnes oil & 7.35 & 1 & 1455 & 1.45 & 40.4 & $4.26 \times 10^{10}$ & $4.26 \times 10^{-8}$ \\
\hline kg coal & $5.05 \times 10^{-3}$ & $6.88 \times 10^{-4}$ & 1 & 0.001 & 0.0278 & $2.93 \times 10^{7}$ & $2.93 \times 10^{-11}$ \\
\hline tonnes coal & 5.05 & 0.688 & 1000 & 1 & 27.8 & $2.93 \times 10^{10}$ & $2.93 \times 10^{-8}$ \\
\hline MCF gas & 0.182 & 0.0248 & 36 & 0.036 & 1 & $1.06 \times 10^{9}$ & $1.06 \times 10^{-9}$ \\
\hline joules & $1.72 \times 10^{-10}$ & $2.35 \times 10^{-11}$ & $3.41 \times 10^{-8}$ & $3.41 \times 10^{-11}$ & $9.48 \times 10^{-10}$ & 1 & $10^{-18}$ \\
\hline EJ & $1.72 \times 10^{8}$ & $2.35 \times 10^{7}$ & $3.41 \times 10^{10}$ & $3.41 \times 10^{7}$ & $9.48 \times 10^{8}$ & $10^{18}$ & 1 \\
\hline
\end{tabular}

Source: “Sustainable Energy: Choosing Among Options," Massachusetts Institute of Technology (2005)

Key: $M W y=$ megawatt-year; bbls = barrels = 42 U.S. gallons; tonnes = metric tons =1,000 kg = 2,204.6 lb; $\mathrm{MCF}=$ thousand cubic feet; EJ = exajoule $=10^{18} \mathrm{~J}$. Nominal calorific values assumed for coal, oil, and gas.

Note: To convert from the first-column units to other units, multiply by the factors shown in the appropriate row (e.g., 1 Btu = 252 calories) 


\section{Appendix B}

\section{Panel-Member Biographies}

Jefferson W. Tester (chair)

Dr. Tester is the H.P. Meissner Professor of Chemical Engineering at the Massachusetts Institute of Technology (MIT). For three decades, he has been involved in chemical engineering process research as it relates to renewable and conventional energy extraction and conversion, and environmental control technologies. He has published extensively in the energy area with more than 185 papers and seven coauthored books, including Geothermal Energy as a Source of Electric Power (1976), Handbook of Geothermal Energy (1982), Heat Mining (1987), and Sustainable Energy - Choosing Among Options (2005). His other appointments have included director of MIT's Energy Laboratory (I989-200I), director of MIT's School of Chemical Engineering Practice (I980-I989), and a group leader in the Geothermal Engineering Group at Los Alamos National Laboratory (I974-I980). Dr. Tester is a member of the advisory boards of the National Renewable Energy Laboratory as chair, Massachusetts Renewable Energy Trust as chair, American Council on Renewable Energy, Los Alamos National Laboratory, Cornell University, and the Paul Scherrer Institute in Switzerland. He was a member of the Energy R\&D Panel of the President's Committee of Advisors on Science and Technology (PCAST) in 1997 and has served as an advisor to the U.S. Department of Energy (DOE) and the National Research Council (NRC) in areas related to concentrating solar power, geothermal energy, and other renewable technologies; and waste minimization and pollution reduction. Dr. Tester received a B.S. and M.S. with distinction in chemical engineering in I966 and I967 at Cornell, and a Ph.D. in chemical engineering at MIT in I97I.

\section{Brian J. Anderson}

Dr. Anderson is an assistant professor and the Verl Purdy Faculty Fellow in the Department of Chemical Engineering at West Virginia University. He received an M.S. and Ph.D. in chemical engineering from MIT, and a B.S. from West Virginia University. Dr. Anderson's research experience includes sustainable energy and development, economic modeling of energy systems, and geothermal energy development. He also has worked with molecular modeling of energy-relevant systems such as natural gas hydrates and hydrogen separation membranes. He has served as a consultant for a major bio-based energy company where he developed production flow sheets and economic models for the production of biodiesel and bio-ethanol from various feedstocks, built a knowledge database in the area of worldwide and domestic fuel production and consumption, and forecast production costs under different tax and demand scenarios.

\section{Anthony Stephen Batchelor}

Dr. Batchelor is chairman and managing director of GeoScience Limited, a specialized geothermal and geotechnical consulting/design company. Dr. Batchelor holds a B.S. in mining engineering (I968) and a Ph.D. in rock mechanics (I972) from the University of Nottingham in England. He is a chartered and European engineer, and a member of both the Society of Petroleum Engineers and the Institute of Materials, Minerals, and Mining. He is a member of the Geothermal Resources Council, and was a founding member of the International Geothermal Association and served on its board. He is an author of more than 60 papers, and a contributor to three books and a biography in "Who's Who in Science and Engineering." He taught rock mechanics at the Camborne School of Mines for more than I2 years, and developed the U.K. Hot Dry Rock Geothermal Project, of which he was project director from I977 to I986. During this time, he was a visiting staff member at Los Alamos National 
Laboratory and held a fellowship under the NATO/Committee on the Challenges of Modern Society (CCMS) program. Dr. Batchelor helped found GeoScience Ltd. in 1986, working on geothermal projects in California, Oregon, Japan, St Lucia, the Azores, Turkey, and Indonesia, and has since consulted for many global oil companies on rock mechanics and fractured reservoirs. In addition, he has taught in-house and SPE courses on wellbore rock mechanics during the past I5 years; and worked for operators, service companies, and regulators on issues with high pressure high temperature (HPHT) wells, "kicks" in oil-based muds, wellbore stability, cuttings reinjections, and sand control. GeoScience Ltd. has established a geothermal heat pump operation in the United Kingdom under the brand name EarthEnergy ${ }^{\mathrm{tm}}$. It is currently the leading installer of such systems in the U.K.

\section{David D. Blackwell}

Dr. Blackwell received a B.S. with a major in geology and mathematics from Southern Methodist University in 1963 and his Ph.D. in geophysics from Harvard University in I967. He joined the faculty at Southern Methodist University (SMU) after a year of postdoctoral study at the CalTech Seismological Laboratory. He has been the W. B. Hamilton Professor of Geophysics since I982. His research specialty is the thermal field of the Earth, and he has worked extensively in geothermal exploration and resource assessment in the United States and worldwide. He has received research grants and contracts for geothermal activities from the U.S. DOE, National Science Foundation (NSF), and many other entities. He has consulted for numerous U.S. geothermal and energy companies. Most recently, he was coeditor with Maria Richards of the "Geothermal Map of North America," published by the American Association of Petroleum Geologists in 2004. Dr. Blackwell is a longtime member of the board of directors of the Geothermal Resources Council and was president in I991/92. He has been a member of the board of the International Geothermal Association, and was extensively involved in the technical aspects of the 1995 and 2000 international geothermal conferences in Italy and Japan. The SMU Geothermal Laboratory maintains a Web site with extensive geothermal data and information at www.smu.edu/geothermal.

\section{Ronald DiPippo}

Dr. DiPippo is Chancellor Professor Emeritus of mechanical engineering and former associate dean of engineering at the University of Massachusetts Dartmouth. He is now a full-time energy systems consultant. Dr. DiPippo received his Ph.D. from Brown University and taught thermodynamics, power plant design, geothermal energy, and other energy-related courses from I967 to 2004. His expertise is the generation of electricity from geothermal resources. He has contributed to the development of several novel power plant designs using hybrid fossil-geothermal systems, and applied the Second Law of thermodynamics to the analysis and design of geothermal power plants. He has published more than Ioo professional papers and reports in areas such as transport properties of fluids, geothermal energy conversion systems, and applications of Second Law analysis to geothermal systems. He is the author of two books, Geothermal Energy as a Source of Electricity (I980), and Geothermal Power Plants: Principles, Applications and Case Studies (2005); and is an editor of and contributor to Sourcebook on the Production of Electricity from Geothermal Energy (ig80). 


\section{Elisabeth M. Drake}

Dr. Drake received her S.B. and Sc.D. degrees in chemical engineering from MIT, and worked for more than 25 years at the consulting firm of Arthur D. Little Inc. At the firm, she specialized in advising industrial and governmental clients worldwide on the risk management of hazardous facilities, ranging from petrochemical plants to offshore drilling rigs. From I986-I988, she was vice president and leader of the firm's Environment, Health, and Safety Practice. She has been at MIT for the past 15 years, where she has served as the associate director for new technologies at the MIT Energy Laboratory. She has been part of a team that developed a graduate-level course on sustainable energy that addresses energy options in a broad context of short- and longer-term economical, societal, and environmental issues. A textbook for this course was published in 2005. From I982I986, Dr. Drake was the Cabot Professor of Chemical Engineering at Northeastern University and served as chairman of its Chemical Engineering Department. Dr. Drake was a visiting associate professor of chemical engineering at MIT during the I973-I974 academic year, while on leave from Arthur D. Little. She also was a lecturer in chemical engineering at the University of California at Berkeley during the spring of I97I. She is a member of the National Academy of Engineering and a fellow of the American Institute of Chemical Engineers (AIChE).

\section{John Garnish}

Dr. Garnish earned his Ph.D. in physical chemistry in I966 from the University of Bristol, United Kingdom, and joined the U.K. Atomic Energy Authority. He was a founding member of the Energy Technology Support Unit, established in 1974 to assist the U.K. Department of Energy with its research programs. Dr. Garnish was responsible for geothermal research in the U.K. during the I970s and I980s. He represented the U.K. in its participation in the NATO/CCMS and International Energy Agency (IEA) geothermal projects, and in the geothermal advisory committee of the European Commission. In I985, he joined the European Commission to take responsibility for the commission's program of geothermal research in Europe - and, in particular, to bring together the expertise developed in the U.K.'s HDR project in Cornwall with related projects in France and Germany. This resulted in the integrated European HDR project at Soultz-sous-Fôrets in France. He was also the commission's representative in the current IEA Geothermal Implementing Agreement (chairman 200I-2002). He has been chairman of the Soultz project's Scientific Advisory Panel since retiring from the European Commission in 2002. He was a member of the Geothermal Resources Council for many years, and is currently in his fourth term as a director of the International Geothermal Association.

\section{Bill Livesay}

Dr. Livesay has more than 40 years experience in all aspects of drilling engineering for oil, gas, and geothermal resources. His varied work experience has permitted Dr. Livesay to see drilling technology from all three critical viewpoints. First, as a drilling engineer at Exxon and as a consultant; second, as a researcher and developer of drilling technology, and builder of drilling equipment for Dresser Security; and, finally, as a researcher of drilling technology as professor of petroleum and mechanical 
engineering at The University of Tulsa, and through 28 years of work with Sandia National Laboratories and other clients. Dr. Livesay has authored more than 30 publications covering most aspects of drilling, drilling costs, equipment, techniques, and procedures. His educational background includes a B.S. in mechanical engineering from Oklahoma State University, and a Ph.D. in mechanical engineering from Kansas State University.

\section{Michal C. Moore}

Dr. Moore is senior fellow at the Institute for Sustainable Energy, Environment, and Economy at the University of Calgary in Alberta, where he teaches economic theory and conducts research on alternative energy technologies and markets. He is the former chief economist at the National Renewable Energy Laboratory in Golden, Colo., and a former regulator of the energy industry in California. Dr. Moore received his B.S. in geology at Humboldt State University and an M.S. in land economics from the Ecology Institute at the University of California at Davis. He obtained a Ph.D. in Economics from the University of Cambridge in England, where he is a member of Darwin College. His primary research interests lie in the areas of urban open space and agricultural land conversion, local government fiscal impacts, and the structure and rules of energy markets.

\section{Kenneth Nichols}

Mr. Nichols is the CEO emeritus of Barber Nichols Inc. He also is a senior project engineer for projects involving turbomachinery and especially high specific energy turbines. Mr. Nichols has been responsible for the design and installation of several binary geothermal plants, some of which have been in commercial operation for more than 20 years. Mr. Nichols has developed and manufactured numerous Rankine Cycle power plants that operate on the heat from cement kilns, diesel exhaust, and other heat sources. This experience provided real cost and economics of these power systems. Mr. Nichols is a graduate of the University of Colorado, holds a B.S.M.E. degree, and is a registered professional engineer in the state of Colorado.

\section{Susan Petty}

Ms. Petty has more than 25 years of experience in the geothermal industry in electrical and direct-use project economics; optimizing of power plants to meet resource conditions; reservoir evaluation; reservoir modeling; well, plant and wellfield performance data analysis; well testing; and test data analysis. She has also assisted in negotiation of geothermal lease agreements, power sales agreements, geothermal project financing agreements, and geothermal property sales and purchases. Ms. Petty has done work on geothermal electrical generation projects in Nevada at Steamboat, Dixie Valley, Rye Patch, Soda Lake, Fallon, Desert Peak, and Brady hot springs; and direct-use projects at Brady, Elko, and Moana. In California, she has worked on the Coso, Salton Sea, East Mesa, Heber, Brawley, Wendell-Amedee, Mt. Lassen, and Medicine Lake resources. She has worked on geothermal projects overseas in Indonesia, the Philippines, and Central America. For a number of years, Ms. 
Petty assisted the Department of Energy in performing policy studies for geothermal energy research including economic modeling of geothermal pricing and the impact of technology improvement on the cost of geothermal power. She performed a signature study, still in use today, of the potential cost of geothermal power supply from projects across the western United States. Ms. Petty received a B.A. in geology from Princeton University in 1973 and an M.S. in groundwater hydrology from the University of Hawaii in I979.

\section{Nafi Toksöz}

Dr. Toksöz is a Robert R. Shrock Professor of Geophysics; founder of the Earth Resources Laboratory and its director from I982 to I998; and director of the George R. Wallace Jr. Geophysical Observatory at MIT. Dr. Toksöz, an honorary member of the Society of Exploration Geophysicists (SEG), received his geophysical engineering degree at Colorado School of Mines and his M.S. and Ph.D. at the California Institute of Technology. He has been a faculty member in the Department of Earth, Atmospheric, and Planetary Sciences at MIT since 1965. Dr. Toksöz has made major scientific contributions in many areas of geophysics, including seismic exploration, plate tectonics, planetary interiors, earthquake seismology, and imaging. In 1976, he received the NASA Exceptional Scientific Achievement Medal. In I995, he received the Distinguished Achievement Medal from the Colorado School of Mines. He is the author or coauthor of more than 300 technical papers, and has edited books, including one on seismic Wave Attenuation, published by the SEG.

\section{Ralph W. Veatch, Jr.}

Dr. Veatch Jr. is president of Software Enterprises Inc., an engineering consulting firm, in Tulsa, Okla. He holds a B.Sc. and M.Sc. in petroleum engineering, and a Ph.D. in engineering science, all from the University of Tulsa. His career began in I960 as a petroleum engineer with Amoco Production Co. In I970, he transferred to Amoco Production Research, serving in various staff and supervisory positions, retiring in I993 as supervisor of the Hydraulic Fracturing and Well Completions and Production Operations groups. He has taught at Louisiana State University in Lafayette and the University of Tulsa. Since I993, he has been involved with petroleum consulting. From I993 to 2003, he taught a five-day industry course on hydraulic fracturing. Dr. Veatch is a professional engineer in Oklahoma and Texas, and a member of the Society of Petroleum Engineers (SPE). He is an SPE distinguished member, distinguished author and a distinguished lecturer; and a recipient of the SPE John Franklin Carll award. He has authored or coauthored 25 technical papers and I2 books. During his career, he has served on numerous advisory committees for the American Petroleum Institute, Completion Engineering Association, Gas Research Institute, Los Alamos National Laboratory, National Petroleum Council, and the U.S. DOE. 


\section{Associate Panel Members}

\section{Roy Baria}

Dr. Baria is a professional geophysicist with specialties in seismic profiling and geothermal reservoir engineering. In I980, he left the British Geological Survey and became deputy director of the U.K. Geothermal Project, operated by the Camborne School of Mines at the Rosemanowes site in Cornwall. In I990, Dr. Baria joined the European project at Soultz near Strasbourg in France at the request of the European Commission (EC). He became one of the coordinators of the European EGS project and as "scientist in charge," he was responsible for planning the program, coordinating scientists from various nations, preparing annual reports for the EC, and developing diagnostic methods to evaluate HDR reservoirs etc. Since 2005, Dr. Baria has been the director of Mil-Tech U.K. Ltd., acting as a consultant on the EGS and associated technologies to various organizations in Europe, United States and Japan.

Chad Augustine: B.S., chemical engineering, Iowa State University (2000); doctoral candidate and graduate research assistant, chemical engineering, MIT

Enda Murphy: B.E., civil and environmental engineering, University College Cork (2004); M.S., civil and environmental engineering, MIT (2006); research associate

Petru Negraru: B.S., geophysics, University of Bucharest (I998); Ph.D., geophysics, Southern Methodist University (2005); postdoctoral researcher, SMU Geophysics Department and Geothermal Laboratory

Maria Richards: B.S., physical geography, Michigan State University (1986); M.S., physical geography, water resource management, University of Tennessee - Knoxville (I99I); research associate, Southern Methodist University Geothermal Laboratory 


\section{Appendix C}

Glossary of Scientific Terms and Abbreviations

AAPG - American Association of Petroleum Geologists. The professional society of petroleum geologists, the source of information on bottom-hole temperatures used in this report.

Abandonment temperature - The average temperature of the active reservoir rock volume at the time heat-extraction operations cease.

Acoustic emissions - Elastic waves produced by defects in a material when that material is placed under stress.

AFE - Authorization for expenditures. The estimated and actual expenditures for wells drilled by a company.

Annualized costs - Determined by using a fixed charge rate applied to invested capital, adding an annualized operating cost, and dividing the sum by the annual electric generation.

Annualized revenues - Calculated returns based on a full year.

Base load - The minimum amount of power that a utility or distribution company must make available to its customers, or the amount of power required to meet minimum demands based on reasonable expectations of customer requirements. Base-load values typically vary from hour to hour in most commercial and industrial areas.

Basin and Range - An area of about $800,000 \mathrm{~km}^{2}$ extending over southeastern Oregon, Nevada, western Utah, southeastern California, southern Arizona, and southwestern New Mexico, characterized by more than 200 low mountain ranges interspersed with shallow basins generally oriented north-northeast by south-southwest. The orientation is controlled by active or recently active normal (extensional) fault systems bounding tilted fault blocks of horst/graben pairs.

Baumann rule - The isentropic efficiency of a vapor turbine operating in the two-phase, liquidvapor region, is reduced I\% for each I\% of moisture present, on average, during the total expansion process.

BHT - Bottom-hole temperature. A measured temperature in the borehole at its total depth. The bottom-hole temperature (BHT) is taken as the maximum recorded temperature during a logging run or, preferably, the last series of runs during the same operation. BHT is the temperature used for the interpretation of logs and heat flow at geothermal gradient. Farther up the hole, the correct temperature is calculated by assuming a certain temperature gradient. The BHT lies between the bottom-hole circulating temperature (BHCT) and the bottom-hole static temperature (BHST).

Binary cycle - An energy-conversion system that uses a closed Rankine cycle having an organic working fluid that receives heat from a hot geofluid and rejects waste heat to the surroundings while generating electrical power. 
Biofuel - Any fuel derived from biomass, i.e., recently living organisms or their metabolic byproducts, such as wood wastes, corn grain, or manure from cows. It is a renewable energy source often made from agricultural crops or residuals grown specifically for conversion to liquid or gaseous fuels.

Blowout preventer (BOP or BOPE) - A fast-acting valve or series of valves at the wellhead used during drilling to control wells from erupting prematurely. When zones of unexpected high pressure are encountered, the well will unload creating a "gusher" that can be extremely dangerous. A BOP can close rapidly and keep the fluid inside the well until the pressure can be released gradually.

Borehole televiewer - An instrument that provides an acoustic "image" of a borehole wall by scanning it with a narrow pulsed acoustic beam from a rotating transducer while the tool is pulled up a hole.

Break-even price - In the context of the analysis contained in this assessment, the price of delivered power to the grid, given forecast increases in technology performance, drilling techniques, and reservoir stimulation and management, where the area utilization (i.e., fraction of utilized thermal resource within a given temperature and depth regime) is limited to $2 \%$ of total capacity.

Caldera - A volcanic basin, roughly circular with steep sides, having a diameter several times larger than the depth, formed by collapse of the central part of a volcanic center due to eruption of a large volume of volcanic ash from the underlying magma chamber.

California Energy Commission (CEC) - An agency of the state of California charged with: (I) forecasting future energy needs and keeping historical energy data; (2) licensing thermal power plants with capacities of 50 MWe or larger; (3) promoting energy efficiency through appliance and building standards; (4) developing energy technologies and supporting renewable energy; and (5) planning for and directing state response to an energy emergency.

Capacity factor - The ratio (usually expressed as a percentage) of the actual electrical generation to the maximum possible generation for a given period of time (usually on an annual basis). Capacity factors for geothermal plants are typically in excess of $90 \%$.

Casing string - An assemblage of tubular materials used to stabilize the hole - it may contain surface pressure-control equipment and downhole production equipment.

Cenozoic - The current geologic era that began about 66 million years ago.

Chemical tracers - A direct means of tracking fluid movement in a reservoir, thus allowing the determination of reservoir heterogeneity and an estimate of the magnitude and direction of any flow in the reservoir formation.

Closed-loop control system - A system that uses feedback to control states or outputs. Its name comes from the information path in the system: Process inputs have an effect on the process outputs, which are measured and processed. The result is used as input to the process, closing the loop.

Cogeneration - The simultaneous generation of electricity and process heat. 
Connectivity - With regard to enhanced geothermal systems, the degree to which production wells communicate with injectors through the fractured volume. Physical boundaries due to pre-existing faults, fractures, and lithology changes may either prevent connection or make too strong a connection within parts of the reservoir. It may be possible to improve reservoir connectivity through pressure-management methods such as producing one well while injecting into another or injecting into two wells simultaneously.

COP - Coefficient of performance. A measure of the efficiency of a heat pump equal to the ratio of the heat delivered to the electrical work needed to operate the unit (in winter-heating mode) or the ratio of the heat removed to the electrical work needed to operate the unit (in summer-cooling mode).

Coproduction - As used in this report, the simultaneous production of oil and/or natural gas, together with hot aqueous fluids or brines that may be used to generate electricity by means of a binary cycle plant.

Cretaceous - The geologic period that began about I44 million years ago and ended about 66 million years ago.

Crustal permeability - The capacity for upflow through tectonically active continental crust, resulting in a pathway for geothermal fluids.

CSP - Concentrating solar power. Also known as "solar thermal power," a method of converting sunlight into electricity by means of capturing concentrated solar energy. CSP technology focuses the suns rays by mirrors, flat or curved, onto a collector or receiver to heat or boil a fluid for use in an energy conversion system such as a steam Rankine cycle for generating electricity.

Cycle - A closed set of processes whereby electricity is generated and heat is exchanged with a hot source and cold sink.

Debt/equity ratio - The comparison of the amount of capital assets financed by bank loans requiring interest payments vs. those assets financed by equity capital from investors.

Decibel, A-weighted, dBA - A measure of the relative loudness of sound in air, normalized to the sensitivity of the human ear. Decibel values are reduced in the low-frequency range $(<\mathrm{I} \circ \circ \circ \mathrm{Hz})$ since humans are less sensitive to sounds at low audio frequencies.

Demand forecast - An assessment of future electrical demand on a given system. The impact of new technology on overall energy consumption plays an important role.

Direct heat - Any application requiring only heat transfer to accomplish some useful end.

Directional drilling - The science of drilling nonvertical wells; it is sometimes known as slant or deviated drilling.

Dispatchability - The ability of a power supply system to follow load. That is, power can be generated from a plant or collection of plants when it is needed to meet peak-system power loads. 
Disruptive drilling technologies - Emerging, ground-breaking, innovative technologies with the potential to drastically improve the economics of drilling deep wells. Examples include projectile drilling, spallation drilling, laser drilling, and chemical drilling.

Double-flash plant - A type of geothermal power plant involving the separation of steam from the twophase, liquid-vapor geofluid, followed by a pressure-reduction (flash) of the remaining liquid to produce more steam, albeit at a lower pressure; both steam flows are used to drive a steam turbine for electricity generation.

Dry-steam plant - A geothermal power plant using dry (or slightly superheated) geosteam to drive the turbine.

EGS - Enhanced geothermal system (sometimes referred to as engineered geothermal system). A system designed for primary energy recovery using heat-mining technology, which is designed to extract and utilize the Earth's stored thermal energy.

EIA - Energy Information Administration. A U.S. government agency that provides official energy statistics and predictions.

EJ - Exajoule. A measure of energy. One EJ equals a quintillion (Io ${ }^{18}$ ) joules or a quadrillion (Iо ${ }^{15}$ ) kilojoules. A joule is an extremely small unit of energy; one kilojoule is slightly less than one British Thermal Unit (Btu).

Energy reserves - The estimated amount of an energy source that is available with current technology at today's energy prices.

Energy Service Providers (ESP) - A company supplying an outsourced energy management service. This service can comprise the collection of energy consumption data, the validation and estimation of these data, and the reporting and even the improving of energy efficiency.

Energy-conversion system - Any device or assemblage of devices that converts thermal energy (heat or exergy) into electricity.

EPA - Environmental Protection Agency. A U.S. government agency whose mission is to protect human health and the environment.

Equity - The value of an entity in excess of the claims against it.

Equity rate of return - An indicator of profitability determined by the net income and the growth rate of the investment.

Exergy - The maximum theoretical work (or power) that can be extracted thermodynamically from a fluid under specified conditions of pressure, temperature, etc. in the presence of a given set of ambient conditions (surroundings or dead state). 
Expandable tubular casing - A novel method for completing a well. It reduces the number of telescopic steps in the casing profile and reduces the loss of diameter each time a new casing string or liner is set. It involves a cold-working process whereby the casing or liner can be expanded by up to $20 \%$ in diameter after being run downhole. This is accomplished by forcing through the pipe an expansion tool that exceeds the inner diameter of the tube by the required amount of expansion. The tool may be inserted either hydraulically, by applying mud pressure, or mechanically.

FERC - Federal Energy Regulatory Commission. An independent agency that regulates the interstate transmission of electricity, natural gas, and oil. FERC also reviews proposals to build liquefied natural gas (LNG) terminals and interstate natural gas pipelines as well as licensing hydropower projects. Among its tasks, it oversees environmental matters related to natural gas and hydroelectricity projects and major electricity policy initiatives.

Fixed charge rate - The annual interest expenses of the money borrowed to build a new construction project, plus the annual costs to operate and maintain it. Fixed charge rates include a range of factors such as construction financing, financing fees, return on debt and equity, depreciation, income tax, property tax, and insurance. The fixed charge rate, when multiplied by the cost of a new construction project, yields the annual "fixed charges."

Fixed costs - Costs that are not subject to change and do not fluctuate.

Fracture - A break in a rock caused by directed stress. Fractures may be caused by shear or tensile failure and may exist as fully or partly propped open or sealed joints.

Fracture cloud - The 3-dimensional loci of microseismic acoustic emissions that are indicative of the stimulated fracture zone in the formation.

Fracture spacing - The average distance between fractures that are open and accepting fluid.

Gas turbine - An energy conversion system consisting of a compressor, combustor, and turbine, usually powered by a gaseous fuel such as natural gas.

Gas-fired combined-cycle plant - A generating facility with both a gas turbine and a steam unit. The gas turbine operates as a normal gas turbine using the hot gases released from burning natural gas to turn a turbine and generate electricity. In combined-cycle plants, the waste heat from the gasturbine process is directed to a waste-heat recovery heat exchanger that raises steam, which is then used to generate additional electricity by means of a steam turbine. Because of their efficient use of the heat energy released from the natural gas, combined-cycle plants are more efficient than steam units or gas turbines alone, typically with thermal efficiencies in excess of 50-55\%.

GEA - Geothermal Energy Association. A trade association composed of U.S. companies who support the expanded use of geothermal energy and are developing geothermal resources worldwide for electrical power generation and direct-heat uses. 
Geofluid - Any fluid produced from a geothermal well; may be dry or superheated steam, pressurized liquid, or a mixture of liquid and vapor, usually accompanied by dissolved solids and noncondensable gases.

Geopressured geothermal resource - A unique form of geofluid found in near-offshore petroleum deposits, containing significant amounts of dissolved natural gas at very high pressure and high temperature.

Geothermal - Referring to the stored thermal energy in, or heat produced from, the Earth's interior.

Geothermal gradient - The rate of increase in temperature per unit depth in the Earth. Although the geothermal gradient varies from place to place, it averages 25 to $30^{\circ} \mathrm{C} / \mathrm{km}$ [I4- $\mathrm{I} 6^{\circ} \mathrm{F} / \mathrm{Io0} \mathrm{ft}$ in normal regions. It can be several times larger in high-grade geothermal regions.

GETEM - Geothermal Electric Technology Evaluation Model (GETEM) is a macro-model that estimates levelized cost of geothermal electric power in a commercial context. It was developed with funding from the U.S. DOE Geothermal Technology Program.

GPM or gpm - Gallons per minute.

$\mathrm{GW}_{\mathrm{e}}$ - Gigawatts electric. A measure of electric power generation. One $\mathrm{GW}_{\mathrm{e}}$ equals one billion (Io ${ }^{9}$ ) watts or I million kilowatts.

Greenhouse gases (GHG) - Gases that permit ultraviolet light energy to enter the Earth's atmosphere but block the transmission of infrared light energy, similar to the effect of a sheet of glass in a "hot house"; such gases notably include water vapor, carbon dioxide, and methane.

Grid - A network of conductors for distribution of electric power. The electrical transmission system is commonly referred to as a "grid."

Ground-source heat pump (GSHP) - A means of controlling the temperature in buildings using the shallow Earth as a heat source in the winter and as a heat sink in the summer; the device is cyclical and behaves thermodynamically in the same way as a refrigerator, but with appropriate control valves to allow for heating or cooling as desired.

GSA-DNAG - Geological Society of America-Decade in North America Geology. This project was established in 1988 as a commemoration of the $100^{\text {th }}$ anniversary of the GSA and consists of numerous volumes on all geological aspects of the North American continent. Twelve volumes deal specifically with geothermal topics.

HDR - Hot dry rock. See also "Heat Mining." A type of geothermal power production system that utilizes the very high temperatures that can be found in rocks a few kilometers below ground. This is done by pumping high pressure water down a borehole into the heat zone. The water travels through fractures of the rock, capturing the heat of the rock until it is forced out of a second borehole as very hot water - the thermal energy of which is converted into electricity using either a steam turbine or a binary power plant system. All of the water, then cooled, is injected back into the ground to heat up again. 
Heat mining - A process that includes the use of at least one injection well and at least one production well to extract heat from the Earth. Cold water is pumped down to and circulates through the fractured reservoir; the natural heat exchanger delivers hot, pressurized water to the production well(s). The thermal energy is converted into electric power by means of a turbine-generator unit; residual thermal energy in the geofluid may be used for space heating. The cooled geofluid is then reinjected deep into the reservoir to maintain a cyclic operation.

Heat rate - A measurement used in the energy industry to calculate how efficiently a power plant uses heat energy. It is expressed as the number of Btus of heat required to produce a kilowatt-hour of energy.

Heat recovery steam generator (HRSG) - A heat exchanger fitted to the exhaust of a gas turbine (or other power plant) to extract heat that would be otherwise wasted for use in a bottoming cycle for additional power generation.

Holocene - The most recent, current epoch of the Quarternary period beginning about Io,००o years ago.

Hydraulic fracturing ("hydrofracing" or "jacking") - A technique involving the application of high fluid pressure on a reservoir to enhance the existing permeability and establish interwell connectivity by opening sealed joints or by creating new fractures to allow geofluid to move more freely through the formation.

Hydroelectric plant - A plant that generates electric power from the flow of water utilizing a hydrostatic or hydrodynamic gradient. Two main types are: (I) storage units that involve a dam and a water reservoir at a higher elevation, and (2) run-of-the-river units involving the steady flow of water. Both use hydraulic turbines to drive electric generators.

Hydrothermal - In the context of geothermal systems, refers to mineralized solutions heated by contact with hot rocks and/or cooling magma and convecting within a reservoir.

IGA - International Geothermal Association. An organization that provides information on geothermal energy use around the world.

Impedance - The pressure drop experienced by the geofluid while circulating through the reservoir.

Intermediate load - Intermediate-load generating units meet system demands that are greater than base load but less than peak load.

JAS - Joint Association Survey. An annual report by the American Petroleum Institute, outlining drilling costs, overall well costs, and other geological information.

Jacking - See hydraulic fracturing.

Kalina cycle - A unique type of binary power plant that uses a mixture of water and ammonia as the cycle working fluid (instead of a simple organic fluid) together with various heat recuperators that improve the cycle thermal efficiency. 
$\mathbf{k W}_{\mathbf{t}}$ - Kilowatts thermal. A measure of thermal power or rate of heat transfer. One $\mathrm{kW}_{\mathrm{t}}$ equals one thousand thermal watts.

Learning curve - A curve plotting performance against practice. The principle states that the more often a task is performed, the lower the cost will be to do it. The task can be the production of any good or service. An example is the decline in unit costs with cumulative output. Sometimes called an "experience curve."

Levelized electricity cost (LEC) - The levelized cost of energy (or levelized electricity cost, LEC) is the most common basis used for comparing the cost of power from competing technologies. The levelized cost of energy is found from the present value of the total cost of building and operating a generating plant over its expected economic life. Costs are levelized in real dollars, i.e., adjusted to remove the impact of inflation.

Lithology - The detailed geologic and mineralogic characteristics of a rock formation, often obtained by taking cuttings of the rock layers as drilling is carried out.

Load center - A particular geographical area within a utility's service territory where electrical energy is used.

Lost circulation - A drilling problem that arises when the circulation of the drilling fluid is interrupted and it does not return to the surface.

Microseismic events - Very weak acoustic emissions often associated with the injection or recovery of fluids from a geothermal reservoir. Magnitudes are usually too weak to be detected by humans.

MIT EGS Model - A model enhanced by the MIT Energy Laboratory as part of its research into EGS systems sponsored by the Geothermal Technologies Office of the U.S. Department of Energy; it was further modified by Brian Anderson of MIT as part of this assessment. The model has been updated using the results of this study with regard to the cost of drilling, plant costs, stimulation costs, and the learning-curve analysis.

MITDD - MIT Depth Dependent drilling cost index. This is used to normalize geothermal well costs from the past 30 years to year 2004 U.S. dollars.

Mud - Drilling fluid. Used to flush the borehole of cuttings produced during drilling and to support the walls of the hole prior to the setting of casing. For liquid-dominated and EGS reservoirs, muds consist of aqueous solutions or suspensions with various additives chosen to provide appropriate thermal and fluid properties (density, viscosity, corrosion resistance, thermal conductivity, etc.). For vapor-dominated reservoirs, air is often used for the drilling fluid to avoid the possibility of clogging the fine fractures associated with a vapor system.

$\mathrm{MW}_{\mathrm{e}}$ - Megawatts electric. A measure of electric power generation. One $\mathrm{MW}_{\mathrm{e}}$ equals I million watts or I,००० kilowatts. 
NEDO - New Energy and Industrial Technology Development Organization. Japan's largest public R\&D management organization for promoting the development of advanced industrial, environmental, new energy, and energy conservation technologies.

Noncondensable gases (NCG) - Gases such as carbon dioxide, hydrogen sulfide, methane, and others in very small concentrations that are constituents of geofluids, either dissolved in geoliquids or as gaseous components of geosteam. These gases do not condense at the normal condensing temperature of steam and will build up in a condenser, raising the back-pressure on the turbine exhaust (thereby lowering the power output) unless they are pumped out of the condenser.

Nuclear plant - A plant that generates electrical power using the heat released from the fission of uranium or other radio-nuclides by moderated neutrons.

OMB - Office of Management and Budget. The White House office responsible for devising and submitting the president's annual budget proposal to Congress.

Packer - A tool with elastomer or cement seals used in a well to hydraulically isolate zones for stimulation or production.

Paleozoic - The geologic era that began about 570 million years ago and ended about 245 million years ago.

Peak load - The point in time when energy needs are highest and the system experiences the largest demand.

Permeability - A measure of the ability of a material's pores or openings to allow liquids or gases to flow through them under a pressure gradient.

Pleistocene - An epoch of the Quarternary period beginning about I.6 million years ago and ending about Io, 000 years ago.

Polycrystalline diamond compact drill bits (PDC) - A type of drill bit invented in the I970s that is very effective in sedimentary formations, particularly in the oil and gas industry, but not used in hard crystalline rock typical of geothermal applications.

Porosity - The percentage of open space or interstices within a volume of rock.

Power - The rate at which work is done; expressed in units of joules per second (J/s) or watts (W), or multiples thereof.

Proppant - Small-sized particles that are mixed with hydrofracting fluids to hold fractures open after a hydraulic fracturing treatment. Proppant materials are carefully sorted for size and shape, hardness, and chemical resistance to provide an efficient conduit for production of fluid from the reservoir to the wellbore. 
PV - Photovoltaic. A means of generating electricity directly from sunlight through solar cells containing materials that are stimulated by the solar energy to produce a flow of electrons.

Quartet configuration - A pattern of production and injection wells in which each injector is surrounded by three producers.

Rankine cycle - A power plant consisting of a closed series of four processes: (I) liquid pressurization, (2) heating-evaporation, (3) vapor expansion, and (4) cooling-condensation. There are many variations on the basic Rankine cycle in practice.

Rate of penetration (ROP) - The speed at which a drill bit proceeds through the rock being drilled.

Rate of return (ROR) - The benefits received from an investment, usually expressed as an effective annual percentage return based on an after-tax, discounted, cash-flow analysis.

Recoverable resource - The amount of an energy resource that is recoverable using current exploration and production technology, without regard to cost.

Recovery factor - The percentage of heat recoverable from a stimulated volume of rock.

Recuperator - A heat exchanger designed to capture heat from one part of a cycle for use in another part of the cycle; typically, a recuperator has no moving parts.

Regenerator - Similar to a recuperator in terms of intended function, but having moving parts, such as rotating heat-transfer elements.

Resource base - The total thermal energy in place in the Earth's crust to the depth that can be reached with current technology.

Revenue - The total income produced by a given source.

Rheology - The science of the deformation and flow of matter under the influence of an applied stress.

Risk - The degree of probability or chance for a loss.

Sedimentary basin - A geologic formation characterized by subsidence and subsequently filled by the deposit of sediments.

Seismicity, induced - The generation of acoustic energy from the opening of fractures in rock by the application of high-pressure fluid through injection wells. Normally, these events are in microseismic range, but it is possible to produce events that are perceptible by humans in the vicinity of the event.

Shear failure - The premature failure of a support element that has been cracked under stress. 
Short circuit - A preferential pathway that allows cool injected water to return too rapidly to the production well without being heated by the hot rock in the reservoir.

Sidetracking - A well-drilling process that involves drilling a deviated leg in an existing well. Often accomplished by setting a packer or suitable drilling tool at a specified depth, cutting an opening in the casing of the well, and drilling a new well through the opening to access another reservoir area.

Single-expansion plant - As used in this report, a power plant that uses a very high-pressure geofluid and one pressure-reducing process to produce steam for use in a steam turbine.

Single-flash plant - A type of geothermal power plant involving the separation of steam from the twophase, liquid-vapor geofluid, and produces steam to drive a steam turbine for electricity generation.

Skin effect - A near-wellbore permeability reduction, usually caused during drilling or work-over, which can increase pressure drop and decrease flow rates.

Solar photovoltaic plant - A power plant that directly converts the energy in sunlight to electricity by means of photovoltaic cells.

Solar thermal plant - A power plant that first collects the energy of sunlight in a thermal receiver using mirrors (flat, parabolic, dish-shaped) and then transfers the heat energy to a working fluid for use in a closed cycle (such as a Rankine cycle) to generate electricity.

Spud - The initiation of the drilling of a well.

Squeeze-cementing - A technique for cementing a section of casing to the well wall by injecting cement into the annulus between the casing and the well wall. This is used in special cases where only a portion of the casing string needs to be supported by cement.

Stimulation - In an EGS system, the enhancement of natural permeability - or its creation when none exists. Stimulation is usually hydraulically achieved by injecting fluids with or without controlling their viscosity and at variable flow rates and pressures; or chemical by injecting acids or other chemicals that will remove the rock. The stresses on the rocks and the elastic and thermal properties of the rocks in the potential reservoir, along with the design of the stimulation, control the extent of the enhanced or created fractures and their ultimate transmissivity.

Stress field - A 3-dimensional region of a solid continuum subjected to forces of either uniform or varying magnitudes and directions.

Strike-slip - A fault along which the movement is horizontal; usually associated with transform boundaries.

Subsidence - The lowering of the surface of the ground caused by the removal of fluid from underground pore spaces (reservoirs). 
Supercritical fluid - A fluid that exists at conditions of pressure and temperature in excess of its critical temperature and pressure (its critical point), above which it cannot exist as a liquid but only as a dense fluid.

Supply curve - The relationship between each possible price of a given good and the quantity of that good that would be supplied for market sale at that price. This is typically represented as a graph showing the hypothetical supply of a product or service that would be available at different price points. The supply curve usually exhibits a positive slope because higher prices give producers an incentive to supply more, in the hope of earning greater revenue.

Technology diffusion model - A way to measure the amount of time and rate of speed that a technology is dispatched into the marketplace and can sustain a certain level of capacity.

Tectonics - The science of the motion of the Earth's crustal plates that results in the creation and deformation of magma and rock.

Tensile failure - An effect caused by tension or stress, often resulting in a fracture. The most likely effect of water injection under high pressures would be to create a new fracture by tensile failure, thus forming the required surface area needed for heat mining.

Tertiary - The geologic period beginning about 65 million years ago and ending about I.6 million years ago.

Thermal conductivity - The intensive property of a material that indicates its ability to conduct heat. Heat flow is proportional to the product of the thermal conductivity and the temperature gradient.

Thermal drawdown rate - The drop in temperature per unit time of a body of reservoir rock, subject to the circulation of water in a closed loop as envisioned in an EGS facility.

Thermal efficiency - For a cycle, the ratio of the net power output to the rate of heat input to the cycle.

Thermal gradient - The rate of change of temperature with depth below the ground surface.

Thermal pollution - The discharge of waste heat into the surroundings (air, bodies of water) - this is a necessary thermodynamic consequence of all thermal engines. The lower the thermal efficiency of the plant, the greater the amount of heat that must be rejected relative to the electrical power being generated.

Transform (boundary) - An interface between tectonic plates, where the plates slide past each other without creating or destroying lithosphere.

Transmissivity - The ability of a reservoir to allow the flow of fluid through a certain area, generally in the horizontal direction. The transmissivity is the product of the permeability (a property of the rock only, related to the interconnectedness and size of fractures or pores) and the thickness of the formation through which the fluid is flowing. Transmissivities in geothermal systems are very high, often having values greater than ioo darcy-meters, compared to oil and gas reservoirs where transmissivities are typically roo to I, ००० times smaller. 
Triple-expansion plant - As used in this report, a power plant that uses a very high-pressure geofluid and three pressure-reducing processes and two separation stages to produce steam at two different pressure levels for use in a steam turbine; altogether the geofluid is subjected to three expansion processes, two of which generate electricity.

Triplet configuration - A pattern of production and injection wells in which each injector is surrounded by two producers.

Trouble (during drilling) - Unanticipated difficulties encountered during drilling, including, for example, stuck drill pipe, twist-off of the drill bit, lost circulation, blowouts, mud pump failure, failed cement jobs, casing collapse, and equipment lost downhole. The cost of trouble becomes more significant the deeper one drills.

Turbine isentropic efficiency - A measure of the performance of a turbine, defined as the ratio of the actual work (or power) delivered by the turbine to the ideal work (or power) that could be delivered if the turbine were adiabatic (no heat losses) and reversible (no friction), i.e., isentropic (constant entropy).

TVD - Total vertical depth. The vertical distance from the wellhead to the bottom of the well. For directionally drilled wells, the TVD is smaller than the total drilled length of the well.

Underbalanced drilling - The practice of intentionally drilling a well with borehole pressure less than the formation pore pressure.

Under-reaming - A method of opening up a wellbore to a larger size, often achieved by setting the drill bit below the bottom of the casing string and expanding it radially.

USGS - United States Geological Survey. A federal agency responsible for characterization and assessment of the Earth's water and mineral resources (including oil, gas, coal, and geothermal), natural hazards, and the environment.

Utilization efficiency - A measure of how close an energy conversion system comes to ideal operation. It is defined as the ratio of actual net power to maximum possible power, usually expressed as a percentage.

Variable costs - Fluctuating costs of operation of a facility. For this study, these include: fuel costs, electricity to run injection and circulating pumps, maintenance, interest and principal repayments, taxes, and depreciation.

Wellcost Lite - A computer model (developed by Bill Livesay, working with staff at Sandia National Laboratories) that estimates the cost of a well of a specific depth, casing design, diameter, and geological environment. 